\title{
HTGR CORE THERMAL DESIGN METHODS AND ANALYSIS
}

Work done by:

I. Edwards

R. M. Edwards

J. T. Ganley

R. J. Kapernick

D. W. McEachern

D. I. Mcnab

J. J. Saurwein

B. I. Shamasundar

A. S. Shenoy

G. L. Smith
Written by:
A. S. Shenoy
D. W. McEachern

This report was prepared as an account of work sponsored by the United States Government. Neither the United States nor the United States Energy Research and Development Administration, nor any of their employees, nor any of their contractors, subcontractors, or their employees, makes any warranty, express or implied, or assumes any legal liability or responsibility for the accuracy, completeness or usefulness of any information, apparatus, product or process disclosed, or represents that its use would not infringe privately owned rights.

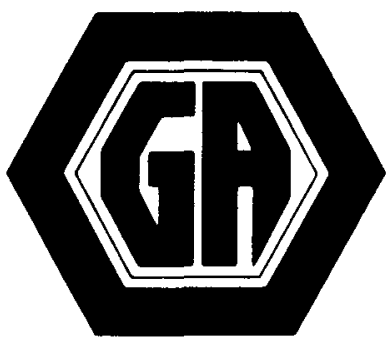




\section{DISCLAIMER}

This report was prepared as an account of work sponsored by an agency of the United States Government. Neither the United States Government nor any agency Thereof, nor any of their employees, makes any warranty, express or implied, or assumes any legal liability or responsibility for the accuracy, completeness, or usefulness of any information, apparatus, product, or process disclosed, or represents that its use would not infringe privately owned rights. Reference herein to any specific commercial product, process, or service by trade name, trademark, manufacturer, or otherwise does not necessarily constitute or imply its endorsement, recommendation, or favoring by the United States Government or any agency thereof. The views and opinions of authors expressed herein do not necessarily state or reflect those of the United States Government or any agency thereof. 


\section{DISCLAIMER}

Portions of this document may be illegible in electronic image products. Images are produced from the best available original document. 
• 
ABSTRACT

This licensing topical report was prepared by General Atomic Company (GA) to describe the methods employed in carrying out the thermal analysis of the core of a High-Temperature Gas-Cooled Reactor (HTGR). This report describes the thermal design basis, computer codes, and thermal data used. These items, contained in Section 3.3; Sections 4.1 and 4.2; and Sections $5.2,5.4$, and 5.7, respectively, are submitted to the U.S. Atomic Energy Commission, Directorate of Licensing, for their endorsement.

The report is generic in the sense that the information on design basis and data, submitted for approval, is applicable to all commercial HTGR core sizes: 2000, 3000, and $3800 \mathrm{MW}(t)$. Core designs for different size plants employ the same core components, coolant conditions, and nearly the same power density. The principal difference between the three cores is the number of fuel columns employed.

The core description and core performance results given in this report are for the $3000 \mathrm{MW}(t)$ plant. Descriptions presented of core design methods and methods of modeling of the core thermal behavior are for those currently in use at GA. Core performance results of the $3000 \mathrm{MW}(t)$ plant are presented to demonstrate the application of the design methods. Detailed results are intended to give the status of the core design as of October 1974, and they are not submitted for approval. 
O 
ABSTRACT ........................... . . . 1 . . . . . . . . .

1. INTRODUCTION ........................ . . . . 1-1

References ...................... . . . . . 1-4

2. CORE DESCRIPTION ...................... . . . 2-1

2.1. Reactor Core.................. . 2-1

2.2. Refueling Region ................. . 2-5

2.3. Fuel Elements .. . . . . . . . . . . . 2-9

2.4. Fuel Rods and Particles . . . . . . . . . . 2-9

2.5. Control Rod System . . . . . . . . . . . 2-16

References . . . . . . . . . . . . . . . . . . 2-23

3. DESIGN BASES . . . . . . . . . . . . . . . . . . . 3-1

3.1. Thermal Characteristics of Core Materials . . . . . . 3-1

3.2. Summary of Fuel Particle Behavior . . . . . . . . 3-2

3.2.1. Kernel Migration . . . . . . . . . . . 3-3

3.2.2. Coating Stress . . . . . . . . . . . 3-7

3.2.3. Fission Product - SiC Layer Interactions . . 3-14

3.2.4. Manufacturing Defects .......... 3-14

3.3. Core Therma1 Design Basis . . . . . . . . . 3-14

3.3.1. Fuel Particles . . . . . . . . . . 3-17

3.3.2. Primary Coolant............. . 3-19

3.3.3. Fuel Elements and Hexagonal Reflector $3-20$

3.3.4. Metallic Core Components ......... 3-20

References . . . . . . . . . . . . . . . . 3-22

4. ANALYTICAL METHODS . . . . . . . . . . . . . . . 4-1

4.1. Steady-State Analysis Codes . . . . . . . . . . . 4-1

4.1.1. Core Flow Distribution FLAC Code . . . . . . 4-4

4.1.2. Region Average Thermal Analysis POKE Code . . 4-13

4.1.3. Half-Column Thermal Network Models . . . . 4-15 
4.1.4. One-Dimensional Unit-Cell Codes BACH and HEXT .............. . . 4-22

4.1.5. Core Performance Code TREVER ........ 4-30

4.1.6. General Purpose Thermal Analysis TAC Code . . 4-32

4.2. Transient Analysis Codes .............. 4-33

4.2.1. System Analysis TAP Code .. . . . . . . 4-34

4.2.2. Single Channel Analysis TAC Model . . . . . 4-34

4.2.3. Detailed Transient Code DETRAC ...... 4-35

4.2.4. Region Average Analysis RECA Code...... 4-38

References . . . . . . . . . . . . . . . . . 4-39

5. DESIGN DATA . . . . . . . . . . . . . . . . . 5-1

5.1. Major Core Design Parameters . . . . . . . . . 5-1

5.2. Coolant Thermal Data . . . . . . . . . . . 5-3

5.3. Coolant Flow Resistance Data . . . . . . . . . 5-4

5.3.1. Orifice Loss Coefficients . . . . . . . . 5-4

5.3.2. Entrance Loss Coefficient . . . . . . . . 5-6

5.3.3. Friction Factor for Coolant Channels . . . . 5-6

5.3.4. Offset Loss Coefficients . . . . . . . . 5-7

5.3.5. Exit Loss Coefficient . . . . . . . . 5-7

5.4. Coolant Channel Heat Transfer Correlations . . . . . . 5-8

5.4.1. Turbulent Flow . . . . . . . . . . 5-8

5.4.2. Laminar Flow . . . . . . . . . . . . 5-9

5.4.3. Transitional Flow ............ 5-11

5.5. Graphite Thermal Data . . . . . . . . . . . 5-11

5.5.1. Graphite Thermal Conductivity . . . . . . . 5-11

5.5.2. Equivalent Graphite Conductance . . . . . . 5-12

5.5.3. Graphite Thermal Expansivity . . . . . . . 5-14

5.5.4. Graphite Thermal Emissivity . . . . . . . 5-14

5.5.5. Graphite Specific Heat . . . . . . . . 5-14

5.5.6. Graphite Density .. . . . . . . . . . 5-18

5.5.7. Irradiation-Induced Graphite Dimensional
Change . . . . . . . . . 5-18 
5.6. Fuel Rod Thermal Data. . . . . . . . . . 5-21

5.6.1. Fuel Rod Thermal Conductivity ........ 5-21

5.6.2. Fuel Rod Thermal Expansivity ........ 5-23

5.6.3. Fuel Rod Emissivity .......... 5-23

5.6.4. Fuel Rod Specific Heat ......... 5-23

5.6.5. Fuel Rod Density ............ 5-24

5.6.6. Irradiation-Induced Fuel Rod Dimensional

Change .............. 5- 5-24

5.7. Fue1-Rod Fue1-Hole Gap Conductance . . . . . . . 5-27

5.8. Nuclear Design Data . . . . . . . . . 5-31

5.8.1. Core Nuclear Designs . . . . . . . . 5-32

5.8.2. Refueling Sequence and Geometric Identifications . . . . . . . . . . . 5-34

5.8.3. Power Peaking Factors . . . . . . . 5-36

5.8.4. Fuel Rod Metal Loading ......... 5-40

5.8.5. Control Rod Programming . . . . . . . 5-40

5.8.6. Core Radial Power Distribution ....... . 5-41

5.8.7. Core Axial Power Distribution . . . . . . . 5-47

5.8.8. Core Fast Neutron Flux Distribution . . . . 5-48

References . . . . . . . . . . . 5 5-57

6. CORE THERMAL AND FLOW ANALYSIS . . . . . . . . . 6-1

6.1. Steady-State Operation . . . . . . . . . 6-1

6.1.1. Flow Distribution from FLAC Code ..... 6-2

6.1.2. POKE Thermal Analysis . . . . . . 6-20

6.1.3. Half Column Thermal Analysis ...... 6-35

6.1.4. Unit Cell BACH Analysis ......... 6-41

6.1.5. Time-Dependent TREVER Analysis ..... 6-57

6.1.6. Comparison of BACH, TREVER, and DEMISE Code Results . . . . . . . . . 6 6-70

6.2. Transient Analysis ........... 6-81

6.2.1. Description of Load Following....... 6-82

6.2.2. Description of Contro1 Rod Movements ... 6- 6-84

6.2.3. Plant Response TAP Results ....... 6-86

6.2.4. Reactor Core Therma1 Response ....... 6-86

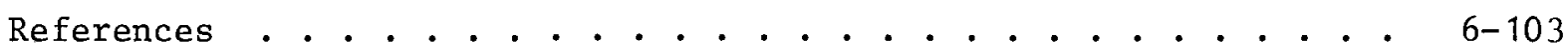


7. FUEL PERFORMANCE ANALYSIS . . . . . . . . . . . . . . . 7-1

7.1. Kernel Migration Analysis . . . . . . . . . . . 7-3

7.1.1. Kernel Migration in TRISO Particles . . . . . 7-3

7.1.2. Kernel Migration in BISO Particles . . . . 7-20

7.2. Pressure Vessel Failure Analysis . . . . . . . . . 7-21

7.2.1. Pressure Vessel Failure in TRISO Particles . . 7-31

7.2.2. Pressure Vessel Failures in BISO Particles . 7-45

7.3. High Temperature Failure of TRISO Particles . . . . . 7-45

7.4. Manufacturing Defects .............. 7-55

7.5. Summary of Fuel Performance . . . . . . . . . . 7-59

References . . . . . . . . . . . . . . . . . 7-63

8. SUMMARY AND CONCLUSIONS . . . . . . . . . . . . . . 8-1

References ......................... $8-5$

\section{FIGURES}

1-1. Core thermal design information flow diagram . . . . . . 1-2

2-1. $3000 \mathrm{MW}(\mathrm{t})$ HTGR general arrangement . . . . . . . . . 2-2

2-2. $3000 \mathrm{MW}(\mathrm{t})$ core plan ................. 2-3

2-3. Seven column refueling region . . . . . . . . . . . 2-6

2-4. Flow control valve and plenum arrangement . . . . . . . 2-7

2-5. Thermocouple probe and core support floor . . . . . . . 2-8

2-6. Standard fuel element . . . . . . . . . . . . . 2-10

2-7. Control fuel element . . . . . . . . . . . . . . 2-11

2-8. Metallographic cross section of a typical HTGR fuel rod . . 2-17

2-9. Typical TRISO and BISO fuel particles . . . . . . . . 2-18

2-10. Control rod assembly and absorber container details . . . 2-19

3-1. Fuel kernel migration in a fuel rod . . . . . . . . . 3-5

3-2. Kernel migration correlation for TRISO and BISO fuel

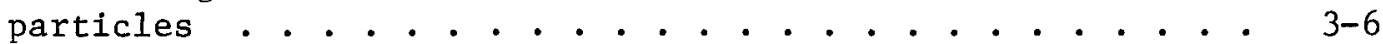

3-3. Time to migrate 85 microns for TRISO and BISO fuel particles as a function of temperature ............. 3-8 
3-4. Iso-fallure envelopes for TRISO fuel particles due to pressure vessel failure as a function of fast neutron fluence . . . . . . . . . . . . . . . 3-10

3-5. Iso-failure envelopes for BISO fuel particles due to pressure vessel failure as a function of fast neutron fluence . . . . . . . . . . . . . . . . . 3-11

3-6. Iso-failure envelopes for TRISO fuel particles due to pressure vesse1 and high temperature effects as a function of burnup . . . . . . . . . . . . . . 3-12

3-7. Iso-failure envelopes for BISO fuel particles due to pressure vessel failure as a function of burnup . . . . . 3-13

4-1. One-sixth core flow model . . . . . . . . . . . . . 4-6

4-2. Typical horizontal branch connections within each region for one-sixth core flow model .. . . . . . . . . . 4-7

4-3. Typical vertical branch connections for each region in one-sixth core flow model ............... 4-8

4-4. Seven-column region flow model . . . . . . . . . . . . . 4-11

4-5. Vertical branch connection for seven-column region model . . 4-12

4-6. Plan view of half standard fuel element column with horizontal node connections - DEMISE . . . . . . . . 4-16

4-7. Plan view of the control fuel element column with horizontal node connections - DEMICE . . . . . . . . . 4-17

4-8. Schematic elevation view of the fuel element column with network representation . . . . . . . . . . . . . 4-18

4-9. Fuel and coolant hole configuration . . . . . . . . . . . 4-23

4-10. Triangular unit cell element used in thermal analysis • • 4-24

5-1. Thermal conductivity of $\mathrm{H}-327$ and $\mathrm{H}-451$ graphite as a function of irradiation temperature and fluence . . . . . 5-13

5-2. Thermal expansion design curve for graphite and fuel rod . . 5-16

5-3. Specific heat of graphite and fuel rods as a function of temperature . . . . . . . . . . . . . . . . 5-17

5-4. Near-isotropic graphite (H-451) dimensional change in parallel and perpendicular directions . . . . . . . . . . . . 5-19

5-5. Needle-coke, graphite (H-327) dimensional change in parallel and perpendicular directions . . . . . . . . . 5-20

5-6. Thermal conductivity of typical HTGR fuel rods as a function of temperature . . . . . . . . . . . . 5-22

5-7. Dimensional change of TRISO, BISO, and shim particles . . 5-26 
5-8. Calculated fuel rod dimensional change (\%) in the top four layers of the large HTGR . . . . . . . . . . . . 5-28

5-9. Calculated fuel rod dimensional change (\%) in the middle three layers of the large HTGR . . . . . . . . . . . 5-29

5-10. Calculated fuel rod dimensional change (\%) in the bottom layer of the large HTGR ................ . 5-30

5-11. Segment and time point identification chart for TREVER study ........................ 5-33

5-12. Refueling sequence and TREVER code identification map . . . 5-35

5-13. Intra-column GAUGE/TREVER identification system . . . . . . 5-37

5-14. Combination of radial and axial peaking factors that results in peak fuel temperature of $2550^{\circ} \mathrm{F}$. . . . . . . . . . 5-44

5-15. Effect of burnup on core average axial power distribution . 5-49

5-16. Effect of control rod motion on axial power distribution in rodded regions . . . . . . . . . . . . . . . 5-50

5-17. Effect of contro1 rod motion in neighboring regions . . . . 5-51

5-18. Effect of axial flux shape due to rod motion . . . . . . . 5-55

5-19. Effect of axial flux shape in neighboring regions due to rod motion . . . . . . . . . . . . . . . . . 5-56

6-1. Core coolant pressure distribution in "no crossflow" case . 6-9

6-2. Core power, flow, and coolant temperature in $3000 \mathrm{MW}(t)$ core "no crossflow" case .. . . . . . . . . . . . . 6-11

6-3. Core coolant pressure distribution in "cross-flow" case . . 6-14

6-4. Core power, flow, and coolant temperature distribution in $3000 \mathrm{MW}(t)$ "crossflow" case . . . . . . . . . . . 6-16

6-5. Crossflow factors as a function of region power peaking factor ........................ . 6-18

6-6. Region crossflow model with open flow control valve . . . . 6-19

6-7. Region crossflow model with near closed flow control valve . . . . . . . . . . . . . . . . . 6-21

6-8. Core power, flow, and coolant temperature distribution in $3000 \mathrm{MW}(t)$ core in "Design" case . . . . . . . . . 6-22

6-9. Core pressure drop during seventh year of depletion study . 6-29

6-10. Core power and flow distribution between variable and fixed orifice regions in "Design" case . . . . . . . . . 6-31

6-11. Intraregion coolant channel exit temperature mismatch as a function of intraregion power tilt . . . . . . . . 6-34

6-12. Temperature distribution in a horizontal plane of sixth fuel element in a standard column calculated using block average axial power and flat radial power . . . . . . . . . 
6-13. Temperature distribution in a horizontal plane at the end of sixth fuel element in a standard column calculated using end of block local axial power and flat radial power . . . . . 6-39

6-14. Axial temperature distribution for fuel rods F2 and F5 . . 6-40

6-15. BUGTRI radial power distribution in column 5 of region 25 at the end of reload 2............... 6-.. 6-42

6-16. Temperature distribution in a horizontal plane of fourth fuel element in a standard column operating in a high power region with a tilted power distribution .. . . . . . . 6-43

6-17. Axial distribution of coolant, graphite, and fuel temperatures in an average power channe1 . . . . . . . . . . 6-50

6-18. Axial distribution of coolant, graphite, and fuel temperatures in the high temperature local channel . . . . . . . . . 6-51

6-19. Fuel centerline temperature as a function of region peaking factor and intraregion tilt at core midlength in unrodded regions . . . . . . . . . . . . . . . . 6-52

6-20. Radial temperature profile in the high-temperature local channe1 . . . . . . . . . . . . . . . 6-54

6-21. Axial fuel temperature distribution in quarter rodded, half rodded, and fully rodded regions . . . . . . . . . 6-55

6-22. Effect of crossflow on fuel temperatures in high and low power regions . . . . . . . . . . . . . . 6-56

6-23. Temperature histories in a typical unrodded region adjacent to a rodded region .................. 6-60

6-24. Temperature histories in a typical rodded region . . . . . 6-61

6-25. Temperature histories in a typical unrodded region . . . . 6-62

6-26. Volume distribution of peak and time-average temperature of fuel in segment 5................. 6-67

6-27. Volume distribution of peak and time-average temperature of graphite in segment 5................. 6-68

6-28. Coolant hole, fuel hole, and fuel rod dimensional change in a typical unrodded region adjacent to rodded region . . 6-69

6-29. Coolant hole, fuel hole, and fuel rod dimensional change in a typical rodded region .............. 6- 671

6-30. Axial profiles of end-of-1ife fuel hole, fuel rod, and gap dimensions in a typical rodded region . . . . . . . . 6-72

6-31. GAUGE and BUGTRI intraregion tilt distribution for region 25, column 5 at end of reload 2 . . . . . . . . . 6-74

6-32. Comparison of fuel temperatures calculated by DEMISE and BACH at core axial mid-height ............ . 6-78 
6-33. Comparison of DEMISE and BACH calculations along a traverse through the half column ............... 6-79

6-34. Time history of core power, flow, and helium pressure during 100-60-100 load transient ...............

6-35. Time history of core helium inlet and outlet helium temperatures during 100-60-100 load following transient . . . . .

6-36. Time history of core average fuel and graphite temperatures during 100-60-100 load following transient... . . . . 6-89

6-37. Hot channel fuel temperature without orifice adjustments during 100-60-100 load following transient ramp up from equilibrium xenon . . . . . . . . . . . . . . .

6-38. Hot channel fuel temperature with orifice adjustments during 100-60-100 transient ramp up from equilibrium xenon . . .

6-39. Local fuel temperature in three-quarter rodded and adjacent to half rodded regions during 100-60-100 transient without orifice adjustments ... . . . . . . . . . . . . . . .

6-40. Axial fuel temperature distribution during 100-60-100 load following transient .. . . . . . . . . . . 6-98

6-41. Time history of local fuel temperature in three-quarter rodded and adjacent to half rodded region during 100-60-100 transient with orifice adjustments . . . . . . . . . . . .

7-1. Behavior of the TRISO kernel migration in a typical fuel rod ....................... 7-4

7-2. Axial profile of the end-of-life TRISO and BISO kernel migration in a typical fuel rod stack . . . . . . . . 7-5

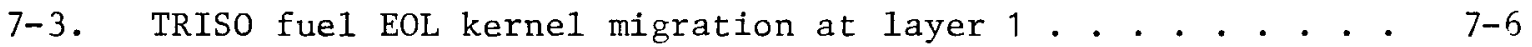

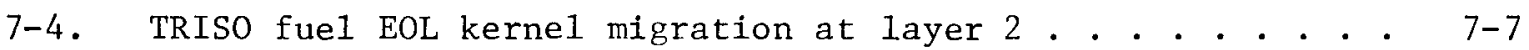

7-5. TRISO fuel EOL kernel migration at layer 3........ . 7-8

7-6. TRISO fuel EOL kernel migration at layer 4. . . . . . . 7-9

7-7. TRISO fuel EOL kernel migration at layer 5 . . . . . . . 7-10

7-8. TRISO fuel EOL kernel migration at layer 6 . . . . . . . 7-11

7-9. TRISO fuel EOL kernel migration at layer 7 . . . . . . . 7-12

7-10. TRISO fuel EOL kernel migration at layer 8 . . . . . . . 7-13

7-11. Fraction of TRISO fuel particle failure by migration at worst axial position............... . . 7-14

7-12. Time history of TRISO amoeba failure fraction in each fuel segment position and in the core. . . . . . . . . 7-15

7-13. Comparison of maximum migration of TRISO and BISO fuel kernels in a typical unrodded region . . . . . . . . . 7-16 
7-14. BISO fuel EOL kernel migration at layer 1 . . . . . . . . 7-22

7-15. BISO fuel EOL kernel migration at layer 2 . . . . . . . . . 7-23

7-16. BISO fuel EOL kernel migration at layer 3 . . . . . . . . 7-24

7-17. BISO fuel EOL kernel migration at layer 4 . . . . . . . . 7-25

7-18. BISO fuel EOL kernel migration at 1ayer 5 . . . . . . . 7-26

7-19. BISO fuel EOL kernel migration at layer 6 . . . . . . . . 7-27

7-20. BISO fuel EOL kernel migration at layer 7 . . . . . . . . 7-28

7-21. BISO fuel EOL kernel migration at layer 8 . . . • • . • . . 7-29

7-22. Fraction of BISO fuel particle failure by migration at worst axial position... . . . . . . . . . . . 7-30

7-23. Time dependence of pressure vessel failure fraction, fluence and burnup in a typical unrodded region . . . . . . . . . 7-32

7-24. Axial profiles of TRISO and BISO end-of-1ife pressure vessel failure fractions in a typical unrodded region . . . . . . . 7-33

7-25. TRISO pressure vessel failure in layer 1 . . . . . . . . . 7-35

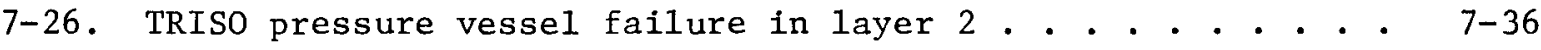

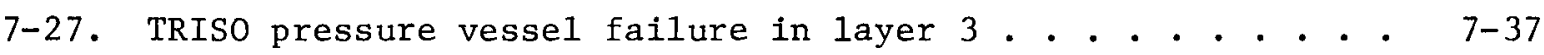

7-28. TRISO pressure vessel failure in layer 4 . . . . . . . . . 7-38

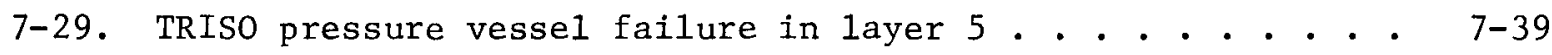

7-30. TRISO pressure vessel failure in layer 6 . . . . . . . . . . 7-40

7-31. TRISO pressure vessel failure in layer 7 . . . . . . . . . 7-41

7-32. TRISO pressure vessel failure in layer 8 . . . . . . . . . 7-42

7-33. Volume distributions of end-of-life fuel temperatures,

7-34. Time history of segment and core average TRISO pressure
vessel failure in the core. . . . . . . . . . . . . . 7-44

7-35. BISO pressure vessel failure in layer 1 . . . . . . . . . . 7-46

7-36. BISO pressure vessel failure in layer 2 . . . . . . . . . . 7-47

7-37. BISO pressure vessel failure in layer 3 . . . . . . . . . . 7-48

7-38. BISO pressure vessel failure in layer 4 . . . . . . . . . . 7-49

7-39. BISO pressure vessel failure in layer 5 . . . . . . . . . 7-50

7-40. BISO pressure vessel failure in layer 6 . . . . . . . . . . 7-51

7-41. BISO pressure vessel failure in layer 7 . . . . . . . . . 7-52

7-42. BISO pressure vessel failure in layer 8 . . . . . . . . . 7-53 
7-43. Time history of segment and core average BISO pressure vessel failure in the core . . . . . . . . . . . . 7-54

7-44. Typical peak fuel temperatures and burnups as compared with threshold temperature envelope of high temperature failure . 7-56

7-45. Time history of segment and core average TRISO manufacturing defects failure in the core . . . . . . . . . . . . .

7-46. Time history of segment and core average BISO manufacturing defects failure in the core . . . . . . . . . . . 7-58

7-47. Time history of core average TRISO fuel failure fraction by various mechanisms . . . . . . . . . . . . 7-60

7-48. Time history of core average BISO fuel failure fraction by various mechanisms . . . . . . . . . . . . 7-62

8-1. Time history of fraction of fissions occurring in fuel with failed coatings .................. 8-3

TABLES

2-1. Major core dimensions of $3000 \mathrm{MW}(\mathrm{t})$ reactor . . . . . . 2-4

2-2. Standard fuel element design parameters . . . . . . . . 2-12

2-3. Control fuel element design parameters . . . . . . . . . . 2-14

2-4. Coated particle design parameters . . . . . . . . . . . 2-20

2-5. Control rod design parameters . . . . . . . . . . . . 2-21

3-1. Representative plant transients in $3000 \mathrm{MW}(\mathrm{t})$ HTGR during 40 year plant life... . . . . . . . . . . . 3-16

3-2. Thermal design bases for HTGR core . . . . . . . . . . . 3-18

4-1. Codes used in core thermal and flow analysis . . . . . . . 4-2

5-1. Major core design parameters . . . . . . . . . . . . . 5-2

5-2. Flow resistances in different power regions . . . . . . . 5-5

5-3. Comparison of heat transfer correlations in turbulent flow region .................... . 5-10

5-4. Equivalent graphite conductance for unit cell . . . . . . 5-15

5-5. Fuel rod metal density and volume percentage of fuel particles in different blends of fuel rods . . . . . . . 5-25

5-6. Rod withdrawal schedule for six shim rod pairs . . . . . . 5-42

5-7. Maximum and minimum region peaking factors during seventh year of burnup study . . . . . . . . . . . . . . 5-46

5-8. Axial nodal points and fractional core length used in TREVER analysis . . . . . . . . . . . . . 5-52 
6-1. Core flow distribution in "no-crossflow" case . . . . . 6-8

6-2. Core flow distribution in 10 mil "crossflow" case . . . . . 6-13

6-3. Region crossflow factors for high and low power regions . . 6-17

6-4. Region flow distribution during seventh year of $3000 \mathrm{MW}(t)$ core operation . . . . . . . . . . . . . . . 6-24

6-5. Expected flow control valve coefficient during seventh year of $3000 \mathrm{MW}(t)$ core operation . . . . . . . . . 6-26

6-6. Core power, flow and helium exit temperatures in variable and fixed orifice regions during seventh year of operation . 6-30

6-7. Comparison of BACH and TREVER results at locations of maximum tilt in column and maximum difference in calculated temperature .................... 6-75

6-8. Comparison of $\mathrm{BACH}$ and TREVER calculations at point of maximum fuel temperature................ 6-76

6-9. Comparison of DETRAC and TAC-2D results for a 100-60-100\% load following transient at the end of seventh fuel block a 6-101 


\section{INTRODUCTION}

The thermal energy produced within the active core and reflector elements of the High-Temperature Gas-Cooled Reactor (HTGR) core is removed by a downward flow of helium coolant. The thermal and fluid flow characteristics are established to ensure the integrity of the fuel particles, fuel rods, and fuel elements. This is achieved by the use of high temperature refractory materials, by the choice of a sound geometrical configuration, and by optimization of core power distribution and flow distribution to control core temperature.

This report describes in detail how the thermal analysis of commercial HTGR cores is carried out. The first five sections present necessary background information required to understand the thermal analysis. Sections are presented describing the core and core components, the basis for the design, analytical methods used to carry out design calculations, and the basic data required for thermal design. In each of the first five sections, information on related design efforts such as core geometry, nuclear design, and coated particle performance is included to the extent that it is relevant to core thermal design. Since these interfacing discussions are necessarily brief, references to more detailed treatments are provided in the text.

In carrying out the thermal analysis of the core, the flow of information is as shown in Fig. 1-1. Thermal properties of core materials are obtained as part of the fuel and graphite irradiation programs (Refs. 1-1, 1-2). A nuclear design is carried out that yields the core power distribution, the isotopic composition of the fuel (burnup), and the neutron flux and fluence distribution. These nuclear parameters are available for times 


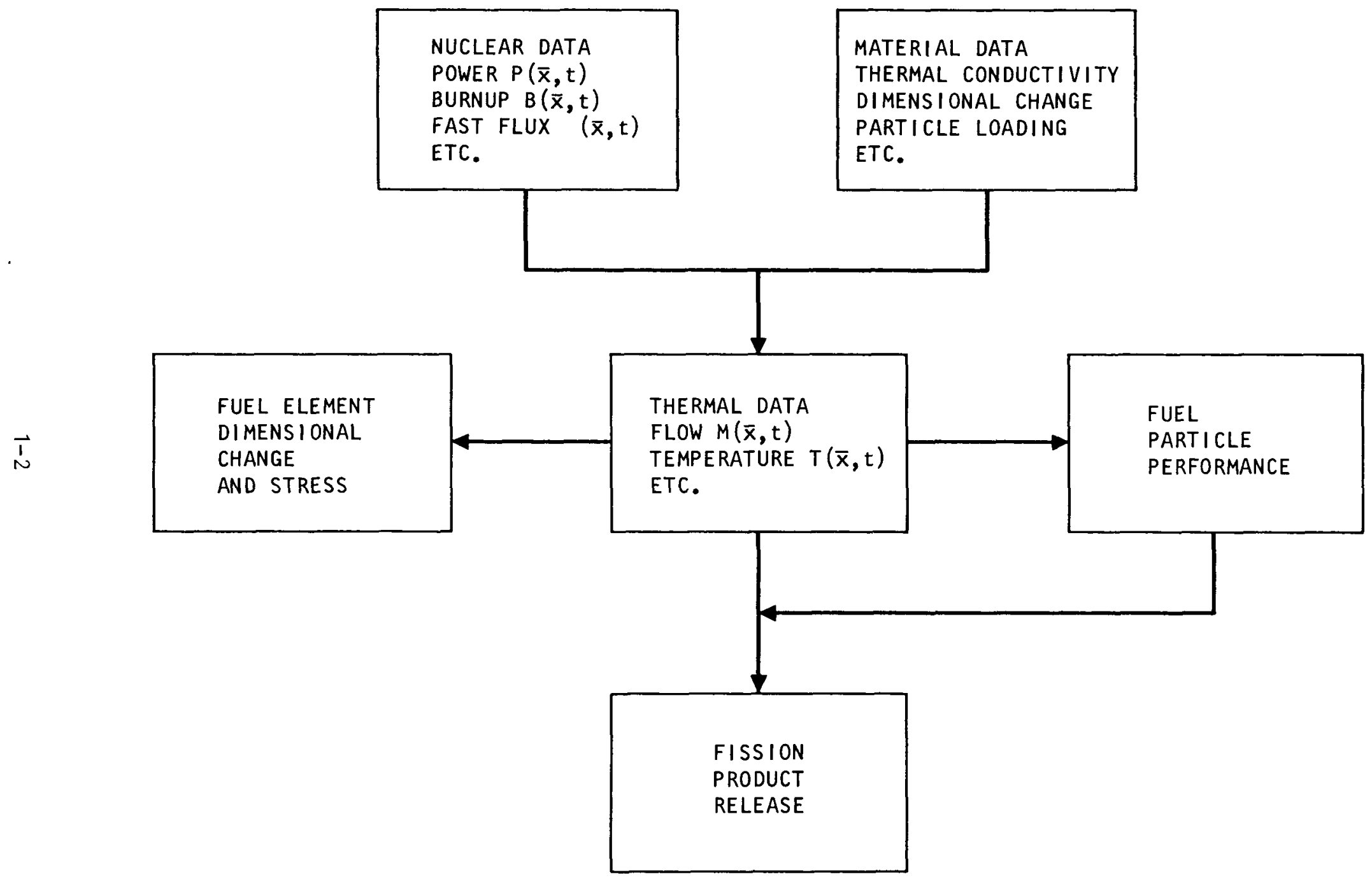

Fig. 1-1. Core thermal design information flow diagram 
throughout the life of the fuel during normal operation and for various transient modes of core operation (Ref. 1-3). As indicated in Fig. 1-1, the resulting temperature as a function of position and time is used in evaluation of (1) fuel particle integrity (Ref. 1-4), (2) dimensional change and stress within the fuel elements (Ref, 1-5), and (3) release rate of fission products (Refs. 1-6, 1-7).

Sections 6,7 , and 8 of this report contain detailed results of analyses of core flow, temperature, and fuel particle coating integrity. Specific results presented represent the status of the core design as of October 1974. 
1-1 Harmon, D. P., and Scott, C. B., "Irradiation Performance and Development of HTGR Fuel," General Atomic Report GA-A13173, to be published.

1-2 Engle, G. B., et al., "Development Status of Near-Isotropic Graphites for Large HTGRs," General Atomic Report GA-A12944, June 1, 1974.

1-3 Hamilton, C. J., "Power Distribution in Large HTGRs," General Atomic Report GA-A13007, December 1974.

1-4 Smith, C. L., "Fuel Particle Behavior Under Normal and Transient Conditions," General Atomic Report GA-A12971, October 1974.

1-5 "Materials and Integrity of Core Structure," General Atomic Report GA-A13188, to be published.

1-6 Haire, M. J., and D. W. McEachern, "Gaseous Radioactivity in the Primary Coolant of an HTGR," General Atomic Report GA-A12946, October 1974.

1-7 "General Atomic Standard Safety Analysis Report," General Atomic Report GA-A13200, Section 11.1, 1974. 


\section{CORE DESCRIPTION}

\subsection{REACTOR CORE}

The active core has the approximate shape of a right-circular cylinder.* It is surrounded by graphite reflector elements above, below, and around the active core. The core is contained within the central cavity of the prestressed concrete reactor vessel (PCRV). Figure 2-1 shows the reactor core in relation to the other main components in the nuclear steam supply (NSS) systems. A 3000 lW(t) plant has six primary coolant loops and three auxiliary coolant loops which surround the core. Helium from the upper cross-ducts flows into the plenum above the core, then downward through the core, removing the energy generated in the core. In the lower plenum of the core, the coolant flows radially outward into the six steam generators where the energy is transferred to the secondary coolant to produce high-pressure, high-temperature steam.

The core assembly consists of vertical columns of hexagonal fuel elements arranged on a uniform triangular pitch. These columns are grouped into refueling regions consisting of a control column surrounded by six or less standard fuel element columns, as shown in Fig. 2-2. Important core dimensions are summarized in Table 2-1. The $3000 \mathrm{lW}(t)$ reactor has 61 refueling regions containing 7 columns of fuel elements, 12 refueling regions containing 4 columns, and 18 single columns at the outer edge of the core which form the approximately circular core. Commercial HTGRs use a 4-year fuel cycle, in which approximately $25 \%$ of the core (called a segment) is refueled at each reload on a nominally annual basis. The four segments of the core are distributed as shown in Fig. 5-12 to give a symmetric radial power distribution.

\footnotetext{
*Ref. 2-1 contains a detailed description of the $3000 \mathrm{MW}(t)$ core.
} 


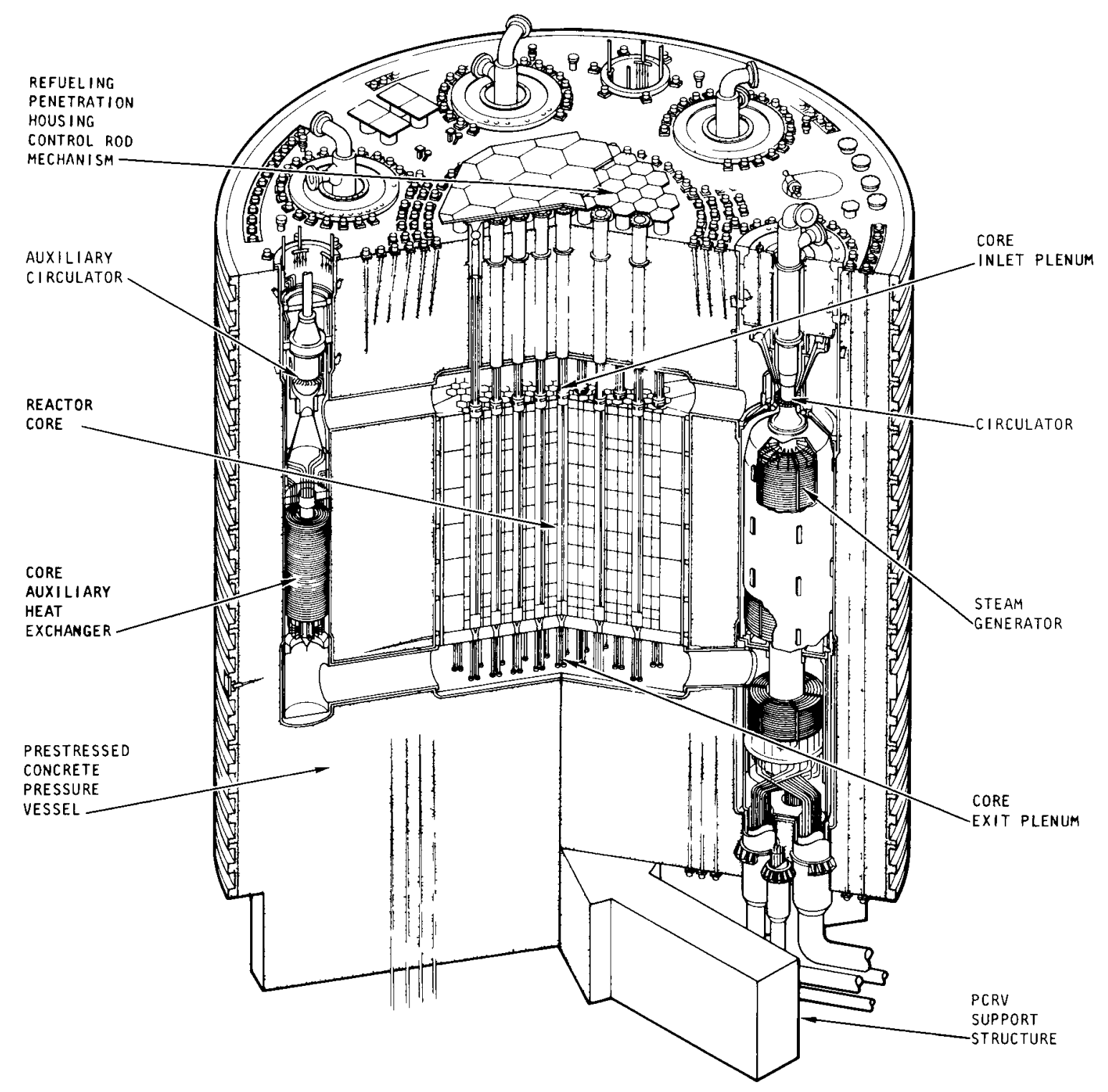

Fig. 2-1. $3000 \mathrm{MW}(\mathrm{t})$ HTGR general arrangement 


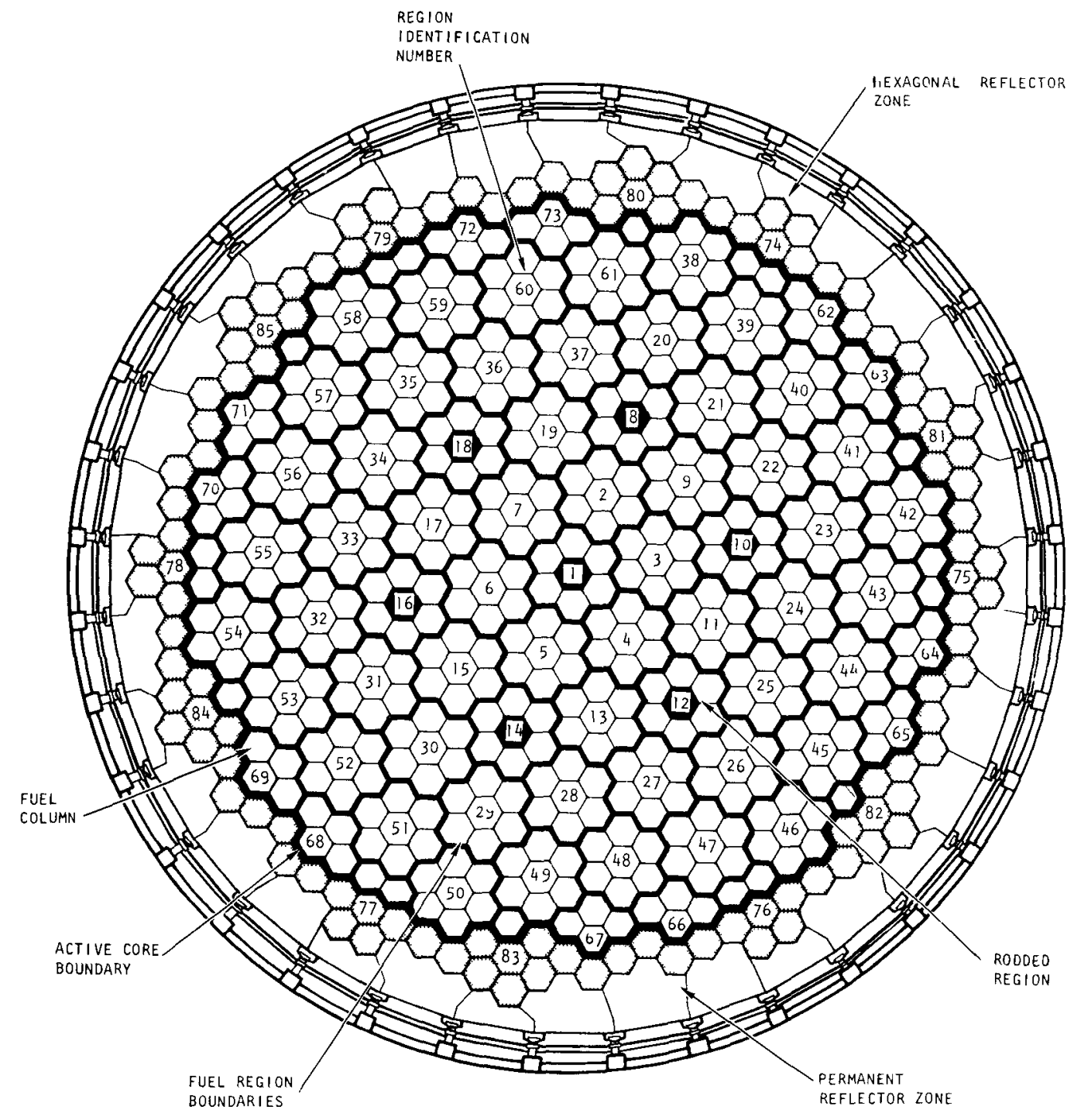

Fig. 2-2. $3000 \mathrm{MW}(\mathrm{t})$ core plan 
TABLE 2-1

MAJOR CORE DIMENSIONS OF 3000 MW( $(t)$ REACTOR

\begin{tabular}{l|l}
\hline & \\
Thermal power, MW(t) & 3000 \\
Effective core diameter, ft & 27.8 \\
Active core height, ft & 20.8 \\
Number of fuel elements & 3944 \\
Number of fuel columns & \\
Standard & 420 \\
Control & 73 \\
Reflector thickness, ft & \\
Top & 3.9 \\
Bottom & 3.9 \\
Side (mean) & 4.5 \\
Core support block height, ft & 2.9 \\
Number of flow regions & \\
Full 7 column & 61 \\
Partial 4 column & 12 \\
Single fixed-orifice columns & 18 \\
Total & 91 \\
Number of control rod drives & 73 \\
Number of control rods & 146 \\
\hline
\end{tabular}




\subsection{REFUELING REGION}

A refueling region consists of seven columns of fuel elements. The columns rest on a single, large, graphite core support block having the same outline as the seven column region. The vertical columns that make up the refueling region include fuel, control, and reflector elements as shown by the schematic in Fig. 2-3. A typical fuel or control column consists of two bottom reflector elements, eight fuel elements, two top reflector elements, and a metallic plenum element. The elements within the central column of each region are displaced axially downward relative to the elements in the surrounding six columns. This offset is a mechanical design feature that prevents the possibility of a continuous shear plane at element interfaces across the core. Each refueling region is located directly below a refueling penetration which, during operation, contains a control rod drive assembly. Two parallel channels are provided for inserting two control rods into the central column of each refueling region. A third channel is provided in the same column for inserting reserve shutdown absorber material. The seven-column regions are keyed at the top by metal plenum elements, which provide a plenum chamber and a valve body for the variable flow control valve (orifice valve). The flow control valve assembly rests on the control colum and admits coolant flow into the top of the control column and, through openings in each of the top plenum elements, to the surrounding six standard fuel columns. The valve is shown in Fig. 2-4.

Four thermocouples, two of which provide readings of region average helium outlet temperature to the operator at all times during operation, are located in a horizontal graphite probe held in the core support block, as shown in Fig. 2-5. During operation of the reactor, the operator uses the average coolant temperature reading from each of the regions as a basis for adjusting the region's coolant flow rate using the region's flow control valve. 


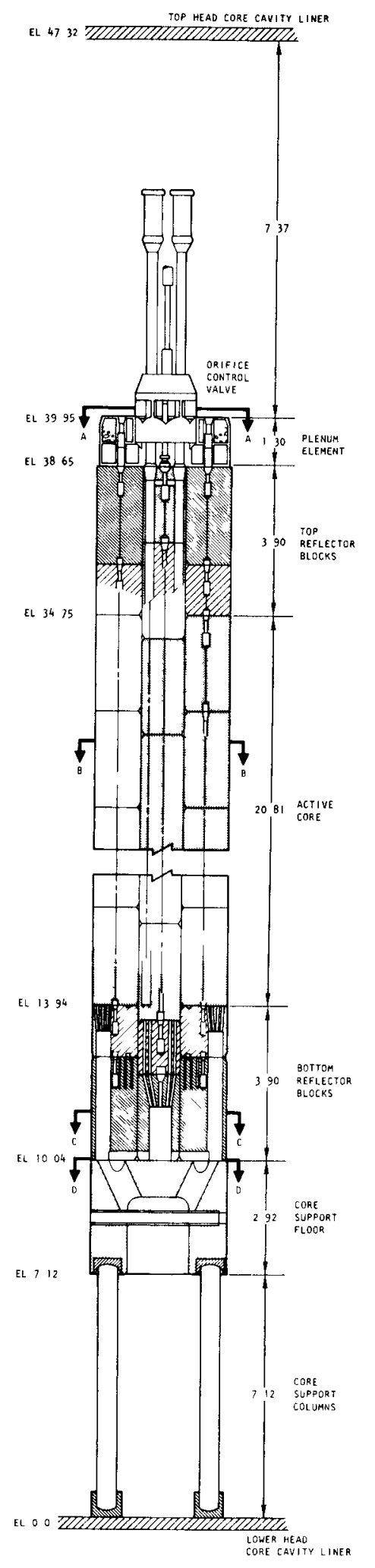

Fig. 2-3. Seven column refueling region 2-6 


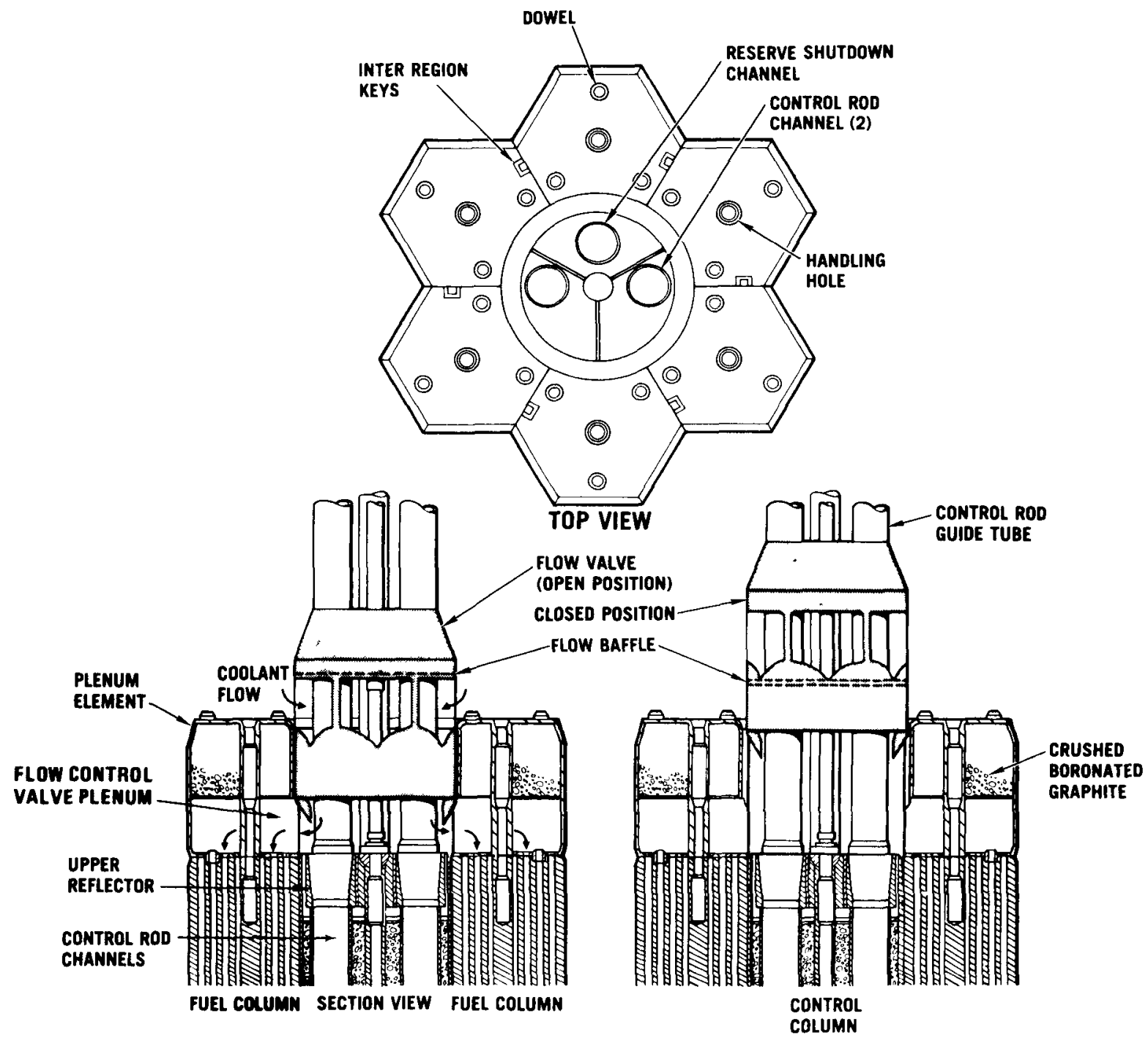

FLOW VALVE IN OPEN POSITION

FLOW VALVE IN CLOSED POSITION

Fig. 2-4. Flow control valve and plenum arrangement 


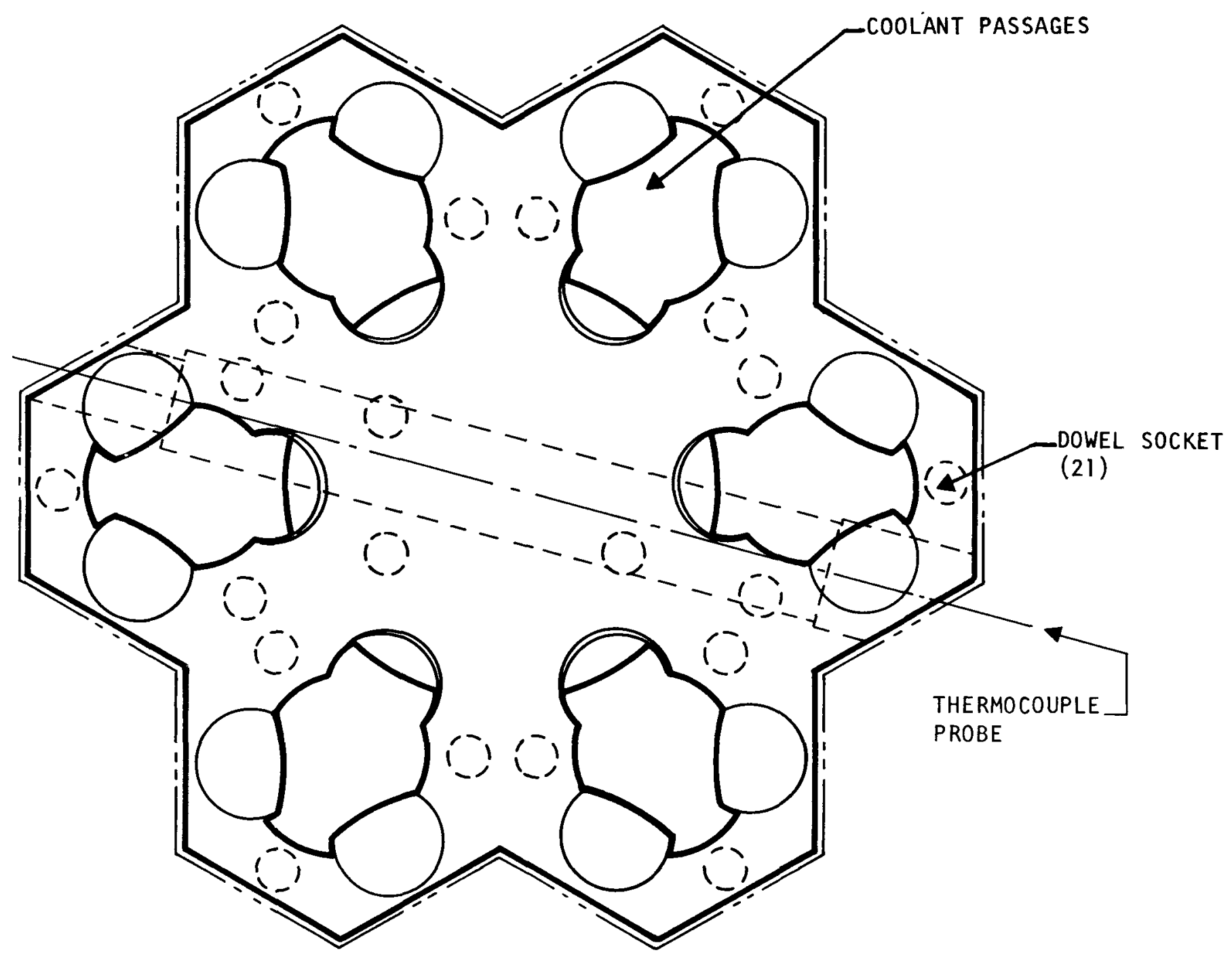

Fig. 2-5. Thermocouple probe and core support floor 


\subsection{FUEL ELEMENTS}

Individual fuel elements are right-regular prisms 31.2 in. high with a hexagonal cross section of 14.17 in. across the flats. A standard fuel element is depicted in Fig. 2-6. Coolant channels extending through each element align with coolant channels in the elements above and below. The active fuel is contained in an array of holes that are parallel with the coolant channels. The fuel holes are drilled blind from the top face of the element and are filled with bonded fuel rods of coated fuel particles. The fuel rods and coolant channels are distributed on a triangular array with an ideal ratio of two fuel rods for each coolant channel. Table 2-2 gives fuel element parameters needed in the thermal design.

Figure 2-7 shows the control rod fuel element used in the center column of each region. This element is similar to the standard element but contains enlarged channels for the two control rods and the reserve shutdown absorber material. The major control fuel block parameters are given in Table 2-3.

Three graphite dowels are located on the top face of each element. These dowels fit into mating socket holes in the bottom face of the element above to keep the coolant channels aligned at all times. Located in the center of each fuel and reflector element is a handling hole, and at the six corners of each standard fuel element there are blind holes for burnable poison rods containing boron carbide.

\subsection{FUEL RODS AND PARTICLES}

The HTGR fuel consists of BISO- and TRISO-coated particles incorporated into fuel rods with a matrix consisting of an organic binder and graphite filler which is carbonized and heat treated to yield a carbonaceously bonded rod. The metallographic cross section of a typical fuel 


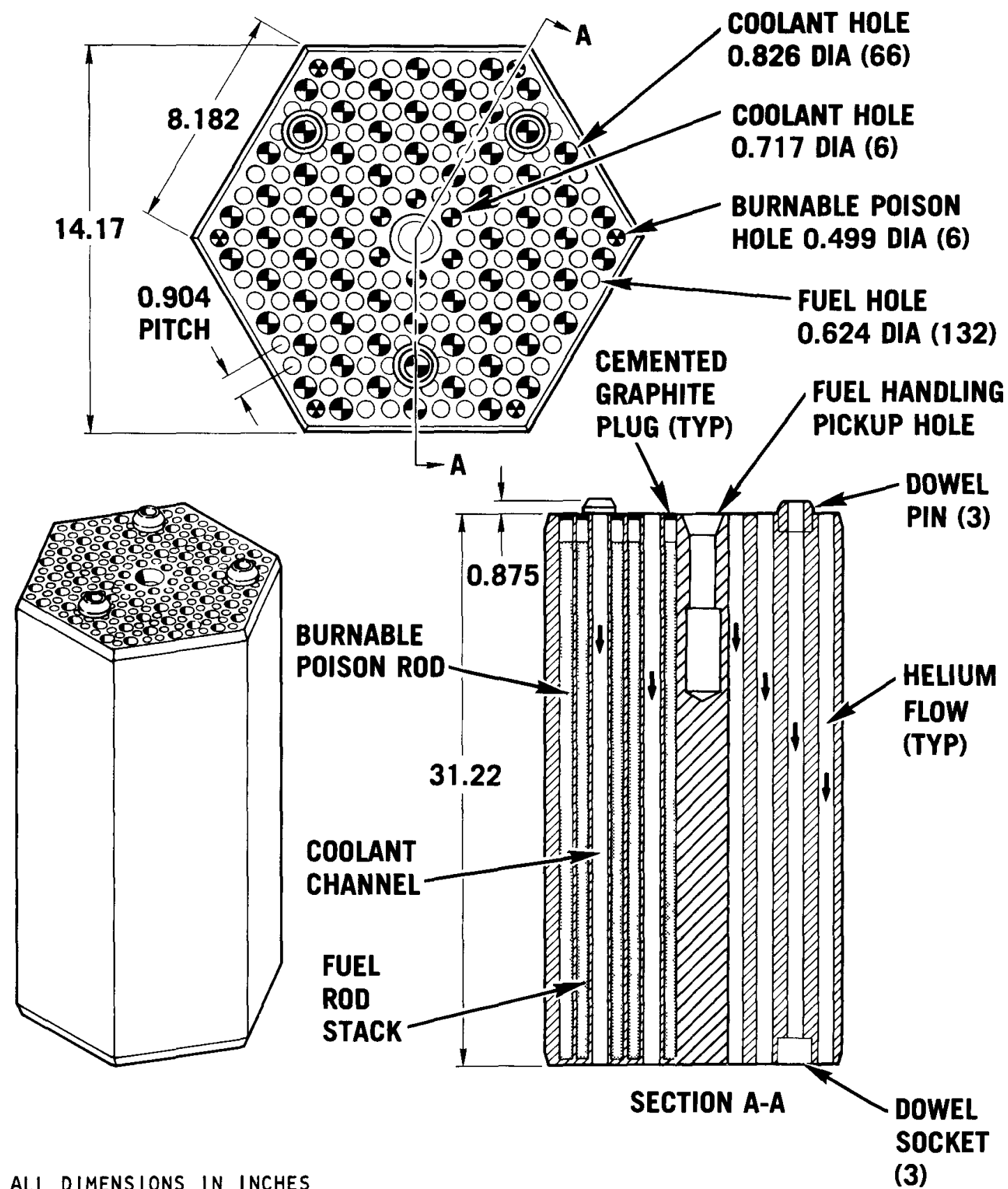

ALL DIMENSIONS IN INCHES

(3)

Fig. 2-6. Standard fuel element 


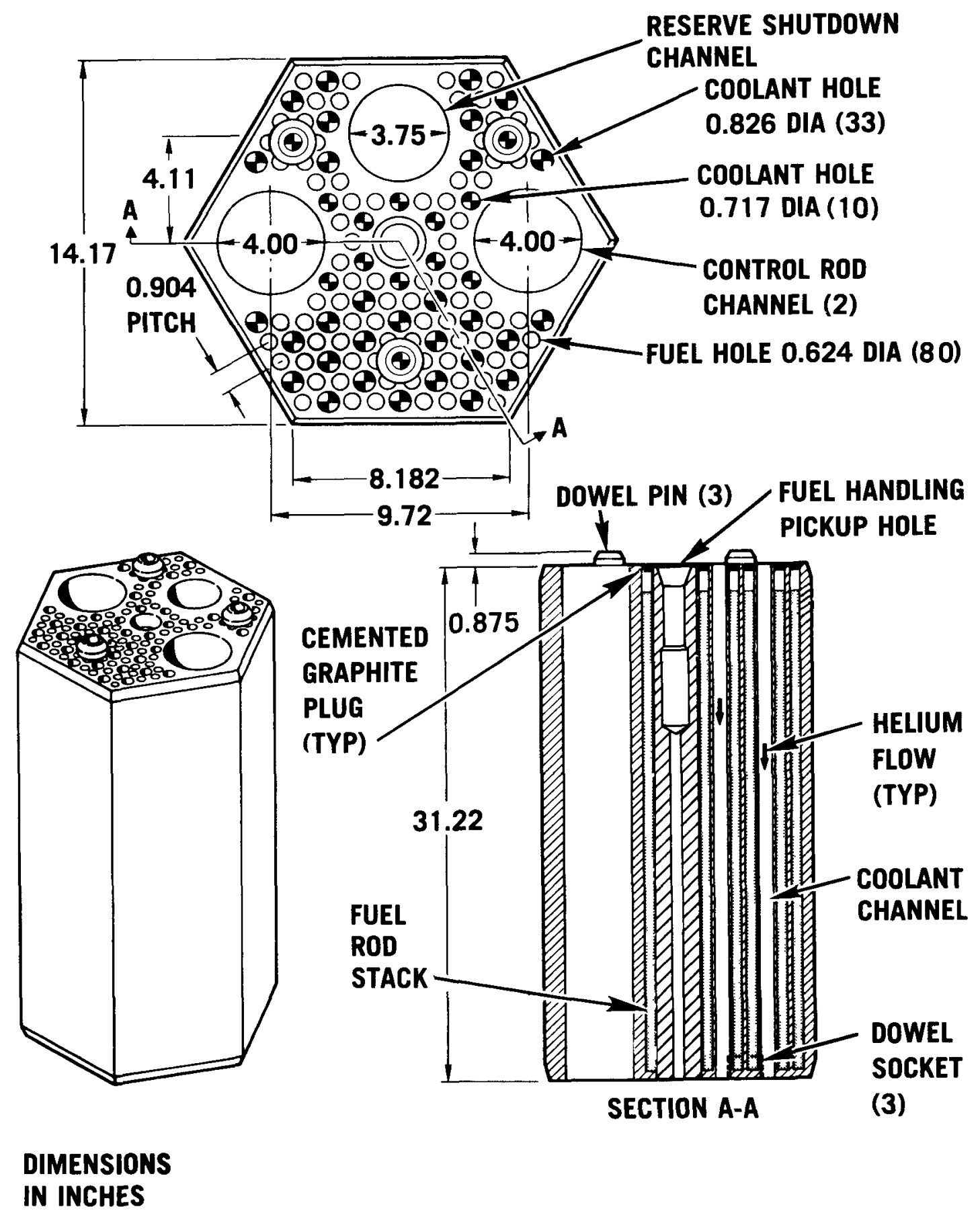

Fig. 2-7. Control fuel element 


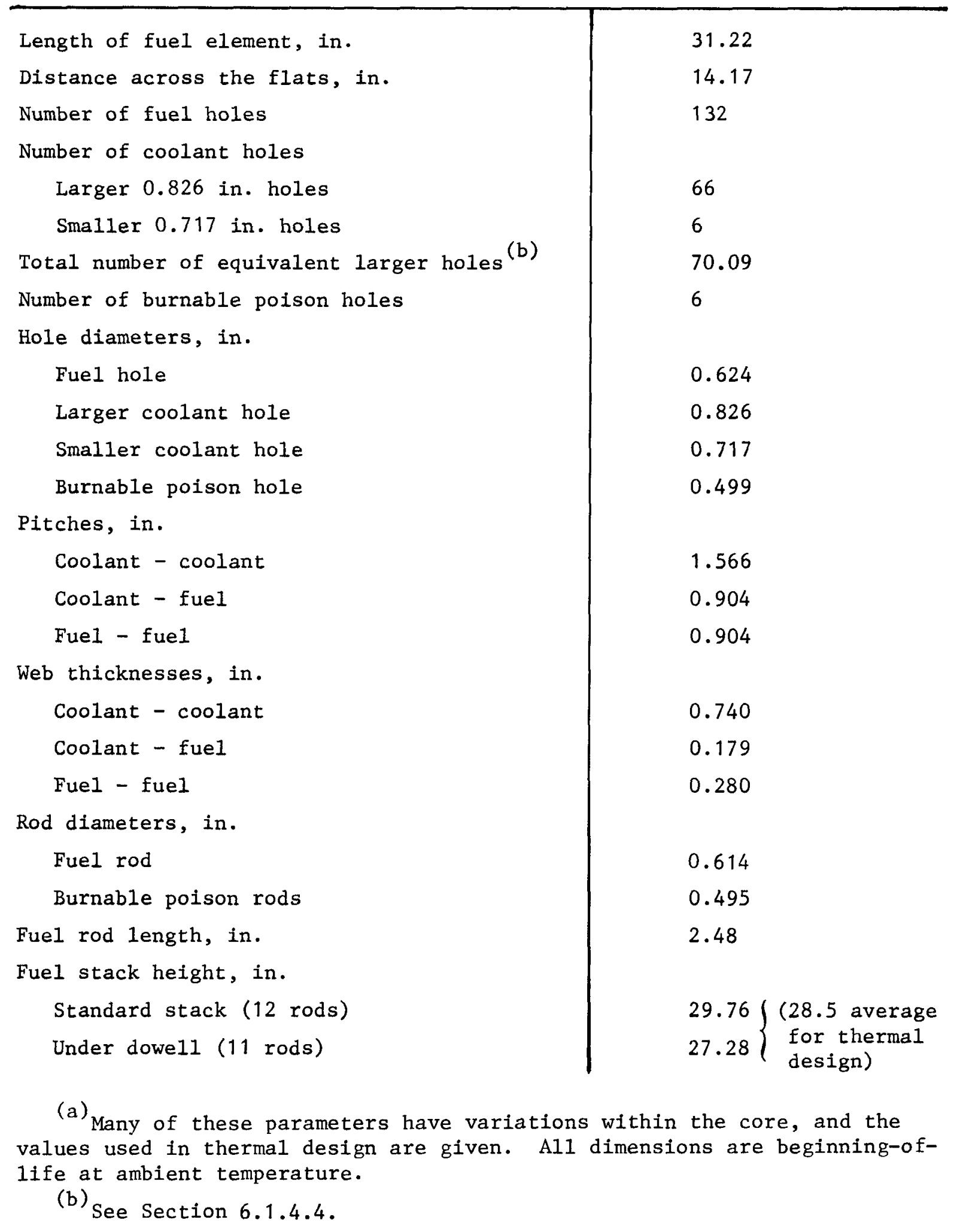


TABLE 2-2 (Continued)

\begin{tabular}{l|r}
\hline Mass of an average element, lbm & 184 \\
Graphite fuel element & 77 \\
Fuel rods & 2 \\
Burnable poison & 263 \\
Total assembly & \\
\hline
\end{tabular}


TABLE 2-3

CONTROL FUEL ELEMENT DESIGN PARAMETERS ${ }^{(a)}$

\begin{tabular}{|c|c|}
\hline 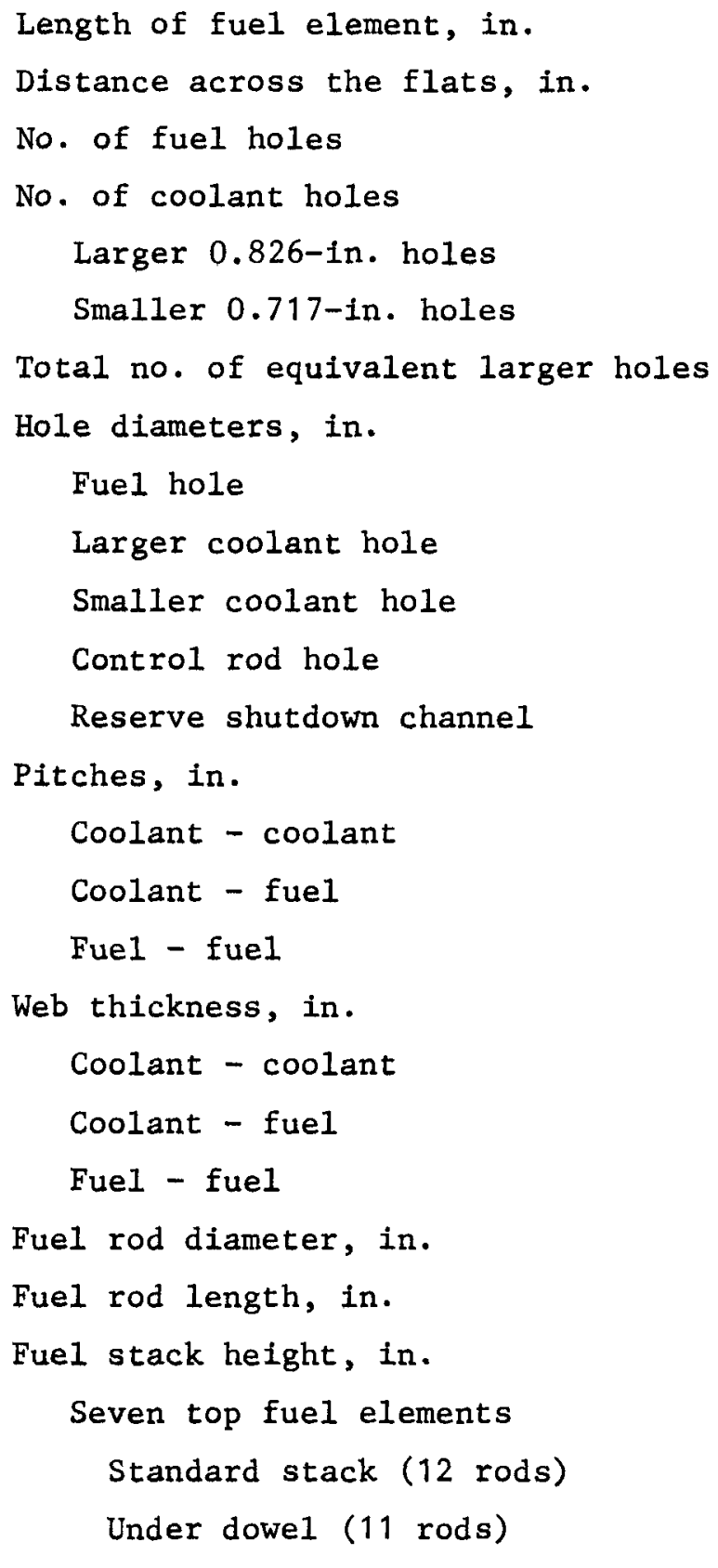 & $\begin{array}{l}0.740 \\
0.179 \\
0.280 \\
0.614 \\
2.48\end{array}$ \\
\hline
\end{tabular}

(a) Many of these parameters have variations within the core, and values used in thermal design are given. 


\section{TABLE 2-3 (Continued)}

\begin{tabular}{|c|c|}
\hline $\begin{array}{l}\text { Bottom-most fuel element } \\
\text { Standard stack ( } 9 \text { rods) } \\
\text { Under dowel ( } 8 \text { rods) } \\
\text { Mass of average element, lbm } \\
\text { Top seven fuel elements } \\
\text { Graphite fuel element } \\
\text { Fuel rods } \\
\text { Total assembly } \\
\text { Bottom-most fuel element } \\
\text { Graphite fuel element } \\
\text { Fuel rods } \\
\text { Total assembly }\end{array}$ & $\begin{array}{l}22.32 \\
19.84\left\{\begin{array}{l}(21.0 \text { in. average } \\
\text { for thermal } \\
\text { design })\end{array}\right. \\
179 \\
46 \\
225 \\
197 \\
30 \\
227\end{array}$ \\
\hline
\end{tabular}


rod is shown in Fig. 2-8. In the HTGR core design, fissile and fertile materials are zoned within the core in both the radial and axial directions. This zoning is achieved by using fuel elements containing different masses of fissile and fertile materlal distributed uniformly within the fuel rods. The fuel rods in all fuel elements have the same dimensions. Varying amounts of high-conductivity granulated graphite are used as shim to make the volume of all the fuel rods equal. The shim is uniformly mixed with the fissile and fertile particles before the rod is formed to produce a homogeneous mixture of particles.

The HTGR is designed to operate on the U-235/Th-232 fuel cycle (Ref. 2-2). Fissile fuel particles for the HTGR consist of spherical $\mathrm{UC}_{2}$ kernels coated with layers of pyrolytic carbon (PyC) and silicon carbide (SiC). This combination of PyC and SiC is referred to as a "TRISO" coating. The fissile fuel kernels are $93 \%$ enriched in U-235. The fertile fuel consists of spherical $\mathrm{ThO}_{2}$ kernels coated with two layers of pyrolytic carbon. This type of coating is referred to as a "BISO" coating. The two particle types are illustrated in Fig. 2-9. The coated particle design parameters are summarized in Table 2-4. (Ref. 2-3.)

\subsection{CONTROL ROD SYSTEM}

Core reactivity is controlled by pairs of control rods inserted into the central column of each refueling region. These rod pairs are moved in and out by electrically powered control rod drives located in PCRV penetrations above the central colum of each region. Each control rod consists of a series of absorber sections held together by a metal spine passing through the center of the assembly, as shown in Fig. 2-10. The major design parameters of the control rod system are given in Table 2-5.

The neutron absorber rod section consists of two concentric sleeves, which are closed at each end. The sleeves enclose graphite compacts 


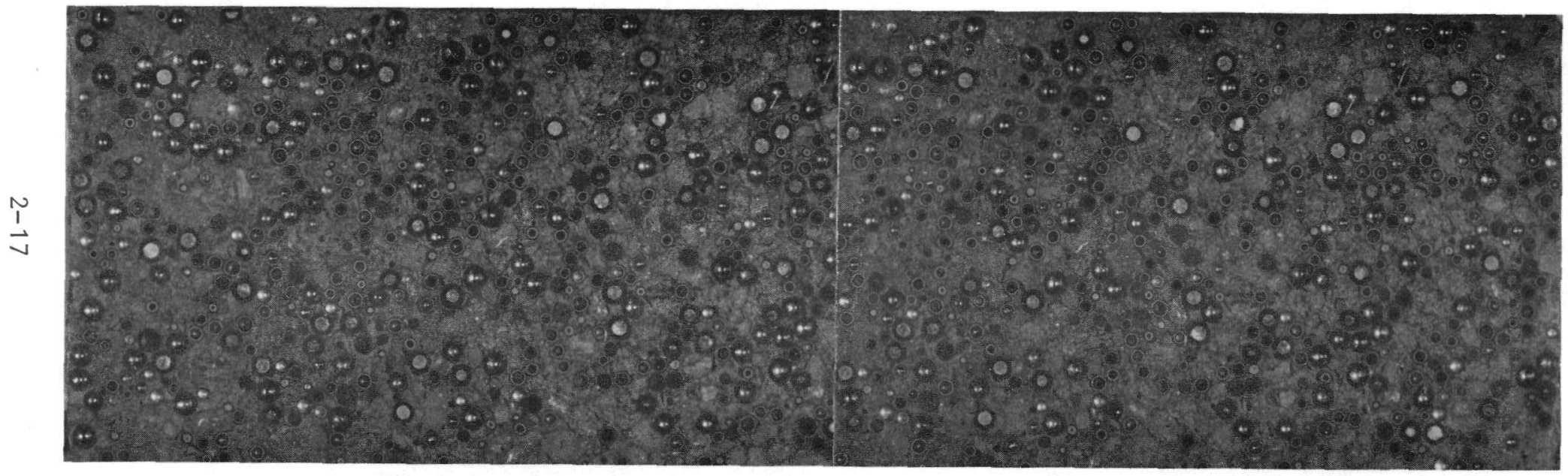

Fig. 2-8. Metallographic cross section of a typical HTGR fuel rod 


\section{FISSILE COATED FUEL PARTICLE}
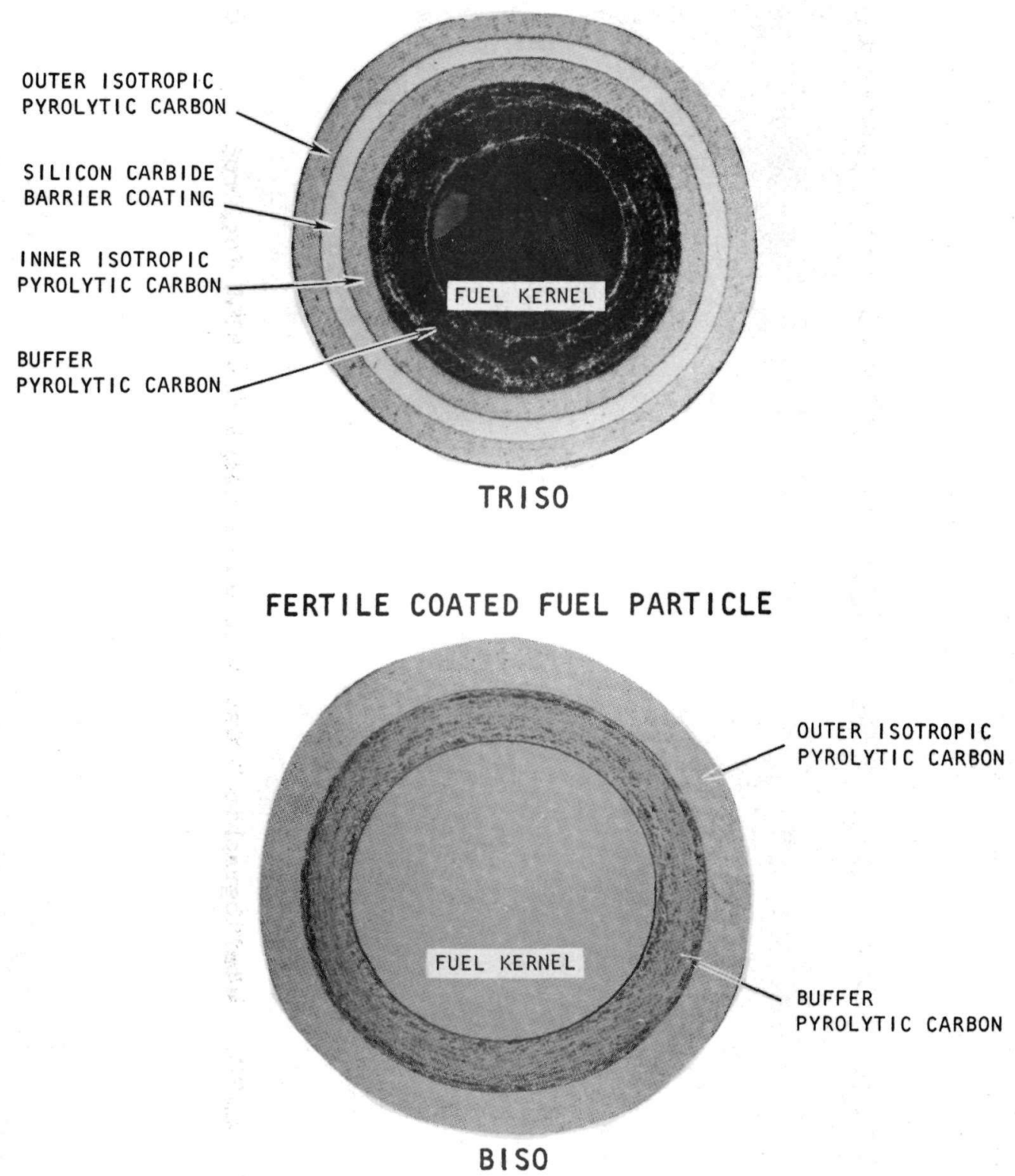

Fig. 2-9. Typical TRISO and BISO fuel particles 

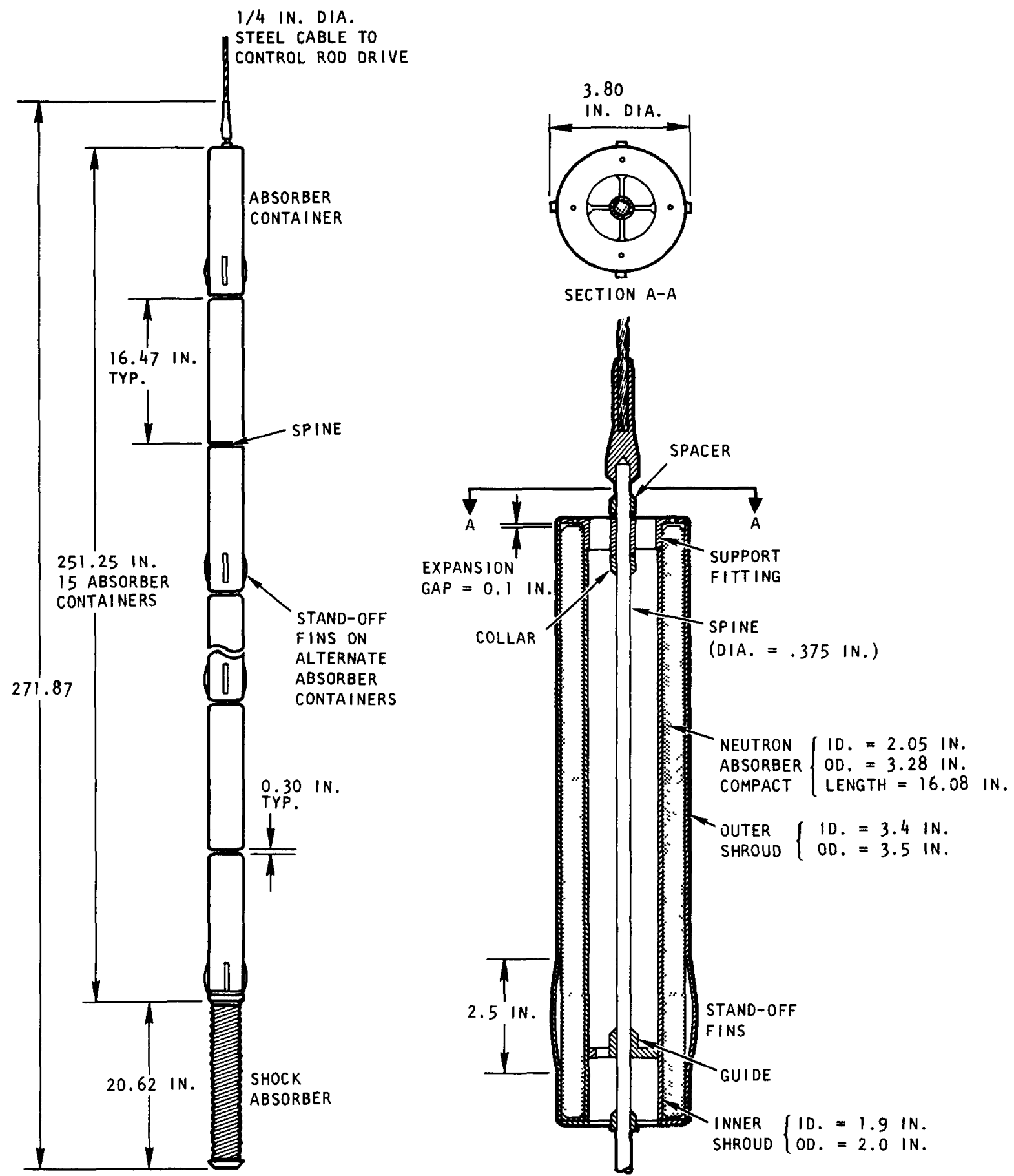

Fig. 2-10. Control rod assembly and absorber container details 2-19 
TABLE 2-4

COATED PARTICLE DESIGN PARAMETERS

\begin{tabular}{l|c}
\hline & $\begin{array}{c}\text { Dimensions } \\
\text { (microns) }\end{array}$ \\
\hline TRISO & 200 \\
Fue1 kernel (UC ${ }_{2}$ ) diameter & 100 \\
Buffer coating thickness & 25 \\
Inner isotropic PyC & 25 \\
Silicon carbide & 35 \\
Outer isotropic PyC & \\
& \\
BISO & 500 \\
Fuel kernel (Th0 ${ }_{2}$ ) diameter & 85 \\
Buffer coating thickness & 75 \\
Isotropic PyC & \\
\hline
\end{tabular}


TABLE 2-5

CONTROL ROD DESIGN PARAMETERS

\begin{tabular}{l|c}
\hline Geometry & 0.050 \\
Cladding thickness, in. & 0.06 \\
Compact - cladding gap, in. & 3.28 \\
Compact OD, in. & 2.05 \\
Compact ID, in. & 0.375 \\
Spine OD, in. & 3.50 \\
Total control rod OD, in. & 4.00 \\
Control rod channel ID, in. & \\
Heat transfer parameters & 13.0 \\
Cladding conductivity, Btu/hr-ft- ${ }^{\circ} \mathrm{F}$ & 3.0 \\
Compact conductivity, Btu/hr-ft ${ }^{\circ} \mathrm{F}$ & \\
Mass flow rates, $1 \mathrm{bm} / \mathrm{hr}$ & 1032 \\
Fully rodded $\{$ inner channel & 688 \\
Unrodded & 1870 \\
\hline
\end{tabular}


containing boron in the form of boron carbide. During reactor operation, primary coolant flows down the control rod channels in the core to cool the rods. This flow, from the upper core plenum, enters the channels through holes drilled in the walls of the control rod guide tube. Part of the flow passes down the annular space between the wall of the fuel element channel and the outside of the control rods. The remainder of the flow passes through the center of the control rods, cooling the rods' central spine. The exit passage for the cooling gas from the control rod channels is in the lower reflector of the control column. The flow through the control rod channels is controlled by a short circular passage machined in the bottom reflector of the control column. The helium flow in the control rod channel is not strongly dependent on whether or not the control rod is inserted into the core. 


\section{REFERENCES}

2-1 "General Atomic Standard Safety Analysis Report," General Atomic Report GA-A13200, Section 4.2, 1974.

2-2 Dahlberg, R. C., R. F. Turner, and W. V. Goeddel, "HTGR Fuel and Fuel Cycle Summary Description," General Atomic Report GA-A12801 (Rev.), January 21, 1974.

2-3 Smith, C. L., "Fuel Particle Behavior Under Normal and Transient Conditions," General Atomic Report GA-A12971, October 1974. 


\section{DESIGN BASES}

The HTGR core thermal design bases have been established to protect the integrity of the fission product barriers and the integrity of the coolant flow geometry. Fuel particle coatings are the primary fission product barrier in the core, while fuel kernels, fuel rod matrix, and the graphite web between the fuel rod and coolant channel act as secondary barriers to the escape of fission products from the core. The prestressed concrete reactor vessel (PCRV) and its liner, penetrations, and closures are a second fission product barrier. A secondary containment structure surrounds the PCRV acting as another effective barrier.

The flow control valves and the core lateral and lower support structure, along with the graphite fuel and reflector elements, define the coolant flow geometry in the core.

To understand the HTGR thermal design basis for fuel particles and other core components, a brief review of the thermal characteristics of core material (Ref. 3-1) and a discussion of fuel particle behavior are helpful. Given below are the thermal characteristics of various HTGR core materials and a brief summary of fuel particle technology. This is followed by statements of the thermal design bases for the fuel and other core components.

3.1. THERMAL CHARACTERISTICS OF CORE MATERIALS

HTGRs use helium as a coolant. Helium has the advantage of being a gas that is chemically inert and noncorrosive; it has a low neutron capture cross section and has good heat transfer characteristics. Because of its 
inertness, helium is compatible with the fuel elements and structural material at all temperatures. The thermal properties of helium are well known and no absolute temperature limit for the core is dictated by the helium coolant.

Graphite, which is used as the core structural material and moderator, has desirable nuclear characteristics and is ideally suited for hightemperature operation. It does not melt but sublimes at temperatures over $6000^{\circ} \mathrm{F}$. Due to its high thermal conductivity, the temperature gradients in the graphite fuel elements are low. Also, the high heat capacity of the large mass of graphite [about 3 million pounds for the 3000 MW( $t)$ HTGR] ensures that any core temperature transients resulting from reactivity changes and interruptions in cooling will be slow and controllable. The use of all-ceramic fuel allows the core to operate at very high temperatures without melting any fuel components.

\subsection{SUIMARY OF FUEL PARTICLE BEHAVIOR}

Fuel design and development at GA is directed toward comprehensive testing of both TRISO fissile and BISO fertile fuel particles and their performance in fuel rods (Ref. 3-2). These fuel particles are part of the family of multilayer coated particles developed at GA during the past several years. Each coating layer serves a specific function in preserving the integrity of the particles as the primary fission product barrier. The inner buffer layer of low-density PyC attenuates fission recoils and provides void volume for accumulated fission gases and for fuel kernel swelling. The inner layer of dense isotropic PyC provides high-temperature containment to fission product gases and, for the TRISO particles, protects the SiC from reactions with the fission products. The outer layer of dense isotropic PyC acts as a backup containment and, in the TRISO particles, provides mechanical support for the SiC. The outer coating layer provides mechanical strength for the particles and acts as a pressure vessel that 
can withstand the stresses resulting from fission gas pressure, swelling of fuel, and radiation-induced densification of the PyC. Both BISO and TRISO coatings provide essentially absolute containment of gaseous fission products. The SiC layer in the TRISO coatings is an excellent barrier to the escape of all metallic fission products from the particle. However, those more volatile fission product metals such as cesium and strontium will gradually diffuse through the PyC layer of the BISO coating over a long period of time.

For the past several years a number of in-pile irradiation tests and out-of-pile heating tests have been performed on BISO- and TRISO-coated fuel particles; they have shown that particle performance is generally limited by four major mechanisms. First, the particle performance is limited by kernel migration, which is the tendency of fuel kernels within a particle to migrate in a temperature gradient toward the hot side of the particle. This migration of fuel kernels within the particles is also known as the "amoeba effect." The second mechanism by which the particle designs are limited is the failure resulting from high coating stresses. The stresses are directly related to particle geometry and to irradiation effects. This pressure vessel type failure of coatings occurs as increasing fission gas pressures and coating densification cause the coatings to be stressed beyond failure limits. The third mechanism is the degradation of the SiC coating in TRISO particles, by chemical reactions between metallic fission products and $\mathrm{SiC}$ coatings at very high temperatures. A small fraction of particles in the core contain missing or incomplete coating layers; the coatings on these particles are expected to fail in service. Each of these particle limits is briefly discussed below; more details are given in Ref. 3-2.

\subsubsection{Kerne1 Migration}

When a temperature difference is imposed across the diameter of a fuel particle kernel, the fuel kernel moves relative to the coating in the 
direction of the hotter side of the kernel. Thermal stability of coated particles in a temperature gradient has been well characterized by workers at GA and at other laboratories (Refs. 3-3, 3-4). Movement of the $\mathrm{UC}_{2}$ kernels of fissile particles results from the following three processes:

1. Carbon from the coating is taken into solution in the kernel on the hot side.

2. Carbon is transported by thermal diffusion down the temperature gradient in the kernel.

3. Carbon is rejected as a graphite on the cool side of the kernel.

The net effect of this mechanism is the movement of the kernel toward the hotter side of the coated particle into the portion of the coating from which the carbon has been removed. Figure 3-1 shows a diametral section of a fuel rod that has been irradiated in a fuel capsule experiment. Generation of heat within the fuel rod and cooling from the outer surface of the rod induced a temperature difference between the hotter center of the rod and the cooler rod surface. The tendency of fuel kernels to move toward the hotter center portion of the rod can easily be seen. One of the kernels from the cross section has been enlarged and is shown at the top of the figure.

Several out-of-pile and in-pile measurements have been made, and the temperature and temperature difference dependence of kernel migration rate in both irradiated and unirradiated carbide particles has been determined. Irradiated kernels migrated at a rate equal to or less than the migration rates of unirradiated particles under identical conditions. The experimental correlation between kernel migration, temperature, and gradient for unirradiated $\mathrm{UC}_{2}$ TRISO particles and $\mathrm{ThO}_{2} \mathrm{BISO}$ particles is shown in Fig. 3-2 (Ref. 3-2). 


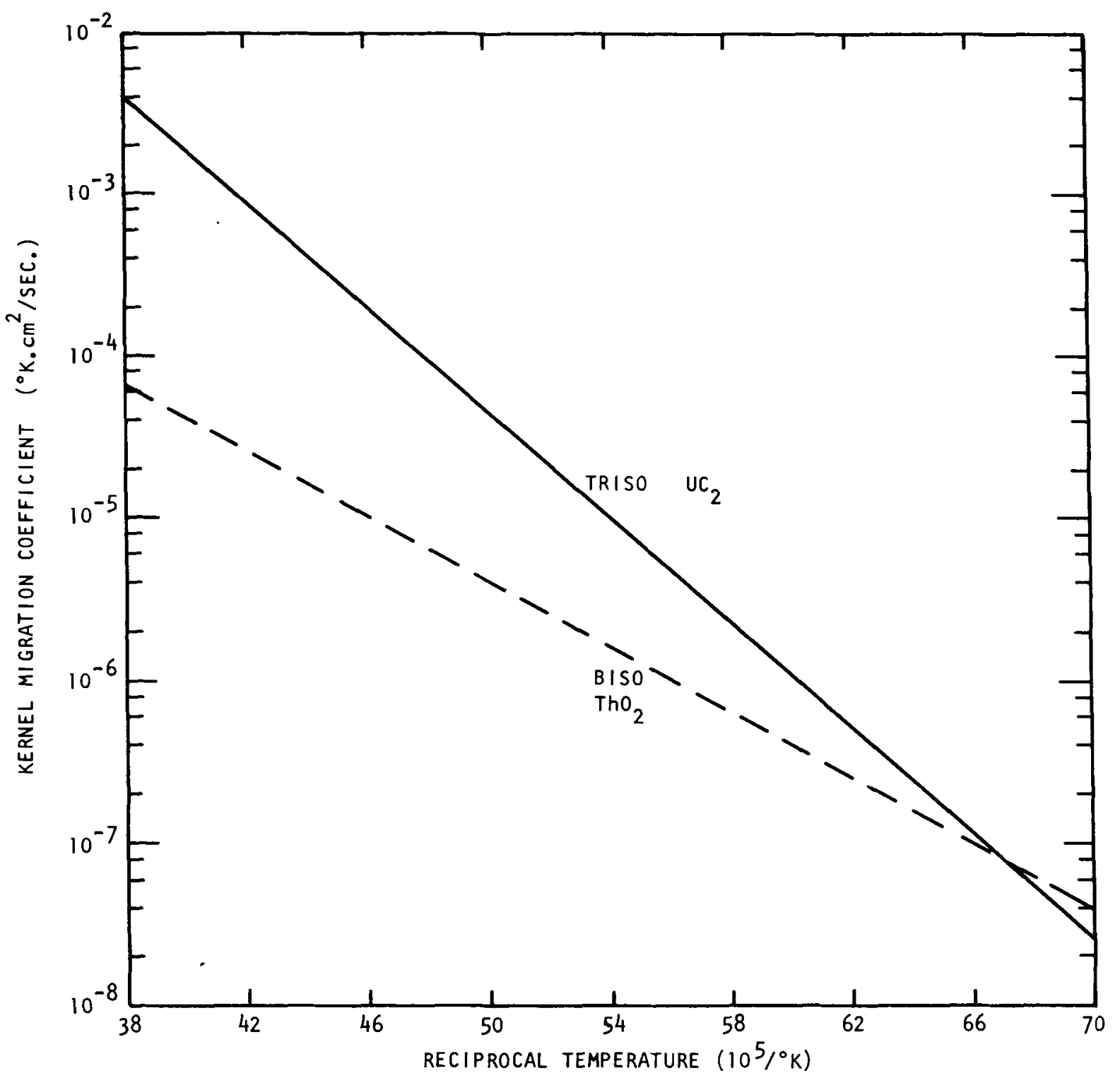

Fig. 3-2. Kernel migration correlation for TRISO and BISO fuel particles 
As the kernel moves through the buffer layer into the structurally important PyC and SIC layers, the coating is weakened and will eventually break. In evaluating fuel performance, coatings are conservatively defined to fail when the kernel has been calculated to have moved through the buffer coating.

Figure 3-3 shows the time required for kernels of $\mathrm{UC}_{2}$ TRISO particles and $\mathrm{ThO}_{2}$ BISO particles to migrate through an 85-micron buffer thickness at various temperatures.* In the figure a temperature gradient of $475^{\circ} \mathrm{F} / \mathrm{in}$., which is characteristic of a fuel rod operating at core average power density, has been used. For a 4-year fuel life at core average gradient, the $\mathrm{UC}_{2}$ TRISO particles can operate at a constant temperature of $2650^{\circ} \mathrm{F}$ and BISO particles can operate at a temperature of $2950^{\circ} \mathrm{F}$ and not migrate more than 85 microns. If the particles in the reactor operate at higher temperatures, the additional distance migrated by the kernel can be compensated for by operating the fuel at lower temperatures for the remaining part of life such that the total migration does not exceed the buffer thickness of 85 microns.

\subsubsection{Coating Stress}

The coated particles are designed as composite pressure vessels. Stresses in various coatings are a function of both the particle parameters, such as the type and size of the particle, and of the reactor parameters to which the particle is exposed in the HTGR core. The primary particle parameters that influence the coating stresses are kernel diameter, coating dimensions, and coating material properties such as density and isotropy. The reactor parameters that influence the stresses in various coatings are the combinations of particle temperature, neutron fluence, and burnup of heavy metal in the kernel. The approach at GA is to design the fuel particles using in-pile testing supported by analytical stress models, which determine the relative stress levels for a given

*The BISO particle uses an 85-micron buffer thickness, the TRISO particle a 100-micron thickness. 


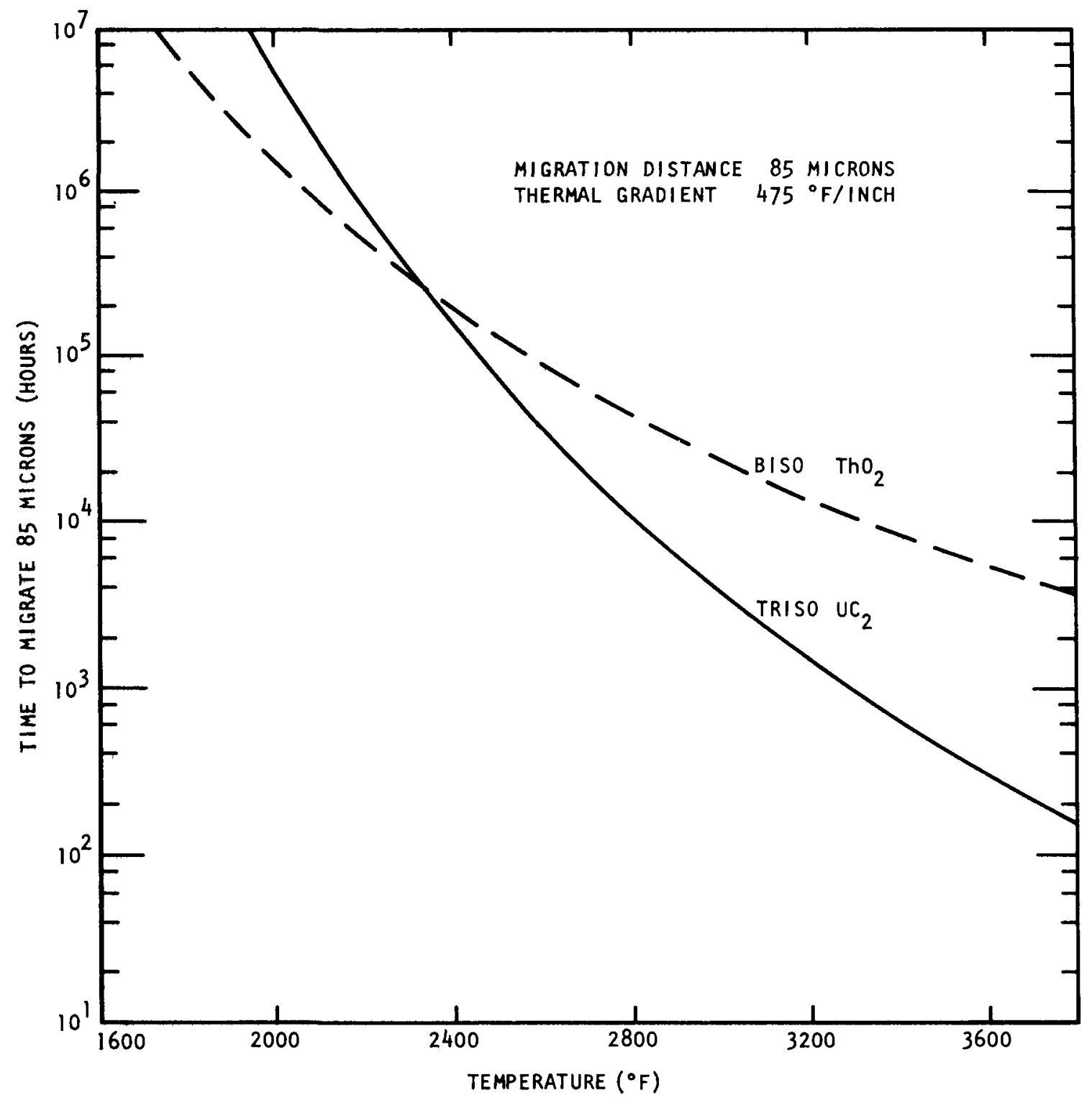

Fig. 3-3. Time to migrate 85 microns for TRISO and BISO fuel particles as a function of temperature 
particle design of kernel and coating dimensions and material properties. The failure fraction of a particle in a given batch is then correlated with the relative stress levels indicated by the analytical model, the distribution of dimensions, and coating properties in the irradiated particle population.

Coatings in HTGR fuel particles are applied in large fluidized beds. It is the nature of this process to produce small variations in thicknesses and properties within each batch of coating layers as well as in the fuel kernels. Under identical irradiation conditions, these variations would result in a distribution of coating stresses within the individual particles of a coating batch. The principal factors influencing coating stresses are variations in fuel kernel diameters (amount of fission gas produced) and the buffer thickness (available void volume). Fuel particles of combinations of kernel size and buffer thicknesses are irradiated in different capsules and compared with analytical models. An example of this design and testing procedure is presented in Ref. 3-5. A good correlation was found between the distribution of fuel kernel and coating parameters, the calculated distribution of coating stresses within each particle batch, and the irradiation performance of the particle batch. As a result of this development, coated particles can be described by specifying mean values and standard deviations on kernel diameter and coating thicknesses in such a way that there is a very small fraction of fuel particles that may fail when a large number of production batches are exposed to combinations of peak temperatures, fast neutron fluence, and burnup.

Based upon the results of the GA irradiation program and supporting particle stress analyses, fractions of particle coating failure for reference HTGR particles have been correlated with irradiation environment and reported in a companion licensing topical report (Ref. 3-2). Iso-coating failure envelopes for BISO and TRISO particles have been constructed including each of the three coating failure mechanisms described above from correlations presented in Ref. 3-2. Figures 3-4 through 3-7, which are derived from Ref. 3-2, are presented here for illustration of the 


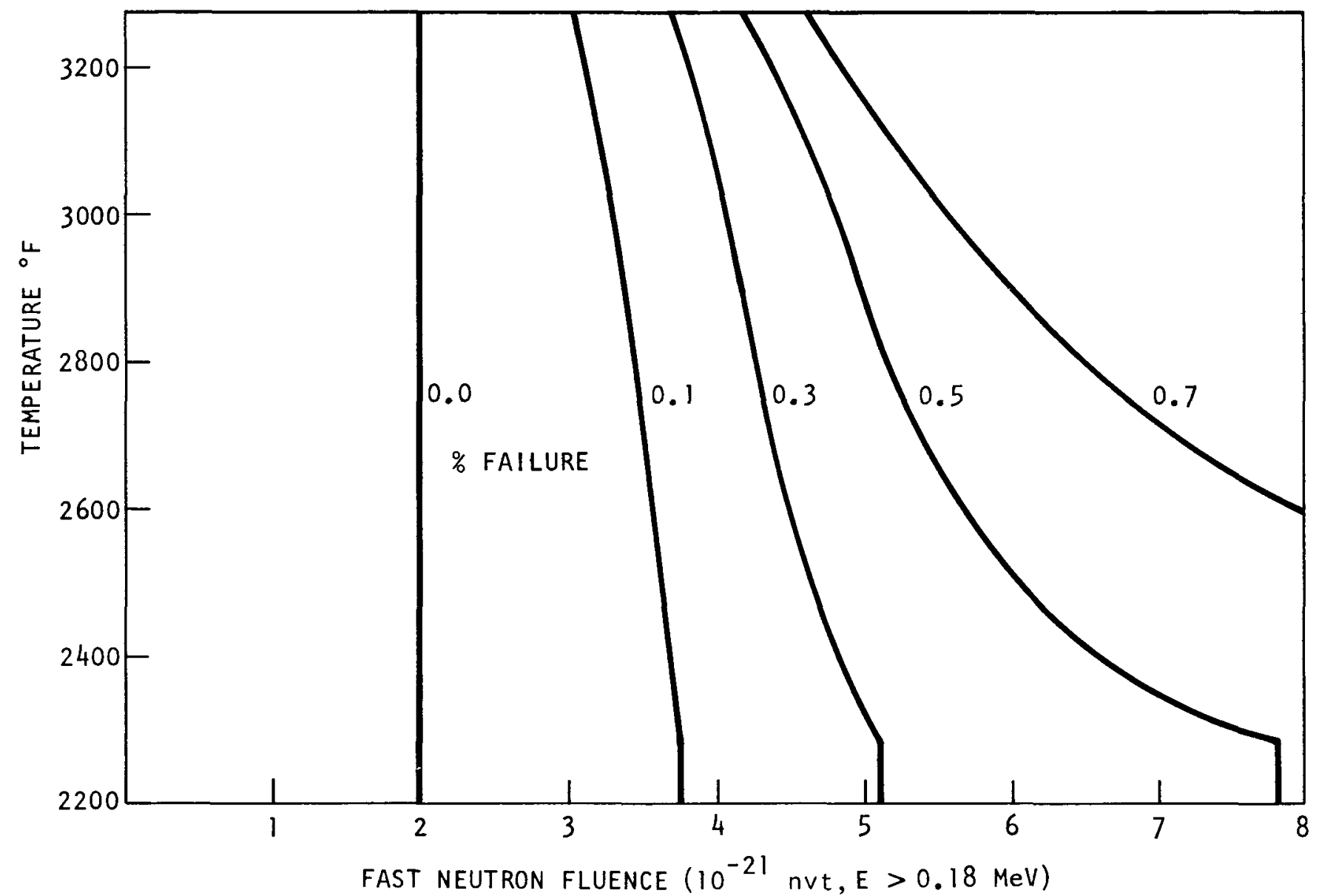

Fig. 3-4. Iso-failure envelopes for TRISO fuel particles due to pressure vessel failure as a function of fast neutron fluence 


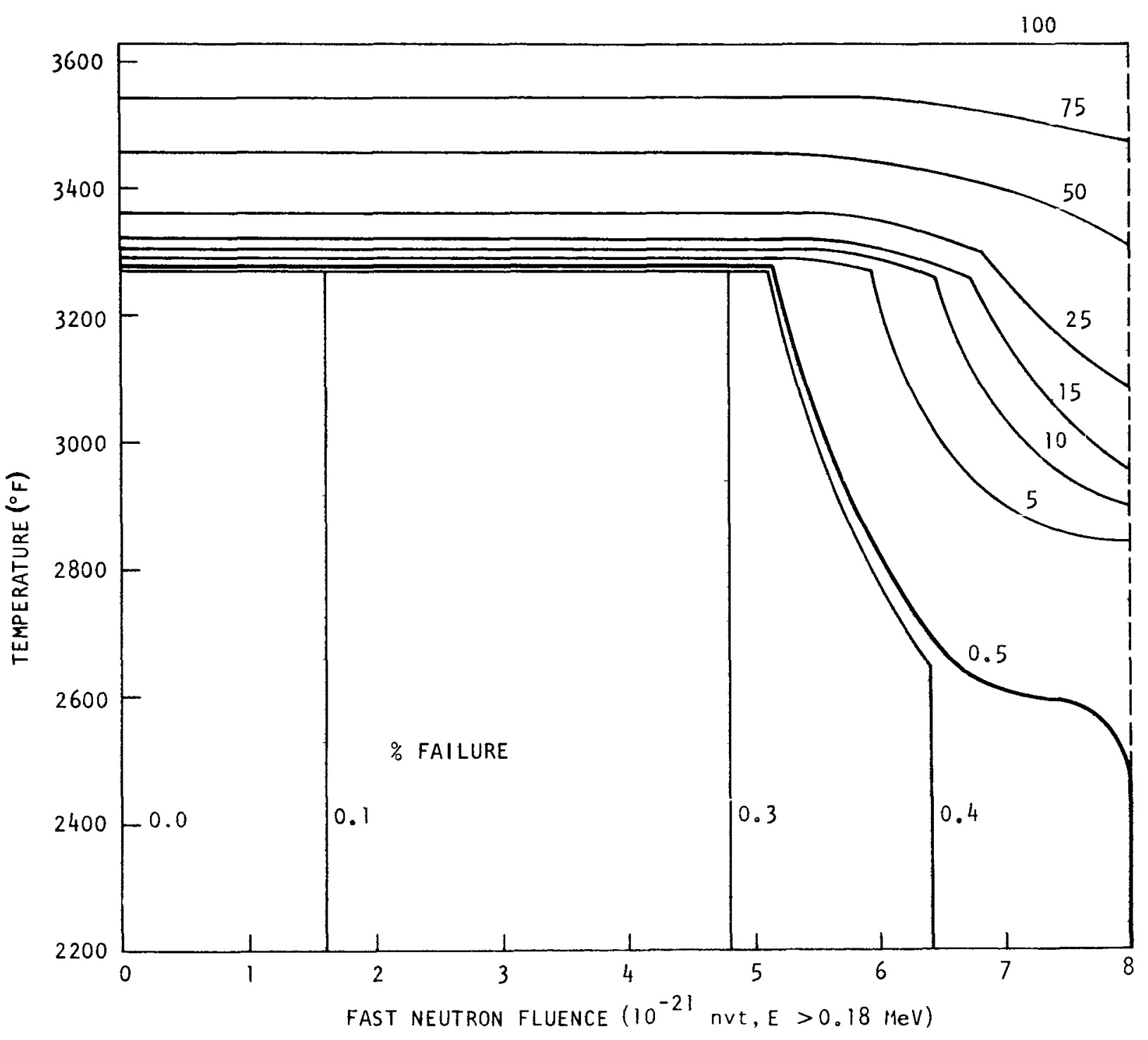

Fig. 3-5. Iso-failure envelopes for BISO fuel particles due to pressure vessel failure as a function of fast neutron fluence 


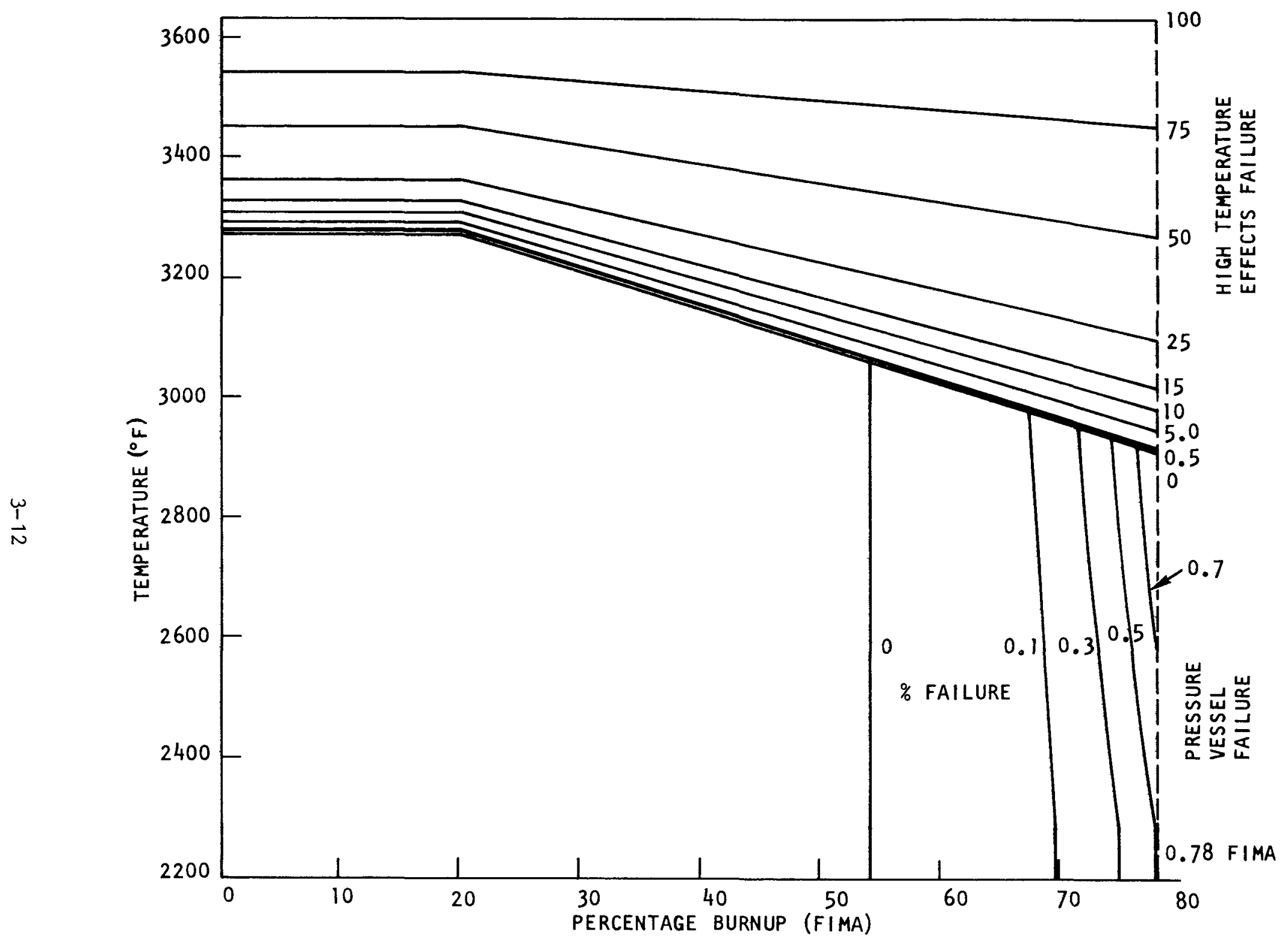

Fig 3-6. Iso-failure envelopes for TRISO fuel particles due to pressure vessel and high temperature effects as a function of burnup 


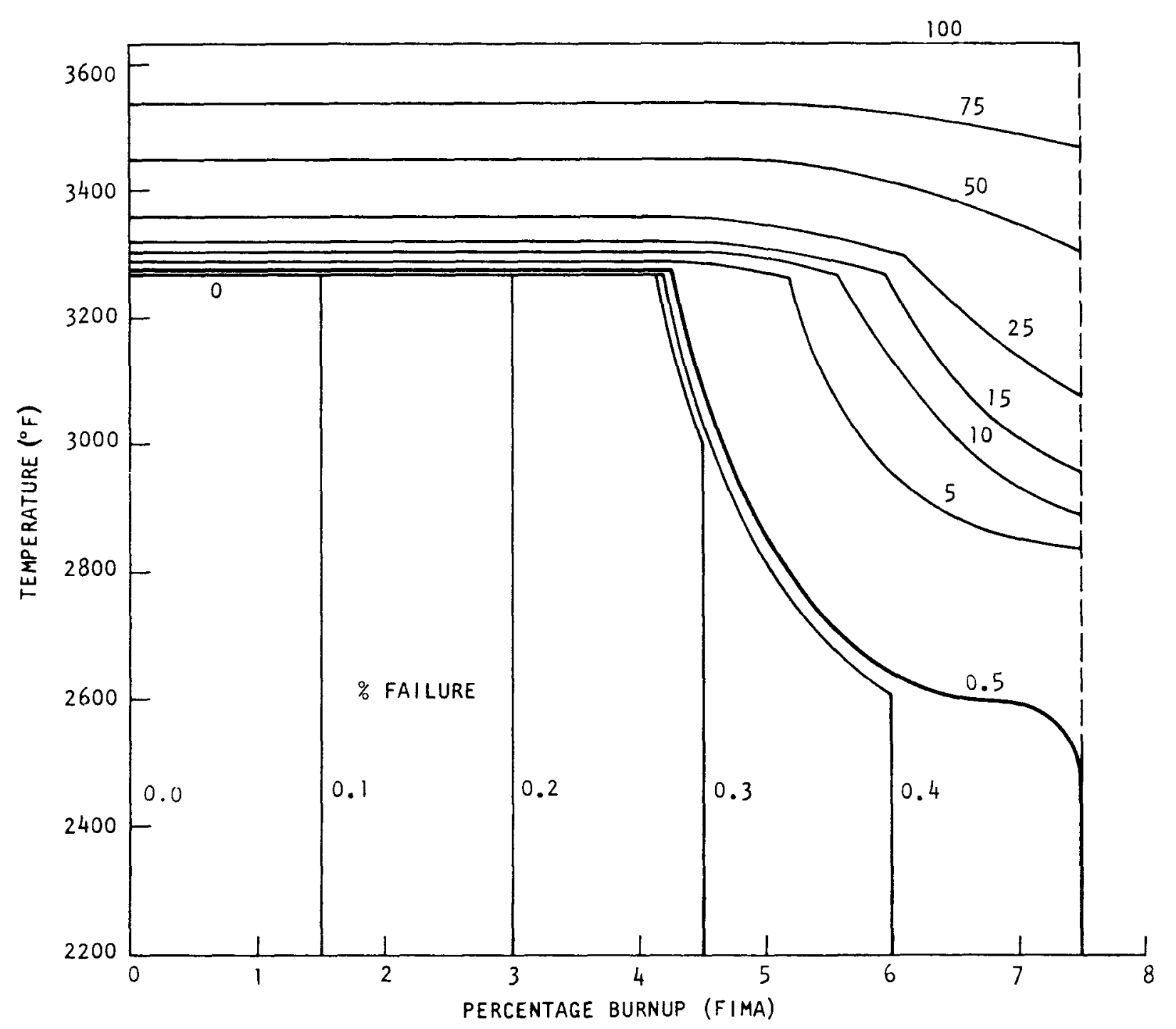

Fig. 3-7. Iso-failure envelopes for BISO fuel particles due to pressure vesse1 failure as a function of burnup 
dependence of the coating failure mechanisms on irradiation environment. These four figures describe the following:

$\begin{array}{ll}\text { Fig. } & \text { Particle Type } \\ 3-4 & \text { TRISO } \\ 3-5 & \text { BISO } \\ 3-6 & \text { TRISO } \\ 3-7 & \text { BISO }\end{array}$

Independent Parameters
Temperature - fast neutron fluence
Temperature - fast neutron fluence
Temperature - fissile burnup
Temperature - fertile burnup

3.2.3. Fission Product - SiC Layer Interactions (High-Temperature Failure)

At temperatures in the range 2900 to $3200^{\circ} \mathrm{F}$, experiments have shown (Ref. 3-2) that coating failure in TRISO particles is caused by chemical interaction between the rare earth fission products that migrate slowly from the $\mathrm{UC}_{2}$ fuel kernels and SiC coatings. The interactions occur on the cold side of TRISO fuel particles. More discussion of this mechanism is included in Ref. 3-2. Based upon this failure mechanism, the iso-failure envelopes have been derived as a function of burnup at high temperatures; they are shown in Fig. 3-6.

\subsubsection{Manufacturing Defects}

Coatings are applied to a large number of fuel kernels simultaneously in a single coating furnace. A small number of particles in some coating batches receive incomplete or otherwise defective coatings. The fraction of these particles with defective coatings is strictly regulated by the fuel specifications and quality control procedures, Particles with defective coatings are expected to fail progressively with increasing burnup (Ref. 3-2).

\subsection{CORE THERMAL DESIGN BASIS}

In HTGRs, the core thermal design bases are defined as a function of plant conditions, of which there are four categories. Two of these categories, normal conditions and upset conditions, are anticipated modes 
of operation. The remaining two, emergency conditions and faulted conditions, are conceivable modes of operation, which through the reactor component and system design are expected to occur infrequent1y. Table 3-1 gives a list of normal, upset, emergency, and faulted transients for the HTGR core. The following definitions are based upon the ASME Boiler and Pressure Vessel Code (Ref. 3-6) and ANS Safety Standards (Ref. 3-7).

1. Normal Operating Transients. Normal conditions are any condition in the course of system startup, operation in the design power range, load following, hot standby, and system shutdown.

2. Upset Transients. Upset operating conditions are defined as any deviations from normal operating conditions that are anticipated to occur often enough that the design should include a capability to withstand the conditions without impairing operation.

3. Emergency Transients. Emergency operating conditions are defined as those deviations from normal conditions that may require shutdown for correction of the conditions or repair of damage in the system. The conditions have a low probability of occurrence but are included to provide assurance that no gross loss of structural integrity will result as a concomitant effect of any damage developed in the system.

4. Faulted Transients. Faulted operating conditions are defined as those combinations of conditions associated with extremely-lowprobability, postulated events whose consequences are such that the integrity and operability of the nuclear energy system may be impaired to the extent that considerations of public health and safety are involved. Such events are not expected to occur over the life of the plant but are postulated only to set the safety design of the plant. 
TABLE 3-1

REPRESENTATIVE PLANT TRANSIENTS

IN $3000 \mathrm{MW}(t)$ HTGR DURING 40 YEAR PLANT LIFE

\begin{tabular}{|c|c|}
\hline & $\begin{array}{c}\text { No. of } \\
\text { Occurrences } \\
\text { Per Plant }\end{array}$ \\
\hline \multicolumn{2}{|l|}{ Normal transients } \\
\hline Startup from refueling status & 145 \\
\hline Startup with full helium inventory & 255 \\
\hline Shutdown to refueling status & 81 \\
\hline Shut down with full helium inventory & 44 \\
\hline Rapid load increase $(5 \% / \mathrm{min})$ & 2,000 \\
\hline Normal load increase $(3 \% / \mathrm{min})$ & 18,000 \\
\hline Rapid load decrease $(5 \% / \mathrm{min})$ & 2,000 \\
\hline Normal load decrease $(3 \% / \mathrm{min})$ & 18,000 \\
\hline Step load increase $(+10 \%)$ & 2,000 \\
\hline Step load decrease $(-10 \%)$ & 2,000 \\
\hline \multicolumn{2}{|l|}{ Upset transients (from full load) } \\
\hline Loop shutdown & 90 \\
\hline Reactor trip & 100 \\
\hline Turbine trip and load rejections & 120 \\
\hline Sudden reduction of feedwater flow & 30 \\
\hline Steam leak to PCRV with correct protective action & 30 \\
\hline \multicolumn{2}{|l|}{ Emergency and faulted transients } \\
\hline Slow primary system depressurization & 3 \\
\hline Rod withdrawal with high flux trip & 3 \\
\hline Loop shutdown with helium valve failure & 3 \\
\hline $\left.\begin{array}{l}\text { Shutdown with three auxiliary cooling loops - up to } 10 \\
\text { Shutdown with two auxiliary cooling loops - up to } 10\end{array}\right\}$ & 10 \\
\hline $\begin{array}{l}\text { Sudden depressurization and shutdown with two auxiliary } \\
\text { cooling loops }(a)\end{array}$ & 1 \\
\hline
\end{tabular}

(a) Faulted. 
The reactor core thermal and fluid flow design bases are established, with the reactor control and protective system and other plant equipment characteristics, to ensure the integrity of the coated fuel particles during normal operation and upset conditions. The design bases for emergency and faulted conditions are established to limit fission product release and to ensure adequate continued core cooling capability. The thermal and fluid mechanical design bases for the reactor are summarized in Table 3-2 and are discussed below. For any given condition, the design shall satisfy each of the individual bases given for fuel, coolant, and other components for that condition.

\subsubsection{Fuel Particles}

The thermal design bases for the fuel particles are:

1. For normal and upset conditions, the calculated number of failed fuel particle coatings shall be limited to be consistent with not exceeding the "Expected" annual averaged value of circulating coolant fission product activity level as specified in Refs. 3-8 and 3-9.

2. Plant protective system limits and technical specifications shall be established to restrict the fuel damage during emergency and faulted conditions.

To attain the design bases, subordinate limits are placed on the fuel particle conditions of temperature, fast neutron fluence and heavy metal burnup in the particle kernel. These limits are then used to establish the design of the core, the plant control system and plant protective system and to establish any limiting safety system settings, the limiting conditions for operation or other requirements in the technical specifications. Specifically, the design bases above are attained through the following two subordinate limits corresponding to design bases 1 and 2 above: 
TABLE $3-2$

THERMAL DESIGN BASES FOR HTGR CORE

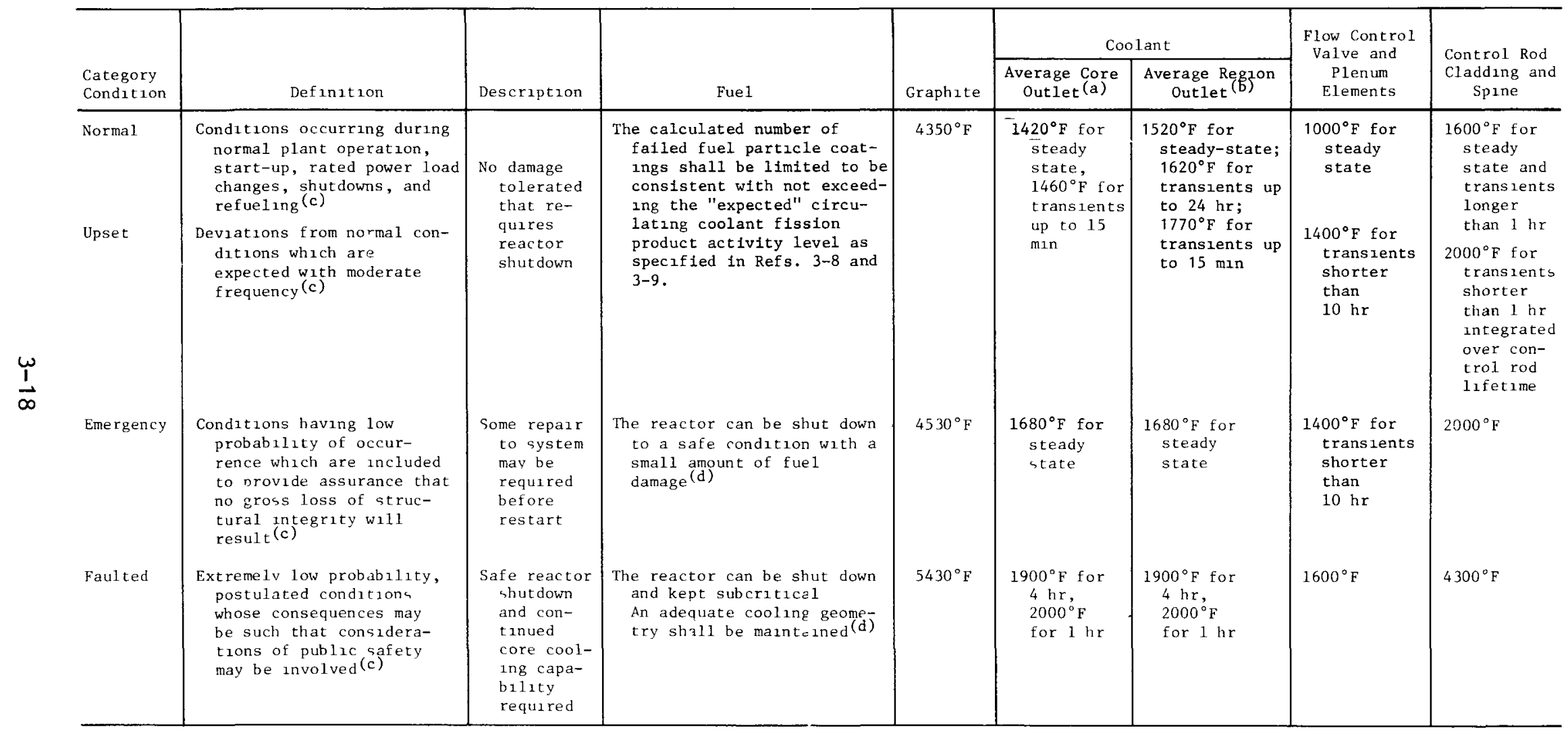

(a) Including fuel element gap, side reflector and control channel bypasses.

(b) Including fuel element gap and control channel bypasses.

(c) ASME III, Par NA 2110 NB 3113 (Ref. 3-6)

(d) Limits w111 be based on 10CFR100. 
1. One method for achieving the conditions of the design basis has been found to be a core with an annual average for the core of about $0.25 \%$ of failed BISO coatings in the core and about $0.3 \%$ of failed TRISO coatings. The method used in determination of the failed coating fraction during normal operation is discussed in Sections 7 and 8 of this report. Determination of fission product release is discussed in Refs. 3-8 and 3-9.

2. To establish the technical specifications for the core, limits on fuel temperature, fast neutron fluence, and kernel heavy metal burnup are established to prevent rapid, thermally-induced coating failures. Specifically, limits are set to control the total coating failure to a fuel volume fraction of $2.5 \%$ which is consistent with not exceeding the "Design" activity level.

These limits are not intended to suppress completely the small quantity of in-service coating failure expected during normal operation, but to prevent rapid thermally-induced failure from propagating to a significant volume of the core.

Designs of some plant components and shielding, as well as initial conditions for safety analysis, have been based on an activity level much higher than the expected activity. This activity is, for most isotopes, about a factor of ten higher than the expected activity and has been defined in Refs. 3-8 and 3-9 as the "Design" activity.

\subsubsection{Primary Coolant}

Helium, the primary coolant, is a chemically inert, single-phase gaseous fluid that contributes no effective reactivity. These properties are retained even at temperatures well above those limits acceptable for structures and materials. The coolant does not itself, therefore, impose a limit on allowable temperatures. However, limits are imposed on the coolant so that flow in the reactor passages is maintained to keep the 
core, support structure, and components inside the PCRV within limits on which their designs are based.

The mixed mean core outlet helium temperature from the core will be limited to $1420^{\circ} \mathrm{F}$ during steady-state operation and $1460^{\circ} \mathrm{F}$ for transients up to 15 minutes. The mixed mean outlet helium temperature of a region will be limited to $1520^{\circ} \mathrm{F}$ for steady-state operation, $1620^{\circ} \mathrm{F}$ for transients up to 24 hours in duration, and $1770^{\circ} \mathrm{F}$ for transients up to 15 minutes.

During emergency conditions the mixed mean core outlet helium temperature is limited to a steady-state value of $1680^{\circ} \mathrm{F}$, which has been fixed so that the core auxiliary heat exchangers will not suffer any loss of integrity. For transient exposures during faulted conditions, mixed mean core and region outlet gas temperatures up to $1900^{\circ} \mathrm{F}$ for less than 4 hours, and $2000^{\circ} \mathrm{F}$ for less than 1 hour, are allowed (Ref. 3-11).

\subsubsection{Fue1 Elements and Hexagonal Reflector Elements}

The principal function of the fuel and reflector elements is to provide an adequate fuel configuration and coolant flow geometry to allow heat to be removed from the core.

The strength of graphite increases with temperature to a maximum at about $4500^{\circ} \mathrm{F}$ and remains usable at higher temperatures. Graphite does not melt but gradually sublimes at temperatures over $6000^{\circ} \mathrm{F}$ (Ref. 3-12).

\subsubsection{Meta1lic Core Components}

The temperature limits for transient conditions are imposed by metallic core components in addition to fuel and core structural graphite. Temperatures of metallic primary system components are limited by design bases to assure effective reactivity control.

The temperature of the flow control valve and plenum element is 1 imited during normal and upset conditions to a maximum of $1000^{\circ} \mathrm{F}$ (Ref. 3-13). 
During emergency and faulted conditions, fallure of these components shall not result in blockage of control rod insertion or coolant channel flow, which may result in violation of the fuel particle or fuel element design basis.

For normal operation and upset conditions, the design bases limit temperatures of the control rod cladding and spine to $1600^{\circ} \mathrm{F}$ (Ref. 3-14) for transients longer than 1 hour and to $2000^{\circ} \mathrm{F}$ for transients shorter than 1 hour. Following an emergency transient, the control rod shall be removable and temperatures of the clad and spine are restricted to a maximum of $2000^{\circ} \mathrm{F}$. Following a faulted condition, the control rod need not be removable but the integrity of the poison compacts shall be maintained in control rod channels. The temperature of the poison compact shall not exceed $4300^{\circ} \mathrm{F}$ (Ref. 3-15) under any reactor condition. The above design bases are summarized in Table 3-2. 
REFERENCES

3-1 Wessman, G. L., and T. R. Moffette, "Safety Design Bases of the HTGR," General Atomic Report GA-A12618, January 7, 1974.

3-2 Smith, C. L., "Fuel Particle Behavior Under Normal and Transient Conditions," General Atomic Report GA-A12971, October 1974.

3-3 Gulden, T. D., "Carbon Thermal Diffusion in the $\mathrm{UC}_{2}-\mathrm{C}$ System," J. Am. Ceram. Soc. 55 (1972).

3-4 Scott, C. B., and 0. M. Stansfield, "Stability of Irradiated Coated Particle Fuels in a Temperature Gradient," General Atomic Report GA-12081, September 18, 1972.

3-5 Gulden, T. D., et al., "The Mechanical Design of TRISO Coated Particle Fuels for the Large HTGR," Nucl. Tech. 16, 100-109 (1972).

3-6 "Nuclear Power Plant Components," ASME Boiler and Pressure Vessel Code, Section III, Article NB-3113, 1971.

3-7 "Nuclear Safety Criteria for the Design of Stationary Gas Cooled Reactor Plants," American Nuclear Society Report ANS-23, Draft No. 9, Rev. 2, January 1974.

3-8 "General Atomic Standard Safety Analysis Report," General Atomic Report GA-A13200, Section 11.1, 1974.

3-9 Haire, H. J., and D. W. McEachern, "Gaseous Radioactivity Levels in the Primary Coolant of an HTGR," General Atomic Report GA-A12946, October 1, 1974.

3-10 "General Atomic Standard Safety Analysis Report," General Atomic Report GA-A13200, Section 15, 1974.

3-11 Schleicher, R. W., et al., "An Analysis of HTGR Core Cooling Capability," Gulf General Atomic Report Gulf-GA-A12504, March 30, 1973, pp. 2-14.

3-12 "General Atomic Standard Safety Analysis Report," General Atomic Report GA-A13200, Section 4.2, 1974. 
3-13 Mechanical and Physical Properties of the Austenitic Stainless Steels at Elevated Temperatures, International Nickel Company Inc., 3rd Edition, November, 1968.

3-14 "Engineering Properties of Incoloy 800," Technical Bulletin T-40, Huntington Alloy Products Division, Huntington, West Virginia.

3-15 Evans, T. W., "The Effects of Irradiation on Boron Carbide," (A Literature Review), Battelle Northwest Laboratory Report BNWL-679, February 1968 . 


\section{ANALYTICAL METHODS}

Analytical methods based on the principles of conservation of mass, momentum, and energy have been developed for application to the design of the HTGR core. These heat transfer and fluid mechanics codes embody a spectrum of generality and complexity. Table 4-1 gives a summary of the computer codes used most often.

Each of the computer codes is discussed briefly and references to more complete descriptions of the codes are given where available. Specific examples of modeling of the core and core components accomplished by input to these codes are discussed in detail in this section. Section 6 presents a variety of results generated using these core models and computer codes.

The design analyses performed for the core are (1) steady-state analyses and (2) transient analyses. Core design as well as derivation of the settings on the plant protective system will be carried out with these codes. The method of analysis and the analytical models used are discussed in this section. Examples of results from steady-state and transient analyses are discussed in later sections of this report.

\subsection{STEADY-STATE ANALYSIS CODES}

The steady-state heat transfer and fluid flow analyses of the reactor core are primarily carried out using seven computer codes. The codes have been in existence for several years and have been continuously updated and improved upon by GA in order to ensure that they incorporate current models and methods. Each computer code serves a specific purpose in the thermal design. A summary of all steady-state computer codes used in thermal design is given in Table 4-1. 
TABLE 4-1

CODES USED IN CORE THERMAL AND FLOW ANALYSIS ${ }^{(a)}$

\begin{tabular}{|c|c|c|}
\hline Code Name & Purpose & Method \\
\hline FLAC & $\begin{array}{l}\text { To determine flow distribution in an arbitrary } \\
\text { cross connected flow network; e.g., coolant } \\
\text { flow in coolant channel and gaps between } \\
\text { blocks in a refueling region. }\end{array}$ & $\begin{array}{l}\text { Solves } 1-D \text { momentum equation for incompress- } \\
\text { ible flow, and solves continuity equations } \\
\text { of mass and energy. Density changes in gas } \\
\text { are modeled. }\end{array}$ \\
\hline POKE & $\begin{array}{l}\text { To determine, under constraints, steady state } \\
\text { orifice valve position, coolant mass flow, } \\
\text { coolant temperature, and fuel temperature } \\
\text { distribution in HTGR core made up of many } \\
\text { parallel coolant channels connecting two } \\
\text { plenums. }\end{array}$ & $\begin{array}{l}\text { Steady-state mass and momentum conservation } \\
\text { equations for parallel channels, using crossflow } \\
\text { correlations, are solved using finite differences } \\
\text { for an imposed power distribution. Equivalent } \\
\text { conductances from HEXT are used to calculate } \\
\text { radial temperature profile within unit cell. }\end{array}$ \\
\hline $\begin{array}{l}\text { DEMISE } \\
\text { DEMICE }\end{array}$ & $\begin{array}{l}\text { To determine steady-state } 3-D \text { temperature } \\
\text { distribution and flow distribution in } 1 / 2 \\
\text { columns of standard elements (DEMISE) and } \\
\text { control elements (DEMICE). }\end{array}$ & $\begin{array}{l}\text { Temperature distribution in network model } \\
\text { of } 1 / 2 \text { column is solved using successive } \\
\text { point iteration. Flow distribution is } \\
\text { calculated by balancing pressure drop in } \\
\text { all coolant passages. }\end{array}$ \\
\hline $\mathrm{BACH}$ & $\begin{array}{l}\text { To calculate steady-state core power/flow } \\
\text { ratio to achieve a desired maximum fuel } \\
\text { temperature in a specified refueling region } \\
\text { of a variable orificed, multiple, parallel } \\
\text { channel HTGR core. Kernel migration rate } \\
\text { within the fuel is determined. Error analysis } \\
\text { of calculated temperatures is performed. }\end{array}$ & $\begin{array}{l}\text { Coolant channel mass flow is calculated by } \\
\text { balancing pressure drop for a single } \\
\text { channel. Calculates gas temperatures from } \\
\text { energy balance equations. Radial tempera- } \\
\text { ture drops in channel are evaluated by } \\
\text { calculating local heat flux and appropriate } \\
\text { conductances from HEXT model. }\end{array}$ \\
\hline
\end{tabular}

(a) These codes are discussed in Section 4.1. 
TABLE 4-1 (continued)

\begin{tabular}{|c|c|c|}
\hline Code Name & Purpose & Method \\
\hline HEXT & $\begin{array}{l}\text { To determine steady-state temperature distribu- } \\
\text { tion and equivalent thermal conductances in fuel, } \\
\text { fuel-moderator gap, and moderator in a unit cell } \\
\text { of HTGR type fuel elements (see Fig. 4-10). }\end{array}$ & $\begin{array}{l}\text { Solves heat conduction equation for a par- } \\
\text { ticular 2-D geometric configuration. }\end{array}$ \\
\hline TREVER & $\begin{array}{l}\text { To determine, from given power distribution } \\
\text { histories, time histories of steady-state } \\
\text { coolant, graphite, and fuel temperatures and tem- } \\
\text { perature gradients for a region. To determine } \\
\text { time and space distribution of coating failure. }\end{array}$ & $\begin{array}{l}\text { Solves 1-D (radial) steady-state heat trans- } \\
\text { fer, coolant distributions from POKE, } \\
\text { equivalent conductances from HEXT. Uses } \\
\text { experimentally determined correlations to } \\
\text { calculate particle coating failure. }\end{array}$ \\
\hline TAC-2D & $\begin{array}{l}\text { General purpose } 2-D \text { steady-state and time- } \\
\text { dependent thermal analysis of specific core } \\
\text { segments; e.g.: } \\
\text { 1. Fuel element temperature distribution. } \\
\text { 2. Control rod temperature distribution. } \\
\text { 3. Core temperatures during transients. }\end{array}$ & $\begin{array}{l}\text { Solves } 2-D \text { heat conduction equation by } \\
\text { finite differences using implicit iteration } \\
\text { method. }\end{array}$ \\
\hline DETRAC & $\begin{array}{l}\text { To determine time histories of coolant, graphite } \\
\text { and fuel temperatures within region average and } \\
\text { local hot channels during transient operation } \\
\text { from given transient power distribution history } \\
\text { and given core total power, total flow, helium } \\
\text { inlet temperature, and pressure response. }\end{array}$ & $\begin{array}{l}\text { Solves 1-D nodal transient heat transfer } \\
\text { equations with no axial conduction or radial } \\
\text { conduction between channels. Uses equiva- } \\
\text { lent conductances from HEXT code in } \\
\text { calculating fuel and graphite temperatures } \\
\text { within a channel. Coolant channel flows } \\
\text { calculated by balancing pressure drop across } \\
\text { individual channels. }\end{array}$ \\
\hline
\end{tabular}




\subsubsection{Core F1ow Distribution FLAC Code}

Flow entering the core upper plenum is partitioned among the coolant passages according to thelr relative flow resistances. The bulk of the coolant passes through the coolant channels in the fuel elements. Helium flowing through the core cavity in passages other than the coolant channels is termed bypass flow. In the core cavity, the core bypass flow is defined to include the flow through the coolant passages in the control rods, gaps between the fuel columns, and gaps between varfous components that serve to make up the side reflector and side wall thermal barrier. This bypass flow varies with fuel age, core elevation, orifice valve position, and core pressure drop.

FLAC (Ref. 4-1), a computer code that treats the coolant flow paths in the core as a cross-connected flow network, is used to calculate the core flow distribution. Constant pressure nodes interconnected by flow branches make up a flow network. The FLAC code is a version of the FLOPSY II code (Ref. 4-2), modified to account for density changes in gases due to heating and provided with an alternate scheme for solving the system of equations.

The FLAC code solves, for an arbitrarily defined flow network, onedimensional, steady-state conservation of momentum equations for pressure loss in each branch of the network. Conservation of mass equations are solved at each network node. Coolant temperatures are computed at each node from the flow rates in each branch and an imposed heat input for each branch. Coolant density is computed in each branch from the branch's temperature and pressure by the perfect gas law.

The HTGR core cavity flow distribution is obtained using several FLAC models of the core and core components. Two models are used extensively in the design; the first is a one-sixth core model and the second a sevencolumn region model. 
The FLAC code models of the core contain flow paths for coolant holes in each region and channels that simulate the vertical gaps between fuel elements within each region and gaps between regions. Horizontal crossconnected channels are also used to simulate horizontal flow paths in the side reflector, the core gap structure, and the horizontal separations at each interface fuel element. All important flow resistances can be included in each branch: region flow control valve, friction resistance, entrance losses, exit losses, losses due to misalignment between coolant holes, and acceleration of the coolant due to heating. Temperature and density of coolant in the branch are used in computing Reynolds number and flow resistance in each branch. The calculational technique used in the FLAC code was established to be applicable for core flow design calculations on the basis of good correlation with a flow test carried out in conjunction with the Fort St. Vrain core development effort. These flow experiments are described and compared to FLAC calculations in Refs. 4-3 and 4-4. FLAC was also used in the core design for the Fort St. Vrain reactor. A continuing flow testing program is described in Section 5.3.

4.1.1.1. One-Sixth Core Flow Model. The largest section of the core described by a FLAC flow network is the one-sixth core model. This model extends over a one-sixth segment of the $3000 \mathrm{MW}(t)$ core from the center of the core to the inside face of the thermal barrier. The principal paths represented in this model are shown in Figs. 4-1 through 4-3. Figure 4-1 indicates, on a transverse core layout, just how the flow paths are represented. The notation of the paths in Fig. 4-1 is:

$\mathrm{R}$ Coolant channel in a region; 1 to 13 represent regions with variable flow control valves, 14 and 15 are fixed orifice regions

C Control rod channels

I Gaps between fuel elements that are entirely internal to refueling regions - these are called internal gaps 


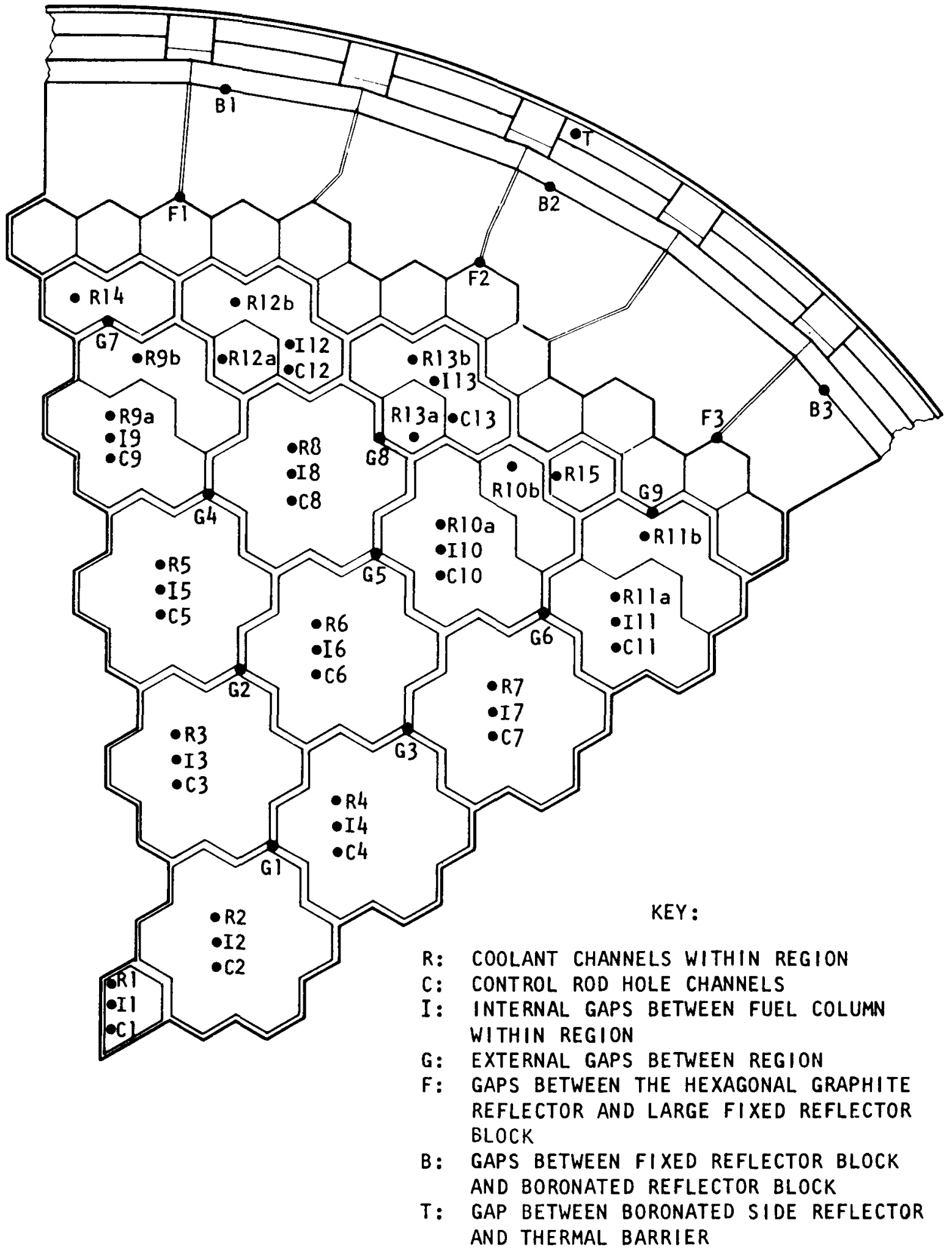

Fig. 4-1. One-sixth core flow model 


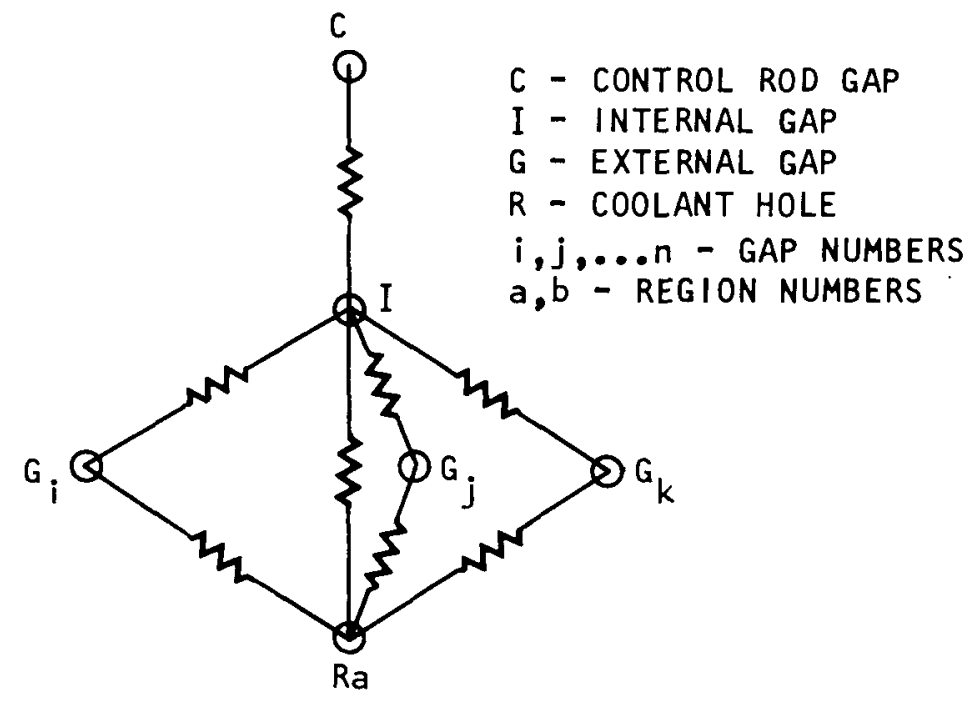

REGION AWAY FROM EDGE OF CORE (REGIONS I THROUGH 8 OF FIGURE 4-1)

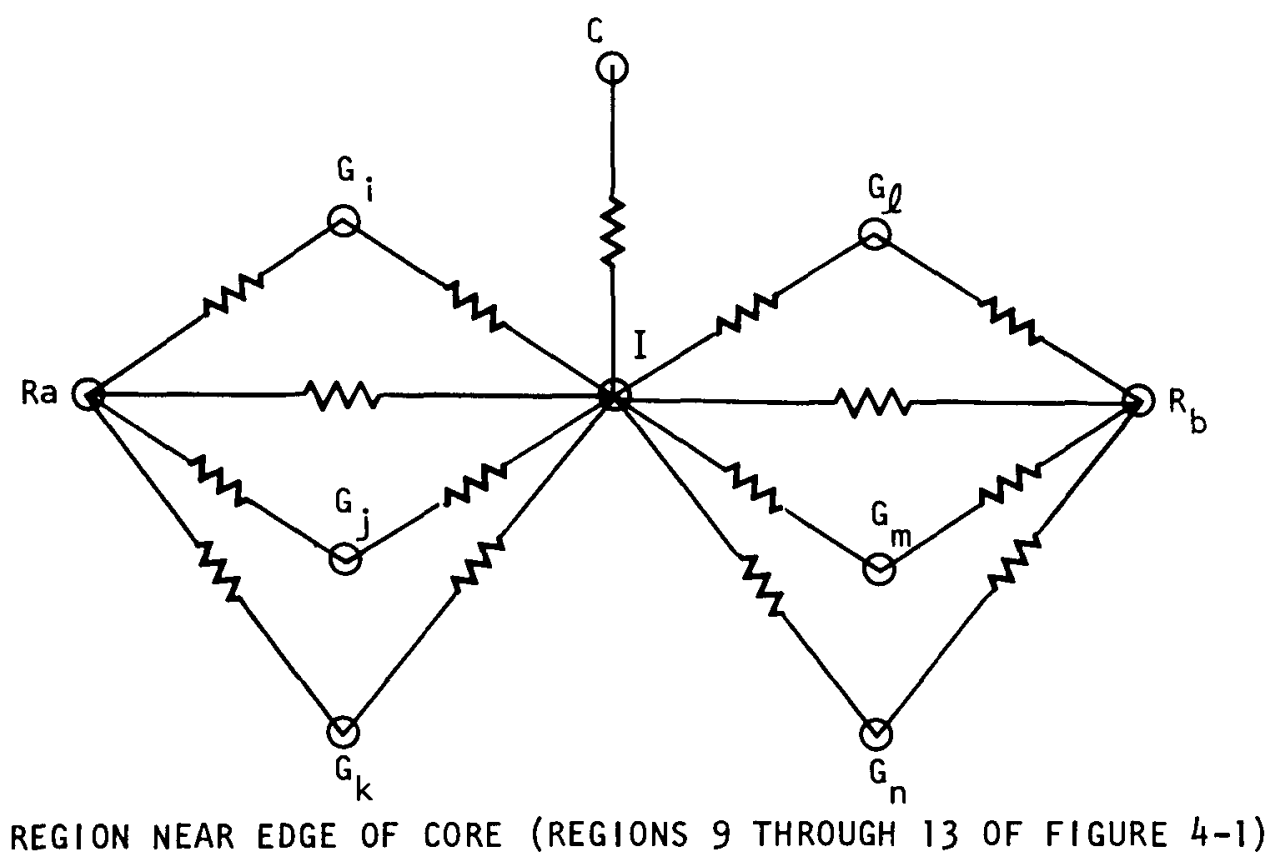

Fig. 4-2. Typical horizontal branch connections within each region for one-sixth core flow model 


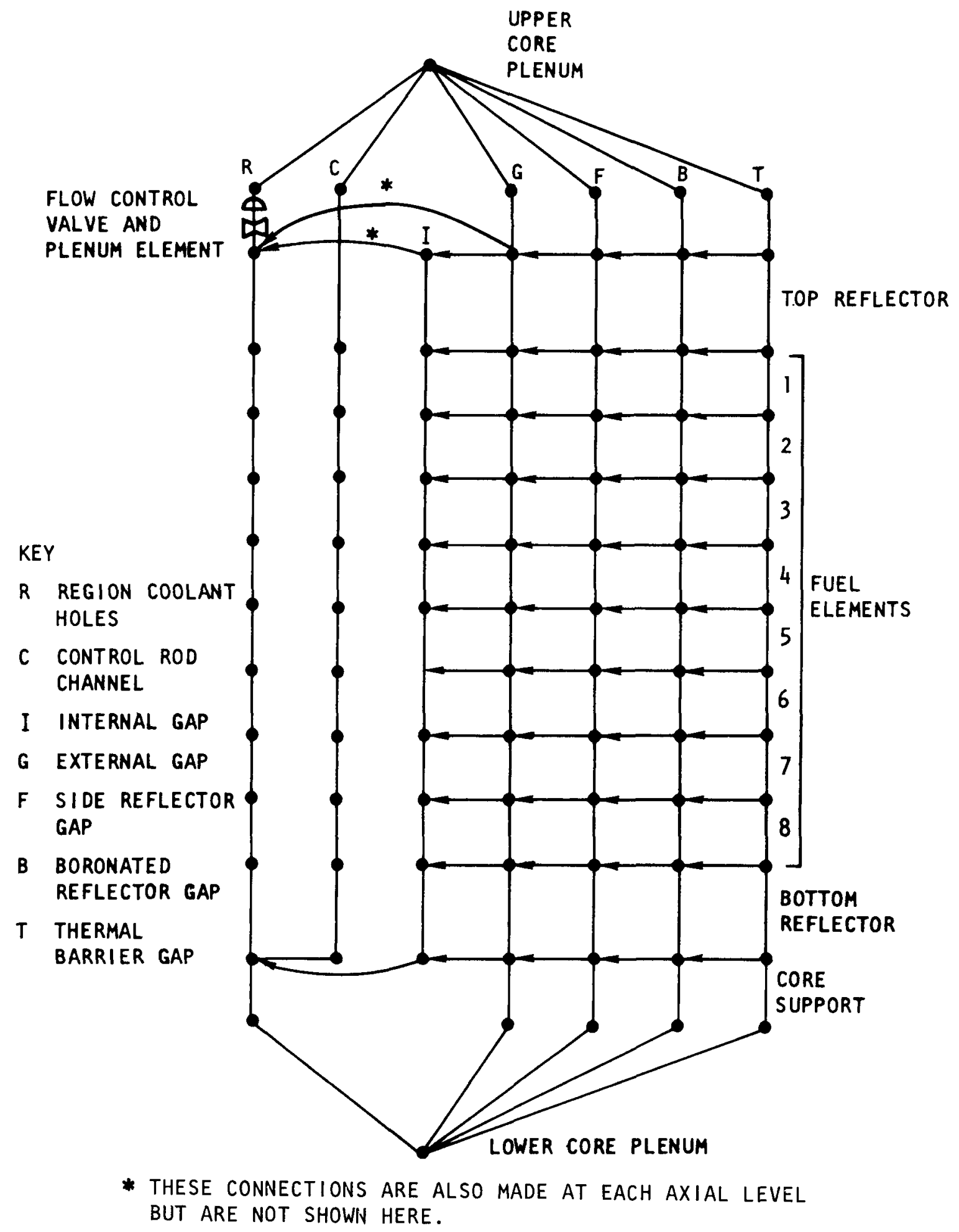

Fig. 4-3. Typical vertical branch connections for each region in one-sixth core flow model 
G Gaps between fuel elements of different regions; a total of nine these are called external gaps

F Gaps between hexagonal graphite reflector elements and permanent side reflector blocks; a total of three

B Gaps between permanent reflector blocks and boronated side reflector blocks

T Gaps between boronated side reflector and the thermal barrier

Each refueling region is represented by either one or two coolant holes (R), a control rod channel (C), and an internal gap (I). These three paths are connected to a common region plenum node the pressure of which is controlled by a flow control valve. Regions adjacent to the side reflector are represented by two coolant channels. In these regions there is a fast flux gradient and a resultant gradient in irradiation-induced fuel element shrinkage across the region. Resulting fuel element bowing produces horizontal interfacial gaps, which allow horizontal crossflow. The two coolant channels allow for two sizes of horizontal gaps within different elements of the same region at each axial level.

Figure 4-2 shows the detailed horizontal connection of flow paths at an axial level. Specifically represented are regions away from and regions near the core periphery. A detailed representation of horizontal and vertical connections is shown in Fig. 4-3. This one-sixth core model includes 764 nodes and 1922 branches connecting these nodes.

4.1.1.2. Seven-Column Region Flow Mode1. The detailed seven-column fuel region flow network model for the HTGR reactor consists of 684 nodes and a total of 1899 branch connections between these nodes. This one region model employs about the same number of nodes and branches as the one-sixth core model, allowing a much more detailed modeling of a single region. 
Coolant flow paths and their corresponding horizontal branch connections are shown in Fig. 4-4. In the model, each of the six standard fuel columns contains three coolant hole paths, R21 up to R73, which are connected horizontally to their neighboring internal and external gaps I1 to I6 and G1 to G6, respectively. Each coolant hole is connected to the other coolant holes in the same block by horizontal branches at each axial level. To avoid excessive cluttering in Fig. 4-4, these connections between coolant holes have been omitted. The fuel column located in the center of the region has provisions for coolant flow paths for a channel in central handling hole $\mathrm{T}$, two control rod channels $\mathrm{C} 1$ and $\mathrm{C} 2$, a reserve shutdown channel $\mathrm{X}$, and four coolant hole paths R11, R12, R13 and R14. These flow paths in the central column are horizontally connected among themselves and also to the six internal gaps as shown in Fig. 4-4.

The vertical node distribution and flow paths through these nodes are indicated in Fig. 4-5. The seven-column region model has provisions to accommodate a flow valve, two top reflector blocks, eight fuel elements, two bottom reflector blocks with extra nodes in the coolant channel path, and a core support block. In the bottom reflector section, the three coolant hole paths of each of the six center columns are interconnected to simulate mixing of three streams before entering the core support block. In the central fuel column, the reserve shutdown channel terminates within the lowest fuel element. The remainder of the flow paths are merged into an enlarged plenum in the lowest central bottom reflector block. At the lower end of the bottom reflector, the enlarged central plenum is connected horizontally to the six surrounding columns by means of six horizontal flow windows.

In addition to the two major flow network models described above, several other smaller flow models of individual core components are used at GA to study the flow distributions in specific core components. The approach at $\mathrm{GA}$ in refining the flow models is to use flow test results to 


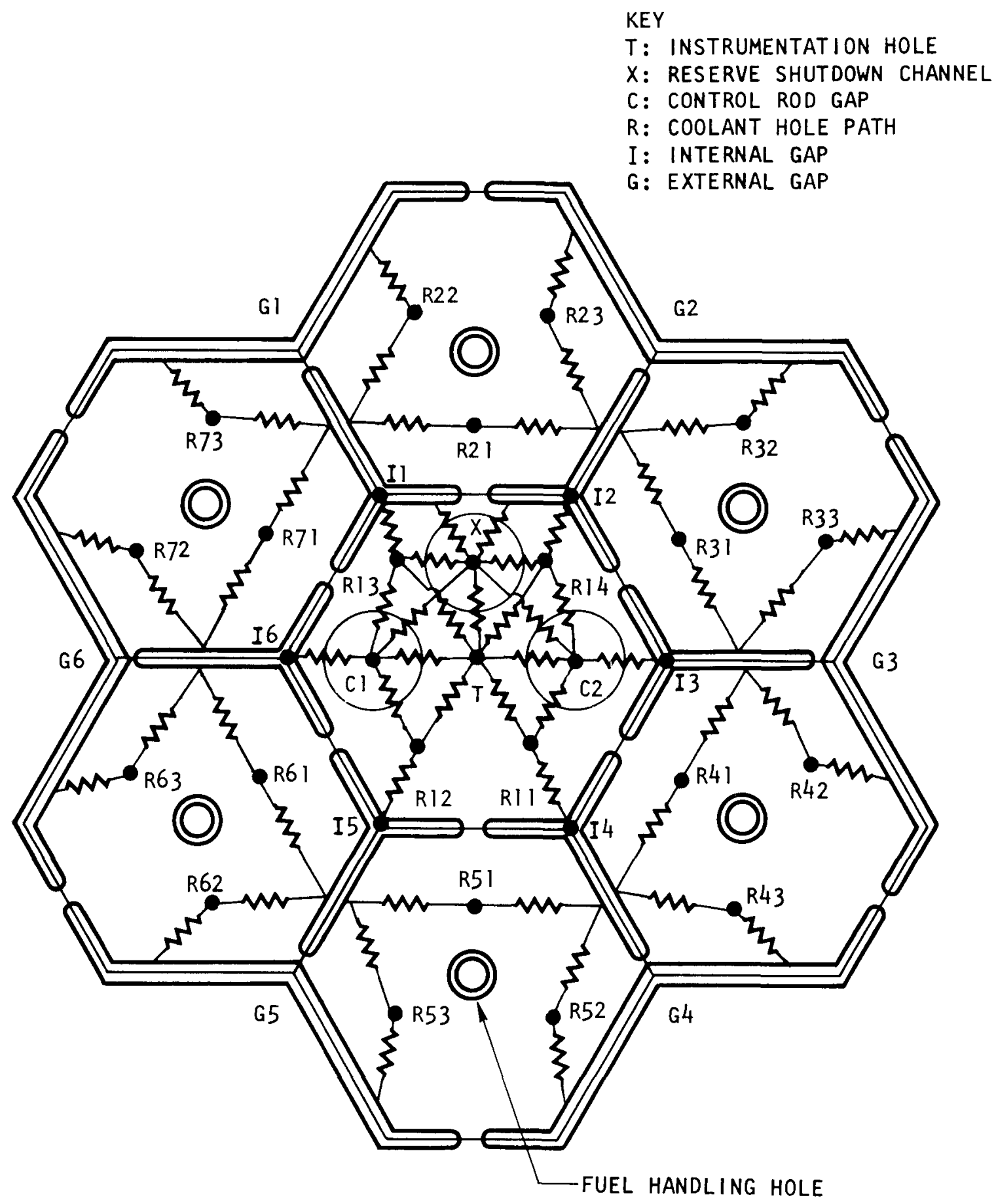

Fig. 4-4. Seven-column region flow model 


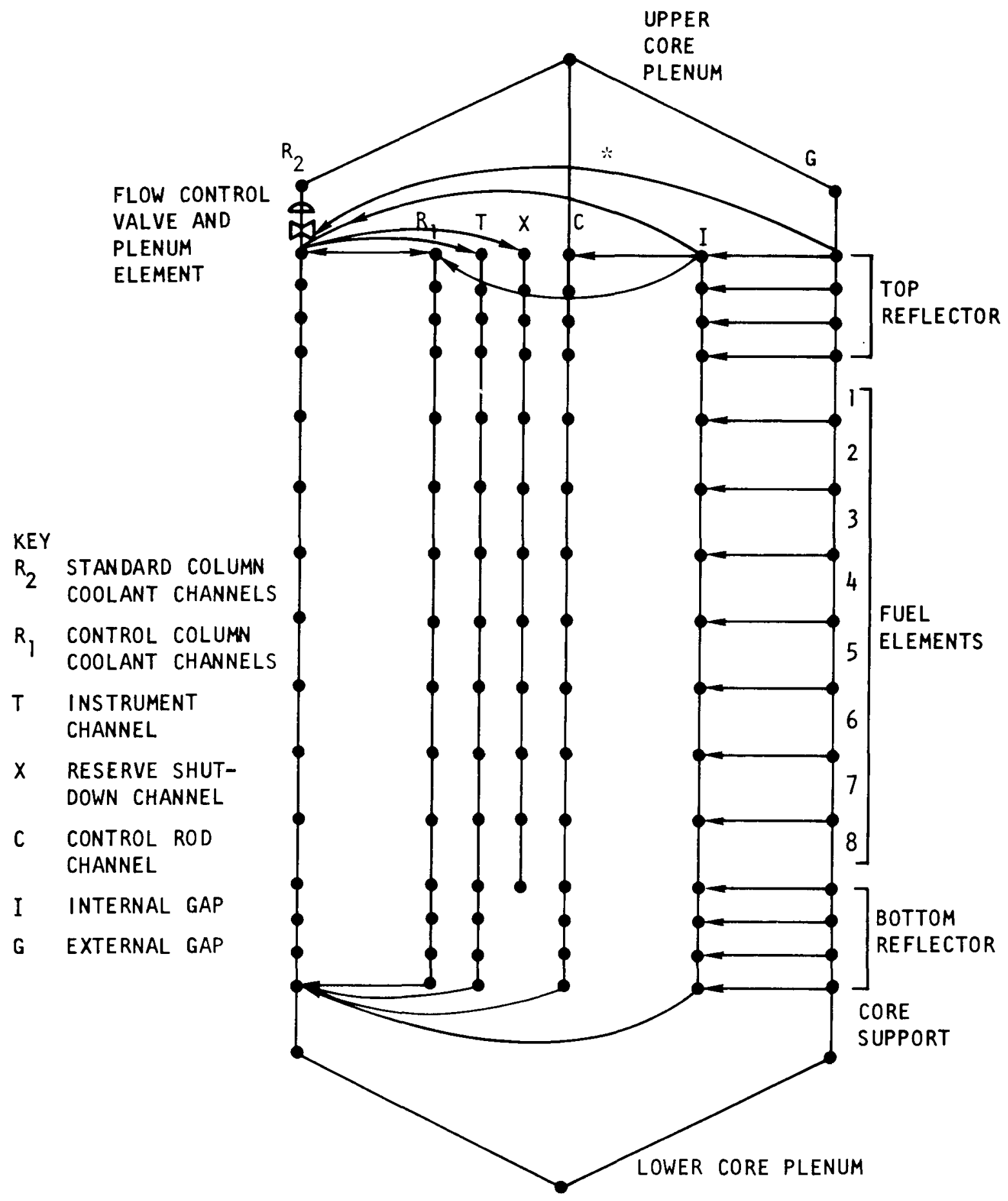

* all horizontal connections are not showid (See fig. 4-4) HORIZONTAL CONNECTIONS ARE MADE AT EACH AXIAL LEVEL BUT ARE NOT SHOWIN HERE.

Fig. 4-5. Vertical branch connection for seven-column region model 
determine the flow resistance (loss coefficients) of complex flow geometries in the core. These experimentally determined loss coefficients are then used in FLAC models to perform design calculations. At the present time two series of experimental programs are underway. In the first series, full-scale models of individual core components, fuel elements, flow control valve, fixed orifice, and lower reflector with a core support block are being tested. In the second series, full-scale models of an entire seven-column region, a four-column region, and a two-column region will be tested. Measurements of detailed flow and pressure distribution and vibration and noise generated by the flow will be made as part of these test programs. More details of these test programs are given in Section 5.3 .

\subsubsection{Region Average Thermal Analysis POKE Code}

The variable flow control valves at the inlet of each region provide on-line control of the coolant flow to each of the refueling regions. In addition, 18 fixed orffices that do not have variable flow control are used on certain fuel columns at the core periphery of the $3000 \mathrm{MW}(t)$ core. The flow control valve adjustment criteria specify that during steady-state operation the flow through the region shall be adjusted so that the average helium outlet temperature from each of the refueling regions is about the same.

A computer program POKE (Ref. 4-5), used to calculate the steady-state flow control valve positions for each of the regions as a function of region power generation, is also used to calculate the distribution of coolant, graphite, and fuel temperatures. The reactor configuration treated by POKE consists of a number of parallel coolant channels connected to common inlet and outlet plenums. Each channel represents an average channel within a refueling region and is axially subdivided into an inlet reflector, active core, and outlet reflector. The channels can be 
connected at several axial positions to a core bypass channel. An iterative solution of the set of one-dimensional mass and momentum conservation equations is used by POKE. For each iteration the flow distribution calculated is used to compute the coolant temperature distribution; coolant temperature and flow distribution are in turn used to compute the flow resistance of each channel. Several options, including the following, are available for the flow analysis:

1. Specification of total core power and power distribution, reactor flow or pressure drop, and region inlet valve loss coefficient, allowing calculation of region outlet temperature and corresponding axial coolant, graphite, and fuel temperatures.

2. Similar to 1 but instead of specifying flow valve loss coefficient, the flow control valve loss coefficlent can be calculated so that the coolant outlet temperatures from all refueling regions are equal.

3. The effects of crossflow may be simulated by inputting crossflow coefficients at the interface of fuel blocks for each region. The coefficients are obtained from flow network analysis (FLAC). (See Section 6.1.1.)

4. After the flow and thermal analyses for the total core have been performed, similar but more detailed analyses may be made for channels within each single region which account for intraregion power tilts.

The code output consists of the flow control valve coefficient; coolant mass flow rate; and the region coolant, graphite, and fuel temperatures at each axial mesh point. 


\subsubsection{Half-Column Thermal Network Models}

For more detalled analysis of the temperatures and flow distribution within individual fuel elements, models of both standard and control fuel elements are used. The two codes DEMISE (an acronym for demi Standard Element) and DEMICE (deml Control Element) are three-dimensional network models of one-half of a fuel column, including the upper and lower reflectors and core support floor. Both use the solution techniques and storage packing features of the general thermal network analyzer CINDA (Ref. 4-6) and the flow distribution calculational scheme of RECA (Ref. 4-7).

The thermal network modeling consists of "lumping" a certain mass of solid or coolant material into a node, specifying the effective conductances between the adjoining nodes, writing an energy balance at each node, and solving the resulting set of simultaneous algebraic equations for the unknown temperatures. The arrangement of nodes at an axial level within the active core for the two models is shown in Figs, 4-6 and 4-7. The arrangement of axial connections is shown in F1g. 4-8. Macroscopic momentum balances for the coolant in parallel coolant passages are solved simultaneously with coupling to the conservation of energy equations in the solid.

In each horizontal plane of the standard half-column model, 70 nodes represent fuel rod and surrounding graphite, 4 nodes represent burnable poison rods, and 1 node represents the solid graphite central portion of the block. The heat generated at these nodes is conducted to 38 nodes representing interior coolant channels and 3 nodes representing coolant flowing in the gaps between elements. At the external boundary of the element, heat may be transferred to a flowing coolant or the boundary may be adiabatic. The boundary of the models drawn through the center of the element is considered to be insulated. There are 11 such horizontal planes to represent the 8 fuel elements in the active core, the top and bottom 


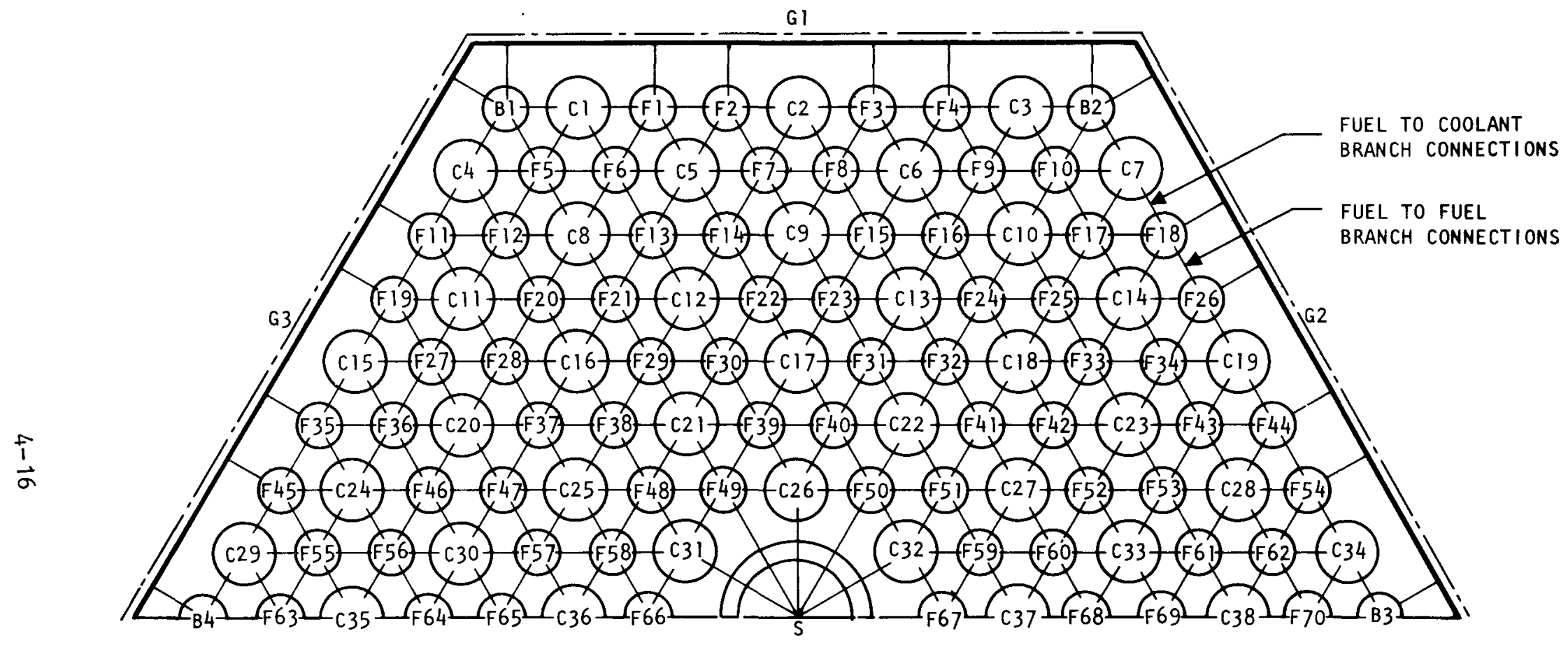

$$
\begin{aligned}
& c=\text { COOLANT CHANNEL NODE } \\
& G=\text { COOLANT GAP NODE } \\
& F=\text { SOLID FUEL ROD NODE } \\
& S=S O L I D \text { GRAPHITE NODE } \\
& B=S O L I D \text { BORONATED GRAPHITE NODE }
\end{aligned}
$$

Fig. 4-6. Plan view of half standard fuel element column with horizontal node connections - DEMISE 


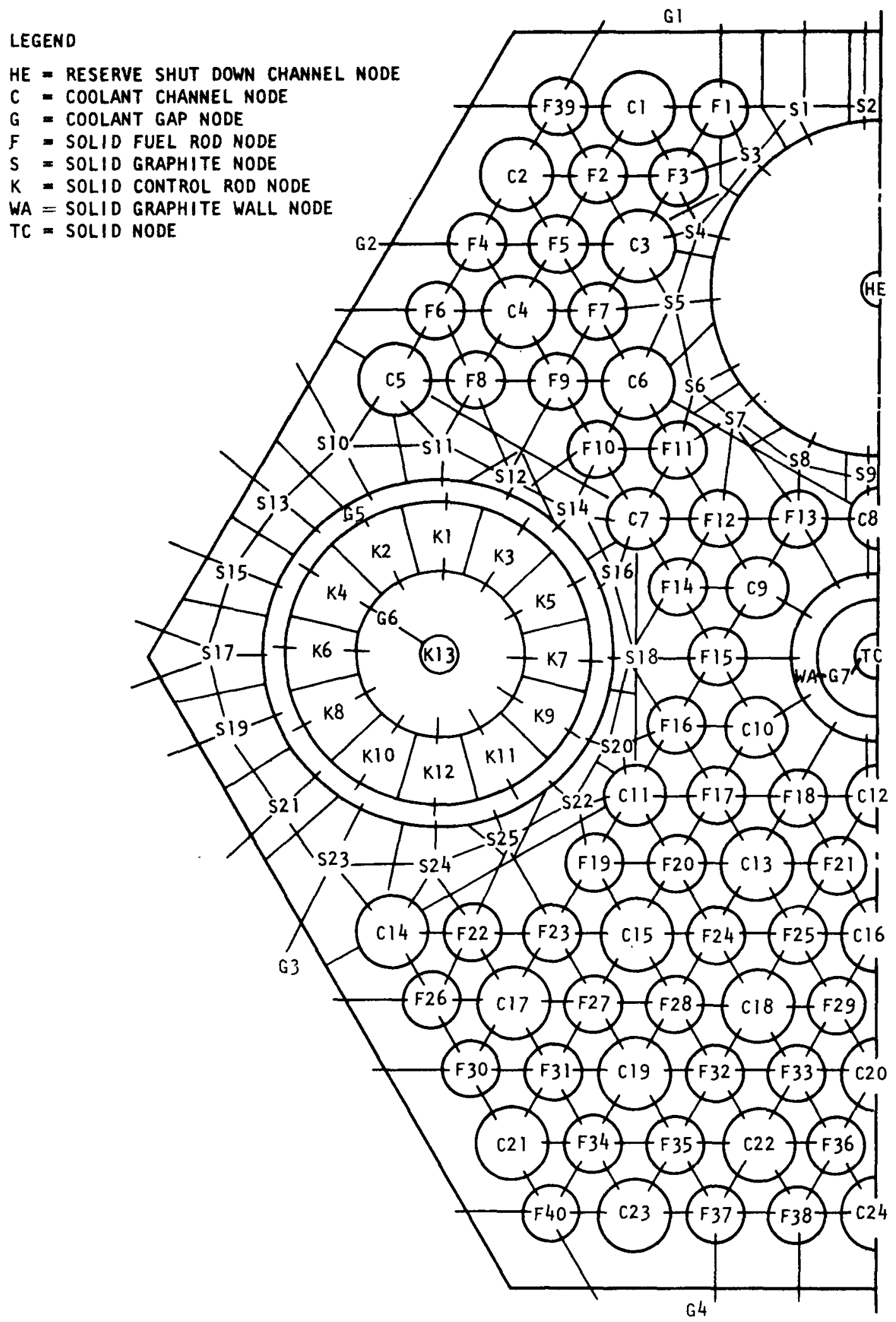

Fig. 4-7. Plan view of the control fuel element column with horizontal node connections - DEMICE 
FLOW CONTROL VALVE

PLENUM

TOP REFLECTOR

ELEMENT

FUEL ELEMENT 1

FUEL ELEMENT 2

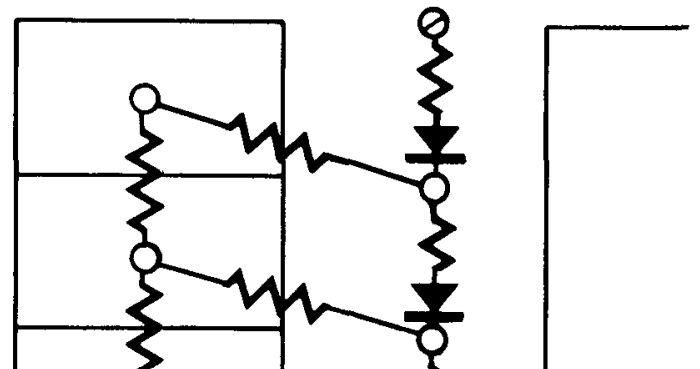

FUEL ELEMENT 3

FUEL ELEMENT 4

FUEL ELEMENT 5

FUEL ELEMENT 6

FUEL ELEMENT 7

FUEL ELEMENT 8

BOTTOM REFLECTOR ELEMENT

CORE SUPPORT BLOCK

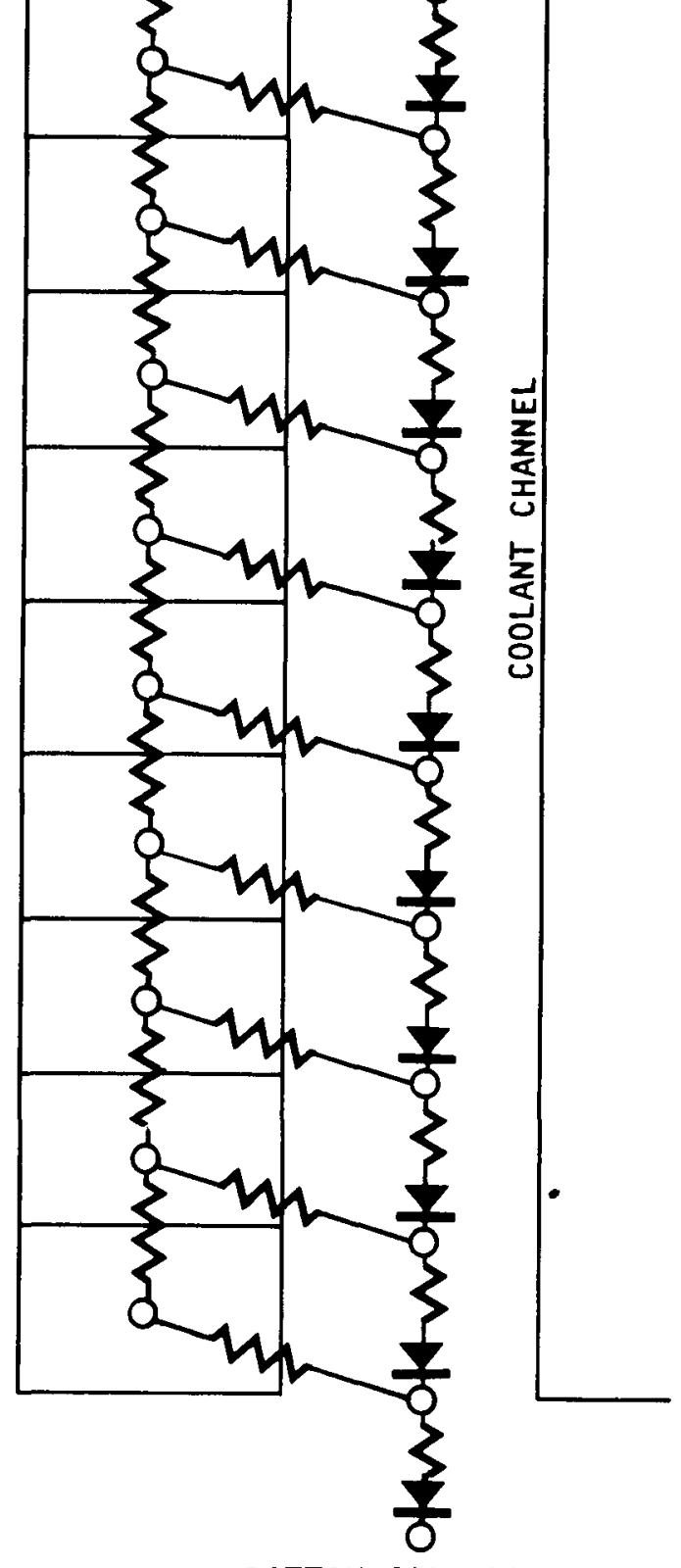

BOTTOM CORE PLENUM

Fig. 4-8. Schematic elevation view of the fuel element column with network representation 
reflectors, and the core support floor. Each node represents a height dimension equal to that of one fuel element (31.22 in.). In the top and bottom reflectors and the core support floor, the solid nodes represent graphite that surrounds the coolant channels.

In each horizontal plane of the control half-colum model, 40 nodes represent fuel and graphite and 26 solid nodes represent graphite material surrounding the control rod hole and the reserve shutdown hole. The control rod is also modeled with 12 nodes representing the control rod compacts and 1 node modeling the central metal spine. The heat generated in these solid nodes is conducted to nodes modeling the 24 coolant holes, the two concentric flow passages in the control rod channel, and the four side gaps between fuel elements. As in the case of the standard halfcolumn model, there are 11 axial levels and each radial node has a height dimension equivalent to that of a standard fuel element of 31.22 in.

The primary results from both models are the radial and axial temperature distributions within the half-columns. The models calculate the coolant temperatures at the bottom of each block and then the effective conductance between fuel and coolant nodes is evaluated by Eq. 4-3. Then the maximum fuel rod temperature at each fuel rod node is computed from $\mathrm{Eq}$. 4-4. However, it is possible to alter, by appropriate input, the conductance to calculate graphite temperatures or other element temperatures at these nodes. In either case the coolant temperature at the bottom of the block is used in computing the temperature difference and the heat flux is based upon a heat generation rate that is averaged axially over a block length. Using these two models, details of heat flow within an HTGR fuel element can be determined.

Typical results from these models are presented in Section 6.1.3. A brief description of the calculation of nodal heat generation, heat transfer, and flow distribution in these models follows. 
1. Nodal Heat Generation

The heat generated within each solid fuel node $i$ is computed from

$$
Q_{i}=\bar{q} \cdot P(r) \cdot \alpha(l, r) \cdot A(l, z),
$$

where $\bar{q}=$ core average heat generation rate for a fuel stack,

$$
\begin{aligned}
P(r) & =\text { region peaking factor (see Section 5.8.3), } \\
\alpha(l, r) & =\text { intraregion local tilt (see Section 5.8.3), } \\
A(l, z) & =\text { axial power peaking factor (see Section 5.8.3). }
\end{aligned}
$$

The heat generation rates in the burnable poison pins, graphite, and control rod compacts are computed in exactly the same manner except a value of $\bar{q}$ appropriate to the type of node is used.

\section{Nodal Heat Transfer}

The rate of heat transfer between any nodes $i$ and $j$ is given by

$$
Q_{i j}=G_{i j}\left(T_{i}-T_{j}\right) \text {, }
$$

where $G_{i j}$ is the effective conductance between nodes $i$ and $j$.

The values of conductances $G_{i j}$ are obtained from detailed models of smaller portions of the fuel element using, for example, the HEXT code and the general purpose TAC models (see Section 4.1.6). The conductance between a coolant and a solid node includes the combined heat flow resistance by the solid material $\left(\mathrm{C}_{\mathrm{s}}\right)$ and the film resistance ( $h$ ) at the coolant surface. These are combined together to obtain the overall conductance by

$$
G_{i j}=\frac{A}{\frac{1}{C_{s}}+\frac{1}{h}} \text {, }
$$


where $A=$ effective heat transfer area, $C_{s}=$ solid conductance based on area $A$, $h=$ heat transfer coefficient.

In CINDA calculations, $h$ is calculated at each iteration using the correlation given in Section 5.4.

3. Nodal Temperature Calculations

The calculations proceed by first evaluating all properties such as the heat generation rates and the conductances between nodes. Following the evaluation of properties, the node temperatures are calculated. The nodes are classified as diffusion nodes, arithmetic nodes, or fixed temperature nodes. The diffusion nodes represent thermal masses whose temperatures must be determined by solving the set of simultaneous equations; the arithmetic nodes represent flowing coolants that have a negligible thermal mass but whose temperatures must also be determined; and the fixed temperature nodes represent nodes whose temperatures are known. The temperatures at the diffusion nodes are calculated first followed by the calculations at the arithmetic nodes.

The simultaneous equations are solved by an implicit finite difference scheme.

The temperature at a node $i$ is calculated from a simple heat balance on the node:

$$
T_{i}=\frac{\sum\left(G_{i j} T_{j}\right)+Q_{i}}{\sum G_{i j}} .
$$


The temperatures $\mathrm{T}_{f}$ are the temperatures of the nodes to which node 1 is joined, and $Q_{1}$ is the heat generation rate at node 1 . The summation is carried out to include all the nodes to which 1 is connected. After this, the convergence of the nodal temperatures and the heat balance of the entire network are examined and the process is repeated until the convergence criteria are satisfied.

\section{Coolant Channel Flow Calculations}

The flow through the half block model is represented by a series of flow channels connected to a common flow valve plenum and core exit outlet plenum. The total flow is given as an input and the flow to each of the coolant channels is distributed depending upon its flow resistances calculated using the one-dimensional macroscopic conservation of momentum equation for incompressible flow given in Section 4.1.4. Note, however, that the flow control valve coefficient $\mathrm{K}_{\mathrm{v}}$ is not included in the equation since only the flow paths between the valve plenum and lower core plenum are modeled.

\subsubsection{One-DimensIonal Unit-Ce11 Codes BACH and HEXT}

The BACH code is a one-dimensional, heat-transfer code describing heat and coolant flow in a single coolant channel in the core. Figure 4-9 shows a typical coolant hole-fuel hole pattern in an HTGR fuel element.

The regular area on the interior of the fuel elements can be built up from triangular shaped unit cells as shown in Fig. 4-9 and enlarged in Fig. 4-10. In a portion of an element where the power generated in each fuel rod is the same, all sides of the cell are bordered by mirror images of the unit cell, and it is assumed that all external boundaries of the triangular 


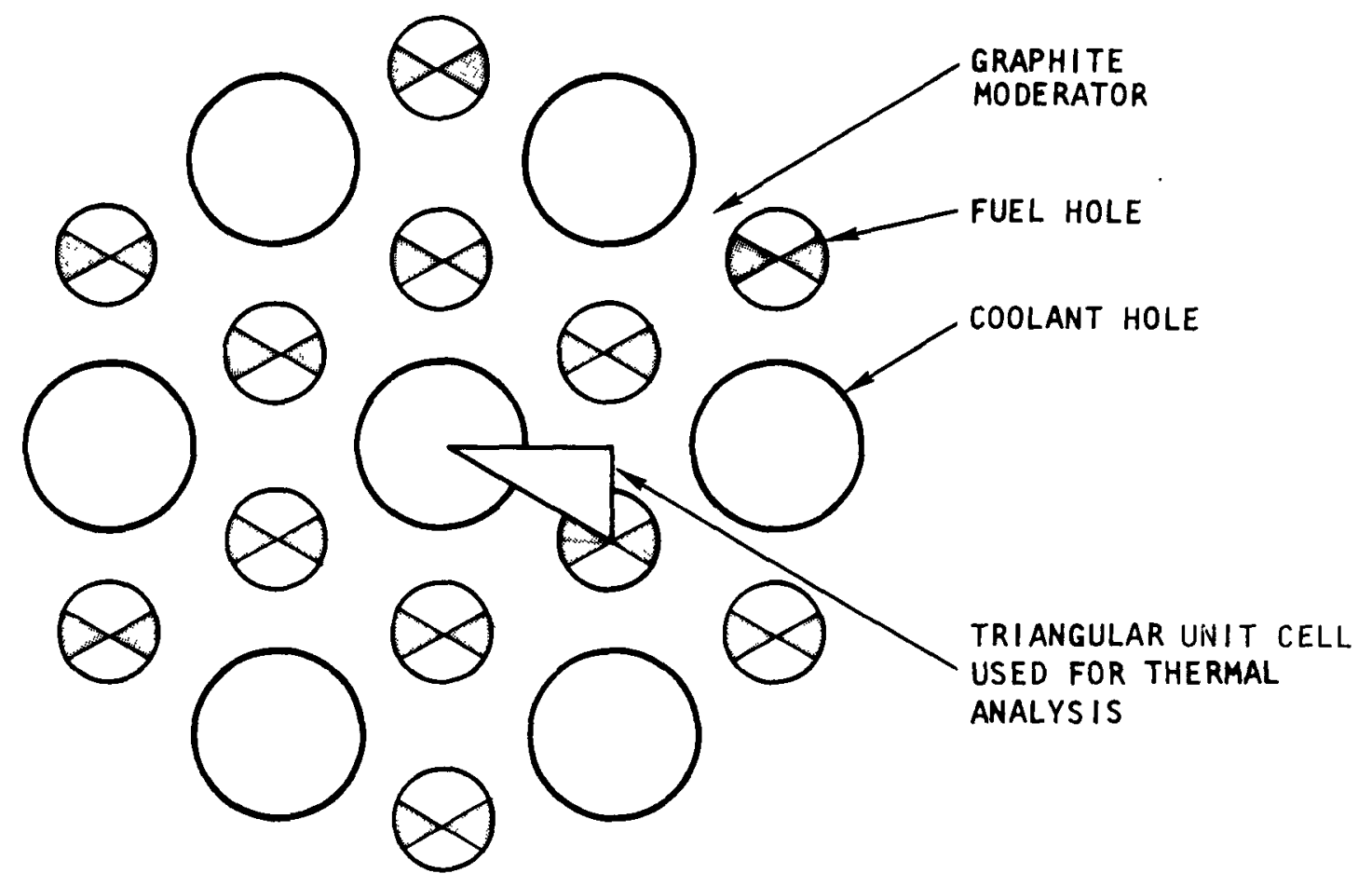

Fig. 4-9. Fuel and coolant hole configuration 


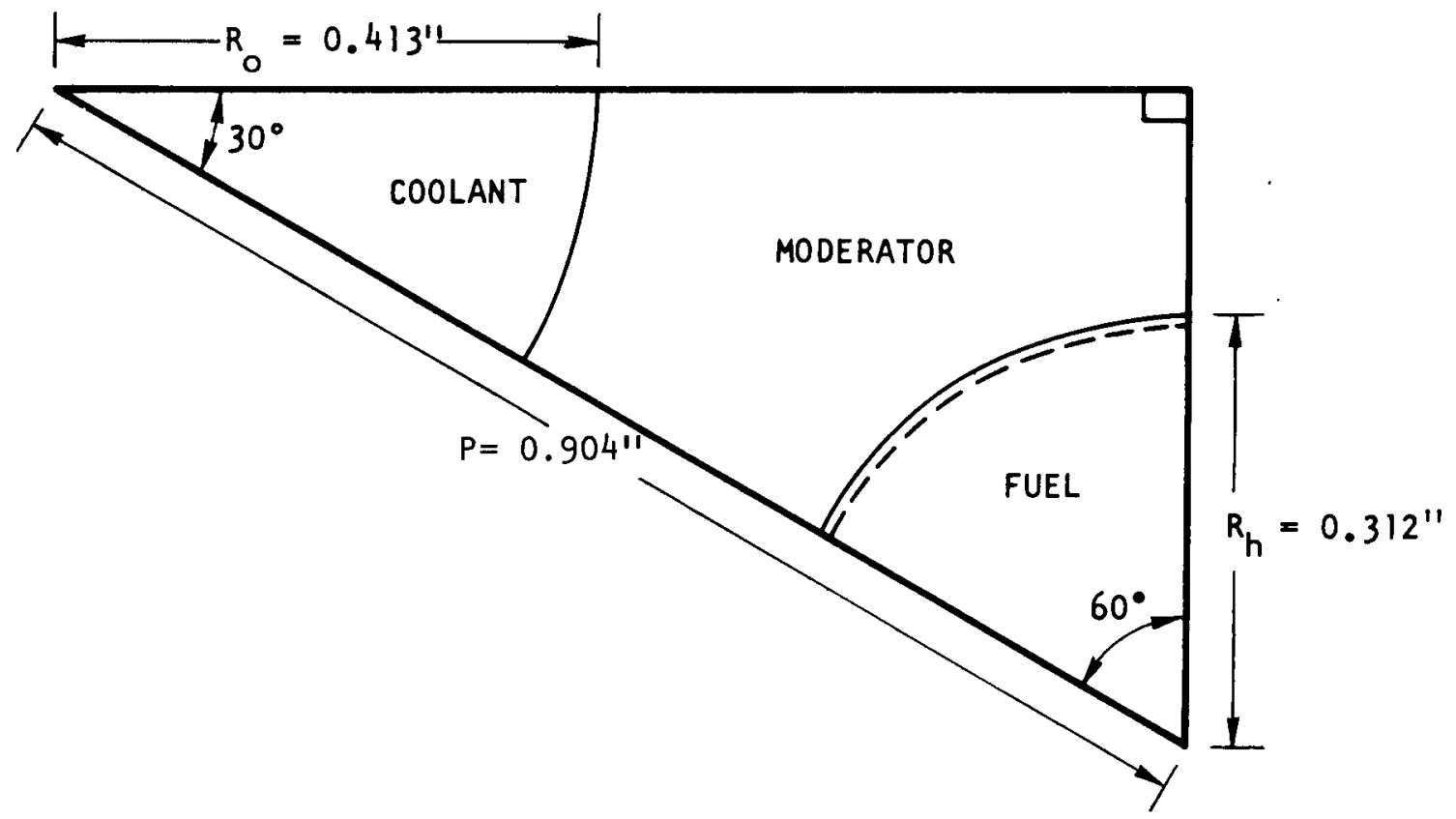

Fig. 4-10. Triangular unit cell element used in thermal analysis 
section are insulated. This is an accurate approximation when the power and flow distribution across the block are unfform and radial conduction to coolant flowing around the fuel element's edges is small. The approximation is conservative when estimating maximum fuel temperature because in hightemperature unit cells heat flows outward to surrounding cells, which reduces the heat flux in the high temperature cell. Section 6.1 .6 presents results of calculations demonstrating this effect.

The fuel centerline temperature $\mathrm{T}_{G}(z)$, at any axial location $z$ in a unit cell with insulated boundaries can be expressed as a sum of temperature rises as follows:

$$
\begin{aligned}
\mathrm{T}_{\mathscr{E}}(z)= & \mathrm{T}_{\text {coolant }}(\mathrm{z})+\Delta \mathrm{T}_{\text {film }}(z)+\Delta \mathrm{T}_{\text {graphite }}(z) \\
& +\Delta \mathrm{T}_{\text {gap }}(z)+\Delta \mathrm{T}_{\text {fuel }}(\mathrm{z}),
\end{aligned}
$$

where the temperature rises $(\Delta T)$ and the bulk coolant temperatures $T_{\text {coolant }}(z)$ are derived below. For heat generation in the fuel rod and cooling at the coolant hole surfaces, all the quantities in Eq. 4-5 are positive.

1. Axial Temperature Profile Along the Length of Channel

The axial variation of the bulk coolant temperature $T_{\text {coolant }}(z)$ is given by:

$$
\mathrm{T}_{\text {coolant }}(z)=\frac{\overline{\mathrm{q}}^{\prime} \int_{\mathrm{o}}^{z} A\left(l, z^{\prime}\right) \mathrm{d} z^{\prime}}{\mathrm{mC_{p }}}+\mathrm{T}_{\text {in }},
$$

where $\quad \bar{q}^{\prime}=$ linear heat rating, averaged over the fuel stack height,

$A(\ell, z)=$ axial power peaking factor (see Section 5.8.3), $\mathbf{m}=$ coolant flow rate in channel, 


$$
\begin{aligned}
C_{p} & =\text { coolant specific heat at constant pressure, } \\
T_{\text {in }} & =\text { coolant inlet temperature, }
\end{aligned}
$$

2. Coolant Channel Film Temperature Rise $\left[\Delta \mathrm{T}_{\mathrm{film}}(\mathrm{z})\right]$

The temperature difference between the bulk coolant and the coolant hole surface is calculated from:

$$
\Delta T_{f i 1 m}(z)=\frac{q_{w}^{\prime \prime}(z)}{h(z)},
$$

where $q_{w}^{\prime \prime}=1$ local heat flux at wall of coolant channel,

$\mathrm{h}=$ heat transfer coefficient at channel wall (see Section 5.4).

\section{Graphite Temperature Rise [ $\Delta \mathrm{T}$ graphite $\underline{(z)}]$}

The temperature difference between the coolant hole surface and the fuel hole surface is:

$$
\Delta \mathrm{T}_{\text {graphite }}(z)=\frac{\mathrm{q}_{\mathrm{w}}^{\prime \prime}(\mathrm{z})}{\mathrm{C}_{\text {graphite }}},
$$

$$
\begin{aligned}
\text { where } \mathrm{C}_{\text {graphite }}= & \text { equivalent conductance of the graphite web; } \\
& \text { the definition is based on the coolant hole heat } \\
& \text { flux } \mathrm{q}_{w}^{\prime \prime}
\end{aligned}
$$

A two-dimensional closed form solution giving the temperature field in the triangular unit cell with insulated boundaries and constant thermal properties in fuel and graphite is available in the HEXT code (Ref. 4-8). The two-dimensional temperature field from HEXT is used to evaluate a one-dimensional conductance, 
Cgraphite, defined in Eq. 4-8. This one-dimensional conductance is used in the BACH code, POKE code, and TREVER codes.

\section{Gap Temperature Rise [ $\Delta \mathrm{T}$ gap $(\mathrm{z})]$}

The temperature rise across the gap between the fuel rod and the graphite web is approximated by:

$$
\Delta \mathrm{T}_{\text {gap }}(z)=\frac{\mathrm{q}_{\mathrm{r}}^{\prime \prime}(z)}{\mathrm{h}_{\text {gap }}},
$$

where $q_{r}^{\prime \prime}(z)=10$ cal heat flux at fuel rod surface $=q_{f}^{\prime \prime \prime}(z) R_{f} / 2$, $q_{f}^{\prime \prime \prime}(z)=10 c a 1$ fuel rod volumetric heat generation rate, $\mathrm{R}_{\mathrm{f}}=$ fuel rod radius,

$h_{\text {gap }}=$ gap conductance (discussed in Section 5.7).

5. Fuel Rod Temperature Rise $\left[\Delta \mathrm{T}_{\text {fuel }} \underline{(z)}\right]$

The temperature difference between fuel rod centerline and fuel rod surface is given by

$$
\Delta T_{\text {fuel }}(z)=\frac{q_{f}^{\prime \prime \prime}(z) R_{f}^{2}}{4 K_{f}},
$$

where $K_{f}=$ thermal conductivity of fuel rod (see Section 5.6.1).

\section{Channe1 Pressure Losses}

In a $\mathrm{BACH}$ analysis a momentum balance is made between a regionaverage condition and an individual coolant channel condition to calculate the coolant channel flow in local channels. 
The pressure drop experienced by the coolant as it flows along the reactor coolant passages arises mainly in three ways: (1) as a result of orificing effect due to the flow control valve at the inlet of each of the refueling regions, (2) as a result of the friction between the coolant and coolant channel surface, and (3) due to acceleration of the coolant as it is heated in the channel. In addition, small drops in pressure will be incurred at the inlet in accelerating the coolant from the plenum of the flow control valve and also at the outlet where the coolant is expanded to a low velocity before discharge into the bottom core plenum.

A simple relation for the plenum-to-plenum core pressure drop is given by Ref. 4-9.

$$
\begin{aligned}
P_{i}-P_{o}= & \frac{1}{2 p_{i}}\left(\frac{m}{A}\right)^{2}\left[K_{v}+K_{i}+\frac{4 f L}{D}\left(\frac{\bar{T}}{T_{i}}\right)+\frac{\left(T_{o}-T_{i}\right)}{T_{i}}\right. \\
& \left.+\sum_{j=1}^{n} K_{j}\left(\frac{T_{j}}{T_{i}}\right)+K_{o}\left(\frac{T_{o}}{T_{i}}\right)\right],
\end{aligned}
$$

where $P_{i}=$ total pressure at core inlet plenum,

$\mathrm{P}_{0}=$ total pressure at core exit plenum,

$\rho_{i}=$ coolant density at inlet to channel,

$\mathrm{m}=$ mass flow rate in a single coolant channel,

$A=$ cross sectional flow area of a coolant channel,

$\mathrm{K}_{\mathrm{V}}=$ loss coefficient due to flow control valve,

$f=$ friction factor,

$\mathrm{L}=$ length of flow passage in the core,

$D=$ diameter of coolant hole,

$\mathrm{T}_{i}=$ coolant inlet temperature, ${ }^{\circ} \mathrm{R}$,

$\mathrm{T}_{j}=$ coolant temperature at the bottom of block $j,{ }^{\circ} \mathrm{R}$, 


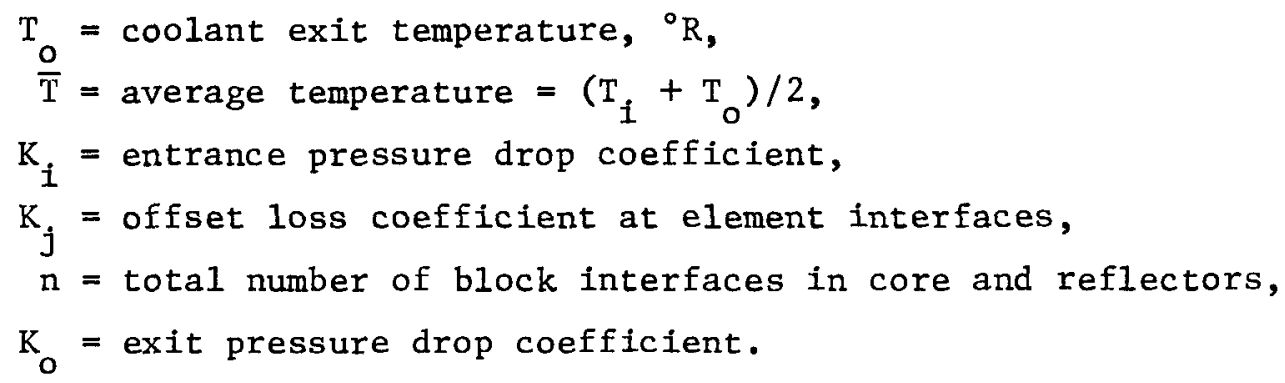

Each of the terms given within the square bracket represent a flow resistance through the core. The plenum-to-plenum total pressure drop $\left(P_{i}-P_{0}\right)$ for all the refueling regions within the core is the same. However, the flow rate through each of the regions is controlled by adjusting the flow control valve port, which determines the value of orifice coefficient $K_{v}$.

The quantity $\mathrm{K}_{i}$ is the entrance pressure drop coefficient, which remains constant for the reactor at Reynolds numbers commonly encountered. The friction loss coefficient is dependent on the friction factor $f$ for the coolant holes and depends on the Reynolds number of the coolant flow and roughness of the coolant channel. The term $\left(\mathrm{T}_{0}-\mathrm{T}_{i}\right) / \mathrm{T}_{i}$ results from acceleration of the coolant due to temperature changes along the length of the channel. The quantity $\mathrm{K}_{j}$ is the offset loss coefficient arising due to possible misalignment of the coolant holes at the graphite block interface. The loss coefficient $\mathrm{K}_{j}$ is a function of the distance between the centerlines of the coolant holes at the block interface and the Reynolds number of coolant flow. The exit loss coefficient $k_{0}$ includes the loss coefficient due to the friction and flow expansion in the bottom reflector and the core support block. It also includes the loss coefficient due to expansion of the coolant into the lower core plenum. Values for the loss coefficients to be used in the final design of the reactor will be obtained from currently planned experiments on 
full-scale models. A brief description of these tests is given in Section 5.3. Equation 4-11 relates in a simple way the pressure drop to various flow resistances along the length of the coolant passages in the core. However, in the codes POKE and BACH the core pressure loss is calculated separately, using equations of the form of Eq. 4-11, for the inlet reflector, each of the eight individual fuel elements, and for the exit reflector. Total core pressure loss is calculated by suming the 10 pressure losses as described in Ref. 4-5.

The above one-dimensional heat transfer and flow model in the BACH computer program is used to calculate axial temperature distributions of coolant, graphite, and fuel in any part of the reactor. The BACH program prints out, in addition to these temperatures, the axial distributions of heat flux, velocity, Reynolds numbers, differential pressure drop, and fuel particle life times for amoeba migration (Section 3.2.1). In the BACH program, options are available to perform an error analysis and to calculate the steady-state core power/flow ratio to achieve a desired maximum fuel temperature in a specified refueling region of the variableorificed, multiple-parallel channel, HTGR core.

\subsubsection{Core Performance Code TREVER}

Coated particle integrity was expressed in terms of their irradiation environment in Section 3.2, where the four quantitatively described failure mechanisms were presented. These failure models relate the fraction of particle coatings that fail by each of the four mechanisms to the local irradiation environment. Environmental parameters that control the failure of particle coatings are temperature, temperature difference across the fuel kernels, heavy metal burnup in the kernel, and fast neutron fluence. The computer code TREVER calculates the time history of the necessary environmental parameters at many locations within the fuel, then uses the 
four coating failure models (Ref. 3-2) to compute the local fraction of failed coatings. By summing the local failure in each segment of the core, the total quantity of failed coatings in the core is calculated.

Time histories of local core temperatures, fluence, burnup, and failed coating fraction calculated by TREVER are subsequently used in fission product release, fuel element dimensional change, and fuel element stress evaluations.

TREVER models the time dependence by performing steady-state thermal calculations at many discrete time points. The TREVER code requires, at each time point, distributions of power, fast neutron flux, and isotopic composition of the fuel (burnup) to be specified in the input to the code. Nuclear analysis codes GAUGE, BUGTRI, and GATT (Ref, 4-10) are used to supply these quantities. The power distribution and fast fluence is accomplished through use of peaking factors from these codes; Section 5.8 describes how this is done.

In addition to the coating behavior models, the environmental dependence of the properties of the core materials is required as input to the code. These properties are described in Sections 5.2, 5.5, 5.6, and 5.7.

The unit cell thermal model described in Section 4.1 .4 is used by the TREVER code. Irradiation-dependent material properties are used to calculate the dimensions of the coolant holes, fuel holes, fuel rods, and the gap between the fuel rod and fuel hole. Temperatures of the coolant, graphite at the coolant hole surface, graphite at the fuel hole surface, fuel rod surface, and fuel centerline are calculated at up to 35 axial levels in the active core. Calculations are made with the same radial resolution as the nuclear codes: 7 points per column for GAUGE and GATT and 24 points per column for BUGTRI. (See Section 5.8.) 
In the TREVER analysis, the coolant flow rate in each coolant channel is calculated using flow correlations obtained from POKE subregion analyses. Derivation of this correlation is described in Section 6.1.2.2.

To calculate fuel particle coating failure, burnup and fast neutron fluence are calculated at each axial level. These local values of burnup and fluence are used with the fuel centerline temperature to estimate fuel failure by pressure vessel and SiC-fission product interaction mechanisms. For coating failure by kernel migration, the fuel rod is divided into 10 radial rings and the temperature and temperature gradient (using a parabolic distribution) of each ring are used to estimate the local kernel migration distance.

The output from the code includes space- and time-dependent histories of temperatures of coolant, graphite, and fuel as well as BISO coating failure by each mechanism; TRISO coating failure by each mechanism; burnup and fast neutron fluence; and dimensions of the coolant hole, fuel hole, and fuel-graphite gap. These quantities may be written on magnetic tape for use by other programs for calculation of fuel element stresses and fission product release.

Application of the TREVER code to the $3000 \mathrm{MW}(t)$ design is described in detail in Section 7.

4.1.6. General Purpose Thermal Analysis TAC Code

The detailed thermal analyses of the several core components are performed using the TAC-2D code (Ref. 4-11). The TAC-2D code provides the capability of performing fine-mesh calculations for small sections in the core (i.e., detailed temperature distributions in specific parts of the fuel element or in a control rod). Material properties that are a function of temperature are evaluated locally for each node point within the 
analytical model. Also, local bulk fluid temperatures are evaluated and used to compute temperature-dependent fluid properties, Reynolds numbers, and film coefficients. More description of the TAC-2D is given in Section 4.2.2.

An additional use of the TAC computer program is in the thermal design for situations where the thermal models given in the above sections are not applicable. In this capacity, the results from $\mathrm{TAC}-2 \mathrm{D}$ analysis are used to substantiate the geometrically simpler one-dimensional design model. Where warranted, corrections for the basic model calculations are made based on TAC results.

\subsection{TRANSIENT ANALYSIS CODES}

Operational occurrences in which the rate of change of major systems parameters and core parameters is fast, relative to the time constants of the HTGR fuel and graphite, are analyzed on a transient basis to calculate accurately time-dependent response of fuel, graphite, and coolant temperatures. Transient analysis of the complete HTGR system is performed using the Transient Analysis Program (TAP code, Ref. 4-12) which gives the time history of major reactor systems design parameters including total core power, total core flow, core inlet temperature, and helium pressure. Following the overall system analysis the time responses of major design parameters are used to evaluate the local and/or region average fuel and graphite temperatures. Three codes are available to evaluate the transient fuel temperature response of the HTGR core. Depending on the transient being analyzed, and scope of the problem, one or a combination of the three codes is used. The systems analysis code and the three transient fuel temperature analysis codes are briefly discussed below. 


\subsubsection{System Analysis TAP Code}

The analytical tool TAP, used to study the overall plant transient behavior of HTGRs, incorporates models of all major components of the nuclear steam supply (NSS). It models the major control system loops, basic plant protection system actions, and that portion of the balance-ofplant and auxiliary equipment having a signfficant effect on NSS transients, as well as options for simulating operator action.

The reactor and primary coolant model in this program accounts for all helium temperature changes in the primary coolant system including heating in the core and cooling in the steam generator. The core side reflector, shroud, and other bypass flows, as well as duct seal leakage, are accounted for in this analysis. The reactor core model in TAP consists of one average coolant channel surrounded by graphite and fuel. This mode1, a simplified version of the TAC code (Ref. 4-11), uses the average heat generation rate in the core and computes the average coolant, graphite, and fuel temperatures in the core. More details of this computer program are given in Ref. 4-12.

\subsubsection{Single Channel Analysis TAC Model}

The variations of coolant, graphite, and fuel temperatures and temperature gradients within a unit cell containing a single coolant channel and a single fuel rod within a refueling region are calculated using the fuel-centered computer code TAC model. The TAC model represents a single fuel rod stack surrounded by a gap and volume of graphite with a heat capacity and conductance, Cgraphite' equal to that of a unit cell. The model extends the entire active core length with five axial nodes per fuel block and includes the top reflector, bottom reflector, and core support blocks. Radially, the fuel rod is subdivided into five nodes and the graphite of the unit cell is represented by two nodes. The helium 
flows along the length of the core and the code can use time- and temperature-dependent material properties such as density, thermal conductivity, and heat capacity. A similar TAC model is also used in the BLOOST code (Ref. 4-13), which is a combined reactor kinetics and heat transfer code used to calculate detailed core response to rapid transients such as a rod withdrawal accident.

Temperatures as a function of time are calculated for these single channel unit ce11 models using the general purpose TAC-2D code (Ref. 4-11).

The digital computer code TAC-2D was developed at GA for obtaining temperature distributions in the wide variety of two-dimensional thermal systems encountered in the field of nuclear engineering. Code calculations are governed by the heat conduction equation:

$$
\nabla \cdot k \nabla T+q^{\prime \prime \prime}=\frac{\partial}{\partial t} \rho c T,
$$

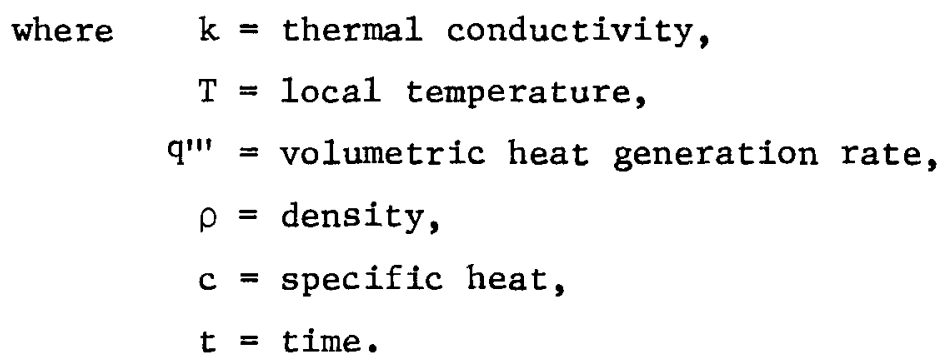

This equation is replaced by equivalent linear finite difference equations, which are solved for the local temperatures at given points in time by the implicit numerical method given in Ref. 4-11. A wide variety of boundary conditions is available.

\subsubsection{Detailed Transient Code DETRAC}

For more comprehensive analysis of the transient fuel temperature distribution throughout the reactor, the DETRAC code is used (Detailed Transient Analysis Code). 
The DETRAC code calculates fuel and graphite temperatures within each refueling region; it includes the capability to perform an arbitrary number of transient unit cell calculations within each refueling region. Graphite and coolant temperatures are calculated at 11 axial positions: top and bottom reflector, solid support floor, and for each of the eight fuel blocks. Average and centerline fuel temperatures are calculated for each fuel block and for selected local channels within a refueling region.

4.2.3.1. Thermal Model. The thermal model employed in DETRAC, based on the unit cell calculations, provides a fast and accurate method of analyzing in detail the transient response of the core. The average fuel, graphite, and coolant temperature equations solved by the code are obtained by applying conservation of energy to an axial level of a coolant channel. The average fuel and graphite temperatures are solved in differential form as follows:

$$
\begin{aligned}
& \frac{d T_{f}}{d t}=-\frac{G_{f g}}{C_{f}} T_{f}+\frac{G_{f g}}{C_{f}} T_{g}+\frac{q_{f}}{C_{f}}, \\
& \frac{d T_{g}}{d t}=\frac{G g}{C_{g}} T_{f}-\frac{\left(G_{f g}+G_{g c}\right)}{C_{g}} T_{g}+\frac{G g}{C_{g}} T_{c}+\frac{q_{g}}{C_{g}},
\end{aligned}
$$

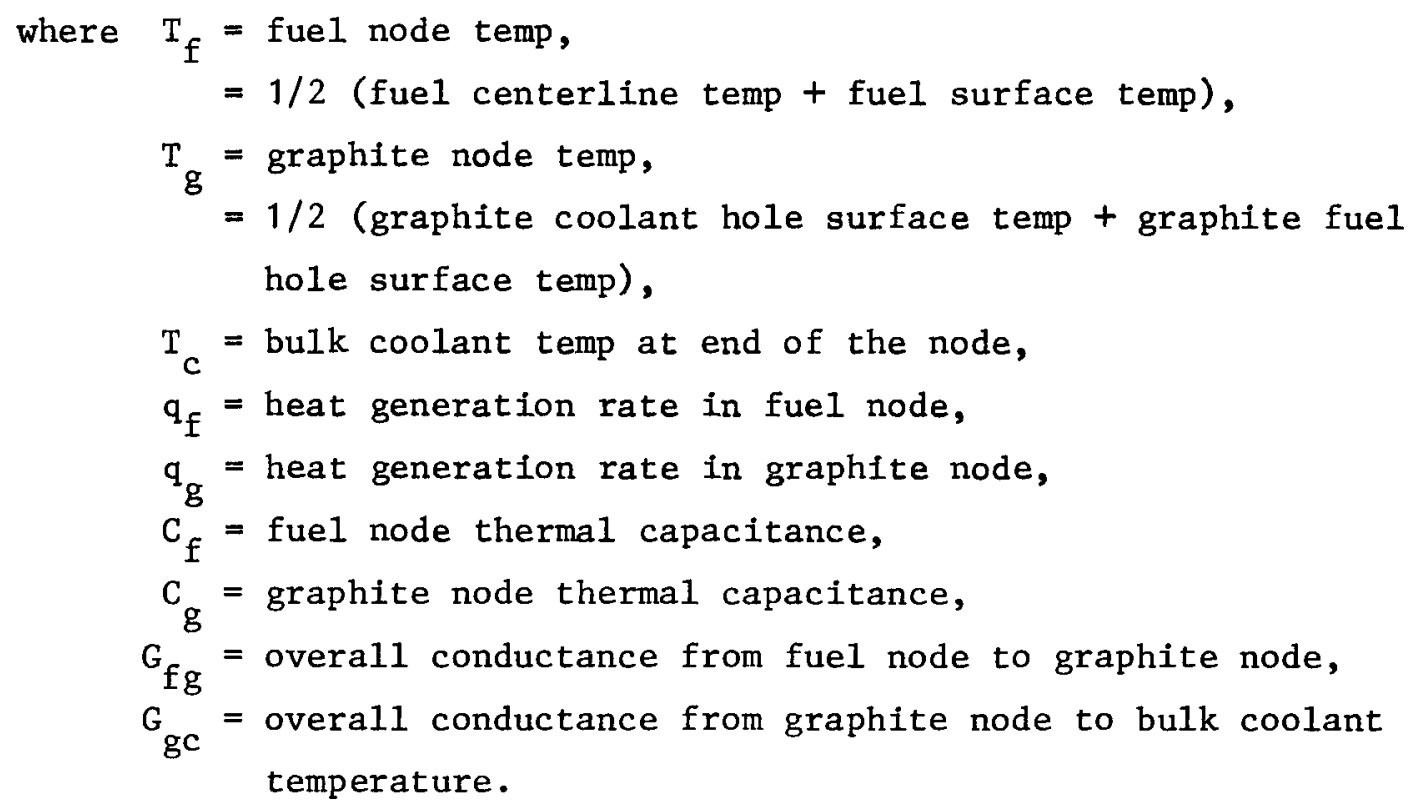


The thermal capacitance of the coolant node is small compared to the thermal capacitances of graphite and fuel nodes and is neglected for transient analysis. The coolant temperature at the end of the node $\left(\mathrm{T}_{c}\right)$ is calculated algebraically from the coolant inlet temperature and the nodal graphite temperature $\left(T_{g}\right)$ :

$$
T_{c}=\left(G_{g c} \cdot T_{g}+m c_{p} \cdot T_{c}^{I N}\right) /\left(G_{g c}+m c_{p}\right)
$$

where $\mathrm{m}=$ helium mass flow rate

$$
\begin{aligned}
& \mathrm{c}_{\mathrm{p}}=\text { helium capacitance, } \\
& { }_{\mathrm{T}}^{\mathrm{IN}}=\text { helium inlet temperature to the node. }
\end{aligned}
$$

The transient centerline fuel temperature is calculated algebraically from the nodal fuel temperature $\left(T_{f}\right)$ and transient heat transfer rate from fuel to graphite nodes:

$$
\mathrm{T}_{\mathrm{L}}=\mathrm{T}_{f}+G_{f g}\left(\mathrm{~T}_{f}-\mathrm{T}_{g}\right) / G_{f},
$$

where $\begin{aligned} T_{G} & =\text { fuel centerline temperature, } \\ G_{f} & =1 / 2 \text { the fuel rod conductance. }\end{aligned}$

The fuel and graphite differential equations are solved numerically using the fourth-order Runge-Kutta method. In transient analysis, the DETRAC code neglects the radial conduction of energy between unit cells and also neglects the axial conduction within the unit cell.

4.2.3.2. Flow Model. The flow distribution between refueling regions in the DETRAC code is calculated using the same method as employed in the RECA code (Ref. 4-7). Flow control valve loss coefficients are input to the code to provide an initially balanced helium outlet temperature from each refueling region. The flow within a unit cell is calculated by iterating 
on the active core and reflector pressure drop of the region in which the unit cell is located. The unit cell flow thus accounts for flow reduction effects of coolant acceleration within unit cells whose temperatures are higher than the region average temperatures.

4.2.3.3. Thermodynamic Properties. Values of conductance used in the DETRAC code are calculated in the same manner as used in the BACH computer code (Section 4.1.4). The code used the same correlations for the heat transfer coefficient at the coolant wall, gap conductance, and fuel and graphite temperature rises. Thermal capacitances of graphite and fuel are calculated as described in Sections 5.5.5 and 5.6.4.

\subsubsection{Region Average Analysis RECA Code}

Under core conditions where radial conduction of energy between refueling regions can be significant, the RECA (Ref. 4-7) code (Reactor Emergency Cooling Analysis) is used. In general, radial conduction of energy between refueling regions is significant for low, or no flow, conditions. The RECA code calculates the axial distribution of average coolant, graphite, and fuel temperatures for each refueling region. RECA is based on the general purpose heat conduction code CINDA (Ref. 4-6), which is capable of handling arbitrary thermal networks.

The core is modeled by a representative set of vertical regions corresponding to the actual refueling regions. In the analytical model, each refueling region is divided vertically into 11 axial nodes: one node for each of the eight fuel block layers, one node each for the top and bottom reflectors, and one node for the support block. Each solid node is connected laterally to the six surrounding solid nodes and to a corresponding coolant node. The coolant flow distribution through the core is modeled by an array of coolant channels, one channel for each refueling region, including the partial regions, which have fewer than seven columns, and one for the side reflector. Reverse flow is possible for low-flow conditions and is accounted for by the code. Crossflow is not considered. 


\section{REFERENCES}

4-1 Malek, G. J., "Development of the Flow Analysis Code FLAC," Gulf General Atomic Report GA-9482, June 1969.

4-2 Strain, B. L., "FLOPSY-II - A Digital Computer Program for Calculating Flows and Pressure Drops in Hydraulic Networks," USAEC Report KAPL-3030, June 1, 1965.

4-3 Walker, W. E., "PSC Region I Flow Model (Series 2) - Test Report," Gulf General Atomic Report GAMD-8625, July 8, 1968.

4-4 Malek, G. J., and Hausermann, R., "Analysis of the Multicolumn Flow Distribution Test Data," Gulf General Atomic Report GAMD-8423, June 5, 1968 .

4-5 Pfeiffer, W., Malek, G. J., and Lund, K., "POKE - A Gas Cooled Reactor Flow and Thermal Analysis Code," Gulf General Atomic Report GA-10226, July 16, 1970.

4-6 Lewis, D. R., et al., "CINDA - Chrysler Improved Numerical Differencing Analyzer," Chrysler Corporation Space Division Report TN-AP-67-287, October 20, 1967.

4-7 Chi, H. W., and Malek, G. J., "Description of the Reactor Emergency Cooling Analysis Code, RECA," Gulf General Atomic Report GA-10273, August 19, 1970.

4-8 Saeger, J., "HEXT - A Special Purpose Heat Conduction Code for the HTGR Core," Gulf General Atomic Report GAMD-10534, March 3, 1971.

4-9 Ha11, W. B., "Reactor Heat Transfer," Nuclear Engineering Monographs, Temple Press, London, 1958.

4-10 Merrill, M. H., "Nuclear Design Methods and Experimental Data in Use at Gulf General Atomic," Gulf General Atomic Report GA-A12652, July 1973.

4-11 Peterson, J. F., "TAC-2D - A General Purpose Two-Dimensional Heat Transfer Computer Code," Gulf General Atomic Report CA-8868, September 6, 1969. 
4-12 Savery, C. W., "TAP - A Fortran IV Program for the Transient Analysis of the HTGR Power Plant Performance," USAEC Report GAMD-7248, General Dynamics, General Atomic Division, October 12, 1966.

4-13 Merrill, M. H., "BLOOST-7, A Reactor Kinetics - Heat Transfer Program," Gulf General Atomic Report GA-9832, January 20, 1970. 


\section{DESIGN DATA}

In this section Information on the design of core and plant components required to carry out the thermal design is presented. The physical layout of the core and fuel elements is given, as well as the conditions of the coolant entering the core, the physical properties of core materials and coolant, the core power distribution, and flow characteristics of core components. Data are presented as they are used in the thermal design calculations.

\subsection{MAJOR CORE DESIGN PARAMETERS}

Total core thermal power, core cavity coolant flow rate, core coolant inlet temperature, and core coolant inlet pressure are fundamental core design parameters which are determined from the performance not only of the core, but of other nuclear steam supply (NSS) and balance of plant (BOP) components.

In adopting core design parameters, uncertalnties in NSS and BOP component performance and any deterioration in component performance over the plant's 40-year design life must be accounted for. In the HTGR system design this is done by first defining an NSS system performance point based on nominal performance of all components. Then uncertaintles in component performance and deterioration allowances are systematically accounted for and a minimum expected design point is derlved. Table 5-1 compares the major core design parameters for the nominal and minimum expected plant performance cases.

At power levels less than the $3000 \mathrm{MW}(t)$ level, coolant temperature and core heat flux levels are both lower and, therefore, fuel and graphite 
TABLE 5-1

MAJOR CORE DESIGN PARAMETERS

\begin{tabular}{c|c|c|c|c}
\hline & $\begin{array}{c}\text { Core } \\
\text { Power } \\
(\mathrm{MW})\end{array}$ & $\begin{array}{c}\text { Core Cavity } \\
\text { Flow } \\
\left(10^{6} 1 \mathrm{bm} / \mathrm{hr}\right)\end{array}$ & $\begin{array}{c}\text { Core Inlet } \\
\text { Helium } \\
\text { Temperature } \\
\left({ }^{\circ} \mathrm{F}\right)\end{array}$ & $\begin{array}{c}\text { Core Inlet } \\
\text { Helium } \\
\text { Pressure } \\
\text { (psia })\end{array}$ \\
\hline Ful1 load operation & 3000 & 10.84 & 606 & 725 \\
Nominal & 3000 & 10.94 & 639 & 725 \\
\hline
\end{tabular}


temperatures are lower than those under steady-state full-power operation at minimum expected conditions.

Because the 3000 MW( $t$ ) minimum expected set of major design parameters represents the most severe steady-state core operating conditions, they are used as the example design calculations reported in Sections 6 and 7 . Minimum expected conditions are also used to form the initial conditions for transient calculations.

\subsection{COOLANT THERMAL DATA}

Thermodynamic and transport properties of the helium coolant are available for a wide range of temperature and pressure in Refs. 5-1 through 5-3. The properties given in these three references are not significantly different. GA uses Ref. 1 for HTGR core design analyses.

Values or data fits taken from Ref. 5-1 are:

\begin{tabular}{l|c|l|l|}
\hline \multicolumn{1}{c|}{ Helium Property } & Symbol & \multicolumn{1}{|c}{ Units } & \multicolumn{1}{|c}{ Representation (a) } \\
\hline Density & $\rho$ & $1 \mathrm{bm} / \mathrm{ft}^{3}$ & $\rho=\frac{\mathrm{P}}{\mathrm{RT}}$ \\
Specific heat & $\mathrm{C}_{\mathrm{p}}$ & $\mathrm{Btu} / 1 \mathrm{bm}-{ }^{\circ} \mathrm{F}$ & $\mathrm{C}_{\mathrm{p}}=1.242$ \\
Viscosity & $\mu$ & $1 \mathrm{bm} / \mathrm{ft}-\mathrm{hr}$ & $\mu=6.9 \times 10^{-4} \mathrm{~T}^{0.674}(5-3)$ \\
Thermal conductivity & $\mathrm{K}_{\mathrm{h}}$ & Btu/hr-ft- ${ }^{\circ} \mathrm{F}$ & $\mathrm{K}_{\mathrm{h}}=1.29 \times 10^{-3} \mathrm{~T}^{0.674(5-4)}$ \\
\hline
\end{tabular}

\footnotetext{
(a) where $\mathrm{P}=$ helium pressure, $\mathrm{T}=$ absolute temperature, ${ }^{\circ} \mathrm{R}$, $\mathrm{R}=$ gas $1 \mathrm{aw}$ constant.
} 


\subsection{COOLANT FLOW RESISTANCE DATA}

Flow distribution calculations described in Section 4.1 .4 require a variety of loss coefficients to describe the flow behavior of the core components. Values of these loss coefficients currently used in core design calculations are presented in Table 5-2. Loss coefficients have been derived from the literature or from experiments performed on HTGR core components. An extensive experimental program is currently in progress to refine the flow characterization of core components employed in design calculations. Below, the loss coefficients are discussed briefly, the source of the current values cited, and planned experimental programs will be described.

\subsubsection{Orifice Loss Coefficients}

The orifice loss coefficient $\mathrm{K}_{\mathrm{v}}$ is a measure of the flow resistance of the core inlet flow control valve; its value therefore depends on the relative position of the fixed and movable parts of the valve. The loss coefficient $\mathrm{K}_{\mathrm{v}}$ is defined in terms of the stagnation pressure loss from the core upper plenum to the inlet of the coolant channels. An important characteristic of the valve is the variation of the orifice loss coefficient with the valve position.

Experimental tests are currently being planned to calibrate the flow control valve and to determine the characteristics of the valve. The full scale experimental rig will consist of the flow control valve assembled with the standard and control plenum elements on top reflector blocks. The coolant used will be air at ambient conditions. Tests will be conducted for a range of flow rates through the valve for each valve position. The valve position will be varied from fully open to fully closed. Static and dynamic pressure measurements at numerous locations in the test rig will be used to plot the characteristic curve giving the loss coefficients for the valve. 
TABLE 5-2

FLOW RESISTANCES AS A FUNCTION OF REGION POWER FACTOR

\begin{tabular}{|c|c|c|c|}
\hline Region Power Factor, $\mathrm{P}(\mathrm{r})$ & 1.6 & 1.0 & 0.4 \\
\hline $\begin{array}{l}\text { Velocity head }(a) \text { in top reflector } \\
\text { coolant holes, psi }\end{array}$ & 0.554 & 0.217 & 0.035 \\
\hline Orifice coefficient, $\mathrm{K}_{\mathrm{V}}$ & 3.47 & 35.0 & 307.3 \\
\hline Entrance loss coefficient, $\mathrm{K}_{i}$ & 0.36 & 0.36 & 0.36 \\
\hline $\begin{array}{l}\text { Frictional resistance } \\
\qquad\left[\frac{4 \mathrm{fL}}{\mathrm{D}} \times \frac{\overline{\mathrm{T}}}{\mathrm{T}_{i}}\right]\end{array}$ & 12.35 & 13.07 & 16.57 \\
\hline $\begin{array}{l}\text { Acceleration due to temp rise } \\
\qquad\left[\frac{\left(\mathrm{T}_{0}-\mathrm{T}_{i}\right)}{\mathrm{T}_{i}}\right]\end{array}$ & 0.74 & 0.74 & 0.74 \\
\hline $\begin{array}{l}\text { Offset loss coefficients } \\
\qquad \sum_{j=1}^{n} k_{j}\left(\frac{T_{j}}{T_{i}}\right)\end{array}$ & 0.50 & 0.50 & 0.50 \\
\hline $\begin{array}{l}\text { Exit loss coefficient } \\
\qquad\left[\mathrm{K}_{\mathrm{o}} \times \frac{\mathrm{T}_{\mathrm{o}}}{\mathrm{T}_{\mathrm{i}}}\right]\end{array}$ & 3.34 & 3.34 & 3.34 \\
\hline
\end{tabular}

(a) A1l flow resistances are expressed in terms of velocity head in top reflector coolant holes. 
As part of the test program, the valve will be tested for leakage flow in the fully closed position. The loss coefficients for fixed orifices as a function of flow rate will also be evaluated.

\subsubsection{Entrance Loss Coefficient}

This loss coefficient $\mathrm{K}_{i}$ is a measure of the total pressure loss experienced by the coolant as it enters the coolant holes of the standard fuel element column in the top reflector blocks and the control plenum element tubes in the control column. Currently, a value from Ref. 5-4 is used. However, experiments will be conducted at different flow rates on the assembly for the flow control valve calibration tests described above to establish the accuracy of the current value.

\subsubsection{Friction Factor for Coolant Channels}

Smooth tube friction factor correlation is currently used for design calculations. Friction factors will be determined on drilled graphite blocks when the drilling technique is finally established.

Meanwhile, in HTGR core design the following friction correlation is used:

$$
f=C_{1}\left(N_{R e}\right)^{C_{2}}
$$

where $\quad \mathrm{N}_{\mathrm{Re}}=$ Reynolds number based on hydraulic diameter, $\mathrm{C}_{1}, \mathrm{C}_{2}=$ experimentally determined coefficients.

For smooth coolant channels, the following values of $C_{1}$ and $C_{2}$ are applicable:

1. Laminar flow $\begin{aligned} & \mathrm{N}_{\mathrm{Re}}<2000, \mathrm{C}_{1}=16.0, \mathrm{C}_{2}=-1.0 \text { for circular } \\ & \text { cross section, }\end{aligned}$ 


$$
\begin{aligned}
& \mathrm{C}_{1}=24.0, \mathrm{C}_{2}=-1.0 \text { for rectangular and } \\
& \text { annular cross section. }
\end{aligned}
$$

2. Transitional flow $2000 \leq \mathrm{N}_{\mathrm{Re}} \leq 4000, \mathrm{C}_{1}=0.0007316, \mathrm{C}_{2}=0.3147$.

3. Turbulent flow $\mathrm{N}_{\mathrm{Re}}>4000, \mathrm{C}_{1}=0.0791, \mathrm{C}_{2}=-0.25$.

\subsubsection{Offset Loss Coefficients}

Pressure loss due to misalignment of the coolant holes at element interfaces has been measured as a function of distance between the centerlines of mating holes at various Reynolds numbers. The value currently used (Table 5-2) is for an offset distance of 0.04 in.

\subsubsection{Exit Loss Coefficient}

The pressure loss due to the bottom reflector blocks, the core support blocks, and the coolant exit into the lower core plenum is represented by a single exit loss coefficient $\mathrm{K}_{\mathrm{o}}$.

Test programs are currently planned on full-scale models of a rig consisting of the bottom reflector and core support blocks, using ambient air as the coolant. Using measured values of the total pressure drop across the rig for different flow rates of air, the exit loss coefficients $\mathrm{K}_{\mathrm{O}}$ can be estimated.

In addition to tests on individual components to determine specific loss coefficients, tests are also planned on full-scale complete region assemblies (seven-, four- and two-column regions) to check the validity of Eq. 4-11 using the loss coefficients obtained experimentally from individual small tests as indicated above. Isothermal tests will be conducted using helium as the coolant for seven- and four-column regions employing the flow control valve, while the two-column region tests will be conducted with a fixed inlet orifice on each column. 


\subsection{COOLANT CHANNEL HEAT TRANSFER CORRELATIONS}

Correlations for the heat transfer coefficient used in core thermal design calculations have been developed from helium in smooth tubes. In HTGR reactor passages, the heat transfer coefficient will be somewhat greater due to coolant channel surface roughness. Between 25 and $100 \%$ power levels, the coolant flow in coolant channels is turbulent. The minimum Reynolds number at $25 \%$ power in the minimum powered region is about 7000. Under shutdown and refueling conditions, flow can be in transition or in the laminar regime.

\subsubsection{Turbulent Flow}

The following correlation for flow in the active core coolant channels Is used.

$$
\mathrm{h}=0.02 \frac{\mathrm{K}_{\mathrm{h}}}{\mathrm{D}} \mathrm{N}_{\mathrm{Re}} 0.8 \mathrm{~N}_{\operatorname{Pr}} 0.4,
$$

for $\mathrm{N}_{\mathrm{Re}}>6000$,

where $h=$ heat transfer coefficient,

$\mathrm{K}_{\mathrm{h}}=$ coolant thermal conductivity evaluated at local bulk coolant temperature,

$\mathrm{D}=$ coolant hole diameter,

$\mathrm{N}_{\mathrm{Re}}=$ Reynolds number evaluated at local bulk coolant conditions,

$\mathrm{N}_{\mathrm{Pr}}=$ Prandt1 number evaluated at local bulk coolant temperature.

This correlation is taken from Ref. 5-5. It is a simple correlation evaluated using bulk coolant properties and does not include entrance effects or effects of coolant property variation across the film. When compared at the hot-spot for the $3000 \mathrm{MW}(t)$ core, where heat flux is high, 
it is in good agreement with other correlations (Refs. 5-6, 5-7, 5-8) which include entrance effects and variation in coolant property across the film. At reactor locations where the heat flux is lower, e.g., In the lower portion of the reactor core, the correlation used is slightly conservative. Table 5-3 shows a comparison of heat transfer coefficlents calculated from Refs. 5-5 through 5-8 at several locations in the core.

For heat transfer in the gaps between fuel column, the following heat transfer correlation (Ref. 5-9) is used:

$$
\mathrm{h}=0.0203 \frac{\mathrm{K}_{\mathrm{h}}}{2 \mathrm{~b}} \mathrm{~N}_{\mathrm{Re}} \mathrm{P}^{0.789} \mathrm{~N}_{\mathrm{Pr}} 0.33,
$$

where $b=$ gap width.

Physical properties are evaluated at the bulk coolant temperature.

\subsubsection{Laminar Flow}

In the laminar flow range that may exist in reactor passages during refueling and startup, the following heat transfer correlation taken from Ref. 5-10 is used:

$$
h=\frac{K_{h}}{D}\left\{3.65+\frac{0.0668(D / L) N_{\operatorname{Re}} N_{P r}}{1+0.04\left((D / L) N_{\operatorname{Re}} N_{\operatorname{Pr}}\right)^{0.66}}\right\}
$$

for $N_{R e}<3000$,

where $L=$ heated length of coolant channel. 
TABLE 5-3

COMPARISON OF HEAT TRANSFER CORRELATIONS IN TURBULENT FLOW REGION

\begin{tabular}{|c|c|c|c|}
\hline Correlation $(\mathrm{a})$ & $\begin{array}{l}\text { Point of Maximum } \\
\text { Fuel Temperature } \\
\qquad \begin{array}{c}P(r)=1.3 \\
\alpha(l, r)=1.4\end{array}\end{array}$ & $\begin{array}{l}\text { Point of Maximum } \\
\text { Heat Flux } \\
P(r)=1.6 \\
\alpha(l, r)=1.2\end{array}$ & $\begin{array}{l}\text { Core Average } \\
\text { Conditions } \\
P(r)=1.0 \\
\alpha(\ell, r)=1.0\end{array}$ \\
\hline $\begin{array}{l}\mathrm{h}=0.02 \frac{\mathrm{K}_{\mathrm{h}}}{\mathrm{D}} \mathrm{N}_{\mathrm{Re}}^{0.8} \mathrm{~N}_{\mathrm{Pr}}^{0.4} \\
\text { Coates \& Galli (Ref. 5-5) }\end{array}$ & 348.8 & 433.8 & 283.7 \\
\hline $\begin{array}{l}\mathrm{h}=0.023 \frac{\mathrm{K}}{\mathrm{D}} \mathrm{N}_{\operatorname{Re}}^{0.8} \mathrm{~N}_{\operatorname{Pr}}^{0.4}\left(\frac{\mathrm{T}}{\mathrm{T}_{\mathrm{b}}}\right)^{-0.57} \\
\text { Sullivan \& King (Ref. 5-6) and } \\
\text { Taylor (Ref. 5-7) }\end{array}$ & $\begin{array}{l}352.5 \\
1.011^{(b)}\end{array}$ & $\begin{array}{l}442.0 \\
1.019^{(b)}\end{array}$ & $\begin{array}{l}298.7 \\
1.053^{(b)}\end{array}$ \\
\hline 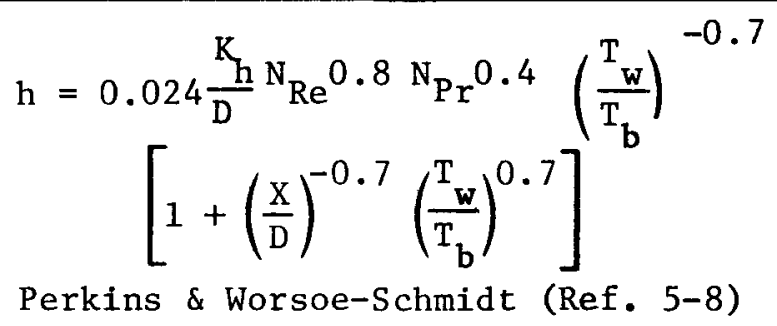 & $\begin{array}{l}369.6 \\
1.060^{(c)}\end{array}$ & $\begin{array}{l}464.2 \\
1.070^{(c)}\end{array}$ & $\begin{array}{l}315.6 \\
1.112^{(c)}\end{array}$ \\
\hline
\end{tabular}

(a) Heat transfer coefficients are in Btu/hr-ft ${ }^{2}{ }^{\circ} \mathrm{F}$, calculated using helium properties from Section 5.2 . (b) Ratio of h (Ref. 5-6)/h (Ref. 5-5).

(c) Ratio of h (Ref, 5-8)/h (Ref. 5-5). 
For heat transfer in the gaps between fuel colums, the following heat transfer correlation (Ref. 5-9) is used.

$$
\mathrm{h}=8.23 \frac{\mathrm{K}_{\mathrm{h}}}{\mathrm{D}}
$$

\subsubsection{Transitional Flow}

For the Reynolds numbers in the range of $3000<\mathrm{N}_{\mathrm{Re}}<6000$, the heat transfer coefficient is determined by interpolation between the laminar range upper value $\left(\mathrm{N}_{\mathrm{Re}}=3000\right)$ and the turbulent range lower value $\left(\mathrm{N}_{\mathrm{Re}}=\right.$ 6000). The heat transfer coefficient obtained from such a correlation is conservative compared to those obtained from experimental measurements and reported in Refs. 5-11 and 5-12.

\subsection{GRAPHITE THERMAL DATA}

A complete review of mechanical and thermal properties for graphites is given in Ref. 5-13. Nuclear purity grade near-isotropic graphite is proposed to be used in the HTGR core for fuel and reflector elements; an example of such a graphite is $\mathrm{H}-451$ grade produced by Great Lakes Carbon Company. In the thermal analysis reported in Sections 6 and 7 properties of H-327 graphite are used. An extensive continuing program to evaluate thermal properties of nuclear graphite is currently being carried out at GA. Properties being measured on irradiated graphites include thermal conductivity, thermal expansivity, emissivity, and irradiation-induced dimensional change in both radial and axial directions. These properties, which are used in thermal analysis, are discussed below.

\subsubsection{Graphite Thermal Conductivity}

The thermal conductivity of a graphite varies both as a function of temperature and fast neutron fluence. Design basis curves for the thermal 
conductivity of Irradiated graphites are developed in Ref. 5-14. These curves are obtained by measuring conductivity of graphite samples that have been irradiated at constant temperatures. These data are further extended to graphite in an HTGR, where the graphite temperatures vary with time. Changes in thermal conductivity result from the formation of irradiationinduced phonon scattering centers within the graphite structure. These scattering centers are produced continuously during irradiation but anneal out at a temperature dependent rate. So for a time-varying irradiation temperature, the dynamic equilibrium concentration of scattering centers changes as a function of time.

For reactor conditions, the thermal conductivity of $\mathrm{H}-451$ and $\mathrm{H}-327$ graphites in the radial (perpendicular to extrusion) direction is given in Fig. 5-1. As can be seen, the thermal conductivity of both types of graphites increases with irradiation temperature and decreases with fluence. The data in Fig. 5-1 are currently not used in HTGR core thermal design. At the present time the more conservative values of thermal conductivity of graphite shown below are employed.

$$
\begin{array}{ll}
\text { 1. Zero-to-one-year-old graphite } & 16.0 \mathrm{Btu} / \mathrm{hr}-\mathrm{ft}-{ }^{\circ} \mathrm{F} \\
\text { 2. One-to-two-year-old graphite } & 12.0 \mathrm{Btu} / \mathrm{hr}-\mathrm{ft}-{ }^{\circ} \mathrm{F} \\
\text { 3. Two-to-four-year-old graphite } & 10.0 \mathrm{Btu} / \mathrm{hr}-\mathrm{ft}-{ }^{\circ} \mathrm{F}
\end{array}
$$

In future design calculations, properties of near-isotropic graphites presented in Ref. 5-14 will be employed.

\subsubsection{Equivalent Graphite Conductance}

The equivalent graphite conductance for the graphite web of the unit cell between the fuel and coolant holes, C graphite, as defined by Eq. 4-8, is not a physical property of graphite but is calculated by the HEXT computer program, using the graphite thermal conductivity. The equivalent 

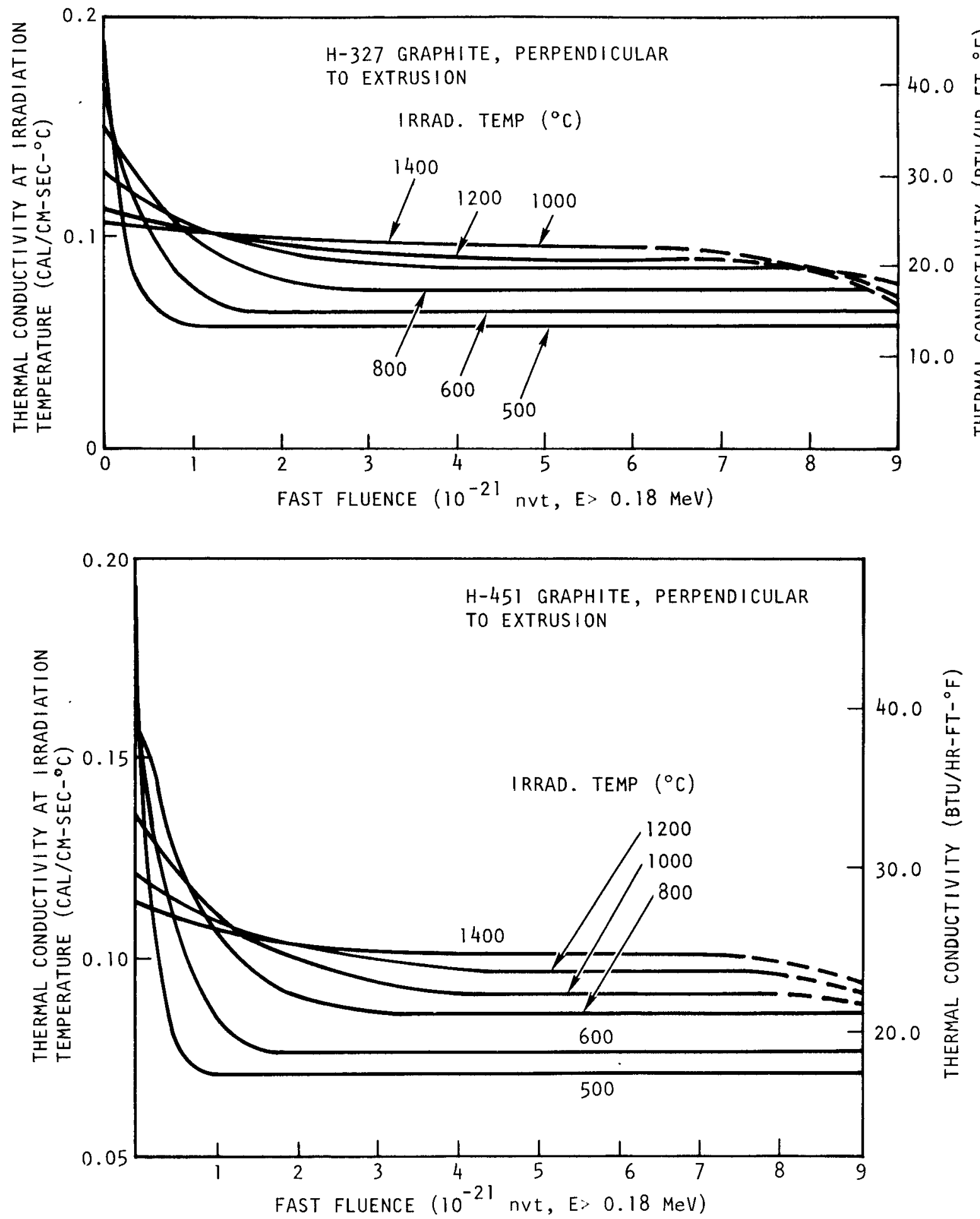

Fig. 5-1. Thermal conductivity of $\mathrm{H}-327$ and $\mathrm{H}-451$ graphite as a function of irradiation temperature and fluence 
conductance is given in Table 5-4 for several values of graphite thermal conductivity. In the conductivity range of HTGR graphites, it can be seen that the equivalent conductance is very nearly proportional to the thermal conductivity of graphite.

\subsubsection{Graphite Thermal Expansivity}

The radial thermal expansion of graphite is used in thermal design to calculate the dimensional changes of coolant and fuel holes with changes in temperature. Design curves of thermal expansion for $\mathrm{H}-451$ and $\mathrm{H}-327$ graphites are shown in Fig. 5-2 (Ref. 5-15), as a function of graphite temperature. HTGR graphite thermal expansion does not change appreciably with irradiation (Refs. 5-16,5-17) in the range of HTGR core operating conditions.

\subsubsection{Graphite Thermal Emissivity}

Heat transfer across the gap between the fuel rod and the fuel hole is by radiation as well as conduction. An emissivity of graphite surfaces is required in this calculational procedure. Graphite emissivity has been studied extensively by several workers (Refs. 5-18,5-19, 5-20) and the values of normal emissivity generally given for an unpolished graphite surface are in the range of 0.85 to 0.9 . In core design, a conservative value of emissivity of 0.8 is used in calculating the heat transfer across the gap between the fuel rod and fuel hole.

\subsubsection{Graphite Specific Heat}

Because of the large amount of graphite in the core, the transient thermal response of the core is rather slow. One important thermal property used in the transient analysis of the HTGR core is the specific heat of graphite. Figure 5-3 shows the specific heat of graphite as a function of graphite temperature. These values are taken from Ref. 5-21. 
TABLE 5-4

EQUIVALENT GRAPHITE CONDUCTANCE FOR UNIT CELL

\begin{tabular}{|c|c|}
\hline $\begin{array}{l}\text { Thermal Conductivity } \\
\text { of Graphite } \\
\left(\mathrm{Btu} / \mathrm{hr}-\mathrm{ft}-{ }^{\circ} \mathrm{F}\right)\end{array}$ & $\begin{array}{l}\text { Graphite Conductance } \\
\text { of Unit Ce } 11, \mathrm{C}_{\mathrm{graphite}} \\
\left.\text { (Btu/hr-ft}{ }^{2}{ }^{\circ} \mathrm{F}\right)\end{array}$ \\
\hline 4.0 & 256.3 \\
\hline 8.0 & 507.3 \\
\hline 12.0 & 757.6 \\
\hline 16.0 & 1007.7 \\
\hline 20.0 & 1257.8 \\
\hline 24.0 & 1507.8 \\
\hline 28.0 & 1757.8 \\
\hline 32.0 & 2007.8 \\
\hline 36.0 & 2257.7 \\
\hline 40.0 & 2507.6 \\
\hline 44.0 & 2757.5 \\
\hline 48.0 & 3007.4 \\
\hline
\end{tabular}

(a) Based on heat flux at the coolant wall surface (see Fig. 4-10 and Eq. 4-8). 


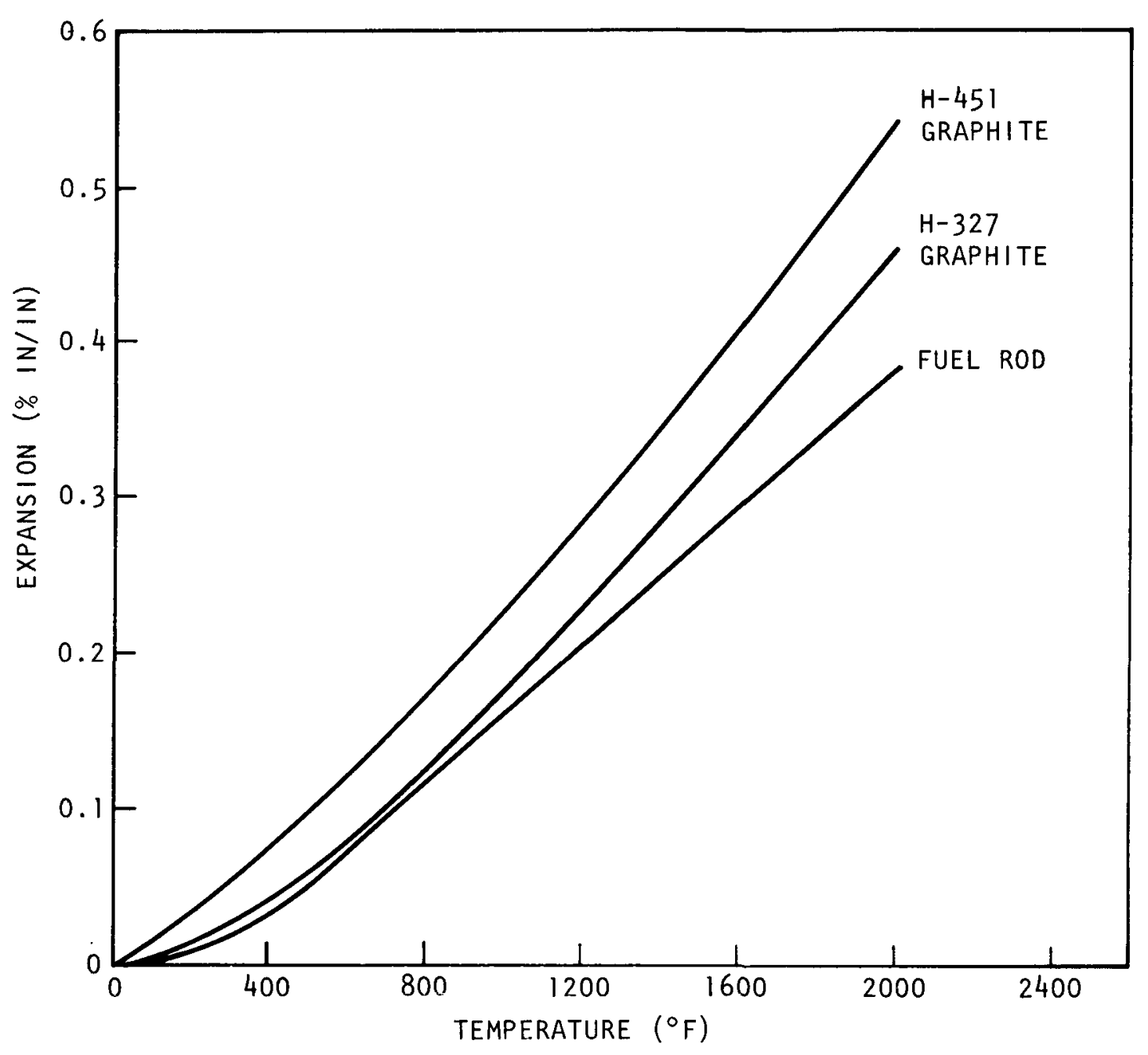

Fig. 5-2. Thermal expansion design curve for graphite and fuel rod 


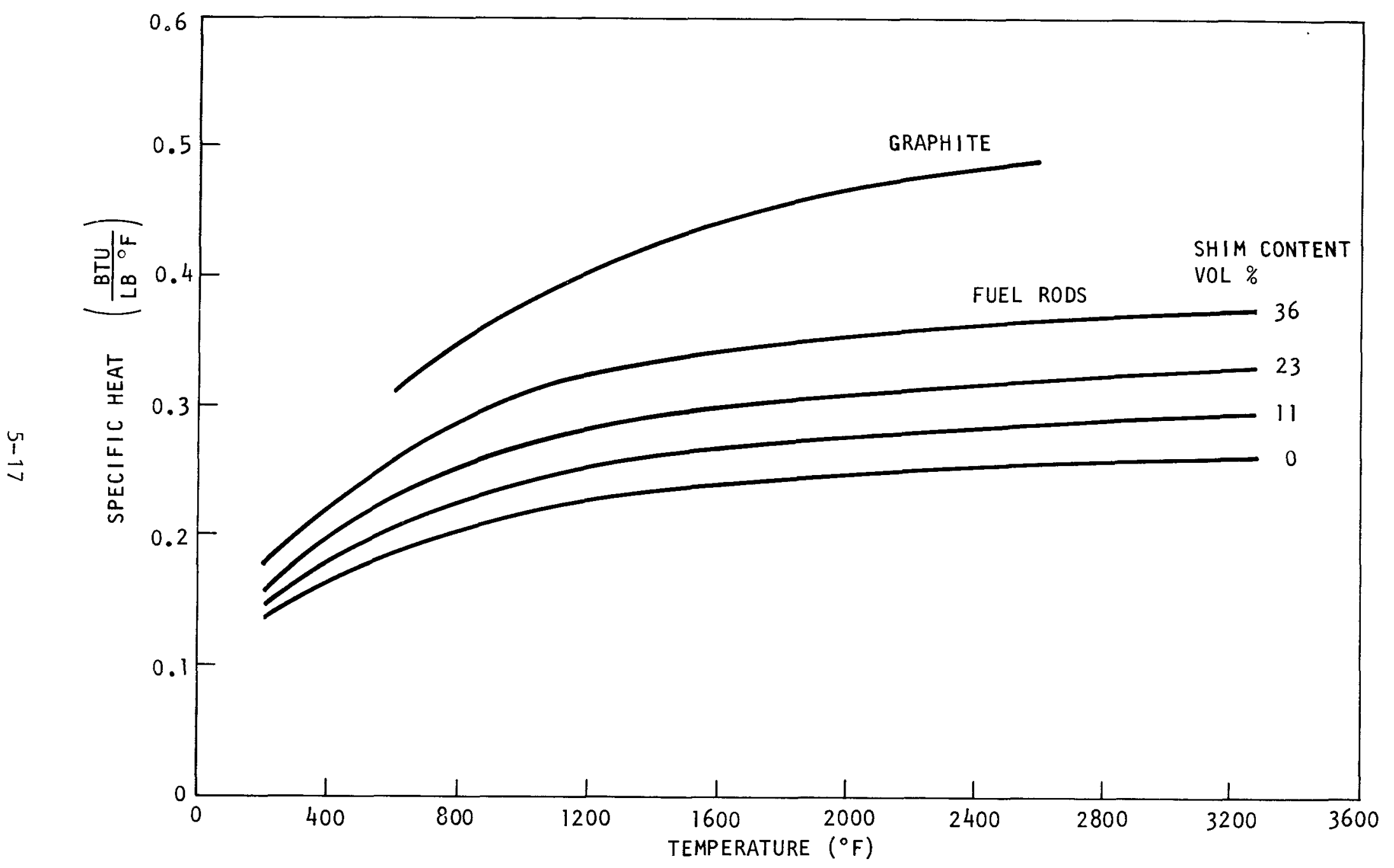

Fig. 5-3. Specific heat of graphite and fuel rods as a function of temperature 


\subsubsection{Graphite Density}

HTGR core graphite density can vary from 106 to $1121 \mathrm{bm} / \mathrm{ft}^{3}$. For thermal analysis a conservative value of $100 \mathrm{lbm} / \mathrm{ft}^{3}$ is used. A typical value for the density of graphite used in the Fort St. Vrain reactor is 110 $1 \mathrm{bm} / \mathrm{ft}^{3}$.

\subsubsection{Irradiation-Induced Graphite Dimensional Change}

Fast-neutron-induced dimensional changes of graphite influence the size of both coolant and fuel holes and thereby affect the heat-transfer and flow characteristics of the HTGR core. Candidate HTGR core graphites are being irradiated in a continuing program to provide data for HTGR design (Ref. 5-17). Based on the data already available, Irradiation strain correlations have been obtained in directions parallel and perpendicular to the graphite extrusion axis. Detailed discussion of the dimensional changes is given in Ref. 5-17. The curves used in the thermal design both in axial and radial direction for $\mathrm{H}-451$ graphite are given in Fig. 5-4 and corresponding dimensional change curves for $\mathrm{H}-327$ graphite are given in Fig. $5-5$.

When applying curves from Figs. 5-4 and 5-5 to obtain the irradiationinduced strain for HTGR conditions where the graphite irradiation temperature changes with time, the irradiation history is divided into irradiation periods short enough so the irradiation temperature can be considered constant. For one such period, the incremental strain is expressed by

$$
\Delta \varepsilon_{i}=\varepsilon_{i}-\varepsilon_{i-1}
$$

where $\quad \varepsilon_{i}=$ the graphite strain at the end of the ith period evaluated at $\mathrm{T}_{i}$, the irradiation temperature for the ith period and at $\Phi_{i}$, the total fast neutron fluence at the end of the ith period, 

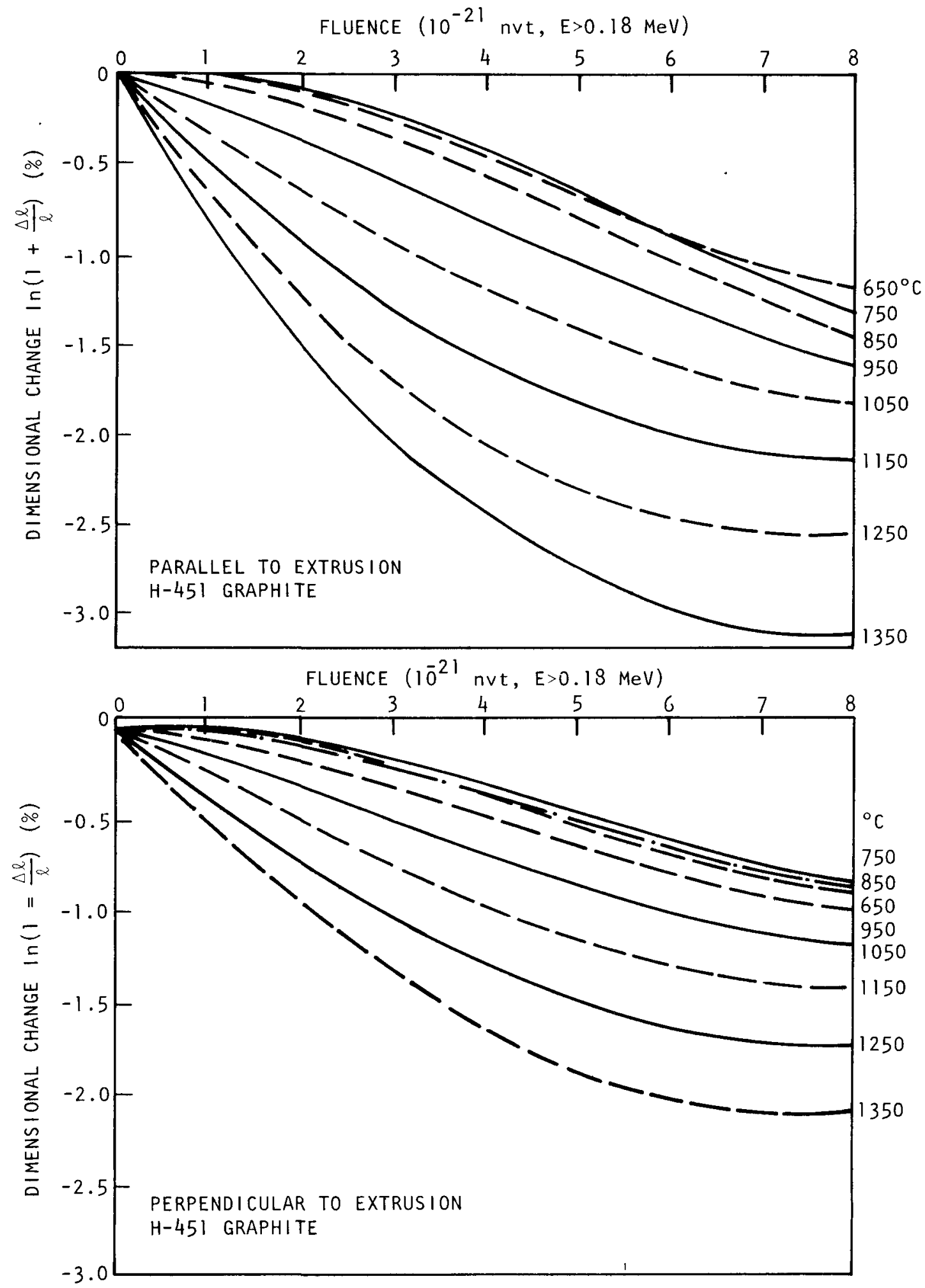

Fig. 5-4. Near-isotropic graphite (H-451) dimensiona1 change in parallel and perpendicular directions 

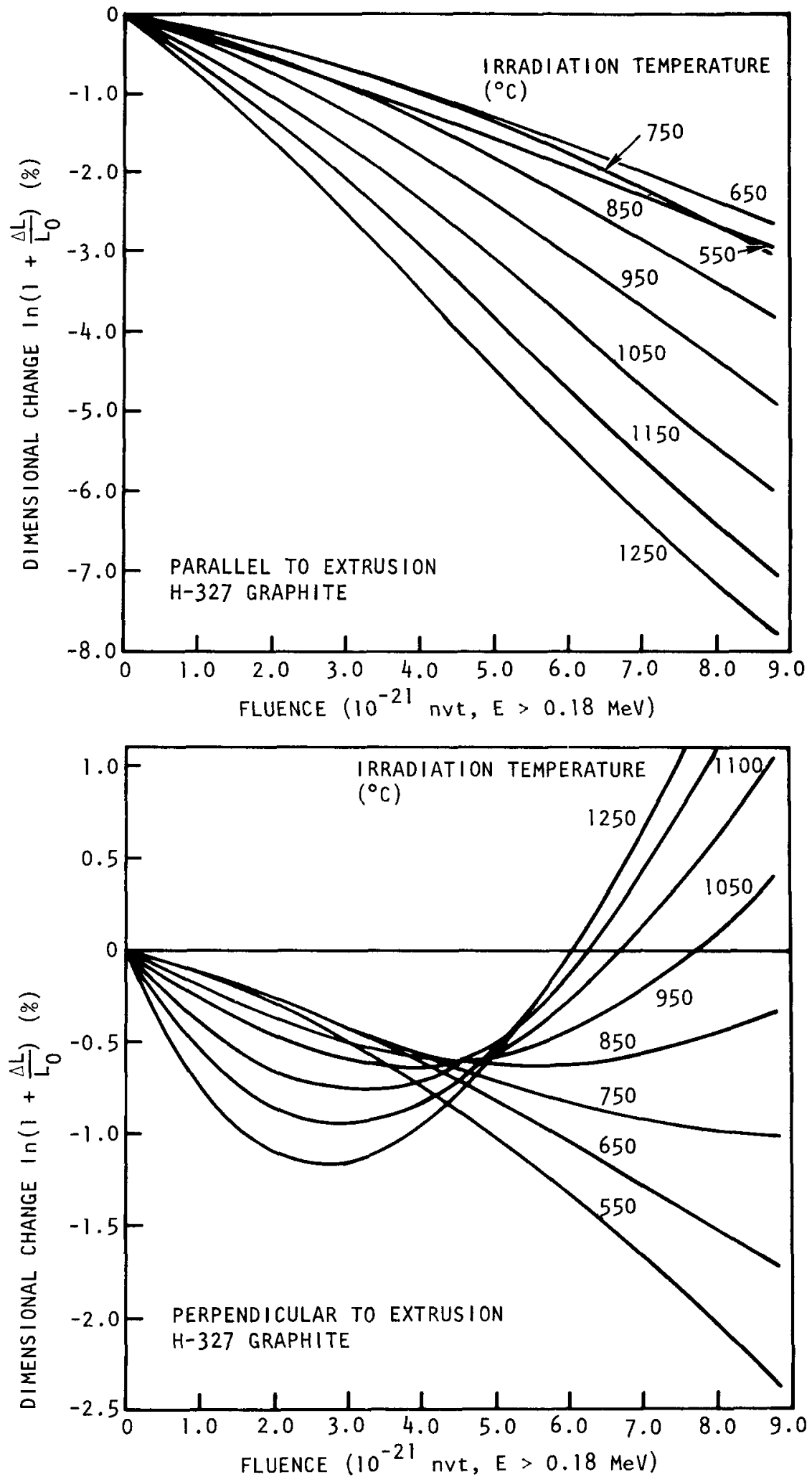

Fig. 5-5. Needle-coke graphite (H-327) dimensional change in parallel and perpendicular directions 


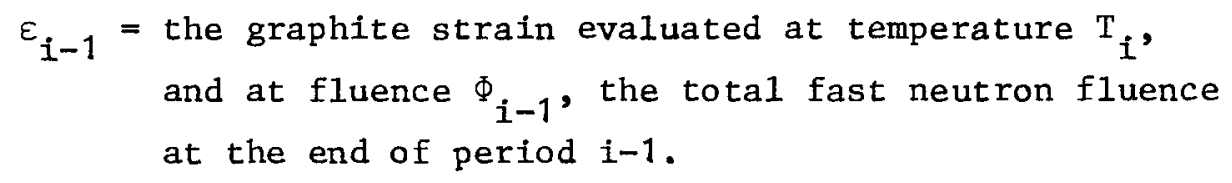

The net strain at the end of I irradiation periods is then given by

$$
\varepsilon_{I}=\sum_{i=1}^{I} \Delta \varepsilon_{i} .
$$

This method is used in calculating graphite and fuel rod dimensional change in both radial and axial directions.

5.6. FUEL ROD THERMAL DATA

Fuel rod data used in the thermal design are thermal conductivity, thermal expansivity, thermal emissivity, specific heat, density, and irradiation-induced dimensional change in radial and axial directions. These properties change with temperatures and the quantity of fissile, fertile, and shim particles.

\subsubsection{Fuel Rod Thermal Conductivity}

Thermal conductivity measured for unirradiated prototype fuel rods containing reference particles, taken from Ref. 5-22, is given in Fig. 5-6 as a function of fuel rod temperatures. The parameter that has the greatest influence on fuel rod conductivity is the volume fraction of graphite shim particles. The thermal conductivity of the fuel rod decreases with increase in temperature as shown in Fig. 5-6.

The thermal conductivity of fuel rods is estimated to decrease with fast neutron fluence (Ref. 5-22). In the present thermal analysis, a fuel rod thermal conductivity of $4.0 \mathrm{Btu} / \mathrm{hr}-\mathrm{ft}-{ }^{\circ} \mathrm{F}$, which is conservative for 


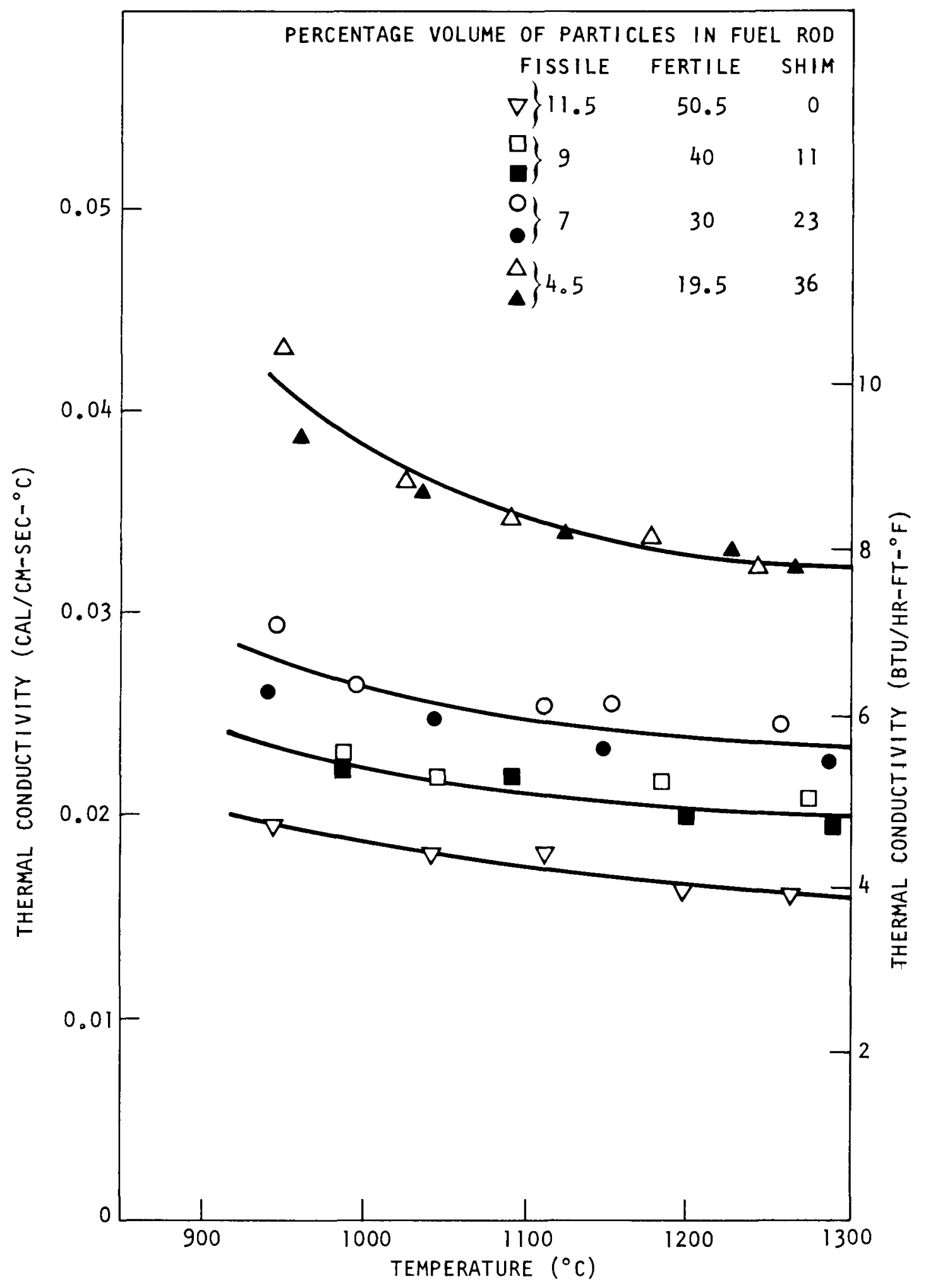

Fig. 5-6. Thermal conductivity of typical HTGR fuel rods as a function of temperature 
both unirradiated and irradiated fuel rods, is used at all temperatures, fluences, and shim particle loading.

5.6.2. Fuel Rod Thermal Expansivity

Expansion of the fuel rod, induced by Increasing temperature, affects the gap between the fuel rod and fuel hole, which in turn affects the heat transfer characteristics of the gap. Figure 5-2 shows the thermal expansion for a typical fuel rod as a function of fuel rod temperature. These values were obtained for reference Fort St. Vrain fuel rods, which have values nearly equal to that of graphite (Ref. 5-23). The commercial HTGR fuel rods differ from Fort St. Vrain fuel rods principally in size, fertile particle content, and shim particle loading; the thermal expansivity of these fuel rods is expected to be about equal to the values shown in Fig. 5-2. Using the values of thermal expansivity for graphite and fuel rods, thermally induced dimensional changes are found to be much less significant than irradiation-induced dimensional changes.

\subsubsection{Fuel Rod Emissivity}

As explained in Section 5.7, some heat is transferred between the fuel rod and the surrounding graphite across the gap by thermal radiation. Fuel rod surface normal spectral emissivities measured by GA lie in a range of 0.86 to 0.92 (Ref. 5-22). These values are comparable with emissivity values of graphite given in Section 5.5.4. In thermal design calculations, a conservative value of 0.8 is used for fuel rods at all temperatures and fluences.

\subsubsection{Fuel Rod Specific Heat}

The specific heat of reference HTGR fuel rods has not been measured; however, sufficient literature data are available on fuel rod components to 
allow the specific heat to be calculated. Fuel rod specific heat is obtained by suming the contributions of individual fuel rod components (matrix, SiC, PyC, etc.) according to Kopp's additivity rule (Ref. 5-24). Figure 5-3 gives the specific heat calculated for fuel rods as a function of temperature. Data are presented for rods of variable shim content and constant fertile/fissile loadings. Specific heat data for individual components were obtained from Refs. 5-25 and 5-26.

\subsubsection{Fue1 Rod Density}

Measurements of density have been made for fuel rods made from different blends of fuel particles; they are given in Table 5-5.

\subsubsection{Irradiation-Induced Fuel Rod Dimensional Change}

As described in Section 2.4, the fuel rods for HTGRs consist of closely packed arrays of coated fuel particles and graphite shim particles bonded with a carbonaceous matrix material. During irradiation of these rods, the matrix material experiences greater irradiation-induced contraction than the fuel or shim particles. Therefore, the dimensional change of fuel rods is controlled mainly by the dimensional change of the closely packed particles.

Characterization of fast-neutron-induced dimensional changes in coated particles and fuel rods, as part of the HTGR fuel development irradiation program (Ref. 5-27), has led to the development of HTGR design curves for the reference TRISO, BISO, and shim particles. Curves for each type are shown in Fig. 5-7.

In thermal design calculations, the dimensional change curve for each fuel rod type is developed from the particle curves in Fig. 5-7 and from the loading fraction of BISO, TRISO, and shim particles. For the initial 
TABLE 5-5

FUEL ROD METAL DENSITY AND VOLUME PERCENTAGE OF FUEL PARTICLES IN DIFFERENT BLENDS OF FUEL RODS

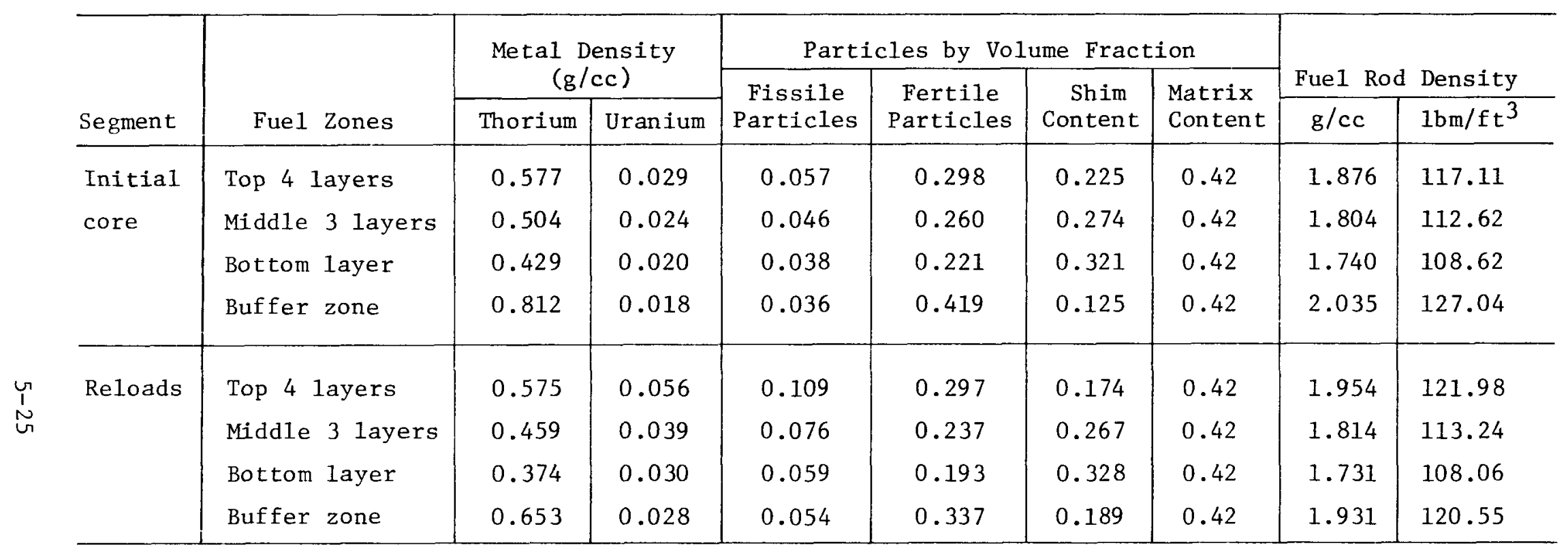



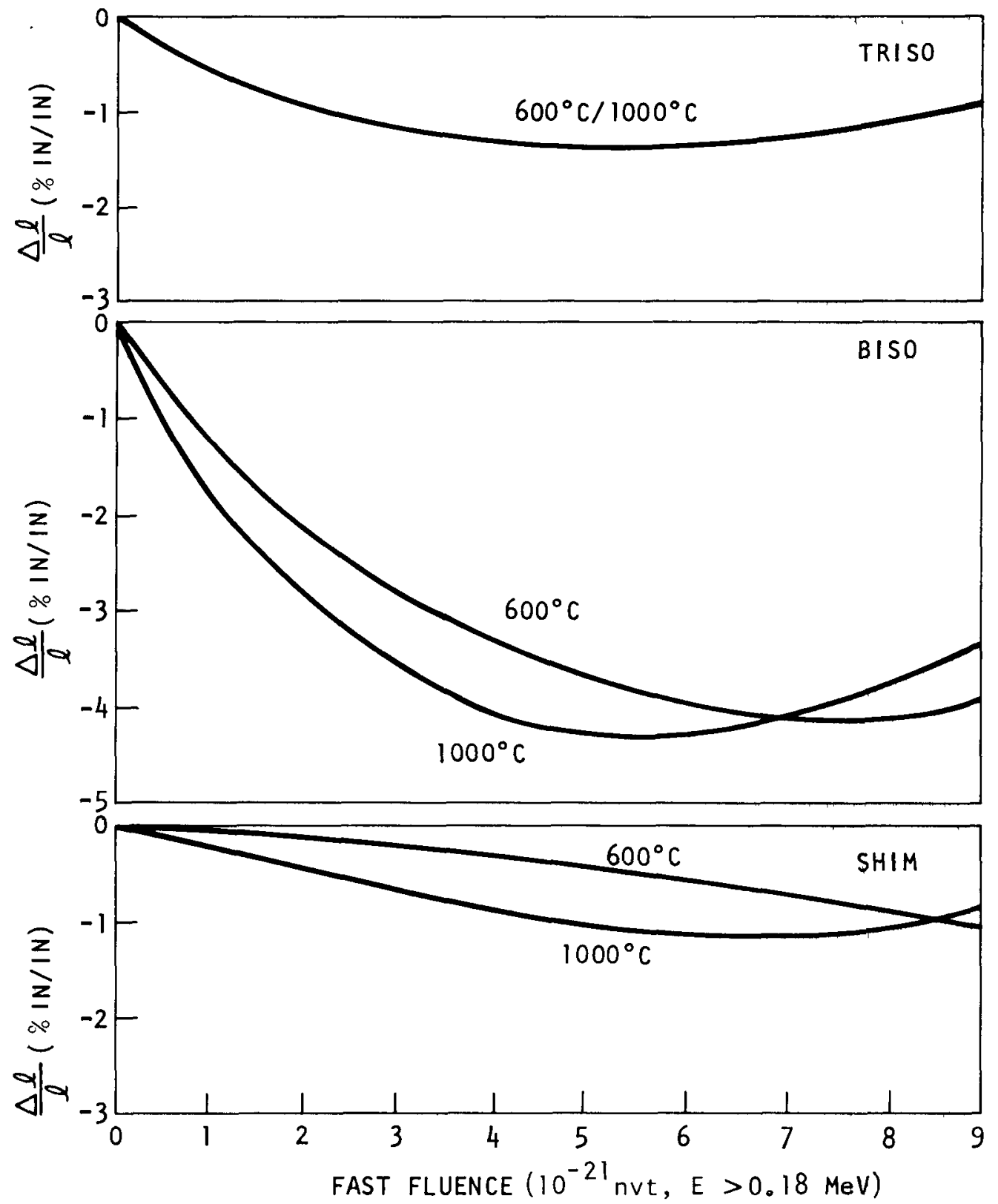

Fig. 5-7. Dimensional change of TRISO, BISO, and shim particles 
core, four fuel particle blends containing different BISO, TRISO, and shim particle mixtures are used. Three blends are used to accomplish axial fuel zoning and the fourth is used in a buffer fuel zone around the core periphery as shown in Table 5-5. The resulting design curves for each of these fuel zones are shown in Figs. 5-8 through 5-10.

To obtain the irradiation-induced dimensional change for time-varying temperatures, the irradiation history is divided into short irradiation periods during which the irradiation temperature is assumed constant. The incremental dimensional change during this irradiation period is calculated in the same manner as that given for graphite in Section 5.5.7.

\subsection{FUEL-ROD FUEL-HOLE GAP CONDUCTANCE}

A conductance of the narrow space between the fuel rod and fuel hole may be defined by Eq. 4-8. Recognizing that the heat transfer across the gap is by both conduction and radiation, the gap conductance can be written in the form

$$
h_{\text {gap }}=\frac{\mathrm{K}_{\mathrm{h}}}{\mathrm{g}}+4 \sigma \varepsilon \overline{\mathrm{T}}^{3} \text { *, }
$$

where $\quad K_{h}=$ thermal conductivity of helium in gap (see Section 5.2),

$$
g=R_{f} \ln \left(1+\frac{R_{h}-R_{f}}{R_{f}}\right),
$$

1

*This expression is derived by the expansion $\mathrm{T}_{\mathrm{f}^{\prime}}^{4}-\mathrm{T}_{\mathrm{g}^{\prime}}{ }^{4}=\left(\mathrm{T}_{\mathrm{f}^{\prime}}^{2}+\mathrm{T}_{\mathrm{g}^{\prime}}^{2}\right)$ $\left(T_{f}^{\prime}+T_{g}^{\prime}\right)\left(T_{f}^{\prime}-T_{g}^{\prime}\right)$ and by taking advantage of the approximation, which is valid for temperatures $>1000^{\circ} \mathrm{F}, \frac{1}{2}\left(\mathrm{~T}_{\mathrm{f}^{\prime}}^{2}+\mathrm{T}_{\mathrm{g}^{\prime}}^{2}\right) \simeq \mathrm{T}_{\mathrm{f}^{\prime}} \mathrm{T}_{\mathrm{g}^{\prime}}$. Then $\left(\mathrm{T}_{\mathrm{f}^{\prime}}^{4}-\mathrm{T}_{\mathrm{g}^{\prime}}^{4}\right)$ $\simeq 4 \vec{T}^{3}\left(T_{f^{\prime}}-T_{g^{\prime}}\right)$. 


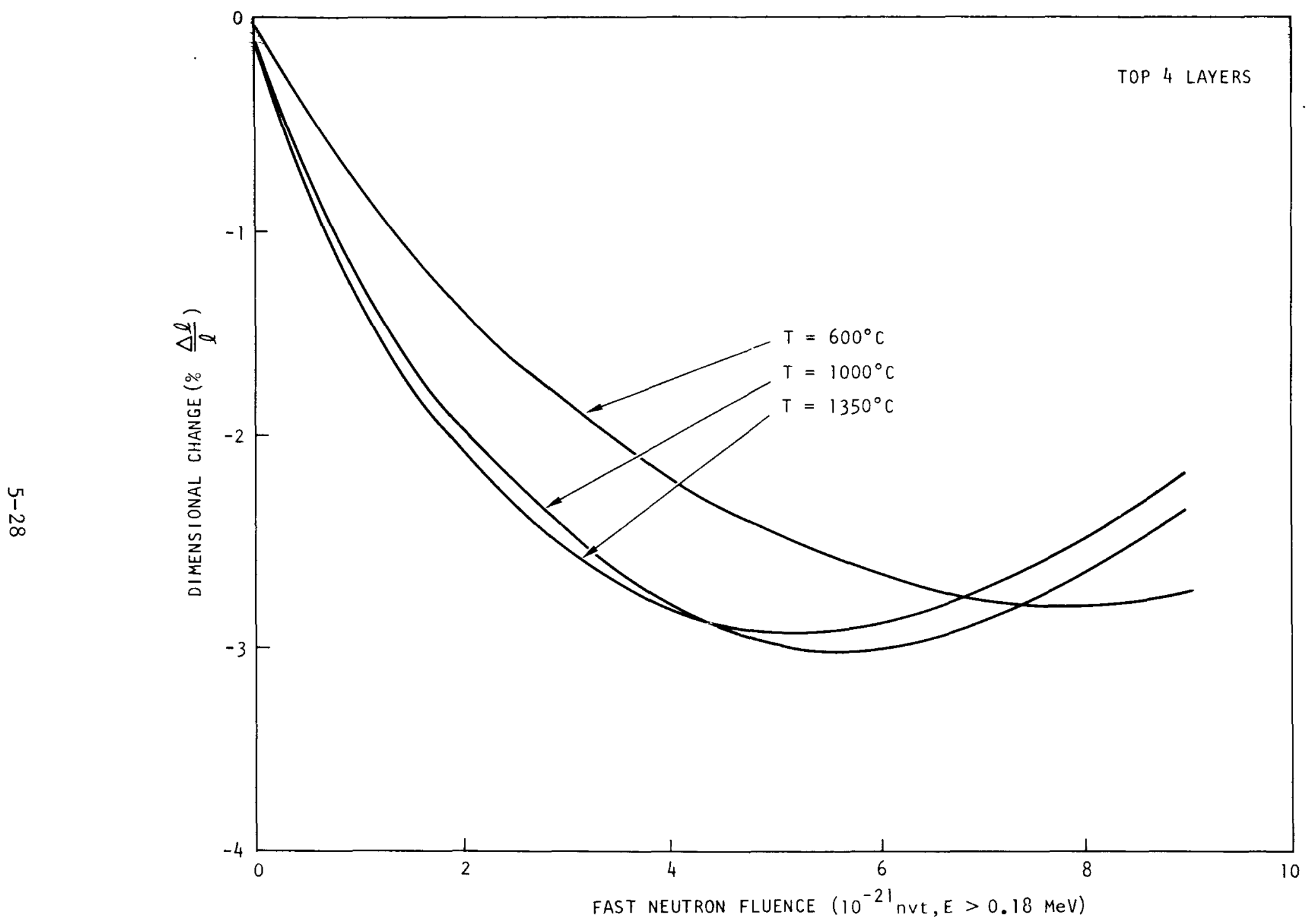

Fig. 5-8. Calculated fuel rod dimensional change (\%) in the top four layers of the large HTGR 


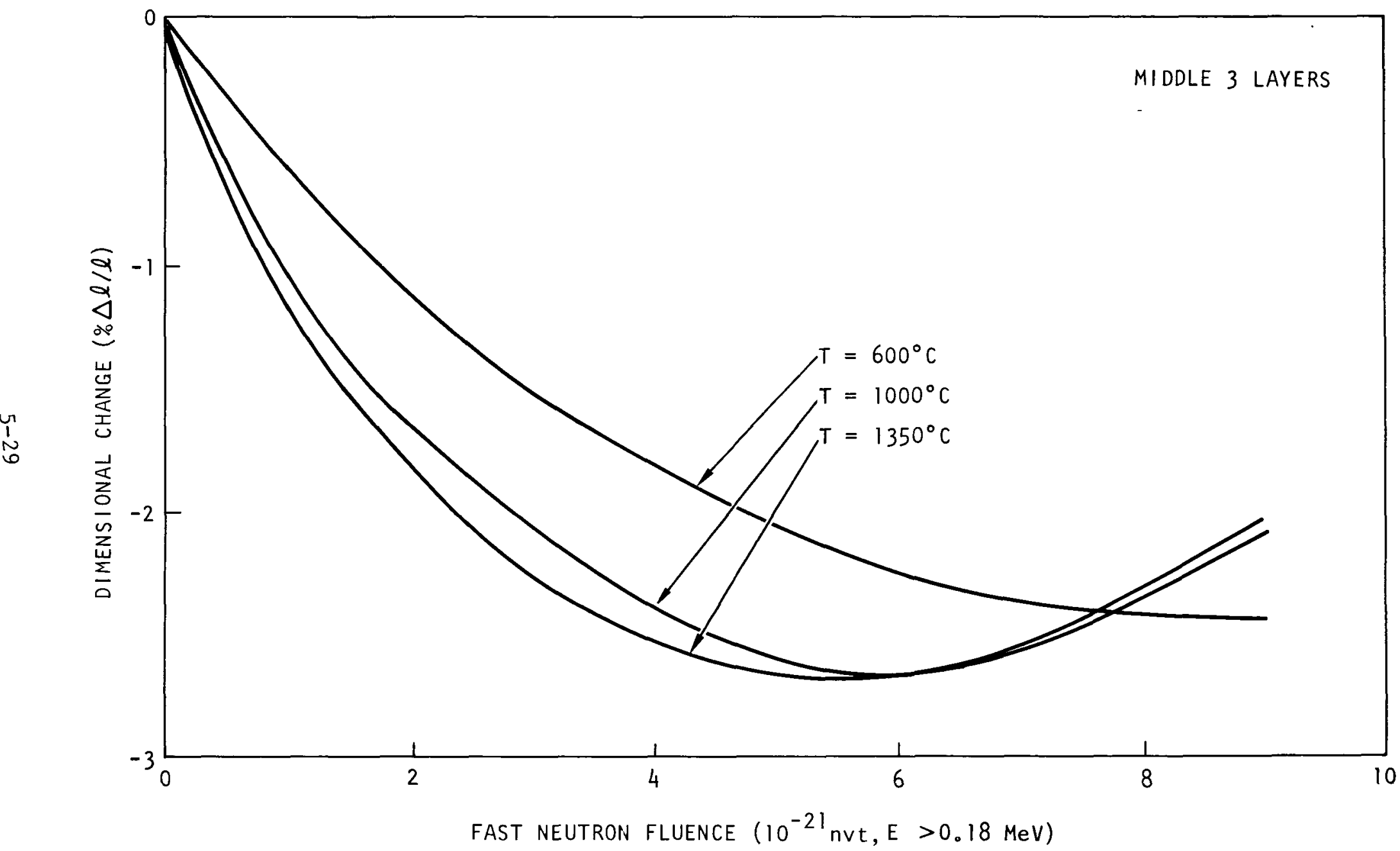

Fig. 5-9. Calculated fuel rod dimensional change (\%) in the middle three layers of the large HTGR 


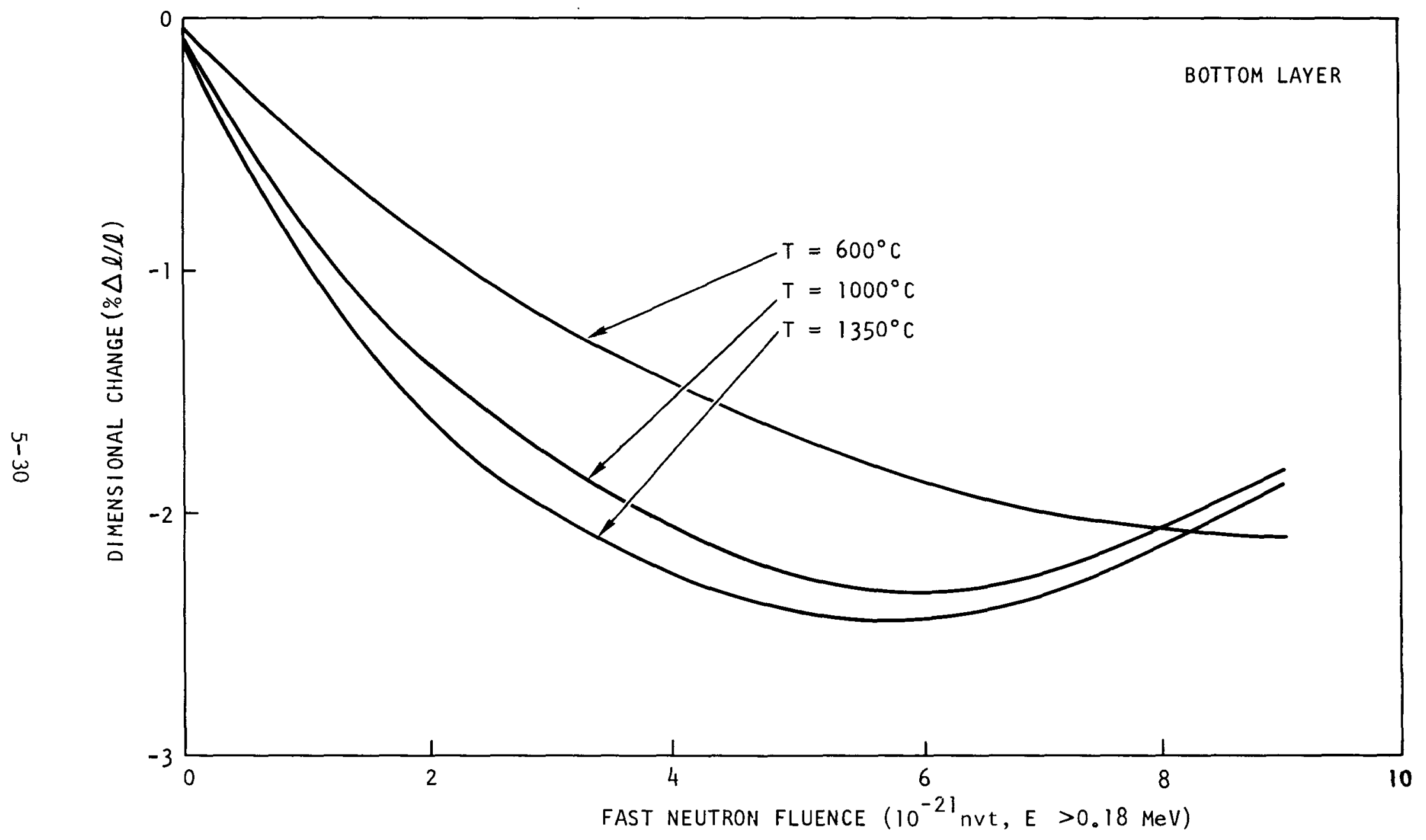

Fig. 5-10. Calculated fuel rod dimensional change (\%) in the bottom layer of the large HTGR 


$$
\begin{aligned}
& \mathrm{R}_{\mathrm{f}}=\text { radius of fuel rod (see Table 2-3), } \\
& \mathrm{R}_{\mathrm{h}}=\text { radius of fuel hole (see Table 2-3), } \\
& \sigma=\text { Stefan-Boltzmann constant, } \\
& \varepsilon=\text { combined emissivities of fuel rod and fuel hole, } \\
& \simeq 1 /\left[\frac{1}{\varepsilon_{\mathrm{f}}}+\frac{1}{\varepsilon_{\mathrm{h}}}-1\right], \\
& \varepsilon_{f}=\text { emissivity of fuel rod surface (see Section 5.5.4), } \\
& \varepsilon_{h}=\text { emissivity of fuel hole surface (see Section 5.6.3), } \\
& \overline{\mathrm{T}}=\text { average of fuel hole and fuel rod surface absolute tempera- } \\
& \text { tures, } \\
& =\frac{1}{2}\left(\mathrm{~T}_{f^{\prime}}+\mathrm{T}_{\mathrm{g}^{\prime}}\right) \text {. } \\
& \mathrm{T}_{\mathrm{f}^{\prime}}=\text { fuel rod surface absolute temperature, } \\
& \mathrm{T}_{\mathrm{g}^{\prime}}=\text { fuel hole surface absolute temperature. }
\end{aligned}
$$

The fuel rod is assumed to be located concentrically in the fuel hole. Any eccentricity would yield a lower maximum fuel temperature than the concentric location.

\subsection{NUCLEAR DESIGN DATA}

Thermal analyses carried out for the HTGR core (1) evaluate temperature and coating integrity throughout the core for rated-power steady-state operation throughout core life, (2) estimate the response of core temperature to transient operations varying from normal startup and loadfollowing to emergency and faulted transient conditions, and (3) establish detailed temperature distributions within local volumes of the fuel elements or core components.

A detailed understanding of the nuclear design is clearly required to supply input for the myriad of thermal calculations. Below, the nuclear 
design data required for the steady-state core survey calculation are discussed.

To carry out the core survey calculations (1) a history of the threedimensional power distribution within the core is required to specify local heat fluxes and power densities, (2) a history of the fast neutron fluence Is required to enable fuel dimensions and coating integrity to be calculated, and (3) the burnup distribution history is required to allow fuel particle coating integrity to be evaluated. Each of these quantities depends on the refueling sequence, the fissile and fertile metal distribution throughout the core, the control rod programming used, and the detailed operating history of the plant.

A licensing topical report has been submitted covering nuclear design of the $3000 \mathrm{MW}(t)$ HTGR core (Ref. 5-28). Only a brief discussion of the nuclear design is given below to show how results of the nuclear design are used in certain aspects of the thermal analyses.

\subsubsection{Core Nuclear Designs}

The thermal analysis described in this report for the $3000 \mathrm{MW}(t)$ reactor is based upon the most recently completed nuclear design. Included in these most recent nuclear calculations was a 7-year burnup study employing the GAUGE code as the analytical tool. A comprehensive evaluation of these calculations is presented in Ref. 5-28. Power distributions were determined at 11 time points in each year for a total of 77 time points as shown in Fig. 5-11. The thermal analysis given in Sections 6 and 7 is based primarily upon the results of these nuclear calculations. Additional information in Ref. 5-30 indicates and quantifies the generally conservative nature of the GAUGE radial power distributions and BUG super cell axial power distributions employed in the thermal design. In all time-dependent analyses, as a first approximation it can be 


\begin{tabular}{|c|c|c|c|c|c|c|c|}
\hline $\begin{array}{l}\text { FUEL } \\
\text { LOAD }\end{array}$ & $\begin{array}{c}\text { YEAR OF } \\
\text { OPERATION }\end{array}$ & $\begin{array}{l}\text { TIME } \\
\text { POINT }\end{array}$ & $\underset{\text { DAYS }}{\text { TIME IN }}$ & \multicolumn{4}{|c|}{ SEGMENT POSITIONS } \\
\hline & & & & A & B & C & D \\
\hline $\begin{array}{l}\text { INITIAL } \\
\text { CORE }\end{array}$ & 1 & $\begin{array}{r}1 \\
2 \\
3 \\
4 \\
5 \\
6 \\
7 \\
8 \\
9 \\
10 \\
11\end{array}$ & $\begin{array}{r}0 \\
5 \\
25 \\
50 \\
100 \\
150 \\
200 \\
225 \\
250 \\
270 \\
292\end{array}$ & SEGMENT I & SEGMENT 2 & SEGMENT 3 & SEGMENT 4 \\
\hline $\begin{array}{c}\text { RELOAD } \\
1\end{array}$ & 2 & $\begin{array}{l}\text { SAME AS } \\
\text { IN } \\
\text { YEAR } 1\end{array}$ & $\begin{array}{l}\text { SAME } \\
\text { IN } \\
\text { YEAR }\end{array}$ & SEGMENT 5 & SEGMENT 2 & SEGMENT 3 & SEGMENT 4 \\
\hline $\begin{array}{l}\text { RELOAD } \\
2\end{array}$ & 3 & 11 & " & SEGMENT 5 & SEGMENT 6 & SEGMENT 3 & SEGMENT 4 \\
\hline $\begin{array}{l}\text { RELOAD } \\
3\end{array}$ & 4 & 11 & $1 "$ & SEGMENT 5 & SEGMENT 6 & SEGMENT 7 & SEGMENT 4 \\
\hline$\underset{4}{\operatorname{RELOAD}}$ & 5 & 11 & " & SEGMENT 5 & SEGMENT 6 & SEGMENT 7 & SEGMENT 8 \\
\hline $\begin{array}{c}\text { RELOAD } \\
5\end{array}$ & 6 & $" 1$ & 11 & SEGMENT 9 & SEGMENT 6 & SEGMENT 7 & SEGMENT 8 \\
\hline $\begin{array}{l}\text { RELOAD } \\
6\end{array}$ & 7 & 11 & 11 & SEGMENT 9 & SEGMENT 10 & SEGMENT 7 & SEGMENT 8 \\
\hline
\end{tabular}

SEGMENT POSITIONS REFUELLED

Fig. 5-11. Segment and time point identification chart for TREVER study 
assumed that the performance during the remaining 33 years of plant life is no worse than the performance during the last 4 years of the first 7 years of operation.

\subsubsection{Refueling Sequence and Geometric Identifications}

Commercial HTGRs employ a 4-year fuel cycle in which about one-quarter of the fuel is replaced each year in a sequence indicated in Fig. 5-11. For rated power operation, a seven-rod pattern is used wherein the control rod pair in region 1 is used under automatic control to regulate main steam temperature and six rod pairs in regions $60^{\circ}$ apart in the ring containing regions 8 through 19 are used as shim rods (see Fig. 2-2). A core with $180^{\circ}$ symmetry results from this combination of reload sequence and control rod pattern. Figure 5-12 depicts one of the symmetric halves and notes the "segment positions" A, B, C, and D. Timing of the reloading of the fuel elements residing in each of the segment positions is noted in Fig. 5-11. For example the initial core consists of fuel segments 1 through 4 . Segment 1 resides in segment position $A$, segment 2 in segment position $B$, etc. for the initial core. After one year of operation, the fuel elements in segment 1 are replaced by a fresh segment, segment 5 in segment position A. At the end of the second year, segment 2 is replaced by segment 6 in segment position $B$. Therefore, during the third year of core operation, segment 5 is in segment position $A$, segment 6 is in segment position $B$, segment 3 is in segment position $C$, and segment 4 is in segment position $D$.

Also shown in Fig. 5-12 is the TREVER code region and column identification map. In general, the pattern is similar to that used in GAUGE (Ref. 5-29), where the core is divided into $60^{\circ}$ sectors and the column orientation within each sector is identical. In Fig. 5-12 the region number is given in the central column; the outer columns are numbered in the clockwise direction. Column numbering is rotated clockwise $60^{\circ}$ about the region's central column when moving from sector to sector in the clockwise direction. 


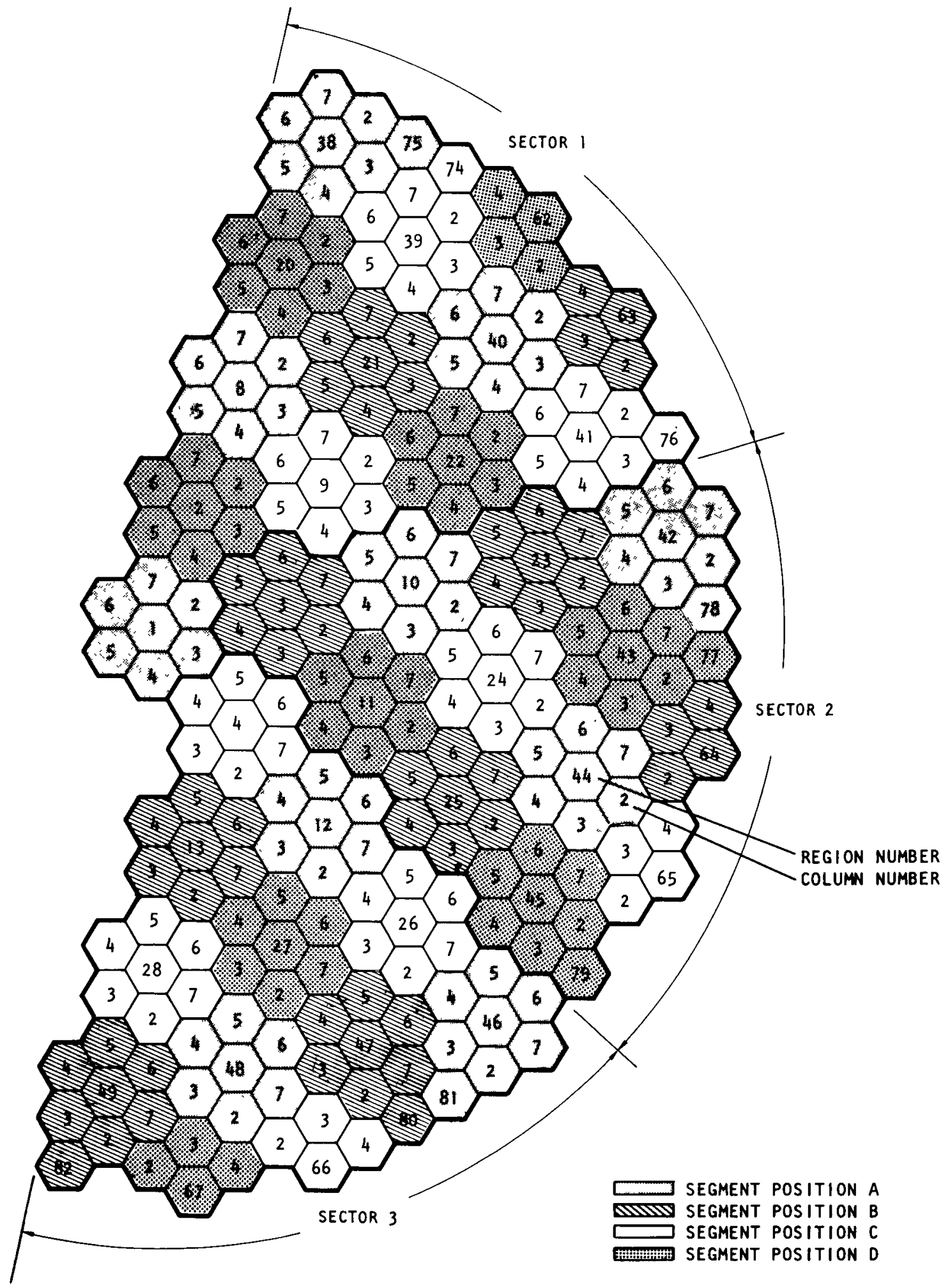

Fig. 5-12. Refueling sequence and TREVER code identification map 
The identification patterns for calculational nodes within a column are given in Fig. 5-13. In this figure one seven-colum refueling region may be seen, one four-column refueling region and three single columns from Sector 1 of Fig. 5-12. Within Sector 1 the other four- and seven-column regions are numbered with the same orientation. The identification pattern for other core sectors is rotated by $60^{\circ}$ in the same direction as the column numbers. In GAUGE/TREVER calculations, there are seven spatial points per column. GAUGE code calculates neutron fluxes and power at points located at the hex corners and in the center of the hex. The approximate fractional column area associated with each node in the results reported in Sections 6 and 7 is one-half for the center node and onetwelfth for each of the six corner nodes.

\subsubsection{Power Peaking Factors}

At any time during the core power operation, the distribution of the local relative power peaking factors, $P(l, z)$, at radial location $\ell$ and axial position $z$ is obtained from the core physics analysis. The local relative power peaking factors are unit normalized such that

$$
\sum_{\text {core volume }} P(l, z) \Delta \ell \Delta z=1.0,
$$

where $\Delta \ell \Delta z$ is the elemental core volume of the local points described in Fig. 5-13. In other words, $P(l, z)$ is the power density at which the radial point $l$ at axial location $z$ is operating relative to the core average power density.

The distribution of $P(l, z)$ may be described in terms of the local radial power peaking factor $P(l)$ and the local axial power peaking factor $A(l, z)$. In turn the local radial peaking factor may be expressed in terms of the region-averaged radial power peaking factor $P(r)$ and the local radial intraregion power tilt $\alpha(\ell, r)$. These parameters are defined as follows: 

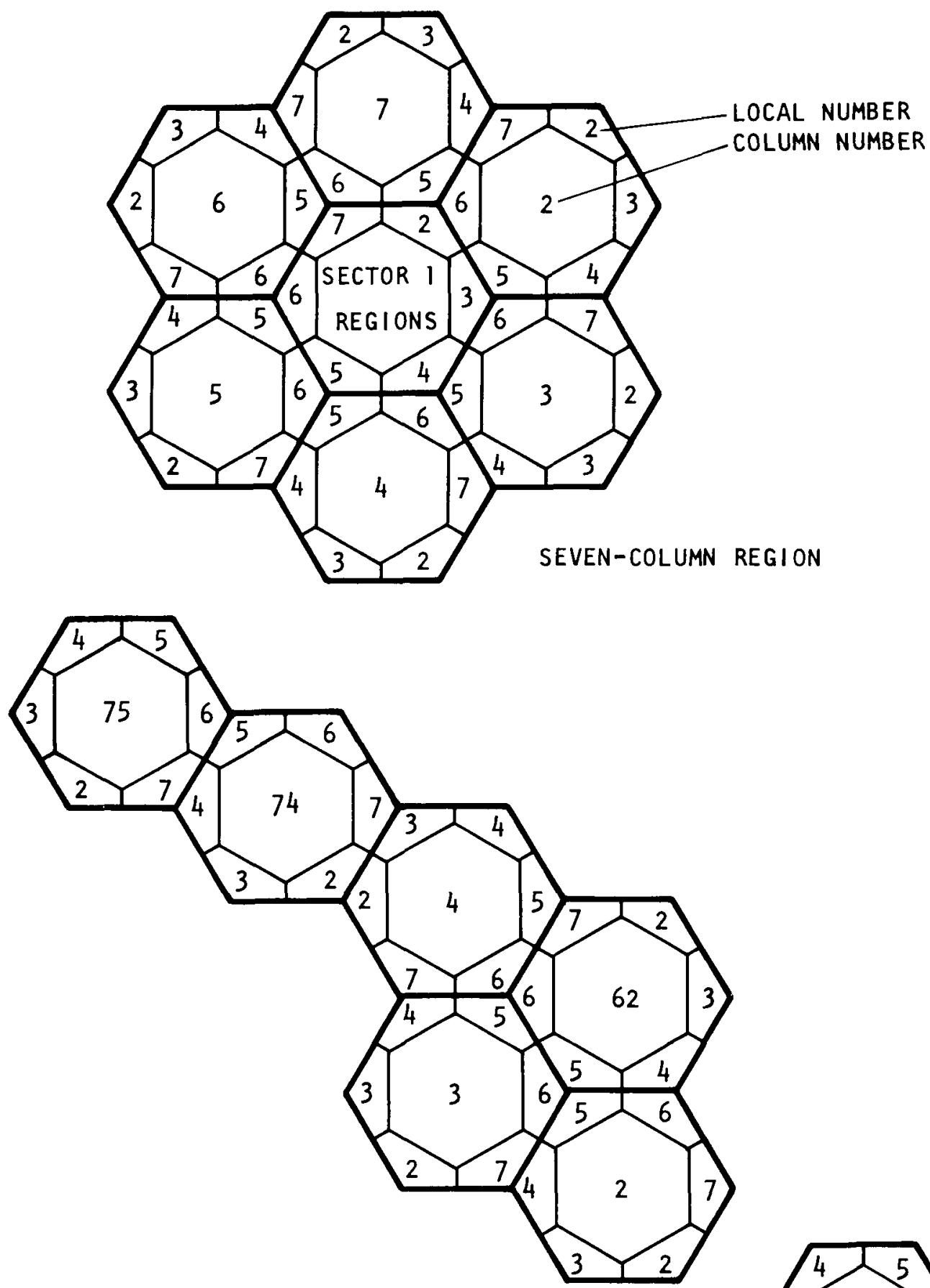

FOUR-COLUMN REGION

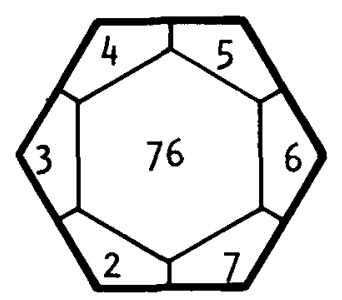

Fig. 5-13. Intra-column GAUGE/TREVER identification system 
1. Local Radial Power Peaking Factor

$$
P(l)=\sum_{\substack{\text { Core } \\ \text { Height }}} P(l, z) \Delta z .
$$

$P(l)$ is the local radial power density at which the local point $\ell$ is operating relative to the core average power density.

\section{Local Relative Axial Power Peaking Factor}

This is given by

$$
A(l, z)=\frac{P(l, z)}{P(l)},
$$

where $A(l, z)$ is the power at which the local point $\ell$ at axial location $z$ is operating relative to the local radial power averaged over the core height.

3. Accumulative Axial Power Peaking Factor

At any fractional core length $z$ in channel $\ell$, the accumulative axial power peaking factor is given by

$$
F\left(l, z_{I}\right)=\sum_{i=0}^{I} A\left(l, z_{i}\right) \Delta z_{i} .
$$

This is proportional to the fraction of the energy added from core inlet to the axial location $z_{I}$. Thus at $z=0, F(l, 0)=0$ and at $\mathrm{z}=1.0, \mathrm{~F}(l, 1.0)=1.0$. 
4. Region Radial Power Peaking Factor

$$
P(r)=\sum_{\text {Region } r} P(l) \Delta l,
$$

where $P(r)$ is the region average radial power at which the region $r$ is operating relative to the core average power.

5. Local Radial Intraregion Tilt

This is given by

$$
\alpha(\ell, r)=\frac{P(\ell)}{P(r)},
$$

where $\alpha(\ell, r)$ is the radial power at which the local point $\ell$ of region $r$ is operating relative to the region average power.

Using Eqs. 5-1, 5-2, and 5-3, the local power peaking factor can be redefined as

$$
P(l, z)=P(r) \cdot \alpha(l, r) \cdot A(l, z) \cdot
$$

A three-dimensional nuclear analysis using GATT (Ref. 5-30) provides the local power peaking factor $P(l, z)$ at each radial and axial location of the core. However, in carrying out the thermal design of commercial HTGRs up to this time, the three-dimensional power distribution is synthesized from a two-dimensional GAUGE (Ref. 5-29) radial power distribution and onedimensional axial power shapes (Ref. 5-28). The GAUGE code provides the region peaking factors $P(r)$ and radial intraregion power tilt $\alpha(l, r)$. The axial shapes are provided by the BUGTRI code (Ref. 5-31) as a function of control rod insertion. The two-dimensional BUGTRI code uses the $\mathrm{R}-\mathrm{Z}$ model to provide axial profiles in rodded regions and in regions adjacent to rodded regions. 


\subsubsection{Fuel Rod Metal Loading}

The fissile and fertile material in commercial HTGR cores is zoned both radially and axially to control the power distribution. The resulting fuel rod metal loadings required to implement the zoning determine the

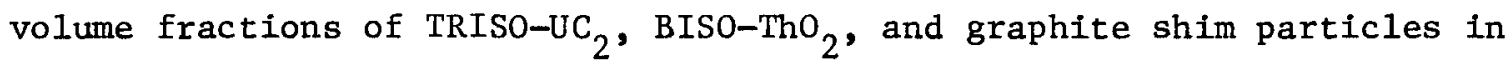
fuel rods in four of the major fuel zones (Table 5-5). The mix of fuel particle types in the rods determines the dimensional change behavior and thermal conductivity of fuel rods in different radial and axial locations of the reactor.

\subsubsection{Control Rod Programming}

In the current core design, three-dimensional power distribution is synthesized (see Section 5.8.3) from a two-dimensional GAUGE radial power distribution and BUGTRI axial power shapes. Eight axial shapes were used (see Section 5.8.7). Selection of the appropriate axial profile for individual regions depends upon the control rod position in the region or adjacent region.

For current core designs, most of the control rod motion occurs (Ref. 5-29) between cold shutdown and about three days into full-power operation. During this period of operation, the majority of the rod pairs will be withdrawn to compensate for reactivity losses that arise from the temperature defect from the cold shutdown to the hot operating conditions, and the buildup of rapidly saturating fission products such as $\mathrm{Xe}-135$ and $\mathrm{Sm}-149$. At the end of 3 days, about seven fully or partially inserted rod pairs provide the control over the remainder of the cycle. Figure 2-2 gives a typical seven-rod pair configuration for the $3000 \mathrm{MW}(t)$ core.

Burnable poison is used to compensate for most of the reactivity loss from long-term operating effects. The burnable poison rod size and 
composition are designed in such a way that during the first period of each annual cycle, which is approximately 200 days of full-power operation, there is minimum control rod motion. The reactivity loss due to depletion of fissile material is compensated for by reactivity gain due to the burnable poison depletion. During the remaining 100 days of a cycle, the seven control rods are slowly withdrawn to balance further loss of reactivity from depletion of fissile material.

A typical control rod program for the $3000 \mathrm{MW}(\mathrm{t})$ reactor is shown in Table 5-6. Using this scheme the 7-year burnup study was made at full power, during which the control rod pair in the central region 1 is used as a regulating rod. During initial and first reload core operation, regions $9,11,13,15,17$, and 19 are rodded; for all subsequent years regions 8 , $10,12,14,16$, and 18 are rodded.

\subsubsection{Core Radial Power Distribution}

The total power generated in a region is proportional to the region radial peaking factor $P(r)$. Flow control valves are manipulated so the flow in each of the refueling regions is proportional to the total power generated in the region.

The flow control valve regulates flow to an entire refueling region. A seven-column refueling region has 475 coolant channels. The heat removed by the coolant in an individual channel is related to the power generated in the fuel surrounding the channel. The power within a refueling region is not specially uniform, but varies with location due to the thermal neutron flux gradients and nonuniform burnup and conversion existing within the region. Neutron gradients within regions are determined by fuel composition in the region and neighboring regions, the control rod pattern, and neutron leakage and reflection at the core periphery. The intraregion power tilt factor $\alpha(\ell, r)$ is used to describe this nonuniform power within a 
TABLE 5-6

ROD WITHDRAWAL SCHEDULE FOR SIX SHIM ROD PAIRS

\begin{tabular}{c|c|l}
\hline Time Point & Time (days) & Shim Rod Position \\
\hline 1 & 0.0 (BOC) & Fully inserted \\
2 & 5.0 & Fully inserted \\
3 & 25.0 & Fully inserted \\
4 & 50.0 & Fully inserted \\
5 & 100.0 & Fully inserted \\
6 & 150.0 & Fully inserted \\
7 & 200.0 & Fully inserted \\
8 & 225.0 & Three-quarter inserted \\
9 & 250.0 & Half inserted \\
10 & 270.0 & Half inserted \\
11 & 292.2 (EOC) & Quarter inserted \\
\hline
\end{tabular}


refueling region. Local tilts cause higher helium, graphite, and fuel temperatures along the length of some local channels within the region.

The axial power distribution within a region also varies as a function of axial position due to fuel loading distribution, thermal neutron flux gradients, and nonuniform burnup. These axial thermal neutron flux gradients are also caused by perturbations resulting from control rod insertion. The local coolant, graphite, and fuel temperatures along the length of the channel are determined by accumulated axial peaking factor $F(l, z)$ and local axial peaking factor $A(l, z)$.

The core power distribution guidelines imposed by thermal design considerations at steady-state full-power operation are given below. These guidelines are used in developing a nuclear design that has a high probability of meeting all thermal design bases. Guidelines based on fuel temperatures, core pressure drop, flow valve design, and fixed orifice design are discussed in the following sections. These goals are not safety related and no specific technical specifications will cover them.

5.8.6.1. Constant Temperature Envelope. In thermal design, the fuel and graphite temperatures are a function of $P(r), \alpha(l, r), A(l, z)$, and $F(l, z)$. In order to establish guidelines for the nuclear design, which are easy to use during the development of the design, an envelope for combinations of $P(r), \alpha(l, r), A(l, z)$, and $F(l, z)$ that can exist at any local point in the core has been generated. The restriction on any combination of these four variables is defined in Fig. 5-14. To define this peaking factor envelope, the combination of four peaking factors that result in a steady-state maximum local fuel temperature of $2550^{\circ} \mathrm{F}$ was arbitrarily used.

Figure 5-14 presents an isothermal solid, all points of which are at $2550^{\circ} \mathrm{F}$. Given any combination of these four variables, any three uniquely define a point within the solid which in turn defines the value of the 


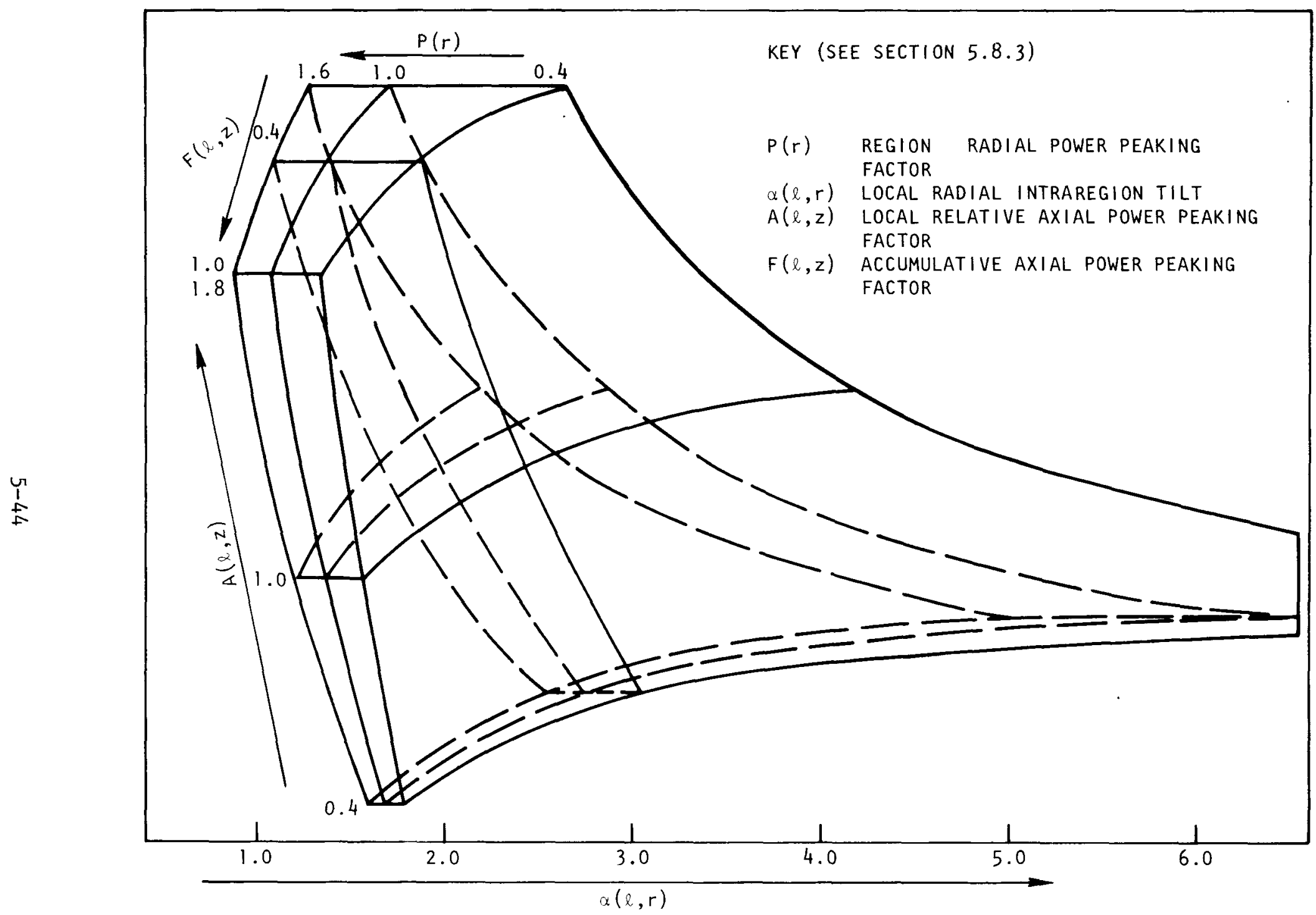

Fig. 5-14. Combination of radial and axial peaking factors that results in peak fuel temperature of $2550^{\circ} \mathrm{F}$ 
fourth variable that will give a fuel temperature of $2550^{\circ} \mathrm{F}$. This is the maximum allowable value of the fourth variable and defines the restriction on that particular combination of $P(r), \alpha(l, r), A(l, z)$, and $F(l, z)$. It must be kept in mind that Fig. 5-14 is only a convenient guideline for the nuclear design and that detailed analyses of the type described in Sections 6 and 7 are ultimately used to judge the adequacy of a particular nuclear design.

5.8.6.2. Maximum Region Power Peaking Factor. Maximum allowable region power generation is set to keep the core pressure drop below an upper limit. The core pressure drop limit is based on efficient plant operation and not on safety considerations. Since the flow valves are operated to yield an approximately equal coolant temperature rise in each core region, the core pressure loss is dictated by the coolant flow requirement of the highest powered region. In operation, the flow control valve for this maximum peaking region is set at wide open and the remaining valves are closed to balance region exit coolant temperatures among the regions. A high maximum region power requires that the flow control valves on other regions be sufficiently closed to divert flow to the high power region. For the $3000 \mathrm{MW}(t)$ reactor, the goal for maximum region peaking factor during steady-state full-power operation is set at 1.6. Table 5-7 shows the maximum and minimum region peaking factor for each time point during the seventh year of the burnup study for a symmetrical half-size 3000 MW( $t$ ) reactor.

\subsubsection{Minimum Region Peaking Factors. A requirement on minimum region} peaking factor is made to provide a lower limit on the range of region flow required in the design of the flow control valve. For $3000 \mathrm{MW}(\mathrm{t})$ reactors a goal of minimum region peaking factor during steady-state full-power operation is set at 0.5 . 
TABLE 5-7

MAXIMUM AND MINIMUM REGION PEAKING FACTORS

DURING SEVENTH YEAR OF BURNUP STUDY

\begin{tabular}{c|c|c}
\hline Time Point & Maximum & Minimum \\
\hline 0.0 & 1.4164 & 0.7033 \\
5.0 & 1.3720 & 0.7131 \\
25.0 & 1.3279 & 0.7254 \\
50.0 & 1.3266 & 0.7383 \\
100.0 & 1.3844 & 0.6958 \\
150.0 & 1.4345 & 0.6696 \\
200.0 & 1.4838 & 0.6510 \\
225.0 & 1.4392 & 0.6121 \\
250.0 & 1.4628 & 0.5906 \\
270.0 & 1.4670 & 0.5804 \\
292.2 & 1.4640 & 0.5741 \\
\hline
\end{tabular}


5.8.6.4. Maximum Column Peaking Factor for Fixed Orifice Column. * The column peaking factor $P_{C}(r)$ is defined as the ratio of power density in a fuel column to the core average power density. The $3000 \mathrm{MW}(t)$ reactor has 18 fuel columns to which the flow is controlled by fixed orifice plenum elements. During operation it is not possible to adjust the flow to these fixed orifice columns. To assure sufficient flow and to control coolant and fuel temperature in these columns, $P_{c}(r)$ for any fixed orifice should not exceed the maximum region average power density in the core at that time. This requirement arises because flow to the fixed orifice columns is dictated by the core pressure drop, which depends to a great extent on the maximum region average power.

5.8.6.5. Average Power for Fixed Orifice Columns. Orifices at the inlet of the fixed column region are sized to provide enough flow to assure that the gas temperature rise in the fixed orifice column does not exceed the core average gas temperature rise when these fixed column regions are producing their maximum allowed power. Therefore, for most of their life in the core these columns are overcooled. The overcooling means that the variably controlled regions have a bit less flow and larger temperature rise. To limit this overcooling of the fixed orifice columns, the average radial power peaking in these columns is set at a minimum of one-half the power peaking in the maximum power region.

\subsubsection{Core Axial Power Distribution}

The main thermal requirement for core axial power distribution is that it peak toward the top of the core to produce an axially flattened fuel centerline temperature along the length of the core. The ideal axial power distribution, which would result in an axially constant fuel temperature, is an exponential distribution peaked toward the top of the core. The continuous zoning scheme required for such an ideal distribution, however, is not practicable and in the current core design three axial fuel zones

*There are no fixed orifice columns in the $2000 \mathrm{MW}(\mathrm{t})$ core. 
are used to shape the axial power. In this zonal scheme the four topmost fuel elements $(4 / 8)$ of the core are in the top zone, the next three elements $(3 / 8)$ in the middle zone, and the bottom element $(1 / 8)$ in the bottom zone. One additional criterion that the axial power distribution must meet is that it should be stable with core burnup. A core average axial power shape and the effect of burnup are shown in Fig. 5-15. A small shift in power shape occurs in each of the axial zones during the first year as the lumped burnable poison is depleted; the shape remains essentially unchanged thereafter.

One of the important effects of control rod movement within a region is to perturb the axial power shape in that refueling region and in regions surrounding it. The thermal analysis includes the effect of control rod motion. Figure 5-16 shows the axial power distribution as a function of rod insertion. Figure 5-17 shows the corresponding effect on axial shape in the adjacent regions. These axial profiles used in thermal analysis are based on a two-dimensional $(r, z)$ BUG model as discussed in Ref. 5-32. More realistic three-dimensional GATT calculations, which use axially temperature-dependent cross section, indicate that the perturbation of control rod motion is less severe compared to those shown in Figs. 5-16 and 5-17. In thermal analysis, the temperature calculations are made at 35 axial locations as shown in Table 5-8.

\subsubsection{Core Fast Neutron Flux Distribution}

Core fast neutron flux distributions are defined in terms similar to those for core power distribution. Radial fast flux values define the fast flux averaged over the core height so that the integral of axial flux peaking factors over core length is normalized to unity. The fast neutron flux is defined as the flux of neutrons with energies greater than 0.18 $\mathrm{MeV}$. 


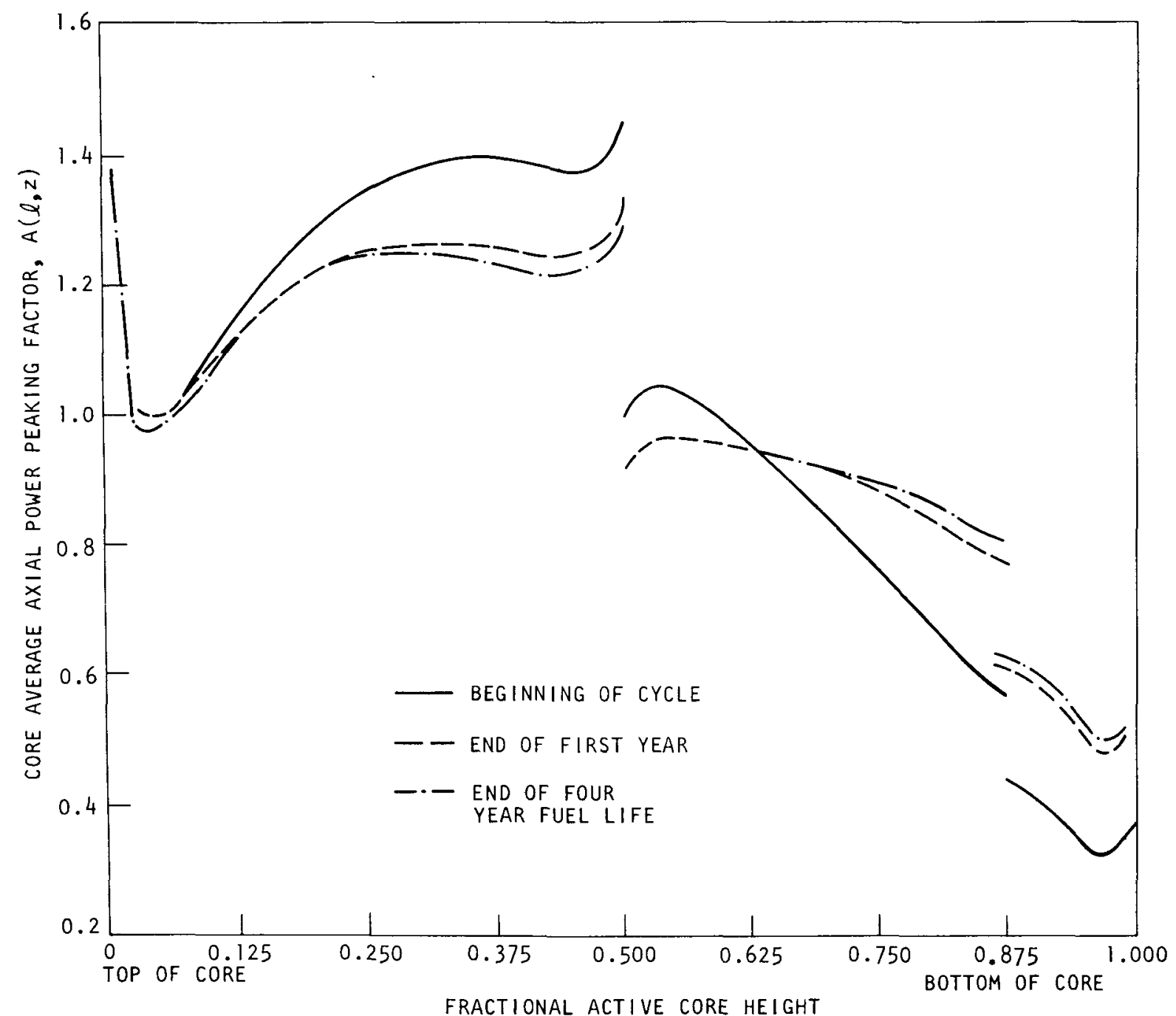

Fig. 5-15. Effect of burnup on core average axial power distribution 


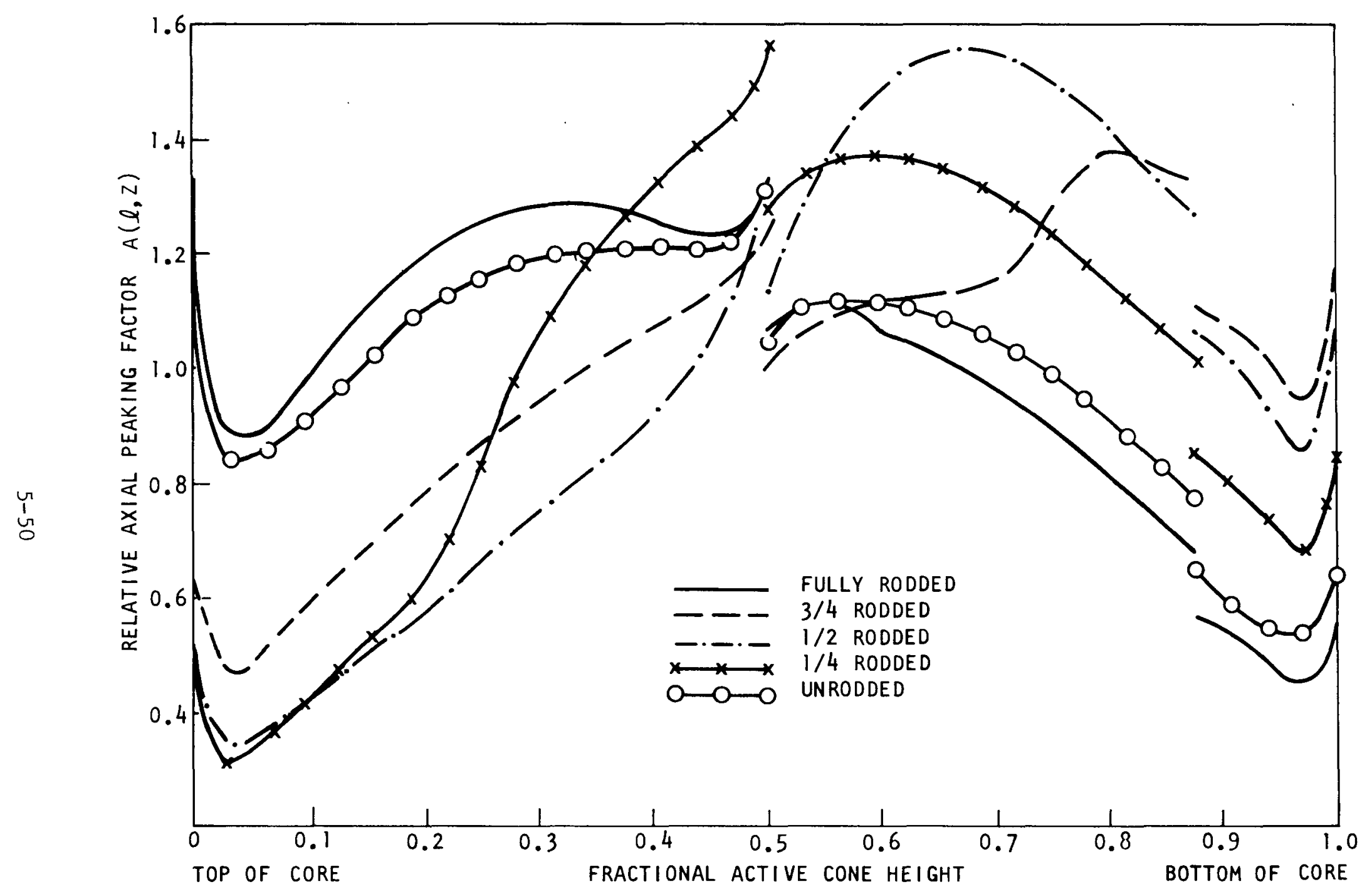

Fig. 5-16. Effect of control rod motion on axial power distribution in rodded regions 


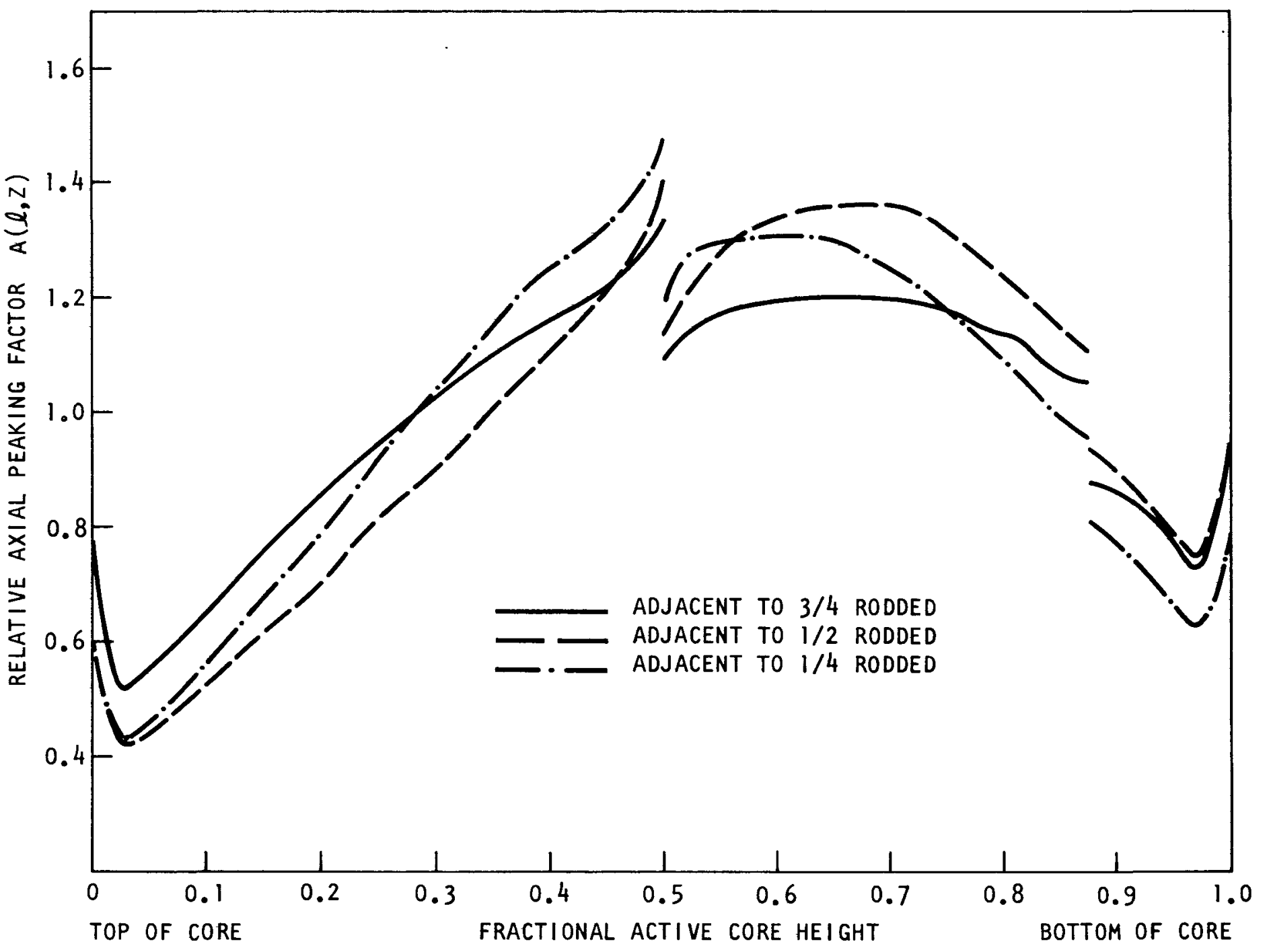

Fig. 5-17. Effect of control rod motion in neighboring regions 
TABLE 5-8

AXIAL NODAL POINTS AND FRACTIONAL CORE LENGTH USED IN TREVER ANALYSIS

\begin{tabular}{|c|c|c|}
\hline Axial Node Number & $\begin{array}{c}\text { Fractional Active Core Length } \\
\text { (From Top of Core) }\end{array}$ & Distance (in.) \\
\hline 1 & 0.000 & 0.0 \\
\hline 2 & 0.031 & 7.8 \\
\hline 3 & 0.063 & 15.6 \\
\hline 4 & 0.094 & 23.4 \\
\hline 5 & 0.125 & 31.2 \\
\hline 6 & 0.156 & 39.1 \\
\hline 7 & 0.188 & 46.9 \\
\hline 8 & 0.219 & 54.7 \\
\hline 9 & 0.250 & 62.4 \\
\hline 10 & 0.281 & 70.3 \\
\hline 11 & 0.313 & 78.1 \\
\hline 12 & 0.344 & 85.9 \\
\hline 13 & 0.375 & 93.7 \\
\hline 14 & 0.406 & 101.6 \\
\hline 15 & 0.438 & 109.4 \\
\hline 16 & 0.469 & 117.2 \\
\hline 17 & 0.500 & 125.0 \\
\hline 18 & 0.500 & 125.0 \\
\hline 19 & 0.531 & 132.8 \\
\hline 20 & 0.563 & 140.6 \\
\hline 21 & 0.594 & 148.4 \\
\hline 22 & 0.625 & 156.2 \\
\hline 23 & 0.656 & 164.1 \\
\hline 24 & 0.688 & 171.9 \\
\hline 25 & 0.719 & 179.7 \\
\hline 26 & 0.750 & 187.4 \\
\hline 27 & 0.781 & 195.3 \\
\hline
\end{tabular}


TABLE 5-8 (Continued)

\begin{tabular}{c|c|c}
\hline & $\begin{array}{c}\text { Fractiona1 Active Core Length } \\
\text { (From Top of Core) }\end{array}$ & Distance (in.) \\
\hline 28 & 0.813 & 203.1 \\
29 & 0.844 & 210.9 \\
30 & 0.875 & 218.7 \\
31 & 0.875 & 218.7 \\
32 & 0.906 & 226.6 \\
33 & 0.938 & 234.4 \\
35 & 0.969 & 242.2 \\
\hline
\end{tabular}


The core thermal design considerations Impose no limit on the core fast flux distribution. However, the core materials are affected by the local fast fluence as described in Section 3.2. The radial core flux distribution used in the $3000 \mathrm{MW}(t)$ reactor core generated by the 7-year two-dimensional fuel depletion analysis in a similar manner to power distribution is discussed in Section 5.8.5.

Control rods perturb the axial fast flux distribution as well as the thermal flux. Figure 5-18 presents axial fast neutron flux shapes in a region as the control rod is inserted. Figure 5-19 shows the corresponding effect on axial flux shape in the neighboring regions. 


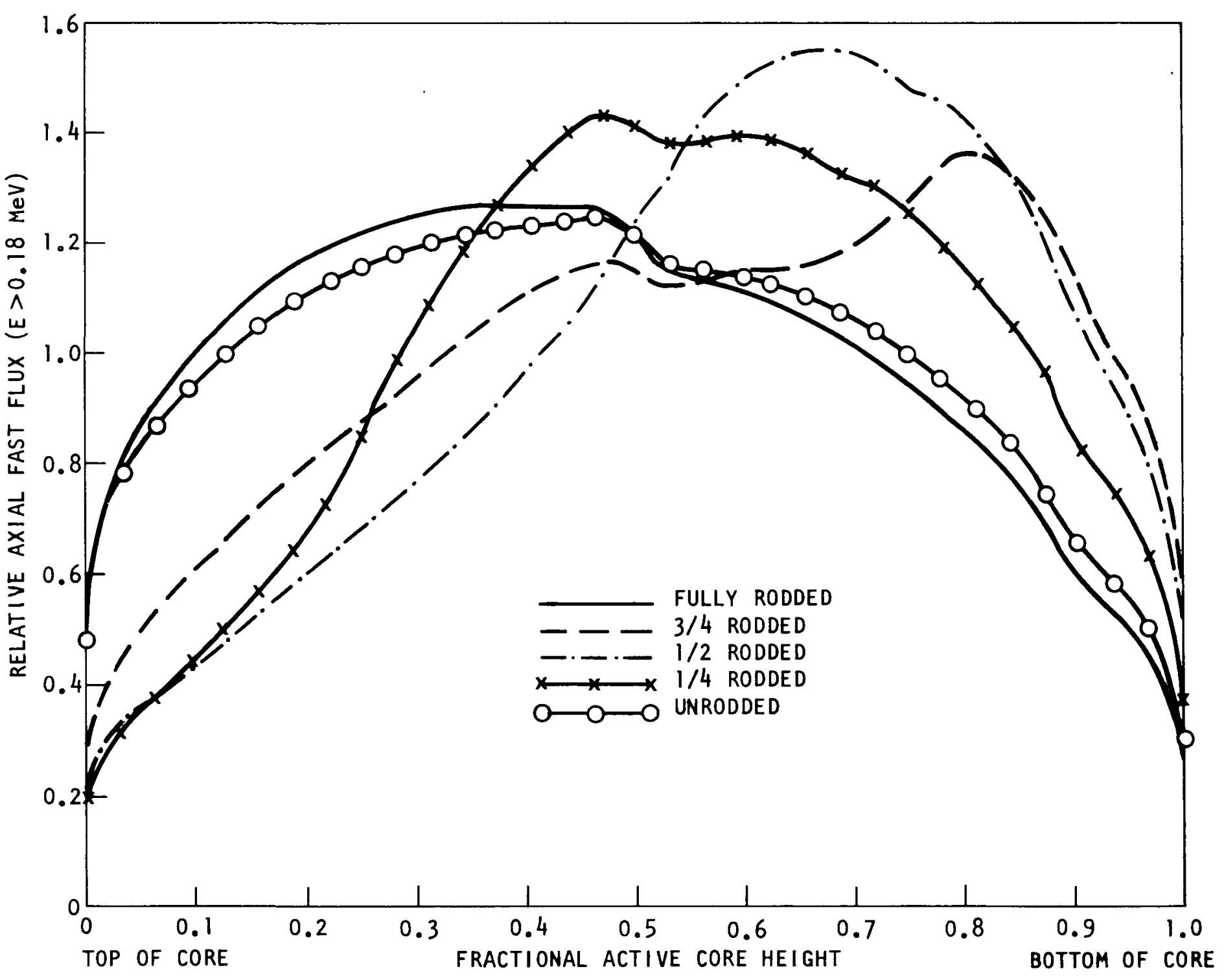

Fig. 5-18. Effect of axial flux shape due to rod motion 


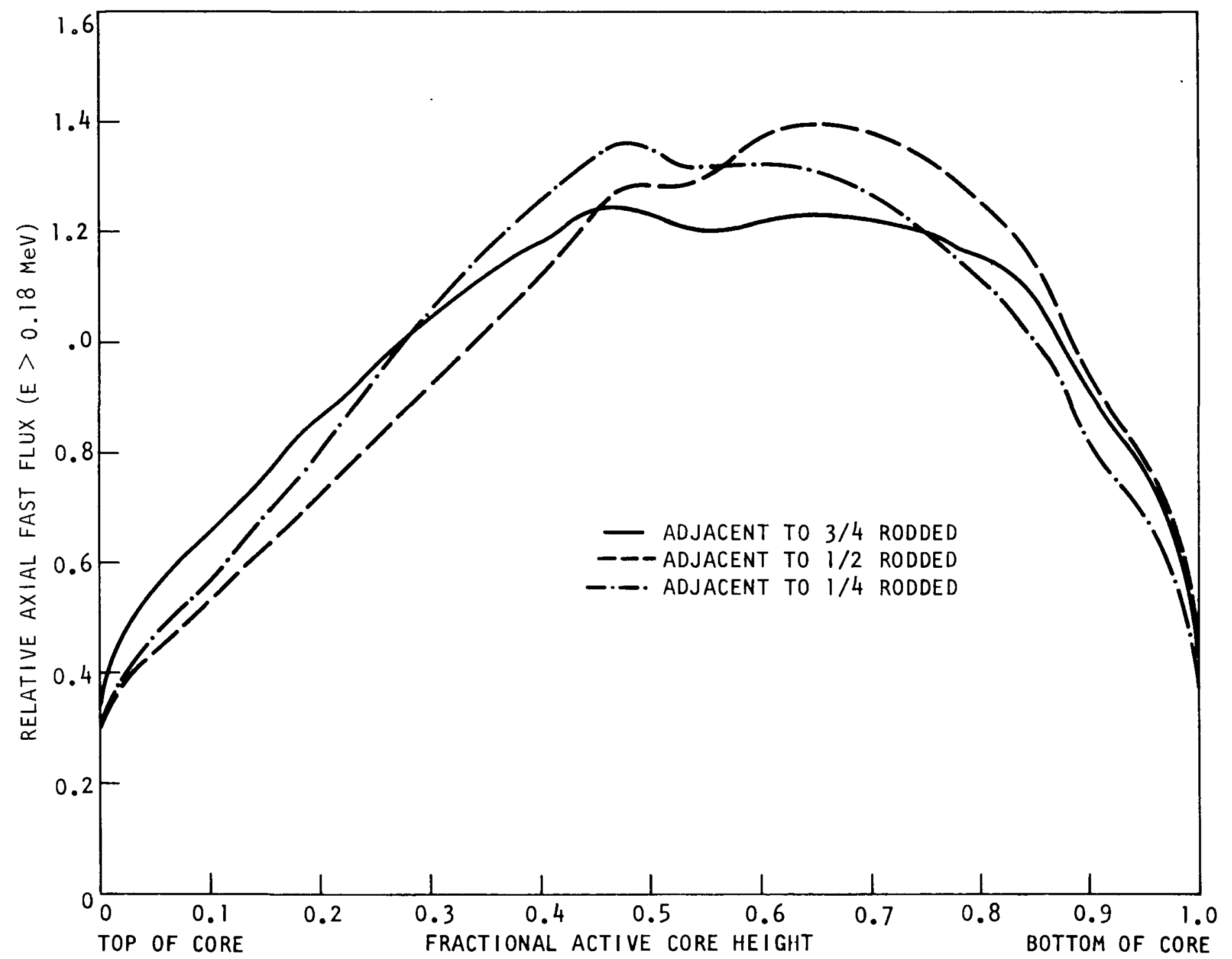

Fig. 5-19. Effect of axial flux shape in neighboring regions due to rod motion 


\section{REFERENCES}

5-1 Wilson, M. P., Jr., "Thermodynamic and Transport Properties of Helium," USAEC Report GA-1355, General Dynamics, General Atomic Division, January 1960.

5-2 "The Thermodynamic and Transport Properties of Helium and Nitrogen," Westinghouse Electric, Astronuclear Laboratory Report WANL-TME-1753, May 1968.

5-3 Petersen, Helge, "Tables of Thermophysical Properties of Helium," Dragon Report 734, A.E.E. Winfrith, Dorchester, Dorset, England, 1971.

5-4 Kays, W. M., and A. L. London, Compact Heat Exchangers, Mc-Graw-Hill, New York, 1964, p. 93.

5-5 Coates, N. H., and Galli, A. F., "Film Coefficients of Heat Transfer for Helium at $2000^{\circ} \mathrm{F}$ to $2500^{\circ} \mathrm{F}$ in Turbulent Flow, "Report 6856, U.S. Department of the Interior, Bureau of Mines, March 1966.

5-6 Sullivan, J. A., and C. R. King, "Measurements of Convective HeatTransfer Coefficients for Subsonic Flow of Hydrogen and Helium in Smooth Tubes at Moderate Surface and Fluid Temperatures," Los Alamos Scientific Laboratory Report LA-4882, March 1972.

5-7 Taylor, M. F., "Correlation of Local Heat Transfer Coefficient for Single-Phase Turbulent Flow of Hydrogen in Tubes with Temperature Ratios to 23," National Aeronautics and Space Administration Report NASA-TN-D-4332, January 1968.

5-8 Perkins, H. C., and P. Worsoe-Schmidt, "Turbulent Heat and Momentum Transfer for Gases in a Circular Tube at Wall to Bulk Temperature Ratios to Seven," Int. J. Heat \& Mass Transfer 8 , 1011-1031 (1965).

5-9 Kays, W. M., Convective Heat and Mass Transfer, McGraw-Hill Book Co., New York, 1966, p. 114. 
5-10 Giedt, N. H., Principles of Engineering Heat Transfer, D. VanNostrand Co. Inc., 1957, p. 155.

5-11 Lane, R. K., and J. F. Petersen, "Core Heat Transfer During Rise to Power in Peach Bottom," Gulf General Atomic Report GAMD-7911, February 1, 1968.

5-12 Coon, C. W., "The Transition from Turbulent to Laminar Regime for Internal Convective Flow with Large Property Variations," Ph.D. Thesis, University of Arizona, 1968.

5-13 Nightingale, R. E., editor, Nuclear Graphite, Academic Press, New York, 1962.

5-14 Price, R. J., "Review of Thermal Conductivity of Nuclear Graphite under HTGR Conditions," Gulf General Atomic Report Gulf-GA-A12615, September 7, 1973.

5-15 Gray, W. J., and A. L. Pitner, "The Increased Lifetime of Graphites Irradiated Above $1200^{\circ} \mathrm{C}$," Carbon 9, 699 (1972).

5-16 Engle, G. B., "The Influence of Pitch-Binder Coke Content on the Properties and Irradiation Behavior of Molded Graphite," Carbon 9 , 383 (1971).

5-17 Engle, G. B., et al., "Development Status of Near-Isotropic Graphites for Large HTGRs," General Atomic Report GA-A12944, June 1974.

5-18 Grenis, A. F., and A. P. Levilt, "The Spectral Emissivity and Total . Normal Emissivity of Commercial Graphites at Elevated Temperatures," Proceedings of Fifth Conference on Carbon, 1961, p. 639.

5-19 Plunkett, J. D., and W. D. Kingery, "The Spectral and Integrated Emissivity of Carbon and Graphite," Proc. Fourth Carbon Conference, p. 457 (1960).

5-20 Autio, G. W., and E. Scula, "The Normal Spectral Emissivity of Isotropic and Anisotropic Materials," Carbon 4, 13-28 (1966).

5-21 Butland, A. T. D., and R. J. Maddison, "The Specific Heat of Graphite: An Evaluation of Measurements," Nucl. Mater. 49, 45-46, North-Holland Publishing Company, (1973/74).

5-22 Johnson, W. R., "Thermal Conductivity of Large HTGR Type Fuel Rods," General Atomic Report GA-A12910, March 15, 1974. 
5-23 Stansfield, 0. M., Gulf General Atomic, "Thermal Expansion of PSC Fue1 Rods," unpublished data, August 25, 1970.

5-24 Darken, S. L., and R. W. Gurry, Physical Chemistry of Metals, McGrawHill, New York, p. 158, 1953.

5-25 Touloukian, Y. S., editor, Thermophysical Properties of High Temperature Solid Materials, Vol. 5, Thermophysical Properties Research Center, Purdue University, MacMillian, 1967.

5-26 Butland, A. T. P., and R. J. Maddison, "Specific Heat of Graphite: An Evaluation of Measurements," Nucl. Mater. 49, 45 (1973).

5-27 Harmon, D. P., and C. B. Scott, "Irradiation Performance and Development of HTGR Fuel," General Atomic Report GA-A13173, to be published.

5-28 Hamilton, C. J., "Power Distribution in Large HTGRs," General Atomic Report GA-A13007, to be published.

5-29 Wagner, M. R., "GAUGE, A Two-Dimensional Few Group Neutron DiffusionDepletion Program for a Uniform Triangular Mesh," Gulf General Atomic Report GA-8307, March 15, 1968.

5-30 Kraetsch, H., and M. R. Wagner, "GATT, A Three-Dimensional Few Group Neutron Diffusion Theory Program for a Hexagonal -3 Mesh," Gulf General Atomic Report GA-8547, January 1, 1969.

5-31 Dorsey, J. P., R. Froelich, and F. Todt, "BUG-2/BUGTRI, TwoDimensional Multigroup Burnup Codes for Rectangular and Hexagonal Geometry," USAEC Report GA-8272, Gulf General Atomic, August 22, 1969. 


\section{CORE THERMAL AND FLOW ANALYSIS}

In this section, application to the HTGR core of the codes introduced in Section 4 and the design data introduced in Section 5 is discussed. Core flows, pressures, and temperatures are presented and the results from various codes are compared.

In this discussion, the core thermal and flow analysis has been divided Into two parts: (1) steady-state power operation and (2) transient operating conditions. The steady-state analysis includes power generation at full and part load conditions for an extended period of time. For steady-state power operation in an HTGR core, the maximum coolant, graphite, and fuel temperatures occur during operation at $100 \%$ of rated power. Therefore, the discussion in this report is limited to the steadystate operation at rated power. The anticipated transient operations in the HTGR consist of normal transients such as startup, load changes, and shutdown and upset transients such as turbine trip and single loop shutdown. The maximum temperatures during normal transients occur during load changes at the maximum planned rate of $5 \%$ per minute from part load to full load when transient xenon reactivity is at a maximum. The discussion in this section is again limited to the worst case load-following transient; all other normal and upset transients have temperature and fuel performance less severe than those reported here. Fuel performance under emergency and faulted transients is discussed in Ref. 6-1.

\subsection{STEADY-STATE OPERATION}

A typical nuclear analysis covers 7 years of steady-state rated power operation. The burnup calculations consist of an inttial core and 
continues through six annual reloads (see Fig. 5-11). During such an operating history, the power distribution, fast neutron flux distribution, and local fuel composition are available from a nuclear analysis of the core. A thermal analysis is carried out wherein the spatial and timedependent temperatures of coolant, graphite, and fuel are calculated. At each time point the dimensional changes of fuel and graphite components are calculated and used in the thermal analysis. The results are reported here in a format similar to Section 4.1.

\subsubsection{Flow Distribution from FLAC Code}

The $3000 \mathrm{MW}(t)$ flow models described in Section 4.1.1 are used to obtain the flow distribution through various flow passages in the core cavity. The majority of the coolant entering the upper core plenum passes through the coolant channels within the elements of the core, and a small fraction of the flow bypasses these coolant channels and passes through alternate flow paths to provide cooling to fuel elements and other components within the reactor core cavity. Each of the flow passages that exist in the 3000 MW( $t$ ) core cavity is briefly discussed below.

6.1.1.1. Coolant Channel Flow. Almost all of the coolant entering the refueling region through the variable flow control valves flows through the coolant channels within the top reflector, active core, and bottom reflector hexagonal graphite blocks. The helium, as it flows down the coolant channels, removes the heat generated in the surrounding fuel rods and graphite and increases in temperature. In the lower reflector, the helium from the coolant channels in the standard fuel column merges into three large 5-in.-diameter coolant holes as shown in Fig. 2-3. The coolant then passes through the full length reflector element with the matching coolant holes and then into the large core support block. The coolant from individual coolant channels in the control column is collected into a single plenum within the bottom reflector element just above the core support block. 
Horizontal slots in the bottom faces of the control column bottom reflector block and matching slots in neighboring elements in the standard columns allow the coolant to be routed to the adjacent standard columns and into the core support block as shown in Fig. 2-3.

A variable flow-control assembly is located in the inlet to each refueling region to provide on-line control of the coolant flow distribution among the refueling regions of the core. Thermocouples, two of which provide readings available to the operator at all times during operation, are located, as shown in Fig. 2-5, in a graphite sleeve penetrating the core support block beneath each of the regions that are fitted with flow control valves. These thermocouples indicate the region-averaged coolant outlet temperatures, which are used as a basis for distributing the coolant flow using the flow valves.

During reactor operation the inlet flow to each of the refueling regions is adjusted by setting the flow valve so that the outlet coolant temperatures of all regions are approximately equal. The flow through each region is then approximately proportional to the power generated in the region. The fraction of reactor power produced in each fuel region changes with time and is dependent upon how long the region has been in the core, the history of the region's neighbors, and the position of the control rods.

In the $3000 \mathrm{MW}(t)$ reactor, 18 fuel columns located around the periphery of the core have been fitted with fixed orifices to control flow through these columns. These fixed orifices can be changed only at the time when the penetration used to refuel the column is open.

6.1.1.2 Bypass Flows. The core cavity flow that does not pass through the fuel element coolant holes is called bypass flow. This bypass flow varies with fuel age and core elevation. Bypass flow is expected to increase as 
spaces between elements increase due to fast neutron induced fuel element shrinkage. The bypass flows provide cooling to components of the core as described below.

1. Control Rod Channel Flow

In order to cool the control rods, a portion of the reactor coolant flow is diverted into the hollow control rods from the core upper plenum. This flow passes through the control rod channel, cooling the control rods that are inserted into the core as well as removing heat from the control column fuel elements. The control rod flow is limited by a small diameter flow restrictor in the control column bottom reflector. The control rod flow merges with the gas flow from the coolant channels in the bottom reflector region. The reserve absorber hole in the central fuel column has a blind bottom. Flow can pass through this hole only by crossflow in and out to surrounding coolant paths.

\section{Flow in Gaps Between Fuel Columns and Crossflow}

A fraction of the core cavity flow bypasses the fuel element coolant holes and passes through the gaps between fuel columns. There are two types of gaps between fuel columns: external gaps and internal gaps. External gaps are those between fuel columns of adjacent refueling regions. A vertical flow path from the upper core plenum to the external gaps is afforded by the vertical gaps in the top plenum elements. Internal gaps are the vertical gaps between fuel columns within a refueling region. A vertical flow path is present between the flow control valve plenum and the internal gaps. Lateral flow occurs between the internal and external gaps of refueling regions. The coolant in the gaps between fuel columns (external gaps) flows downward and 
exits at the bottom reflector through the flow windows between the control and standard fuel column bottom reflector elements. There it mixes with the coolant hole and control rod channel flow. A small portion of the external gap flow exits through the vertical spaces between core support floor blocks. In the reactor core, small lateral pressure differences develop between the gap flow and coolant channel flow resulting in the potential for an exchange of coolant between the bypass gaps and coolant channels. This flow is termed "crossflow" and is discussed below.

In high power regions with open-flow control valves, the pressure In the coolant holes in the upper reflector and some portions of the active core is higher than the pressure in the coolant flowing in spaces between fuel elements. This pressure difference can lead to flow leaving coolant holes in a high power region through the small horizontal interfacial gaps which may develop between fuel blocks. The external and internal gap pressures and flow distribution are affected by many variables, but one of the dominant influences is the design of the core support floor. The core support floor is made from graphite blocks having the same outline as the seven column region. Gap spacing between the support blocks is governed by the design of the side restraint system. When the core is operating at power, the temperature of the support floor is about equal to the coolant exit temperature. At full power, where core exit coolant temperature reaches a maximum, the gap spaces are smali. This means that little flow can escape through the floor. The core support floor design also minimizes gaps between fuel columns, thus producing the maximum axial and lateral flow resistance which minimizes the gap flow between fuel columns. 
The amount of crossflow between core gaps and coolant channels depends on the potential pressure difference between core gaps and region coolant channels. The orifice pressure drop in regions generating less than maximum power varies between about 1.5 and 10 psi depending on the flow valve setting and core power distribution. This pressure drop through the valve determines the coolant hole pressure in the regions. The helium pressure in coolant channels of a region with a partially closed valve is lower than the surrounding gap pressures. This pressure distribution will lead to flow entering the coolant holes through fuel element interface gaps.

\section{Side Reflector and Reflector Gaps}

Helium coolant flows through spaces between graphite reflector blocks. This flow removes the heat deposited in the side reflector components by gamma and neutron attenuation.

Helium flow also passes between the permanent reflector and the core cavity liner but is limited by a core peripheral seal near the level of the core support floor.

6.1.1.3. Flow Distribution With and Without Crossflow. The core cavity flow distribution has been calculated using the FLAC code one-sixth core model described in Section 4.1.1.1. Figures 4-1, 4-2, and 4-3 show the physical relationship between the flow paths and the FLAC flow network used in these calculations. Results from two extreme cases have been included to demonstrate the influence of fuel element dimensional change and bowing induced by fast neutron irradiation. First, calculations were made for the initial core when all the graphite elements were new and could be assembled to give nearly zero interfacial gaps. This limiting case is referred to as the "no crossflow" case. 
Summary results from the no crossflow case calculation at a total core cavity flow of $10.936 \times 10^{6} \mathrm{lb} / \mathrm{hr}$ are shown in Table 6-1. There the percent of the core cavity flow in various flow paths is given as a function of axial position. Figure 6-1 shows the pressure distribution in coolant holes, gaps between fuel columns and side reflector gaps. The pressure in the borated reflector and thermal barrier gaps is controlled by the core peripheral seal flow restrictor at the level of the core support floor. This seal limits the flow passing out through the seal to approximately 1.0\%. Since most of the thermal barrier and borated reflector gap pressure drop occurs at the peripheral seal, the thermal barrier and borated reflector gap pressures are greater than the side reflector gap pressures. This condition results in flow from the thermal barrier and borated reflector gaps passing laterally into the permanent side reflector gaps. The pressure in the permanent side reflector gaps also being higher than the active core gaps, radial inflow occurs from reflector gaps into the core gaps. Table 6-1 reflects this inflow by an axlally increasing flow in the core internal and external gaps. Also as a result of this lateral flow, the axial coolant flow along the length of the core decreases in the reflector gaps and increases in the core gaps, as shown in Table 6-1.

The coolant pressure in the upper reflector internal gaps is dependent upon the region flow control valve position. In regions with fully open flow control valves, the internal and external gap pressures are nearly identical. However, in regions with nearly closed flow control valves the internal gap pressure is low because the helium at the entrance to these internal gaps experiences the full flow control valve pressure drop. Flow is driven horizontally from the external gaps to the internal gaps in these low power regions. In regions where the flow control valve is nearly fully closed, an upward helium flow has been calculated in the internal gaps in the top reflector blocks. This flow is transferred from the external gaps horizontally to the internal gaps and upward to the flow control valve 
TABLE 6-1

CORE FLOW DISTRIBUTION IN "NO-CROSSFLOW" CASE (PERCENTAGE OF TOTAL FLOW)

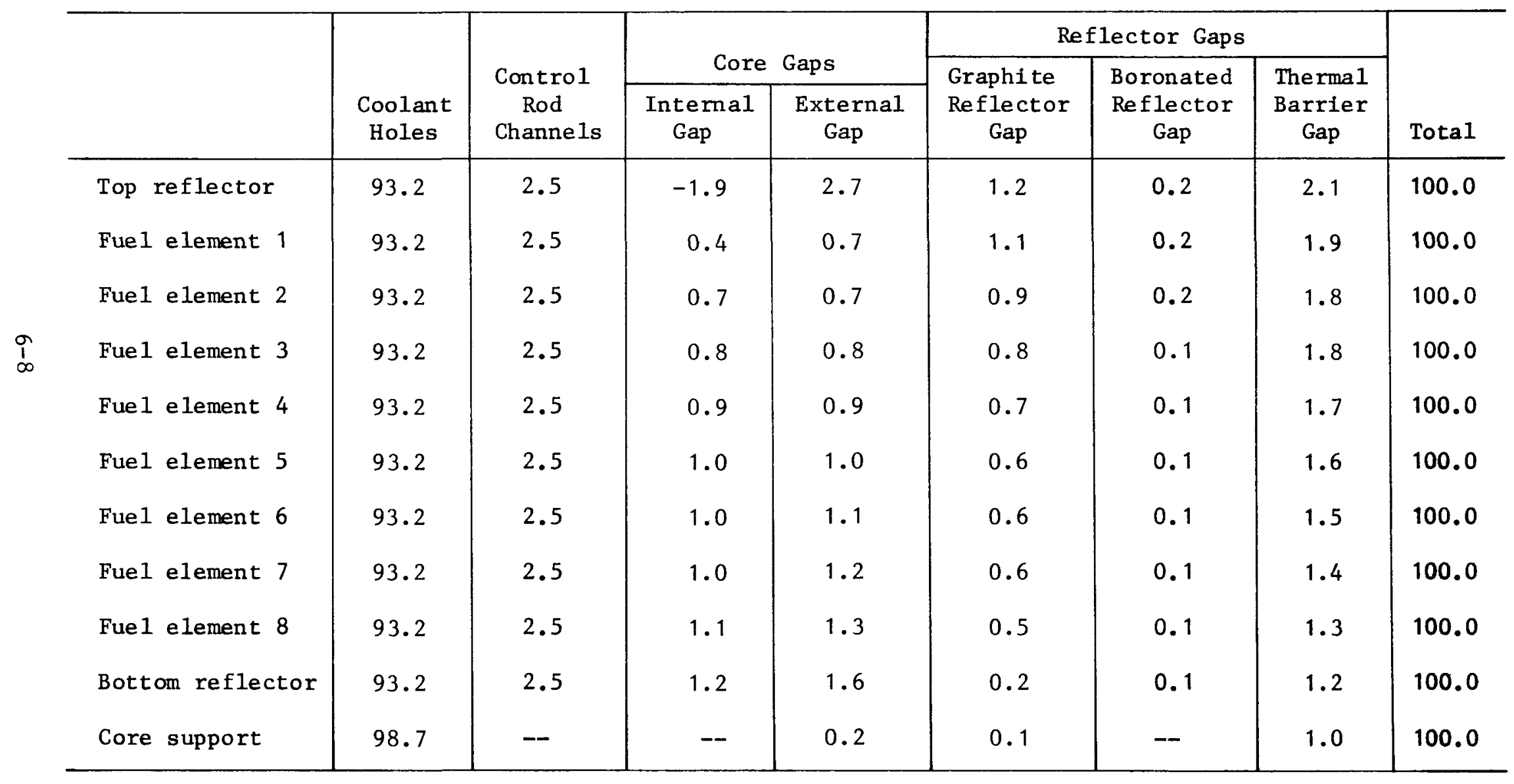




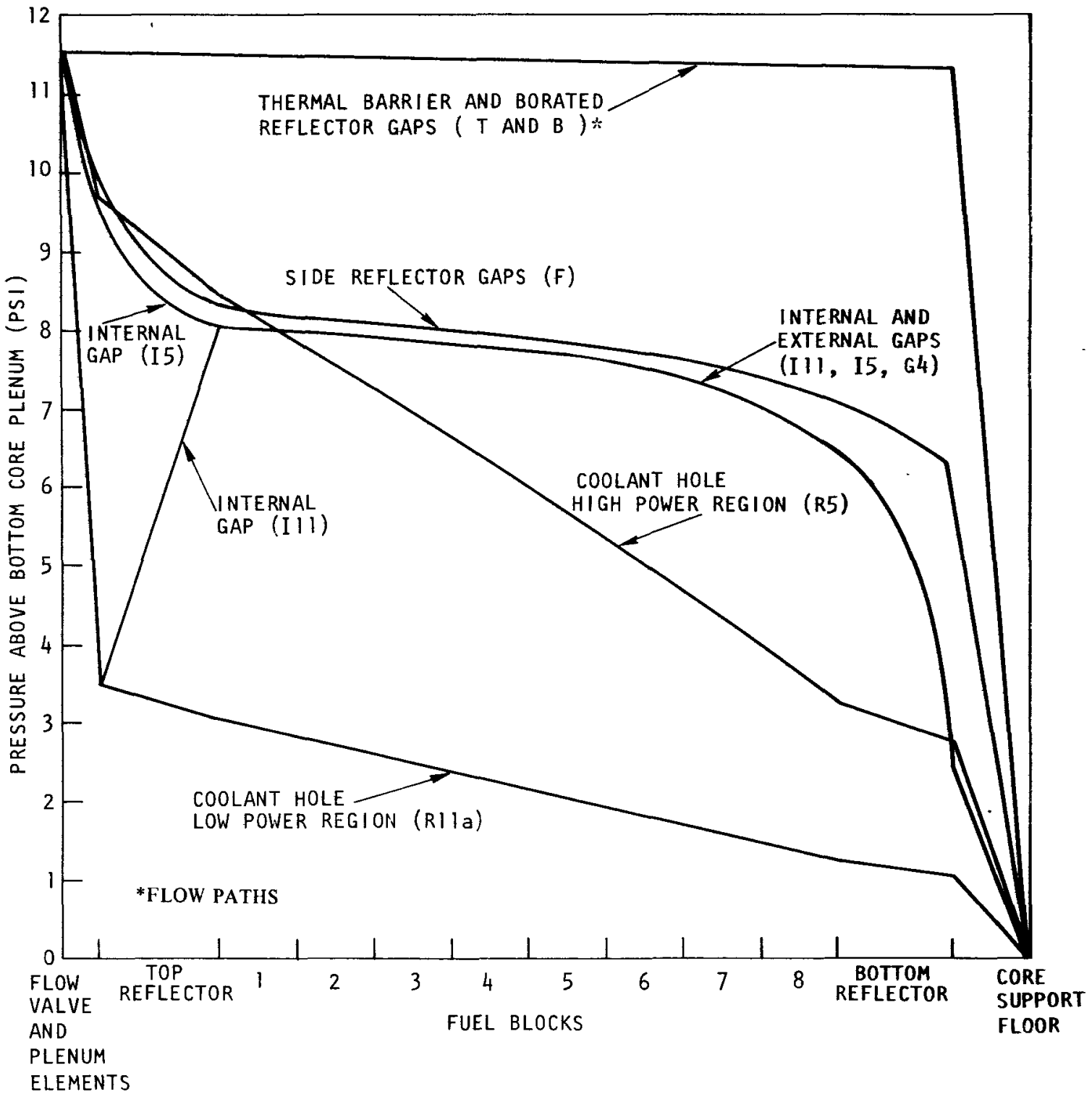

Fig. 6-1. Core coolant pressure distribution in "no crossflow" case (*Flow paths are defined in Fig. 4-1) 
plenum. In the orifice plenum it foins the flow entering through the flow control valve and passes down through the coolant holes. This flow is in effect a small leak around the closed-flow control valve that has been considered in the valve design. Similar upward flow in the upper reflector was measured in core flow tests of a three-region model of the Fort St. Vrain core (Ref. 6-2).

At the core support floor, the internal gaps, external gaps, and side reflector flows are effectively blocked by the narrow spaces between support blocks. At this point these gap flows pass into the lateral slots in the lower reflector blocks, join the coolant channel flow, and pass through the core support block into the lower plenum. In the no crossflow case the flow in coolant holes and control rod channels is constant along the length of the core as shown in Table 6-1.

Helium coolant passing through the core cavity flow passages removes the thermal energy generated in the fuel elements, control rods, and reflector elements. The core flow, power, and the hellum temperature distributions under no crossflow conditions are shown in Fig. 6-2. About $95 \%$ of the heat is removed by the helium flowing through the coolant channels. The helium flowing through the reflector gaps removes the relatively small fraction $(0.8 \%)$ of the total heat deposited there by gamma and neutron attenuation. About $2.8 \%$ of the helium exiting from the narrow core gaps between fuel columns is very effective in removing $2.5 \%$ of the total heat load (see Section 6.1.3). Two and one-half percent of helium flowing through the control rod coolant channels removes about $1.2 \%$ of the total heat while maintaining the control rod clad and compact temperature within design limits.

For the $3000 \mathrm{MW}(\mathrm{t})$ HTGR core a second extreme case was considered. Flow distribution was calculated considering horizontal crossflow paths between fuel blocks to account for potential fuel element bowing induced by 


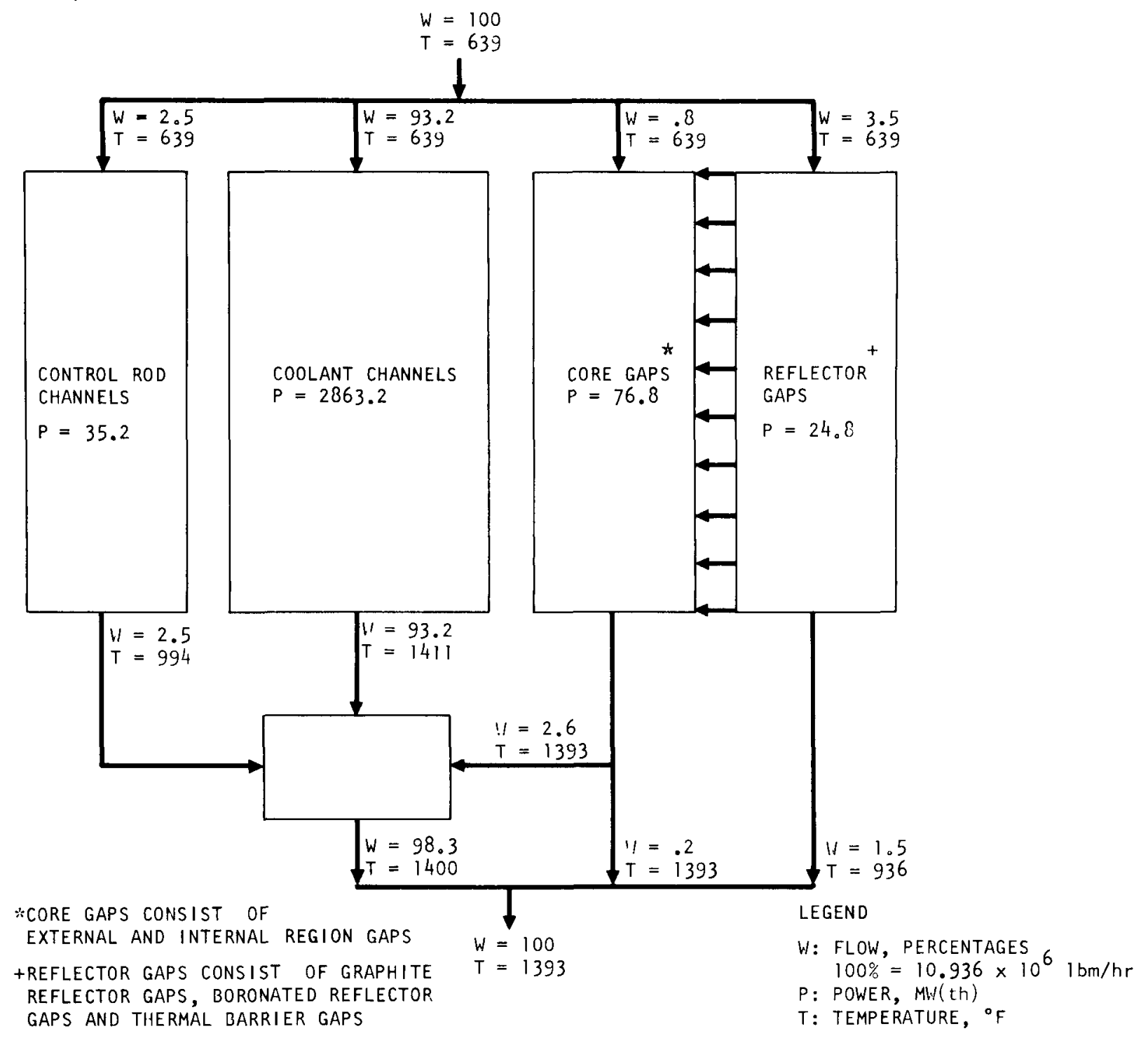

Fig. 6-2. Core power, flow, and coolant temperature in $3000 \mathrm{MW}(t)$ core "no crossflow" case 
fast neutron fluence. Generally the crossflow paths may occur near the core reflector boundary, where a fast neutron flux gradient exists. However, in flow distribution calculations with crossflow, a horizontal flow path of $0.01 \mathrm{in}$. was included between all fuel blocks in the core. These crossflow paths connect the internal gaps and the external gaps directly with the coolant channels at each horizontal interface between fuel blocks. Crossflow paths between the control rod channels and region internal gaps were also included to represent the axial transfer of coolant from the control rod channels.

Summary results for the crossflow case calculation are shown in Table 6-2 where the percentages of the total core cavity flow in each of the flow paths is given as a function of axial position. Figure 6-3 shows the pressure distribution in several of the core cavity flow paths. When the horizontal crossflow gaps are considered, there is an overall inward flow from the reflector gaps and core internal and external gaps into coolant holes. The total flow entering the reflector and core gap system from the core plenum is higher than for the no crossflow case. As a result, the helium flow entering the coolant channels through the flow valves has decreased as shown in Table 6-2. A fraction of the gap flow, however, enters the coolant channels at different axial levels and as a result the coolant channel helium flow increases from the top of the core to the bottom. The control rod channel flow is also decreased in the lower portion of the core as a result of crossflow from the control rod channel into the coolant channel. The decreased internal and external gap pressures resulting from crossflow result in an increased inward flow from the borated reflector and thermal barrier gaps, thus contributing to active core gap flow.

Figure 6-3 shows the coolant hole pressure distribution under crossflow conditions for both high power and low power regions. For the high power region, the external gap, internal gap, and reflector gap 
TABLE 6-2

CORE FLOW DISTRIBUTION IN 10 MIL "CROSSFLOW" CASE

(PERCENTAGE OF TOTAL FLOW)

\begin{tabular}{|c|c|c|c|c|c|c|c|c|}
\hline & \multirow[b]{3}{*}{$\begin{array}{c}\text { Coolant } \\
\text { Holes }\end{array}$} & \multirow{3}{*}{$\begin{array}{l}\text { Con trol } \\
\text { Rod } \\
\text { Channels }\end{array}$} & \multirow{2}{*}{\multicolumn{2}{|c|}{ Core Gaps }} & \multicolumn{3}{|c|}{ Reflector Gaps } & \multirow[b]{3}{*}{ Total } \\
\hline & & & & & \multirow{2}{*}{$\begin{array}{c}\text { Graphite } \\
\text { Reflector } \\
\text { Gap }\end{array}$} & \multirow{2}{*}{$\begin{array}{c}\text { Boronated } \\
\text { Reflector } \\
\text { Gap }\end{array}$} & \multirow{2}{*}{$\begin{array}{c}\text { Thermal } \\
\text { Barrier } \\
\text { Gap }\end{array}$} & \\
\hline & & & $\begin{array}{c}\text { Internal } \\
\text { Gap }\end{array}$ & $\begin{array}{c}\text { External } \\
\text { Gap }\end{array}$ & & & & \\
\hline Top reflector & 84.8 & 7.3 & -0.3 & 3.9 & 1.8 & 0.3 & 2.2 & 100.0 \\
\hline Fuel element 1 & 85.5 & 7.0 & 1.7 & 1.9 & 1.7 & 0.2 & 2.0 & 100.0 \\
\hline Fuel element 3 & 87.8 & 6.0 & 1.5 & 1.5 & 1.2 & 0.2 & 1.8 & 100.0 \\
\hline Fuel element 4 & 89.0 & 5.5 & 1.3 & 1.4 & 1.0 & 0.1 & 1.7 & 100.0 \\
\hline Fuel element 5 & 90.1 & 5.0 & 1.1 & 1.3 & 0.8 & 0.1 & 1.6 & 100.0 \\
\hline Fuel element 8 & 93.4 & 3.3 & 0.7 & 0.8 & 0.4 & 0.1 & 1.3 & 100.0 \\
\hline Bottom reflector & 95.1 & 2.2 & 0.5 & 0.7 & 0.2 & 0.1 & 1.2 & 100.0 \\
\hline Core support & 98.7 & -- & -- & 0.2 & 0.1 & -- & 1.0 & 100.0 \\
\hline
\end{tabular}




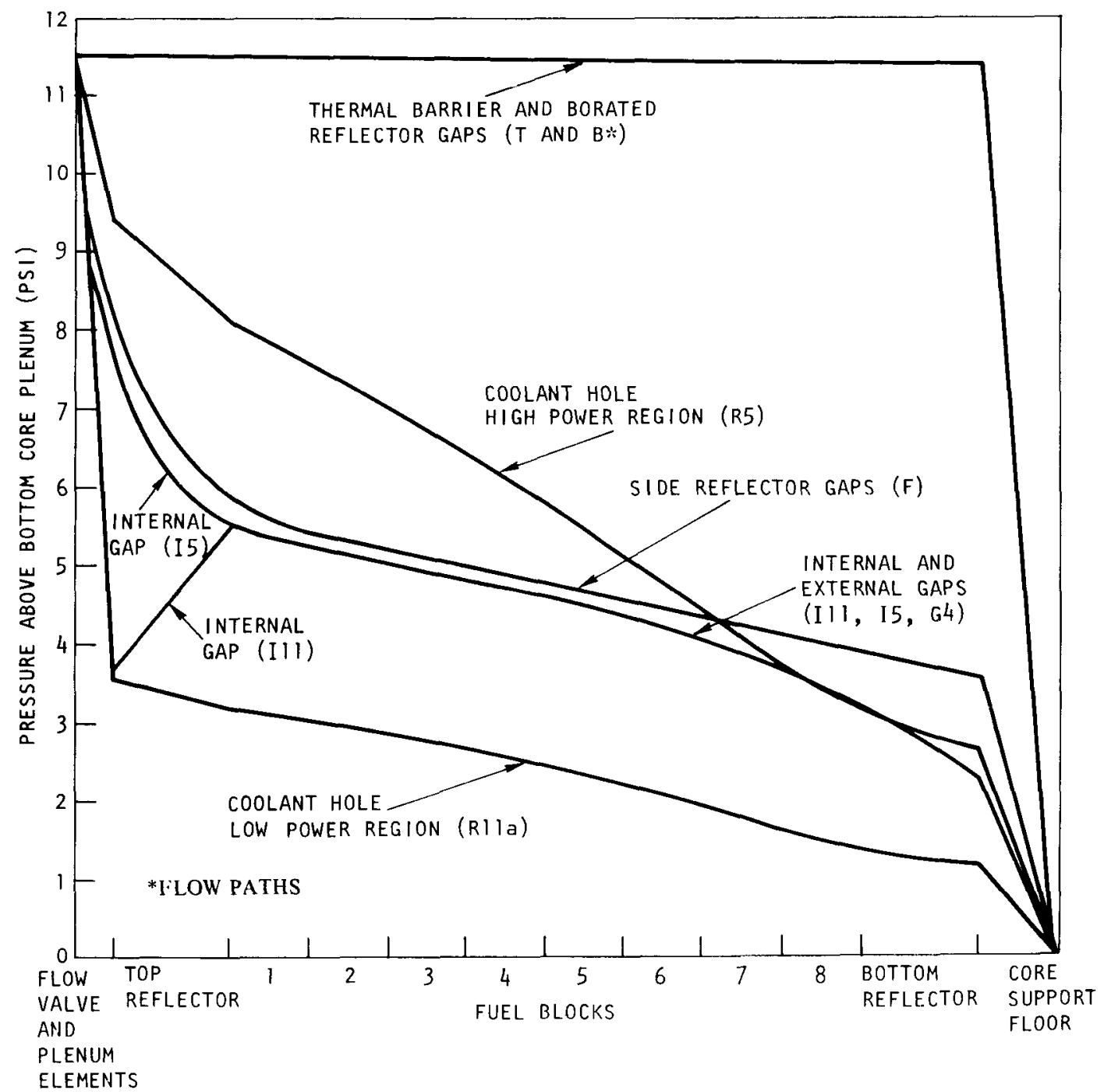

Fig. 6-3. Core coolant pressure distribution in "crossflow" case (*Flow paths are defined in Fig. 4-1) 
pressures are lower than the coolant hole pressure and an outward flow of coolant results in the top reflector and most of the active core length. In a low power region, where the flow control valve is nearly closed, the coolant hole pressure is much lower than the gap pressure and flow is driven inward into the coolant holes.

The coolant exit temperature distribution and relative heat removed in the core cavity flow paths under crossflow conditions are given in Fig. 6-4. As a result of more helium flowing through the gaps between fuel columns, the fraction of heat removed in the gaps is increased, as shown in Fig. 6-4. The mode of heat transfer from the fuel rod into the internal and external gaps is discussed in Section 6.1.3.

Region crossflow factors have been derived from the one-sixth core FLAC model calculations as a function of region power factor (related to the flow valve position) and core axial position. These crossflow factors are defined as

Crossflow factor $=\frac{\text { Coolant channel flow in region at axial level } i}{\text { Coolant channel flow at core exit }}$

If the crossflow factor $>1.0$, an outflow is indicated; if the crossflow factor $<1.0$, an inflow is indicated. Table 6-3 gives calculated crossflow factors for a high power region, $P(r)=1.6$, and a low power region, $P(r)=0.5$. Also shown are more conservative values of design crossflow factors currently used in thermal analysis. Figure 6-5 presents curves of calculated crossflow factors as a function of axial position and region power factor which have been derived from this extreme crossflow case. Figure 6-6 shows the flow distribution in a high power region using design crossflow factors. About $20 \%$ more flow enters the orifice valve, and as it flows through the coolant holes in that region a part of the flow escapes through the interfacial gaps into the gaps between fuel columns. Another extreme flow pattern in a low power region with the flow control valve near 


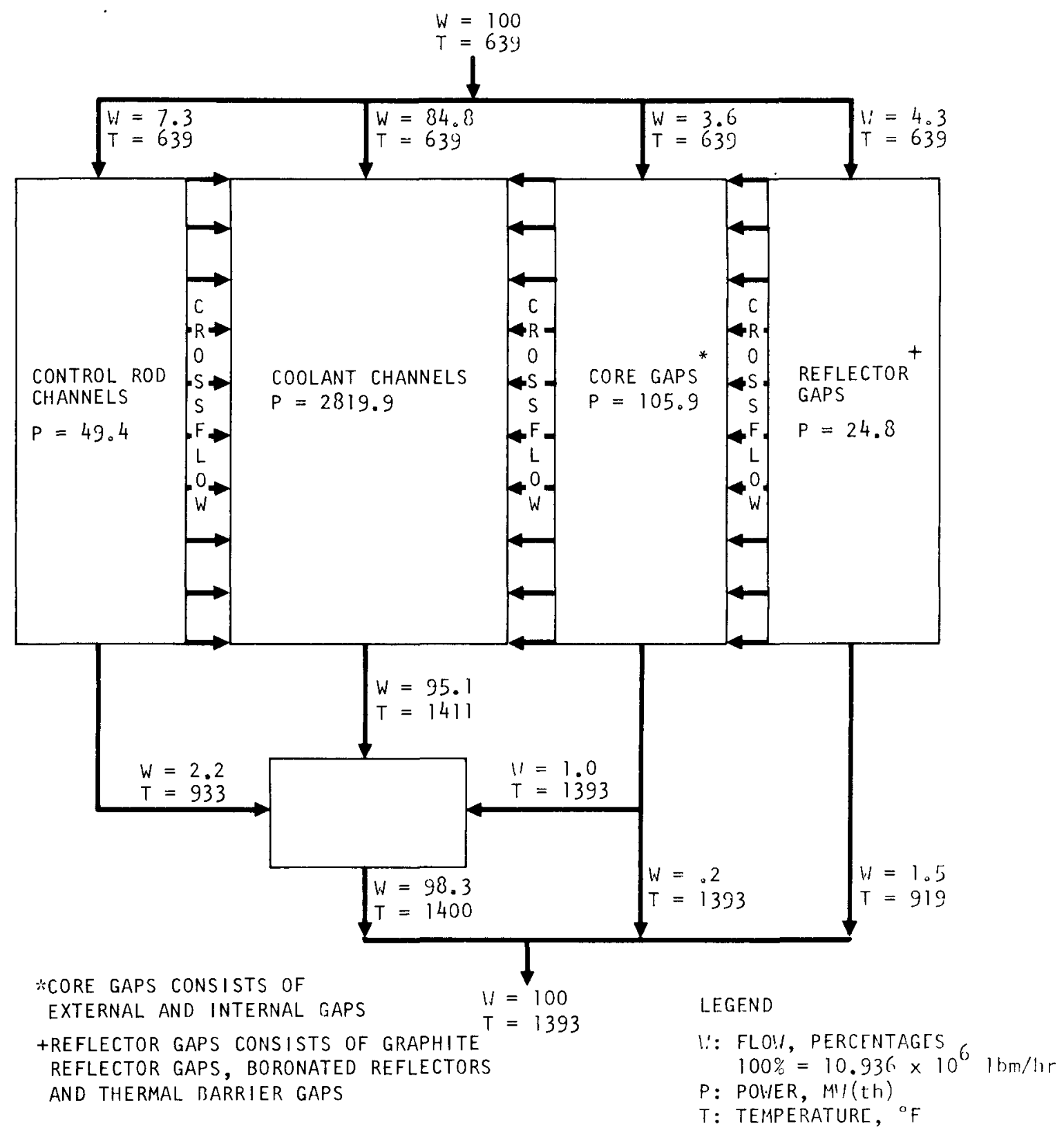

Fig. 6-4. Core power, flow, and coolant temperature distribution in $3000 \mathrm{MW}(t)$ core in "crossflow" case 
TABLE 6-3

REGION CROSSFLOW FACTORS FOR HIGH AND LOW POWER REGIONS

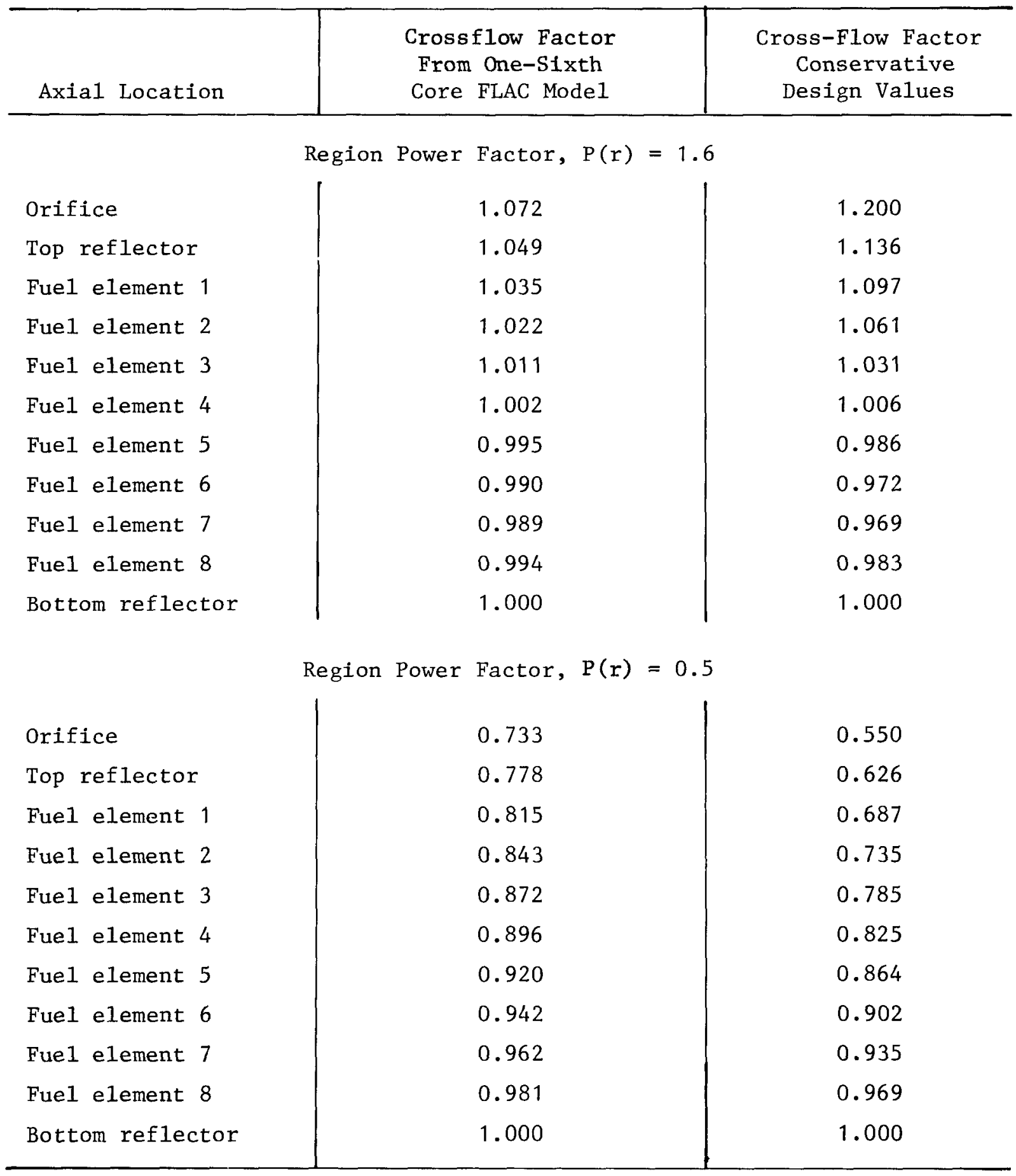




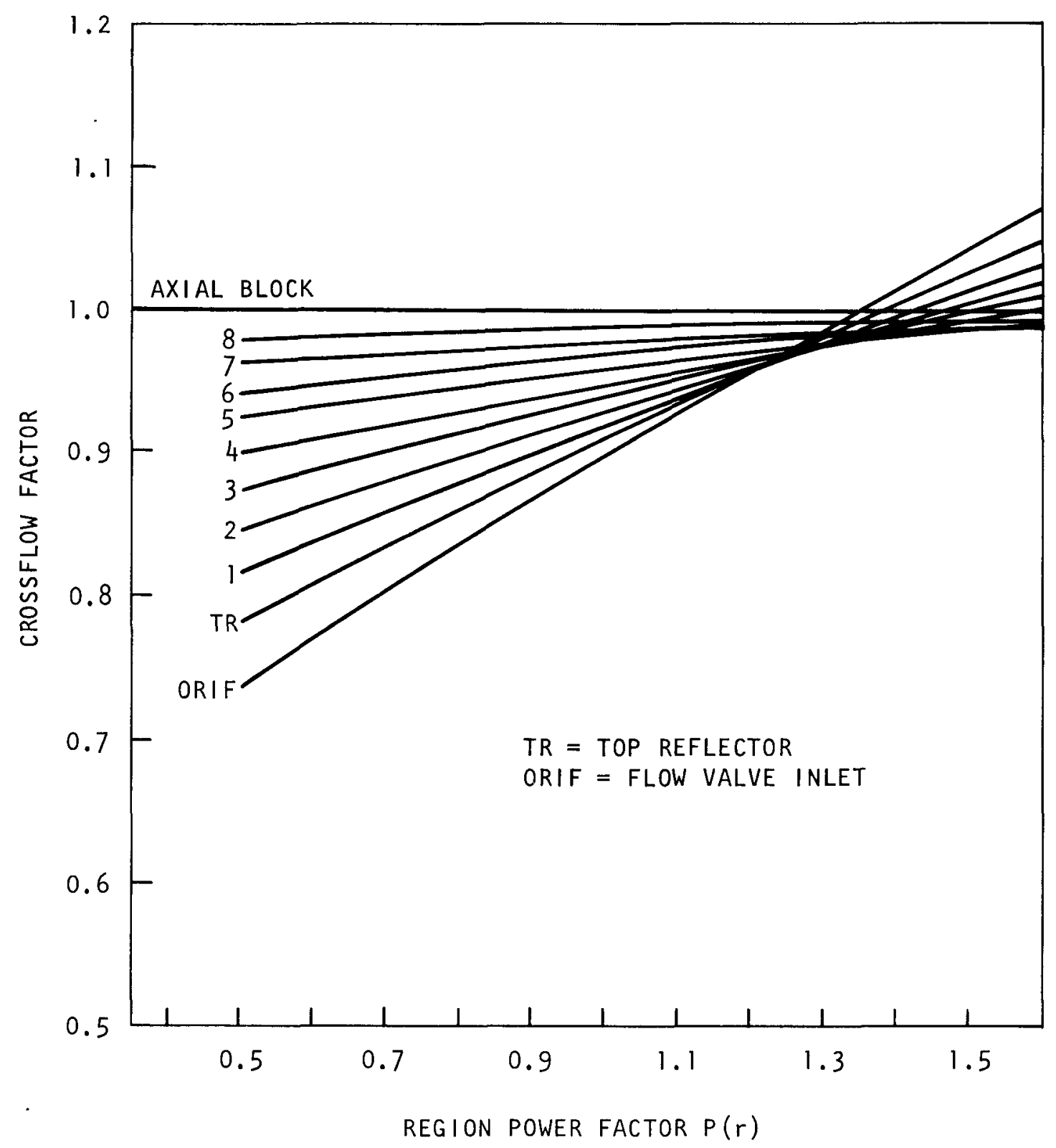

Fig. 6-5. Crossflow factors as a function of region power peaking factor 


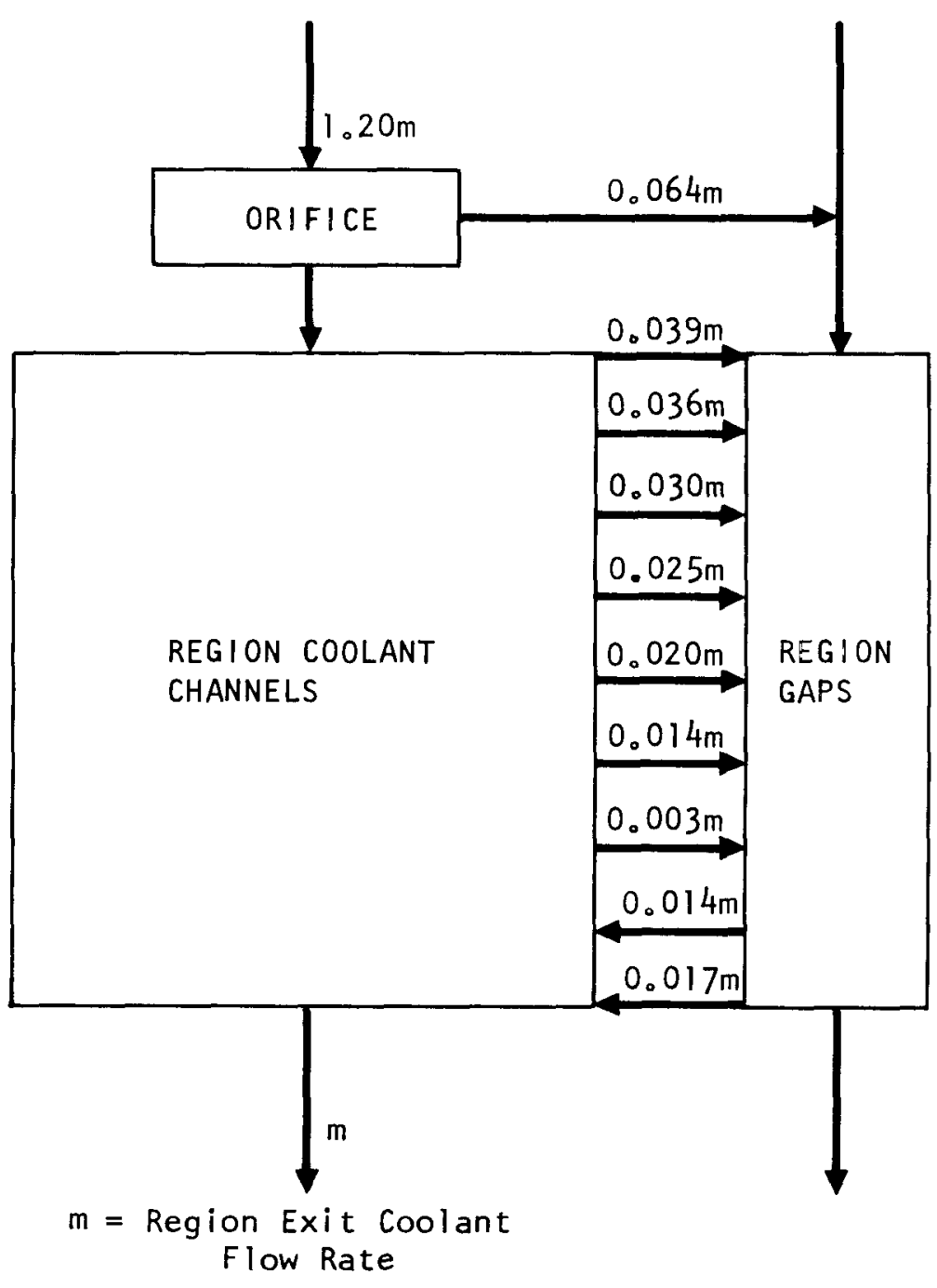

Fig. 6-6. Region crossflow model with open flow control valve 
the closed position is shown in Fig. 6-7. In this case, about $45 \%$ of region exit flow enters from the gaps between fuel columns into the coolant channel. The effect of crossflow on local fuel temperature is discussed in Section 6.1 .4 .

Many of the flow resistances used in the one-sixth core model are obtained either from the flow tests conducted for the Fort St. Vrain reactor (Refs. 6-3 and 6-4) or for various geometries reported in the literature (Refs. 6-5 and 6-6) described in Section 5.3. General Atomic is presently undertaking a full-scale flow test of individual core components including the flow control valve, top reflector, bottom reflector, and core support block. Also, experiments are planned to carry out full-scale region flow tests with and without simulated horizontal crossflow gaps at fuel element interfaces. Meanwhile, in the thermal analysis a conservative core power, flow, and coolant temperature distribution is used, as shown in Fig. 6-8, to account for crossflow in the core cavity. This core power and flow distribution results in higher coolant hole exit gas temperatures than coolant hole exit temperatures under the no crossflow or crossflow cases shown in Figs, 6-2 and 6-4.

\subsubsection{POKE Thermal Analysis}

The thermal analysis code POKE, described in Section 4.1.2, is used to calculate power and flow split between variable and fixed orifice regions and also to provide a correlation that can be used to predict the local channel coolant outlet temperature within a refueling region. To obtain these two types of results, the POKE code is used to perform two types of analysis: (1) the region average analysis of the entire core, which provides the region flow distribution, flow control valve positions, and core pressure drop as well as the flow and coolant temperature distribution in variable and fixed orifice regions, and (2) the subregion analysis, which provides a correlation used to calculate local coolant exit 


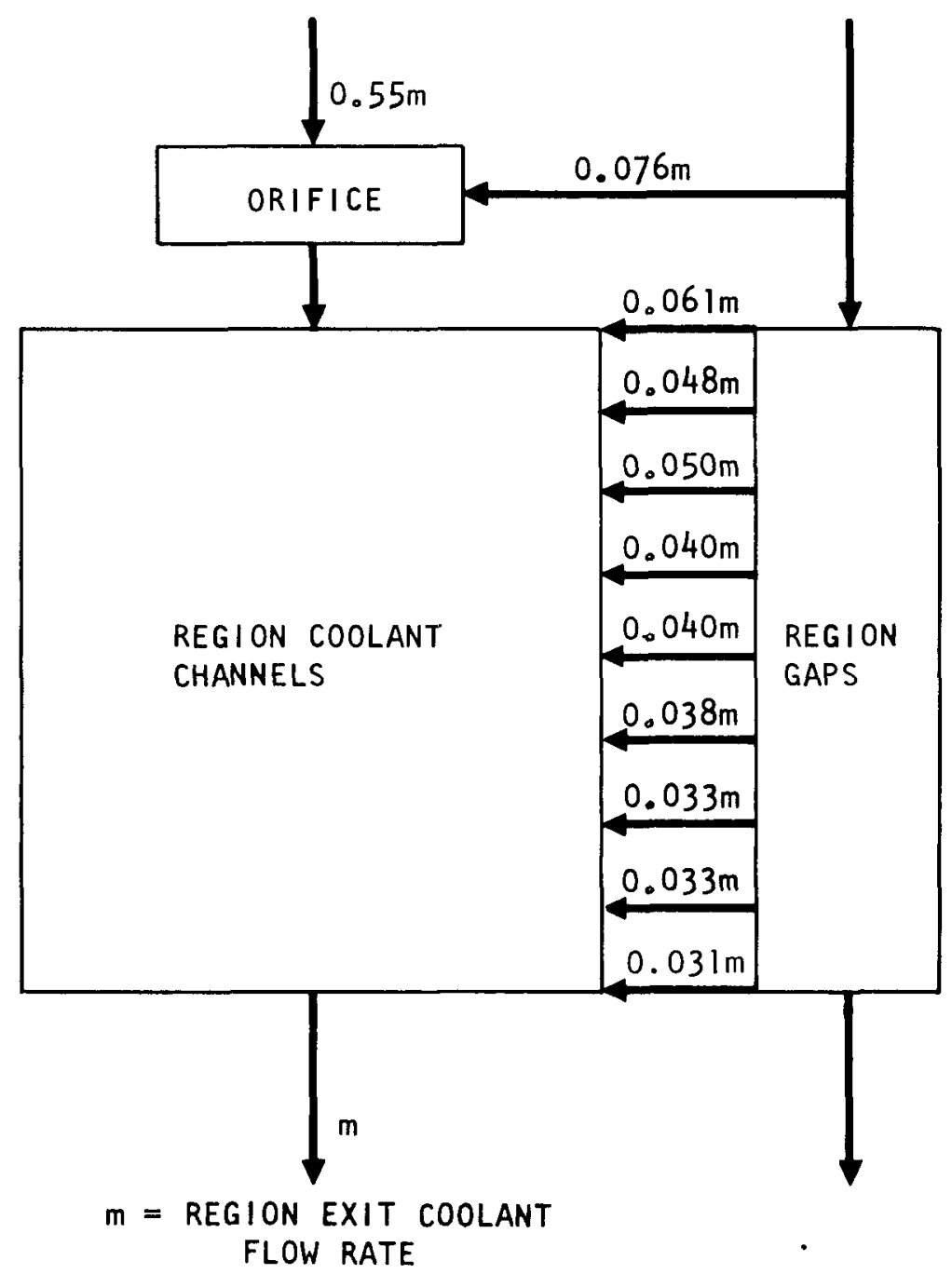

Fig. 6-7. Region crossflow model with near closed flow control valve 


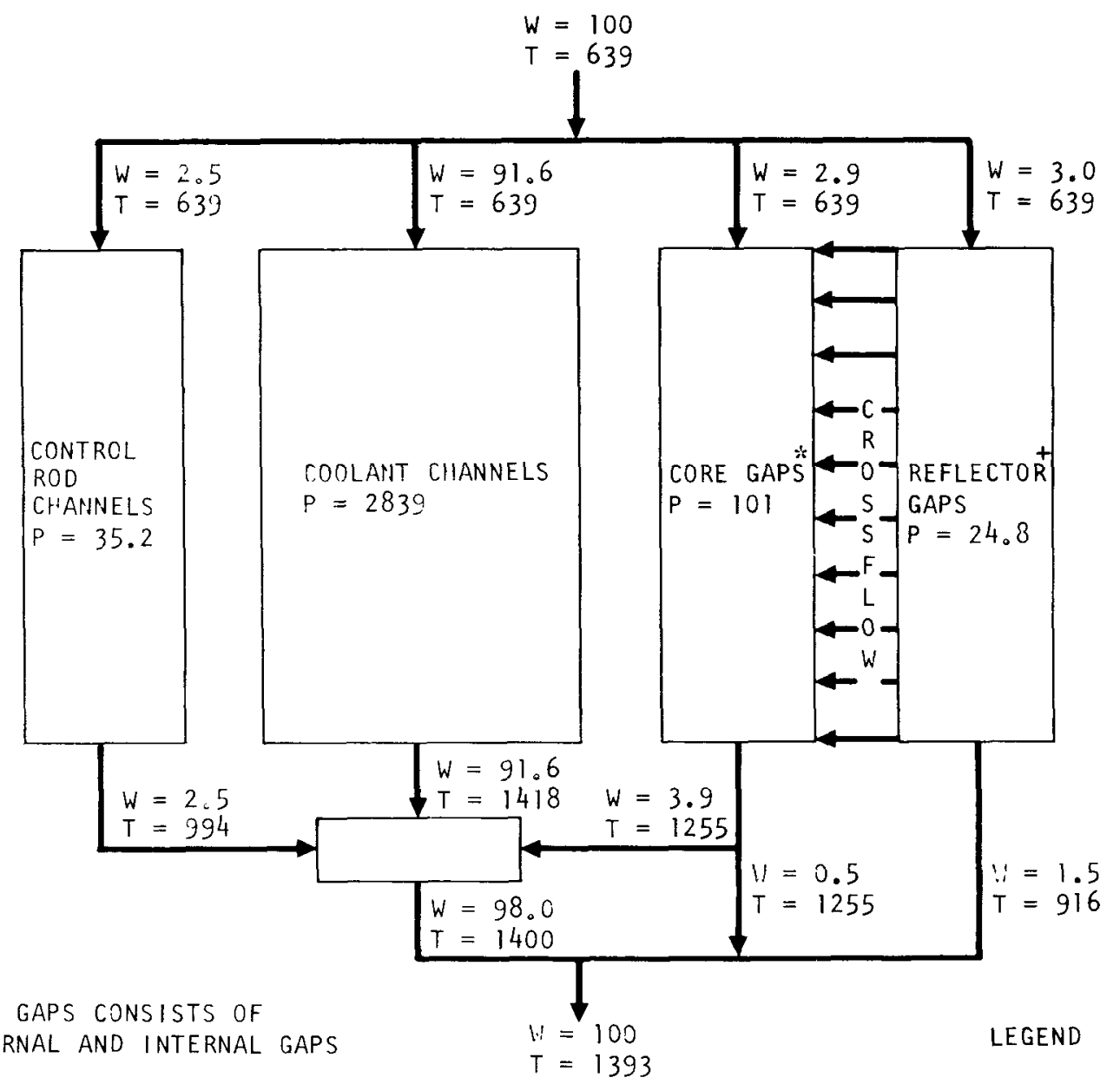

EXTERNAL AND INTERNAL GAPS

$T=1393$

+ REFLECTOR GAPS CONSISTS OF

GRAPHITE REFLECTOR GAPS,

BORONATED REFLECTOR GAPS AND

THERMAL BARRIER GAPS.

\author{
U: FLOW, PERCENTAGE \\ $100 \%=10.936 \times 10^{6} \mathrm{lbm} / \mathrm{hr}$ \\ D: POWER, MW(th) \\ $T$ : TEMPERATURE, ${ }^{\circ} \mathrm{F}$
}

Fig. 6-8. Core power, flow, and coolant temperature distribution in 3000 MW(t) core in "Design" case 
temperatures within a refueling region. This correlation is used in the TREVER analysis (Section 6.1.5) to calculate the local coolant channel temperature and mass flow. The results from these two types of POKE analysis are discussed below.

6.1.2.1. Region Average POKE Analysis. During core operation, the power distribution among the regions changes because of fuel and burnable poison burnup and control rod motion. POKE code analyses are carried out to find the impact of these power distribution changes on region flow control valve positions, region coolant flow, core pressure drop, and region coolant exit temperatures.

Table 6-4 shows the region average flow through each of the 73 variable orifice regions and 18 fixed orifice fuel columns at each of the 11 time points during the seventh year of core operation. The corresponding flow control valve coefficients required to attain equal coolant exit temperature in each region with a valve are shown in Table 6-5.

As can be seen, for most of the regions changes required in the position of the flow control valve are very slow as a function of time. In the shim rodded regions, the flow control valve positions do not significantly change for the first 200 days of operation of each cycle, but during the last 92 days the flow control valves are slowly opened as the shim rods are withdrawn. The effect shim rod withdrawal has on the neighboring region orifice position requirements is rather modest.

Tables 6-4 and 6-5 also show the helium flow and flow control valve coefficient for 12 four-column partial regions and 18 single-column fixed orifice columns. The flow required through the four-column partial regions is lower so the flow control valves are more nearly closed than those on the seven-column region. 
TABLE 6-4

REGION FLOW DISTRIBUTION DURING SEVENTH YEAR OF 3000-MW( $(t)$ CORE OPERATION

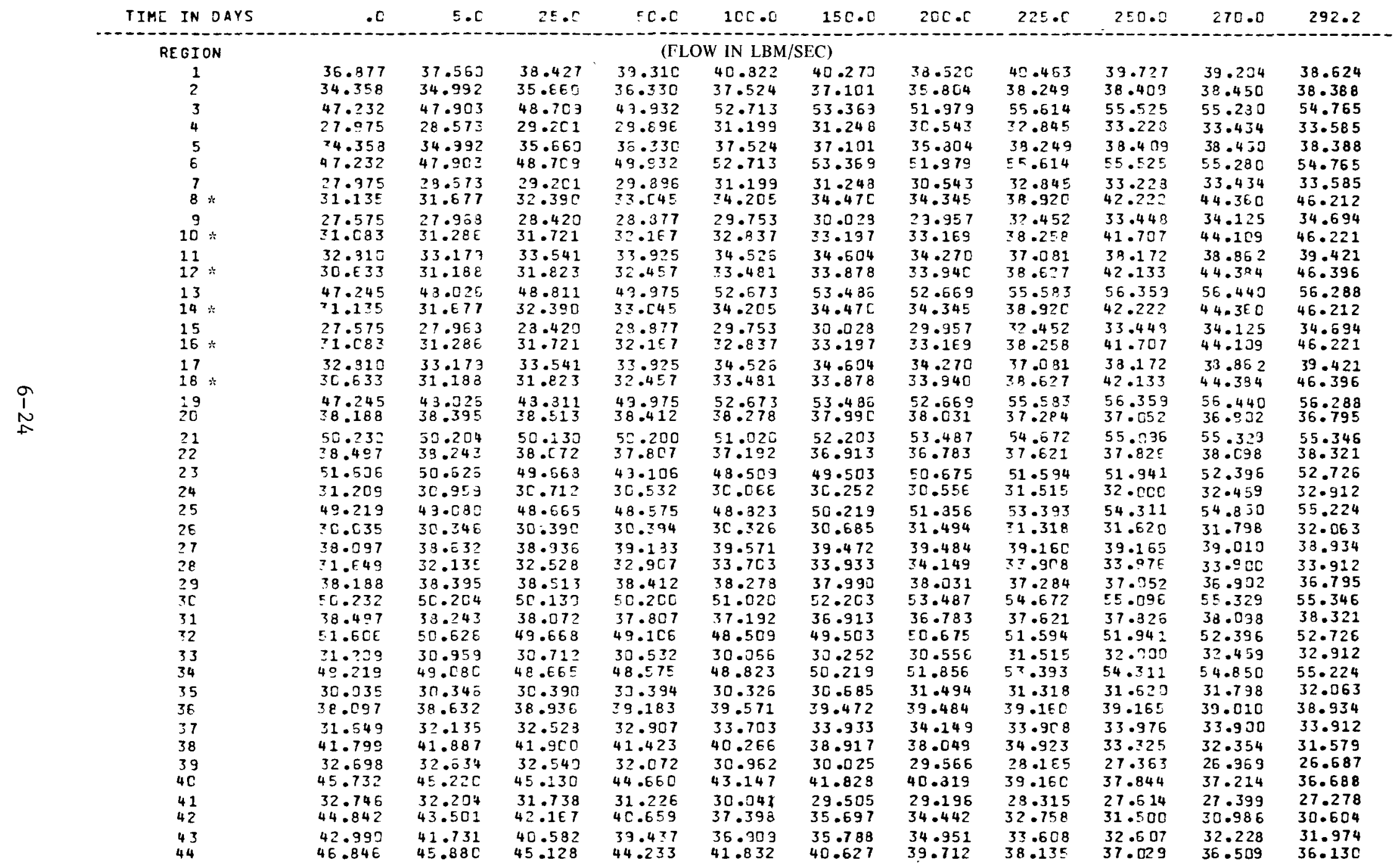

* $8,10,12,14,16$, AND 18 ARE RODDED REGIONS 
TABLE 6-4 (Continued)

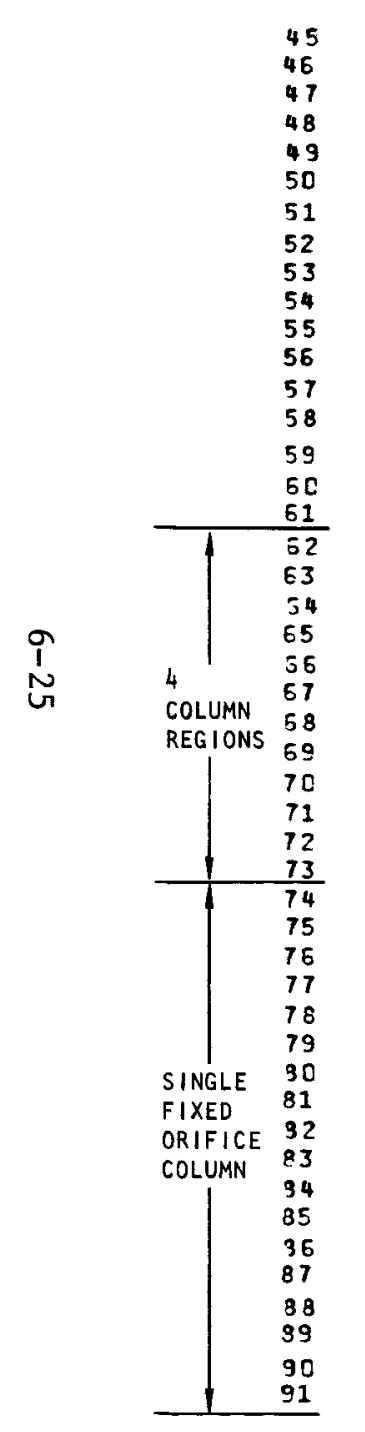

\begin{tabular}{|c|c|c|c|}
\hline $\begin{array}{r}37.532 \\
4 C .284 \\
47.134 \\
44.060 \\
50.523 \\
41.799\end{array}$ & $\begin{array}{l}37.277 \\
40.432 \\
47.711 \\
44.622 \\
51.033 \\
41.887\end{array}$ & $\begin{array}{r}36.686 \\
40.156 \\
47.770 \\
45.152 \\
51.303 \\
41.900\end{array}$ & $\begin{array}{l}35.835 \\
39.482 \\
48.142 \\
45.579 \\
51.889 \\
41.423\end{array}$ \\
\hline $\begin{array}{l}32.598 \\
45.732 \\
32.746 \\
44.842 \\
42.990 \\
46.846\end{array}$ & $\begin{array}{l}32.534 \\
45.220 \\
32.204 \\
43.501 \\
41.731 \\
45.880\end{array}$ & $\begin{array}{l}32.540 \\
45.130 \\
31.738 \\
42.167 \\
40.582 \\
45.128\end{array}$ & $\begin{array}{l}32.072 \\
44.660 \\
31.226 \\
40.659 \\
39.437 \\
44.233\end{array}$ \\
\hline 37.532 & 37.277 & 36.686 & 35.835 \\
\hline 40.284 & 40.482 & 40.156 & 33.432 \\
\hline $\begin{array}{l}47.104 \\
44.360 \\
50.623\end{array}$ & $\begin{array}{l}47.711 \\
44.622 \\
51.033\end{array}$ & $\begin{array}{l}47.770 \\
45.152 \\
51.303\end{array}$ & $\begin{array}{l}48.142 \\
45.579 \\
51.889\end{array}$ \\
\hline $\begin{array}{l}18.594 \\
26.148 \\
28.714\end{array}$ & $\begin{array}{l}13.573 \\
25.749 \\
27.924\end{array}$ & $\begin{array}{l}13 \cdot 407 \\
25.357 \\
25.902\end{array}$ & $\begin{array}{l}17.982 \\
24.926 \\
26.092\end{array}$ \\
\hline 16.054 & 15.842 & 15.497 & $\begin{array}{l}25 . C 92 \\
15 . C E B\end{array}$ \\
\hline $\begin{array}{l}14.771 \\
18.921\end{array}$ & $\begin{array}{l}15.237 \\
19.218\end{array}$ & $\begin{array}{l}15.202 \\
19.328\end{array}$ & $\begin{array}{l}15.341 \\
19.431\end{array}$ \\
\hline $\begin{array}{l}18.694 \\
26.148\end{array}$ & $\begin{array}{l}18.573 \\
25.749\end{array}$ & $\begin{array}{l}18.407 \\
25.357\end{array}$ & $\begin{array}{l}17.982 \\
24.926\end{array}$ \\
\hline $\begin{array}{l}28.714 \\
16.054 \\
14.771 \\
18.921\end{array}$ & $\begin{array}{l}27.324 \\
15.842 \\
15.037 \\
19.218\end{array}$ & $\begin{array}{l}26.902 \\
15.497 \\
15.262 \\
19.323\end{array}$ & $\begin{array}{l}25.092 \\
15.068 \\
15.341 \\
19.431\end{array}$ \\
\hline $\begin{array}{l}8.463 \\
8.190 \\
8.303\end{array}$ & $\begin{array}{l}8.357 \\
8.085 \\
8.308\end{array}$ & $\begin{array}{l}8.416 \\
8.147 \\
8.383\end{array}$ & $\begin{array}{l}8.552 \\
6.293 \\
8.530\end{array}$ \\
\hline 8.051 & 7.291 & $8 . C 88$ & 8.244 \\
\hline $\begin{array}{l}7.971 \\
8.201 \\
7.945 \\
8.241\end{array}$ & $\begin{array}{l}7.315 \\
8.16 E \\
7.315 \\
8.118\end{array}$ & $\begin{array}{l}8.021 \\
8.261 \\
7.365 \\
8.168\end{array}$ & $\begin{array}{l}8.192 \\
8.409 \\
7.964 \\
8.279\end{array}$ \\
\hline $\begin{array}{l}7.932 \\
8.463\end{array}$ & $\begin{array}{l}7.362 \\
3.357\end{array}$ & $\begin{array}{l}7.903 \\
8.416\end{array}$ & $\begin{array}{l}7.989 \\
8.552\end{array}$ \\
\hline $\begin{array}{l}8.190 \\
8.393\end{array}$ & $\begin{array}{l}3.095 \\
8.309\end{array}$ & $\begin{array}{l}8.147 \\
8.288\end{array}$ & $\begin{array}{l}8.293 \\
8.530\end{array}$ \\
\hline $\begin{array}{l}3.051 \\
7.971\end{array}$ & $\begin{array}{l}7.991 \\
7.915\end{array}$ & $\begin{array}{l}8.088 \\
8.021\end{array}$ & $\begin{array}{l}3.244 \\
8.192\end{array}$ \\
\hline $\begin{array}{l}8.291 \\
7.945\end{array}$ & $\begin{array}{l}8.185 \\
7.815\end{array}$ & $\begin{array}{l}8.261 \\
7.665\end{array}$ & $\begin{array}{l}8.409 \\
7.964\end{array}$ \\
\hline $\begin{array}{l}8.241 \\
7.982\end{array}$ & $\begin{array}{l}8.118 \\
7.862\end{array}$ & $\begin{array}{l}8.163 \\
7.963\end{array}$ & $\begin{array}{l}8.279 \\
7.989\end{array}$ \\
\hline
\end{tabular}

33.819
37.784
49.496
46.176
53.913
40.266
30.952
43.147
30.041
37.398
36.909
41.832
33.819
37.784
49.496
46.176
53.910
16.902
23.900
24.344
14.011
15.646
19.667
16.902
23.900
24.344
14.011
15.645
19.667
3.992
8.753
8.376
8.724
8.700
8.874
8.307
8.661
8.296
8.992
8.753
8.976
8.724
8.700
8.874
8.307
8.561
8.296

32.862
36.959
51.645
46.167
55.657
38.917
30.025
41.828
29.505
35.697
35.788
40.627
32.862
36.959
51.645
46.167
55.667
15.950
23.032
23.391
13.435
15.963
19.672
15.953
23.032
23.391
13.435
15.968
19.672
9.375
9.160
3.343
9.109
9.103
9.254
8.580
8.973
8.581
9.376
9.160
9.343
9.109
9.103
9.254
$8.58 E$
8.973
3.581

\begin{tabular}{|c|c|}
\hline $\begin{array}{l}32.489 \\
36.974\end{array}$ & $\begin{array}{l}31.014 \\
34.290\end{array}$ \\
\hline $\begin{array}{l}54.782 \\
46.535 \\
57.434 \\
38.049\end{array}$ & $\begin{array}{r}51.974 \\
43.225 \\
53.496 \\
34.923\end{array}$ \\
\hline $\begin{array}{l}29.566 \\
40.819 \\
29.195 \\
34.442 \\
34.951 \\
39.712 \\
32.489\end{array}$ & $\begin{array}{l}28.165 \\
39.160 \\
28.315 \\
32.758 \\
33.608 \\
38.135 \\
31.014\end{array}$ \\
\hline 36.374 & 34.290 \\
\hline 54.782 & 51.974 \\
\hline $\begin{array}{l}46.535 \\
57.434\end{array}$ & $\begin{array}{l}43.225 \\
53.496\end{array}$ \\
\hline $\begin{array}{l}15.260 \\
22.208\end{array}$ & $\begin{array}{l}14.214 \\
20.799\end{array}$ \\
\hline $\begin{array}{l}22.459 \\
13.030\end{array}$ & $\begin{array}{r}2 \pi .975 \\
12.267\end{array}$ \\
\hline $\begin{array}{l}16.572 \\
19.811\end{array}$ & $\begin{array}{l}15.358 \\
18.0 C 5\end{array}$ \\
\hline $\begin{array}{l}15.250 \\
22.208\end{array}$ & $\begin{array}{l}14.214 \\
20.799\end{array}$ \\
\hline $\begin{array}{l}22.459 \\
13.030 \\
16.572 \\
19.811\end{array}$ & $\begin{array}{l}20.975 \\
12.267 \\
15.308 \\
18.005\end{array}$ \\
\hline $\begin{array}{l}9.742 \\
9.544 \\
9.701 \\
9.48 B\end{array}$ & $\begin{array}{l}3.473 \\
9.301 \\
9.413 \\
9.223\end{array}$ \\
\hline $\begin{array}{l}9.493 \\
9.611 \\
8.846 \\
9.261 \\
8.879\end{array}$ & $\begin{array}{l}9.229 \\
9.349 \\
3.644 \\
9.078 \\
3.690\end{array}$ \\
\hline 9.742 & 0.473 \\
\hline $\begin{array}{l}9.544 \\
9.701\end{array}$ & $\begin{array}{l}9.301 \\
9.413\end{array}$ \\
\hline $\begin{array}{l}9.488 \\
9.493\end{array}$ & $\begin{array}{l}9.223 \\
9.229\end{array}$ \\
\hline $\begin{array}{l}9.611 \\
8.846\end{array}$ & $\begin{array}{l}9.349 \\
8.644\end{array}$ \\
\hline $\begin{array}{l}9.261 \\
8.879\end{array}$ & $\begin{array}{l}9.028 \\
8.69 \mathrm{C}\end{array}$ \\
\hline
\end{tabular}

30.291
33.171
51.124
41.815
51.723
33.325
27.363
37.844
27.514
31.500
32.507
37.029
30.291
33.171
51.124
41.915
51.723
13.537
19.764
19.947
12.447
14.391
17.245
13.537
19.754
19.947
12.447
14.991
17.245
9.653
9.492
9.533
9.412
9.425
9.524
8.333
9.204
8.992
9.651
9.492
9.588
9.412
9.420
9.524
8.833
9.204
8.892

29.910

32.436

29.682 39.948 $50.323 \quad 49.157$ $32.354 \quad 31.579$

25.96925 .687 $37.214 \quad 36.588$ 27.39927 .278 $30.986 \quad 30.604$ $32.228 \quad 31.979$ $36.509 \quad 36.130$ $\begin{array}{ll}29.910 & 29.682 \\ 32.436 & 31.930\end{array}$ $50.346 \quad 49.757$ $40.753 \quad 39.948$ $\begin{array}{ll}40.753 & 39.948 \\ 50.323 & 49.157\end{array}$ $13.208 \quad 12.963$ $19.2 E 5 \quad 18.864$ $19.448 \quad 19.067$ $12.473 \quad 12.446$ $\begin{array}{ll}14.590 & 14.403\end{array}$ $13.208 \quad 12.953$ $19.265 \quad 18.854$ $19.448 \div 19.067$ $12.473 \quad 12.446$ $14.590 \quad 14.403$ $16.711 \quad 16.314$ $9.537 \quad 9.531$ $9.617 \quad 9.598$ $9.450 \quad 9.438$ $9.459 \quad 9.448$ $9.560 \quad 9.545$ $8.837 \quad 8.889$ $9.247 \quad 9.238$ $3.952 \quad 8.959$ $9.686 \quad 9.572$ $9.537 \quad 9.531$ 9.6179 .598 $9.450 \quad 9.438$ $9.450 \quad 9.438$ $9.459 \quad 9.448$ $9.550 \quad 3.545$ $8.887 \quad 8.889$ $\begin{array}{ll}9.247 & 9.238 \\ 8.952 & 8.959\end{array}$ 
EXPECTED FLOW CONTROL VALVE COEFFICIENT (a) DURING SEVENTH YEAR OF 3000-MW( $t$ ) CORE OPERATION

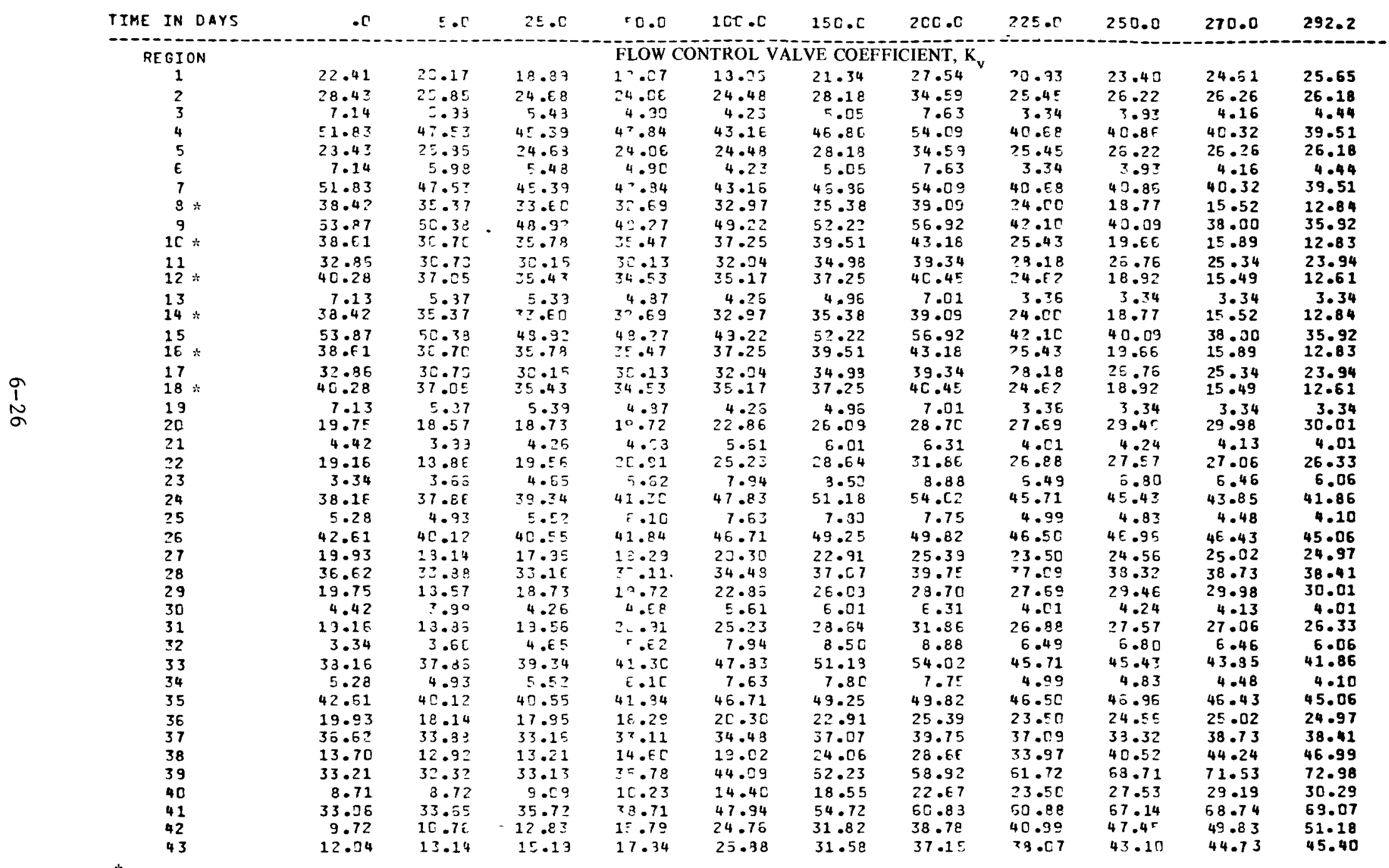

* $8,10,12,14,16$, AND 18 ARE RODDED REGIONS 
TABLE 6-5 (Continued)

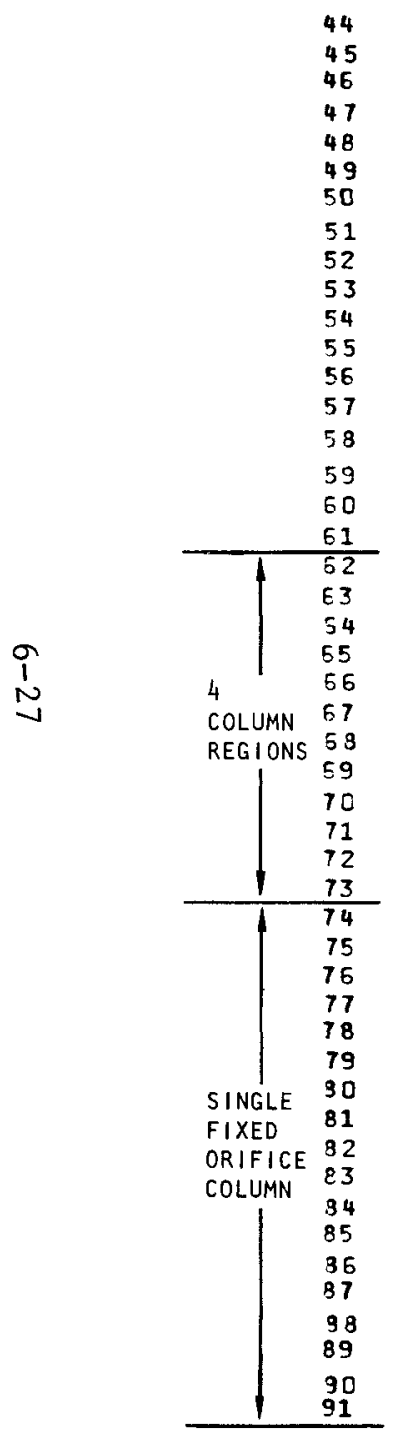

\begin{tabular}{|c|c|}
\hline $\begin{array}{r}7.53 \\
21.05\end{array}$ & $\begin{array}{r}8.00 \\
20.74\end{array}$ \\
\hline $16 . \mathrm{CH}^{-}$ & 15.01 \\
\hline $\begin{array}{r}7.27 \\
10 . E 6 \\
4.11\end{array}$ & $\begin{array}{l}6.15 \\
3.4 \mathrm{C} \\
3.34\end{array}$ \\
\hline $\begin{array}{r}4.111 \\
13.70\end{array}$ & $\begin{array}{r}3.37 \\
12.92\end{array}$ \\
\hline $\begin{array}{r}33.21 \\
8.71\end{array}$ & $\begin{array}{r}32.32 \\
8.72\end{array}$ \\
\hline 33.06 & 33.65 \\
\hline 9.72 & $15.7 \varepsilon$ \\
\hline $12 . .74$ & 13.14 \\
\hline 7.53 & $3.0 \mathrm{C}$ \\
\hline $21 . .25$ & 20.74 \\
\hline 15.34 & 15.21 \\
\hline 7.27 & E.IF \\
\hline $13 . E 5$ & $3.4 \mathrm{~J}$ \\
\hline 4.11 & 2.34 \\
\hline 95.99 & 34.50 \\
\hline 21.26 & 21.32 \\
\hline 3.26 & $10.3 z$ \\
\hline 151.13 & $1=2 . ? 2$ \\
\hline 139.49 & 174.04 \\
\hline 92.21 & 84.47 \\
\hline $\begin{array}{l}95.89 \\
21.26\end{array}$ & $\begin{array}{r}34.55 \\
21.92\end{array}$ \\
\hline 8.26 & 10.35 \\
\hline 151.13 & $152.2 ?$ \\
\hline 189.49 & 174.34 \\
\hline 92.21 & 84.47 \\
\hline 144.16 & $144.1^{-}$ \\
\hline $144.1 F$ & $144.1 \mathrm{C}$ \\
\hline 144.15 & 144.15 \\
\hline $144.1 F$ & 144.16 \\
\hline 144.16 & $144 \cdot 13$ \\
\hline $144.1 E$ & $144.1 E$ \\
\hline 144.16 & 144.13 \\
\hline 144.16 & $144.1 f$ \\
\hline 144.15 & 144.25 \\
\hline $144.1 F$ & 144.15 \\
\hline $\begin{array}{l}144.16 \\
144.16\end{array}$ & $\begin{array}{l}244.15 \\
144.15\end{array}$ \\
\hline $\begin{array}{l}144.15 \\
144.16\end{array}$ & $\begin{array}{l}144.15 \\
144.1 E\end{array}$ \\
\hline $\begin{array}{l}144.16 \\
144.16\end{array}$ & $\begin{array}{l}144.12 \\
144.1 E\end{array}$ \\
\hline $\begin{array}{l}144.15 \\
144.16\end{array}$ & $\begin{array}{l}144.15 \\
144.1 \xi\end{array}$ \\
\hline
\end{tabular}

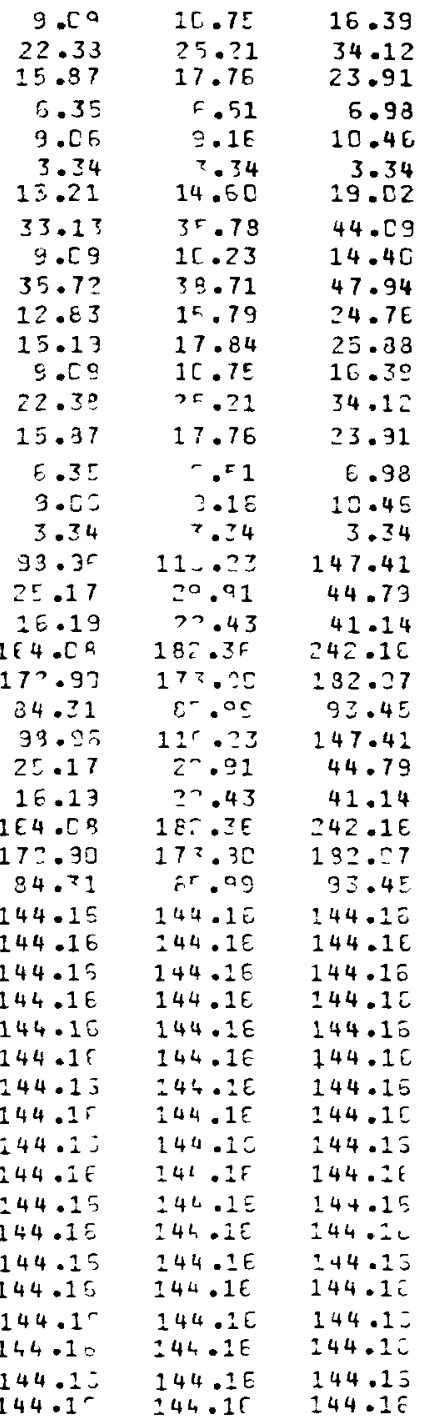

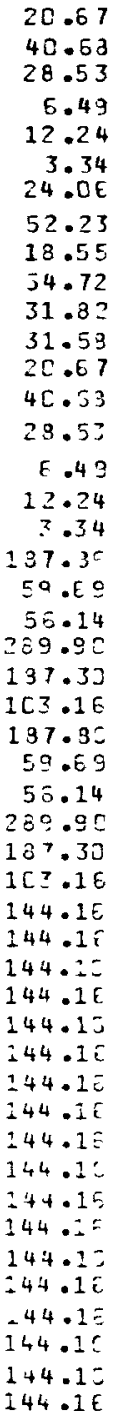

\begin{tabular}{|c|c|}
\hline $\begin{array}{l}24.91 \\
45.74 \\
31.36\end{array}$ & $\begin{array}{l}25.7 \\
47.7 \\
35.8\end{array}$ \\
\hline $\begin{array}{r}5.2 E \\
13.58\end{array}$ & \\
\hline $\begin{array}{r}3.34 \\
28.6 E\end{array}$ & $\begin{array}{r}4.9 \\
33.9\end{array}$ \\
\hline $\begin{array}{l}58.32 \\
22.67 \\
60.88\end{array}$ & \\
\hline $\begin{array}{l}62.88 \\
28.78\end{array}$ & $\begin{array}{l}50.8 \\
4 \mathrm{C} .9\end{array}$ \\
\hline 37.15 & 39.0 \\
\hline 24.91 & 25. \\
\hline 45.74 & 47. \\
\hline 31.36 & 75. \\
\hline$=.2 C$ & 6.1 \\
\hline $\begin{array}{r}13.52 \\
3.34\end{array}$ & $\begin{array}{r}15 . ? \\
4.9\end{array}$ \\
\hline .27 .74 & $z=7$. \\
\hline 70.43 & 95.9 \\
\hline $\begin{array}{r}73.46 \\
-35.34\end{array}$ & $\begin{array}{r}33.5 \\
\times 5.0\end{array}$ \\
\hline 133.39 & $\begin{array}{l}223.3 \\
1 \times 4.3\end{array}$ \\
\hline $1 \pm[. \varepsilon \varepsilon$ & 124.7 \\
\hline 227.74 & -52.7 \\
\hline $7 E .4 Z$ & $95.0^{\circ}$ \\
\hline 73.45 & 33.5 \\
\hline 735.34 & $P E=.0$ \\
\hline 133.89 & $273 \cdot$ \\
\hline 115.88 & 134.7 \\
\hline $144.1=$ & $144 \cdot 1$ \\
\hline $144.1 E$ & 144.3 \\
\hline $144.1 \%$ & 144.1 \\
\hline $144.1 F$ & 144.1 \\
\hline $144.1 \varepsilon$ & $144 . ?$ \\
\hline 244.12 & 144.2 \\
\hline $144.1 \mathrm{r}$ & $144 \cdot 1$ \\
\hline 144.15 & 144.1 \\
\hline 144.125 & 144.1 \\
\hline 144.17 & 144.1 \\
\hline $144.2 \mathrm{~F}$ & 244.1 \\
\hline $\begin{array}{l}744.1 r \\
144.18\end{array}$ & $\begin{array}{l}144.1 \\
144.1\end{array}$ \\
\hline $\begin{array}{l}144.16 \\
144.16\end{array}$ & $\begin{array}{r}144.1 \\
144.1\end{array}$ \\
\hline $\begin{array}{l}144.16 \\
144.26\end{array}$ & $\begin{array}{l}144.1 \\
144.1\end{array}$ \\
\hline 144.15 & 144.1 \\
\hline & \\
\hline
\end{tabular}

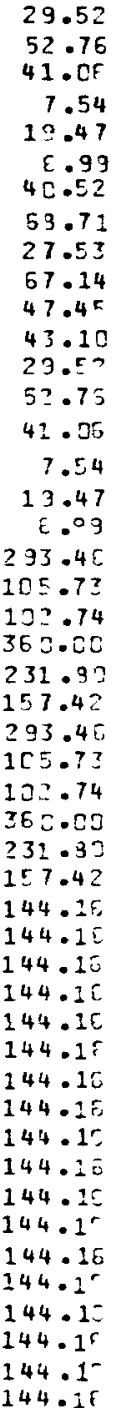

31.00
54.79
43.93
8.35
21.50
8.38
44.24
71.53
29.19
68.74
49.83
44.73
31.00
54.79
43.33
8.35
21.50
8.38
312.57
114.87
111.62
360.00
244.33
172.25
312.57
114.87
111.52
360.00
244.93
172.25
144.16
144.16
144.16
144.16
144.16
144.16
144.16
144.16
144.26
144.16
144.16
144.16
144.116
144.16
144.16
144.18
144.16
144.16
4

31.77 55.54 45.58 8.81 22.86 9.43
46.99 72.98 30.29 69.07 51.18 45.40 31.77 55.54 45.58 45.58
8.81 8.81
22.86 9.43 324.98 121.41 117.60 $360 \cdot .20$ 251.38 182.48 324.98 121.41 117.60 360.00 251.38 182.48 144.16 144.16 144.16 144.16 144.16 144.16 144.16 144.16
144.16 144.16 144.16 144.16 144.16 144.16 $144.1 E$ 144.16 144.16 144.16
144.16

(a) FLOW CONTROL VALVE COEFFICIENTS ARE BASED ON REGION INLET COOLANT HOLE VELOCITY HEAD (SECTION 5.3.1) 
Flow trimming by flow valve motion will yleld a time-varylng core pressure drop as shown in Fig. 6-9 for the seventh year of reactor operation. The core pressure drop is highest when the maximum region peaking factor $P(r)$ is high.

Since the fixed orifice regions, noted in the tables as regions 74-91, have fixed flow resistances, their flow will vary approximately as the square root of the core pressure drop. Of course, the power generated in these regions also changes with time. Those power and flow changes as well as resulting coolant exit temperature changes are given in Table 6-6 for the fixed and variably orificed regions.

In the TREVER analysis a conservative power and flow split between fixed and variable orifice regions is used. The splft used is shown in Fig. 6-10; it assumes the constant presence of the maximum region peaking factor in the core, $P(r)=1.6$, which yields the maximum core pressure drop of 11.5 psi. This yields a flow in fixed orifice regions of $6.3 \%$ of the core cavity flow. It is assumed that these regions, which contain $3.7 \%$ of the fuel, generate only $3.1 \%$ of the core thermal power. Such a conservative power and flow split gives higher region outlet temperatures $\left(1448^{\circ} \mathrm{F}\right)$ from variable orifice regions than the expected temperatures shown in Table 6-6.

For a wel1-balanced core the region exit helium temperatures from all seven and four column regions are equal; however, during actual operation the temperatures are allowed to deviate slightly from this ideally balanced core to obviate continuous valve adjustment. For flow control valve operation, administrative controls are set, such that during normal steadystate operation the maximum deviation of region average coolant exit temperature (mismatch) for any region is not to be more than $50^{\circ} \mathrm{F}$. In thermal analysis using the TREVER code in calculating region average coolant exit temperature, a $50^{\circ} \mathrm{F}$ mismatch alluded to in Fig. 6-10 is used conservatively 


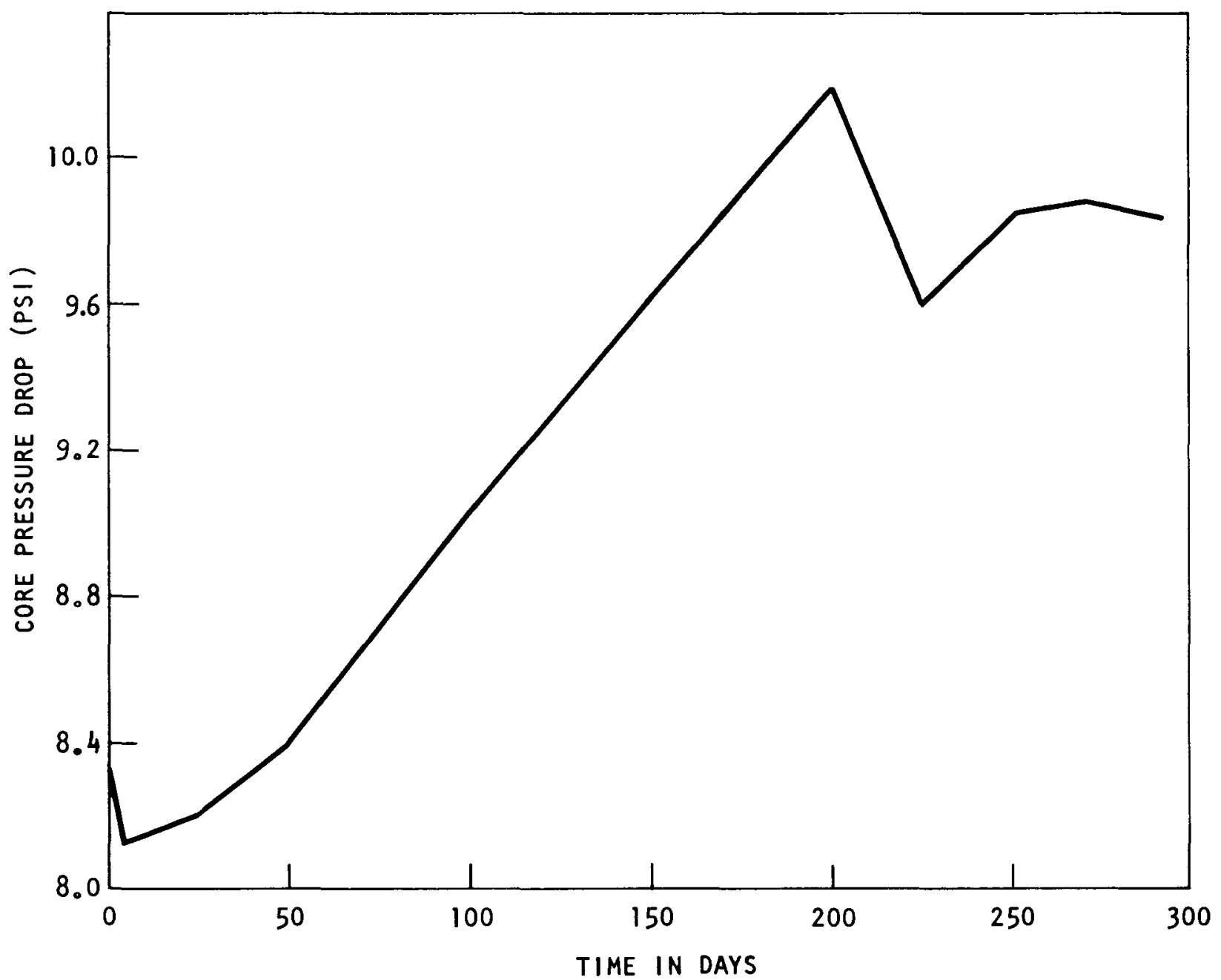

Fig. 6-9. Core pressure drop during seventh year of depletion study 
TABLE 6-6

CORE POWER, FLOW AND HELIUM EXIT TEMPERATURES IN VARIABLE AND FIXED ORIFICE REGIONS DURING SEVENTH YEAR OF OPERATION

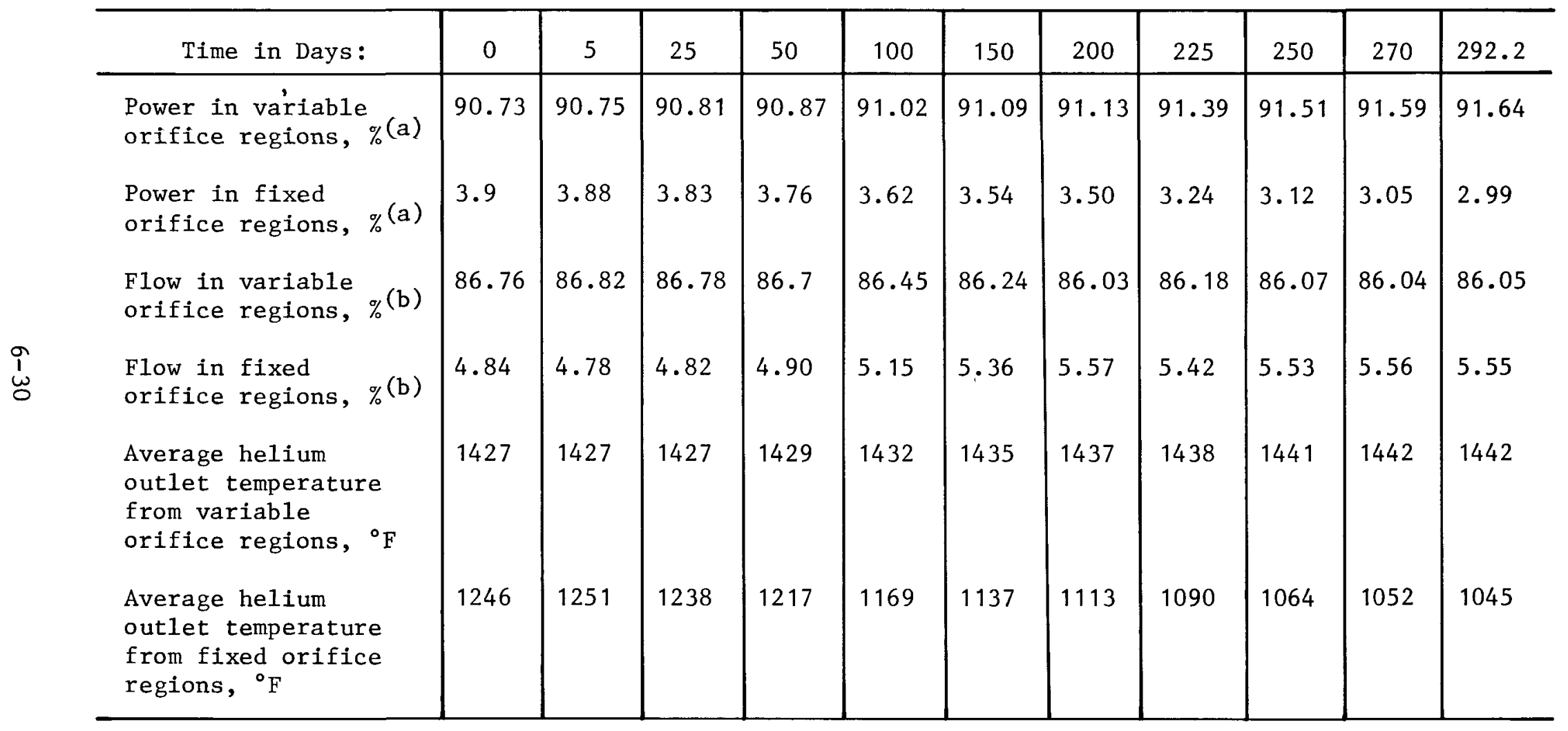

(a) $100 \%$ power $=3000 \mathrm{MW}(\mathrm{t})$
(b) $100 \%$ flow $=10.936 \times 10^{6} 1 \mathrm{bm} / \mathrm{hr}$ 


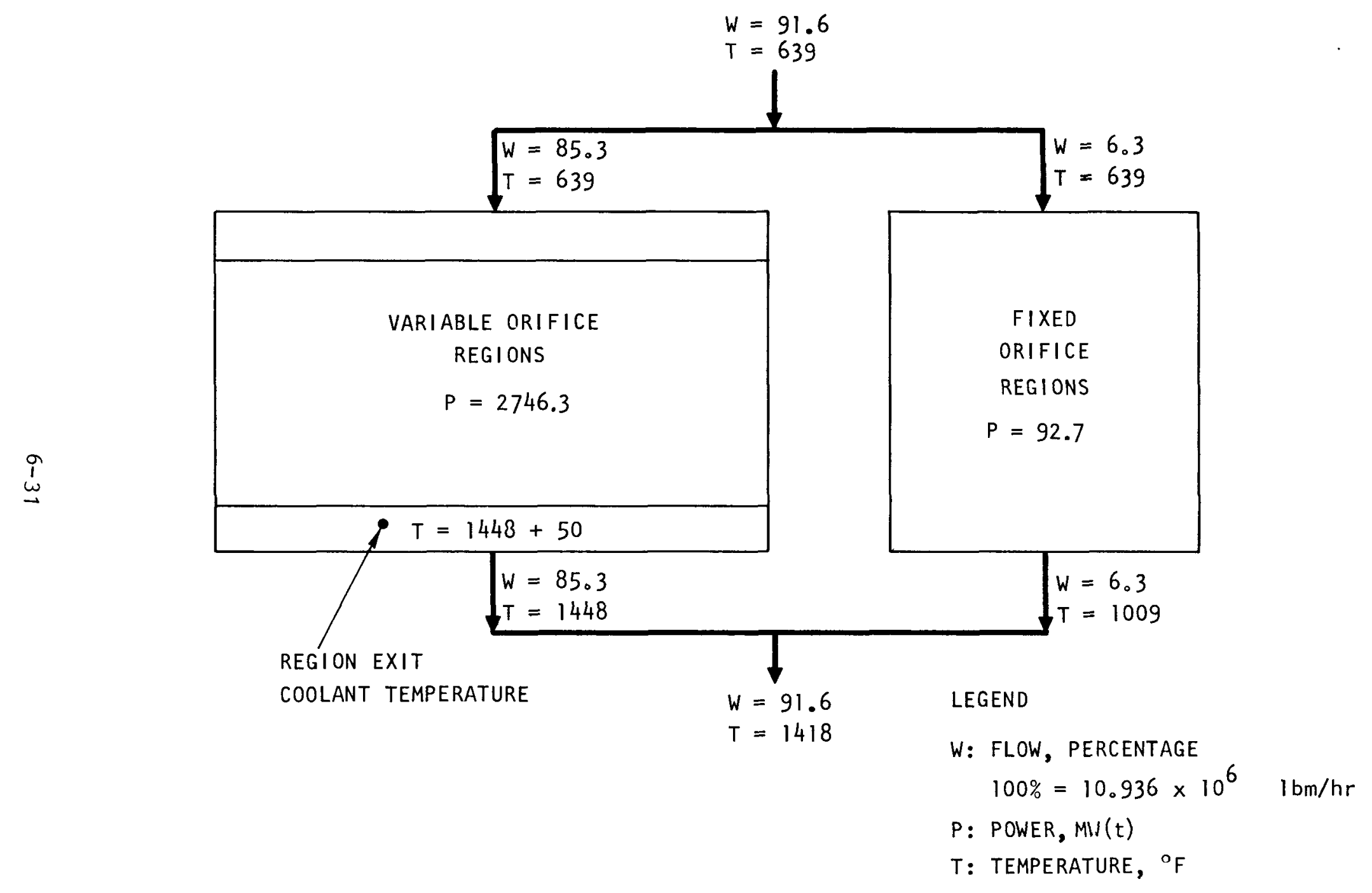

Fig. 6-10. Core power and flow distribution between variable and fixed orifice regions in "Design" case 
for all regions and at all times during core operation. The region average coolant hole outlet temperature for all regions is therefore assumed to be $1498^{\circ} \mathrm{F}$.

6.1.2.2. POKE Subregion Analysis. POKE subregion calculations consider the distribution of the flow to the individual coolant holes within the plenum elements of a single region. A set of equations, of the form of Eq. 4-11 with $\mathrm{K}_{\mathrm{v}}=0$, are solved, one for each coolant hole represented, to give the coolant flow in each individual coolant hole. The power distribution within the region $\alpha(l, r), A(l, r)$ as specified and the coolant flow distribution, $m(l, r)$, are determined from the simultaneous solution of the momentum balance equations.

For the subregion analysis, an exit temperature mismatch $\Delta \mathrm{T}_{\mathrm{mm}}$ is used as explained in the previous section. The flow in a channel with a mismatch $\Delta \mathrm{T}_{\mathrm{mm}}$ is found from the flow in the balanced core by applying an energy balance as follows:

$$
\mathrm{m}_{2}=\mathrm{m}_{1}\left(\frac{\overline{\mathrm{T}}_{\text {core }}-\mathrm{T}_{i}}{\overline{\mathrm{T}}_{\text {core }}+\Delta \mathrm{T}_{\mathrm{mm}}-\mathrm{T}_{i}}\right),
$$

where $\mathrm{m}_{2}=$ region average coolant channel flow for subregion analysis,

$\mathrm{m}_{1}=$ region average coolant channel flow obtained from region average POKE analysis; i.e., when $\overline{\mathrm{T}}_{\text {core }}=\mathrm{T}(\mathrm{r})$ for all variably orificed regions, $r$, $\overline{\mathrm{T}}_{\text {core }}=$ average coolant hole exit temperature from all variable orifice regions,

$\Delta \mathrm{T}_{\mathrm{mm}}=$ Region-to-core average exit gas temperature mismatch $=T(r)-\bar{T}_{\text {core }}$,

$\mathrm{T}_{1}=$ core inlet gas temperature, $T(r)=$ average coolant temperature leaving region $r$. 
After a study in which subregion analyses were performed on regions with various intraregion power tilt distribution, it was observed that the coolant exit temperature mismatch in a region was independent of the radial region peaking and could be accurately represented by a data fit of the form:

$$
T(l)-T(r)=A+B \cdot \alpha(l, r)+C \cdot[\alpha(l, r)]^{2},
$$

where $T(l)=$ the coolant exit temperature of a coolant channel having intraregion tilt of $\alpha(l, r)$.

Coefficients A, B, and C may be evaluated from a POKE subregion analysis under the desired conditions. A particular set of coefficients is valid only under the conditions of core power, region mismatch, core coolant inlet temperature and range of region peaking factors, and intraregion tilts used to generate the coefficients.

Equation 6-3 indicates that flow through channels that remove greater than average power $\alpha(l, r)>1.0$ receive less than average flow. This, of course, arises from greater resistance in the higher powered channels resulting from higher coolant temperature rise and a lower density coolant in the channel.

The correlation in Eq. 6-3 can be used to determine the flow distribution within regions without the necessity of performing the solution to several simultaneous equations. Use of this correlation in the TREVER code has allowed the computing time to be greatly reduced with minimum sacrifice in accuracy of determination of the intraregion flow distribution.

An example of the intraregion coolant hole temperature mismatch, $T(l)$ - $\mathrm{T}(\mathrm{r})$ of the form of $\mathrm{Eq} \cdot 6-3$ is shown in Fig. 6-11. POKE was used to evaluate the values of the temperature mismatch for a wide range of values 


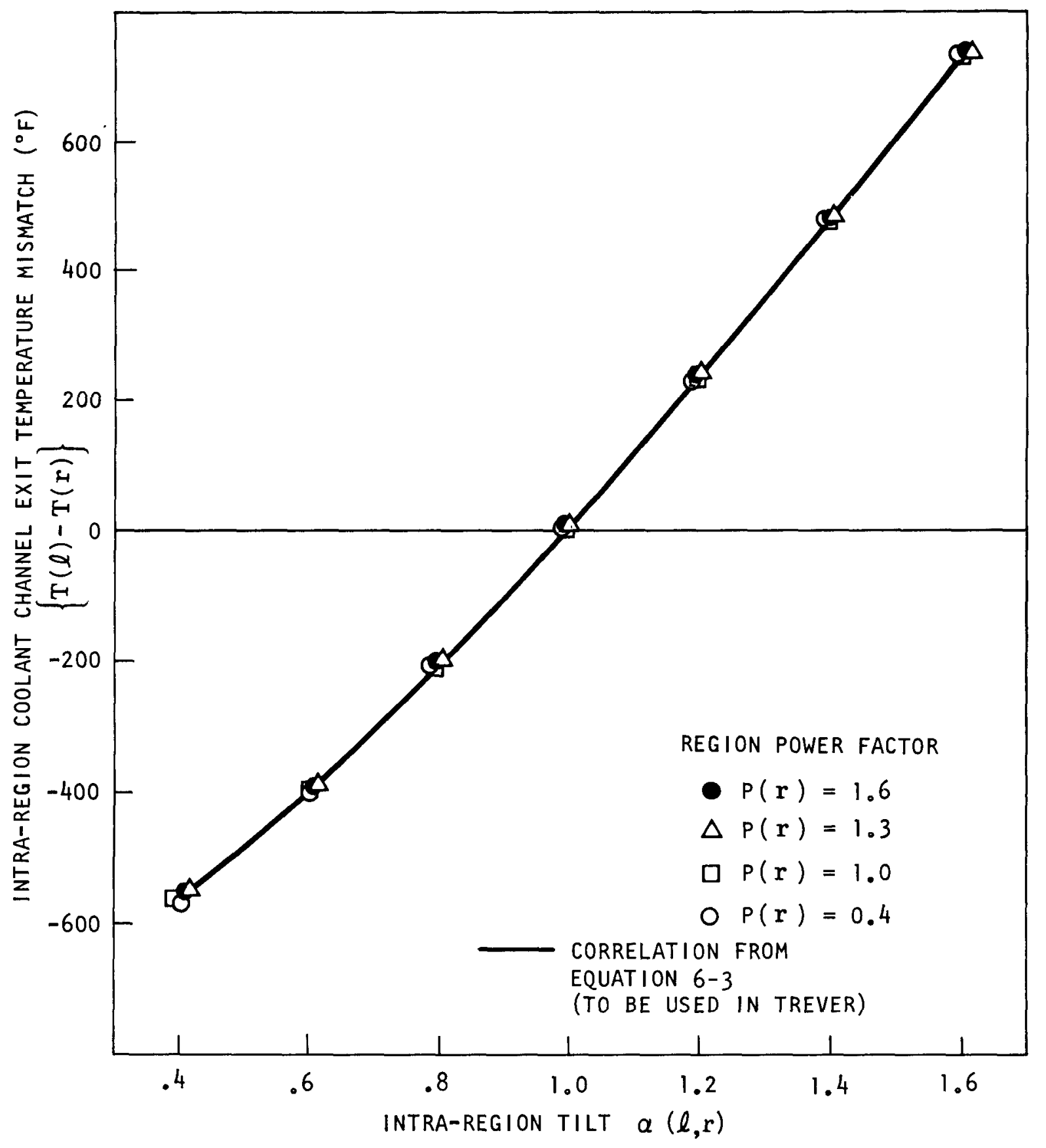

Fig. 6-11. Intraregion coolant channel exit temperature mismatch as a function of intraregion power tilt 
of region peaking. The minor dependence of $T(l)-T(x)$ on the region peaking factor is demonstrated in the figure. The quadratic curve fit based on $P(r)=1.0$ contributes an error of less than $10^{\circ} \mathrm{F}$ in the exit coolant temperature for a range of region peaking factor $P(r)$ from 0.4 to 1.6 .

6.1.3. Half Column Thermal Analysis

The three-dimensional network models DEMISE and DEMICE, described in Section 4.1.3, are used to obtain detailed temperature distributions within half-column portions of the core. Using these codes, it is possible to ascertain the effect on fuel element temperature of variations in power across the fuel element and the effect of departure from the unit cell geometry at the edges of the fuel elements and in the area around the fuel handling hole. In addition, DEMISE computes the temperature of the burnable poison pins in the corners of the element while DEMICE determines the temperatures of the graphite near the control rod channel and the reserve shutdown hole, the temperatures of the control rod compacts, and the temperatures in the central instrumentation channel. Both codes have also been used in studies to determine the amount of heat removed by the flow in the internal and external gaps and control rod channels and the temperature distributions in coolant flowing in these paths. To illustrate the performance of the fuel elements under various operating conditions and to provide examples of typical output from the DEMISE code, the following two cases are presented:

1. A column of standard fuel elements with a uniform, radially flat, power distribution operating in a region with $P(r)=1.0$ and $\alpha(\ell, r)=1.0$.

2. A column of standard fuel elements operating in a high power region with a tilted power distribution; region peaking factor 
$P(r)=1.557$ and a maximum value of intraregion power tilt $\alpha(\ell, r)$

$=1.199$.

The results of these two cases are presented below.

6.1.3.1. Colum of Standard Fuel Elements with Flat Power Distribution. Fuel and coolant temperature distributions in a horizontal plane at the end of each fuel block based on block average axial heat generation are calculated, and Fig. 6-12 shows the temperature distribution at the sixth axial layer of the half-column model. At this axial level the maximum fuel temperatures occur in the central portion of the fuel element in the area near the fuel handling hole. The fuel rods in this area exhibit higher temperatures because they experience a reduction in total effective heat transfer area due to the presence of the smaller diameter (0.717 in.) coolant holes in the central portion of the element. This indicates that the diameter of these coolant holes may be increased slightly to improve the temperature distribution within the fuel element.

Higher fuel temperatures are also observed at boundary fuel pins (e.g., F2 and F3). This is due to a combination of three factors:

1. An appreciable amount of graphite between a boundary fuel rod and the edge of the fuel element increases both the amount of heat to be transferred to the coolant and the thermal resistance in the solid material. The boundary nodes include about $124 \%$ more graphite than nodes in the interior of the block; this increases the heat generated at these boundary nodes by about $8 \%$.

2. The mass flow rate in the gap is about one-third of that in a standard diameter coolant hole. As a result, the gas in the gap tends to heat up quickly in its passage down the side of the fuel element. This gas is typically $100^{\circ} \mathrm{F}$ to $200^{\circ} \mathrm{F}$ hotter than the gas in the adjacent boundary coolant holes. 
$C=$ COOLANT CHANNEL NODE

$G=$ COOLANT GAP NODE

$F=$ SOLID FUEL ROD NODE

$S=$ SOL ID GRAPHITE NODE

$B=$ SOLID BORONATED GRAPHITE NODE

1383.

Q1

1359.1125.1574.2035.12E7.2035.1374.1125.1359.

$1125 \cdot 1929 \cdot 1927 \cdot 1338 \cdot 1994 \cdot 1594 \cdot 1338 \cdot 1927 \cdot 1819.1125$.

$\begin{array}{llllllllllllll} & 5 & F 5 & F 5 & 05 & F & F 3 & C 5 & F 3 & F 10 & C 7\end{array}$

1974. $1927.1214 .1398 .2 C 12.134 E \cdot 2 C 12.1998 .1314 .1927 .1974$.

F11 F12 63 F13 F14 C9 F15 F15 C10 F17 F13

1389. 2035.1338.1958.20C7.1345.2522.2522.1349.25C7.1998.1338.2C35. $\quad 2389$.

G3 F19 C11 F2C F2I C12 F22 F23 C13 F24 F25 C14 F26

12E7. 1994.2C12.1343.2C23.2528.1350.2028.2C23.1349.2C12.1994.1267.

C15 F27 F28 C1: F29 F3C C17 F31 F32 C13 F33 F34 C19

2035.1994.1346.2022.2C23.135E.2050.2550.1358.2C28.2022.1346.1994.2035.

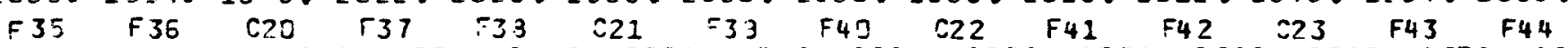

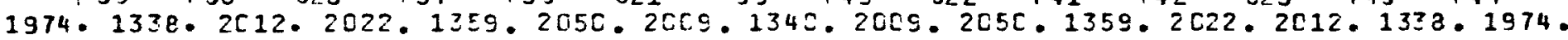

$\begin{array}{llllllllllllllll}F 45 & 54 & F 46 & F 47 & 62 & F 48 & F 49 & C 25 & F 5 C & F 51 & C 27 & F 52 & F 53 & 023 & F 54\end{array}$

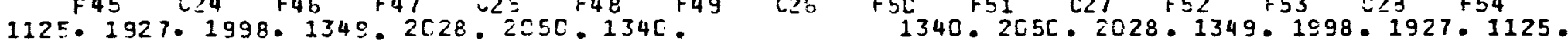

$623 \quad F 55 \quad F 56 \quad C 3 C \quad F 57 \quad F 53 \quad 631 \quad C 32 \quad F 59 \quad F 60 \quad C 33 \quad F 61 \quad F 52 \quad 634$

1350.181\%.1314.2CG7.2023.1358.2009. 20.2009.1358.2023.2007.1314.1819.1359.

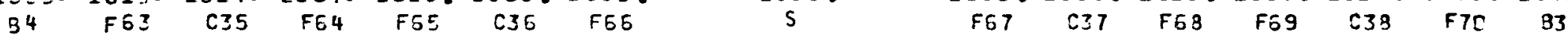

Fig. 6-12. Temperature distribution in a horizontal plane of sixth fuel element in a standard columm calculated using block average axial power and flat radial power $[P(r)=1.0$, $\alpha(\ell, r)=1.0]$ 
3. In the modeling of the area between the boundary fuel rods and the side gaps, conservative, constant values for the conductance of the solid material have been used. Detailed studies using the TAC-2D code have shown that these conductances are actually a function of the temperature difference between the coolant in the gap and the coolant in the adjacent coolant hole $\left(\Delta \mathrm{T}_{\mathrm{GC}}\right)$. The values of this conductance, based on an effective area of 0.2673 $\mathrm{ft}^{2}$, vary linearly from 0 at $\Delta \mathrm{T}_{\mathrm{GC}}=+360^{\circ} \mathrm{F}$ to $98 \mathrm{Btu} / \mathrm{hr}-\mathrm{ft}^{2}-{ }^{\circ} \mathrm{F}$ at $\Delta \mathrm{T}_{\mathrm{GC}}=-200^{\circ} \mathrm{F}$. The values used in the code range from 17 to 20 $\mathrm{Btu} / \mathrm{hr}-\mathrm{ft} \mathrm{t}^{2}-^{\circ} \mathrm{F}$ depending on the axial level and are lower than those estimated by TAC-2D by about a factor of 2 .

The DEMISE code also includes an approximate calculation of the coolant and fuel temperatures at the bottom of each fuel element. This calculation is carried out at the completion of the block average calculations using the local axial power peaking, $A(l, z)$, at the end of each block.

These calculations provide additional information on the performance of the fuel elements and also facilitate comparison with the results of one-dimensional codes (Section 6.1.6) which typically use end-of-block axial power factors.

The results of the end-of-block calculations for block 6 are presented in Fig. 6-13. Under these conditions, the maximum fuel temperatures in this fuel element are observed near the boundary nodes although the temperatures at interior points have nearly the same value. The maximum fuel temperature in the entire column is found to be at the bottom of the fourth fuel element. A plot of the axial temperature distribution for the fuel rod with maximum temperature (fuel rod F2) is shown in Fig. 6-14. For the purposes of comparison, the axial distribution of the fuel node F5, which exhibits the lowest temperature, is also shown. 


\section{LEGEND}

$C=$ COOLANT CHANNEL NODE

$G=$ COOLANT GAP NODE

$F=$ SOLID FUEL ROD NODE

$S=$ SOLID GRAPHITE NODE

$B=$ SOLID BORONATED

1389.

GRAPHITE NODE

C1

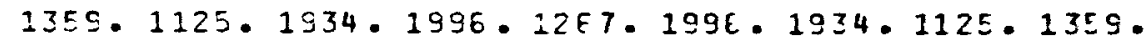

$1175 \cdot 1785 \cdot 183 C \cdot 1338 \cdot 1957 \cdot 1 \cdot 57 \cdot 1338 \cdot 189 C^{3} \cdot 1785 \cdot 1125$.

C4 FE FE $65 \quad=7$ F3 C5 F3 F10 C7

1034. 139C. 1314. 19EZ . 197E.1346.197E . 19E2.1314.189C.1934.

F1: F:2 C3 F13 F14 C9 F15 F1E C1C F17 F18

$\stackrel{i}{i}$

1389. 1995.1378.19E2.1371.1349.198E.1'18E.1349.1971.1962.1338.1996. 1389.

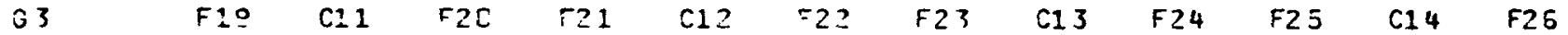
1267. 1057.197E. $1349.1936 .1951 .1359 .1991 .198 E \cdot 1349.1976 .1957 .1267$.

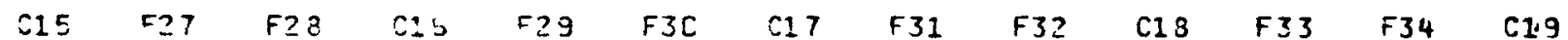
199E. 1957. $134 \varepsilon .1986 .1991 .1358 .2611 .2611 .1258$. 1931.1986.1246.1957.199F.

$\begin{array}{lllllllllllllllllll}F 35 & F 35 & C 20 & 537 & .33 & 021 & 533 & 540 & C 22 & F 41 & F 42 & C 23 & F 43 & F 44\end{array}$ 1934. 1338.1975. 198E. 1255. 2011. 1973.1340.1973.2611.1259.1985.197E.1338.1934. $\begin{array}{lllllllllllllllllll}F 45 & C 24 & F 46 & F 47 & 525 & 143 & F 49 & C 26 & F 50 & F 51 & C 27 & F 52 & F 53 & C 28 & F 54\end{array}$ 2125.1893.19EC.1349.1991. 2E12.134C. 1340.2C12.1991.1349.19E0.1893.112E. 229 F55 FSE CSE FE7 F53 C31 C32 F5G F6C C33 F51 F5? C34

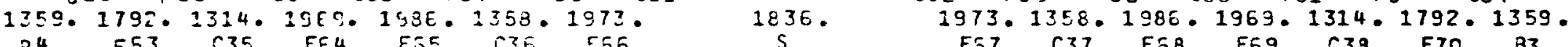

Fig. 6-13. Temperature distribution in a horizontal plane at the end of sixth fuel element in a standard column calculated using end of block local axial power and flat radial power $[P(r)=1.0, \alpha(\ell, r)=1.0]$ 


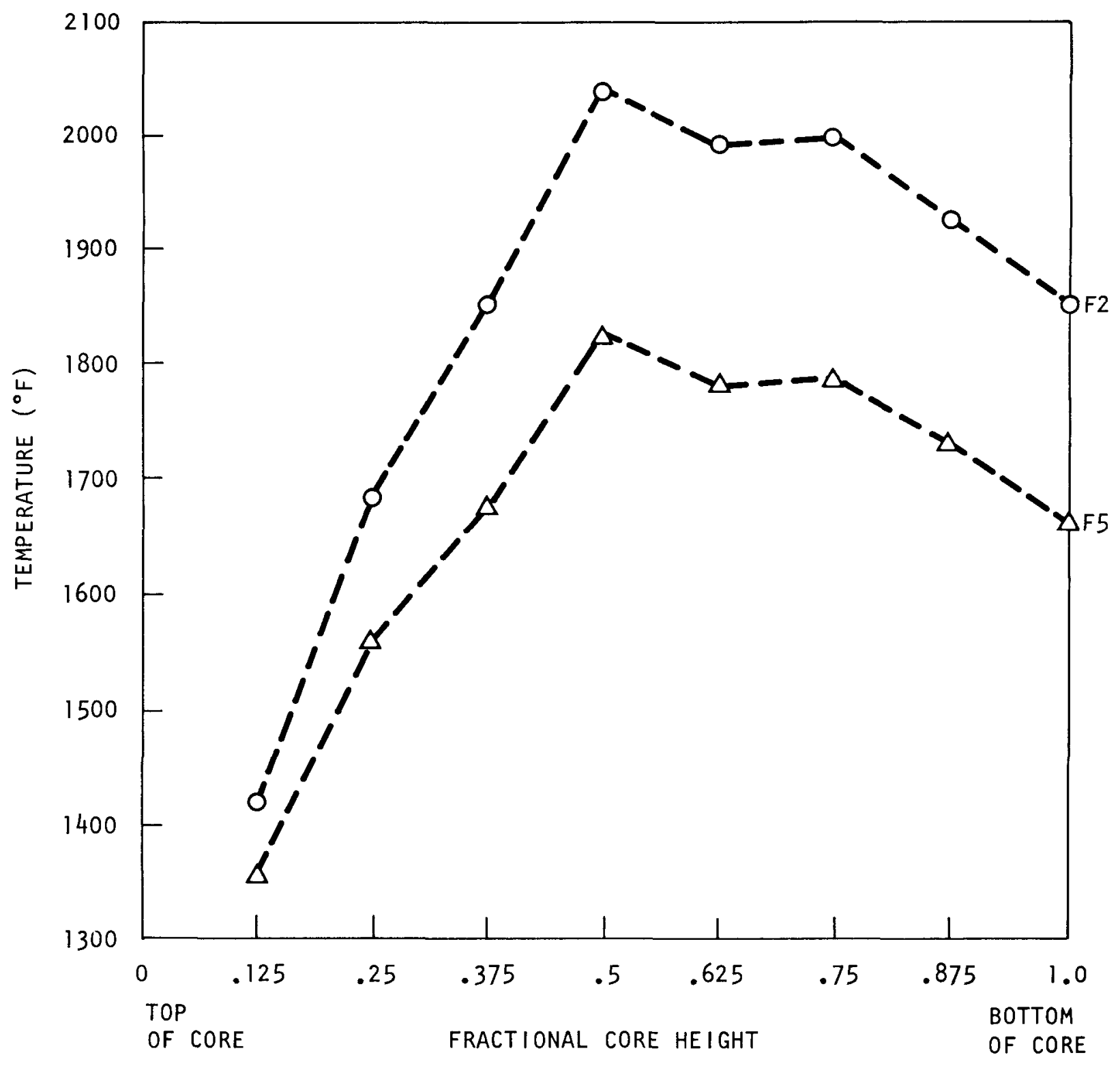

Fig. 6-14. Axia1 temperature distribution for fuel rods F2 and F5 
6.1.3.2. Standard Column with Tilted Power Distribution. Results for a column of standard fuel elements located on the periphery of a region with a tilted power distribution are presented in this section. The input power distribution for this case was taken from BUGTRI code output using data for region 25 at the end of the second reload. In this burnup, power peaking factors are available at 19 locations in each column instead of the 7 available from GAUGE. A description of this BUGTRI burnup is given in Ref. 6-7. These fuel elements had been operating in the reactor for one year at this time point. These data were selected for analysis because the region power factor (1.557) and the maximum intraregion tilt (1.199) are close to the maximum power conditions at rated power observed in the reactor.

To determine the input for DEMISE, the 19 radial point powers computed by BUGTRI are input to a code that calculates and plots lines of constant tilt as shown in Fig. 6-15. Values of $\alpha(l, r)$ for each fuel rod are then taken from the shaded area of the column and used as input to DEMISE along with the region power factor, the total mass flow for the half-block, and the proper axial power profile. The temperatures calculated for this case are shown in Fig. 6-16 at the end of the fourth fuel block. The highest fuel temperatures occur at the boundary of the fuel element because the maximum tilts are located there. The maximum fuel temperature is $2600^{\circ} \mathrm{F}$. Fuel temperatures are lower at points closer to the central portion of the fuel element since the tilt decreases radially inward. An interesting comparison of the fuel temperatures calculated with DEMISE and those calculated with the one-dimensional BACH code is made in Section 6.1.6.

\subsubsection{Unit Cell BACH Analysis}

The basic unit cell model shown in Figs. 4-9 and 4-10 is used to represent the fuel element geometry in the BACH, POKE, and TREVER codes. For unit cell calculations, an ideal fuel-hole-to-coolant-hole geometry is assumed which is in fact present only at the fuel element locations 


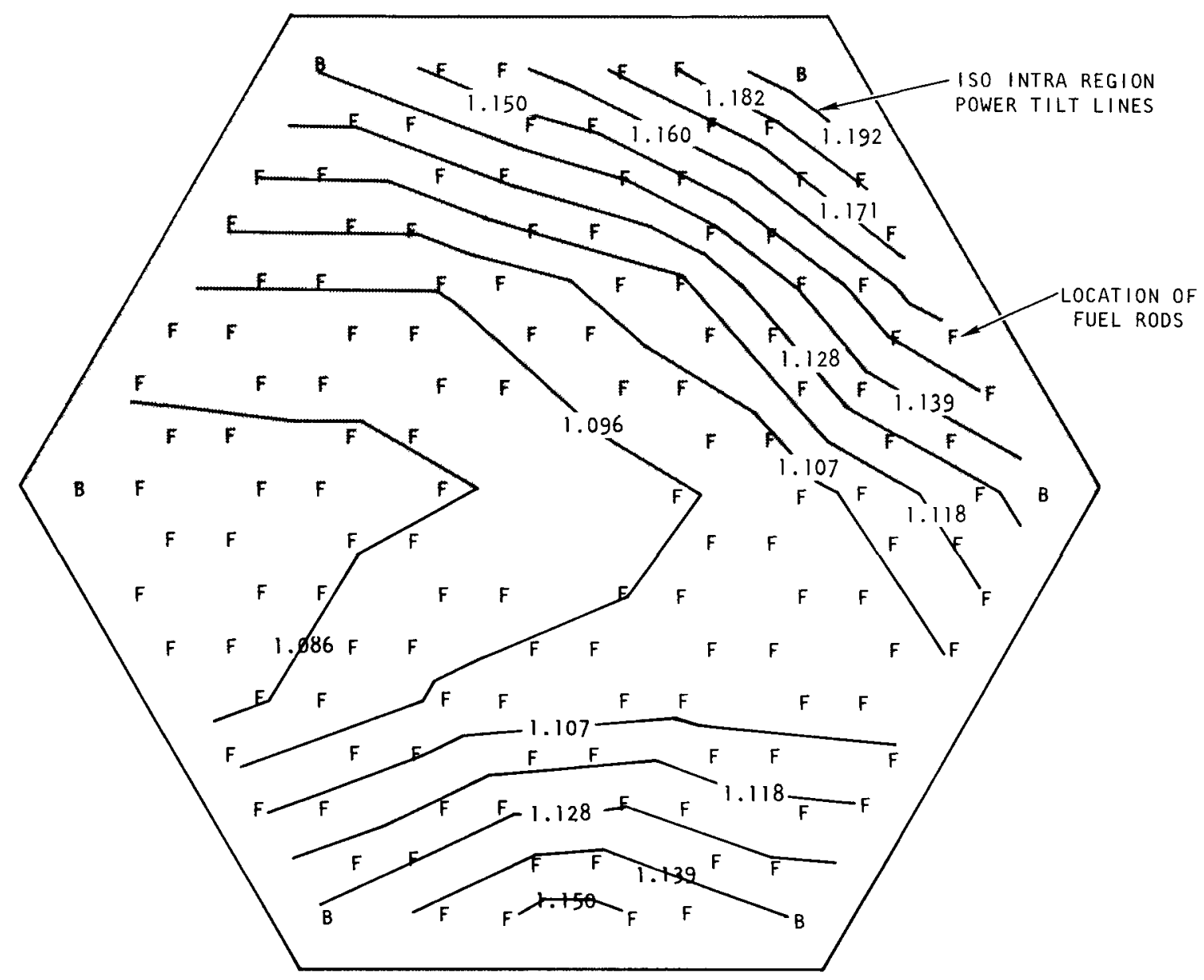

Fig. 6-15. BUGTRI radial power distribution in column 5 of region 25 at the end of reload 2 


\section{LEGEND}

$C=$ COOLANT CHANNEL NODE

$G=$ COOLANT GAP NODE

$F=$ SOLID FUEL ROD NODE

$S=$ SOLID GRAPHITE NODE

$B=$ SOLID BORONATED GRAPHITE NODE

1136 .

$\Leftrightarrow 1$

1274. 924. 251E. 2E7E, 1C30.2ECC. 2565. 935.13C4.

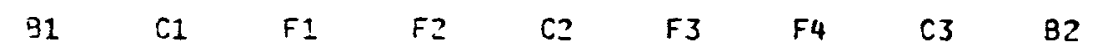

$919.2224 \cdot 23 E 8 \cdot 1 C E C \cdot 244 C \cdot 24 E 1 \cdot 1090 \cdot 2422 \cdot 2295 \cdot 935$.

$\begin{array}{llllllllll}C 4 & 55 & F & & \end{array}$

$246 \mathrm{C} \cdot 234 \mathrm{C} \cdot 1 \mathrm{C54} \cdot 24 \mathrm{CC} \cdot 2419 \cdot 1075 \cdot 2438 \cdot 2442 \cdot 1 \mathrm{CT1} \cdot 2424 \cdot 2567$.

$\begin{array}{lllllllllllll}F 11 & F 12 & C 3 & F 13 & F 14 & 63 & F 15 & F 16 & C 10 & F 17 & F 18\end{array}$

11C5. 243C.10E5.2Z73.2373.1CE7.2454.2413.1075.2428.2442.1090.2E03. 1137.

G3 F19 C11 F2C F21 C12 F22 F23 C13 F24 F25 C14 F26

1CD6. 2361. 23EC. 1CE1. 2374.23EE.1C72.2402.240E.1C75.2438.2453.1031.

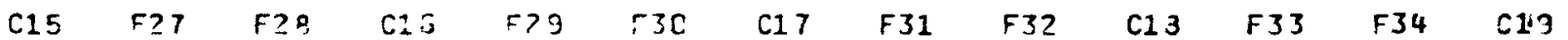

2464. 335 C. 1055.23EC.2ZE7. 1CE4.2422.243C.1C70.24C5.2415.1077.2445.?578.

$\begin{array}{lllllllllllllllllllllll}F 35 & F 36 & C 2 C & F 37 & 533 & C 21 & 539 & F 40 & C 22 & F 41 & F 42 & C 23 & F 43 & F 44\end{array}$

241C. 1C56.2347.2351.1061.24JE.2342.105C.2352.2432.1073.2408.2423.1081.2516.

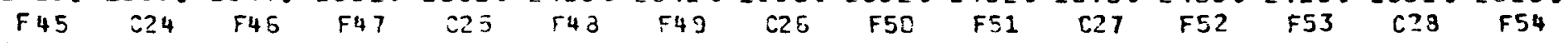

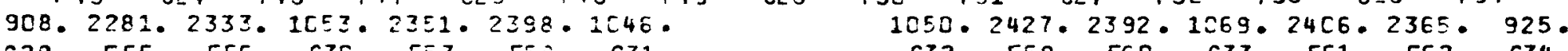

$\begin{array}{lllllllllllllll}29 & F 5 & F 5 E & C 3 C & F 57 & 530 & C 31 & F 32 & F 59 & F 60 & C 33 & F 61 & F 52 & C 34\end{array}$

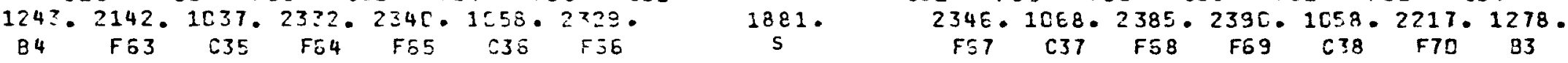

Fig. 6-16. Temperature distribution in a horizontal plane of fourth fuel element in a standard column operating in a high power region with a tilted power distribution $[P(r)=1.557$, $\alpha(\ell, r)=1.199]$ 
removed from element edges and other features such as control rod channels and fuel handling holes. The coolant channel bulk gas temperature is calculated by using Eq. 4-6 in which $\bar{q}^{\prime}$ is defined as

$$
\overline{\mathrm{q}}^{\prime}=\frac{\mathrm{Q}}{\mathrm{N}} \times \frac{\mathrm{P}(\ell)}{\mathrm{L}}
$$

where $Q=$ total thermal power removed by the helium flowing in the coolant holes in variable orifice regions (see Fig. 6-10) $=2746.3 \mathrm{MW}$

$$
\begin{aligned}
& \mathrm{N}=\text { equivalent numbers of } 0.826-1 \text {. -diameter coolant holes in variable } \\
& \text { orifice regions (see Eq. 6-9), } \\
& L=\text { active core length }(31.22 \times 8),
\end{aligned}
$$

and $P(l)=$ local radial power peaking factor (see Eq. 5-14).

The local coolant channel flow $\mathrm{m}$ in Eq. 4-6 is a function of the region peaking factor $P(r)$, region to core average gas outlet temperature mismatch, $\Delta \mathrm{T}_{\mathrm{mm}}$, and intra-region tilt, $\alpha(l, r)$ and is calculated using the one dimensional conservation of momentum Eq. 4-11 as given in Section 4.1.4.

To calculate the average coolant hole wall heat flux $q_{w}^{\prime \prime}$ from the code input for use in the unit cell codes several geometric correction factors are introduced. The computation of the core-average coolant hole heat flux in the unit cell codes is accomplished by

$$
\bar{q}_{\mathrm{w}}^{\prime \prime}=\frac{\mathrm{Q}}{\mathrm{NA}} \mathrm{G}_{1} \cdot \mathrm{G}_{2} \cdot \mathrm{G}_{3} \cdot \mathrm{G}_{4},
$$

where $A=$ heat transfer area of one coolant hole, $\pi D L$,

$\mathrm{D}=$ coolant hole diameter (0.826 in.),

and $G_{1}, G_{2}, G_{3}$, and $G_{4}$ are correction factors defined and discussed below. 
6.1.4.1. Unfueled Length Correction Factor, $G_{1}$. The total coolant hole surface area of the entire 31.22-in. axial length of each coolant hole is not equally effective in transferring energy to the coolant. Only a portion of the axial length of the fuel block contains fuel. The unfueled length consists of the top and bottom graphite end caps and a void above the top fuel rod to accommodate differential irradiation-induced contraction between the fuel rods and the graphite block. On a coreaverage basis, accounting for 12 fuel rods in a nominal fuel rod stack and 11 fuel rods in the fuel rod stacks under the dowels, and accounting for a maximum end-of-life contraction of $1 \mathrm{in}$. for fuel rod stack contraction during irradiation, the average fueled length of a block is 28.5 in. The average coolant hole heat flux is therefore increased by the factor $G_{1}=$ $31.22 / 28.5=1.10$. Even though some portions of the fuel element length contain no fuel rods, heat will flow through the graphite at the ends of the block and be transferred to the coolant. Ignoring this portion of the element is conservative.

\subsubsection{Fuel to Coolant Hole Ratio Correction Factor, $G_{2}$. On a core-} average basis, the fuel-rod-to-coolant-hole ratio is approximately 1.89 . The deviation from the ideal ratio of 2.0 of the basic unit cell (Fig. 4-9) arises from fuel element features such as edges, fuel handling hole, control rod channel, reserve shutdown channel, and burnable poison holes interrupting the regular pattern. The heat flux to a local coolant hole must therefore be increased by the factor $G_{2}=2.0 / 1.89=1.06$, which accounts for the larger amount of energy on the average that must be removed by coolant holes within the interior of a fuel block where the coolant-fuel ratio is exactly 2 .

6.1.4.3. Bypass Heat Correction Factor, $G_{3}$. The power removed via various flow paths in the HTGR core as assumed to be distributed in the core performance thermal design calculations is shown in Fig. 6-8. Approximately $0.8 \%$ of the thermal energy is deposited, principally through 
$(n, y)$ reactions, in the borated side reflector shielding, the steel segmented core barrel, and near the cooling holes in the permanent side reflector blocks. The remaining 99.2\% (2975 MW) of the thermal energy is removed in various flow paths within the core as is illustrated in the figure. In the core thermal design calculations, it is assumed that the heat transferred to the vertical gaps and control rod channels is generated in fuel and graphite nodes near these energy removal paths [this assumption has been verified with detailed three-dimensional thermal models of the standard and control rod fuel blocks (Section 6.1.3)]. This results in a lower coolant hole heat flux in coolant holes near the edges of the fuel elements and control rod channels. The heat flux at coolant holes away from the gaps and control rod channels is higher and therefore is corrected by including the heat deposited in gaps and control rod by the correction factor $G_{3}$ given by

$$
\begin{aligned}
G_{3} & =\frac{Q+\text { heat deposited in gaps }+ \text { heat deposited in control rod channels }}{Q} \\
& =\frac{2746.3+101+35.2}{2746.3}=1.05
\end{aligned}
$$

The factor $G_{3}$ accounts for the higher-than-core average energy generated away from the boundaries of the block and removed via local coolant channels.

6.1.4.4. Heat Transfer Area Correction Factor, $G_{4^{\circ}}$. Within the variable orifice regions of the core there are 28,941 coolant channels of 0.826 in. diameter and 3142 coolant channels of 0.717 in. diameter. The BACH, POKE, and TREVER codes use as input the number of coolant channels defined as the equivalent number of flow channels.

In a region within the core the plenum-to-plenum pressure drop is equal for 0.826-in.-diameter coolant holes and 0.717-in.-diameter coolant holes. Frictional resistance experienced in the channels is the principal flow resistance when flow passes through the core. Eliminating all the terms in Eq. 4-11 except friction, the relationship between the flow in 
the 0.826-in.-diameter coolant hole and the flow in a 0.717-in.-diameter coolant hole in the same region is given by

$$
\mathrm{P}_{i}-\mathrm{P}_{\mathrm{O}} \alpha\left[\left(\frac{\mathrm{m}}{\mathrm{A}}\right)^{2} \frac{\mathrm{fL}}{\mathrm{D}}\right]_{\mathrm{D}=0.826 \text { in. }}=\left[\left(\frac{\mathrm{m}}{\mathrm{A}}\right)^{2} \frac{\mathrm{fL}}{\mathrm{D}}\right]_{\mathrm{D}=0.717 \mathrm{in} .} \text {, }
$$

where the notation is the same as that of Eq. 4-11 and subscripts indicate the coolant hole diameter to be used in evaluating the quantities. The friction factor may be expressed as

$$
f=\frac{C}{\operatorname{Re}^{0.25}}=\frac{C}{\left(\frac{4 m}{\pi \mu D}\right)^{0.25}}
$$

Equations 6-6 and 6-7 may be combined to give

$$
\frac{m_{0.717}}{m_{0.826}}=\left(\frac{0.717}{0.826}\right)^{\frac{4.75}{1.75}}=0.681
$$

Therefore, in the active core the equivalent number of coolant holes from a coolant hole flow standpoint is

$$
\mathrm{N}=28,941+0.681 \times 3142=31,081
$$

This number is entered into TREVER and BACH as the number of coolant holes in the core. When the heat transfer surface area is determined to calculate the core average heat flux, the equivalent number of 0.826-in.diameter coolant holes that yield the total heat transfer surface area must be used rather than the equivalent number of coolant channels used as the core input. The heat transfer surface area is proportional to the ratio of the coolant hole diameters, or $0.717 / 0.826=0.868$.

Therefore, the equivalent number of 0.826-in.-diameter coolant holes to compute the heat transfer area is 


$$
28,941+0.868 \times 3142=31,668
$$

The quantity ( $P / N A$ ) must then be multiplied by the correction factor $G_{4}$, where

$$
G_{4}=\frac{31,081}{31,668}=0.98
$$

The core average heat flux for local coolant channels away from the boundary of the fuel blocks is therefore determined from the relationship

$$
\overline{q_{w}^{11}}=Q / N A \times 1.1 \times 1.06 \times 1.05 \times 0.98 \text {. }
$$

The local heat flux at any radial location $\ell$ within a refueling region $r$ and axial location $z$ is obtained by

$$
q_{w}^{\prime \prime}(l, r, z)=\overline{q_{w}^{\prime \prime}} \cdot P(r) \cdot \alpha(l, r) \cdot A(l, z),
$$

where $P(r), \alpha(\ell, r)$ and $A(l, z)$ are power peaking factors as described in Section 5.8 .3 .

Although $q_{w}^{\prime \prime}$ has been calculated based on the variable orifice regions this value is applicable to the fixed orificed region in the $3000 \mathrm{MW}(t)$ core.

The region-to-region variation of core radial power distribution is compensated for by radial flow distribution control using core inlet flow control valves. However, the variation of radial power distribution within the refueling regions results in some localized high coolant, graphite, and fuel temperatures in a small volume of the core. The variation of the radial power peaking within the regions is characterized by the intraregion tilts $[\alpha(l, r)]$ as indicated in Section 5.8.6. In addition to the intraregion power tilt, the axlal varlation of the local temperature is also dependent on the variation of axial power peaking, $A(l, z)$, as described in Section 5.8.7. The unit-cell BACH code described in Section 6.1.4 is used to calculate local channel axial coolant, graphite, and fuel temperatures within the refueling regions. 
The influence of radial region peaking factor $P(r)$, intraregion tilt factor $\alpha(l, r)$, and axial power peaking factor $A(l, z)$ on coolant, graphite, and fuel temperature is elucidated below using results from the BACH code. Figure 6-17 depicts the axial distribution of coolant, graphite, and fuel temperature in an average power channel $[P(r)=1.0, \alpha(l, r)=1.0]$. Corresponding temperatures in a high-temperature channel $[P(r)=1.3$, $\alpha(l, r)=1.4$ ] are shown in Fig. 6-18. Fuel temperatures in both these channels are low in the inlet half of the core length, and a nearly constant fuel centerline temperature is exhibited in the lower half of the core.

In the average-power channel, the coolant exit temperature is about equal to the core average coolant channel exit temperature, $1448^{\circ} \mathrm{F}$. By contrast, in the higher power region, $P(r)=1.3$ (Fig. 6-18), the total coolant flow will be $30 \%$ greater than the average power region and the measured exit temperatures will be equal to the average power region. However, in the local unit cell being considered the power is an additional $40 \%$ higher. But there is no control of flow distribution within the region, so the coolant hole in a unit cell with high intraregion power tilt will receive about the region average flow. Then the helium flowing in the high temperature channel with $\alpha(l, r)=1.4$ will experience an approximately $40 \%$ higher coolant temperature rise, which is seen in Fig. 6-18, and it will exit at $1780^{\circ} \mathrm{F}$.

In the high temperature unit cell, all the temperature rises in the fuel element are also higher than the average because of the higher heat flux. The combination of higher gas temperature rise and higher solid temperature rise yields a fuel temperature in Fig. 6-18 about $500^{\circ} \mathrm{F}$ greater than in the average power channel depicted in Fig. 6-17.

A plot generated by BACH in Fig. 6-19 shows the local maximum fuel centerline temperature at core midheight as a function of region peaking factor $P(r)$ and intraregion tilt $\alpha(l, r)$. These temperatures correspond to the core operating at rated power. 


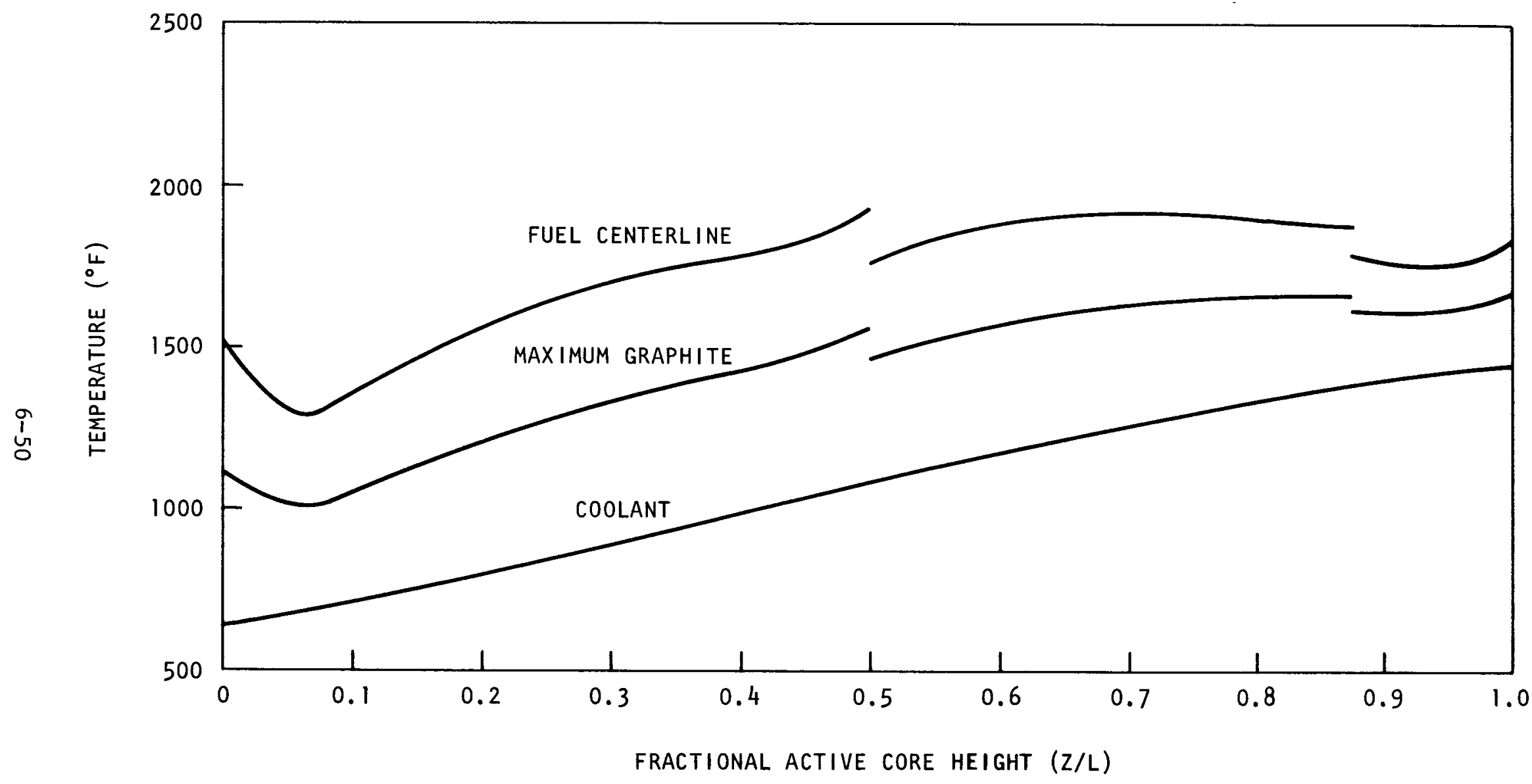

Fig. 6-17. Axial distribution of coolant, graphite, and fuel temperatures in an average power channel 


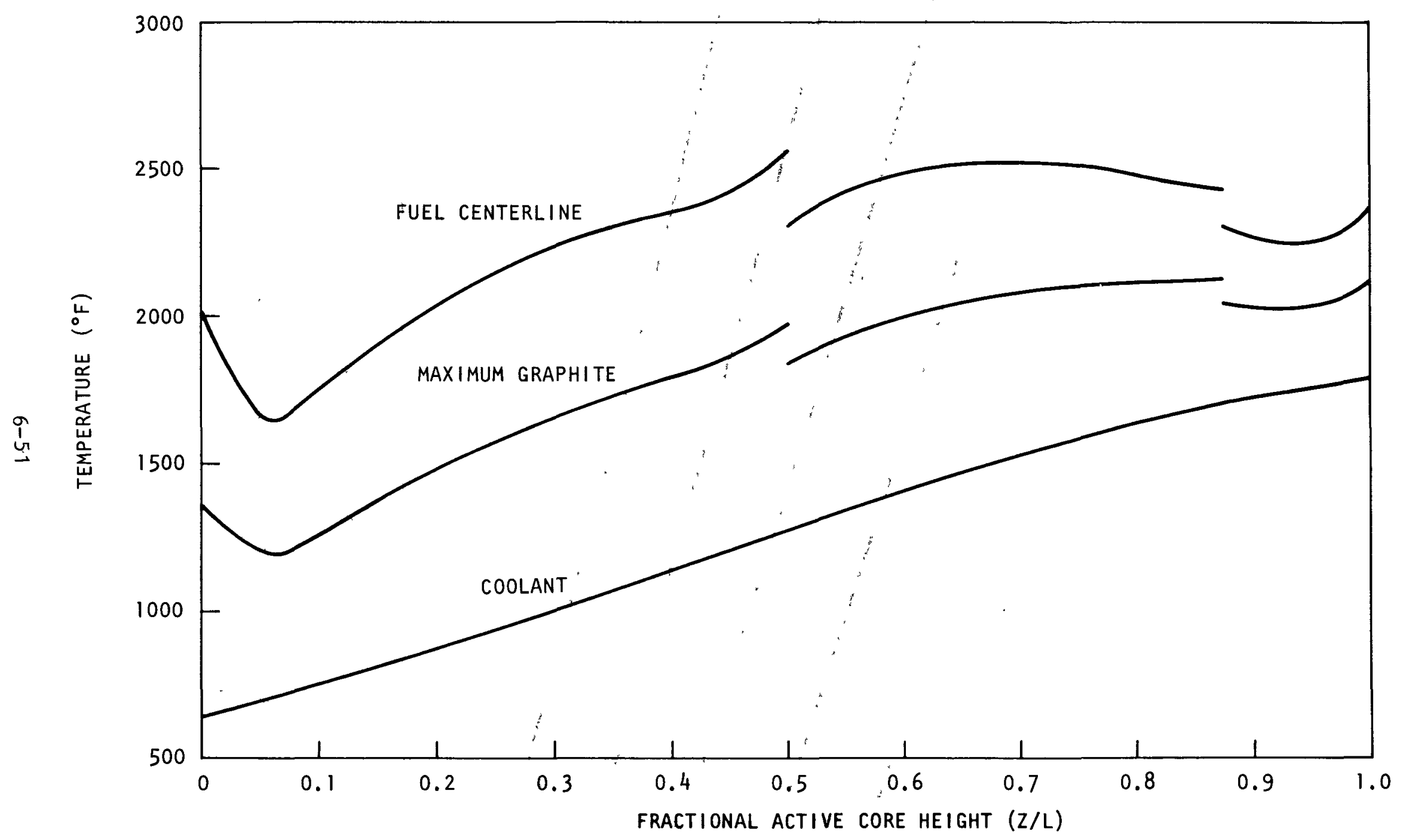

Fig. 6-18. Axial distribution of coolant, graphite, and fuel temperatures in the high temperature local channel 


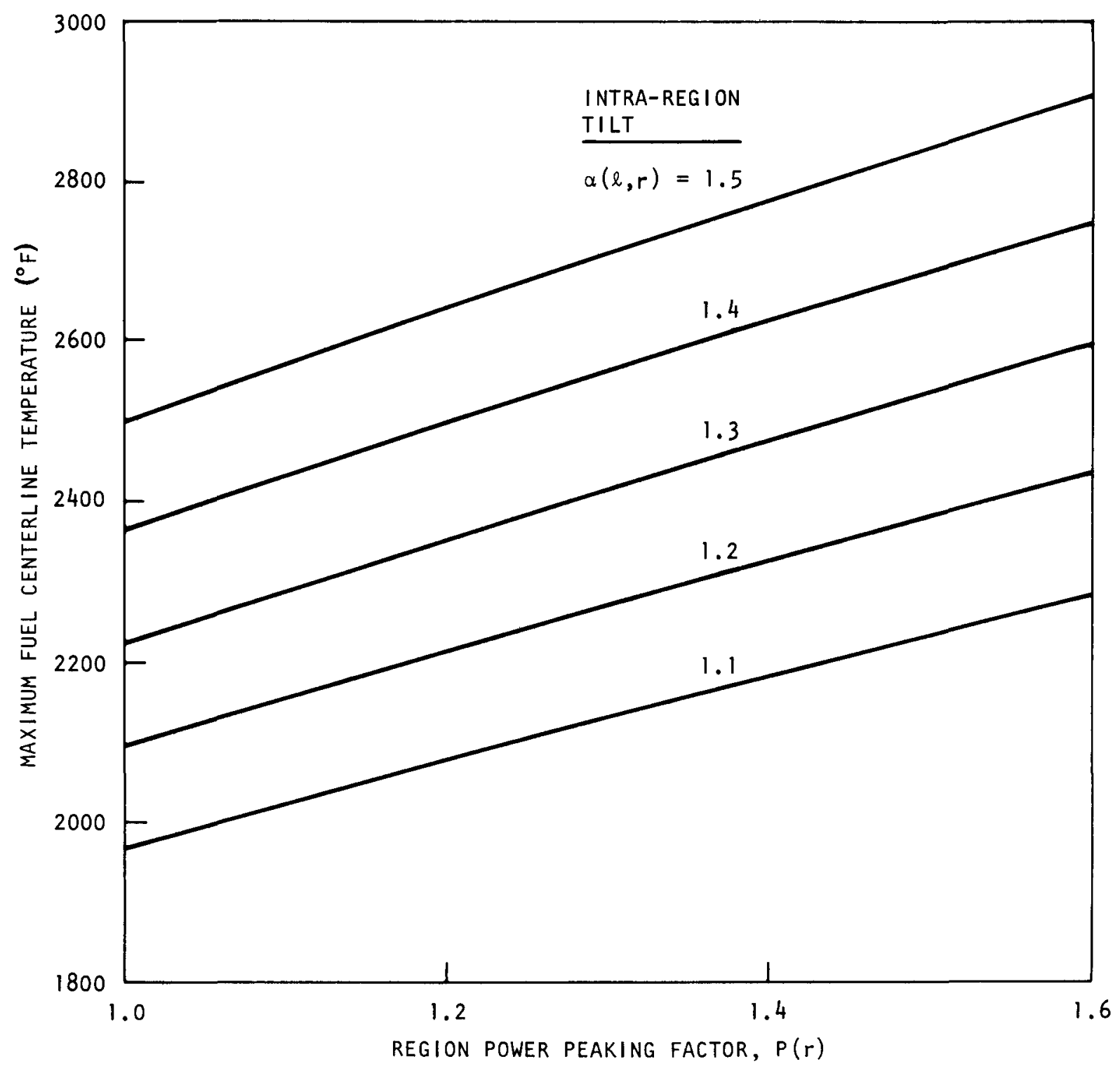

Fig. 6-19. Fuel centerline temperature as a function of region peaking factor and intraregion tilt at core midlength in unrodded regions 
Figure 6-20 presents a radial temperature distribution from the fuel centerline to the bulk coolant temperature at core midhefght for the region with $P(r)=1.3$ and $\alpha(l, r)=1.4$. Under these conditions, the largest heat flow resistances are in the fuel rod and at the coolant hole wall.

At full-power operation, the control rod pairs are slowly withdrawn during the last 100 days of each cycle to balance the core reactivity (Section 5.8.5). As the rods are wlthdrawn, in rodded regions the region peaking factor $P(r)$ increases, the region's maximum intrareglon tilt $\alpha(l, r)$ tends to decrease, and the axial power shape $A(l, z)$ peaks near the lower end of the core. Figure 6-21 shows the combined effect of these power distribution changes during the withdrawal of the rod on fuel centerline temperature in a typical rodded region for four rod positions. The axial profiles for regions where rods are partially inserted are taken from Section 5.8 .

In Section 6.1.1, the crossflow and the resulting flow and pressure distribution between the coolant channel and the gaps between fuel columns are described. The $\mathrm{BACH}$ code can be used to evaluate the effect of axial flow distribution resulting from crossflow on fuel and graphite temperatures in a core with no region exit temperature mismatch. The effect of crossflow on fuel temperature in a high power $P(r)=1.6$ region and a low power $P(r)=0.5$ region may be seen in Fig. 6-22. There the axial temperature distributions of these two regions with and without crossflow are plotted. As can be seen the effect of crossflow in high power region $P(r)=1.6$, where flow is outward from the coolant holes, is to decrease fuel temperature in the top half of the core and increase the temperature in the bottom of the core relative to the no-crossflow case. On the other hand, in the low power region, where the flow is inward, fuel temperatures are increased toward the top half of the core and decreased in the bottom of the core relative to the no-crossflow situation. 


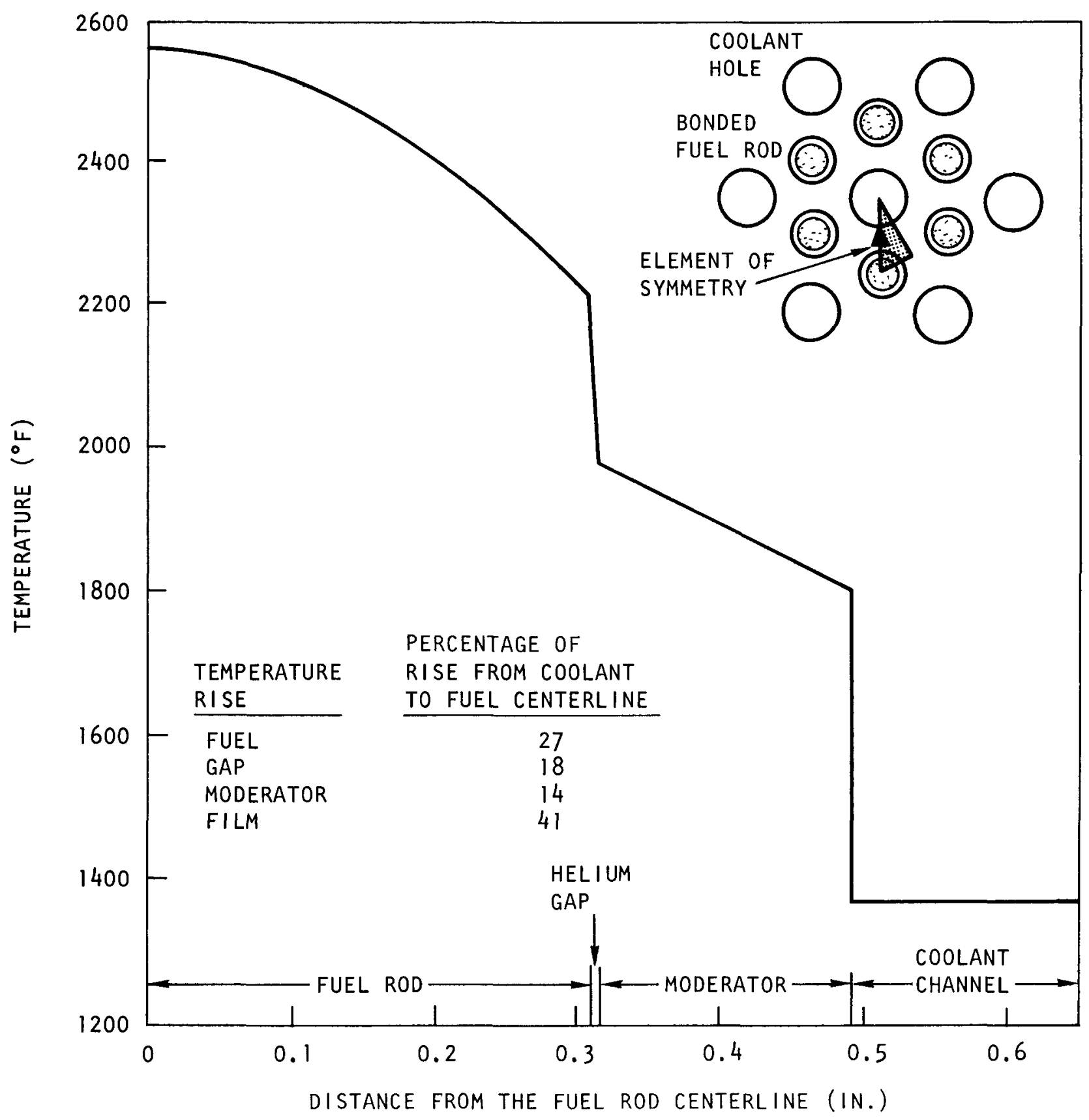

Fig. 6-20. Radial temperature profile in the high-temperature 1ocal channel $[P(r)=1.3, \alpha(l, r)=1.4]$ 


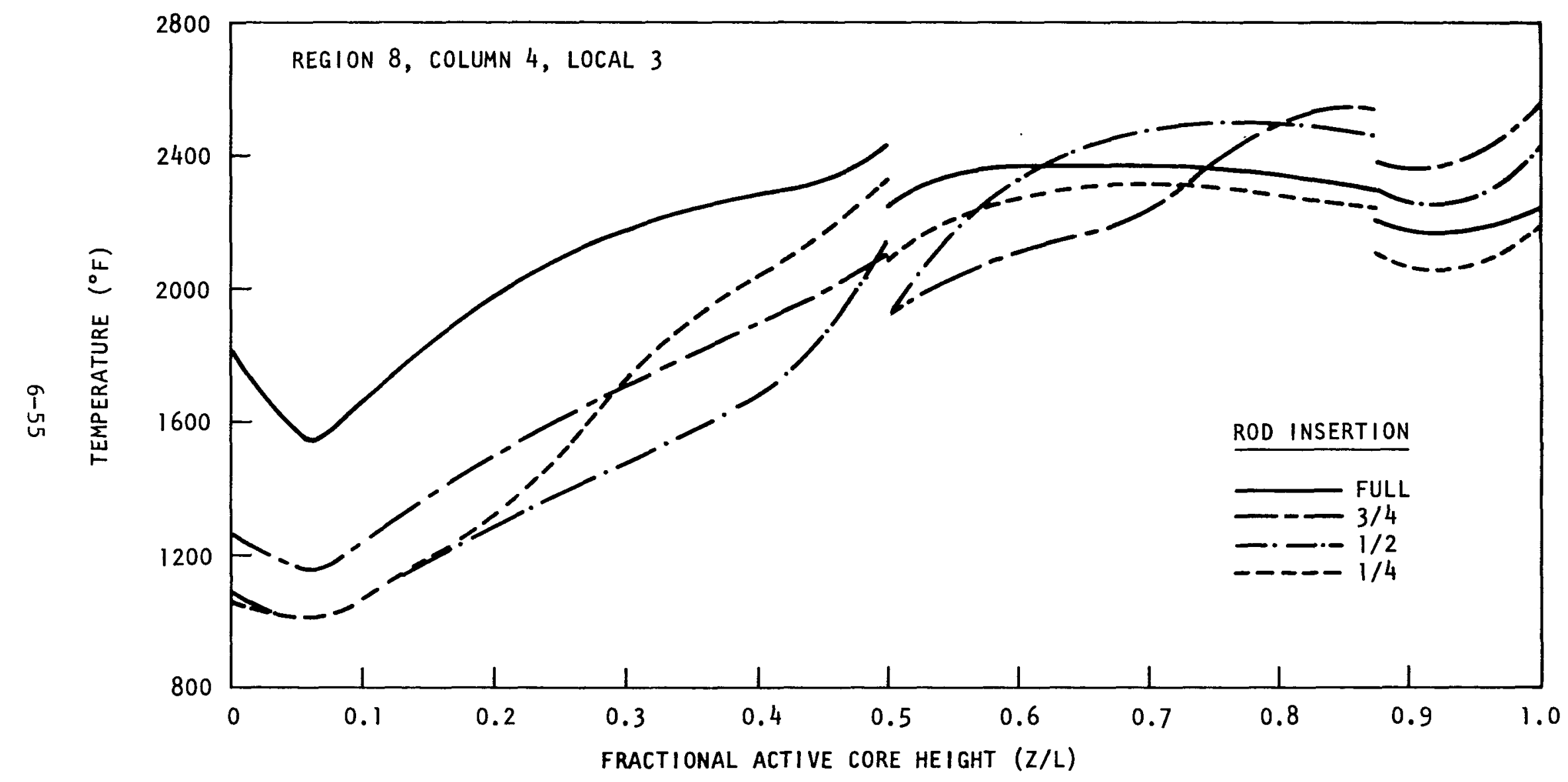

Fig. 6-21. Axial fuel temperature distribution in quarter rodded, half rodded, and fully rodded regions 


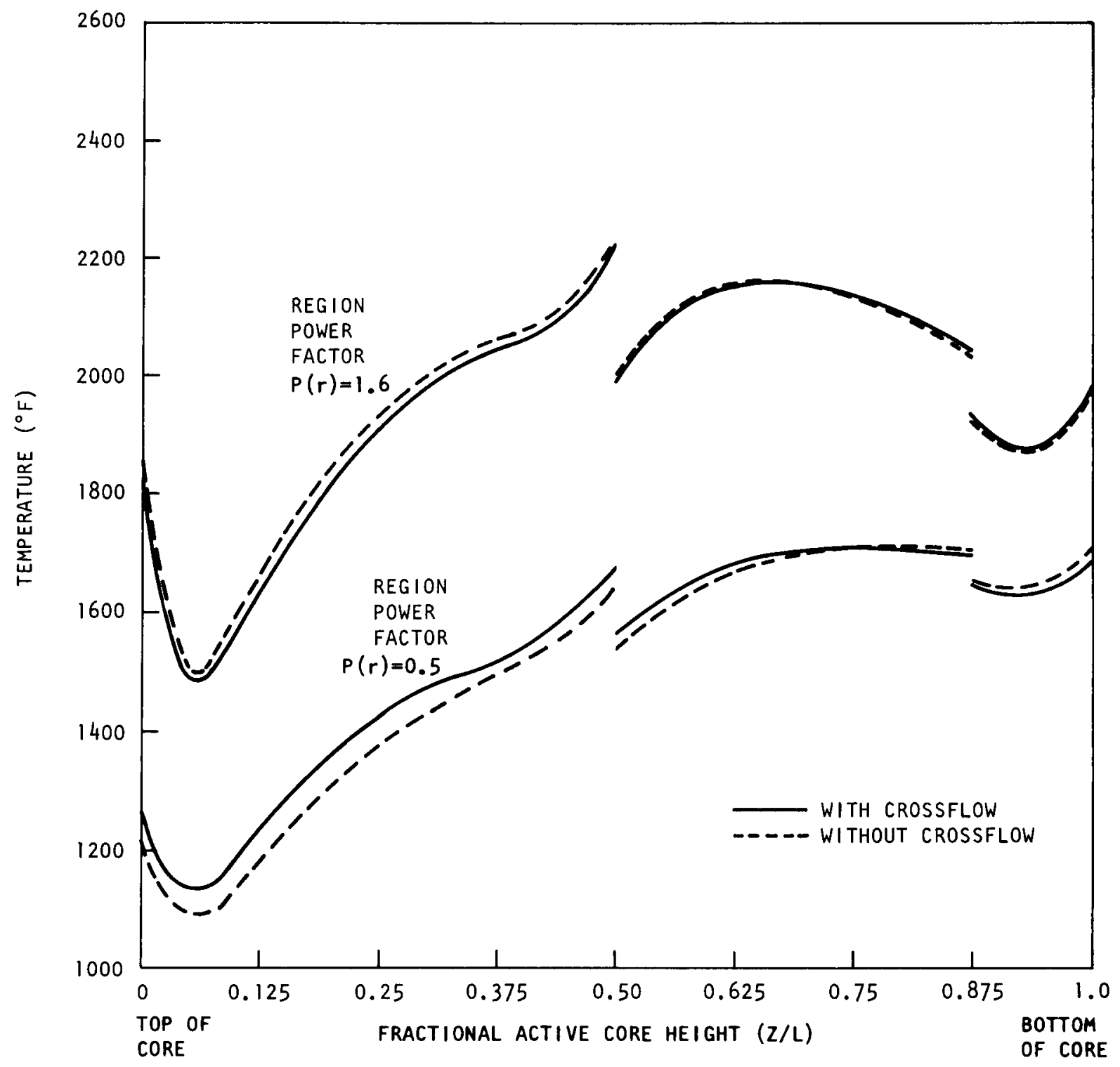

Fig. 6-22. Effect of crossflow on fuel temperatures in high and low power regions 
Even with the more pessimistic crossflow factors chosen for design (see Table 6-3) the impact of crossflow between coolant channels and the core interelement gap structure is still quite minimal.

6.1.5. Time-Dependent TREVER Analysis

A number of important phenomena affecting the performance of the fuel, fuel elements, and core are dependent upon the long-term time history of core temperature, fast neutron fluence, and burnup. Reference 6-8 describes the fuel particle behavior quantitatively in terms of these core environmental parameters. Dimensional changes in graphite and fuel rods (Section 5.5) and metallic fission product release (Ref. 6-9) are also time and temperature dependent. A need became apparent as the design progressed for the ability to survey an entire core to find areas where design parameters are near their limits and therefore more careful attention to local effects is merited. The TREVER code (see Section 4.1.5) was developed to carry out the temperature survey of the entire core quickly using simple but accurate approximations. Capability has been added to facilitate the use of temperature histories to define coating failure, fuel element stress (Ref. 6-10), and fission product release (Ref. 6-11).

The heat transfer model used is the unit cell model also used by the POKE and BACH codes. In the current TREVER analysis, several conservative assumptions are made:

1. The major core design parameters such as core thermal power, total core helium flow, and inlet helium temperature used in the calculations correspond to plant end-of-life minimum expected conditions. These conditions are conservative for the core as indicated in Section 5.1.

2. A conservative flow split between fixed orifice columns and variable orifice regions is used (Section 6.1.2.1). 
3. Currently the coolant exit temperature in each refueling region has been set to exceed the core average exit temperature by $50^{\circ} \mathrm{F}$ (Section 6.1.2.1). This is equivalent to assuming that there is about a $6 \%$ coolant flow deficiency to each region at all times.

4. The graphite thermal conductivity values as a function of temperature and fluence are given in Fig. 5-1. Currently the thermal analyses use a temperature-independent but conservatively age-dependent thermal conductivity of graphite as shown below.

$\begin{array}{ll}0 \text { to } 1 \text { year } & 16 \mathrm{Btu} / \mathrm{hr}-\mathrm{ft}-{ }^{\circ} \mathrm{F} \\ 1 \text { to } 2 \text { years } & 12 \mathrm{Btu} / \mathrm{hr}-\mathrm{ft}-{ }^{\circ} \mathrm{F} \\ 2 \text { to } 4 \text { years } & 10 \mathrm{Btu} / \mathrm{hr}-\mathrm{ft}-{ }^{\circ} \mathrm{F}\end{array}$

5. The fuel rod thermal conductivity is dependent on the shim content and temperature as discussed in Section 5.6.1. A conservative value of $4.0 \mathrm{Btu} / \mathrm{hr}-\mathrm{ft}-{ }^{\circ} \mathrm{F}$ is used at all temperatures, fluences, and shim particle content.

6. The beginning-of-life gap between fuel rod and graphite hole depends upon the type of process used in the fuel element assembly. In the current reference cure-in-place process, the molded green fuel rods are placed in the fuel holes and the complete fuel element is heated to high temperature to cure the rods. This process yields gaps between fuel rod and graphite hole as low as 0.002 in. Also, at some locations along the length the rods are bonded to fuel holes. A beginning-of-life gap of 0.005 in. is conservatively used.

7. The fuel rod dimensional change model used in the thermal design is described in Section 5.6.6. Capsule results (Ref.6-12) 
indicate that this model over-predicts the fuel rod shrinkage and therefore the gap width and the gap temperature drops calculated are expected to be conservative.

8. As indicated in Sections 5.5.4 and 5.6.3, the measured values of graphite hole and fuel rod surface emissivities are in the range of 0.86 to 0.92 . A value of 0.8 is used for both graphite and fuel hole surfaces.

\subsubsection{Time-Temperature History. For steady-state, rated-power} operation, temperature history calculations are made for coolant, graphite, and fuel components at numerous locations within the core. To characterize the spectrum of fuel temperature behavior, three typical high-temperature fuel channels are presented in this report. Each of the channels is representative of those in one of the following three categories of refueling regions:

1. A refueling region which is itself not rodded but which is adjacent to a rodded region.

2. A refueling region into which control rods are inserted; i.e., a rodded region.

3. A refueling region that is not rodded itself and is not adjacent to a rodded region.

Complete 4-year histories of fuel centerline temperature, fuel hole surface graphite temperature, coolant helium temperature, and fuel rod surface temprature gradient for each of the three channels are shown in Figs. 6-23, 6-24, and 6-25. These temperatures are plotted for the axial location having maximum fuel temperatures. The temperatures are typical of an equilibrium cycle. 


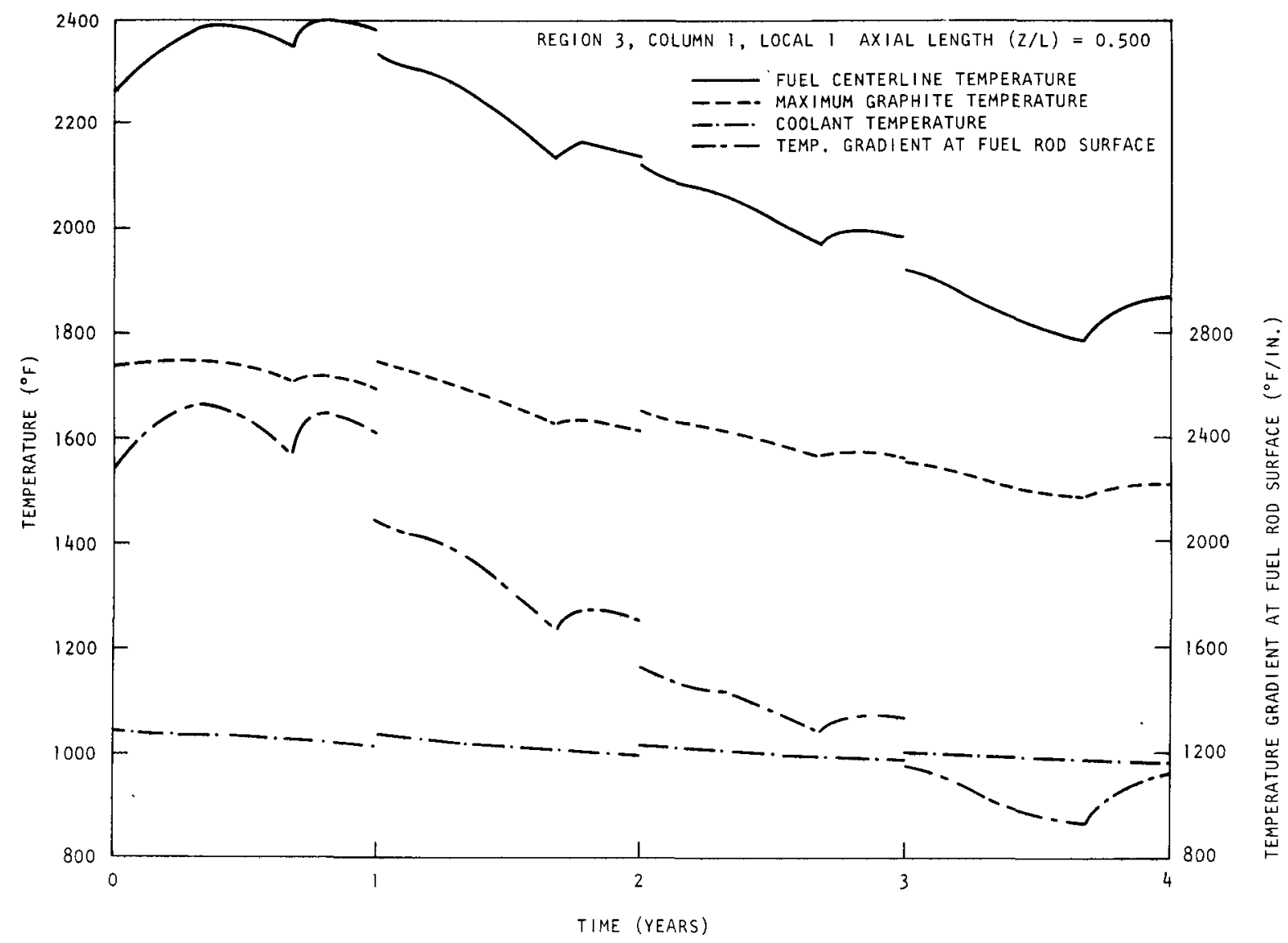

Fig. 6-23. Temperature histories in a typical unrodded region adjacent to a rodded region 


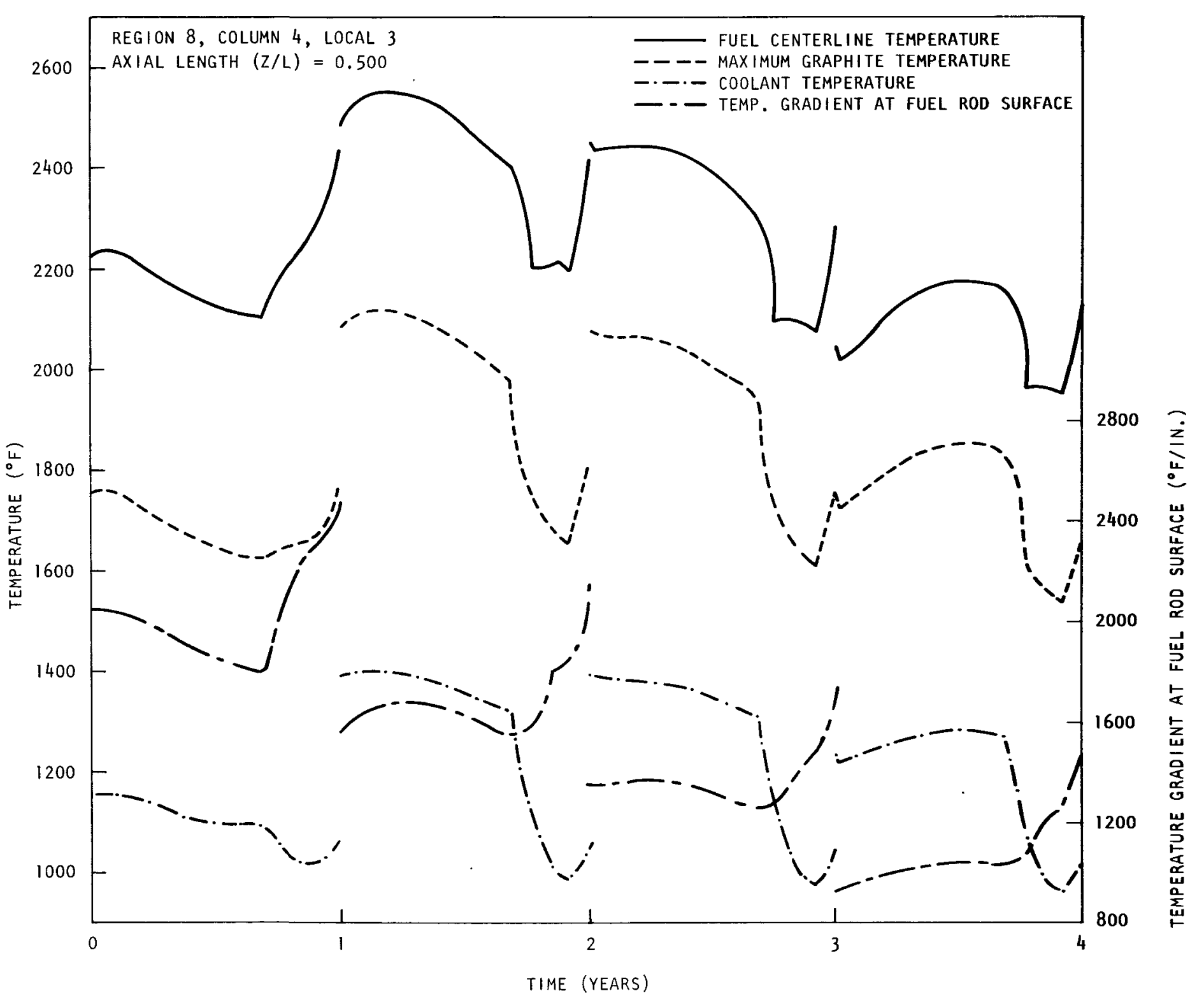

Fig. 6-24. Temperature histories in a typical rodded region 


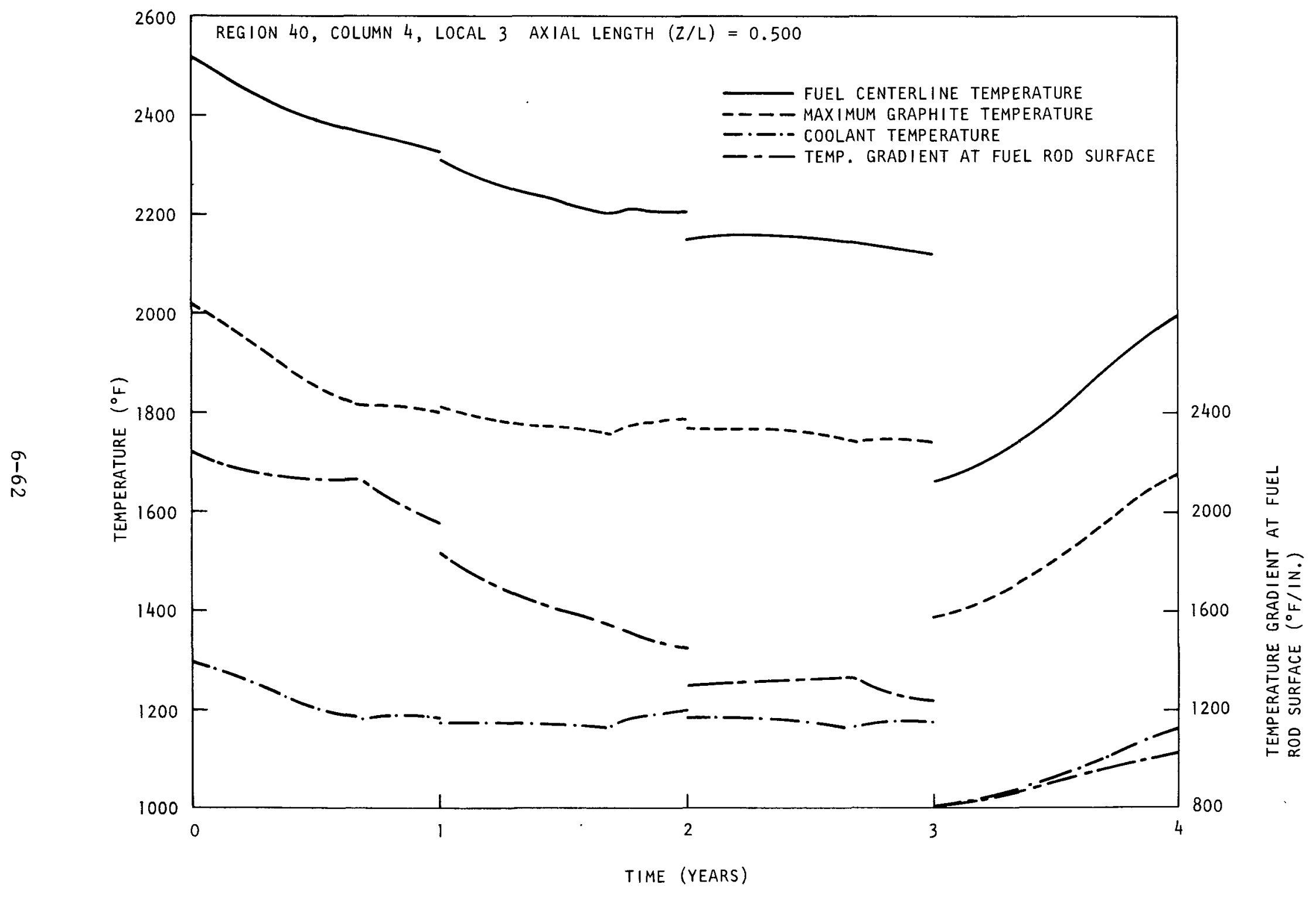

Fig. 6-25. Temperature histories in a typical unrodded region 
The temperature histories plotted in Fig. 6-23 are for a typical fuel rod stack in an unrodded region adjacent to a rodded region. The region shown, region 3, is located near the center of the core in the first ring of refueling regions (see Fig. 2-2). The time shown on the abscissa is the time since the region was reloaded. The fuel temperature increases slowly during the first 125 days (an 80\% load factor is assumed for all data presented) as the burnable poison is depleted. This is followed by a slight radial shift in power from the center of the core toward the boundary. This radial shift at 125 days into the reload interval occurs as a result of the radial zoning of the fuel and burnable poison. This shift in power toward the boundary and depletion of the fuel tends to cause the temperature to decrease slightly. At about 200 days into the reload interval, the control rods begin to withdraw from the core. As the rods are withdrawn, the power level and temperatures increase in regions near the rodded regions.

This same general pattern of temperature behavior is repeated for subsequent reload intervals. However, the burnable poison is essentially depleted after the first reload interval. Continued depletion of the fissile material tends to cause the fuel temperature pattern to exhibit a slight downward trend with time. But as the fuel depletes, the power density decreases which in turn results in a decrease in the rate of depletion. Hence, during the last year of the 4-year cycle the fuel temperature is relatively constant except for the perturbation resulting from the motion of control rods. During the 4-year time history, the graphite and fuel temperatures slowly decrease while the coolant temperature is held relatively constant by the adjustment of flow control valves.

The temperature and temperature gradient data typical of a rodded region are presented in Fig. 6-24. During most of the first year of this cycle, region 8 is not rodded and behaves in a manner similar to that of 
the region described above. However, during the second, third, and fourth intervals of the 4-year cycle, the region is fully rodded for about the first 200 days of power operation. Thereafter, control rods are gradually withdrawn during the last 100 days of each cycle.

During the second and third year, the fuel temperatures decrease slowly during the first 200 days of operation as the fuel depletes. As the control rods are withdrawn, the intraregion power tilt is reduced but as there is little change in axial peaking at this location, the fuel temperature decreases sharply up to about 225 days. Thereafter, the fuel temperatures increase until the end of each year as the control rods are withdrawn further, which causes an increase in radial and axial power peaking. During the beginning of the last year of this reload, the region power decreases as an adjacent region is reloaded with fresh fuel. Therefore the fuel temperature is low at the beginning and increases as the region power increases due to depletion of the fresh fuel in the adjacent region. The temperature behavior during the last part of this year is determined by the removal of the control rods as in previous years. The coolant and the graphite temperature behavior is similar to that of fuel temperature, whereas the surface temperature gradient in the latter part of each year increases with region power as the control rods are withdrawn.

Figure 6-25 is a plot of the temperature data for an unrodded region, region 40, near the boundary of the core. During the first 3 years, the temperature decreases slowly as a function of time. This region being unrodded and being away from the rodded region, it does not experience any noticeable temperature perturbations due to control rod motions. At the start of the last year of the 4-year fuel cycle, the fuel temperature undergoes a step reduction with the decrease in region power as an adjacent region is reloaded with fresh fuel. As the fresh fuel in the adjacent region depletes, the region power and, consequently, the fuel temperature increases rapidly until the end of the reload cycle. The graphite and 
coolant temperature distributions behave in a similar manner as that of the fuel temperature.

The above temperature plots are for some typical high-temperature locations in the core. From detail core survey calculations, the following general conclusions can be made:

1. The initial core is very well behaved and has very low temperatures in all the locations of the core.

2. The regions that are loaded at the end of first year have higher temperatures as a result of higher age peaking.

3. In general, the highest temperatures are experienced during the first year of the fuel's life in the core, then there is a gradual decline in temperature throughout the remaining 3 years.

4. In various locations in the core significant, discontinuous temperature reductions occur at the end of each year as a result of shifts in power caused by refueling of adjacent regions.

5. The impact on both radial and axial power distribution caused by control rod motion is most apparent in rodded regions, but to a smaller extent in regions adjacent to rodded regions. Even the regions near the core boundary feel a small radial perturbation of local power due to control rod motion near the center of the core.

6. During the part of the year when the shim rods are being withdrawn, fuel temperatures increase in the bottom portion of the partially rodded region as a result of the rod-induced axial power shift. 
One of the quantities of interest is the distributions of the volume fractions of the fuel and graphite experiencing peak and time-averaged temperatures during the 4-year residence time of a typical segment in the core. Figure 6-26 shows such fuel volume distributions in segment 5 (defined in Fig. 5-11) for illustrative purposes; the other segments have quite similar distributions. One of the curves in Fig. 6-26 shows the distribution of the fuel volume fractions experiencing peak values of the fuel centerline temperature during the 4-year residence time. The other curve is the distribution of the fuel volume fractions experiencing temperatures averaged over the 4-year residence time in the core. Corresponding distributions for graphite are shown in Fig. 6-27. It is apparent that even though a small fraction of the fuel and graphite experiences relatively high temperatures, the time-averaged values of temperatures are low.

6.1.5.2. Dimensional Changes of Core Graphite and Fuel Rods. Variation of the flow and heat-transfer geometry with irradiation is computed as part of the TREVER analysis. The dimensional change behavior model for graphite and fuel rods under thermal and irradiation environments used in the analysis is given in Section 5.5. The histories of dimensional changes are shown at the same core locations for which the temperature histories are given in Section 6.1.5.1. The coolant hole, fuel hole, and fuel rod diameters as a function of fuel life in a typical unrodded region adjacent to a rodded region are plotted in Fig. 6-28. Initial diameters of the coolant and fuel holes and the fuel rod are slightly larger than the room temperature dimensions given in Tables 2-2 and 2-3 because the components operate at elevated temperatures. As can be seen, the graphite and fuel components both shrink with irradiation resulting in decreases in coolant hole and fuel hole diameters. Fuel rods shrink at a slightly faster rate with fluence than graphite, leading to an increase in fuel moderator gap during operation. In both cases the major fraction of the total dimensional change occurs during the first year of operation. 


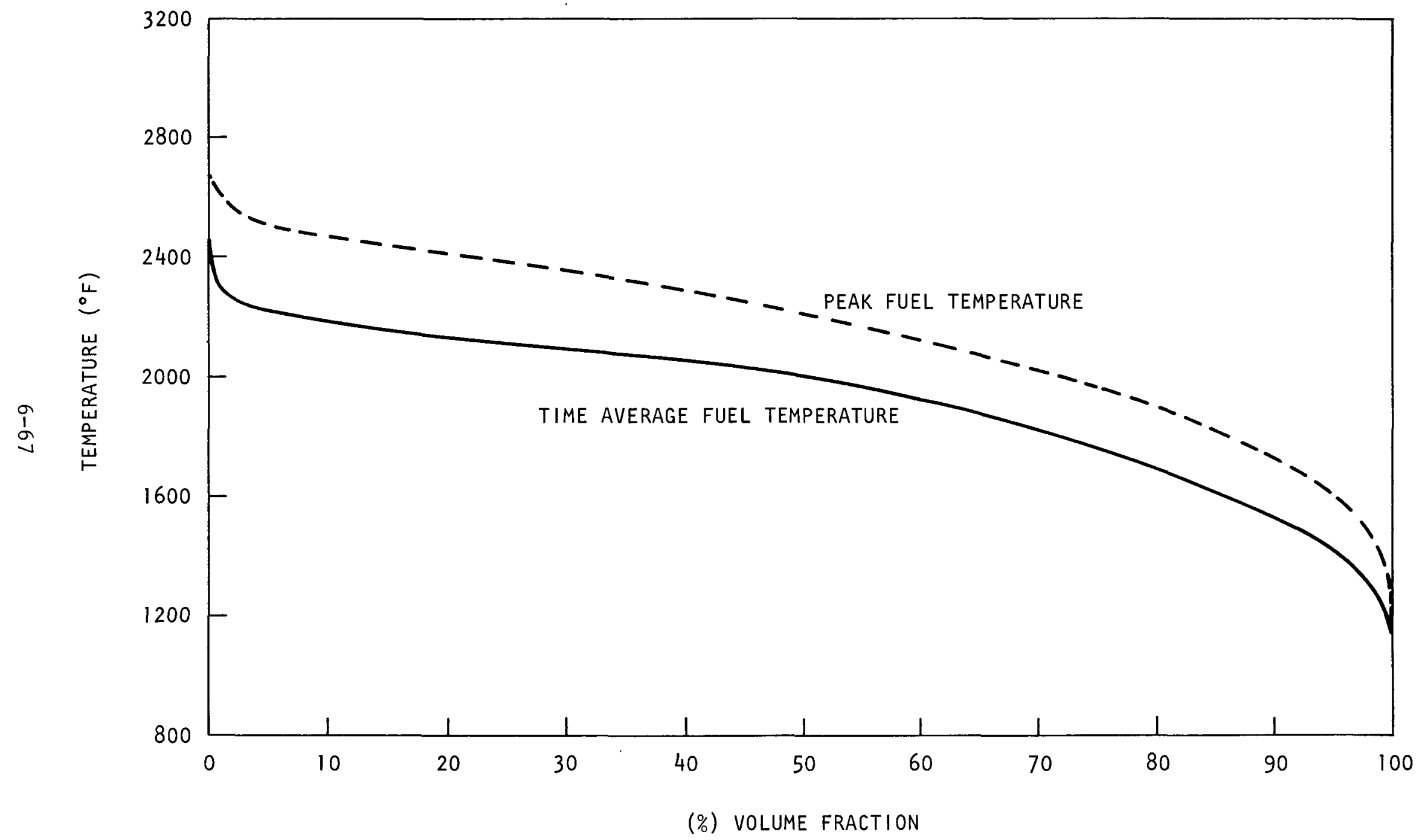

Fig. 6-26. Volume distribution of peak and time-average temperature of fuel in segment 5 


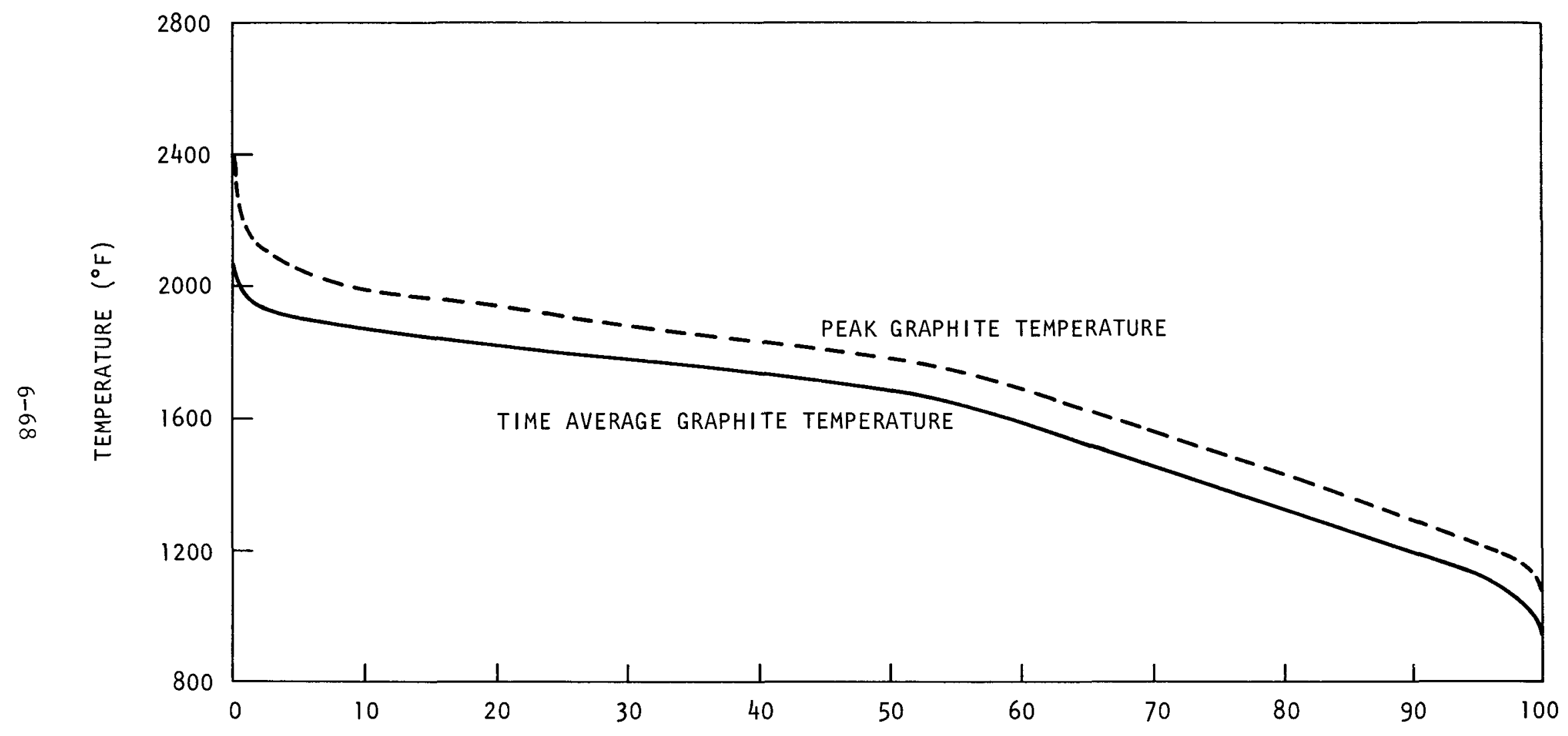

(\%) VOLUME FRACTION

Fig. 6-27. Volume distribution of peak and time-average temperature of graphite in segment 5 

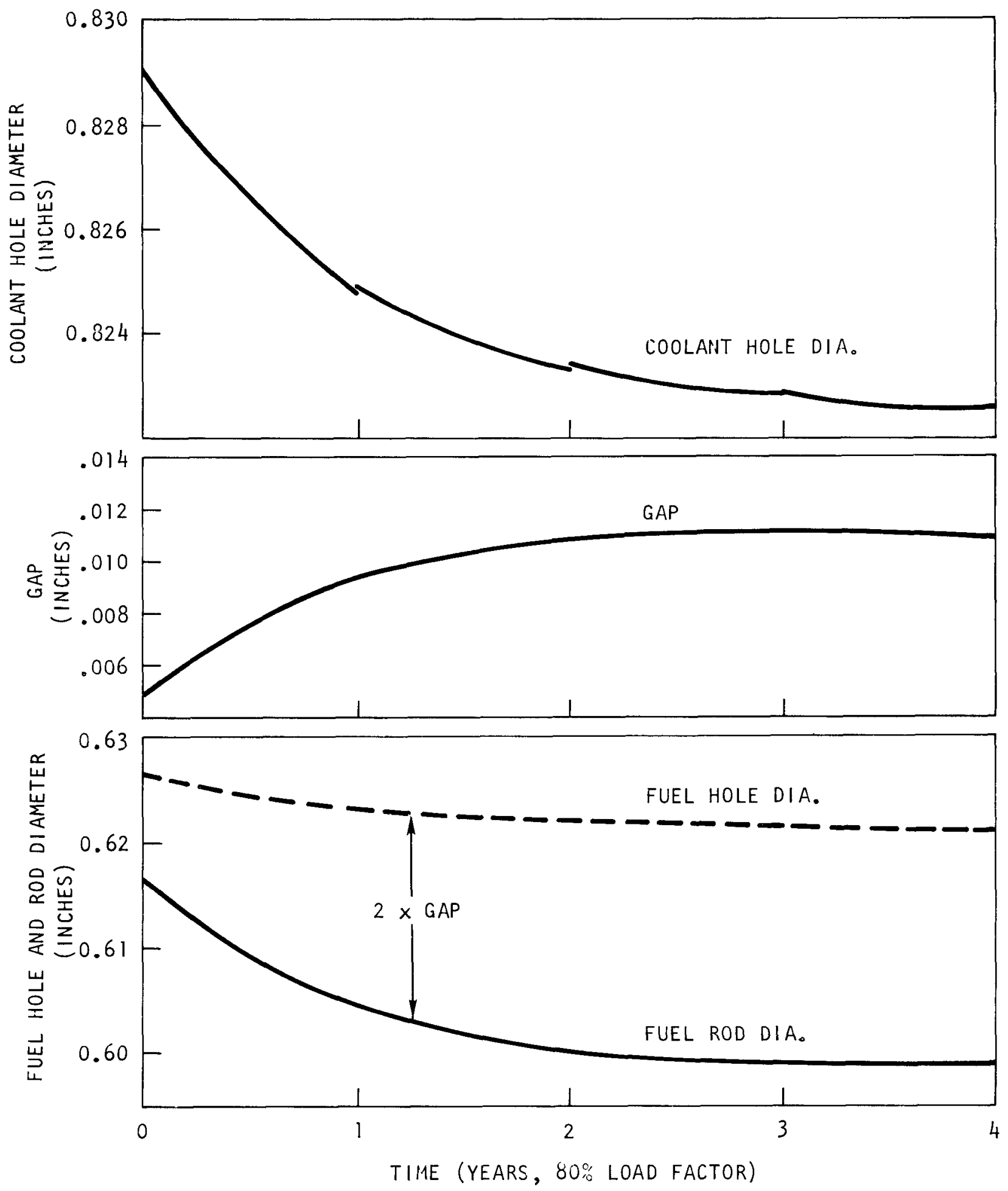

Fig. 6-28. Coolant hole, fuel hole, and fuel rod dimensional change in a typical unrodded region adjacent to rodded region 
In the TREVER analysis, the gap widths are calculated at each time point at all locations and are used to calculate the gap conductance and the temperature drop across the gap. Figure 6-29 shows the typical dimensional change of coolant and fuel hole diameter in rodded region 8 at axial midheight $\mathrm{Z} / \mathrm{L}=0.5$. It should be noted that the impact on the gap width of the rather large variation of fuel and graphite temperatures during the last 100 days of each annual cycle is rather small.

The axial variation of temperatures, fluences, and shim loading results in an axially varying gap width. In Fig. 6-30 an axial gap distribution for fuel rods from a typical rodded region at the end of 4 years of irradiation is plotted. It can be seen that near the inlet and outlet of the active core the dimensional changes are smaller as a result of lower fast neutron fluences at their locations. The maximum dimensional changes occur toward the middle of the core.

In Section 7 the use by TREVER of the time histories of fuel temperature to predict the fuel performance is discussed.

6.1.6. Comparison of BACH, TREVER, and DEMISE Code Results

The results of a comparison of the fuel temperatures calculated by the $\mathrm{BACH}$, TREVER, and DEMISE codes are presented and discussed in this section. The analyses were carried out using power distribution data generated by the BUGTRI code (Ref. 6-7) for region 25 at the end of the third year (Table 5-11). The comparison is presented in two parts: (1) a TREVER/BACH comparison utilizing nuclear data computed with the GAUGE code (Ref. 6-7) and, (2) a BACH/DEMISE comparison using power distribution from nuclear BUGTRI analysis (Ref. 6-7). Two different nuclear codes were used because the TREVER code is set up to interface with the GAUGE code via tapes generated by GAUGE while DEIISE requires the more detailed power distributions furnished by BUGTRI. Figure 6-31 gives the pointwise powers 

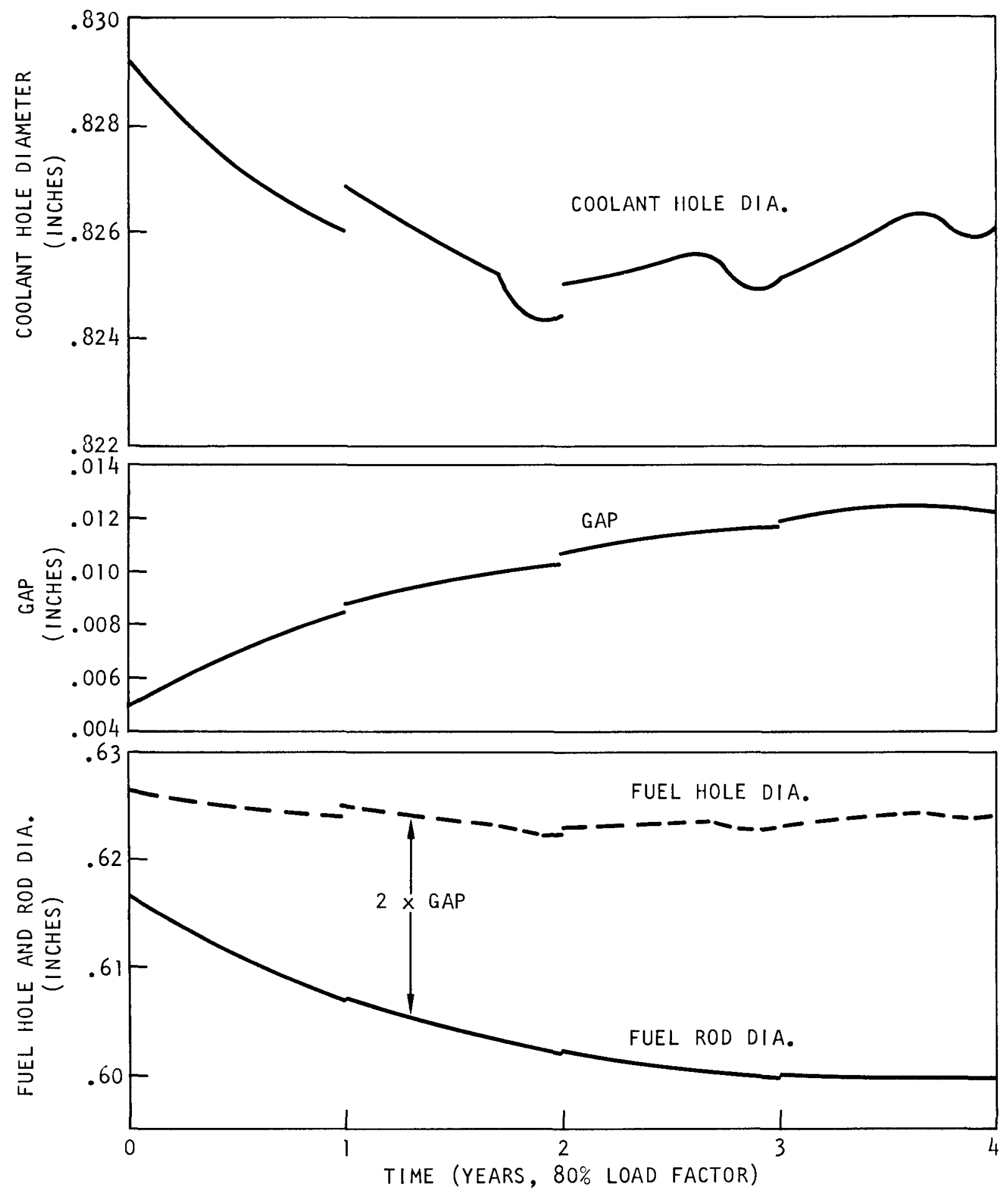

Fig. 6-29. Coolant hole, fuel hole, and fuel rod dimensional change in a typical rodded region 


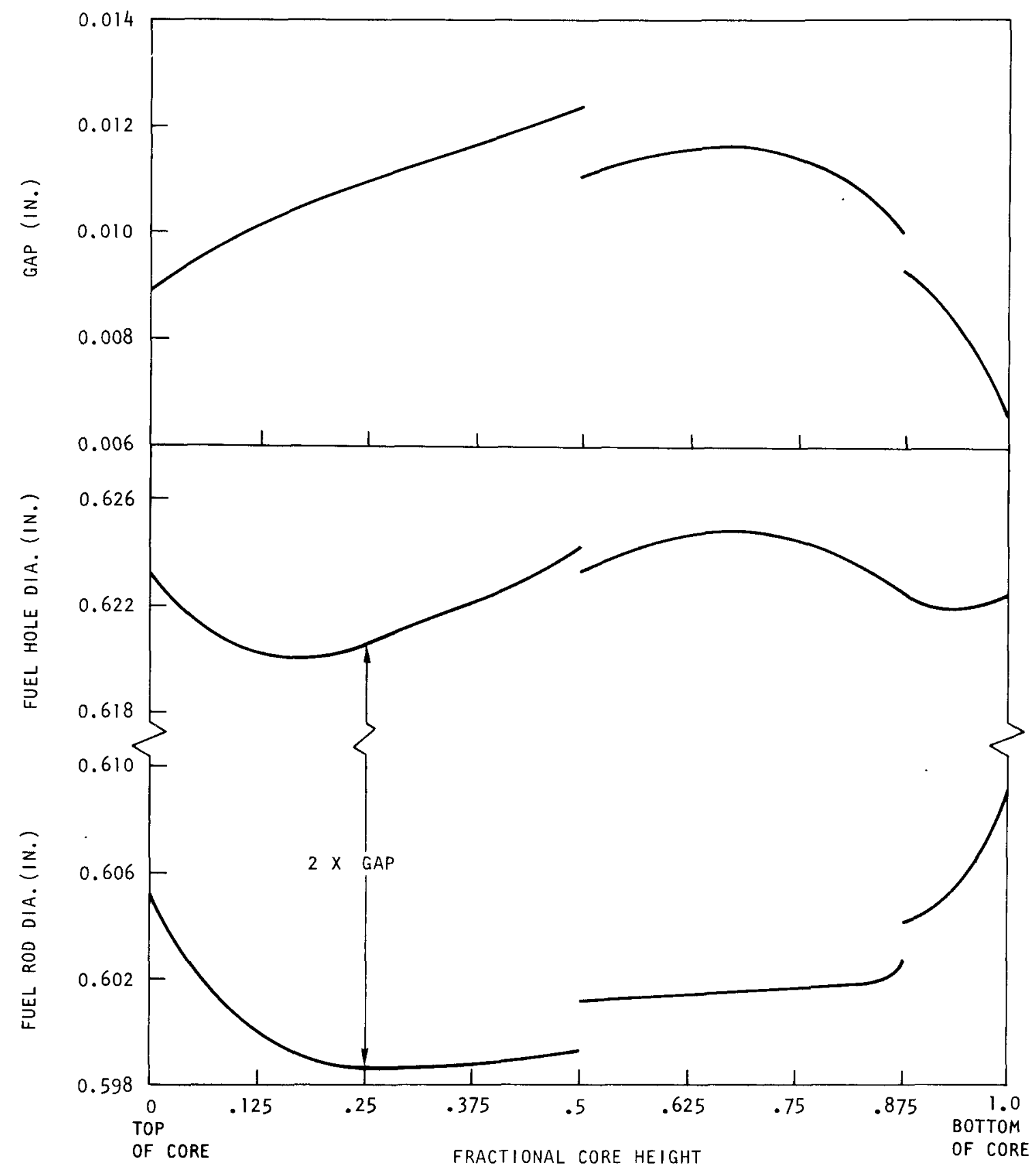

Fig. 6-30. Axial profiles of end-of-1ife fuel hole, fuel rod, and gap dimensions in a typical rodded region 
calculated by the two nuclear codes for an identical location and time in terms of intraregion power tilt. Data shown is for a fuel column in region 25, which contains the points with quite high tilts. It can be seen that the power distributions calculated by the two codes are quite similar although the GAUGE region power factor is about $2-1 / 2 \%$ higher than that calculated by BUGTRI. The comparison of the BACH and TREVER codes was performed using the half of the block containing the point with the highest tilt as indicated by the shaded areas in Fig. 6-31.

For the TREVER/BACH comparison, the codes were set up with the same assumptions and input insofar as possible. Slight differences in calculational methods exist between the two codes as explained in Sections 4.1.4 and 4.1.5. The results presented here indicate that these differences do not introduce significant differences in the calculated fuel temperatures.

A TREVER run was obtained to provide middle-of-block temperatures for local points 1, 2, 3, 4, and 7 in the fuel element (see Fig. 6-31). A BACH run was then made for each of these local points using the fuel rod and coolant hole dimensions calculated by TREVER and the identical radial and axial power distributions. One would expect the codes to be in excellent agreement since they are both one-dimensional unit cell calculations and employ nearly identical assumptions. The results of the comparison, given in Table 6-7, demonstrate that this indeed is the case. The maximum difference in temperature calculated by the two codes is at most $9^{\circ} \mathrm{F}$. This occurs in the middle of the fourth block at point location 4 and arises because TREVER uses a value of $28.50 \mathrm{in}$. for the height of the heat transfer area in a standard element for which BACH uses a core-averaged value of 28.38 in. Therefore, the heat flux at the coolant channel wall calculated by BACH will be a factor of $1.0042(28.50 / 28.38)$ higher than that calculated by TREVER. A detailed comparison of the various temperature drops calculated by the two codes at the location of maximum fuel temperature is given in Table 6-8. Table 6-8 also includes a 
(a) GAUGE DATA

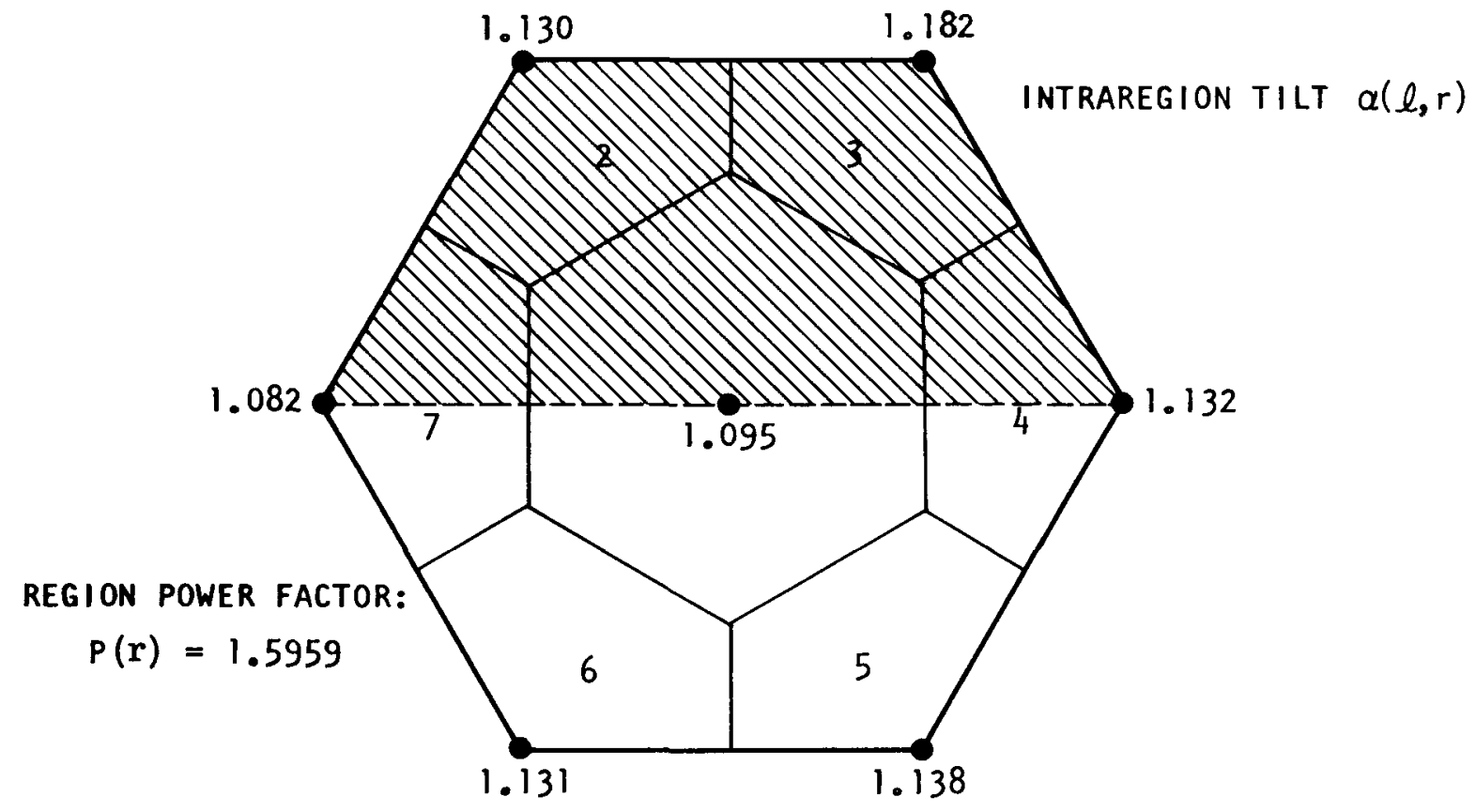

(b) BUGTRI DATA

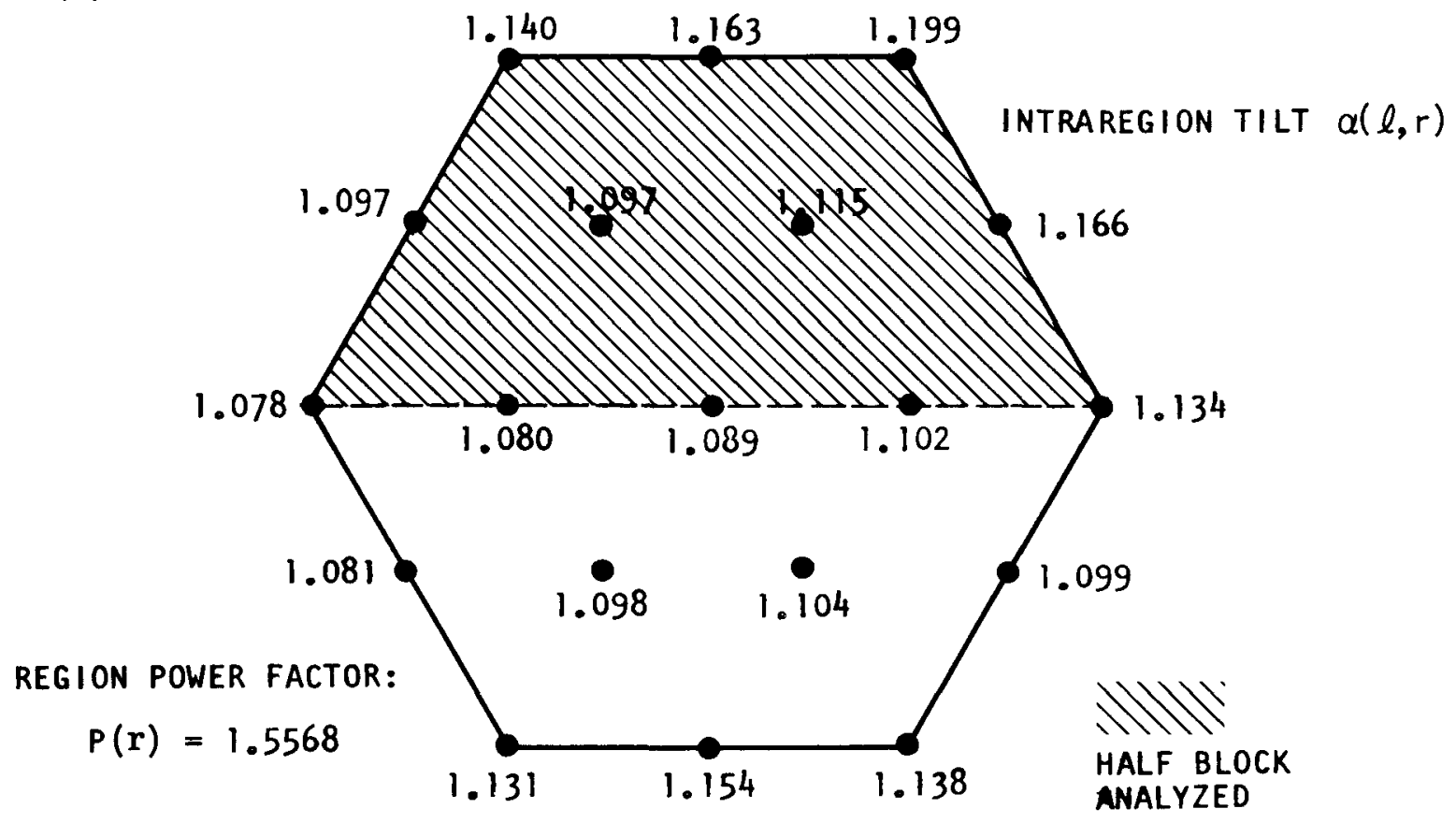

Fig. 6-31. GAUGE and BUGTRI intraregion tilt distribution for region 25, column 5 at end of reload 2 
TABLE 6-7

COMPARISON OF BACH AND TREVER RESULTS AT LOCATIONS OF MAXIMUM TILT IN COLUMN AND MAXIMUM DIFFERENCE

IN CALCULATED TEMPERATURE

\begin{tabular}{|c|c|c|c|c|}
\hline \multirow{2}{*}{$\begin{array}{l}\text { Axial } \\
\text { Location }(\mathrm{Z} / \mathrm{L})\end{array}$} & \multicolumn{2}{|c|}{$\begin{array}{l}\text { Local Pt. } 3 \\
\text { Fuel Centerline } \\
\text { Temperature }\left({ }^{\circ} \mathrm{F}\right)\end{array}$} & \multicolumn{2}{|c|}{$\begin{array}{l}\text { Local Pt. } 4 \\
\text { Fuel Centerline } \\
\text { Temperature }\left({ }^{\circ} \mathrm{F}\right)\end{array}$} \\
\hline & TREVER & $\mathrm{BACH}$ & TREVER & $\mathrm{BACH}$ \\
\hline 0.0625 & 1193 & 1196 & 1167 & 1171 \\
\hline 0.1250 & 1364 & 1367 & 1330 & 1333 \\
\hline 0.1875 & 1550 & 1554 & 1508 & 1513 \\
\hline 0.2500 & 1758 & 1764 & 1707 & 1714 \\
\hline 0.3125 & 1957 & 1963 & 1899 & 1906 \\
\hline 0.3750 & 2146 & 2153 & 2083 & 2091 \\
\hline 0.4375 & 2308 & 2316 & 2240 & 2249 \\
\hline 0.5000 & 2513 & 2519 & 2437 & 2445 \\
\hline 0.5625 & 2388 & 2393 & 2315 & 2322 \\
\hline 0.6250 & 2458 & 2463 & 2382 & 2389 \\
\hline 0.6875 & 2474 & 2477 & 2397 & 2402 \\
\hline 0.7500 & 2460 & 2463 & 2383 & 2387 \\
\hline 0.8125 & 2416 & 2417 & 2339 & 2342 \\
\hline 0.8150 & 2365 & 2365 & 2288 & 2289 \\
\hline 0.9375 & 2154 & 2152 & 2083 & 2083 \\
\hline 1.000 & 2293 & 2292 & 2215 & 2215 \\
\hline
\end{tabular}


TABLE 6-8

COMPARISON OF BACH AND TREVER CALCULATIONS AT POINT OF MAXIMUM FUEL TEMPERATURE

Region 25, Timepoint 33, $\mathrm{Z} / \mathrm{L}=0.4375$

(End of Reload 2)

\begin{tabular}{|c|c|c|}
\hline \multirow[b]{2}{*}{ Parameter } & \multicolumn{2}{|c|}{ Code } \\
\hline & $\mathrm{BACH}$ & TREVER \\
\hline $\begin{array}{l}\text { Coolant channel wall heat } \\
\text { flux, Btu/hr-ft } t^{2}\end{array}$ & $1.80 \times 10^{5}$ & $1.785 \times 10^{5}$ \\
\hline $\begin{array}{l}\text { Coolant channel mass flow } \\
\text { rate, } 1 \mathrm{bm} / \mathrm{hr}\end{array}$ & 472.3 & 469.8 \\
\hline Coolant temperature, ${ }^{\circ} \mathrm{F}$ & 963 & 964 \\
\hline $\begin{array}{l}\text { Film heat transfer } \\
\text { coefficient, Btu/hr-ft } t^{2}-{ }^{\circ} \mathrm{F}\end{array}$ & 406.3 & -- \\
\hline$\Delta \mathrm{T}_{\text {film }},{ }^{\circ} \mathrm{F}$ & 442 & 440 \\
\hline$\Delta \mathrm{T}_{\text {graphite }}{ }^{\circ} \mathrm{F}$ & 178 & 177 \\
\hline$\Delta \mathrm{T}_{\text {gap }},{ }^{\circ} \mathrm{F}$ & 318 & 313 \\
\hline$\Delta \mathrm{T}_{\text {rod }}{ }^{\circ} \mathrm{F}$ & 347 & 346 \\
\hline $\mathrm{T}_{\text {fue } 1},{ }^{\circ} \mathrm{F}$ & 2249 & 2240 \\
\hline $\begin{array}{l}\text { TREVER heat flux corrected } \\
\text { for difference in stack } \\
\text { heights }\end{array}$ & - & 179,279 \\
\hline $\begin{array}{l}T_{\text {fuel }} \text { based on corrected } \\
\text { heat flux }\end{array}$ & - & 2245 \\
\hline
\end{tabular}


calculation of the fuel temperature based upon a correction of the TREVER coolant channel heat flux for the difference in heat transfer areas. After this correction is included, the two calculations differ by only $4^{\circ} \mathrm{F}$. The bulk of this remained difference is attributable to the difference in the method of calculating the $\Delta \mathrm{T}_{\text {gap }}$ where small differences exist.

The BACH/DEMISE comparison was performed using the DEMISE results presented in Fig. 6-16 and $70 \mathrm{BACH}$ runs set up so that an input value of $\alpha(l, r)$ for a BACH case corresponded to a value of $\alpha(l, r)$ which had been input to the DEMISE code for each of the 70 fuel rods. Thus, the temperature of each fuel rod computed by DEMISE could be compared to a onedimensional $\mathrm{BACH}$ calculation. Figure 6-32 presents the results of the DEMISE and BACH calculations for the fourth element, which is the axial layer with the maximum fuel temperatures. The temperatures calculated by BACH for each fuel pin are shown in parentheses above the corresponding DEMISE calculation.

Examination of Fig. 6-32 shows that both codes indicate that the maximum temperatures are found on the boundary of the element and that the temperatures decrease radially inward and down towards the left-hand corner of the figure. This is in accord with what one would expect after studying the power distribution in the block (Fig. 6-15).

Figure 6-33 is a plot of the fuel temperatures calculated by the two codes at nine nodes along a traverse approximately normal to the lines of constant power. The calculated temperature points have been joined as an aid to viewing. This figure provides an illustration of the differences in results between the two codes. It can be seen that BACH calculates higher temperatures than DEMISE at nodes F 3 and F8 and lower temperatures at nodes F15, F23, and F31. Differences in temperature are intuitively obvious and are due to a radial heat transfer from the high power boundary nodes to lower power interior nodes which is properly modeled only in DEMISE. The 


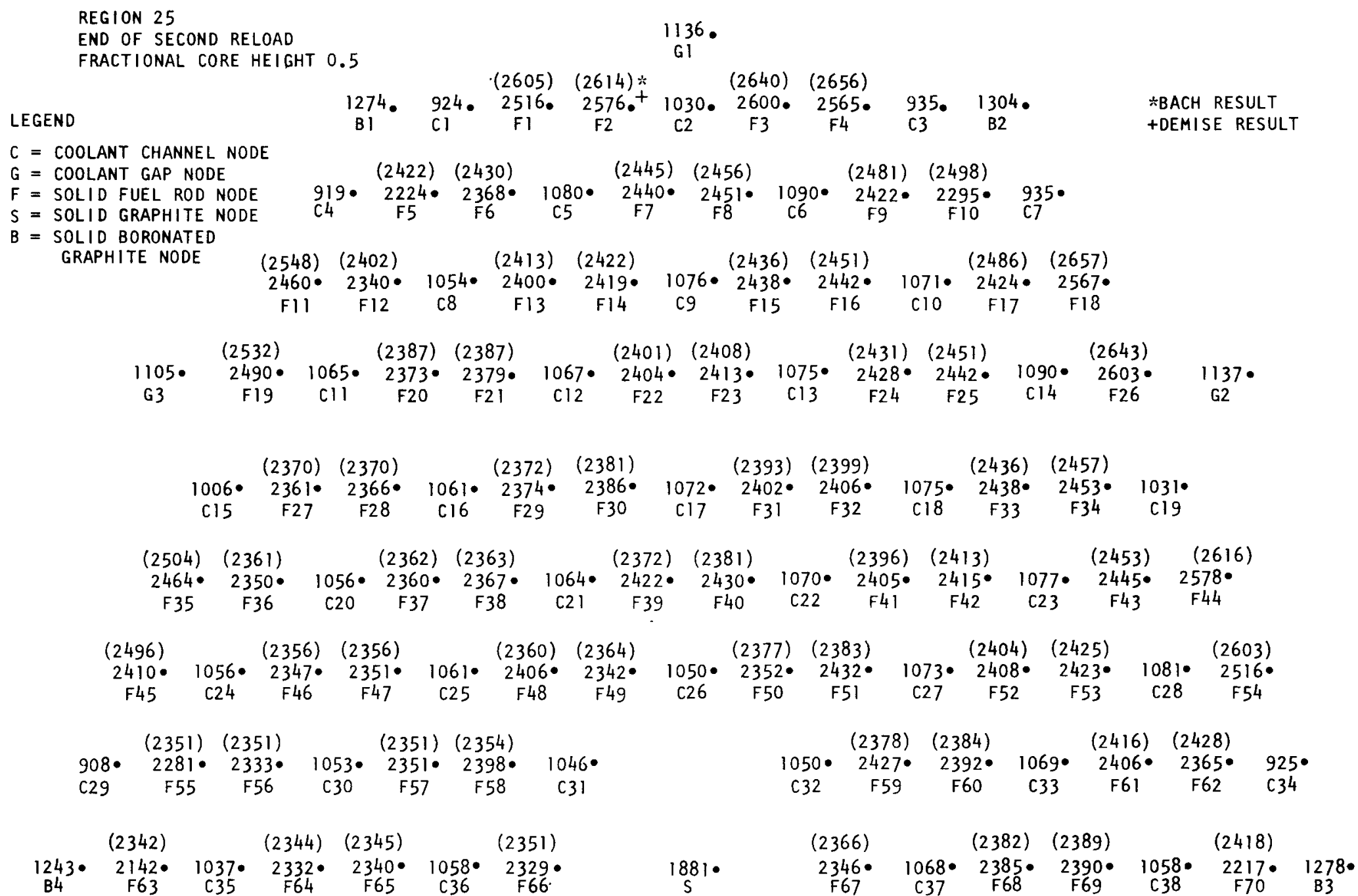

Fig. 6-32. Comparison of fuel temperatures calculated by DEMISE and BACH at core axial mid-height 


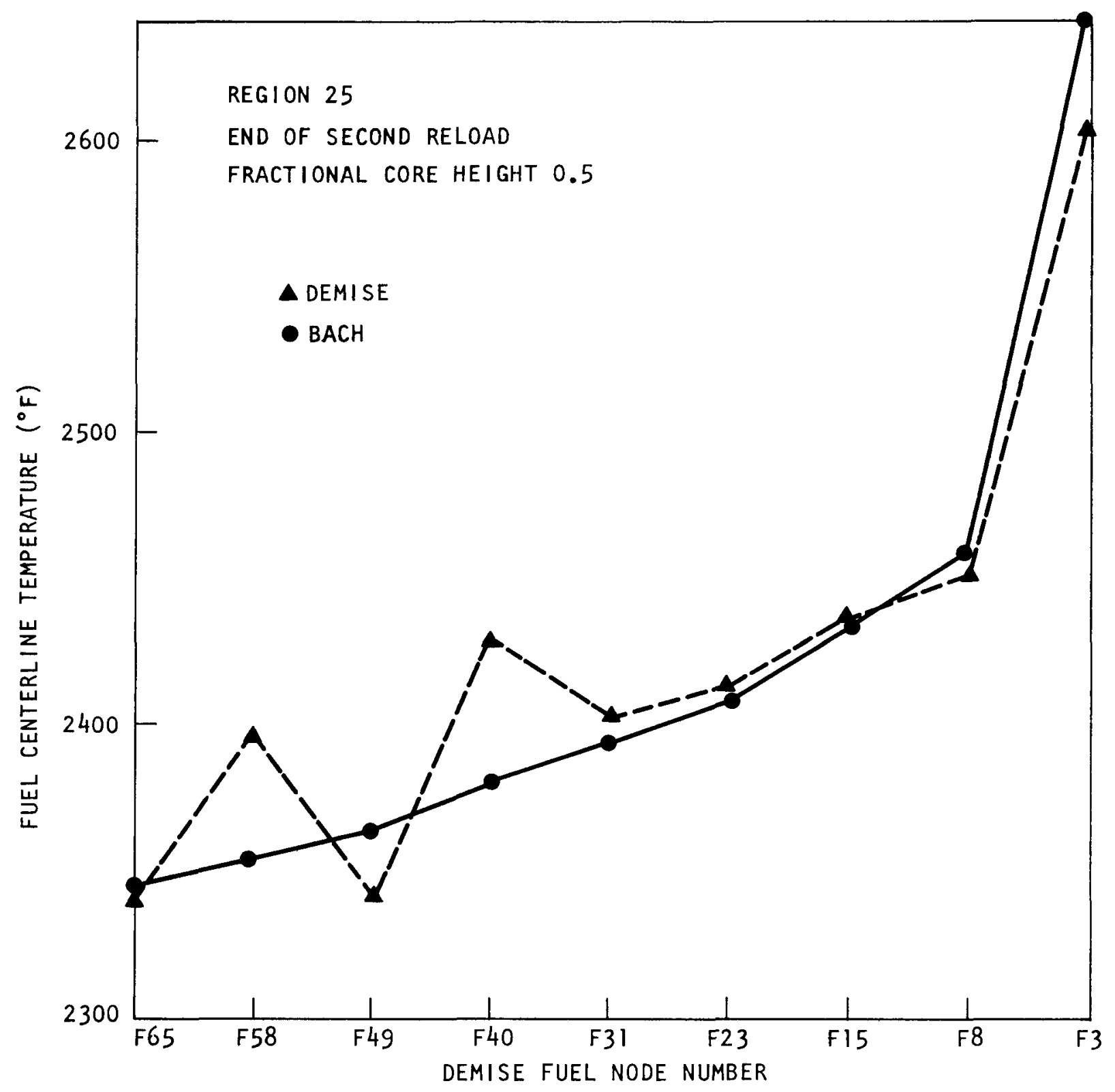

Fig. 6-33. Comparison of DEMISE and BACH calculations along a traverse through the half column 
temperatures calculated with DEMISE in the regions of maximum power will be lower than the comparable $\mathrm{BACH}$ calculation because $\mathrm{BACH}$ assumes that the boundary of the unit cell is adiabatic. In like manner, DEMISE will calculate higher temperatures at the interior nodes because of this radial heat transfer across the block.

At node $\mathrm{F} 40$ it is noted that the temperature predicted by DEMISE is $49^{\circ} \mathrm{F}$ higher than the comparable BACH calculation. There is a loss in total heat transfer area at this node caused by the presence of a smaller diameter (0.717-in. vs 0.826-in.) coolant hole (C26). In all other respects this node conforms to the unit cell geometry. This calculation may be contrasted with the temperature calculated at node F49. Node F49 adjoins two smaller diameter coolant holes but the DEIISE temperature prediction is lower than the corresponding BACH calculation. This result could have been anticipated because node F49 is joined to fuel rods on only two sides and to graphite with lower power generation on the third side. Since the temperatures in the graphite are lower than that of the fuel rods, heat is transferred from the fuel node through the surrounding graphite into the coolant. This may be thought of as an increase in the effective conductance of the node, which lowers its temperature. The DEMISE calculation for node $\mathrm{F} 58$ is higher than the corresponding. BACH calculation for the same reasons given in the discussion of node F40. Node F65 corresponds to the unit cell geometry and is in a region where the gradient in power is low. The DEMISE and BACH calculations are in good agreement at this and other such points.

This comparison of the three codes indicates that: (1) the TREVER and $\mathrm{BACH}$ one-dimensional unit cell calculations are in general agreement when the same nuclear input is used for both codes, (2) the BACH one-dimensional code and DEMISE three-dimensional calculations are in general agreement at points in the column where the gradient in power is low and the insulated boundary assumption for the unit cell geometry is approximated, (3) at 
points where the gradient in power is large, the three-dimensional calculations show that heat will be transferred from the high-power fuel pins to the lower power fuel pins resulting in a reduction in the maximum fuel temperature calculated with a one-dimensional code, and (4) at points in the column where a departure from the unit cell geometry is experienced, a decrease in total conductance will result in an increase in fuel temperature relative to the unit cell calculations. Increases in conductance will have the opposite effect.

\subsection{TRANSIENT ANALYSIS}

Transients for which the HTGR is designed are divided into several categories depending on their expected frequency or probability of occurrence as described in Section 3.3.

Table 3-1 summarizes the normal, upset, emergency, and faulted transients for which the HTGR is designed. Of the normal transients in Table 3-1, the first four (startup and shutdown) are sufficiently slow, compared to the thermal time constant of the core, that the thermal analysis can be performed using steady-state codes. The remaining normal transients are fast, compared to the thermal time constant of the core, and require transient thermal analysis. The upset transients result in fuel temperatures lower than the normal transients discussed above. The emergency and faulted transients can result in some high core average fuel temperatures but their occurrence is not expected at high frequency and in general result in lower fuel temperatures when the appropriate corrective action is taken. Emergency and faulted transients are discussed in Ref. 6-1.

In the HTGR reactor, the peak transient temperatures occur during a transient that results in a simultaneous increase in core power-to-flow ratio and a perturbation in core radial and axial power distributions. 
Plant transients which include all of these effects and result in local fuel temperatures above steady state are the normal (3\%/minute) and the rapid ( $5 \% /$ minute) load-following transients. Analyses of load-following transients which result in local fuel temperature increases are presented in this section for the 3000-MW(t) plant equilibrium core. The first transient presented is a 100-60-100\% load-following transient with a $5 \% / m i n u t e$ return to power occurring at the time point corresponding to the steady-state $60 \%$ load xenon concentration. The second transient analyzed is a worst-case 100-60-100\% load-following transient with return to full power at the time point during the core xenon transient that produces the highest transient fuel temperatures.

\subsubsection{Description of Load Following}

A brief description of events occurring during the load-following transient is helpful in understanding the subsequent discussion.

In the present HTGR plant design, the method of control that has been developed is based on the nuclear steam supply system "following" the turbine generator system. To facilitate the use of modern steam turbines, the nuclear steam supply system is controlled to provide the design steam conditions at the inlet to the high pressure and intermediate pressure turbines. During a load change transient, the throttle valve position on the high pressure turbine is adjusted to provide the steam flow required to generate the electrical load of the station. The automatic control system makes adjustments in the nuclear steam supply system (feedwater flow rate, helium flow rate, and reactor power) to maintain the design steam conditions at the turbines. A description of the automatic control system is provided in Ref. 6-13.

The ability of the HTGR plant to follow, load, and maintain the design steam conditions requires that the nuclear steam supply system be capable 
of delivering energy to the turbines at a rate equal to the turbine generator requirements. The HTGR nuclear steam supply system contains significant energy storage components (graphite core and steam generators) which result in a lag between power generation in the core and energy removal from the nuclear steam supply system.

During transients, power generation in the reactor core and helium flow are controlled such that the energy supplied by the nuclear steam supply system is equal to the turbine generator requirements. During transients, the energy produced in the reactor core will not equal the energy removed from the nuclear steam supply system. The difference between the energy produced and energy removed results in a change in stored energy in the reactor core and steam generators. For the reactor core, the change in internal energy is reflected by a change in fuel and graphite temperatures.

The nuclear steam supply system and control system response to changes in load are analyzed with the TAP code. The plant response obtained from the TAP code provides the plant transient response of core power, core helium flow, inlet helium temperature, and helium pressure, which is necessary for detailed core thermal analyses. In addition to these changes in the plant parameters, the core radial and axial power distribution changes during the load-following transient as a result of control rod movements in balancing the reactivity of the core. In order to understand the events leading to the changes in radial and axial power distribution, a description of control rod movement during two 100-60-100\% 1oad-following transients with return to power at different xenon concentration is given below.

Flow control valves on the core regions are not normally adjusted during load-following maneuvers. But, as results presented later will show, they can in some cases be used to advantage in limiting core coolant exit temperatures and fuel temperatures. 


\subsubsection{Description of Control Rod Movements}

The two transients discussed below are considered to occur near the beginning of cycle in an equilibrium core when the inner shim rod group (regions $8,10,12,14,16$, and 18) are fully inserted and the regulating rod in region 1 is half inserted. To reduce load the regulating rod in region 1 and the outer shim rod group (regions 40, 44, 48, 52, 56, and 60) are inserted to balance the increased reactivity due to the core cooling down. When the desired load is reached, the iodine concentration and thus xenon production through lodine decay nearly correspond to full-power levels. Removal of xenon has decreased approximately proportional to the thermal power. Xenon concentration and xenon contribution to negative reactivity increases are kept in balance by slow withdrawal of first the outer shim rod group and then the regulating rod and inner shim rod group. This withdrawal of rods results in a shift of power toward the center of the core. Higher power peaking factors are experienced not only in the inner shim rod regions but also in other regions ( 2 through 7 and regions $9,11,13,15,17$ and 19) near the center of the core. Higher powerpeaking factors result in undercooling of these regions in the absence of flow redistribution by flow control valve movement. As the reactivity transient continues, the inner shim rod bank continues to be withdrawn until the negative reactivity contribution resulting from xenon buildup peaks. At this point the inner shim rod bank begins a slow insertion and finally the outer shim rod bank is partially inserted as the xenon concentration approaches its part-load equilibrium value.

\subsubsection{Load Increase at Part-Load Xenon Equilibrium. The core power} distribution at part-load equilibrium xenon results in increases in the region radial peaking factors toward the center of the core because of the partial insertion of the outer shim rod bank. Upon return to full-load, the outer shim rod bank is withdrawn to balance the negative reactivity introduced through increased core temperatures. The control rod motion 
results in a more uniform radial power distribution and the radial peaking factors of the central regions of the core decrease during the return-topower.

\subsubsection{Load Increase at Part-Load Peak Xenon Concentration. The core} power distribution at part-load xenon concentrations also results in increases in the region radial peaking factors toward the center of the core due to the withdrawal of the inner shim rod bank. Upon return to full-load, the central regulating rod and inner shim rod bank are further withdrawn to balance the negative reactivity introduced through increased core temperature. The region outlet helium temperature mismatch in the shim rod regions, which developed during the low-power operations, increases during return to full-load. At full-power, the xenon removal rate by neutron capture increases while the production rate is nearly that of the lower power iodine inventory. A decrease in xenon concentration over the next 2 to 4 hours is balanced by shim rod bank insertion to approximately the full-power shape before the load swing.

In addition to the radial power redistribution resulting from load change transients, perturbations to the core axial power shape result from the control rod movements. This effect is most pronounced in the shim bank regions when these rods are partially inserted and result in increased local power densities in the fuel blocks in the bottom half of the core.

The preceding perturbations to the core power, flow, inlet temperature, radial power distributions, and axial power distributions thus necessitate the detailed analysis of the transient fuel temperatures resulting from plant transients. Methods of analysis and models used are discussed in Section 4.2. The results of each type of analysis for two transients are given below. 


\subsubsection{Plant Response TAP Results}

The TAP results for the plant response for a 100-60-100\% loadfollowing transient is shown in Figs. 6-34, 6-35, and 6-36. The load reduction at $5 \% / \mathrm{min}$ begins at $100 \mathrm{sec}$ and continues until $60 \%$ load is achieved. The $60 \%$ load condition is maintained for $1000 \mathrm{sec}$ to allow the system to equilibrate thermally, and then the return to full-load begins at $1580 \mathrm{sec}$. The transient system response parameters are valid for return at any time during the xenon transient as the TAP code is primarily concerned with thermal equilibrium.

The main and reheat steam flow follow the load requirement during the transient. The main and reheat steam temperature response is used by the automatic control system to drive the reactor power and helium flow as shown in Fig. 6-34. The power undershoot during the load decrease, and overshoot during the load increase, drives the volume average fuel temperature (Fig. 6-36) such that the total energy removal from the reactor core is sufficient to deliver the required steam conditions. The variation of the core inlet and outlet helium temperatures during the transient is shown in Fig. 6-35.

In the following sections, the TAP results for total power, helium flow, helium pressure, and helium inlet temperature versus time are used to evaluate the local temperature response of the reactor core during the load increase portion of the load-following transient.

\subsubsection{Reactor Core Thermal Response}

In Section 6.2.3, the major system transient response parameters obtained from the TAP computer code include the core-average coolant outlet temperature and fuel temperatures. These temperatures provide the helium inlet conditions for the steam generator and indicate the core reactivity 


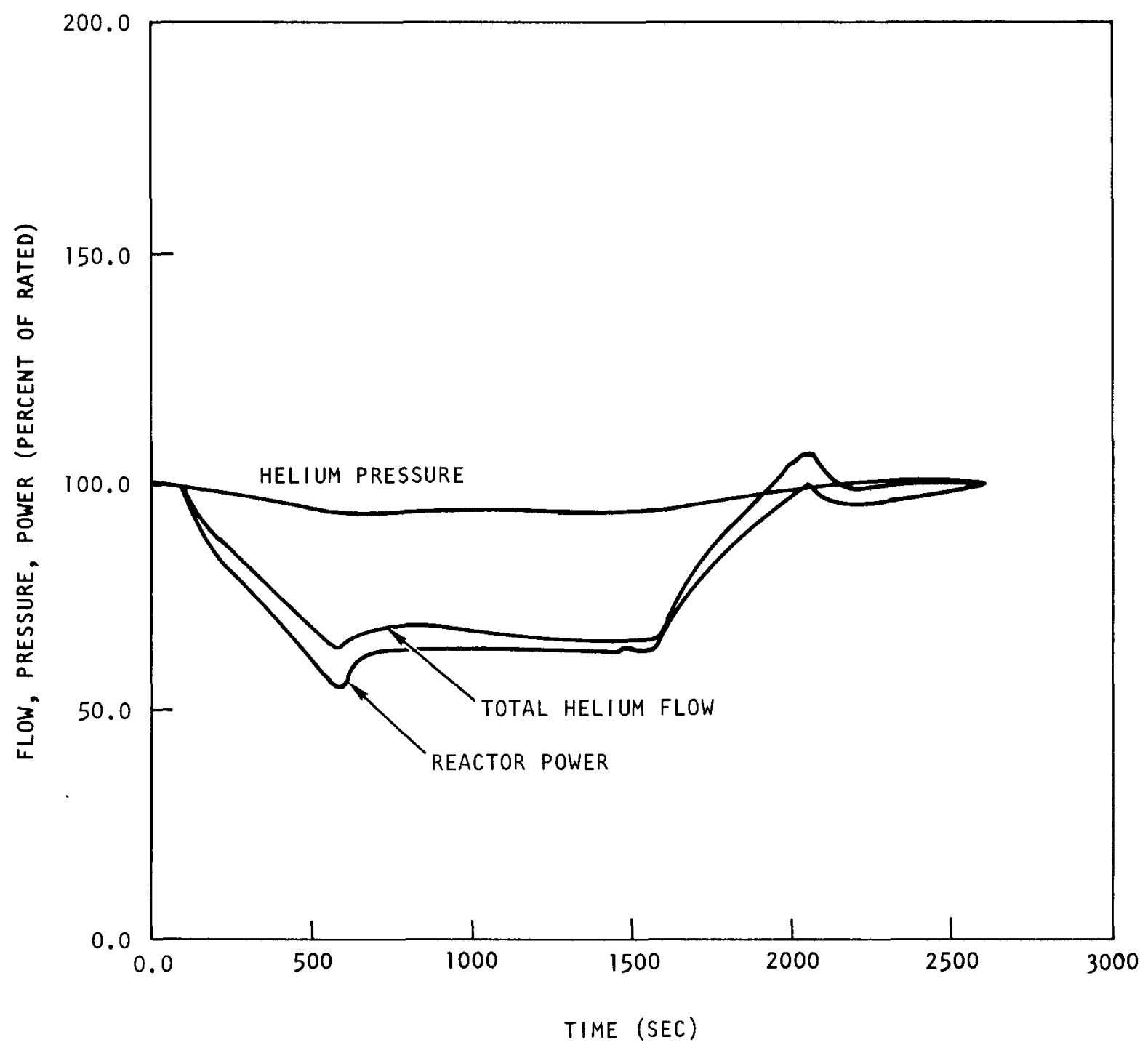

Fig. 6-34. Time history of core power, flow, and helium pressure during 100-60-100 load transient 


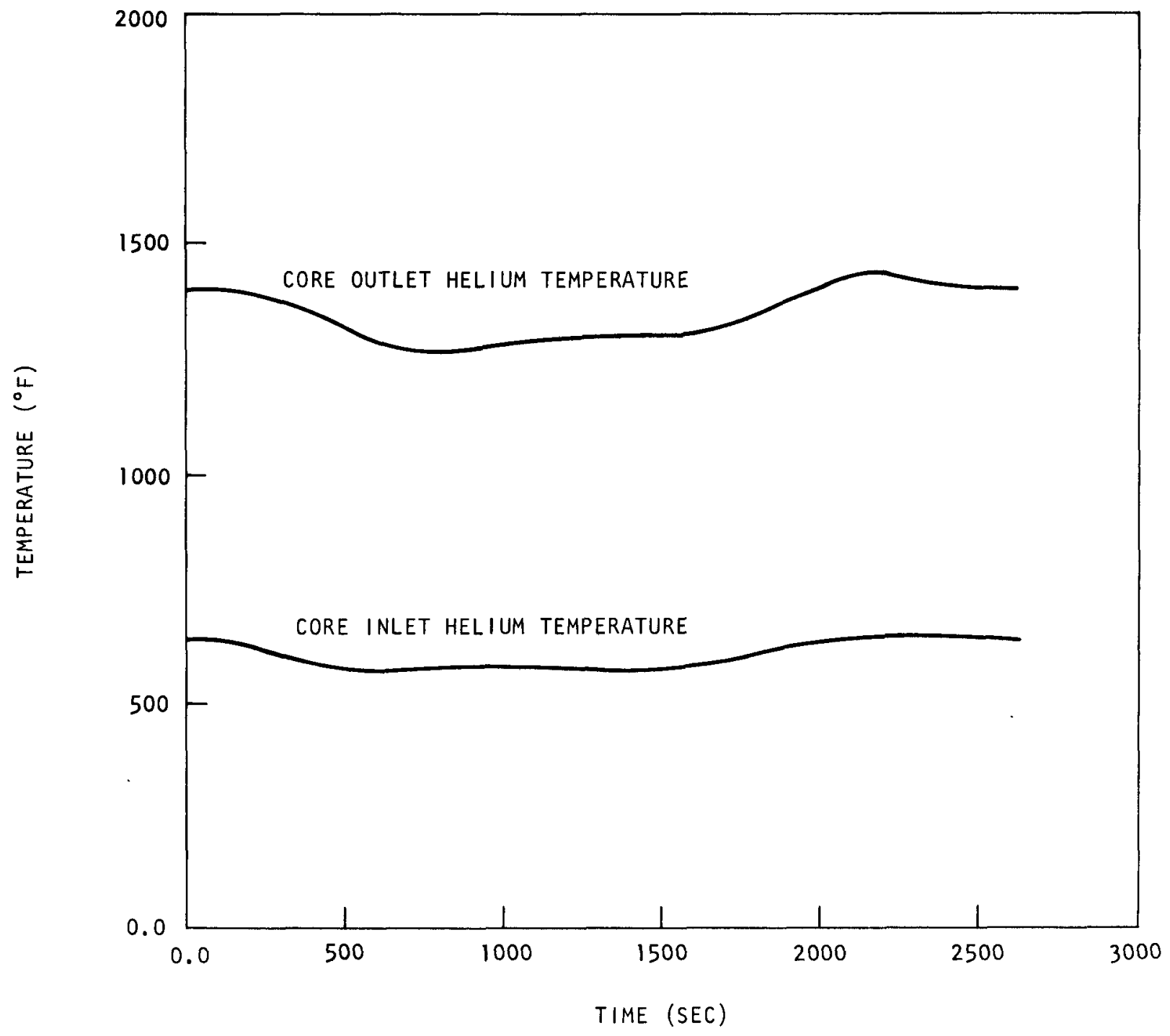

Fig. 6-35. Time history of core helium inlet and outlet helium temperatures during 100-60-100 load following transient 


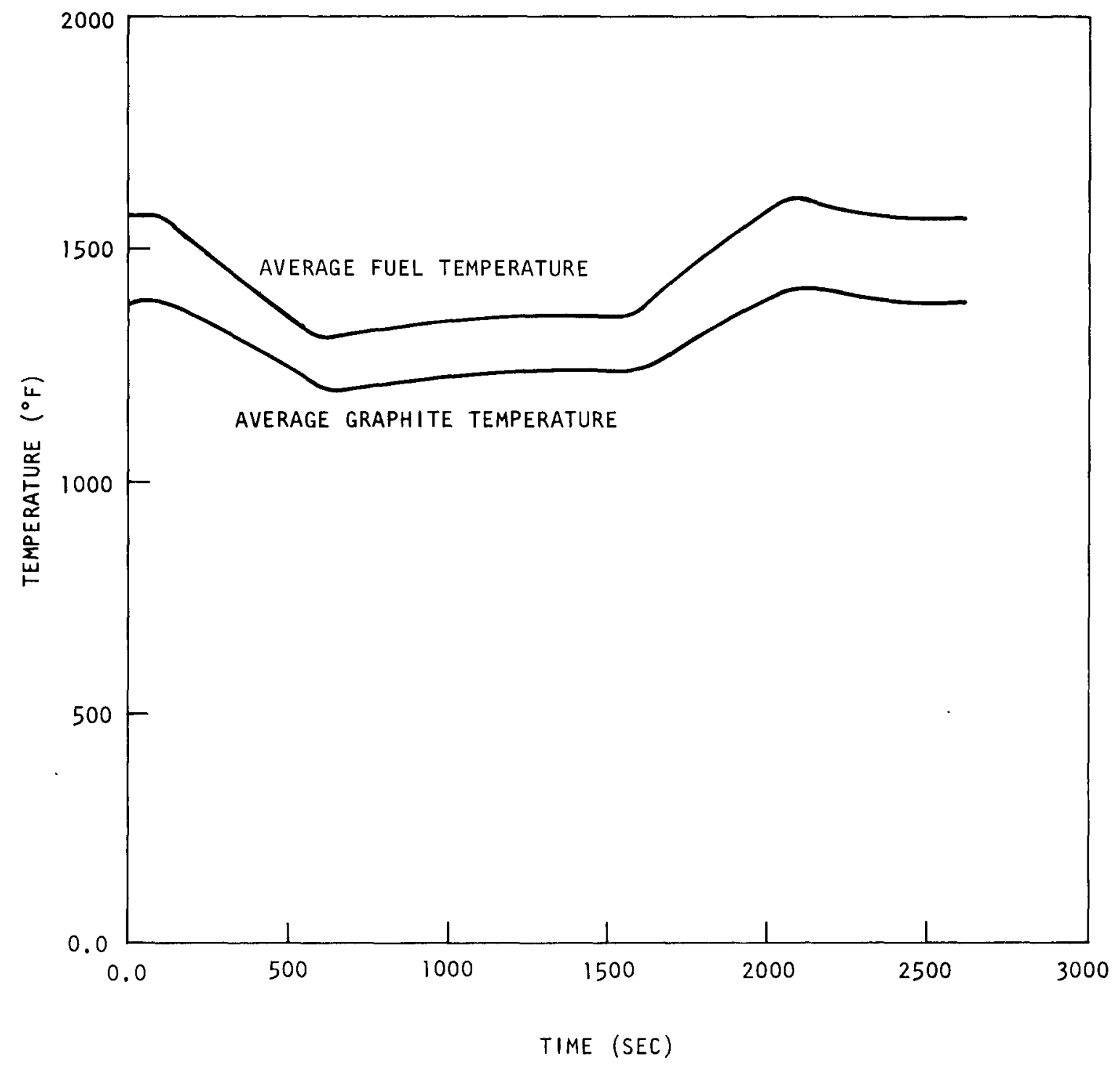

Fig. 6-36. Time history of core average fuel and graphite temperatures during 100-60-100 load following transient 
changes for control rod motion. In order to evaluate the performance of local graphite and fuel components during the transient, a detail thermal analysis of the core is required that includes the effect of changes in local radial and axial power distribution. Detailed transient analyses are performed to evaluate the short term coolant, graphite, and fuel temperature increases above the steady-state conditions.

Examples of operational transients that result in a short-term temperature increase above steady-state values corresponding to full load power are included in this section as illustrations of the results obtained with the DETRAC and TAC codes. The transients analyzed and discussed include the 100-60-100\% transient (5\%/minute) load increase at part-1oad equilibrium xenon transient. During 100-60\% transient the coolant, graphite and fuel temperatures are below that of $100 \%$ steady-state operation. However, during return-to-power the core power-to-flow ratios increased as high as 1.08 and the region outlet helium temperature mismatches increased to $160^{\circ} \mathrm{F}$. When the inner shim rod bank is partially inserted, this results in adverse local axial power distributions and provides local maximum fuel temperature increases above steady-state conditions. Therefore the results reported here correspond to these adverse conditions during the return-to-power transient.

The transients were analyzed using the multichannel DETRAC code discussed in Section 4.2.3 and a detailed TAC-2D unit cell model was used to check the accuracy of the transient response of the DETRAC code. Both codes include thermal assumptions consistent with the BACH code discussed in Section 4.1.4, temperature-dependent fuel and graphite specific heats and fuel and graphite volumes corresponding to a single fuel channel. The detailed transient core power distributions are obtained from physics analyses which determine the core radial and azimuthal power distribution as a function of the overall core reactivity change resulting from xenon changes and the core temperature defect. Transient local axial power 
distributions are also determined from the core transient reactivity change using shim rod bank reactivity worth curves to provide the transient control rod positions. Axial power distributions as presented in Section 5.8.7 are then used in the transient analyses.

6.2.4.1. Load Increase at Part-Load Xenon Equilibrium. As discussed in Section 6.2.1, sustained part-load operation until xenon equilibrium is reached results in a partial insertion of the outer shim rod bank. The radial power redistribution that occurs initiates the largest increase in region radial peaking factors in region 1 with smaller increases in regions in the second ring (regions 2 through 7) and third ring (regions 8 through 19) of the core. In the absence of flow control valve adjustments, the region outlet helium temperature imbalances increase in the central and inner regions and become negative in the outer rings of the core.

In addition to the redistribution of radial power in the core, the axial power is also perturbed and pushed toward the bottom half of the inner regions by the partial insertion of outer shim rods. Another consequence of this redistribution of power in the absence of the valve adjustment is to increase the coolant, graphite, and fuel temperatures in the inner regions specifically in the bottom half of the core; however, the temperatures in the outer regions are considerably reduced. Given below are the temperature histories of some of the local areas in the core where the maximum temperature increases occur over steady-state values.

Figure 6-37 shows the local fuel centerline temperature histories for regions 1 and 3 in the bottom half of the core $(z / L=0.875)$. The highest fuel temperature occurs at this axial location. The local areas in region 1 have the largest intraregion tilt, the largest region outlet helium temperature mismatch, and an axial power profile corresponding to a partially rodded region. The region 3 shown in Fig. 6-37 is among the highest power regions of the core with intraregion tilt greater than unity 


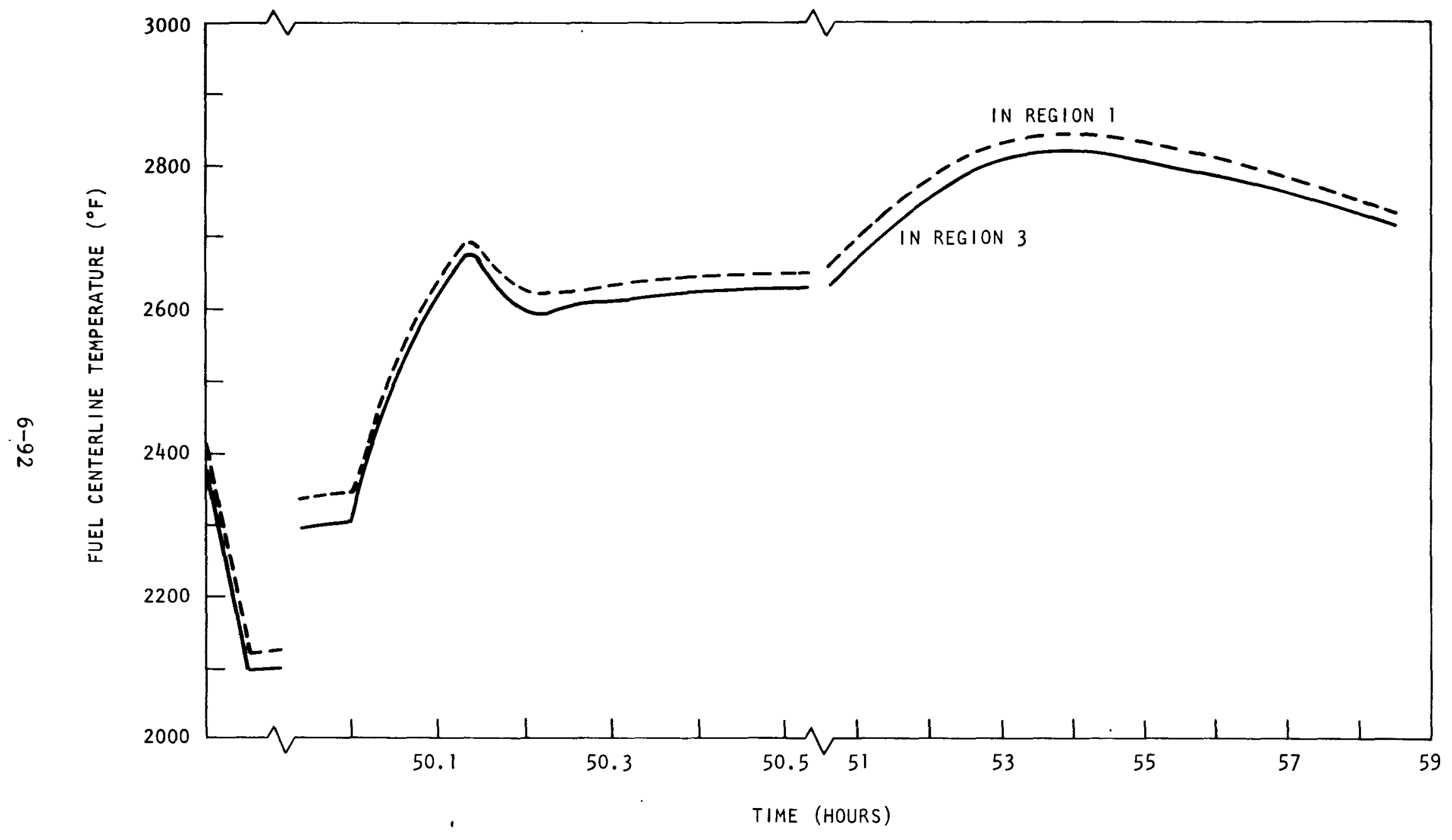

Fig. 6-37. Hot channel fuel temperature without orifice adjustments during 100-60-100 1oad fo11owing transient ramp up from equilibrium xenon 
and a large helium outlet temperature mismatch. In both cases the peak fuel temperatures initially decrease as the load is reduced to $60 \%$ because of the decreased coolant inlet temperature and core power density. The peak temperatures then increase as the region radial peaking factors and region power-to-flow imbalance increase until the xenon concentration equilibrates at 50 hours as shown in Fig. 6-37. At this point the plant is returned to full power at $5 \% /$ minute as shown in Fig. 6-34. The initial short-term temperature overshoot of $100^{\circ} \mathrm{F}$ is due to the core thermal power overshoot. As the core attains full power, an additional long-term temperature transient occurs as the outer shim rod bank is again inserted to maintain core reactivity as the xenon decreases from its part-load level. After several hours of operation at $100 \%$ load, the xenon concentration will return to that of $100 \%$ equilibrium conditions, the outer shim rods will be slowly withdrawn, and the fuel temperature will return to about $2400^{\circ} \mathrm{F}$ from where the transient was started. As can be seen from Fig. 6-37, with no operator action except to move the control rods, the net effect is to increase the peak fuel temperature to about $2840^{\circ} \mathrm{F}$.

To provide examples of the operating flexibility designed into the HTGR core, additional analysis of this transient was performed to determine the transient response with operator action to adjust three flow control valves just prior to the return to $100 \%$ load. The flow control valve in region 1 is assumed to be opened to balance the region outlet temperature. The flow control valves in the two high-powered regions in the second refueling ring are opened to their full-open position thus increasing the coolant flow and reducing the helium outlet temperature mismatch in those regions. With flow control valve adjustments to these three regions, Fig. 6-38 shows that the peak fuel temperatures in region 1 are reduced by $230^{\circ} \mathrm{F}$, while the peak fuel temperature in region 3 is reduced by approximately $130^{\circ} \mathrm{F}$. Continued flow control valve adjustments in region 1 over the 10-hr period following the return to $100 \%$ load can maintain a balanced outlet temperature in region 1 , thus nearly eliminating the temperature transient in region 1 after return to full-power. 


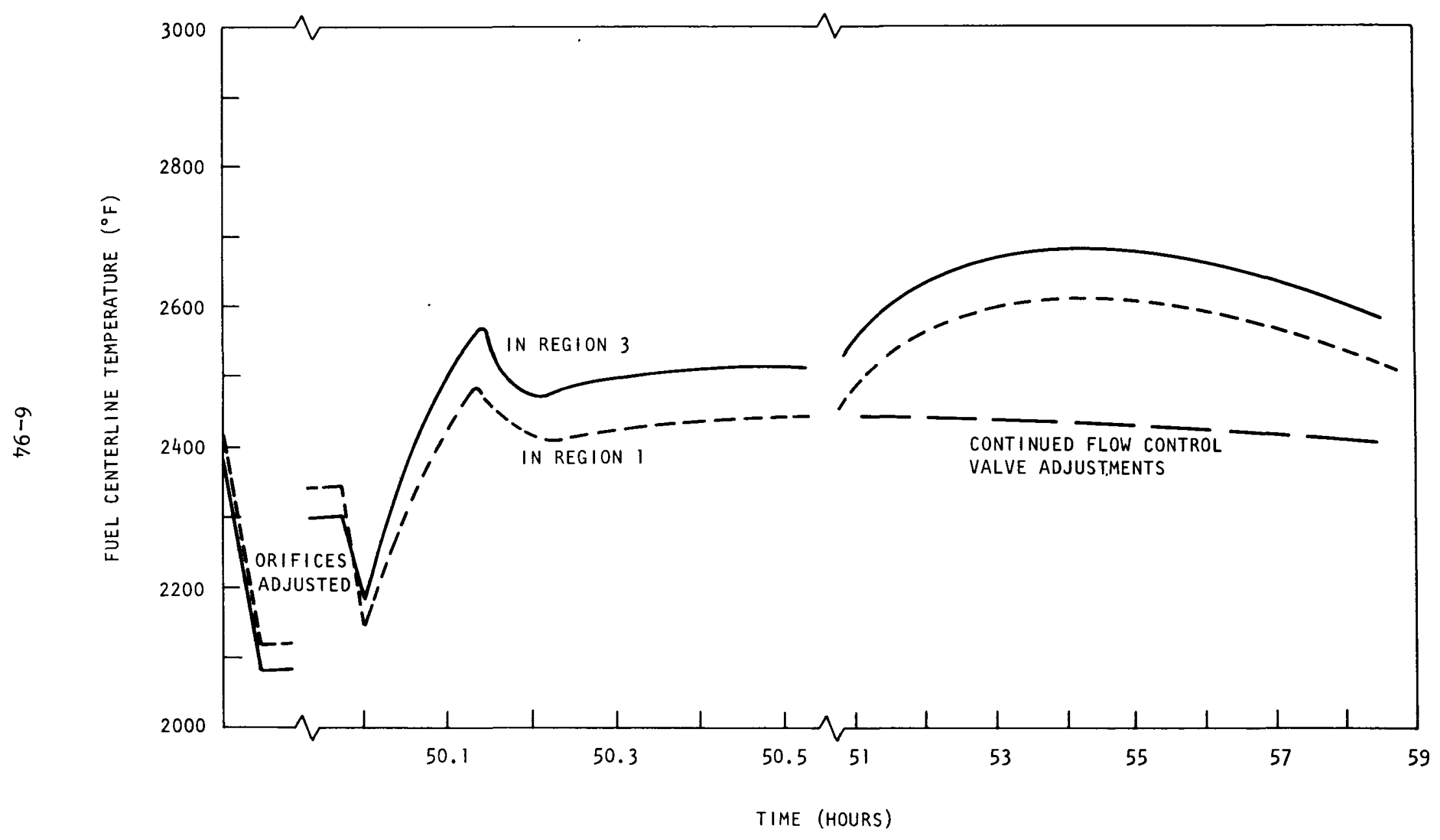

Fig. 6-38. Hot channel fue1 temperature with orifice adjustments during 100-60-100 transient ramp up from equilibrium xenon 
With only flow control valve adjustments to three refueling regions, the peak fuel centerline transient temperature is less than $2680^{\circ} \mathrm{F}$. Additional options, such as repositioning of the central regulating rod, would both improve the axial power profile in region 3 and reduce the power-to-flow mismatch, thus reducing the peak transient fuel temperatures even further.

\subsubsection{Load Increase at Peak of Xenon Transient. The return to ful1} power at the peak of the xenon transient occurs at the time point where the inner shim rod bank is partially inserted as discussed in Section 6.2.2. The localized reactivity perturbations, therefore, result in increased region radial peaking factors and adverse axial power in the partially rodded regions, and increased radial peaking factors in the adjacent regions. The regions that have the largest transient temperature increases are the partially rodded inner shim rod regions and the highest powered region adjacent to the central regulating rod. Local points of selected regions are analyzed to determine the local transient response as affected by intraregion power tilts, region power-to-flow imbalances, and axial power distributions.

Figure 6-39 shows the transient peak fuel temperature response for the highest powered channels of two fuel regions that have the highest temperature increases. One of the regions in which the peak fuel temperatures occur is the highest-powered channel of one of the shim rod regions (region 8) that has the control rods partially inserted. Another channel is the highest powered channel of a high-powered region (region 3) immediately adjacent to the shim rod region and also adjacent to the central regulating rod which is assumed to be inserted to the core midplane. These regions, therefore, have a region outlet temperature imbalance resulting from the inner shim rod bank being partially withdrawn and also have an adverse axial power profile. With these conditions, the peak fuel temperatures of these local channels increase to as high as $2900^{\circ} \mathrm{F}$ during the transient. 


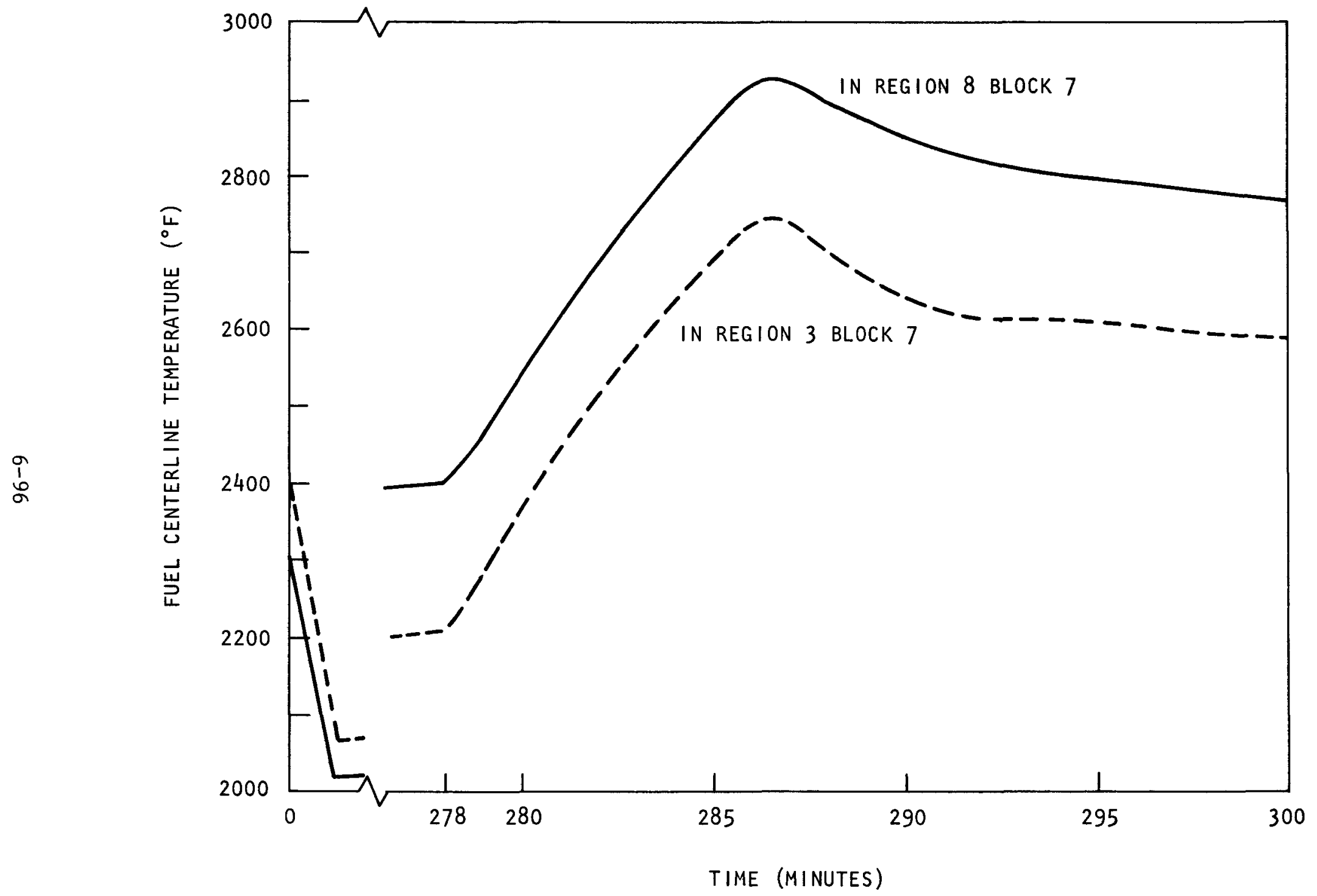

Fig. 6-39. Local fuel temperature in three-quarter rodded and adjacent to half rodded regions during 100-60-100 transient without orifice adjustments 
Figure 6-40 shows the axial temperature profile for the highest powered channel of the inner shim rod bank region at four time points during the transient. At the time point just prior to return to full-power the peak fuel temperatures are skewed toward the bottom of the core. This is a result of the partial rod insertion and undercooling of the region. Upon return to full power, the axial fuel centerline temperature profile increases to that shown in curve 2 due to the core thermal power overshoot, resulting from the control system response. Curve 3 shows the fuel temperature at $100 \%$ power. The temperature profile returns to steady-state over the next two hours as the inner shim rod bank approaches its fullpower equilibrium value.

Figure 6-41 shows the transient peak fuel centerline response if the six flow control valves of the inner shim rod bank are balanced during the xenon transient. The peak fuel temperatures of these regions attained during the transient are decreased to approximately $2700^{\circ} \mathrm{F}$. Additional temperature reductions if required can be easily attained by adjusting the flow control valves to overcool these six regions. With these flow control valve adjustments, the high-powered region adjacent to the partially rodded regions would have the highest transient temperatures. The temperatures in this region can be reduced through flow control valve adjustments or repositioning of the central regulating rod to the three-quarter rodded position. The latter option would both improve the axial power in the adjacent high-powered region and reduce radial peaking factor, thus reducing the region outlet helium temperature mismatch. Through a combination of six to eight flow control valve adjustments and repositioning of the central regulating rod, it is easily possible to limit the maximum shortterm peak fuel temperatures to less than $2600^{\circ} \mathrm{F}$ during the $100-60-100 \%$ load-following transient with return to full power at the most adverse time point during the xenon transient. 


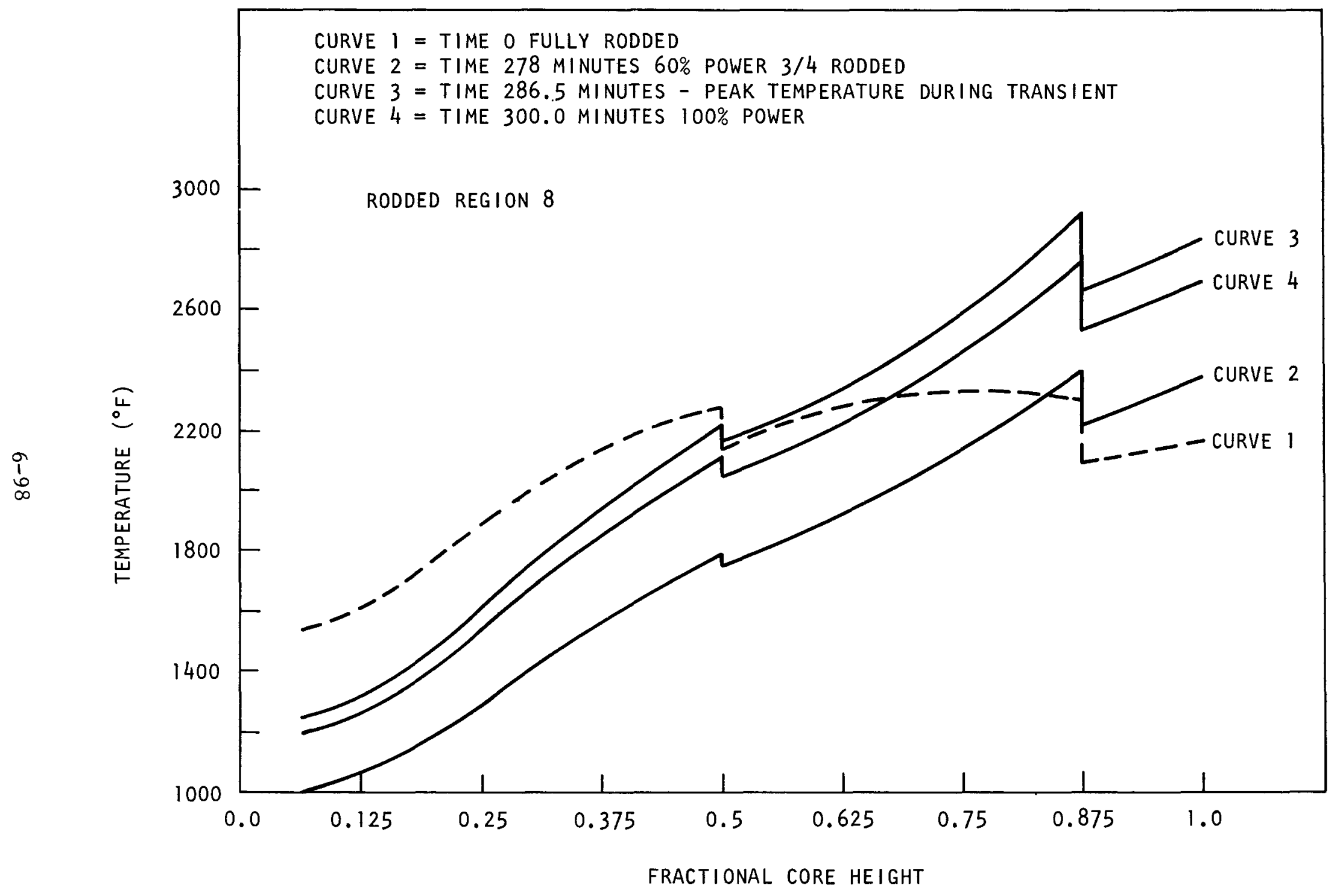

Fig. 6-40. Axial fuel temperature distribution during 100-60-100 load following transient 


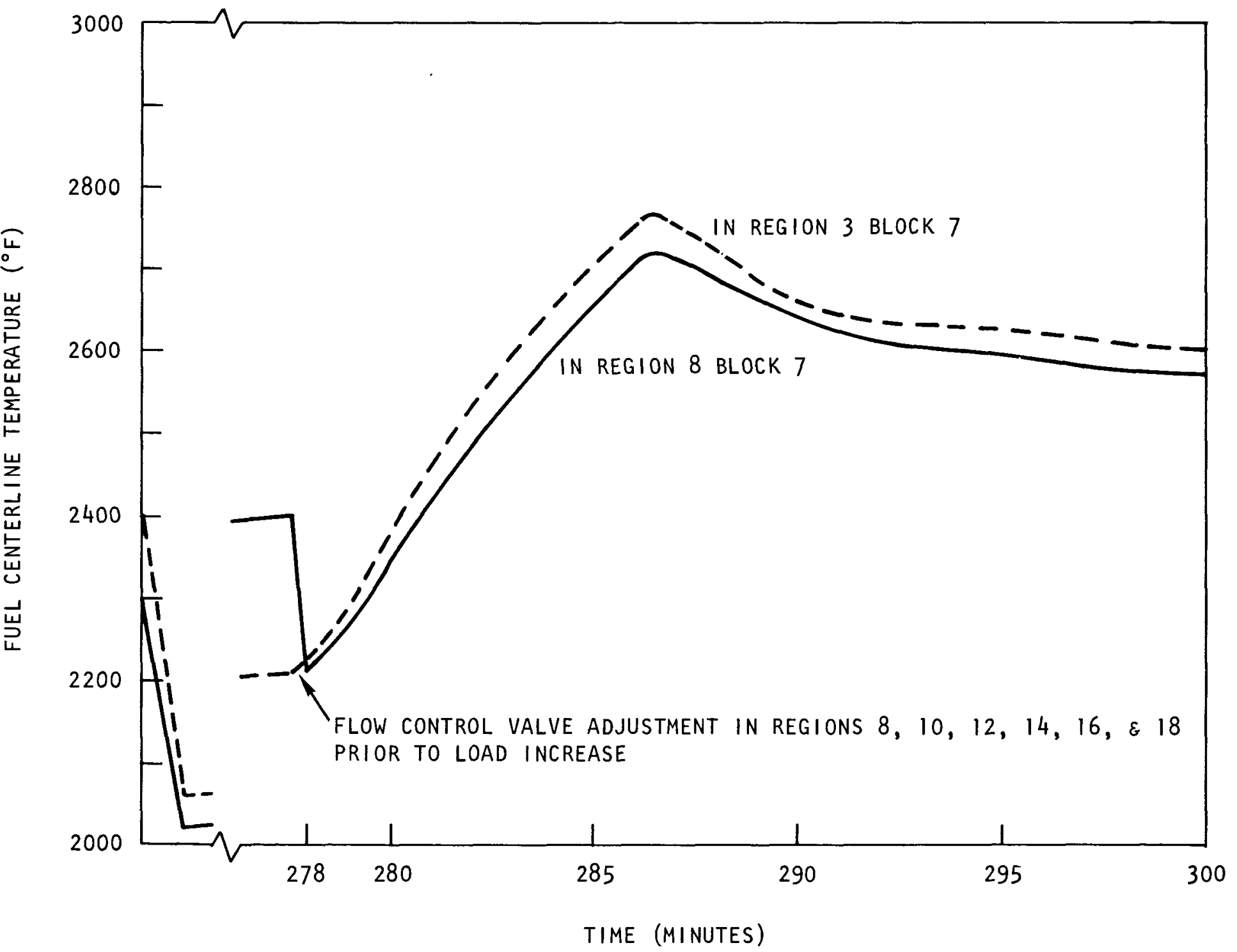

Fig. 6-41. Time history of local fuel temperature in three-quarter rodded and adjacent to half rodded region during 100-60-100 transient with orifice adjustments 
Return to full power at transient time points other than those analyzed will result in peak fuel temperatures less than presented in this section, since the region outlet helium temperature mismatches and the axial power peaking will not be as large as presented. Also only a small fraction of the fuel in the core approaches the fuel temperatures presented in this section. The points selected were the highest power points of regions with the largest transient temperature increases and the data were presented for the hottest axial point.

The inherent operating flexibility of the HTGR core and the ability to orifice individually selected refueling regions to provide the required degree of cooling enhances the HTGR's load-following capability. Additional flexibility is available in alternate control rod programming schemes to reduce the variation in radial power redistributions and the resulting helium outlet temperature mismatches.

6.2.4.3. Comparison of DETRAC and TAC Code Results. As verification of the DETRAC codes calculational method, the TAC-2D code described in Section 4.2.2 was used to analyze the hot channel temperature response during the 100-60-100\% load-following transient with return at peak xenon. The DETRAC results for the peak centerline fuel temperature in region 8 is obtained from Fig. 6-39. The TAC results for the peak fuel centerline temperature of region 8 are provided in Table 6-9 along with the DETRAC results from Fig. 6-39. The two codes use different methods of determining the flow through a coolant hole. The TAC-2D model determines the coolant hole flow by multiplying the average coolant hole flow during the transient by an input flow table which accounts for the change in total core flow, region power peaking, and intraregion tilt. The DETRAC code determines coolant hole flows by performing a momentum balance across the core at each calculation using the equation given in Section 4.1.4. 
TABLE 6-9

COMPARISON OF DETRAC AND TAC-2D RESULTS FOR A 100-60-100\% LOAD FOLLOWING TRANSIENT AT THE END OF SEVENTH FUEL BLOCK

\begin{tabular}{l|c|c|c|c|c|c}
\hline \multirow{2}{*}{} & \multicolumn{3}{|c|}{ TAC-2D } & \multicolumn{3}{c}{ DETRAC } \\
\cline { 2 - 6 } Time in & $\begin{array}{c}\text { F1ow } \\
(\text { Ib/hr })\end{array}$ & $\begin{array}{c}\text { Coolant } \\
\text { Temperature } \\
\left({ }^{\circ} \mathrm{F}\right)\end{array}$ & $\begin{array}{c}\text { Fuel } \\
\text { Centerline } \\
\text { Temperature } \\
\left({ }^{\circ} \mathrm{F}\right)\end{array}$ & $\begin{array}{c}\text { Flow } \\
(1 \mathrm{~b} / \mathrm{hr})\end{array}$ & $\begin{array}{c}\text { Coolant } \\
\text { Temperature } \\
\left({ }^{\circ} \mathrm{F}\right)\end{array}$ & $\begin{array}{c}\text { Fuel } \\
\text { Centerline } \\
\text { Temperature } \\
\left({ }^{\circ} \mathrm{F}\right)\end{array}$ \\
\hline $278(\mathrm{a})$ & 168 & 1620 & 2418 & 168 & 1622 & 2403 \\
280 & 195 & 1659 & 2562 & 195 & 1655 & 2534 \\
282 & 218 & 1719 & 2711 & 217 & 1718 & 2678 \\
284 & 238 & 1765 & 2833 & 236 & 1773 & 2806 \\
286 & 256 & 1800 & 2932 & 253 & 1819 & 2918 \\
286.5 & 253 & 1809 & 2937 & 249 & 1835 & 2927 \\
287 & 250 & 1813 & 2927 & 246 & 1842 & 2924 \\
288 & 245 & 1804 & 2895 & 242 & 1835 & 2900 \\
290 & 245 & 1771 & 2846 & 243 & 1803 & 2854 \\
292 & 249 & 1749 & 2819 & 248 & 1777 & 2822 \\
294 & 253 & 1742 & 2809 & 251 & 1765 & 2808 \\
300 & 255 & 1725 & 2778 & 254 & 1746 & 2775 \\
\hline
\end{tabular}

(a) Steady state $60 \%$ 1oad. 
The results for peak fuel centerline temperature obtained from TAC-2D and DETRAC are within $10^{\circ} \mathrm{F}$ at the point during the transient when fuel temperatures reach their maximum. The DETRAC code provides a fast and accurate method to evaluate in detail HTGR thermal transients at considerably less cost than single-channel TAC-2D analysis. Therefore, the DETRAC code will be used in most of the future transient thermal analyses of the HTGR core. 


\section{REFERENCES}

6-1 Schleicher, R. W., et al., "An Analysis of HTGR Core Cooling Capability," Gulf General Atomic Report Gulf-GA-A12504, May 30, 1073.

6-2 Malek, G. J., and R. Hausermann, General Atomic, "Analysis of the Multicolumn Flow Distribution Test," USAEC Report GAMD-8423, Genera1 Atomic, June 5, 1968.

6-3 Katz, R., General Atomic, "Offset Loss Coefficient Test Results," unpublished data.

6-4 Malek, G. J., General Atomic, "PSC Fuel Element Crossflow Loss Coefficient Test," unpublished data.

6-5 Kays, W. M., and A. L. London, Compact Heat Exchangers, McGraw-Hill, New York, 1964, p. 93.

6-6 Idel Chik, I. E., Handbook of Hydraulic Resistance, AEC-tr-6630, C.F.S.T.I., Springfield, Virginia, 1966.

6-7 Hamilton, C. J., "Power Distribution in Large HTGR," General Atomic Report GA-A13007, December 1974.

6-8 Smith, C. L., "Fuel Particle Behavior Under Normal and Transient Conditions," USAEC Report GA-A12971, General Atomic, October 1974.

6-9 "General Atomic Standard Safety Analysis Report," General Atomic Report GA-A13200, Section 11.1, 1974.

6-10 "Materials and Integrity of Core Structure," General Atomic Report GA-A13188, to be published.

6-11 Haire, M. J., and D. W. McEachern, "Gaseous Radioactivity in the Primary Coolant of an HTGR," General Atomic Report GA-A12946, 1974.

6-12 Harmon, D. P., and Scott, C. B., "Irradiation Performance and Development of HTGR Fuel," General Atomic Report GA-A13173, to be published.

6-13 Wunderlich, R. G., et al., "Fulton Station HTGR Instrumentation and Control," Nuclear Engineering International, p. 656, August 1974. 


\section{FUEL PERFORMANCE ANALYSIS}

This section describes the calculation of the level of integrity of the fission product barriers within the core which are the particle coatings. Calculations are for steady-state operation at rated power. Results of these calculations are used in the estimation of fission product inventory in the HTGR primary coolant circuit.

Protection of the fuel particle coatings as fission product barriers is one of the bases for the core thermal design. Four mechanisms that cause the fuel particle coatings to fail have been identified. These mechanisms are described in detail in Ref. 7-1 and briefly in Section 3.2 of this report. Coating failure is dependent upon the particle properties and on environmental effects, the temperature of the particles, the fast fluence accumulated by the coating, and the burnup in the kernel.

Environmental effects of temperature and temperature gradient in the HTGR fuel are defined by the core thermal analysis. Fast fluence and burnup taken from core nuclear analyses (Ref. 7-2) are used with the temperature environment to evaluate the distribution of coating failure throughout the core as a function of time in the fuel cycle.

- Space-time distributions of particle coating failure are presented for the four coating failure mechanisms: kernel migration, coating stress failure, high temperature failure in TRISO particles, and manufacturing defects.

Calculations of the fuel particle performance reported here were carried out using the TREVER code (Section 4.1.5). Fuel behavior correlations from Ref. 7-1 are al1 included in a subroutine of the code. 
The fuel performance analysis is carried out using local power peaking factors (Section 5.8.3) and the resolution of the calculations based on the current GAUGE-BUG power distributions are as follows (see Ref. 7-2).

Power Distribution:

Number of radial points for core (a)

Number of types of axial profiles for core $(b)$

Nuber of axial nodes along the length of the core ${ }^{(c)}$

Fast Flux Distribution:

Number of radial points for core (a)

Number of types of axial profile used (d)

Number of axial nodes along the length

of the core ${ }^{(c)}$

Burnup Calculation:

Number of radial points for core ${ }^{(a)}$

Number of types of axial profile for core ${ }^{(a)}$

Number of axial nodes along the length

of the core ${ }^{(a)}$

1 (unrodded)

8

Time Steps:

Number of years of core burnup study $(e) \quad 7$

Number of time steps per year (e)

Fuel Performance Calculations:

Number of radial points for core $(f)$

Number of axial points for core $(\mathrm{g})$

1750

Number of radial locations within fuel rod $(\mathrm{h})$
(a) $\operatorname{Ref}$. 7-2.
(b) $\operatorname{Ref}$. 5-28
(c) $\operatorname{Ref}$. 5-28. 
(d) See Section 5.8.8.

(e) See Section 5.8.2.

(f) Half symmetrical core (see Fig. 5-12).

(g) At end of each block.

(h) For kernel migration calculations only. Other mechanisms are evaluated using the fuel rod centerline temperature.

7.1. KERNEL MIGRATION ANALYSIS

The rate of kernel migration, as described in Section 3.2.1, is a function of particle temperature, kernel temperature gradient, and fuel kerne1 composition.

\subsubsection{Kernel Migration in TRISO Particles}

Some results of TREVER code analysis of steady-state operation at rated power for TRISO particles are presented in Figs. 7-1 through 7-13 to provide insight into the spatial distribution of migration rates within the core. Starting on a small scale, Fig. 7-1 presents the distance migrated by TRISO kernels as a function of the radial location within a fuel rod at the end of each 4-year residence time. This fuel rod has experienced the temperature and temperature gradient history shown earlier in Fig. 6-28 for a fuel rod in an unrodded region near the core outer boundary. In the radial direction of the fuel rod, the temperature, which is approximately parabolic in shape, has a maximum in the center and a minimum at the outer surface. By contrast, the temperature gradient is zero at the center and increases linearly reaching a maximum at the fuel rod surface. The kernel migration rate is linearly dependent upon the temperature difference across the kernel and exponentially upon the temperature. Therefore, the kernel migration distance is small near the center of the fuel rod where the gradient is small and it increases with the fuel rod radius reaching its maximum before it decreases with temperature near the fuel rod surface. Figure 7-1 indicates this behavior and also that a significant fraction of 


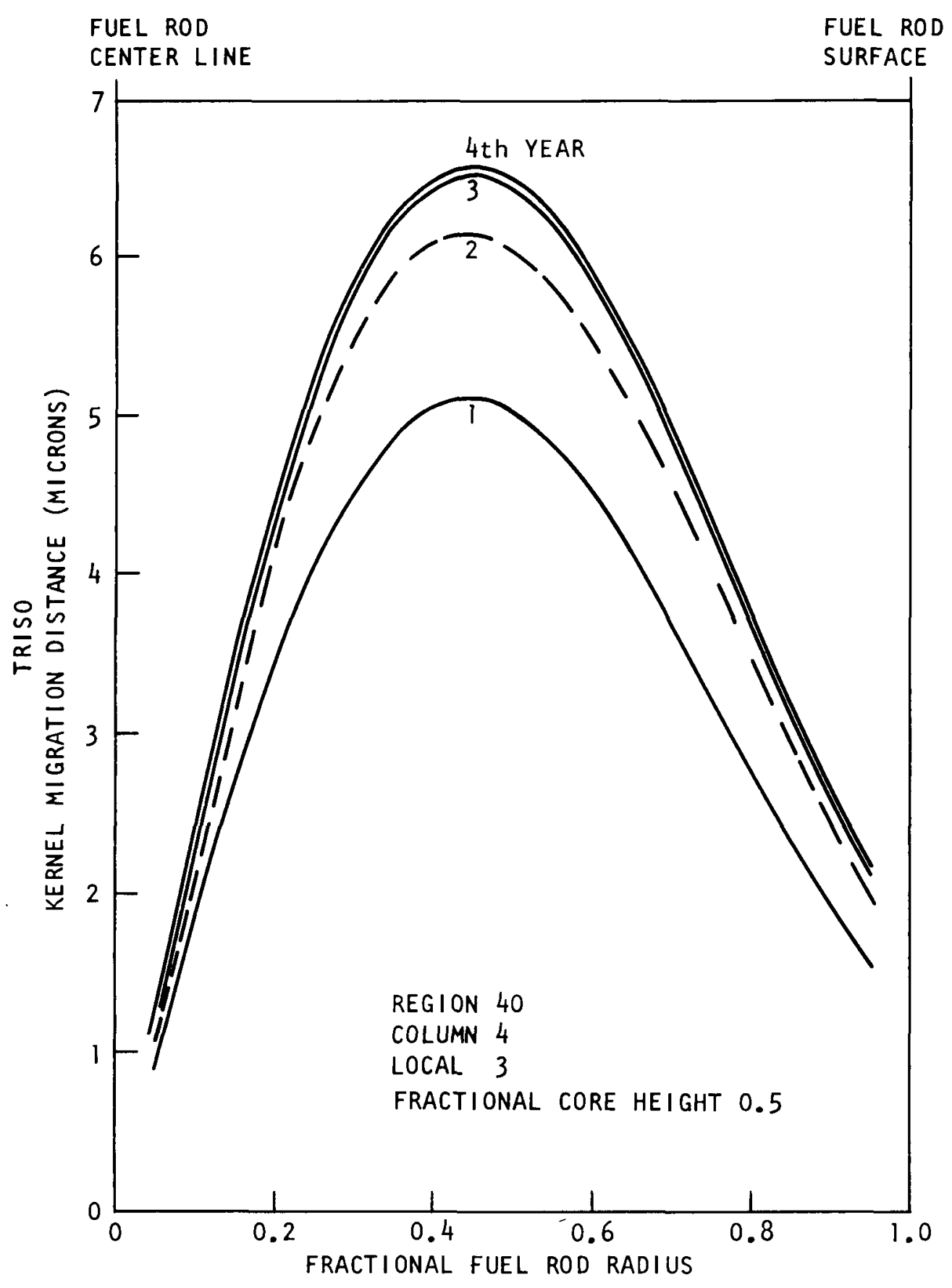

Fig. 7-1. Behavior of the TRISO kernel migration in a typical fuel rod 


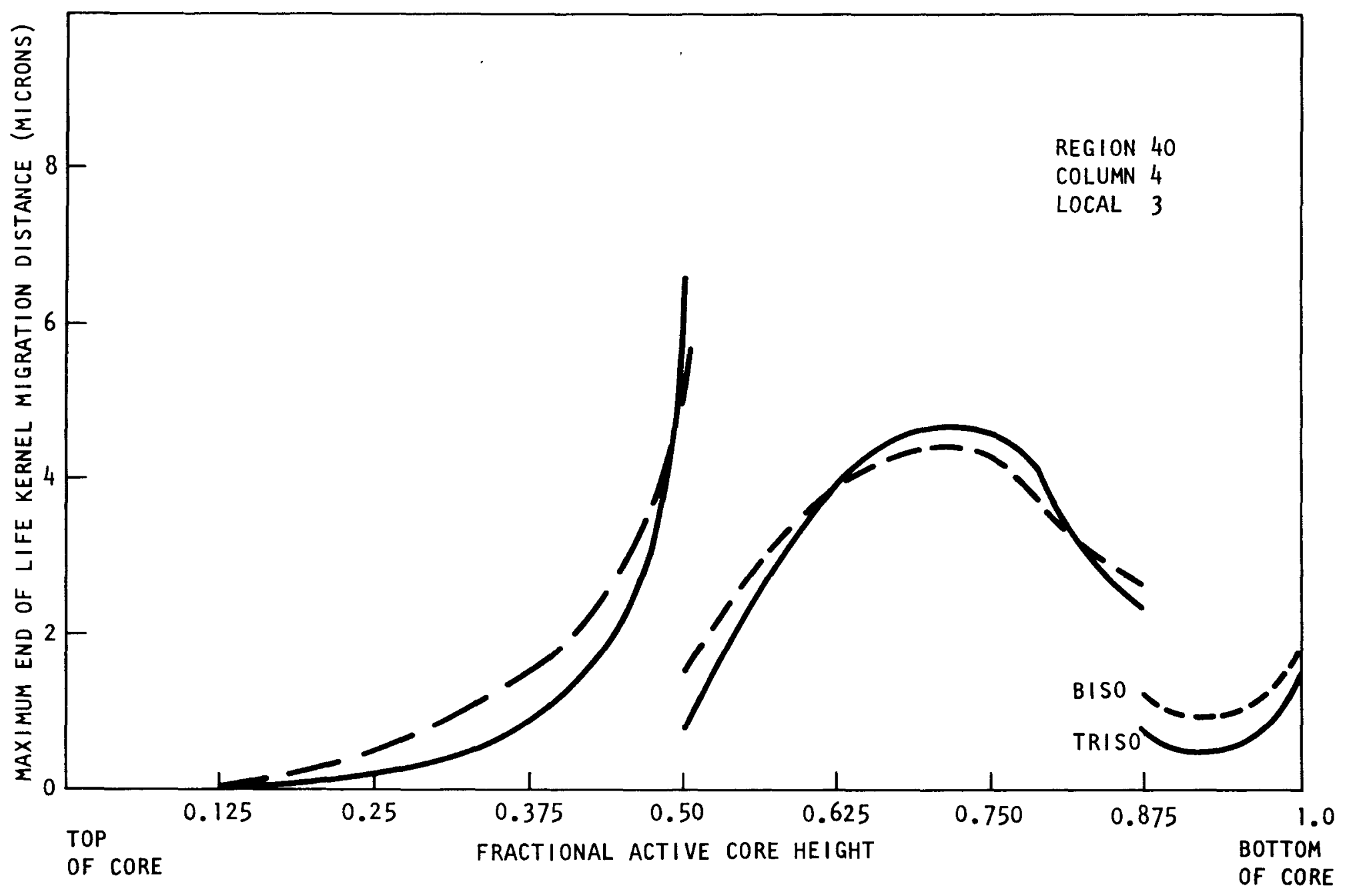

Fig. 7-2. Axial profile of the end-of-life TRISO and BISO kernel migration in a typical fuel rod stack 


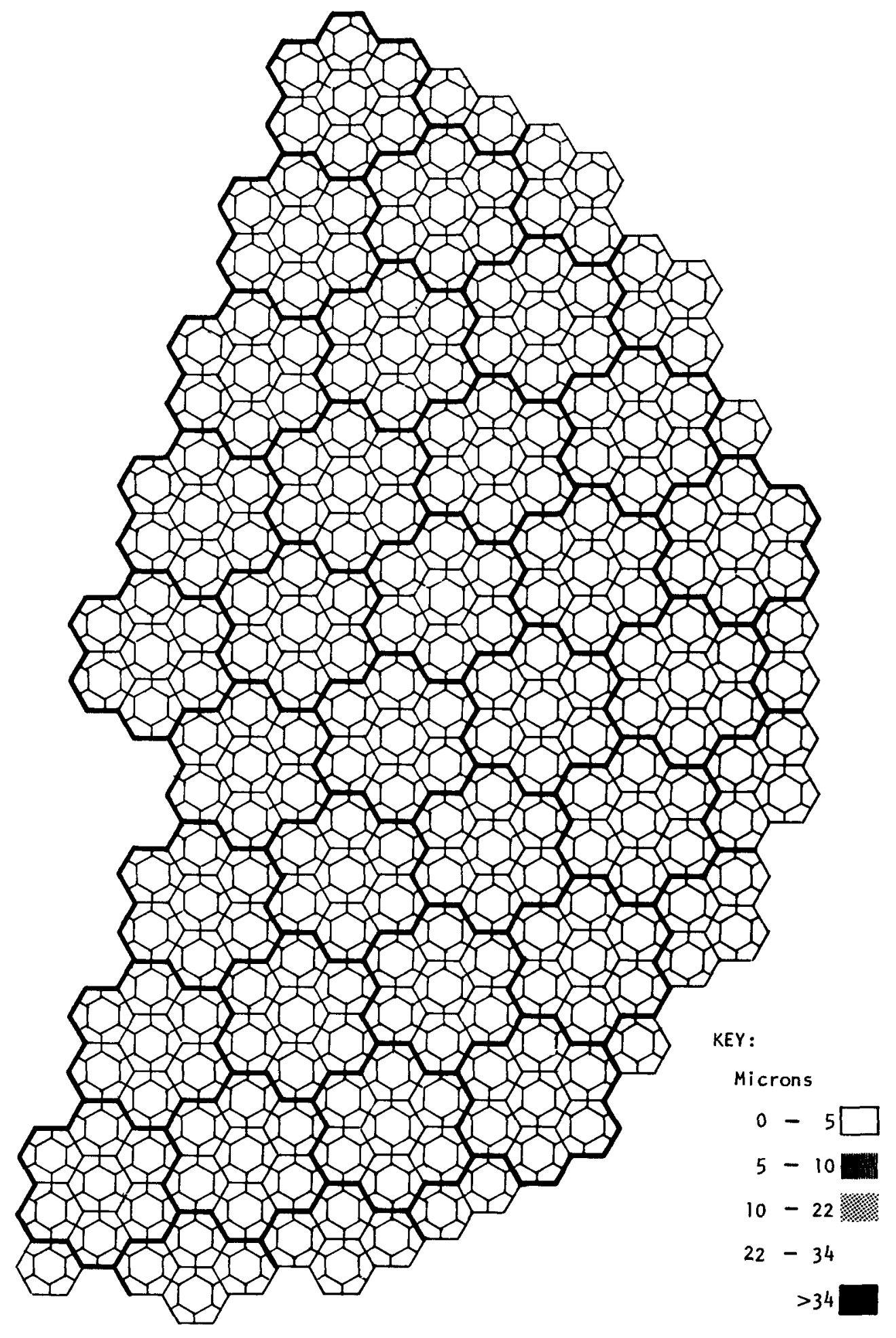

Fig. 7-3. TRISO fuel EOL kernel migration at layer 1 


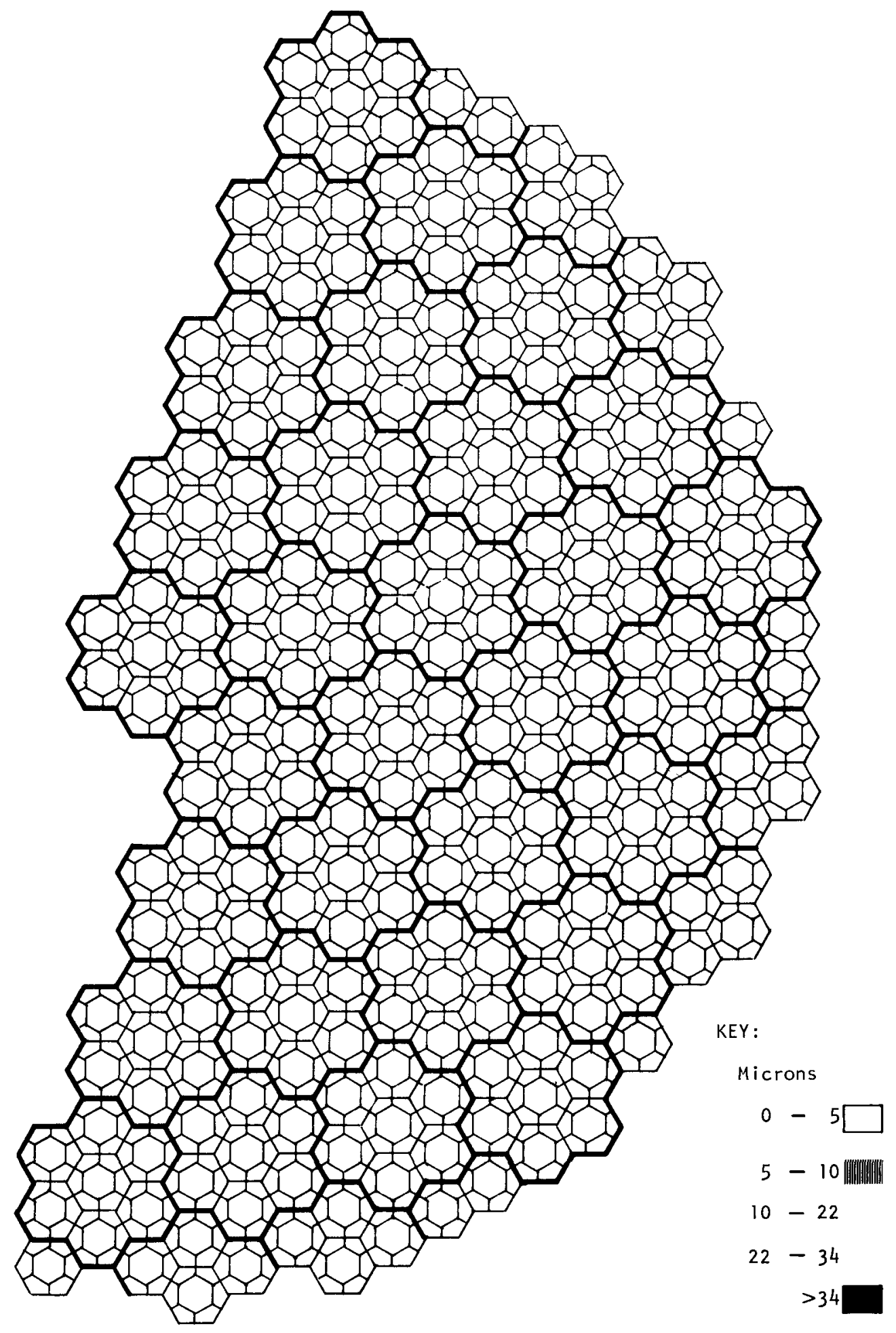

Fig. 7-4. TRISO fuel EOL kernel migration at layer 2 


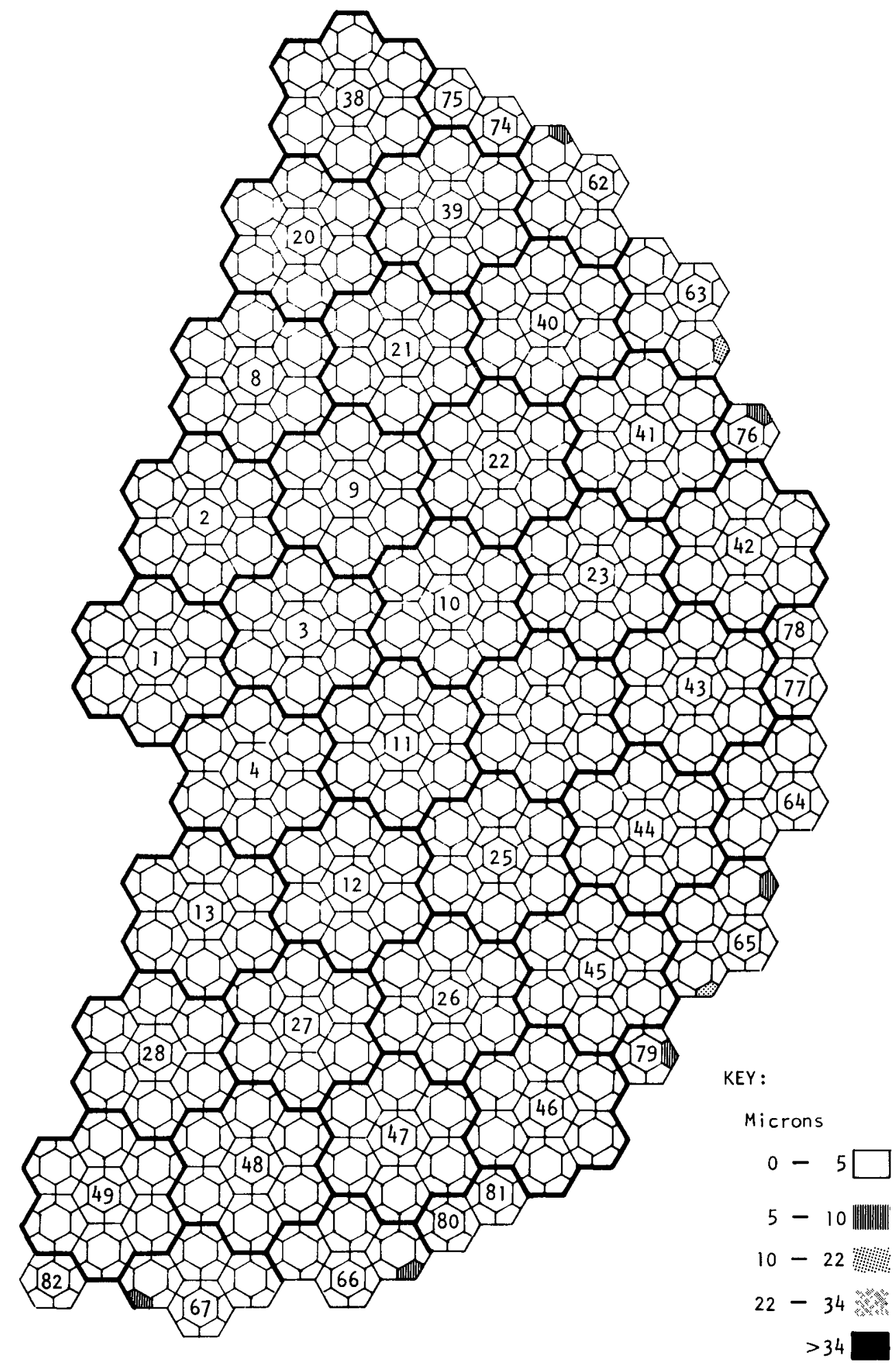

Fig. 7-5. TRISO fuel EOL kernel migration at layer 3 


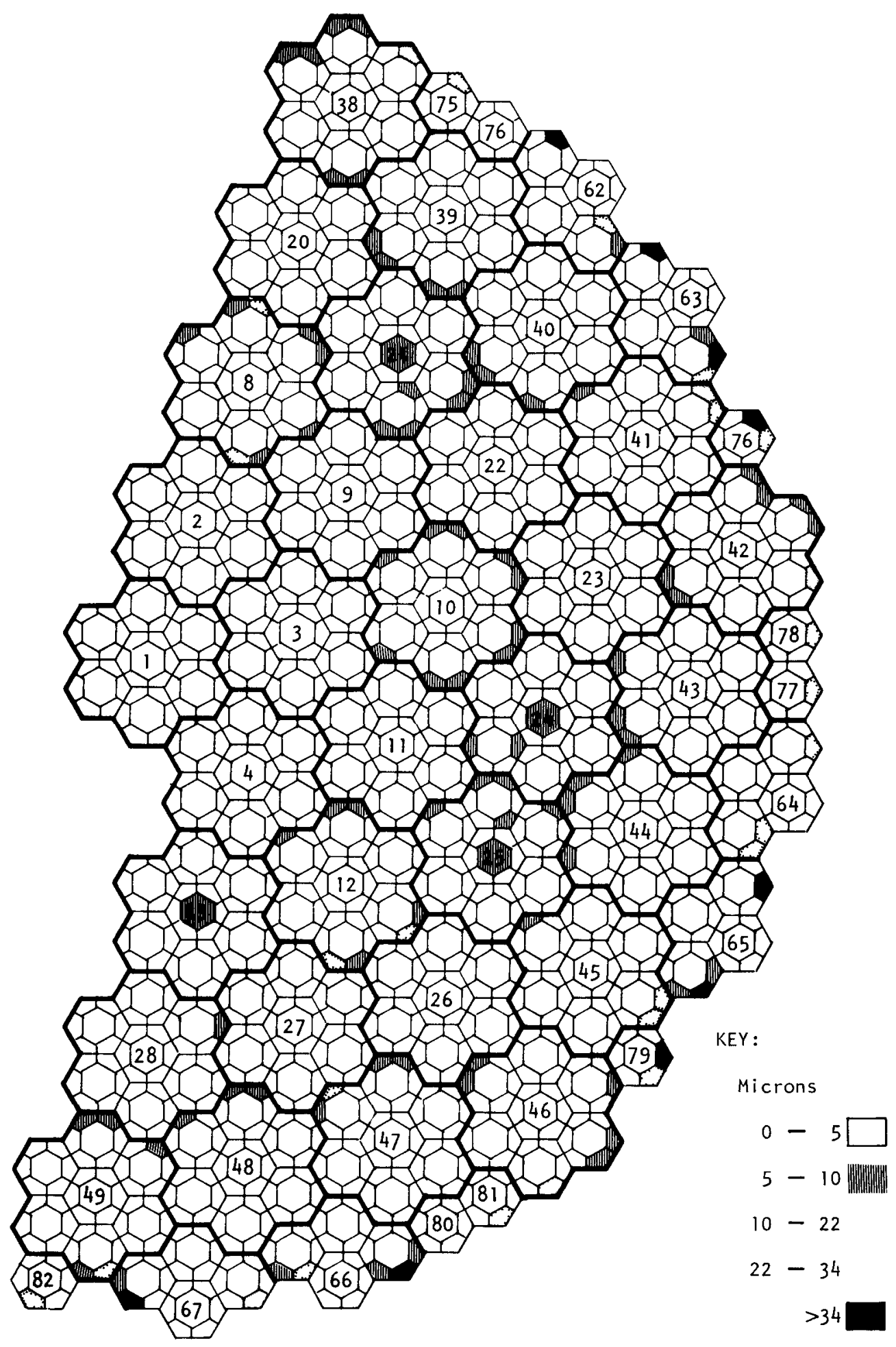

Fig. 7-6. TRISO fuel EOL kernel migration at layer 4 


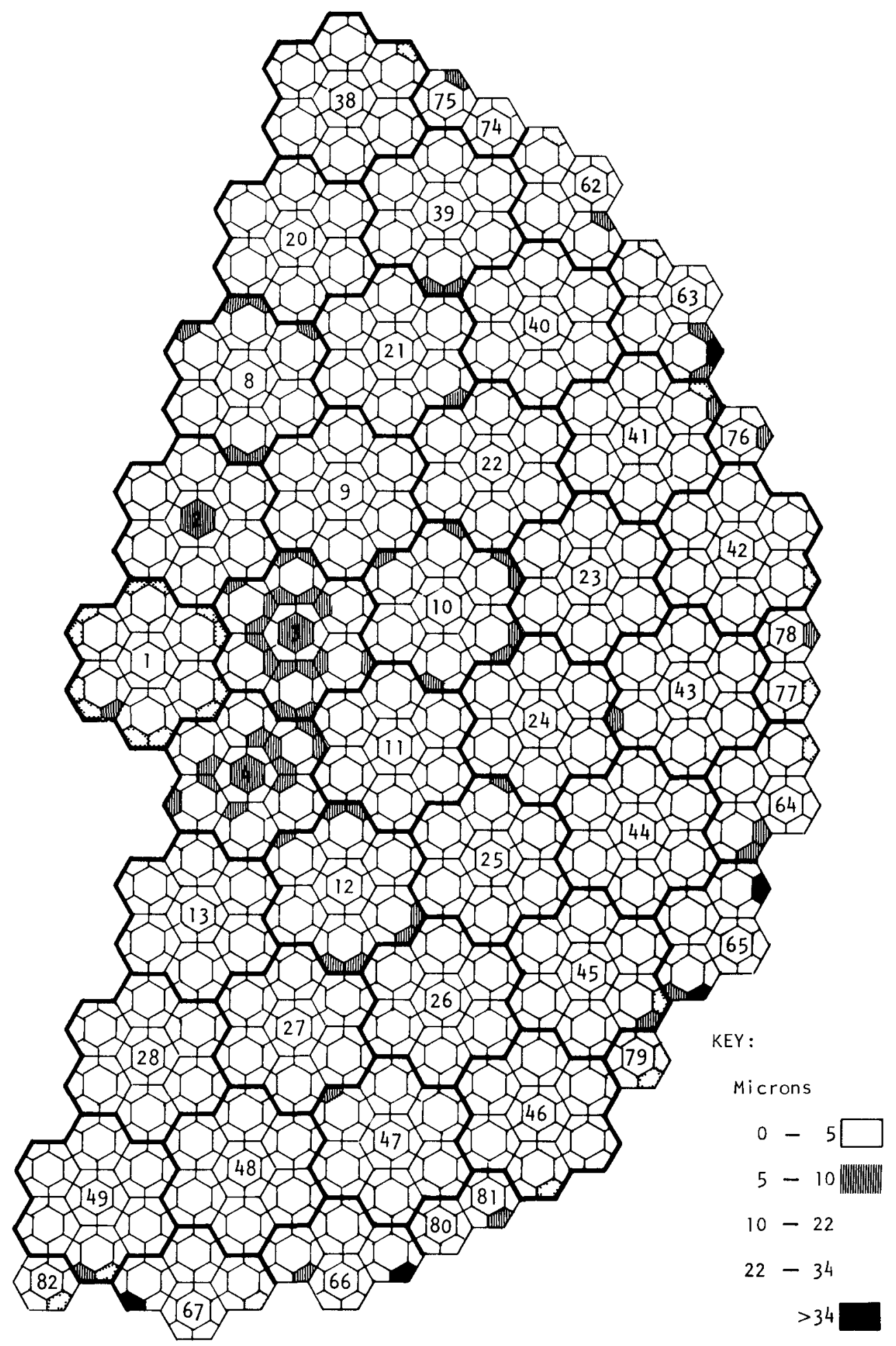

Fig. 7-7. TRISO fuel EOL kernel migration at layer 5 


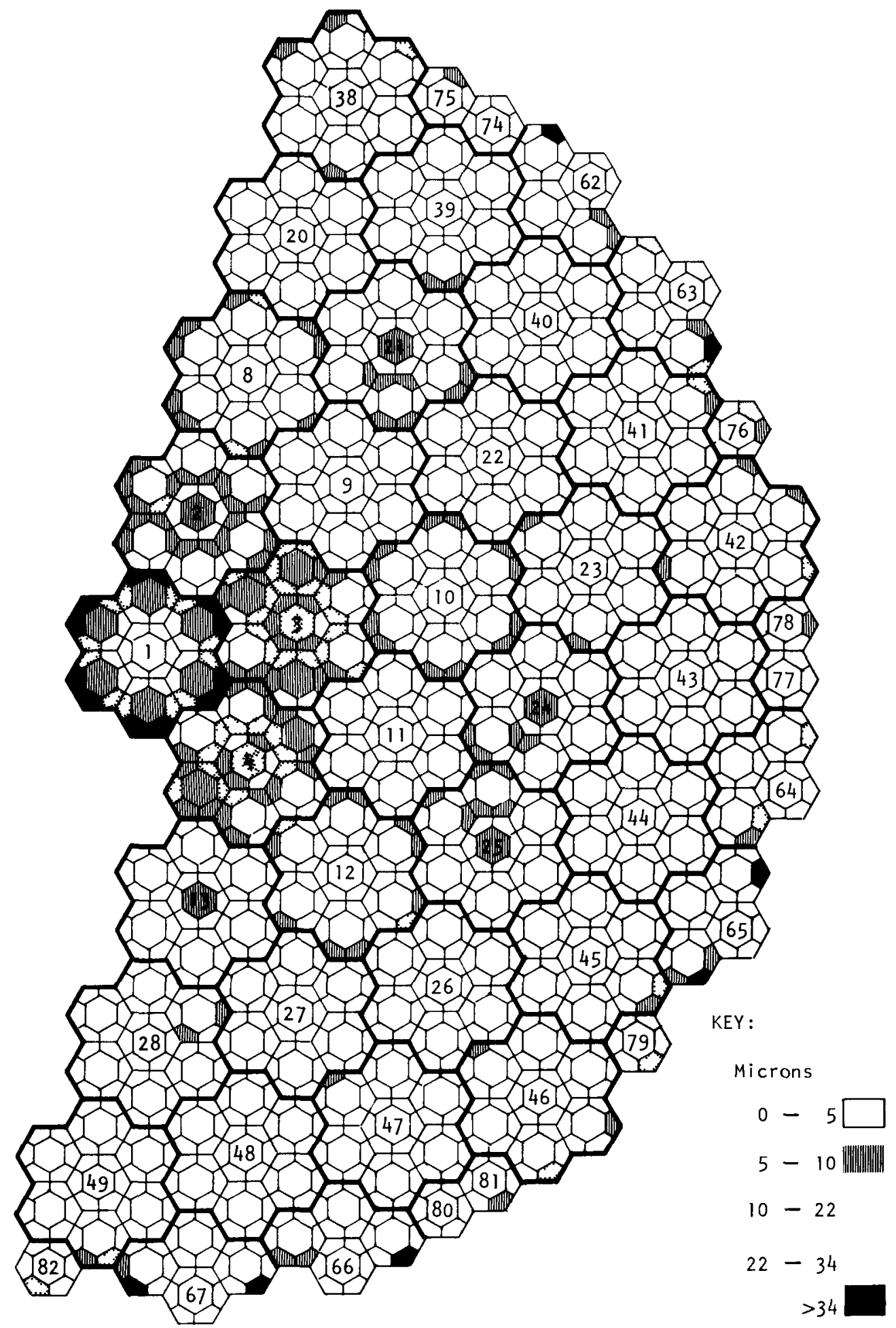

Fig. 7-8. TRISO fuel EOL kernel migration at layer 6 


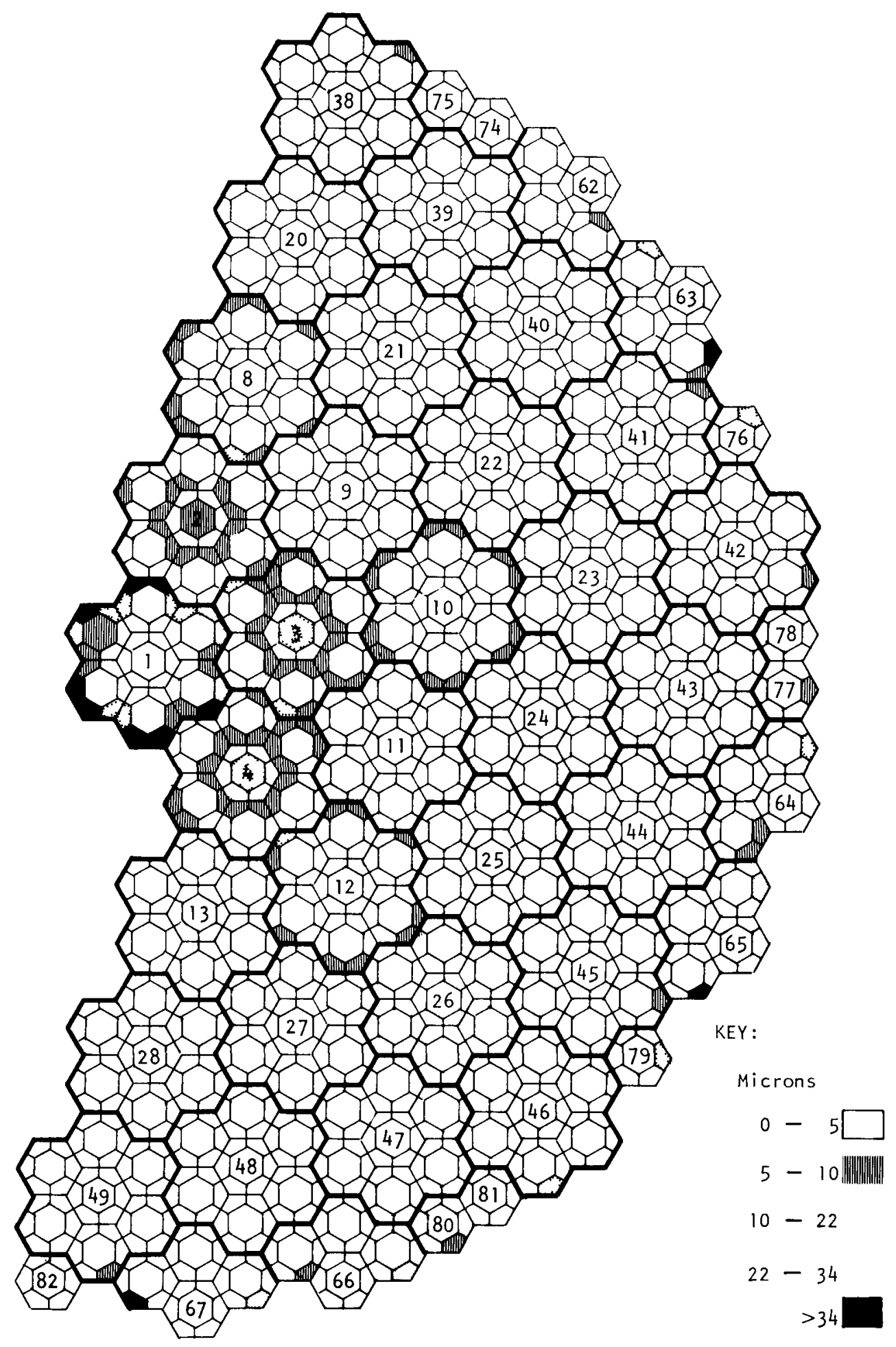

Fig. 7-9. TRISO fuel EOL kernel migration at layer 7 


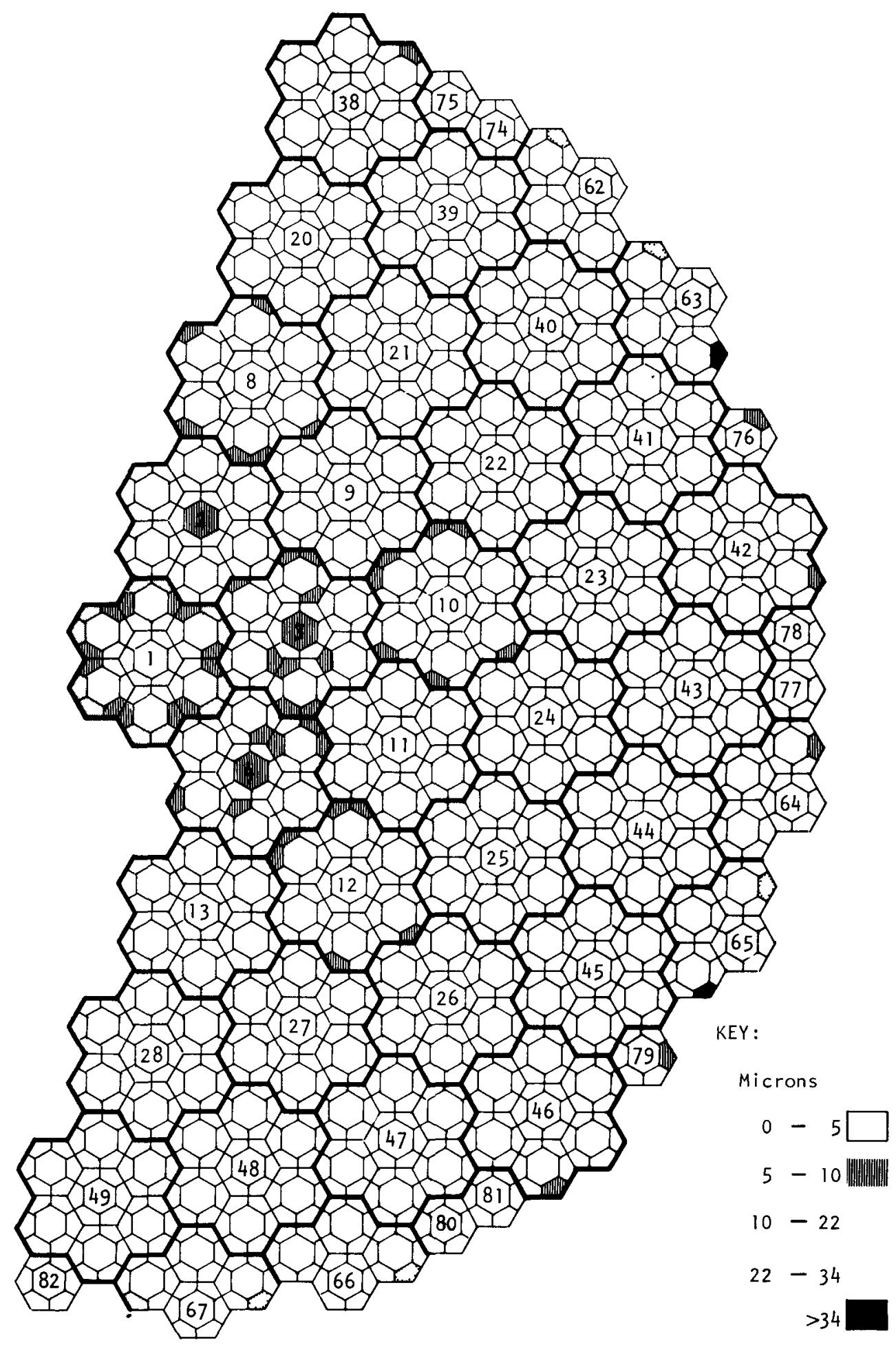

Fig. 7-10. TRISO fuel EOL kernel migration at layer 8 


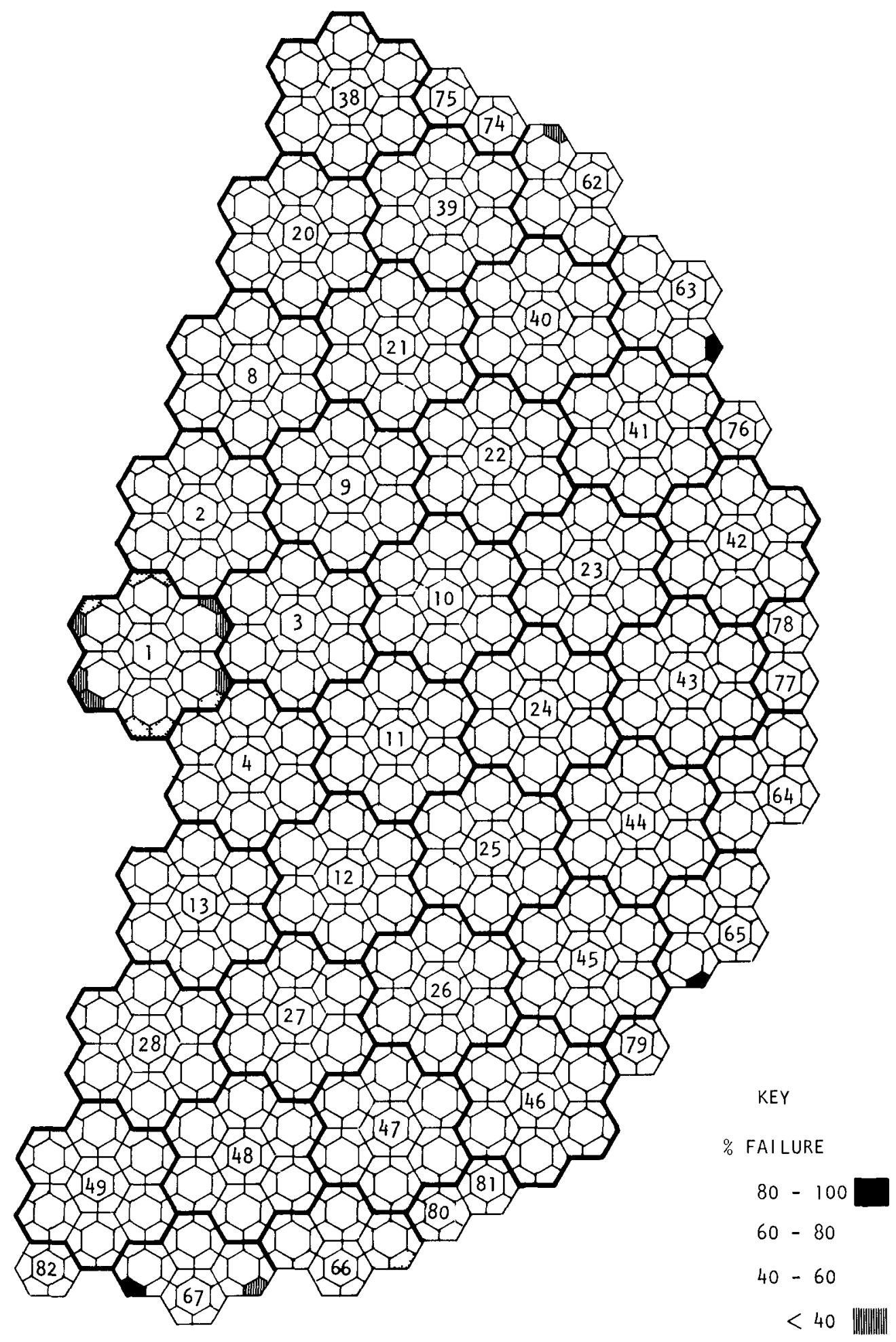

Fig. 7-11. Fraction of TRISO fuel particle failure by migration at worst axial position $(\mathrm{Z} / \mathrm{L}=0.75)$ 


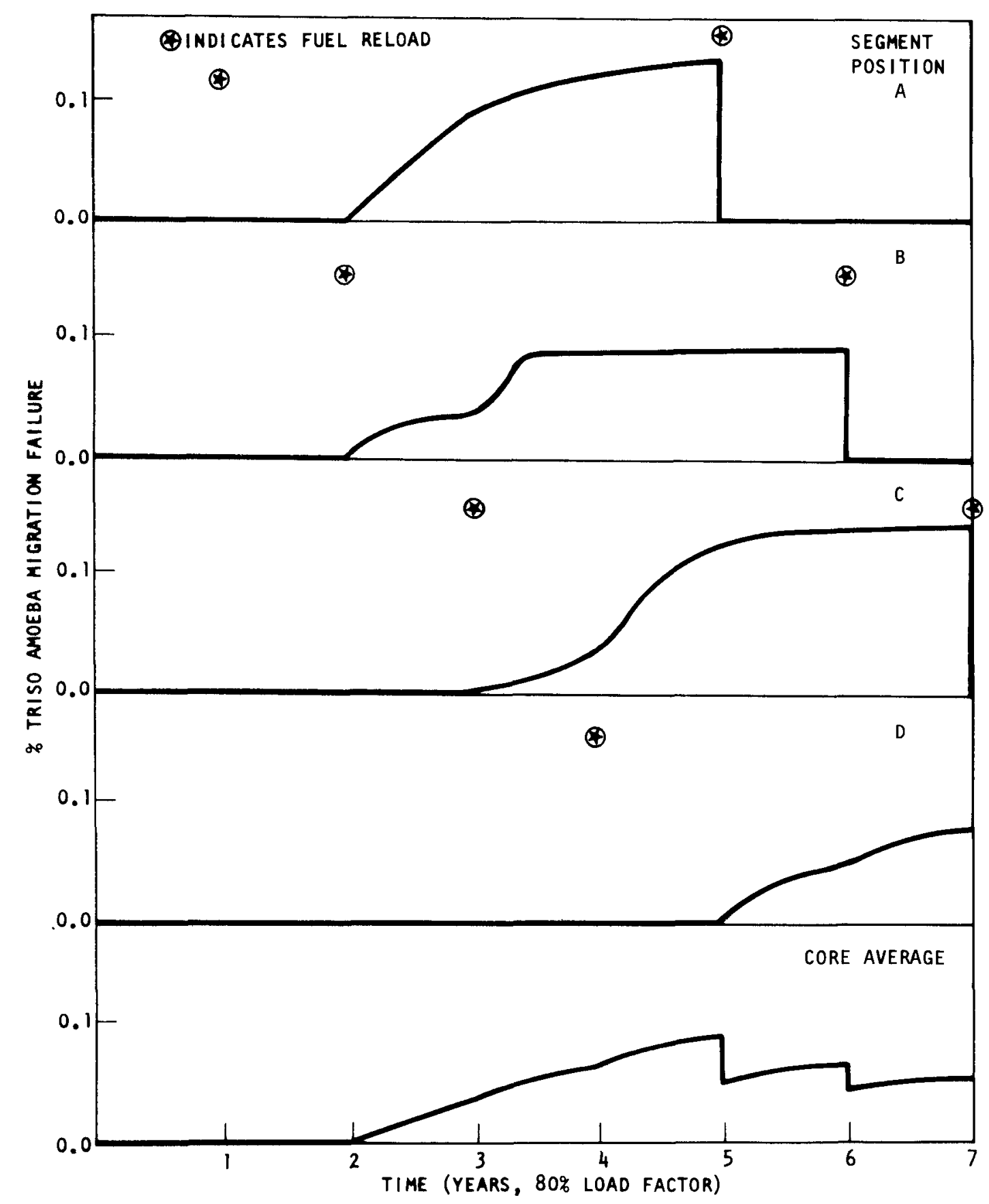

Fig. 7-12. Time history of TRISO amoeba failure fraction in each fuel segment position and in the core 


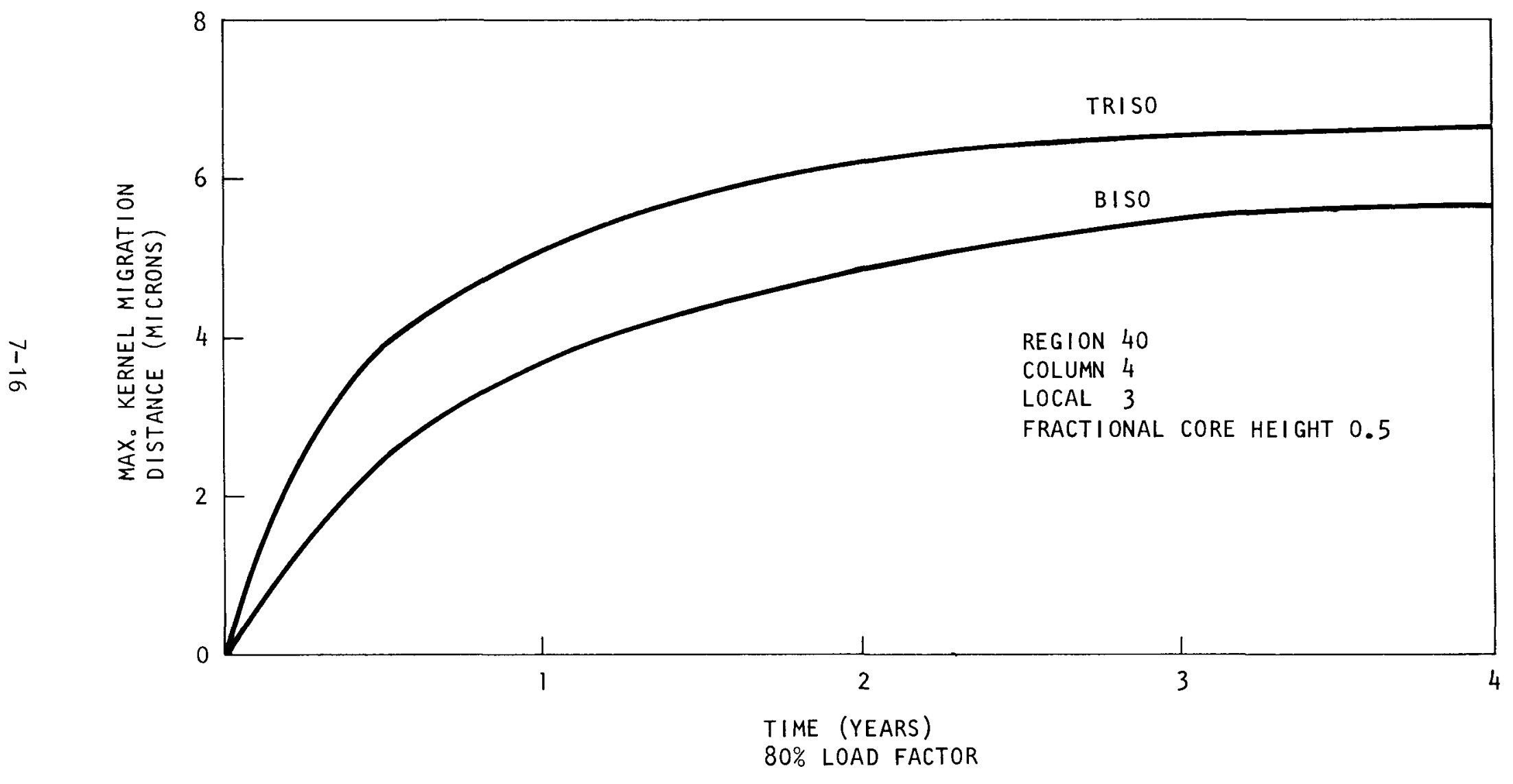

Fig. 7-13. Comparison of maximum migration of TRISO and BISO fuel kernels in a typical unrodded region 
the kernel movement occurs during the first year of core life when the fuel temperature level is highest.

Turning to Fig. 7-2, the end-of-life (4-year) migration distance for the fuel shown in Figs. 6-28 and 7-1 is plotted along the axial length of an entire fuel rod stack from the top to the bottom of the core. Distances for both BISO particles that contain $\mathrm{ThO}_{2}$ kernels and TRISO particles that have $\mathrm{UC}_{2}$ kernels are presented. In the three topmost fuel elements; temperatures are lower than in the rest of the core (see Fig. 6-20 for an example); therefore, the end-of-life migration distances are smaller here than for the downstream elements in the core. In the fourth block, the temperature and the power density both increase; this high temperature and maximum temperature difference across the kernel combine to yield a maximum in kernel migration at this particular axial location. Lower in the fuel rod stack, the temperature is nearly equal to the temperature at the core midplane $(Z / L=0.5)$ but the decrease in axial power peaking (see Fig. 5-15) yields a lower radial temperature gradient and a lower migration distance.

After looking at migration distances in an individual fuel rod and a single fuel rod stack, a series of figures is presented to show the distance migrated by the $\mathrm{UC}_{2}$ kernels in the TRISO particles throughout the core. Figures 7-3 through 7-10 are a series of one-half 3000-MW( $t$ ) cores divided into a grid corresponding to the calculational resolution of the GAUGE code. There are eight core layouts, one for each fuel layer in the active core; the location shown for each layer is the plane at the bottom end of each fuel element. The maximum migration distance at each transverse location is noted in four discrete ranges. Indicated is the maximum kernel movement distance for any location across the radius of the fuel rod (see Fig. 7-1 for example). Only one-half of the columns in the core are shown; the other half is identical to the half shown but rotated $180^{\circ}$ about the center of region 1 . 
The distribution of migration distances in these figures does not represent an instantaneous picture at any one time; what is shown are the kernel movement distances for each region just before it is to be reloaded.

Paging through the core maps, no significant kernel movement is noted until the fourth block shown in Fig. 7-6. As one looks further down the core, a pattern develops indicating significant migration distance in the regions in the center section of the core, regions 1 through 7 , and on the periphery of the core. The pattern of kernel migration can be understood by examining the control rod programing.

A regulating rod, which is ideally held near the half inserted position, is used in region 1 with a bank of six shim rods used in regions $8,10,12,14,16$, and 18. Shim bank rods are fully inserted for about the first 200 days of each year. During the last 100 days they are slowly moved out of the core, ending near the fully withdrawn position at the end of the annual cycle. Rod pairs inserted in the central column of a region tend to push the power to the periphery of the region; i.e., produce intraregion radial power tilts $\alpha(\ell, r)$ that exceed 1.0. Regions 2 through 7, which lie between the central rod and the shim rod bank, have power forced toward their centers. Additionally in region 1 the rod is assumed to be at the one-half inserted position, a position that shoves the power axially toward the bottom of region 1 and to a lesser degree in regions 2 through 7. So, in general, the migration is caused on the periphery of rodded regions by combination of intraregion tilts and axial profiles skewed toward the bottom of rodded regions and regions adjacent to the rodded regions. In addition to the rodded regions, significant TRISO kernel migration also occurs at the core-reflector interface in the bottom half of the core as shown in Figs. 7-6 through 7-10.

As discussed in Section 3.2.1.1, the particles are not structurally weakened by kernel migration until the kernel begins to attack the iso- 
tropic coatings. However, the particles are assumed here to fail when the kernel has migrated through only $40 \%$ of the 85 micron low-density buffer coating surrounding the fuel kernel; i.e., $85 \times 0.4=34$ microns. Figure 7-11 shows the distribution of failed locations and failed fuel fractions from TRISO kernel migration. The distribution shown in Fig. 7-11 is for each region just before it is to be reloaded and, therefore, does not represent an instantaneous picture at any one time.

The two principal failed fuel locations due to TRISO kernel migration are at the periphery of region 1 and at core-reflector interface as indicated by Fig. 7-11.

For the peripheral locations in region 1, additional analysis indicates that when the control rod is held at one-fourth or three-fourths insertion (Section 5.8.7) the axial power profile improves and migration is reduced considerably. There are other solutions such as special zoning of fuel within region 1 or overcooling of region 1 which would improve the kernel migration considerably.

At the core-reflector interface, in order to minimize the power peaking a ring of four rows of fuel rods is specially zoned (thin buffer zone) in the outer fuel columns. The GAUGE analysis uses burnup regions consisting of full columns and therefore does not accurately model the thin buffer zone. The results from a more detailed two-dimensional BUGTRI analysis (Ref. 7-2), which models the thin buffer, explicitly indicate that the intraregion tilts $\alpha(l, r)$ at the core reflector boundary are considerably lower than those used here from the GAUGE analysis. A thermal analysis using higher resolution BUGTRI data also indicates that the kernel migration at the core-reflector interface is considerably lower than the results shown in Figs. 7-3 through 7-10. 
In the above paragraphs the discussions were limited to end-of-life fuel failure; however, in fission product analysis the time history as well as the spatial distribution of fuel failure is required. The time history of the fraction of TRISO fuel particles failed due to kernel migration is shown in Fig. 7-12 for each of the four segment positions (see Fig. 5-12) during the first 7 years of core operation. During the first 2 years of operation, there is no TRISO fuel failure in any location of the core. That is, the kernel migration in all TRISO fuel particles in the core is less than 34 microns. During subsequent years, the kernel migration exceeds 34 microns in a small fraction of fuel particles. The last of the plots in Fig. 7-12 sums up the failure in the four segment positions and expresses the core average value of migration-failed TRISO particles. At the end of the fifth year of the initial core, the TRISO fuel coating failure by kernel migration reaches a maximum value of about $0.09 \%$. Most of this failure is in region 1 and at the core periphery.

\subsubsection{Kernel Migration in BISO Particles}

The kernel migration calculations are made for $\mathrm{ThO}_{2}$ BISO particles in a manner similar to fissile TRISO particles presented in Section 7.1.1. Figure 7-13 shows a comparison of kernel migration in TRISO and BISO particles in a fuel rod experiencing the temperature and temperature gradient histories shown in Fig. 6-28. Most of the kernel migration in both particle types occurs during the first year of life when the temperatures are relatively high. For the same history of temperature and temperature gradient, the kernel migration distance in BISO particles is lower than TRISO particles. The reason for this is due to the fact that during the first year this fuel rod is experiencing a temperature greater than $2300^{\circ} \mathrm{F}$. At this condition the BISO kernels migrate slower than TRISO kernels (see Fig. 3-3). However, the total kernel migration rate for either particle type at temperatures below $2300^{\circ} \mathrm{F}$ is quite low. 
Figures 7-14 through 7-21 show the maximum BISO kernel migration distance in fuel rods in each of the core subregions at the end of their 4-year fuel life. Trends similar to TRISO particle migration are apparent. Maximum BISO kernel migration occurs at the same locations where the maxima for TRISO particles occur. Throughout the core the BISO kernel migration is less than 10 microns except for some isolated locations in the bottom half of region 1 and a few local points near the core-reflector boundary. Even at these higher migration points, migration distances are less than 34 microns except for one location as shown in Fig. 7-22. The design improvements in region 1 and detail BUGTRI analysis at the core-reflector boundary (Ref, 7-2), which decrease the kernel migration in TRISO particles, also decrease the kernel migration in BISO particles.

\subsection{PRESSURE VESSEL FAILURE ANALYSIS}

Attributes such as particle dimensions and coating properties are specified for coated particles to be used in commercial HTGRs which irradiation testing has shown describe particles which will not fail in normal service in the HTGR. However, only samples of the fuel product are checked for each of the specified attributes during fuel manufacturing operations. There is thus a possibility that some small fraction of the fuel particle product will not possess the required attributes and may fail in service under extreme conditions of temperature, burnup, and fluence. Particularly important parameters are kernel diameter and buffer coating thickness. Particles with larger kernel diameters or thinner coatings can fail before reaching their full service limits. The stresses in the coatings are a function of internal gas pressure and the irradiationinduced changes in the dimensions and properties of fuel coatings. The gas pressure within the particles is directly determined by the temperature, burnup of fuel kernel, and fraction of gas released from the kernel. Fuel particle behavior correlations (Ref. 7-1) for pressure vessel failure are used in the TREVER code to calculate volume fraction and distribution of 


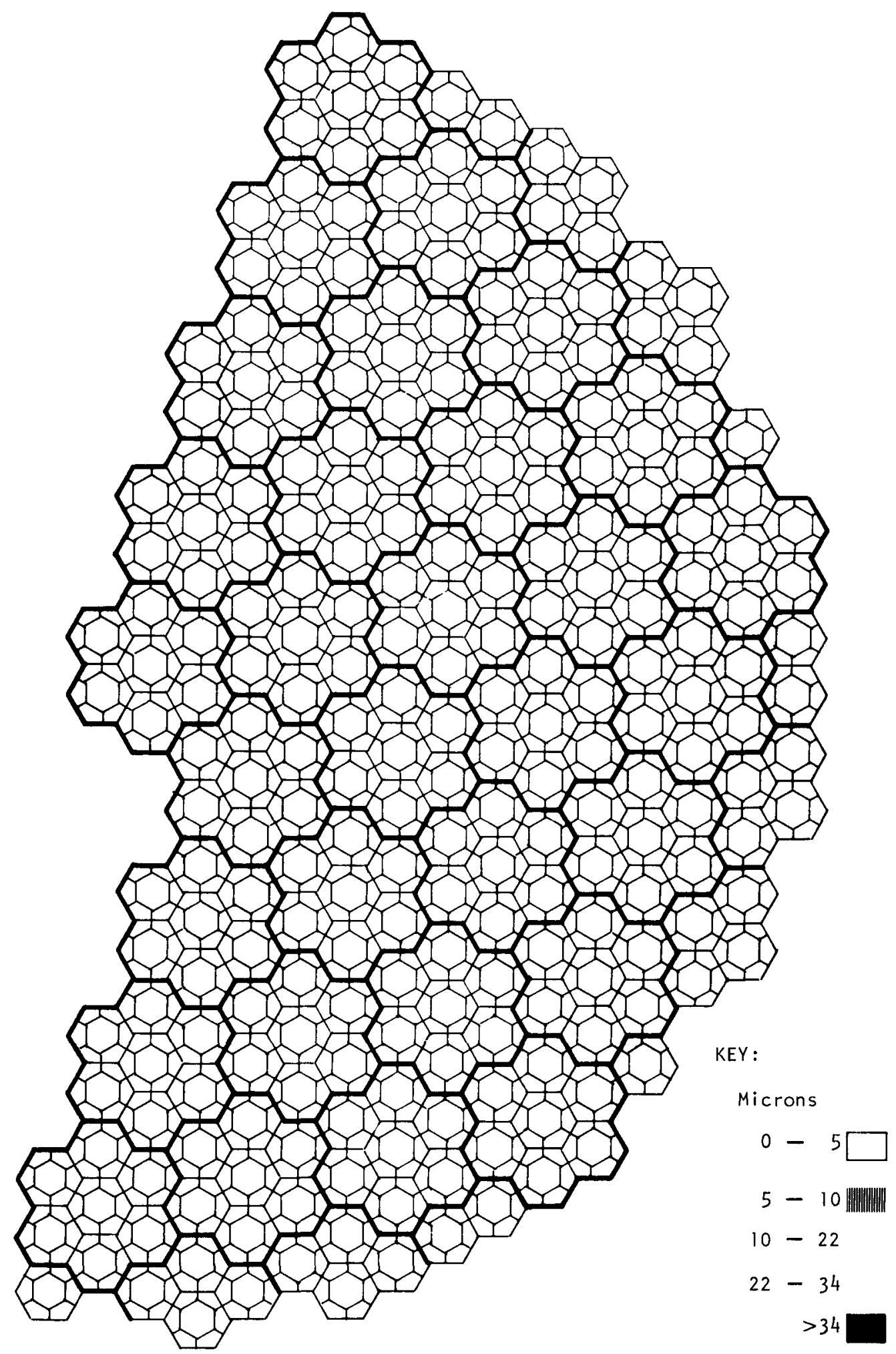

Fig. 7-14. BISO fuel EOL kernel migration at layer 1 


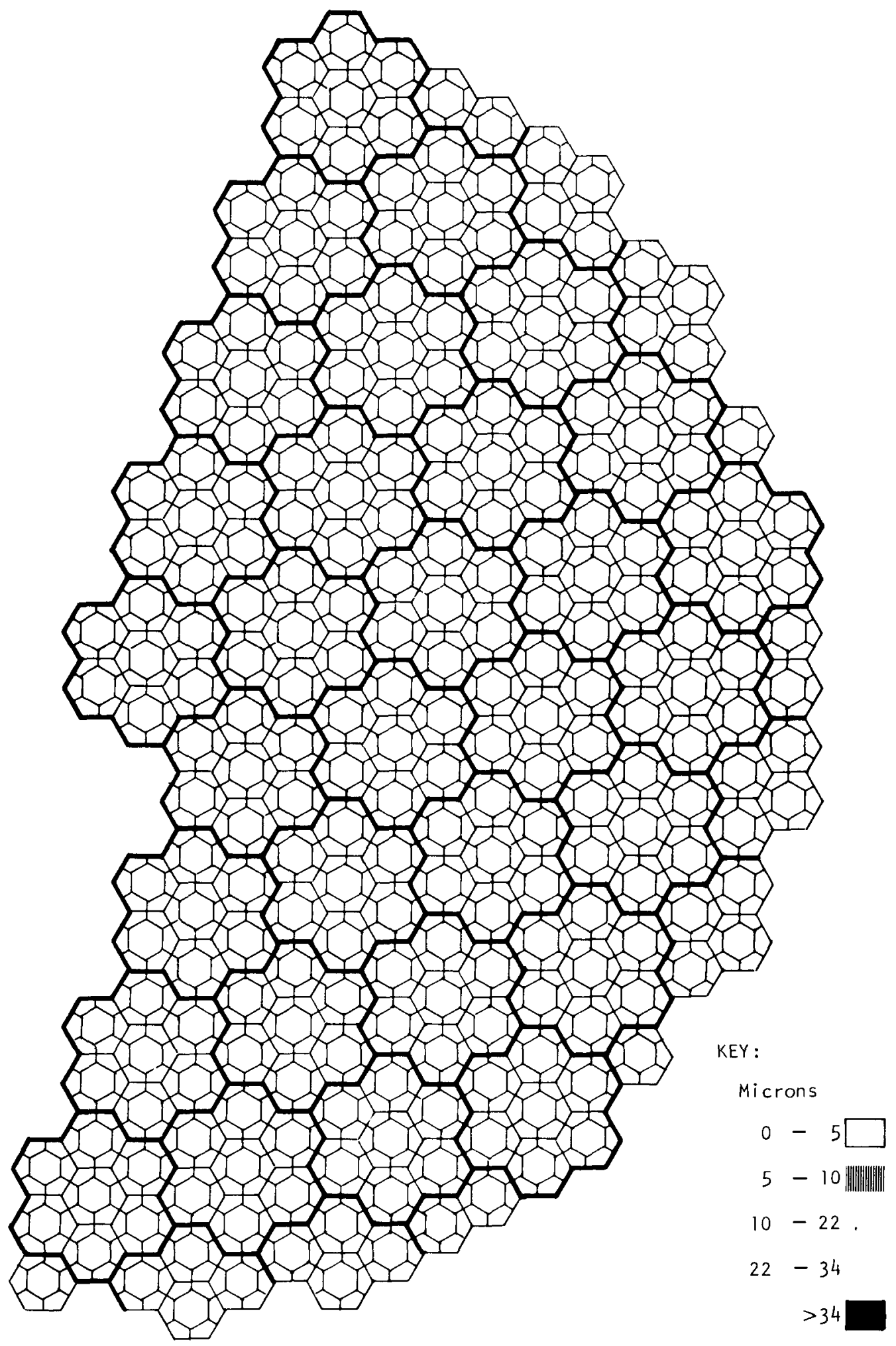

Fig. 7-15. BISO fuel EOL kernel migration at layer 2 


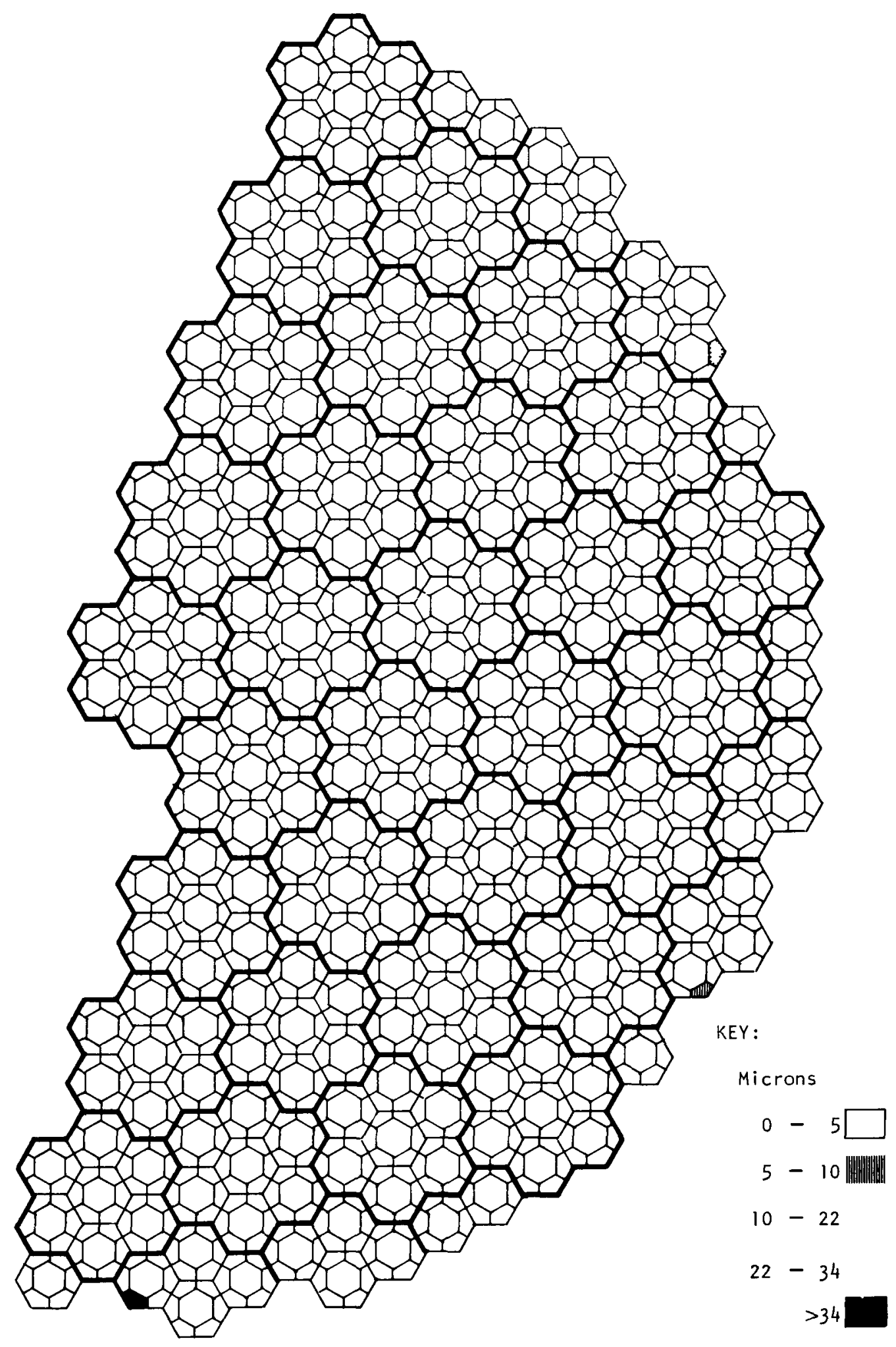

Fig. 7-16. BISO fuel EOL kernel migration at layer 3 


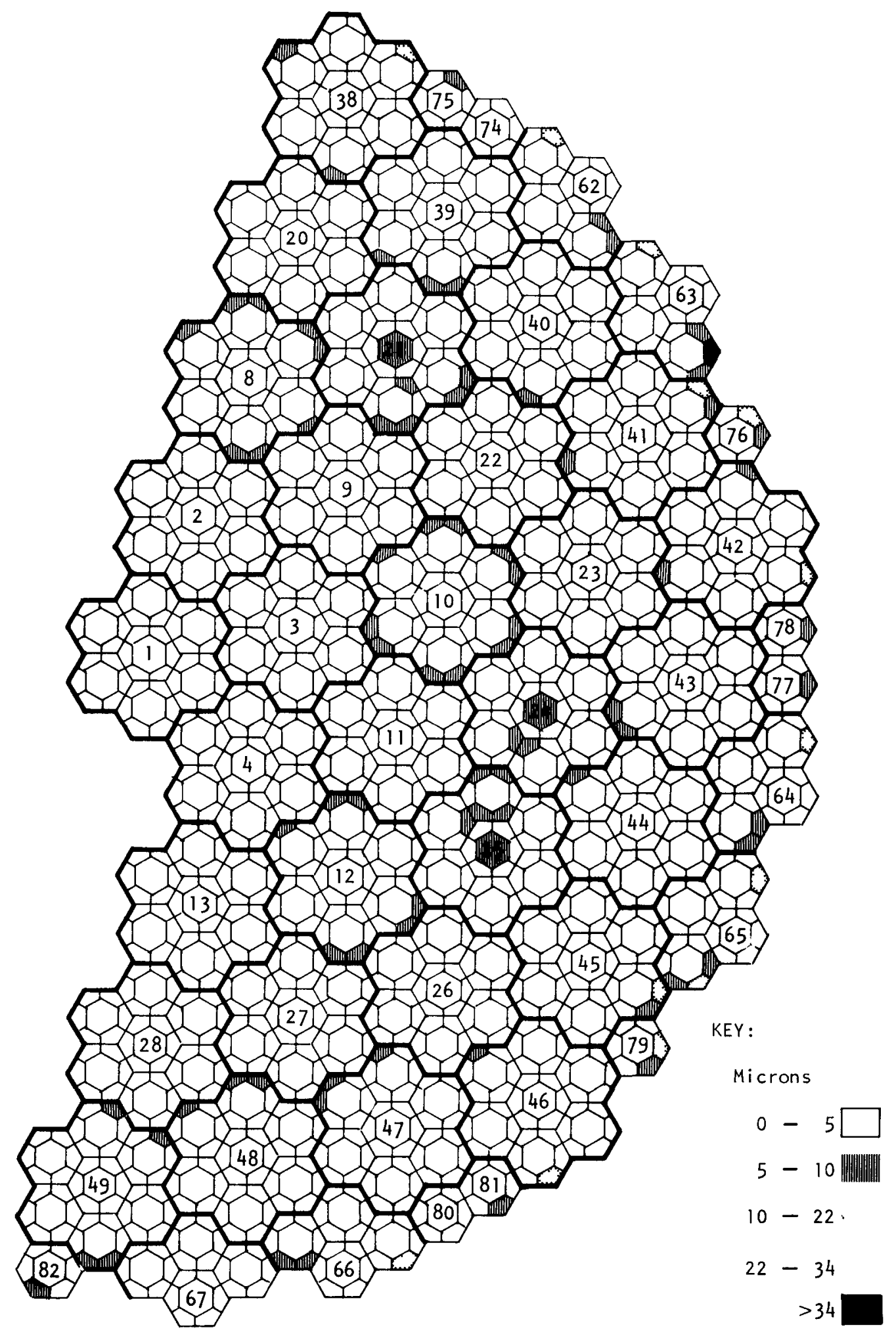

Fig. 7-17. BISO fuel EOL kernel migration at layer 4 


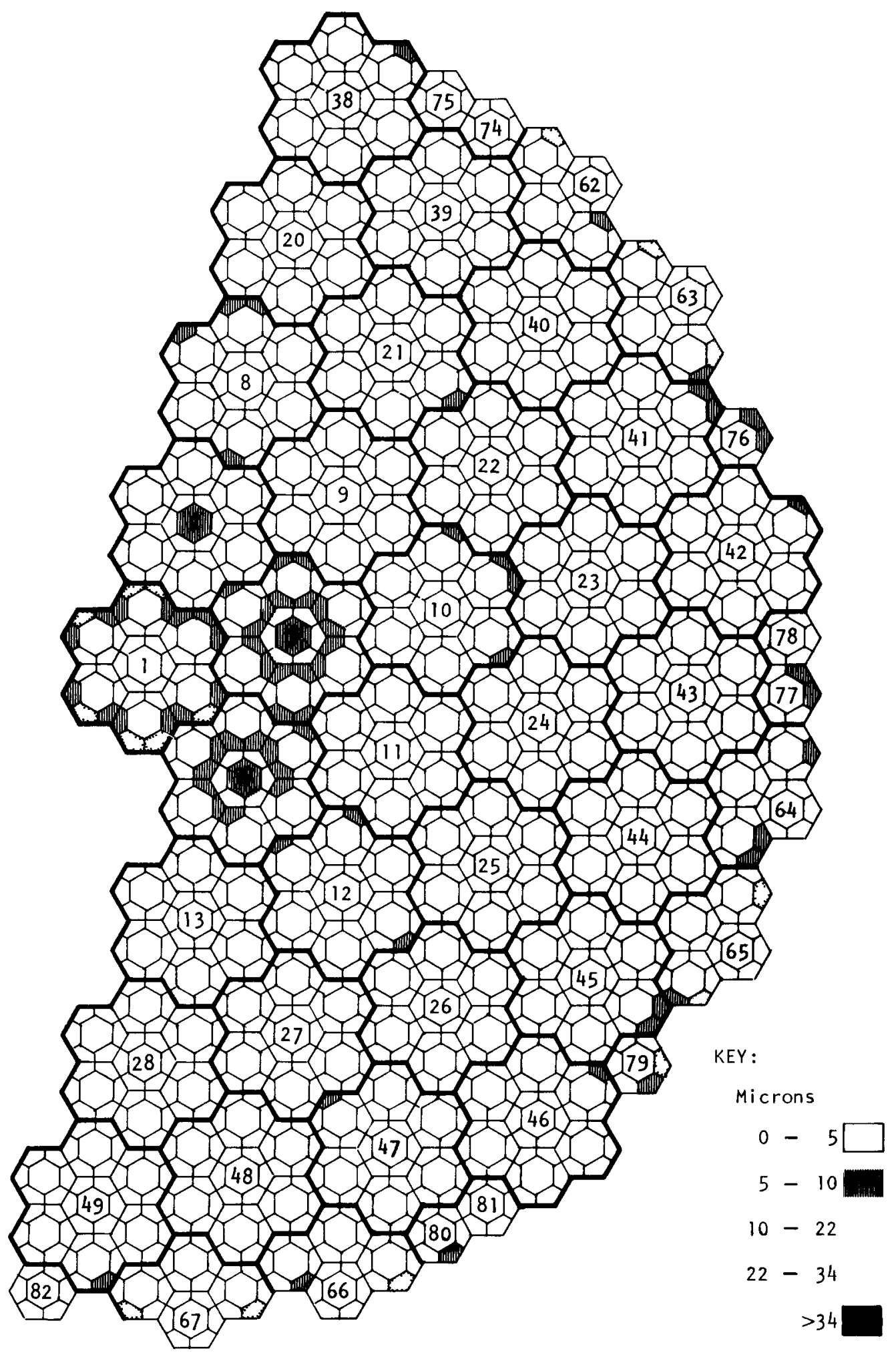

Fig. 7-18. BISO fuel EOL kernel migration at layer 5 


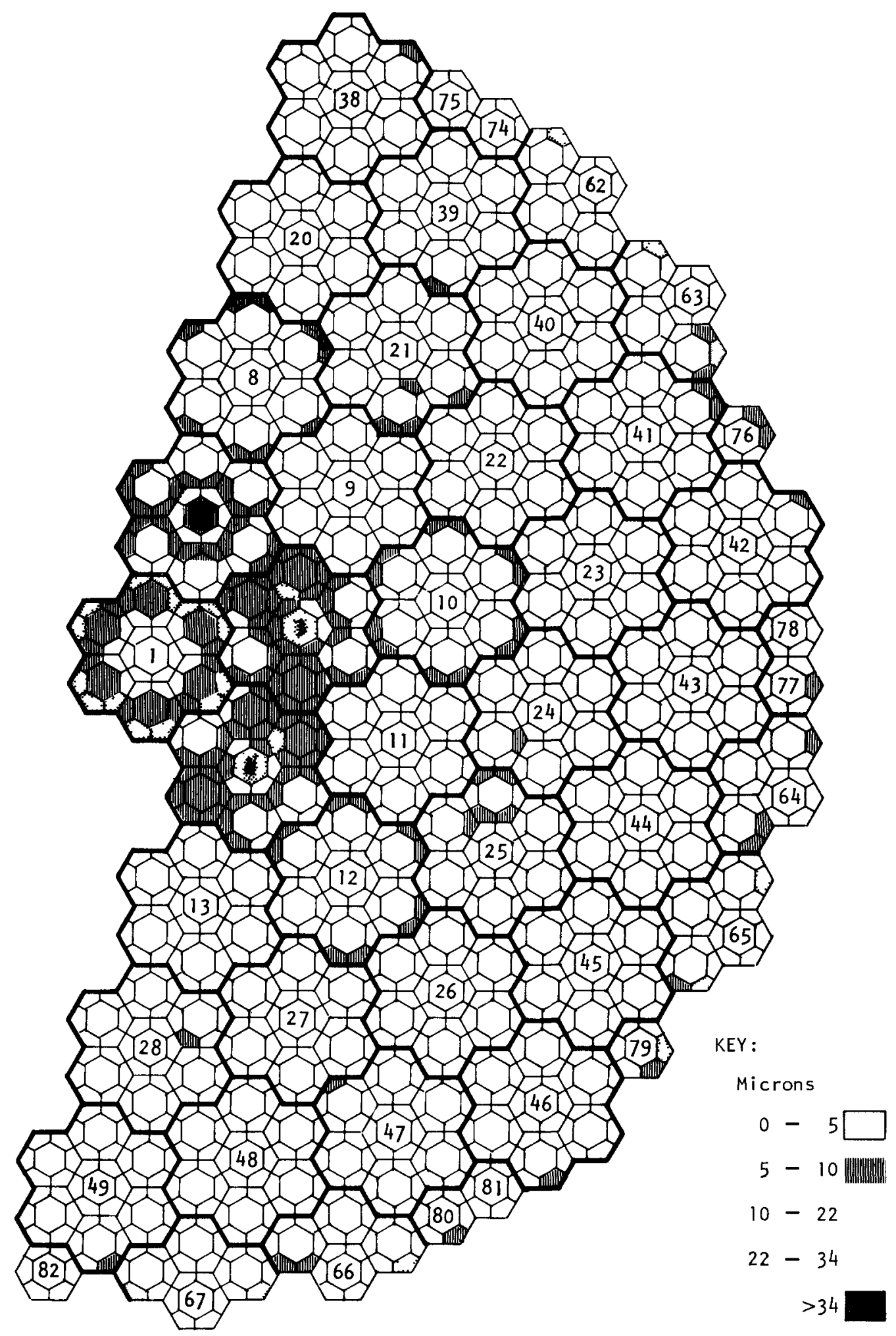

Fig. 7-19. BISO fuel EOL kernel migration at layer 6 


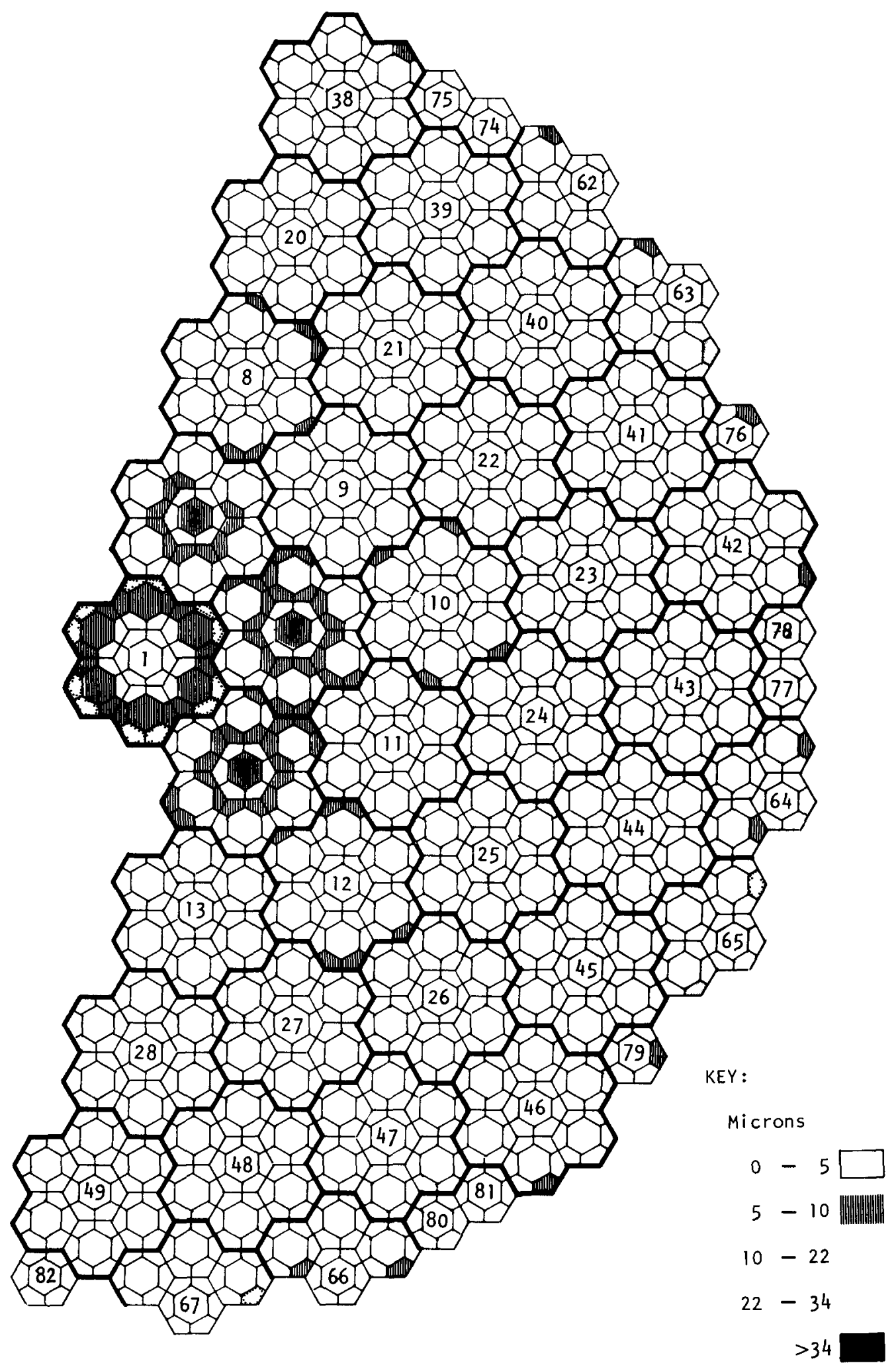

Fig. 7-20. BISO fuel EOL kernel migration at layer 7 


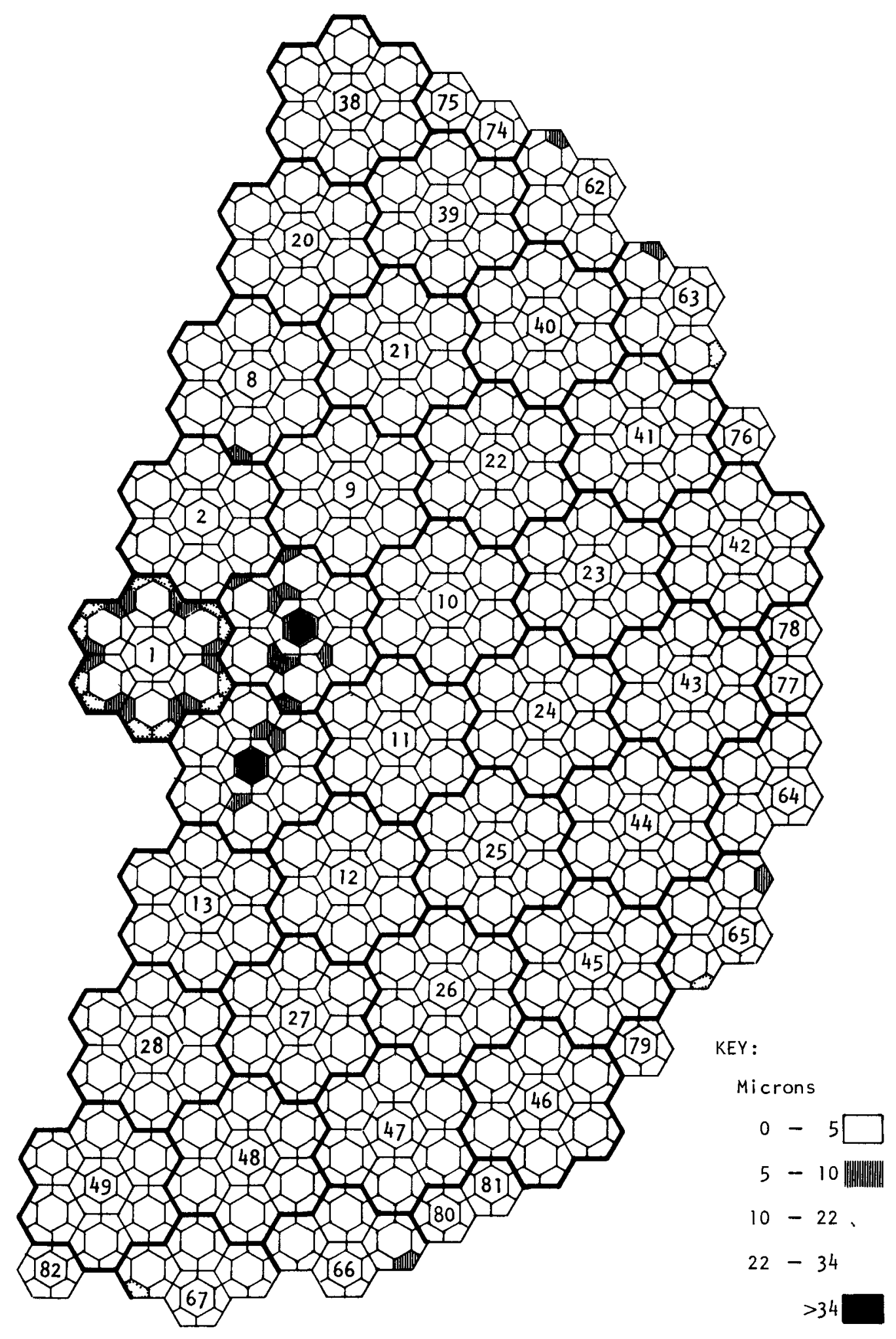

Fig. 7-21. BISO fue1 EOL kernel migration at layer 8 


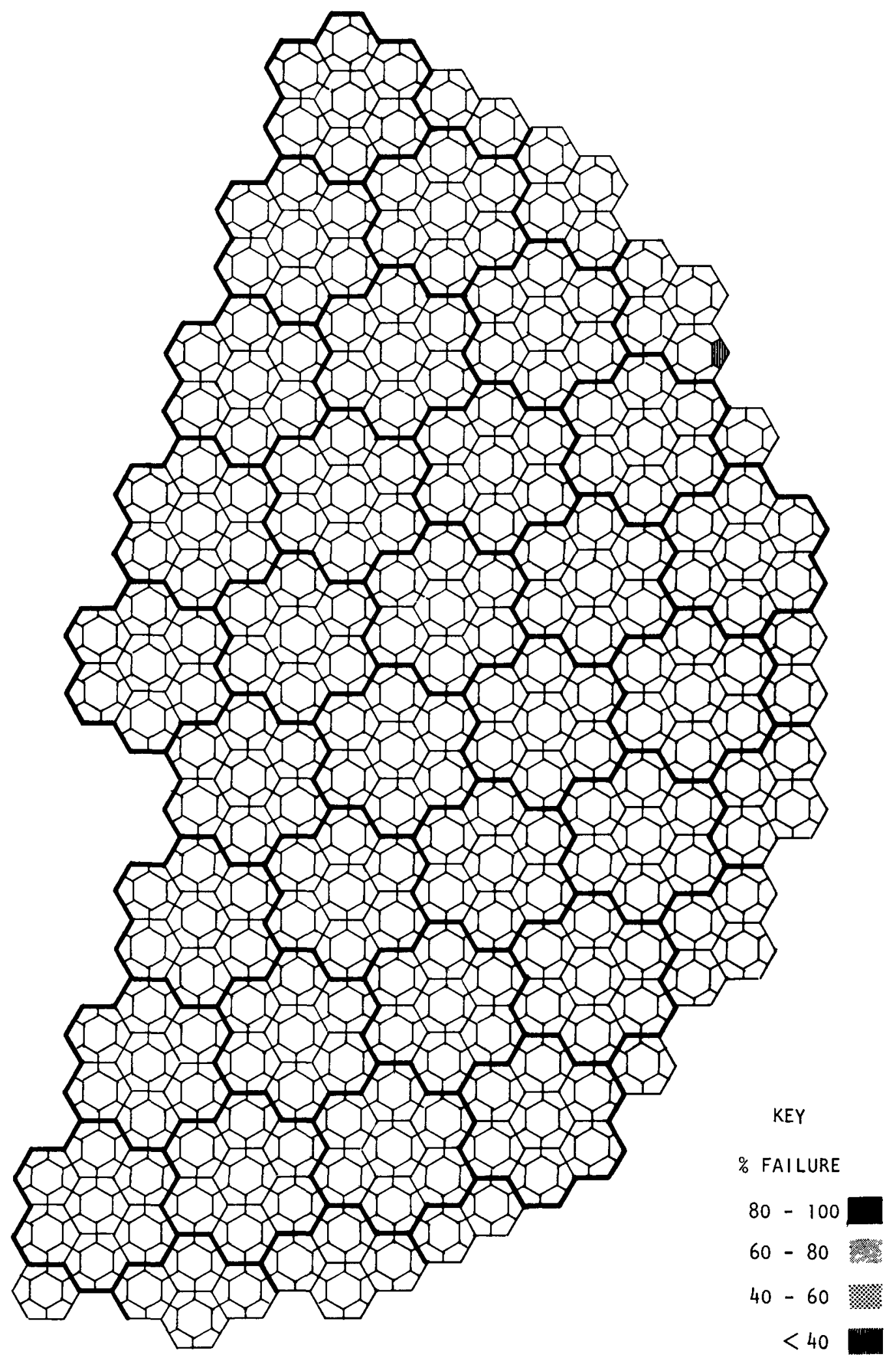

Fig. 7-22. Fraction of BISO fuel particle failure by migration at worst axial position $(\mathrm{Z} / \mathrm{L}=0.5)$ 
failed fuel due to high stresses in both TRISO and BISO fuel particle coatings.

\subsubsection{Pressure Vessel Failure in TRISO Particles}

Fuel temperatures are calculated for the spatial resolution shown in Fig. 5-12. GAUGE-calculated (Ref. 7-3) fast neutron fluence and heavy meta1 burnup are input to TREVER for use in the pressure vessel failure calculations at each time point and spatial location. At each time point during the 7-year burnup study, the fraction of TRISO fuel coatings failed at any spatial location by the pressure vessel mechanism is taken to be the maximum of the values determined by the temperature-fluence and the temperature-fissile burnup correlation in Ref. 7-1.

The failure fraction determined for the temperature-history given in Fig. 6-28 for the center of an individual fuel rod at the core midplane in region 40 is shown in Fig. 7-23 along with the history of burnup and fast neutron fluence for that location. The figure shows that the TRISO local pressure vessel failure is small at the beginning of the cycle and it reaches only a maximum value of $0.45 \%$ at the end-of-life, when the local fluence and burnup are maximum.

Figure 7-24 shows the axial distribution of pressure vessel failure for the same core radial location. The failure fraction is lower at the top and bottom of the core and reaches a maximum value towards the center of the core. This axial behavior is influenced by the higher level of fast neutron flux and burnup near the midplane of the core.

During the HTGR performance analysis a survey is made for the 3000-MW(t) reactor to calculate fraction of TRISO fuel particles failed by the pressure vessel mechanism for eight axial locations at the end of each fuel element just as was done for the amoeba effect. These calculations 

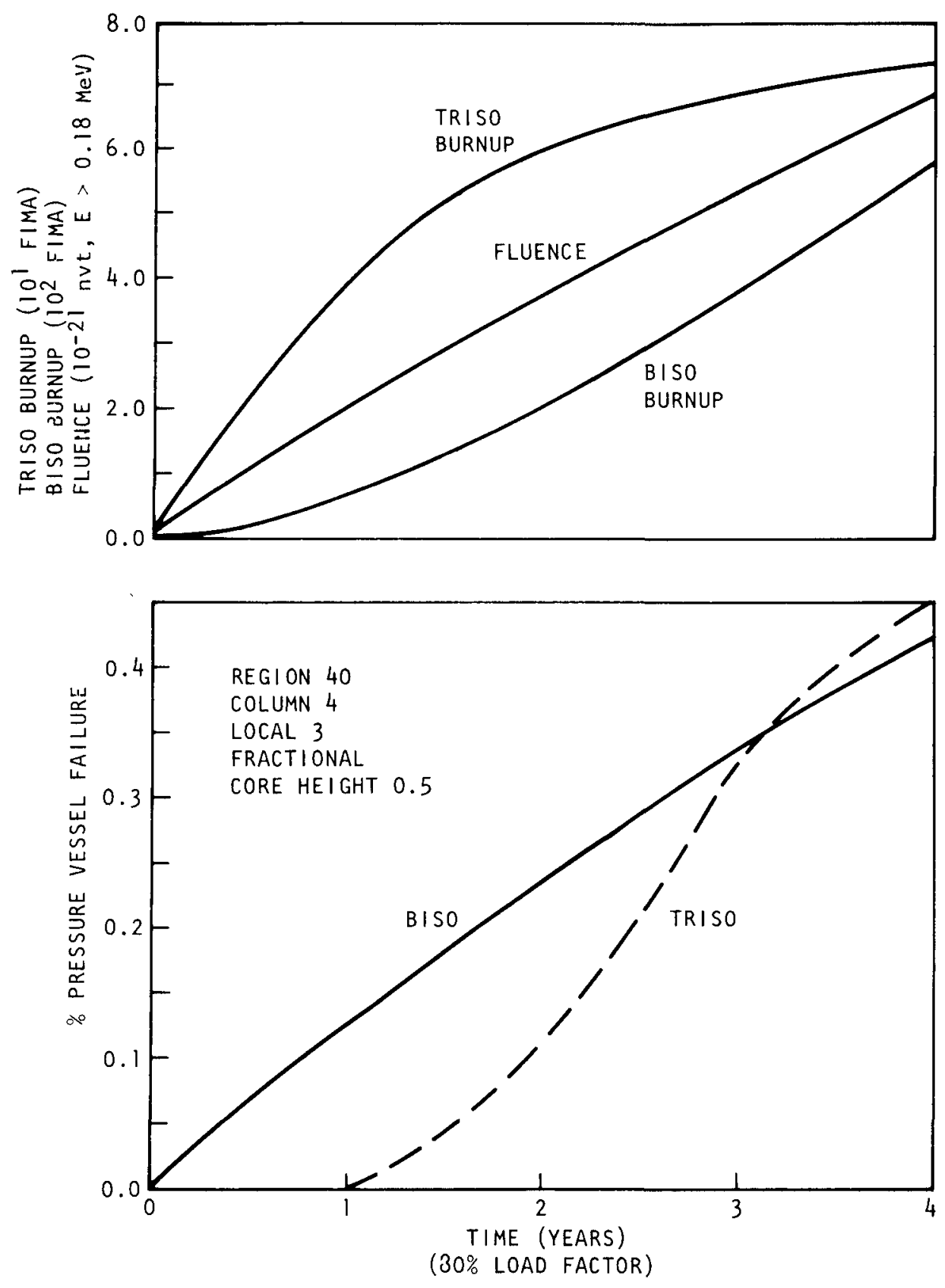

Fig. 7-23. Time dependence of pressure vessel failure fraction, fluence and burnup in a typical unrodded region 


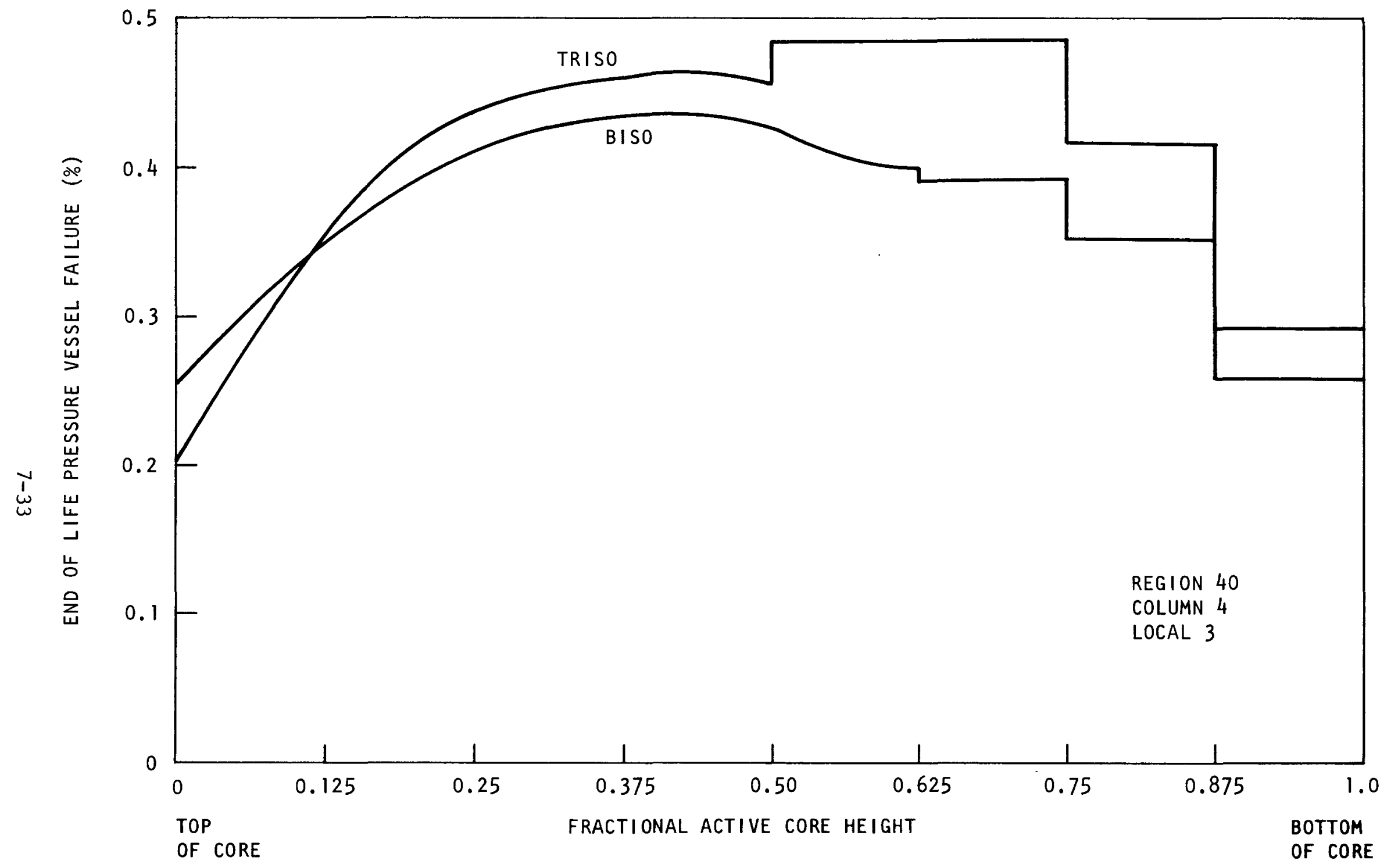

Fig. 7-24. Axial profiles of TRISO and BISO end-of-life pressure vessel failure fractions in a typical unrodded region 
are made for all the radial locations of half core symmetry and the results are shown in Figs. 7-25 through 7-32. Each of these figures indicates the fraction of TRISO particles failed at the end of the 4-year life time Just before the fuel is to be replaced. From these results, it can be seen that the failure in the top and bottom layers of the active core is small and increases towards the middle of core with maximum about the fourth layer of the core. In contrast to the kernel migration induced failure, in the radial direction the pressure vessel failure is distributed uniformly across the core except near the core-reflector interface boundary where the end-of-life (EOL) fast neutron fluence and burnup are low. At the end-oflife conditions, only a small fraction of the TRISO fuel fails by pressure vessel mechanism but coating fallure occurs in almost all the locations of the core. This EOL pressure vessel fallure distribution is influenced by the EOL fuel temperatures, fast neutron fluences, and burnups shown in Fig. 7-33. Characteristics of segment 7 in segment position $C$ (defined in Fig. 5-11) are shown in Fig. 7-33. Greater than $99 \%$ of the fuel volume in this segment experiences an EOL fuel temperature less than $2280^{\circ} \mathrm{F}$; in this temperature range the failure correlations in Ref. 7-1 indicate pressure vessel failure is independent of temperature. Thus the failure is governed by the fluence and burnup characteristics of the segment. For TRISO fuel particles, greater than $95 \%$ of the fissile particles reach EOL burnup between 70 and $80 \%$ FIMA* resulting in only $0.5 \%$ of the TRISO particles falling in this reload segment. Figure 7-33 also shows that only $6 \%$ of the fuel volume reaches an EOL fast neutron fluence between 7 and $8 \times 10^{21}$ nvt, which Indicates that at the EOL conditions a majority of the TRISO pressure vessel fallure is governed by high EOL burnup.

To appreciate how these pressure vessel coating fallures progress with time, Fig. 7-34 1s presented. The development of the fallure fraction with time in each of the segment positions beginning with the initial core is sketched. Segment position $A$ is reloaded after 1 year and experiences essentially no coating fallure. During the second year, small fractions of

*Fissions per Initial Metal Atom. 


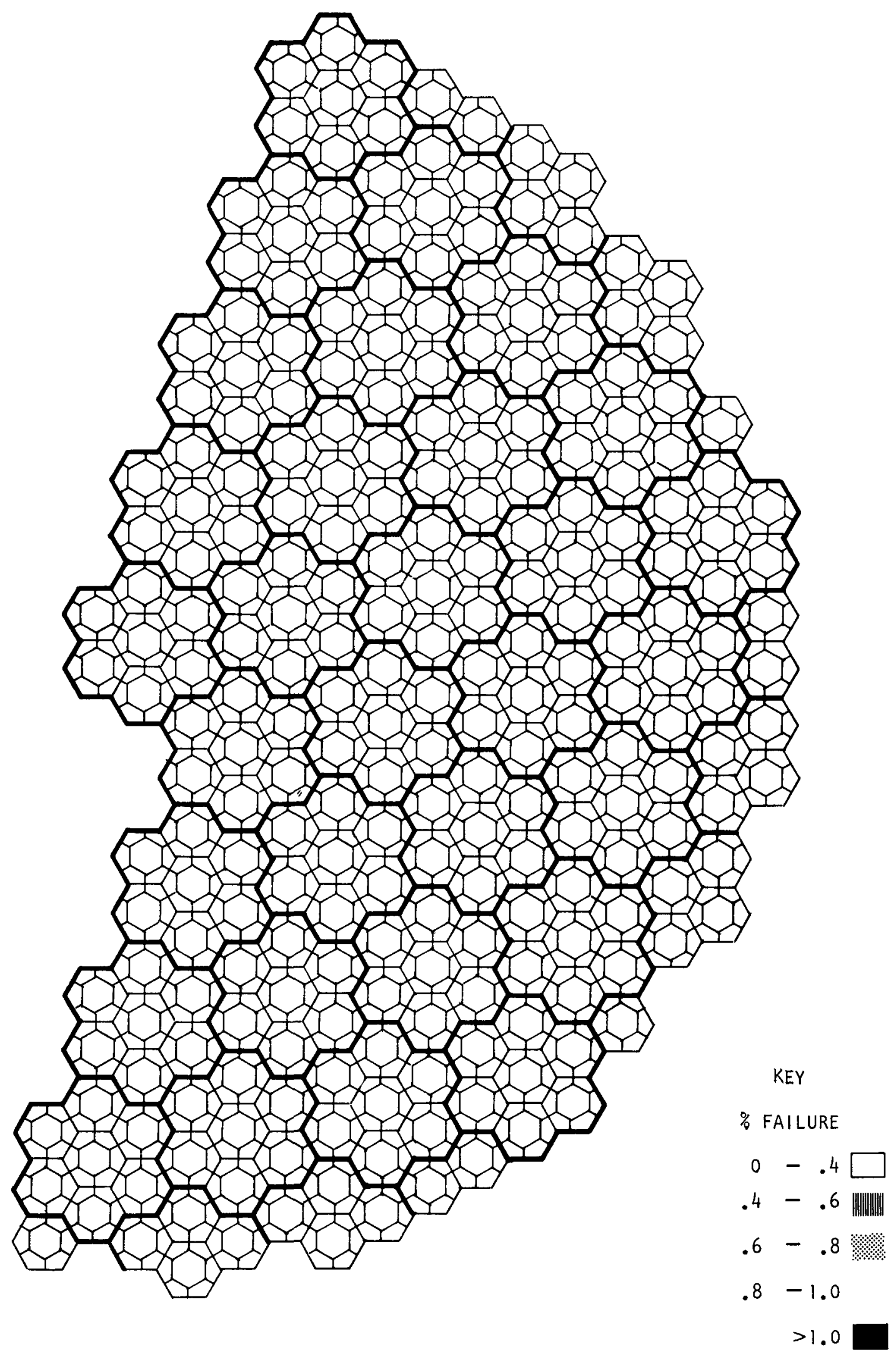

Fig. 7-25. TRISO pressure vessel failure in layer 1 


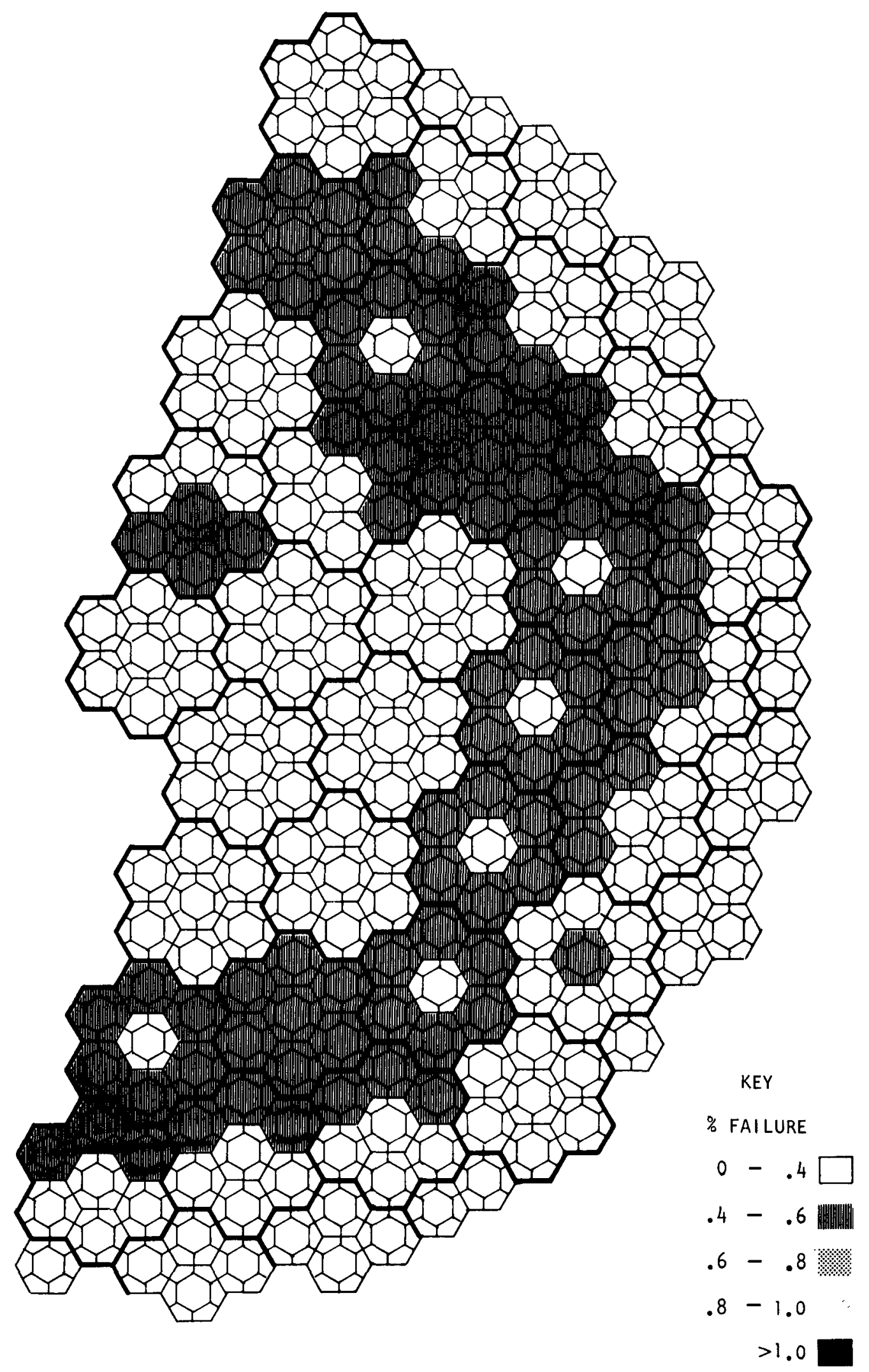

Fig. 7-26. TRISO pressure vessel failure in layer 2 


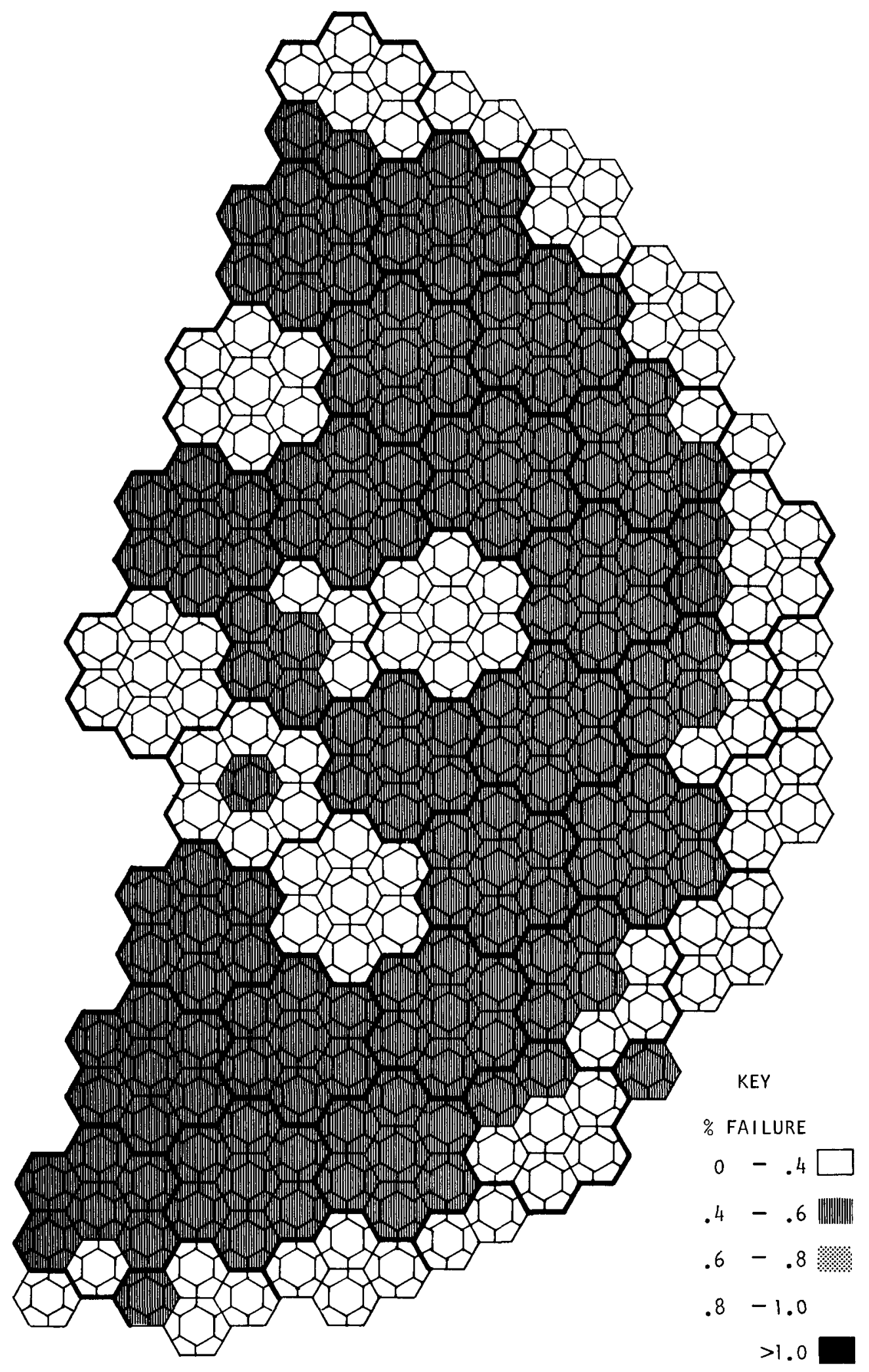

Fig. 7-27. TRISO pressure vessel failure in layer 3 


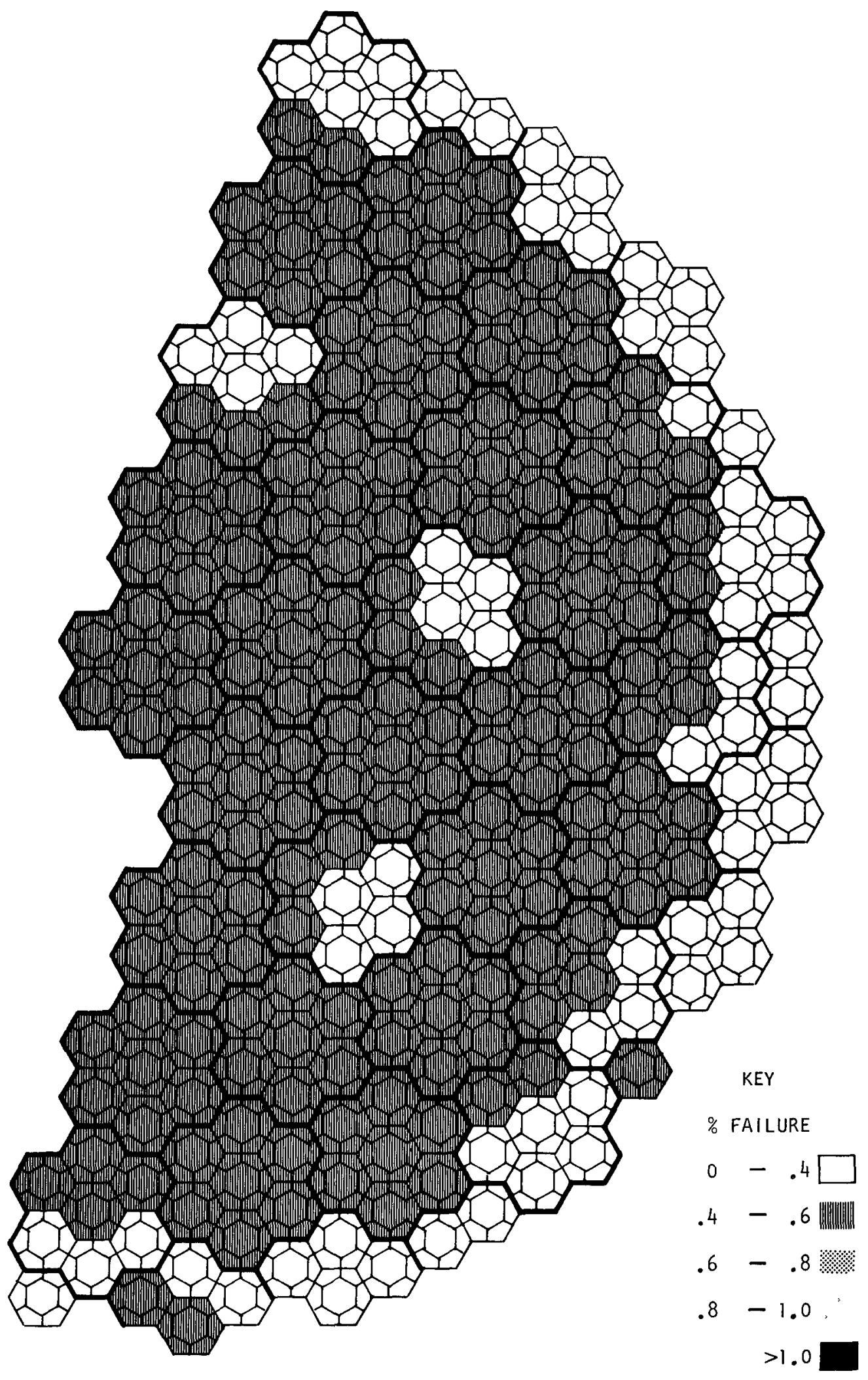

Fig. 7-28. TRISO pressure vessel failure at layer 4 


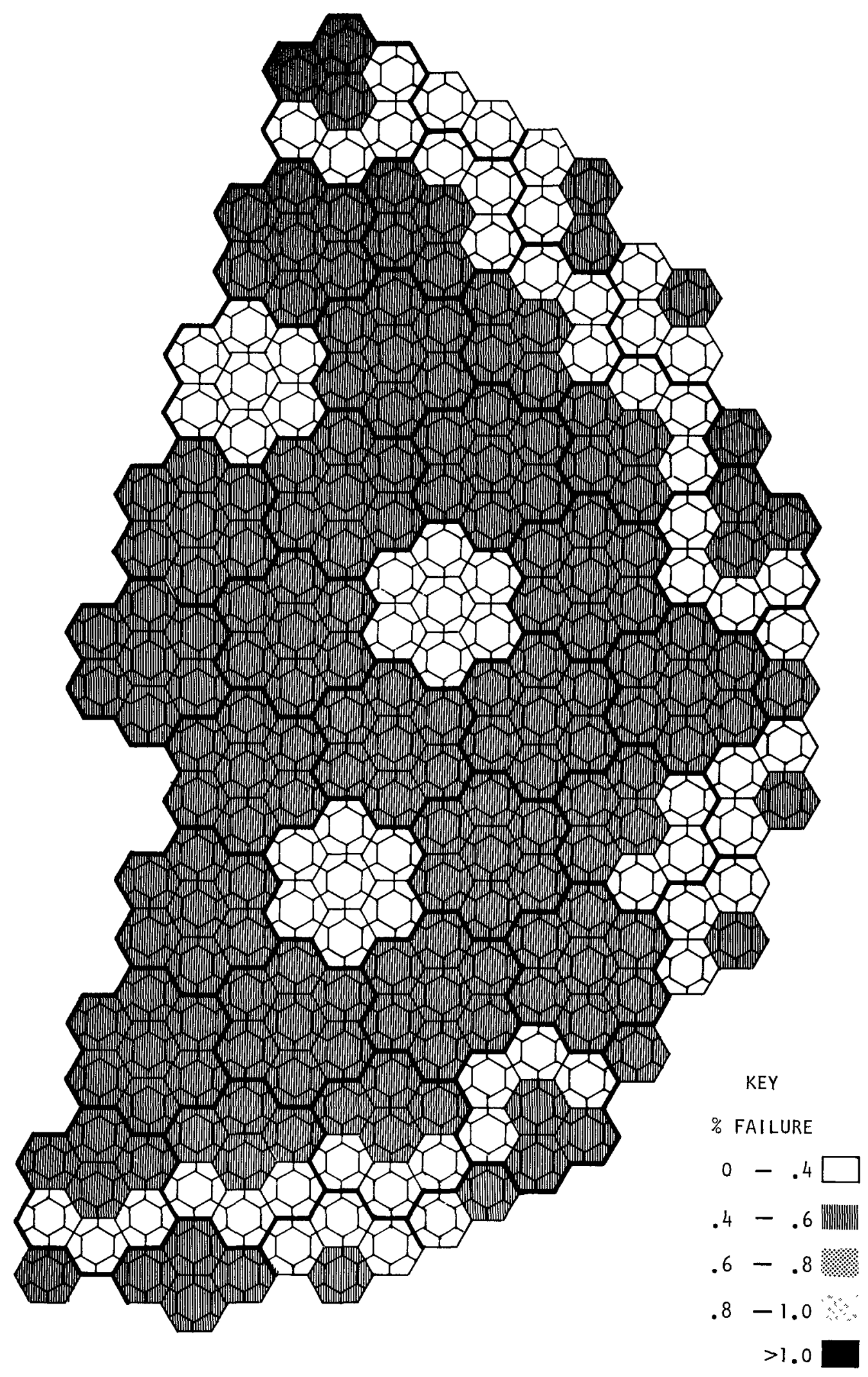

Fig. 7-29. TRISO pressure vessel failure at layer 5 


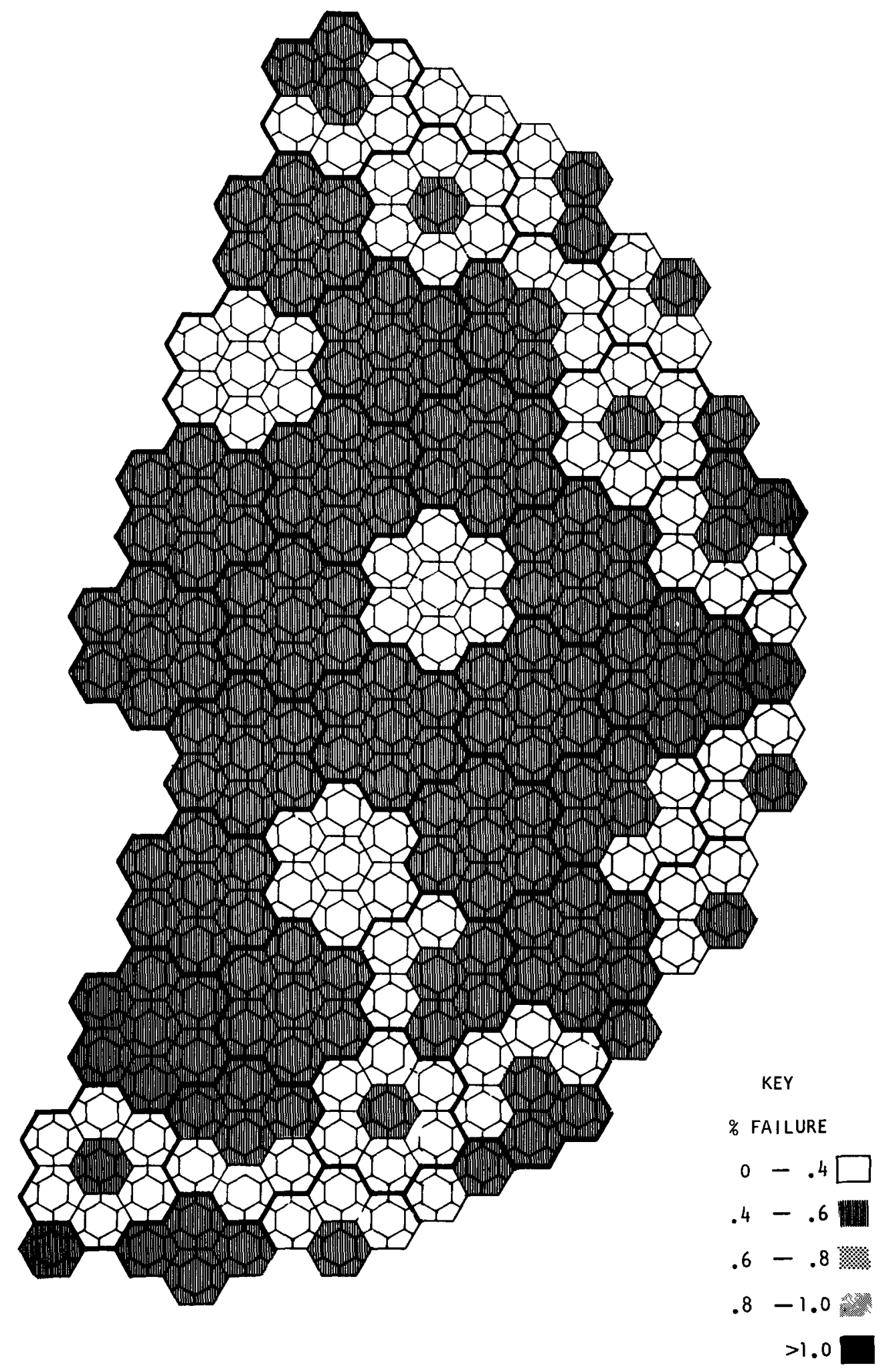

Fig. 7-30. TRISO pressure vessel failure in layer 6 


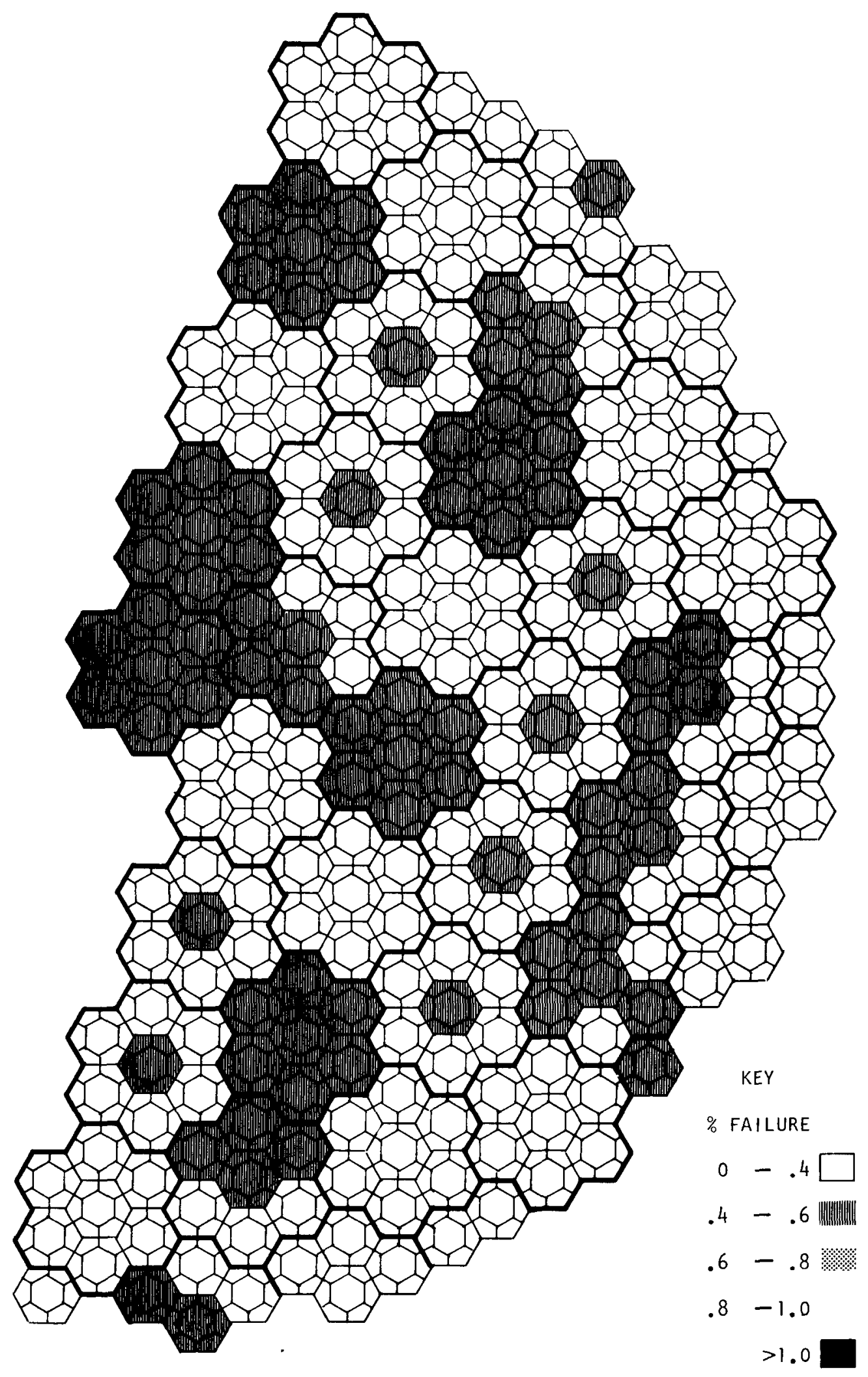

Fig. 7-31. TRISO pressure vessel failure at layer 7 


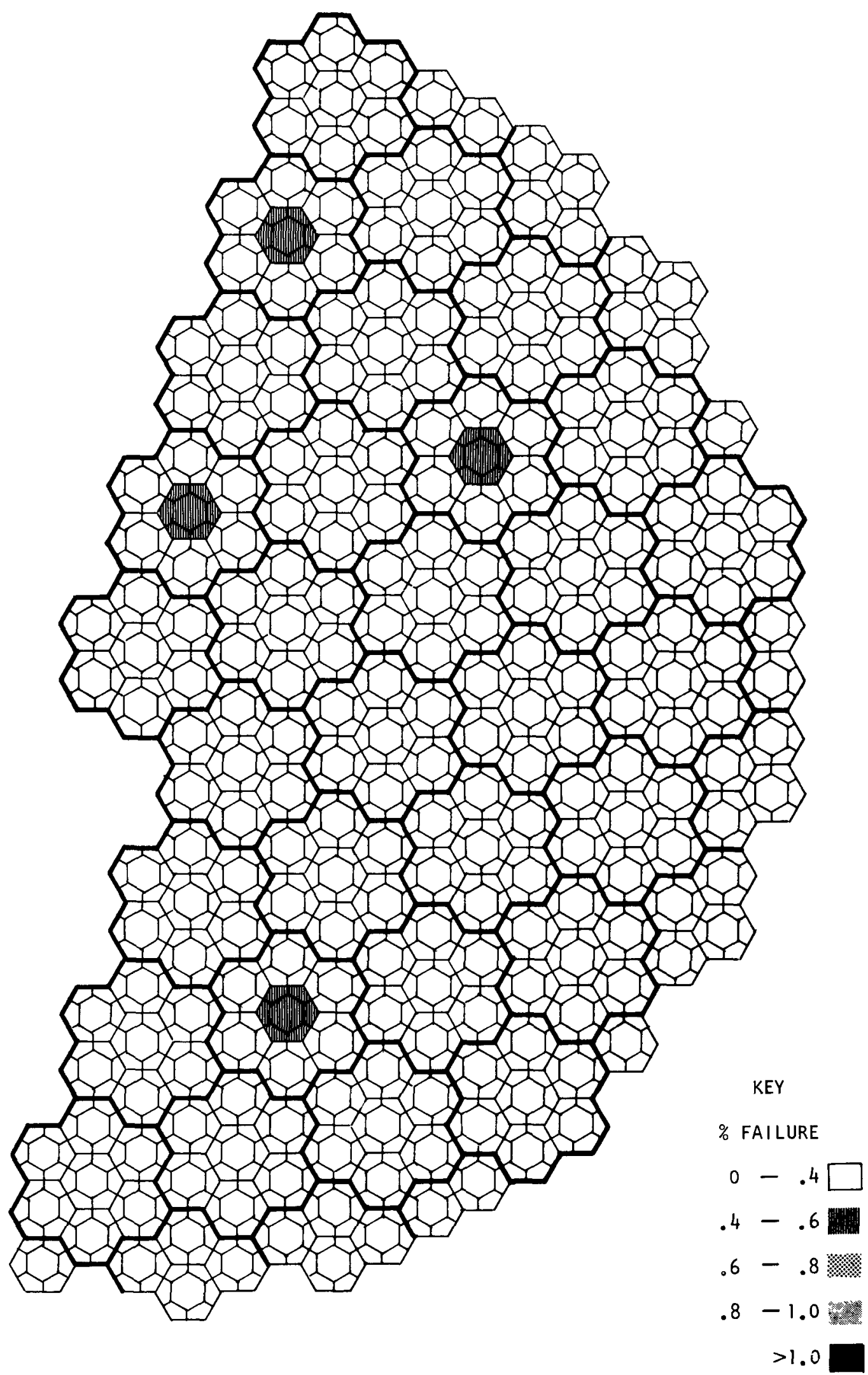

Fig. 7-32. TRISO pressure vessel failure at layer 8 


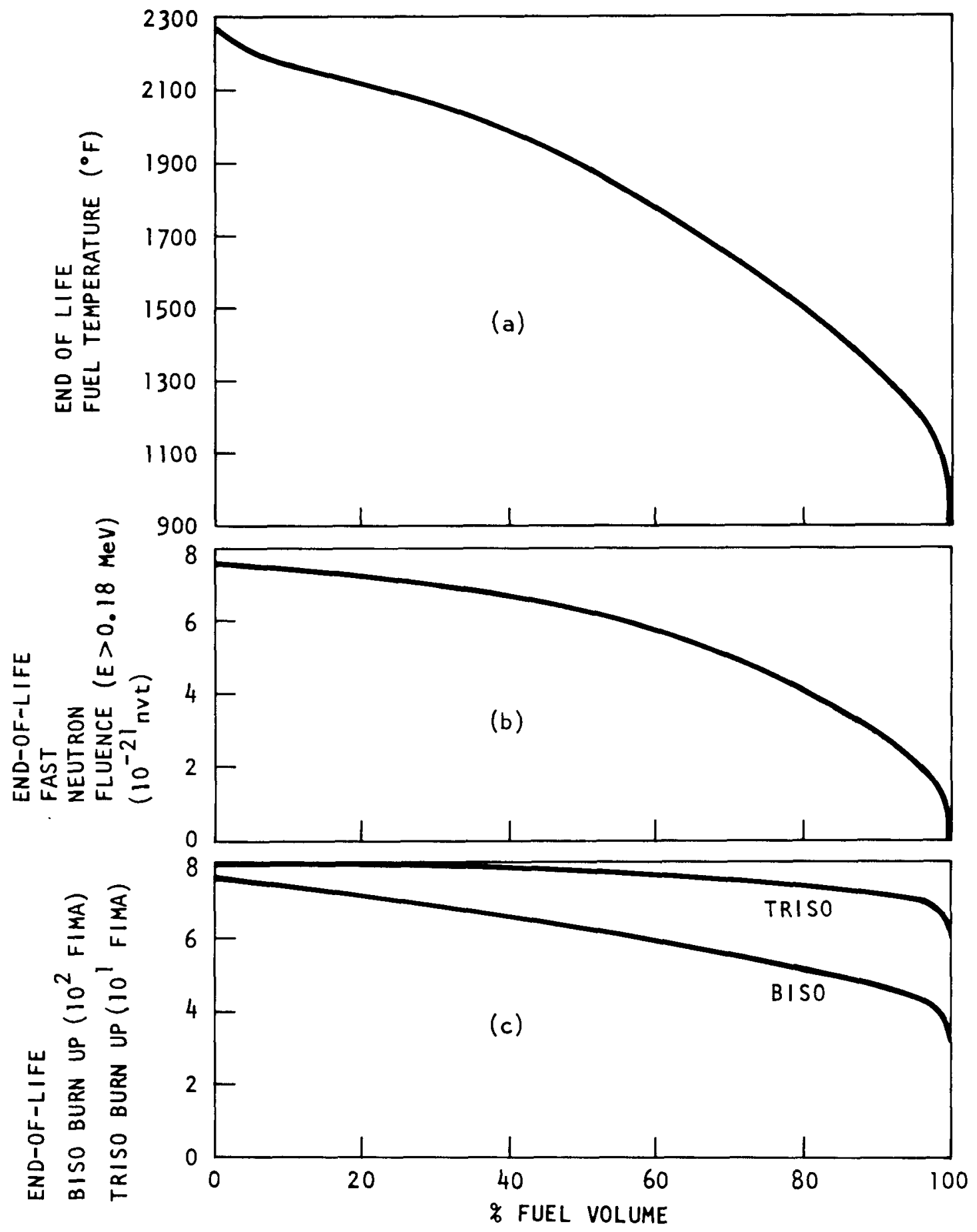

Fig. 7-33. Volume distributions of end-of-1ife fuel temperatures, fluence and burnup in third reload fuel 


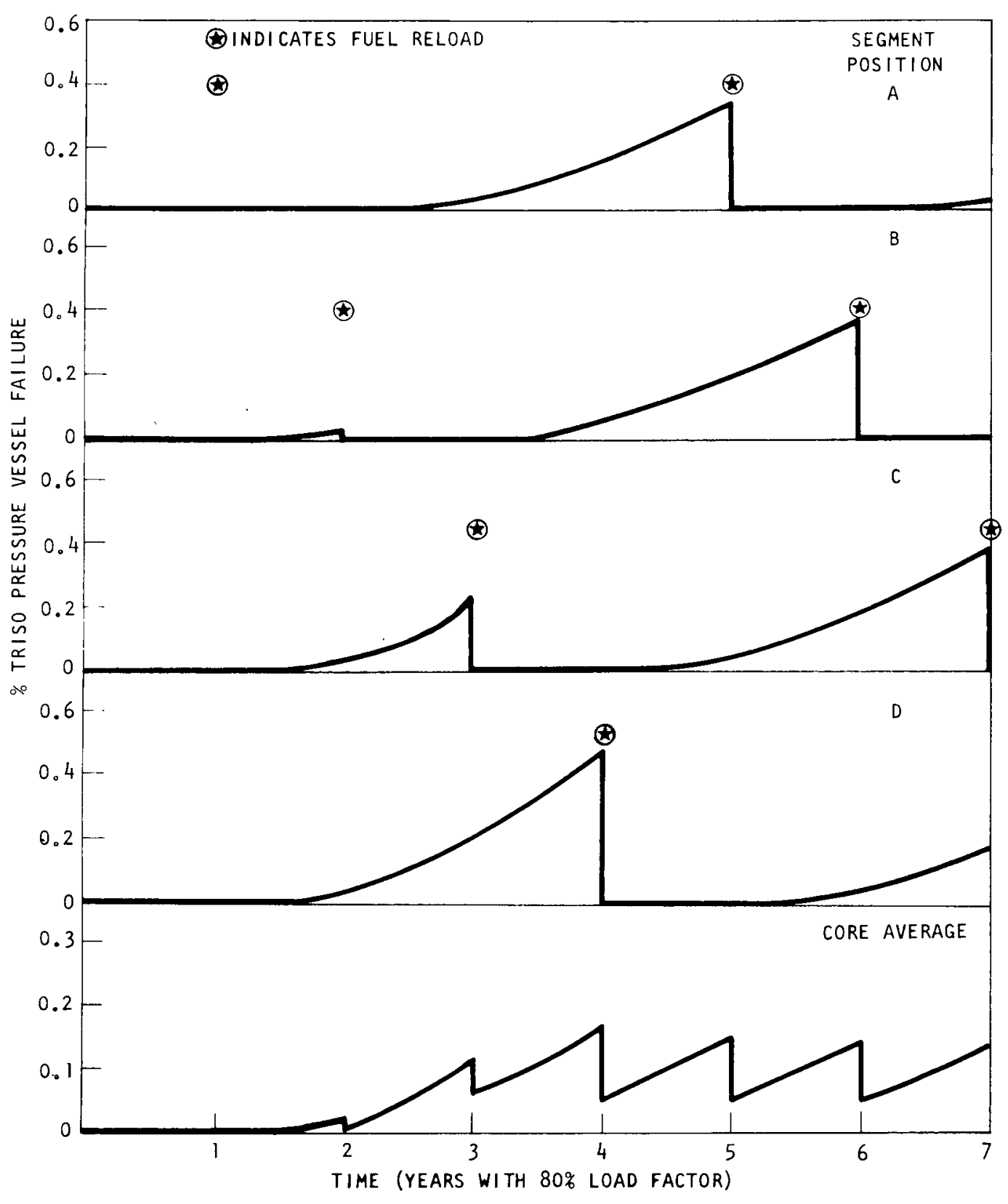

Fig. 7-34. Time history of segment and core average TRISO pressure vessel failure in the core 
failure are noted in the two-year-old fuel in segment positions $B, C$, and D. Segment position $B$ is reloaded at the end of the second year and a step decrease is noted in the total failure fraction. In the third year, failure progressively increases in the now 3-year old fuel in segment positions $C$ and $D$. Segment position $A$, now 2 years old, is starting to develop a few failures. Then at the end of the third year, segment position $C$ is reloaded and another step decrease is observed in the core average value. After 4 years of core operation, the time behavior of coreaverage fuel failure approaches a fixed annual repetitive cycle. Peak values in the equilibrium core are about $0.18 \%$ of the TRISO particles failing at the end of each year.

\subsubsection{Pressure Vesse1 Failures in BISO Particles}

BISO and TRISO coating failure by pressure vessel failures have a very similar morphology. Figures paralleling those of TRISO particles are presented. Local time behavior for BISO particles is given in Fig. 7-23. BISO core end-of-life failure fraction maps are shown in Figs. 7-35 through 7-42. Time behavior in the segments and core average are shown in Fig. 7-43.

Comparing the pressure vessel failure fractions of BISO and TRISO particles at the same location, the BISO particles begin to fail earlier in life as is dictated by the failure correlation given in Ref. 7-1.

In the equilibrium core, the BISO failure fraction of $0.22 \%$ due to pressure vessel effects is just slightly larger than for TRISO particles.

\subsection{HIGH TEMPERATURE FAILURE OF TRISO PARTICLES}

Reference 7-1 indicates that if the fissile TRISO fuel particles at lower burnup are exposed to temperatures above $3272^{\circ} \mathrm{F}$ and at full burnup, 


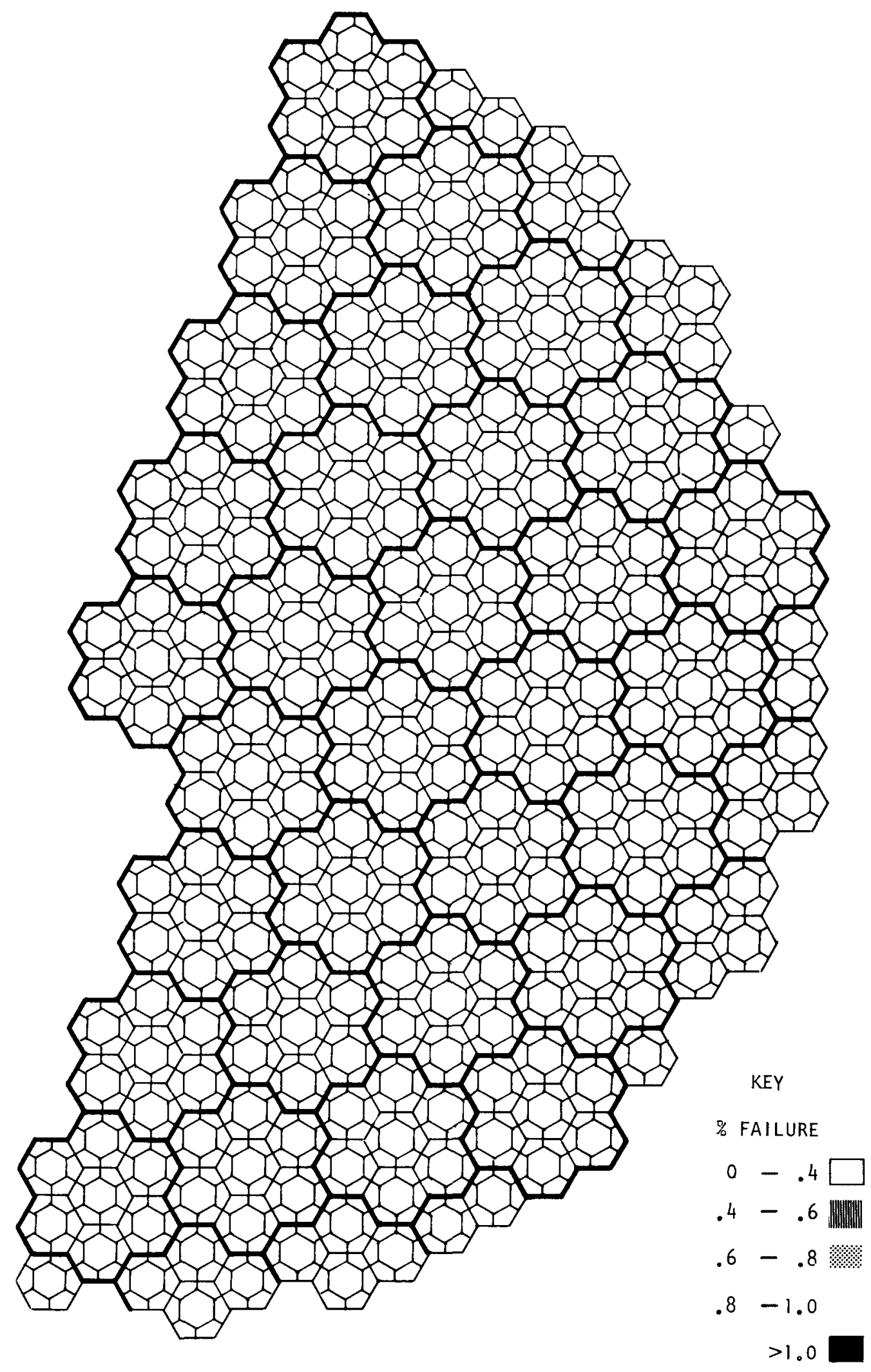

Fig. 7-35. BISO pressure vessel failure in layer 1 


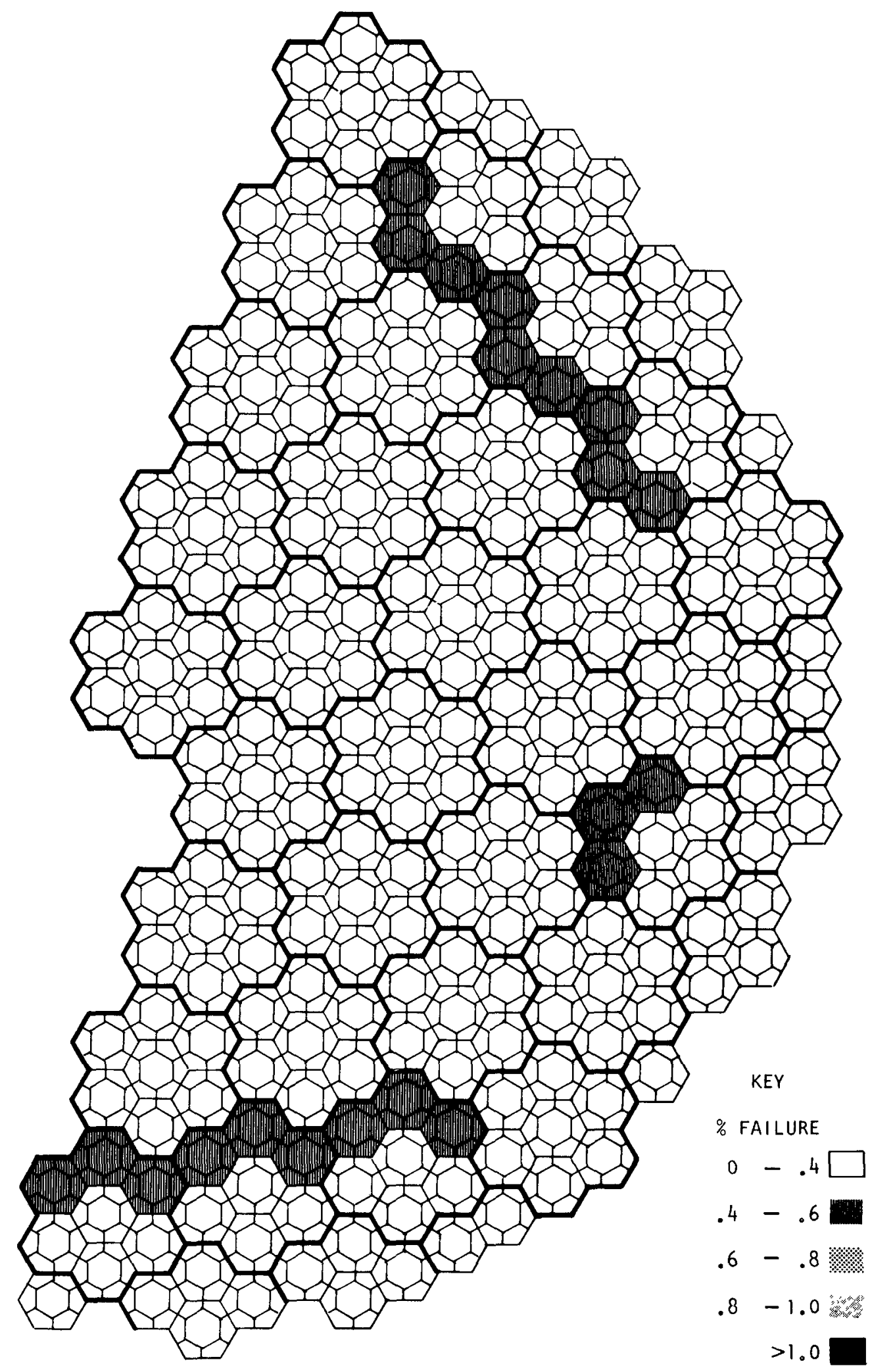

Fig. 7-36. BISO pressure vessel failure in layer 2 


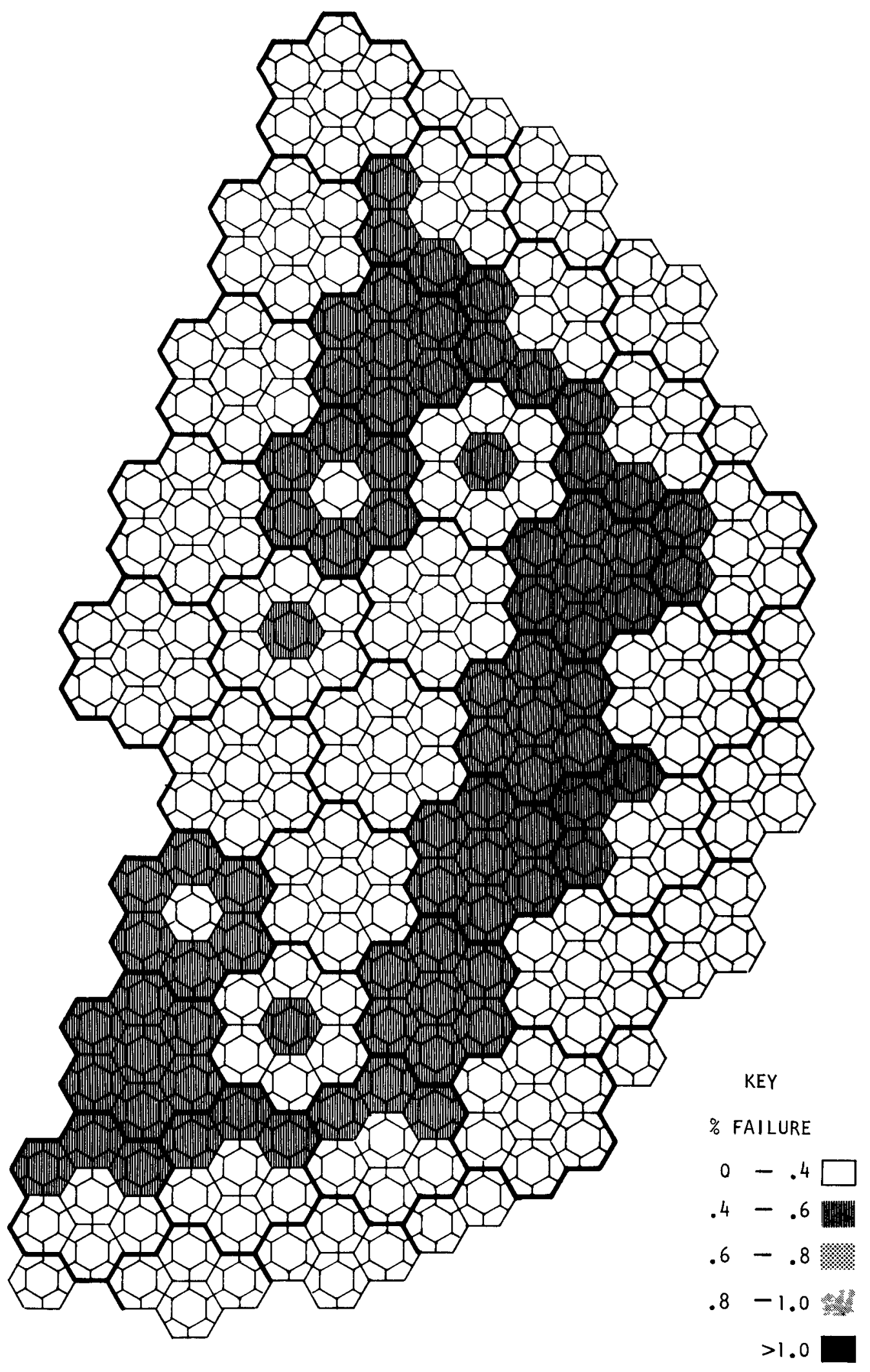

Fig. 7-37. BISO pressure vessel failure in layer 3 


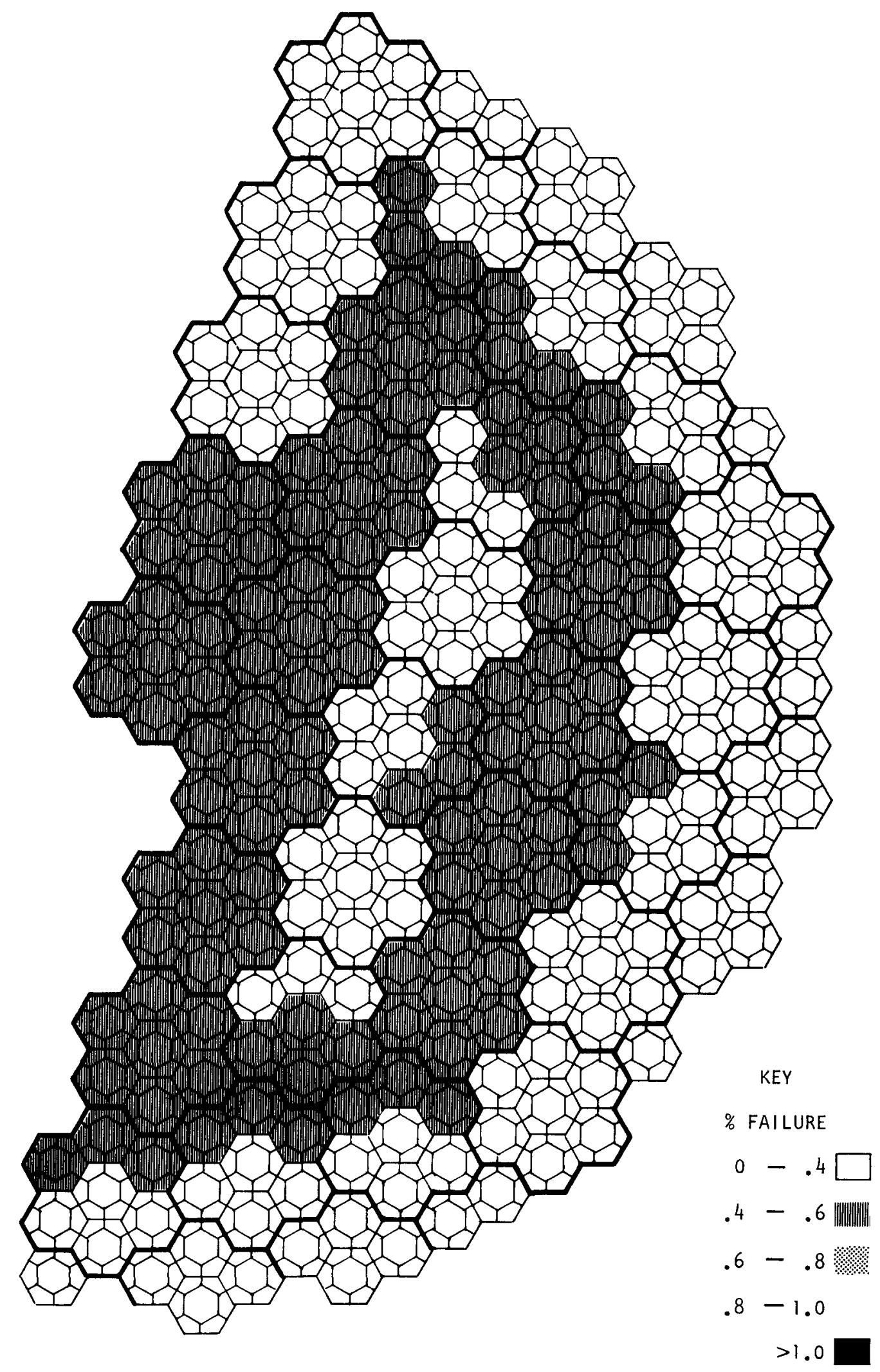

Fig. 7-38. BISO pressure vessel failure in layer 4 


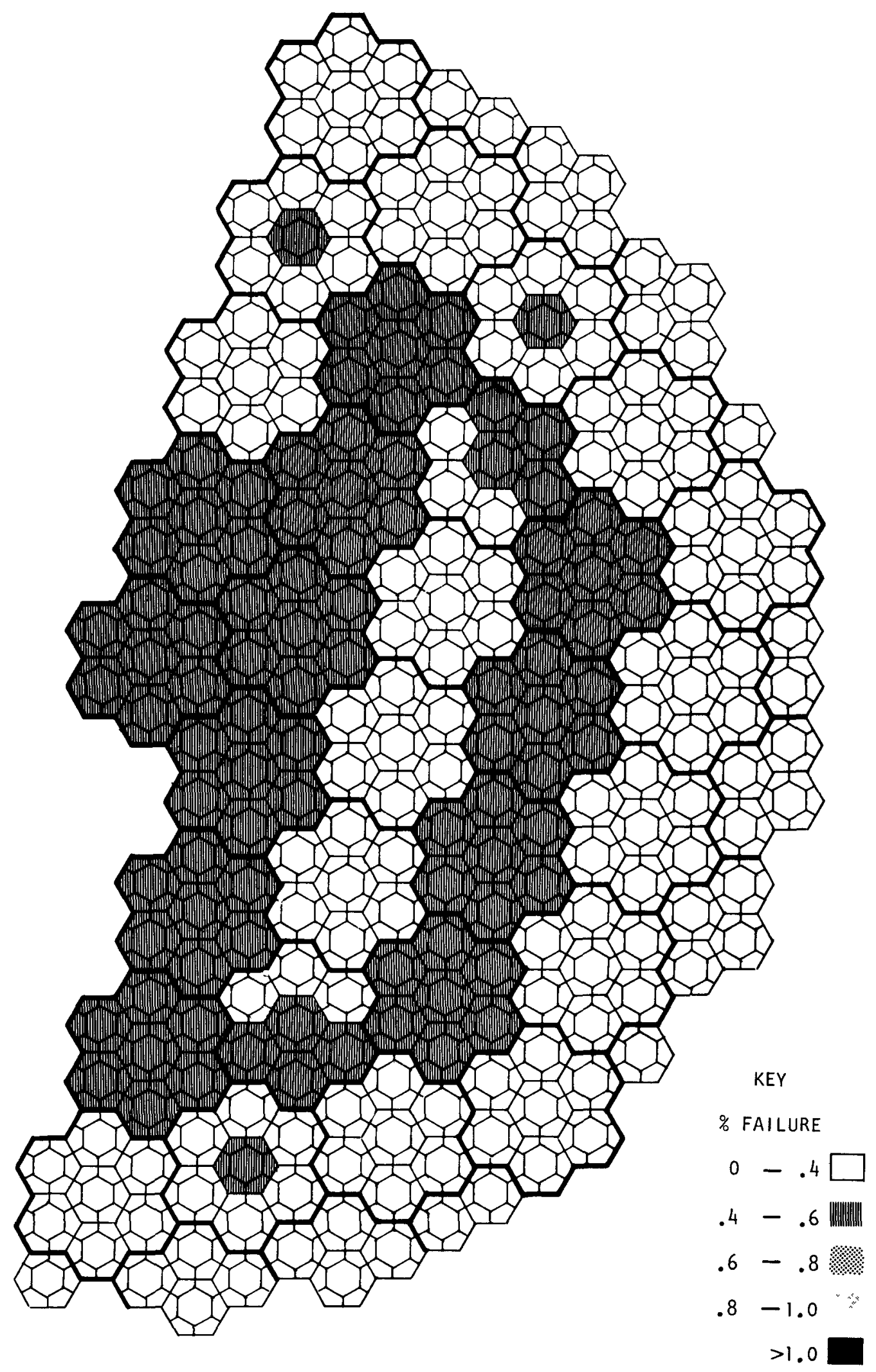

Fig. 7-39. BISO pressure vesse1 failure in layer 5 


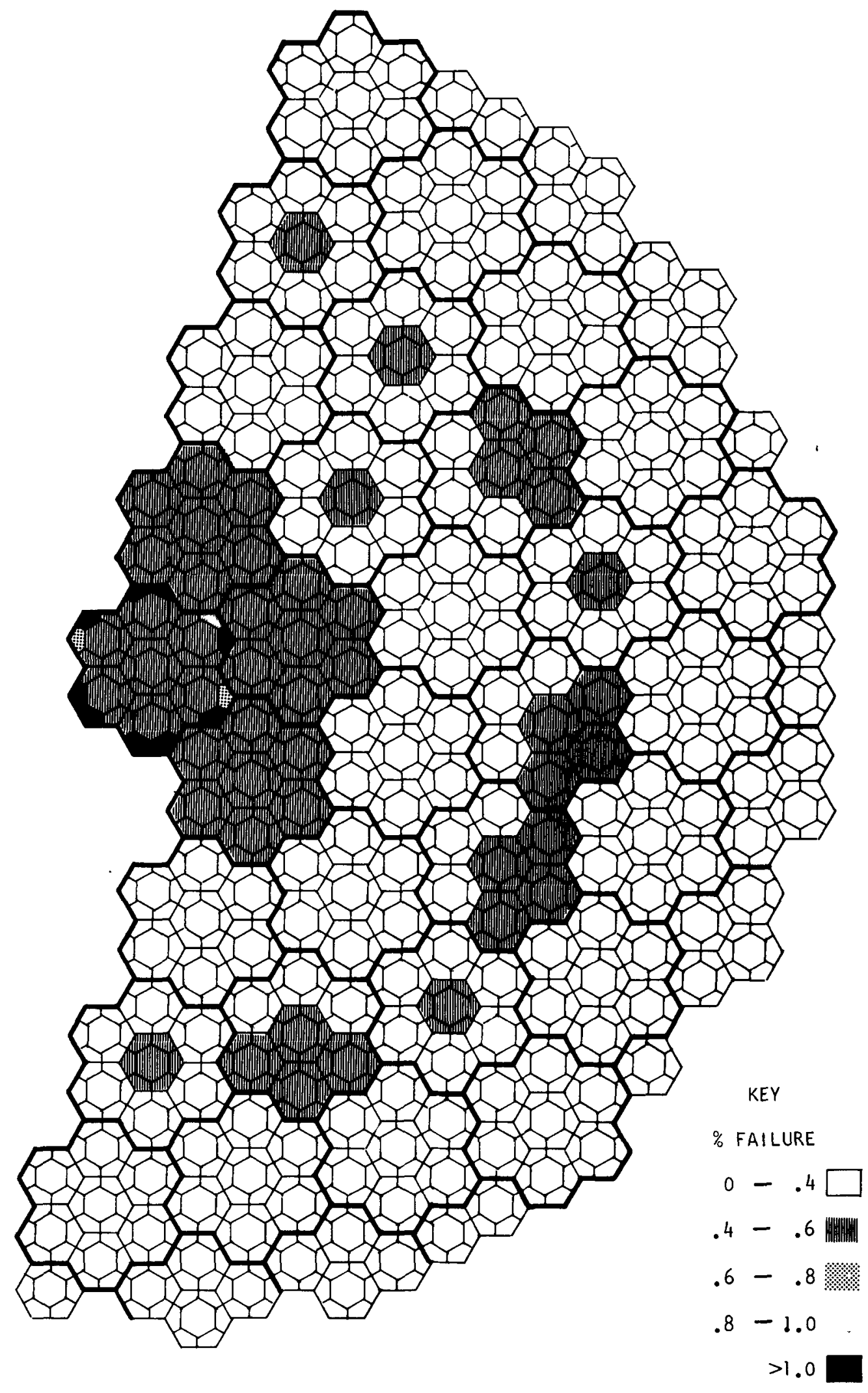

Fig. 7-40. BISO pressure vessel failure in layer 6 


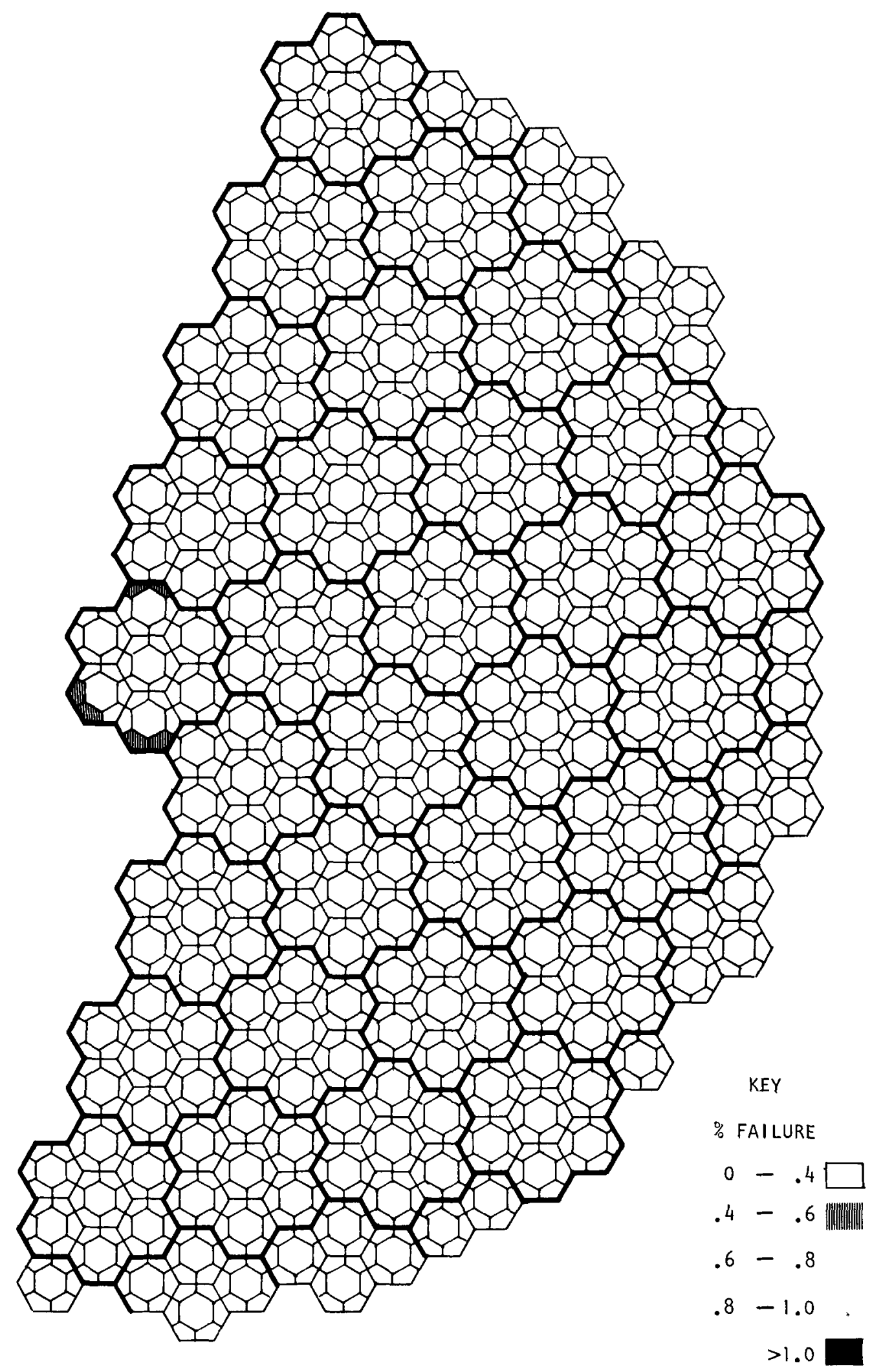

Fig. 7-41. BISO pressure vessel failure in layer 7 


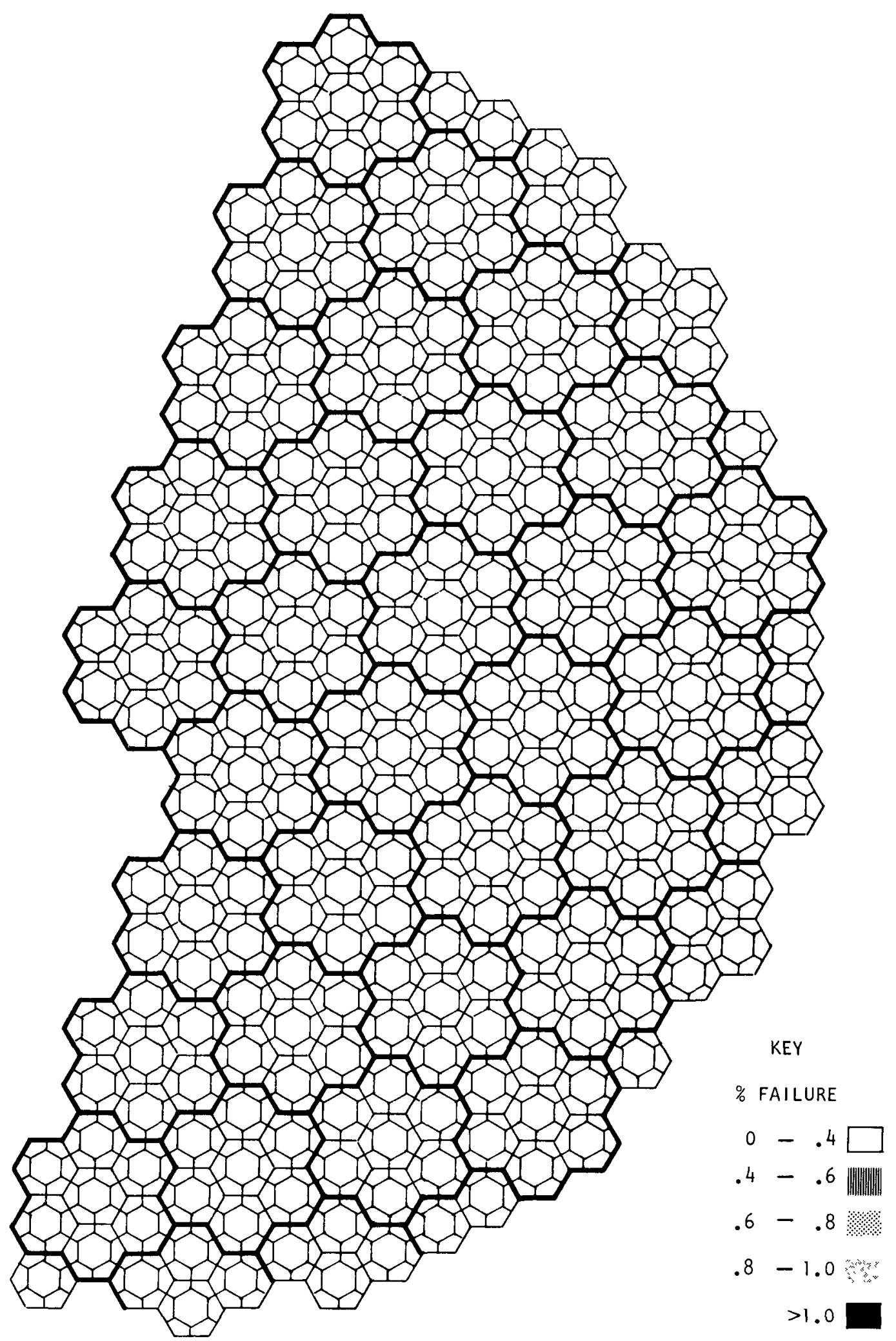

Fig. 7-42. BISO pressure vesse1 failure in layer 8 


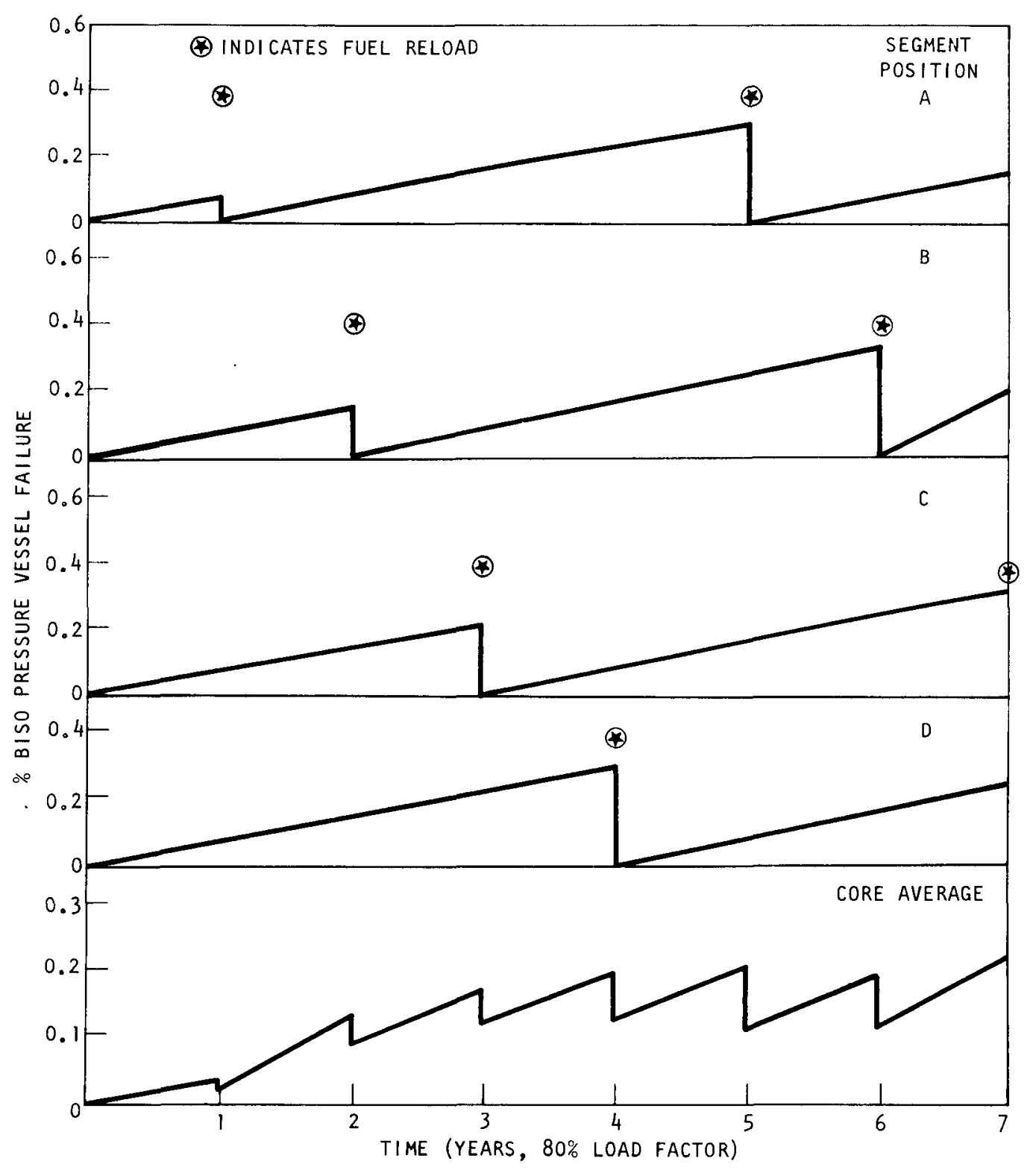

Fig. 7-43. Time history of segment and core average BISO pressure vessel failure in the core 
temperatures above $2912^{\circ} \mathrm{F}$, the fuel particles will fail by combinations of several high temperature effects. The envelope of the threshold temperatures and the burnup above which the TRISO fuel particles begins to fail due to high temperature effects are shown in Fig. 7-44.

No fuel coatings are in the core that fails by this mechanism. This observation can be noted from Fig. 7-44 where some of the calculated typical peak fuel temperatures and its associated burnups are shown to be well below the threshold envelope for high temperature failure.

\subsection{MANUFACTURING DEFECTS}

In a commercial scale fuel manufacturing plant, it is recognized that a small fraction of the particles will have missing or incomplete coating layers. HTGR fuel specifications limit the fraction of these defective particles to a maximum of $0.3 \%$ of the TRISO particles in a production batch and a maximum of $0.2 \%$ of the BISO particles in a production batch. Particles with missing or incomplete coatings may fail prematurely in service. Reference 7-1 specifies that the failure of the defective particles will progress linearly with the particle burnup to $0.2 \%$ at a maximum design burnup of $78 \%$ for TRISO and $7.5 \%$ for BISO particles.

Using this behavior correlation, the time-distribution of coreaveraged coating failure due to these manufacturing defects is calculated for TRISO particles to have a maximum value of $0.15 \%$ and for BISO particles a maximum value of $0.085 \%$. The time history of this failure for TRISO and BISO particles is shown in Figs. 7-45 and 7-46, respectively. TRISO fissile particle burnup increases rapidly at the beginning but proceeds more slowly toward the end of life. However, in BISO fertile particles the burnup increases slowly at the beginning and accelerates near the end of life. The failure due to manufacturing defects follows this trend as shown in Figs. 7-45 and 7-46. 


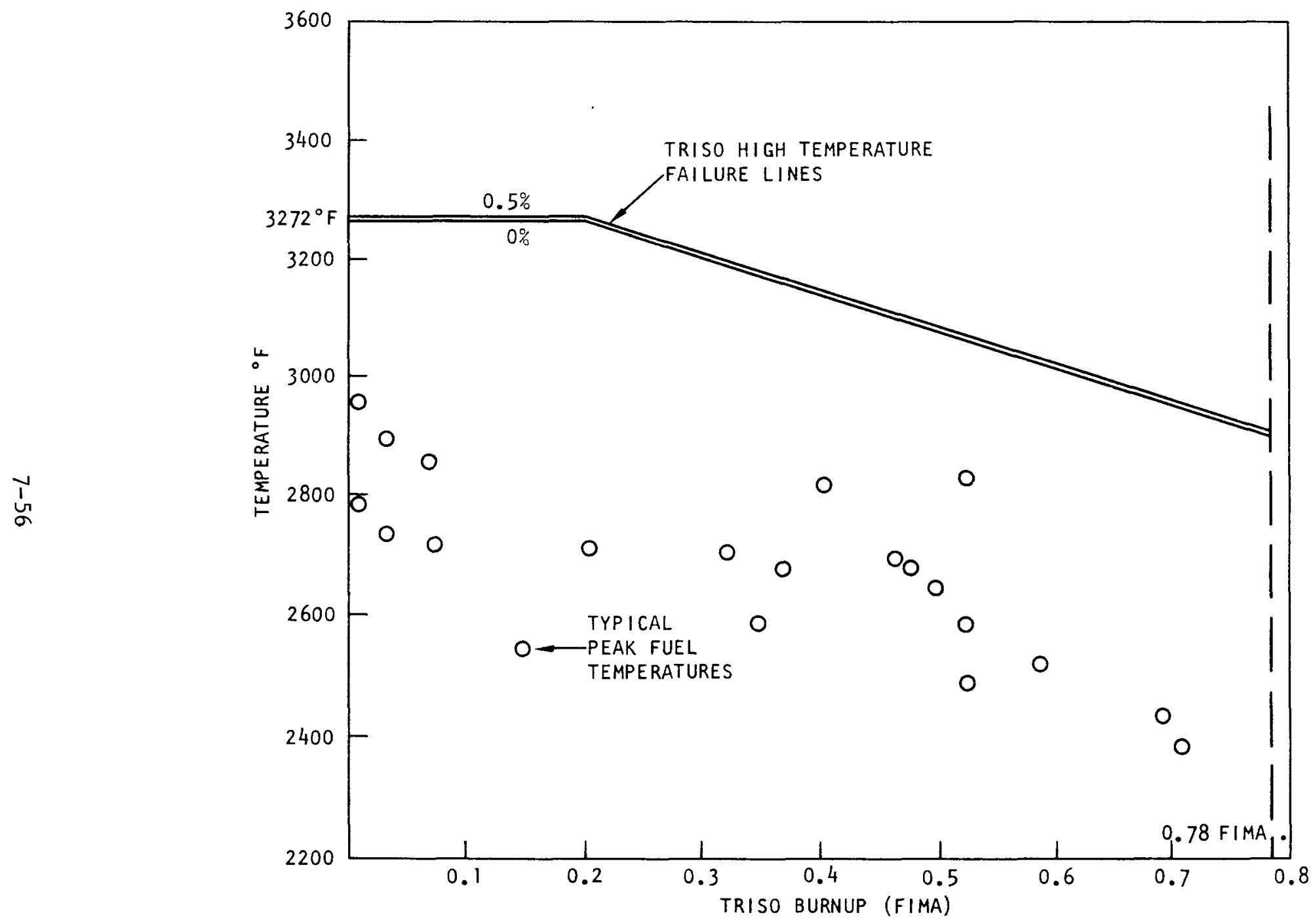

Fig. 7-44. Typical peak fuel temperatures and burnups as compared with threshold temperature envelope of high temperature failure 


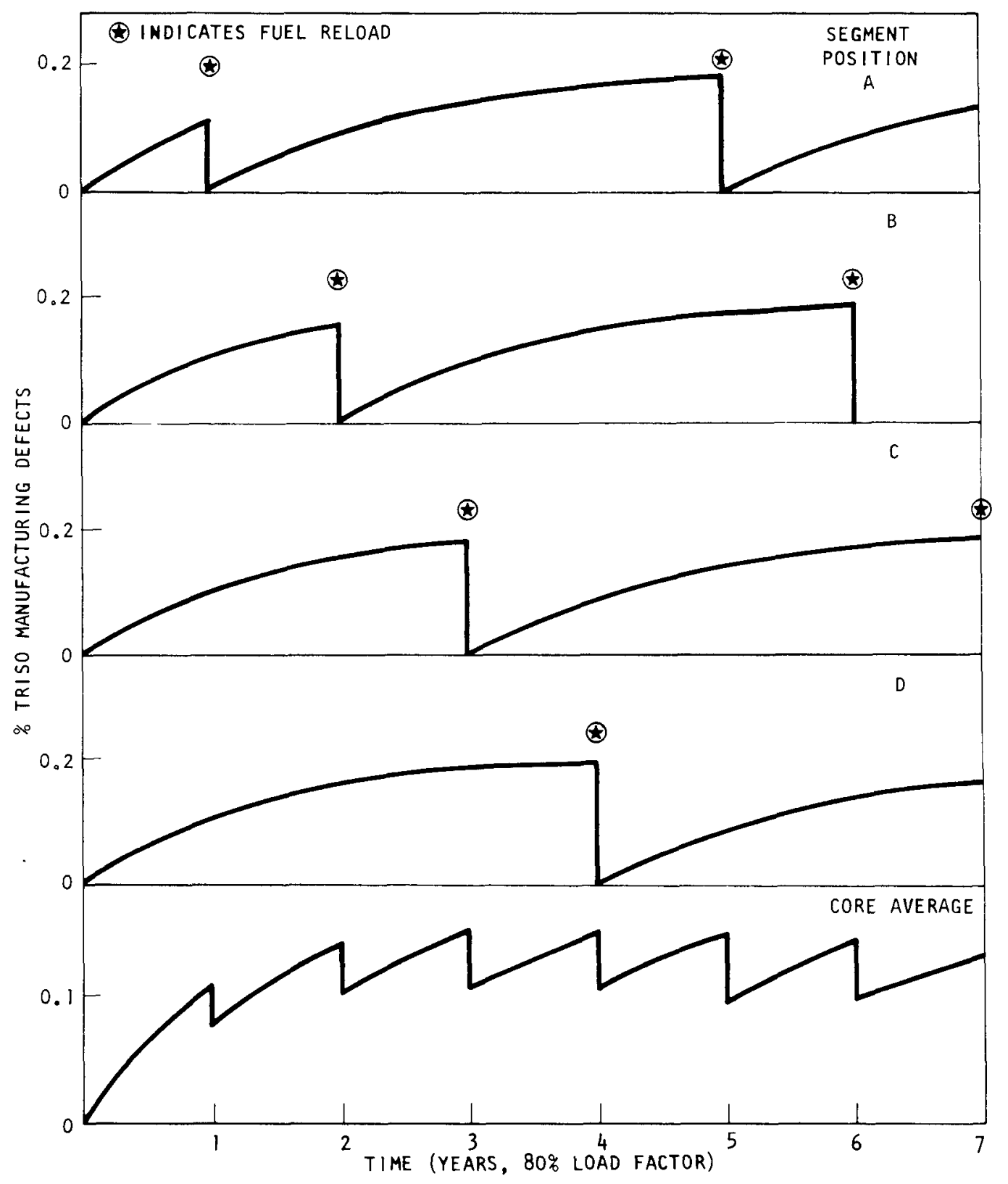

Fig. 7-45. Time history of segment and core average TRISO manufacturing defects failure in the core 


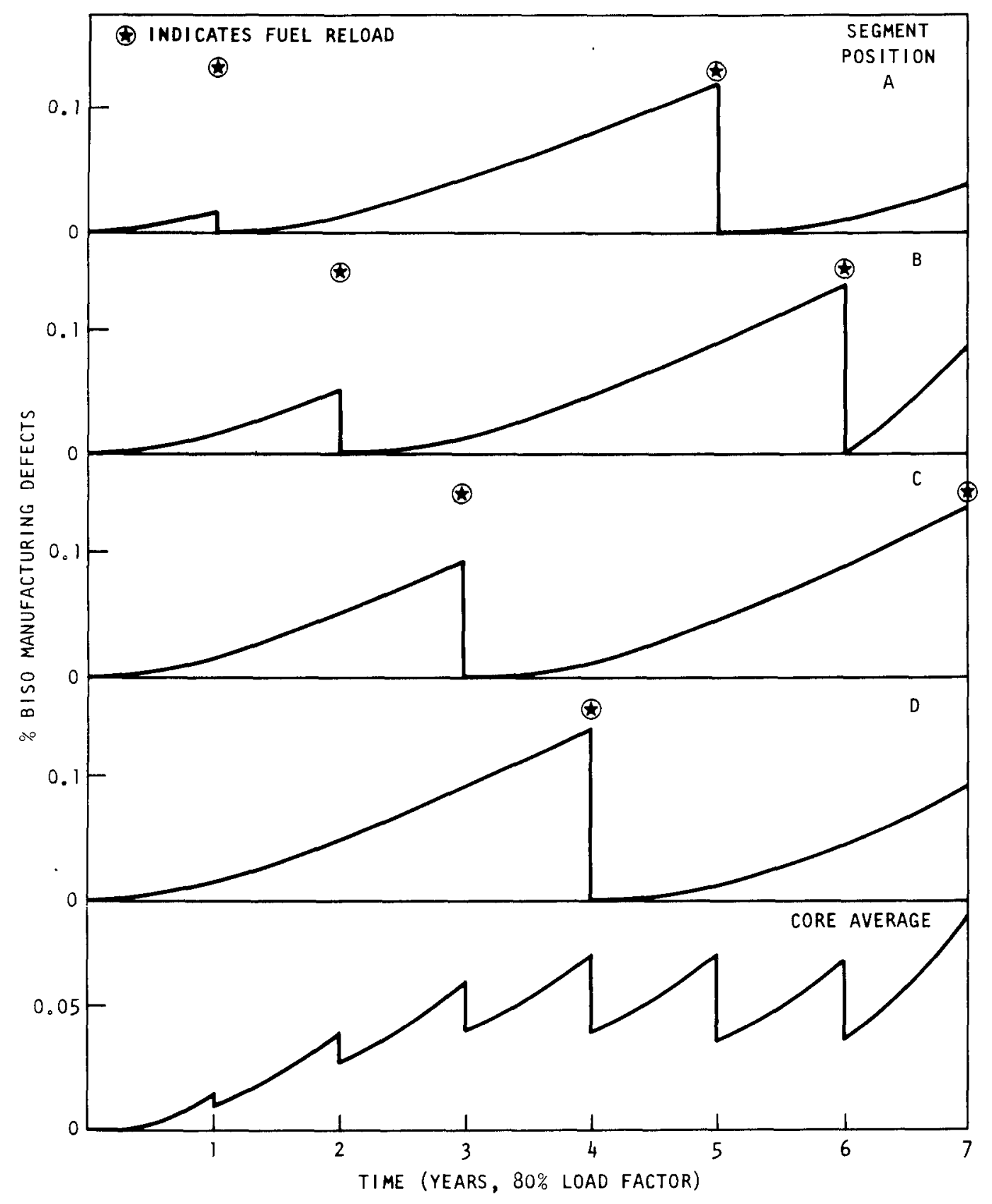

Fig. 7-46. Time history of segment and core average BISO manufacturing defects failure in the core 


\subsection{SUMMARY OF FUEI PERFORMANCE}

Fallure of particle coatings during steady-state rated power operation has been evaluated. Coating failure by all mechanisms has been calculated to be less than $0.39 \%$ for TRISO particles and $0.3 \%$ for BISO particles. The principal consequence of these coating failures is a small increase in the rate of release of fission products from the core. Reference 7-4 discusses the influence of this fuel performance on the release of gaseous fission products from the HTGR core.

In the HTGR fuel element, the principal fission product barrier within the core, the particle coatings, is physically separate from the core graphite fuel element structure, which defines the coolant flow and heat transfer geometry of the core. Failure of the fission product barrier therefore results in no change in core flow or heat transfer characteristics. Detection of changes in circulating fission gas release then is a satisfactory measure of the condition of the core fission product barriers.

In many cases it is possible that individual coatings were calculated to fail by more than one mechanism; however, this possibility is ignored in summing the contributions from the individual mechanism to find the total core average failure fractions.

Figure 7-47 presents a summary of the calculated core average coating failure fraction for TRISO coatings as a function of time beginning with the unirradiated initial core. All three mechanisms calculated to cause TRISO coating failure are shown along with a plot of the calculated core average coating failures due to all three mechanisms. In the equilibrium core the yearly variation in calculated core average TRISO coating failure is seen to be from about $0.20 \%$ at the beginning of the year to $0.39 \%$ at the end of the year. 

Figure 7-48 shows the history of core average fallure for BISO coatings including the individual mechanisms and the sum of all mechanisms. The core average coating failure for BISO particles in an equilibrium core is calculated to increase from about $0.16 \%$ at the beginning of the year to a maximum of about $0.3 \%$ at the end of the year.

Failure in particles containing manufacturing defects are the largest contributor to the coating failures calculated for both TRISO and BISO particles. Next in importance is the pressure vessel failure mechanism followed by very small contributions from kernel migration. No hightemperature-induced failures in TRISO particles were observed. 


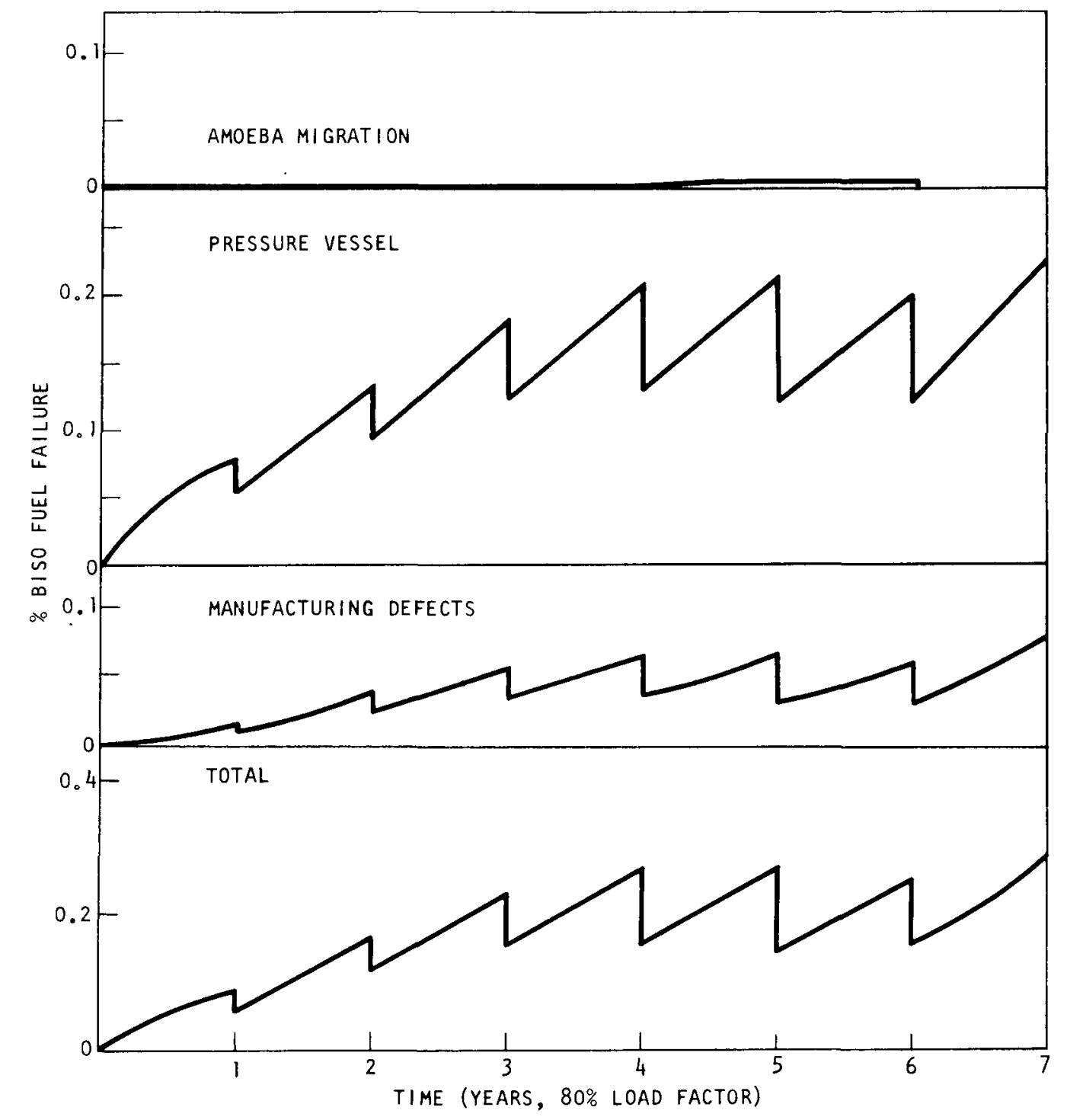

Fig. 7-48. Time history of core average BISO fuel failure fraction by various mechanisms 


\section{REFERENCES}

7-1 Smith, C. L., "Fuel Particle Behavior Under Normal and Transient Conditions," USAEC Report GA-A12971, General Atomic, October 1974.

7-2 Hamilton, C. J., "Power Distribution in Large HTGRs," General Atomic Report GA-A13007, to be published.

7-3 Wagner, M. R., "GAUGE, A Two-Dimensional Few Group Neutron Diffusion-Depletion Program for a Uniform Triangular Mesh," USAEC Report GA-8307, Gulf General Atomic, March 15, 1968.

7-4 Haire, M. J., and D. W. McEachern, "Gaseous Radioactivity Levels in the Primary Coolant of an HTGR," General Atomic Report GA-A12946, October 1, 1974.

7-5 "General Atomic Standard Safety Analysis Report," General Atomic Report GA-A13200, Section 11.1, 1974. 


\section{SUMMARY AND CONCLUSIONS}

The purpose of this report is to present the HTGR core thermal design basis, the thermal data employed, and to discuss the analytical methods and design philosophy adopted in demonstrating how the design bases are met. The core thermal design bases are presented for fuel, coolant, graphite and metallic core components under normal, upset, emergency, and faulted conditions.

In evaluating the core thermal design, several analytical models are used. Analyses using these models encompass the spectrum from simple onedimensional unit cell calculations to more complicated three-dimensional coupled flow and thermal analysis models.

Time-temperature history determines the performance of HTGR fuel in the core. Analytical methods are discussed which follow the time history of temperature, fluence, and burnup and evaluate the fuel particle performance at numerous core locations. Analytical methods that are used in transient analyses, including startup and load following, are presented and examples of their use in design calculations are discussed.

The design data including physical properties of coolant, graphite, and fuel, and the flow characteristics of core components and core power distribution play an important role in evaluation of core thermal performance. A complete set of data currently used in thermal design is presented. These data are conservatively selected from a complete review of mechanical and thermal properties, and they will be updated from time to time as planned experiments are completed. 
In establishing the final design for the commercial HTGR, additional design iterations will be performed. The most recent results of core and fuel performance analysis are discussed here in detail as an example of how the HTGR core thermal and flow analysis is performed. The fuel particle coating failure calculations are also made to evaluate the fraction of failed TRISO and BISO particles by various fuel coating failure mechanisms. These failure fractions are then used in estimation of the release of fission products from the core to confirm that the fuel particle integrity design basis is achieved.

The results of the steady-state full power operation indicate that the fuel particle integrity design basis presented in this report is met. The total fuel coating failure by all mechanisms has been calculated to be less than $0.38 \%$ for TRISO and $0.28 \%$ for BISO particles. This maximum value of fraction of coating failure is reached at the end of the fifth year after the initial core and the coating failure fraction is lower at all other times, as shown in Fig. 8-1. In an HTGR core, the fission product release is controlled by controlling the fraction of fissions occurring in fuel with failed coatings (Ref. 8-1). Figure 8-1 shows the fraction of fissions occurring in particles with failed coatings for TRISO fuel particles, $\mathrm{F}_{\mathrm{T}}$, and for BISO fuel particles, $F_{B}$, as a function of time. The sum of these two fractions for TRISO and BISO particles gives the total fraction of fissions occurring in particles with failed coatings $F_{\text {core }}$. Figure 8-1 shows the fraction of fissions occurring in particles with failed coatings

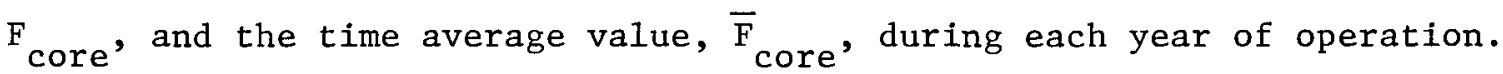
As can be seen, the maximum value of $\bar{F}_{\text {core }}$ is reached during the fifth year of core operation and has a value of $0.22 \%$. For establishing the "expected" activity level, Ref. 8-1 used a value of $\bar{F}_{\text {core }}$ of $0.268 \%$. Therefore the fuel particle coating integrity basis is not exceeded for full-power, steady-state core operation.

The current core design results indicate that the primary coolant design basis on region helium outlet temperature components is met during 

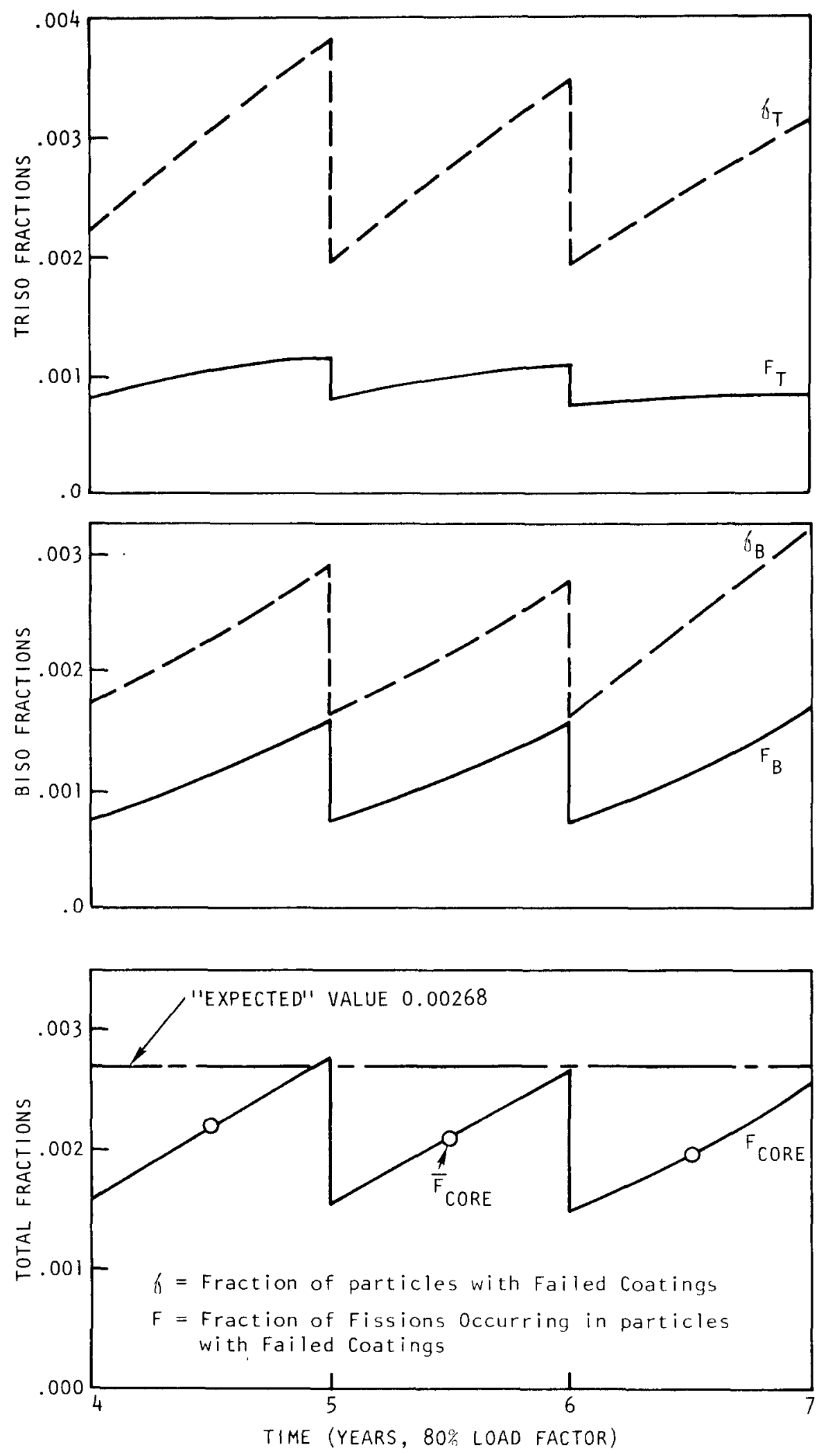

Fig. 8-1. Time history of fraction of fissions occurring in fuel with failed coatings 
steady-state, full power operation. The thermal analysis during normal and upset transients is limited to calculation of coolant, graphite, and fuel temperature during the load-following transients. The core thermal analyses during emergency and faulted conditions are performed separately and reported in Ref. 8-2.

The HTGR core design has gone through two iterations and the thermal design bases have been met during steady-state, full power operation. Additional iterations will be made before the early FSARs are to be submitted. These iterations, which will include the results of the completed flow distribution testing and the fuel irradiation programs, will further define the core performance during transients, and will define quantitatively the necessary technical specifications required by the core. 


\section{REFERENCES}

8-1 Haire, M. J., and D. W. McEachern, "Gaseous Radioactivity in the Primary Coolant of an HTGR," General Atomic Report GA-A12946, October 1, 1974.

8-2 Schleicher, R. W., "An Analysis of HTGR Core Cooling Capability," Gulf General Atomic Report Gulf-GA-A12504, May 30, 1973. 